\title{
Three-dimensional magnetotelluric (MT) modeling of the Northern Negros Geothermal Project, Central Philippines
}

\author{
by \\ Carlos Emmanuel Fajardo Los Banos
}

\author{
A thesis \\ submitted to the Victoria University of Wellington \\ in fulfilment of the \\ requirements for the degree of \\ Master of Science \\ in Physics.
}

Victoria University of Wellington 2012 



\begin{abstract}
The latest magnetotelluric (MT) survey was conducted in the Northern Negros Geothermal Project (NNGP), which is one of the geothermal fields being developed in the Philippines, from December, 2010 to April, 2011. 66 new MT soundings were added to the previous MT dataset. The new stations were located mainly in the southeastern and southern regions to define the extent of drilled high-temperature resource in these areas.

Phase tensor analysis show that the MT data in general is only 1-D in the short period range of $<1 \mathrm{~s}$ and becomes 3-D at longer periods. 1-D, 2-D and 3-D modeling were performed on the MT dataset after stripping it for distortion based on the phase tensor and correcting for static shifts using Transient Electromagnetic (TEM) data. The resistivity structure from all models show three main layers: a $>100 \mathrm{ohm}-\mathrm{m}$ resistive top layer, a middle $<10 \mathrm{ohm}-\mathrm{m}$ conductive layer and a $>20 \mathrm{ohm}-\mathrm{m}$ moderately resistive bottom layer. The highly resistive top layer is associated with the relatively fresh volcanic deposits of the Canlaon Volcanics $(\mathrm{CnV})$. Correlating the $3-\mathrm{D}$ resistivity structure with subsurface data from the drilled wells shows that the thick conductive layer overlaps with the low-temperature alteration minerals such as smectite while the moderately resistive bottom layer coincides with the high-temperature alteration minerals like illite and epidote. These observations are also consistent with the measured well temperatures wherein the elevated temperatures drilled beneath the Pataan sector coincide with the shallow occurence or doming portion of the bottom resistive layer.

Tracing the shallow occurrence of the bottom resistive layer revealed
\end{abstract}


a northeast extension to the drilled resource beneath Pataan. The delineated resource area in Pataan is about 3 to $7 \mathrm{~km}^{2}$.

Other possible high-temperature areas are located within the Upper Hagdan and Hardin Sang Balo sectors. However, resolution of the resistivity structure is not well pronounced in these areas due to limited data coverage. 


\section{Acknowledgments}

This thesis would not have been possible without the guidance and support of the following individuals who in one way or the other contributed to its completion. It is to them I sincerely express my gratitude:

First and foremost, to my supervisor, Dr. Malcolm Ingham, for unselfishly sharing his knowledge about MT particularly 3-D inversion modeling,

Mssrs. Richard Tantoco and Manuel Ogena, on behalf of the management of Energy Development Corporation, for giving me the opportunity to pursue an MSc. degree to enhance my technical capability,

To my family, especially to my wonderful wife Glenda, who took care of our two lovely daughters while I was studying,

To my colleagues in EDC, namely, Mr. Domie Layugan, Mr. Boyie Rigor, Mr. Rhoel Olivar, Mr. Randy Tugawin, Mr. Mike Pastor, Ms. Menchie Melo, Mr. Andy Caliwag, Mr. Manny Teoxon, Ms. Sylvia Ramos and Mr. Jericho Omagbon for providing additional data that I needed,

And of course, to God, who made all these possible. 


\section{Contents}

List of Figures $\quad$ ix

List of Tables $\quad$ xiii

1 Introduction 1

2 The basics of Magnetotelluric (MT) method 5

2.1 Signal sources .................. 6

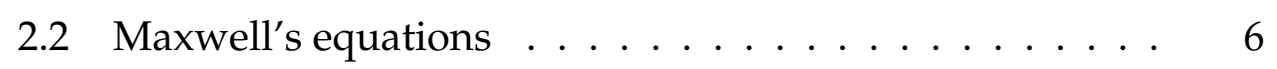

2.3 Skin depth . . . . . . . . . . . . . . . 8

2.4 A 1-D solution to the induction problem . . . . . . . . 9

2.5 Solution to a 2-dimensional Earth . . . . . . . . . . . 13

2.6 Solution to a 3-dimensional Earth . . . . . . . . . . . 15

2.7 MT sounding: concept of impedance and tipper . . . . . 15

2.8 Distortion . . . . . . . . . . . . . . . . . . 19

2.9 Phase tensor analysis . . . . . . . . . . . . 20

2.10 Static shift . . . . . . . . . . . . . . 22

2.11 Modeling . . . . . . . . . . . . . . . . . . . . . . . . . . . . . .

2.11 .1 1-dimensional modeling . . . . . . . . . 25

2.11 .2 Bostick inversion . . . . . . . . . . . . . 25

2.11 .3 Simple layered model . . . . . . . . . . . . . 26

2.11 .4 Occam inversion . . . . . . . . . . . . . 27

2.11 .5 2-dimensional modeling schemes . . . . . . . 29

2.11.6 3-dimensional modeling . . . . . . . . . 30 
2.12 Instrumentation and data acquisition . . . . . . . . 31

2.13 Data processing ............... 33

3 Northern Negros Geothermal Project 35

3.1 Geology .......................... 38

3.2 Gravity survey . . . . . . . . . . . . . . . 39

3.31995 and 2000 MT surveys . . . . . . . . . . . 43

3.4 Hydrothermal system . . . . . . . . . . . . . 45

$4 \quad 2011$ MT survey $\quad 47$

4.1 Data quality and description . . . . . . . . . . . 48

4.2 Phase tensor analysis . . . . . . . . . . . 50

4.3 Induction arrows . . . . . . . . . . . . 57

4.4 Static shift correction . . . . . . . . . . . 57

5 Modeling 63

5.1 1-D inversion modeling . . . . . . . . . . 63

5.1 .1 Isoresitivity maps . . . . . . . . . . . . 63

5.2 2-D inversion modeling . . . . . . . . . . 64

5.2 .1 Isoresistivity maps . . . . . . . . . . . 66

5.3 3-D inversion modeling . . . . . . . . . . . 69

5.3.1 Comparison of initial models . . . . . . . . 70

5.43 -D inversion results . . . . . . . . . . . . 83

5.4 .1 MT data curves .............. . . 83

5.4 .2 Isoresistivity maps ............. 83

5.4 .3 Resistivity profiles ............ 84

$5.4 .4 \quad \mathrm{YZ}$ slices . . . . . . . . . . . . . . . 90

$5.4 .5 \quad$ XZ slices .................... 95

5.5 Comparison of 1-D, 2-D and 3-D models . . . . . . . . . 100

5.5 .1 Isoresistivity maps . . . . . . . . . . . . 100

5.5 .2 Profile lines . . . . . . . . . . . . 101 
CONTENTS vii

6 Discussion and interpretation $\quad 111$

6.1 Resistivity structure of NNGP . . . . . . . . . . . . . . . 111

6.1.1 Correlation with alteration, temperature and lithology . . . . . . . . . . . . . . . . 112

6.2 Geothermal resource area . . . . . . . . . . . . . 118

7 Summary and Conclusions 123

$\begin{array}{ll}\text { References } & 127\end{array}$

Appendix I: Data curves and phase tensor analysis 133

Appendix II: MT data description 169

Appendix III: Static shift correction applied 187

Appendix IV: 3-D inversion data file 193

Appendix V: 3-D inversion curve fit 221 


\section{List of Figures}

2.1 A simple 2-D model . . . . . . . . . . . . . . . . . . . . 14

2.2 The phase tensor ellipse $\ldots \ldots \ldots \ldots \ldots . \ldots 22$

2.3 Simple 1-D layered model . . . . . . . . . . . . . . . 26

2.42 2-D modeling . . . . . . . . . . . . . . . . . . . . . . . . . 29

2.5 Typical MT station layout $\ldots \ldots \ldots \ldots$

2.6 MT data processing flowchart . . . . . . . . . . . 34

3.1 Location map of the Northern Negros Geothermal Project (NNGP) . . . . . . . . . . . . . . 36

3.2 Location map of wells and thermal areas in NNGP . . . . 37

3.3 Simplified geologic map of NNGP _ . . . . . . . . . 40

3.4 Structural map of NNGP . . . . . . . . . . . . . . . 41

3.5 Residual Bouguer anomaly map . . . . . . . . . . . 42

3.6 Apparent isoresistivity map at $0.33 \mathrm{~s} \ldots \ldots \ldots 44$

3.7 1-D layered model along profile S-01 . . . . . . . . 44

3.8 2-D resistivity model . . . . . . . . . . . . . . . . . 45

3.9 Delineated resource area at NNGP . . . . . . . . . 46

4.1 MT and TEM stations location map . . . . . . . . . . 49

4.2 Samples of extremely noisy MT data . . . . . . . . . 51

4.3 Strike directions of MT stations based on phase tensor . . 53

4.4 Dominant strike directions of the MT data . . . . . . . 54

4.5 Phase tensor ellipse at different periods . . . . . . . . 56

4.6 Induction arrows at $300 \mathrm{~Hz} \ldots \ldots \ldots \ldots$ 
4.7 Induction arrows at $10 \mathrm{~Hz} \ldots \ldots \ldots \ldots$

4.8 Induction arrows at $1 \mathrm{~Hz} \ldots \ldots \ldots 59$

4.9 Induction arrows at $0.1 \mathrm{~Hz} \ldots \ldots \ldots$

4.10 Induction arrows at $0.01 \mathrm{~Hz} \ldots \ldots$. . . . . . . 60

4.11 Induction arrows at $0.001 \mathrm{~Hz} \ldots \ldots 60$

5.1 1-D isoresistivity map at $300 \mathrm{~m}$ depth . . . . . . . . 64

5.21 -D isoresistivity map at $1000 \mathrm{~m}$ depth . . . . . . . . . 65

5.31 -D isoresistivity map at $2000 \mathrm{~m}$ depth . . . . . . . . . . 65

5.4 2-D isoresistivity map at $300 \mathrm{~m}$ depth . . . . . . . . . 67

5.5 2-D isoresistivity map at $1000 \mathrm{~m}$ depth . . . . . . . . . 68

5.6 2-D isoresistivity map at $2000 \mathrm{~m}$ depth . . . . . . . . . . 68

5.7 Model A isoresistivity map at $300 \mathrm{~m}$ depth . . . . . . . 72

5.8 Model B isoresistivity map at $300 \mathrm{~m}$ depth . . . . . . . . 72

5.9 Model C isoresistivity map at $300 \mathrm{~m}$ depth . . . . . . . 73

5.10 Model A isoresistivity map at $2000 \mathrm{~m}$ depth . . . . . . . . 74

5.11 Model B isoresistivity map at $2000 \mathrm{~m}$ depth . . . . . . . . 74

5.12 Model C isoresistivity map at $2000 \mathrm{~m}$ depth . . . . . . . 75

5.13 Model B isoresistivity map at $1000 \mathrm{~m}$ depth . . . . . . . . 75

5.14 Model A profile line $X=-0.25 \mathrm{~km} \ldots \ldots . \ldots 76$

5.15 Model B profile line $X=-0.25 \mathrm{~km} \ldots \ldots . \ldots 77$

5.16 Model C profile line $X=-0.25 \mathrm{~km} \ldots \ldots . \ldots 77$

5.17 Model A profile line $\mathrm{Y}=0.75 \mathrm{~km} \ldots \ldots$

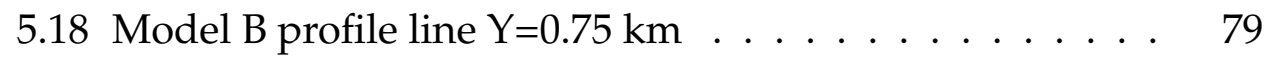

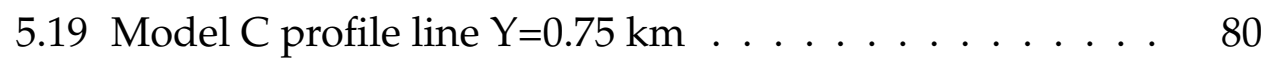

5.20 Curve fit of model vs data of MT station $4 \ldots$. . . . . 81

5.21 Curve fit of model vs data of MT station $14 \ldots 82$

5.22 Isoresistivity map at $10 \mathrm{~m}$ depth . . . . . . . . . . . . 85

5.23 Isoresistivity map at $100 \mathrm{~m}$ depth . . . . . . . . . . . . . . . . 85

5.24 Isoresistivity map at $300 \mathrm{~m}$ depth . . . . . . . . . . . 86

5.25 Isoresistivity map at $500 \mathrm{~m}$ depth . . . . . . . . . . 86

5.26 Isoresistivity map at $1 \mathrm{~km}$ depth $\ldots . . \ldots 87$ 
LIST OF FIGURES - xi

5.27 Isoresistivity map at $2 \mathrm{~km}$ depth . . . . . . . . 87

5.28 Isoresistivity map at $3 \mathrm{~km}$ depth . . . . . . . . . . 88

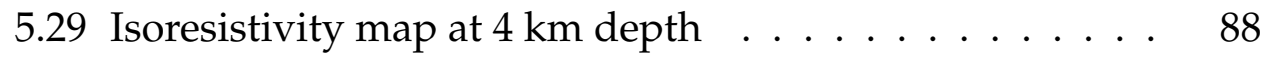

5.30 Isoresistivity map at $5 \mathrm{~km}$ depth . . . . . . . . . . . 89

5.31 Isoresistivity map at $8 \mathrm{~km}$ depth . . . . . . . . . . . 89

5.32 Resistivity profile along $X=-4.25 \mathrm{~km} \ldots \ldots . \ldots 91$

5.33 Resistivity profile along $X=-3.75 \mathrm{~km} \ldots \ldots 91$

5.34 Resistivity profile along $X=-2.75 \mathrm{~km} \ldots \ldots . \ldots 92$

5.35 Resistivity profile along $X=-2.25 \mathrm{~km} \ldots \ldots 92$

5.36 Resistivity profile along $X=-0.25 \mathrm{~km} \ldots . . \ldots 93$

5.37 Resistivity profile along $X=0.25 \mathrm{~km} \ldots \ldots$. . . . . . 94

5.38 Resistivity profile along $X=2.75 \mathrm{~km} \ldots \ldots . \ldots 94$

5.39 Resistivity profile along $X=3.25 \mathrm{~km} \ldots \ldots$. . . . . . . 95

5.40 Resistivity profile along $Y=-2.75 \mathrm{~km} \ldots \ldots . \ldots 96$

5.41 Resistivity profile along $\mathrm{Y}=-1.75 \mathrm{~km} \ldots \ldots$. . . . . . . 96

5.42 Resistivity profile along $Y=-0.75 \mathrm{~km} \ldots \ldots . \ldots 97$

5.43 Resistivity profile along $\mathrm{Y}=0.75 \mathrm{~km} \ldots \ldots . \ldots 98$

5.44 Resistivity profile along $Y=1.25 \mathrm{~km} \ldots \ldots . \ldots 98$

5.45 Resistivity profile along $Y=3.75 \mathrm{~km} \ldots \ldots . \ldots 99$

5.46 Resistivity profile along $\mathrm{Y}=4.25 \mathrm{~km} \ldots \ldots . . \ldots 99$

5.47 Profile lines location map . . . . . . . . . . . . . 102

5.48 Profile line NW-SE1 . . . . . . . . . . . . . . . . . . . . 104

5.49 Profile line NW-SE2 . . . . . . . . . . . . . . . . . 106

5.50 Profile line NW-SE3 . . . . . . . . . . . . . . . . 108

5.51 Profile line SW-NE1 . . . . . . . . . . . . . . . . . . 110

6.1 Resistivity model vs. alteration minerals along NW-SE2 . 113

6.2 Resistivity model vs. measured temperatures along NWSE2 .......................... 114

6.3 Resistivity model vs. lithology along NW-SE2 . . . . . 115

6.4 Resistivity model vs. alteration minerals along SW-NE1 . 116 
6.5 Resistivity model vs. measured temperatures along SWNE1 . . . . . . . . . . . . . . . . . . . . 117

6.6 Resistivity model vs. lithology along SW-NE1 . . . . . 117

6.7 Profile line SW-NE2 location map . . . . . . . . . . . . . . 119

6.8 Resistivity model along SW-NE2 . . . . . . . . . . . . 120

6.9 Delineated resource area in NNGP based on 3-D inversion 121

7.1 Delineated resource area at NNGP . . . . . . . . . 126 


\section{List of Tables}

4.1 Summary of data types based on quality . . . . . . . . 50

6.1 Common mineral geothermometers in Philippine geothermal areas . . . . . . . . . . . . . . . . . 112 


\section{Chapter 1}

\section{Introduction}

In the past 15 years, the magnetotelluric (MT) method has been one of the effective tools used for understanding and exploring geothermal resources and related environments (Heise et al., 2008; Uchida, 2005; Cumming et al., 2000; Ingham et al., 2005). Significant advancement in the processing and modeling techniques of MT data has been made in recent years (Ogawa, 2002; Siripunvaraporn, 2011). This included the improvement of 3-dimensional inversion softwares for MT data, such as the WSINV3DMT, which enables the processing of data on a personal PC in a shorter time than before (Siripunvaraporn et al., 2005).

The Northern Negros Geothermal Project (NNGP) is one of the geothermal fields currently being developed in the Philippines. It is located in the northern portion of the central Island of Negros and lies about eight kilometers northwest of the active Canlaon Volcano. MT studies have been conducted in NNGP as early as 1995. However, data processing and analysis have been limited to 1-dimensional and 2-dimensional inversion modeling.

MT data in a highly-fractured environment such as NNGP, are in reality highly 3-dimensional and the use of 1-D or 2-D techniques can often lead to misrepresentation of resistivity features which in turn can lead to misinterpretation of the data. In line with this, 3-dimensional 
modeling was applied to the MT data of NNGP to be able to accurately define a resistivity structure, which can be related to the hydrothermal system of the study area. Other objectives include the refinement of the delineated boundaries of the high temperature field drilled in Pataan sector particularly to the south-southeastern regions, and to pinpoint areas with similar resistivity characteristics that may be potential resource targets in NNGP.

Additional MT data were collected specifically for this 3-D modeling project with emphasis on getting better quality suited for 3-D inversion. Other new techniques that were applied during processing include the correction for static shifts using the Transient Electromagnetic (TEM) data that were acquired from the TEM survey that was conducted together with the latest MT survey, and the phase tensor analysis technique by Caldwell et al. (2004) to identify data dimensionality, determine the dominant strike direction, and remove distortions in the dataset. Detailed explanation for these applications are found in chapter 2 and 4 .

Chapter 2 reviews the main theories behind MT. It also gives brief discussion of the different processing techniques applied to the MT data such as the phase tensor distortion, static shifts, etc. The concept behind the different MT modeling methods that were applied during this project are also discussed in this chapter. An overview of the equipment used and the general steps in data processing is also given.

Chapter 3 gives an overview of NNGP with emphasis on the previous geoscientific studies conducted in the area, such as the geological mapping, gravity, earlier MT surveys and the subsurface data based on the drilled wells. The postulated hydrothermal model is also presented.

Chapter 4 described the MT dataset that was used during modeling. This included data from the latest MT survey that was conducted primarily to get better quality data than the previous surveys that would suitable for 3-D inversion. This chapter also deals with the treatment of 
the MT data which involves the mapping of induction arrows, correcting for static shift using TEM data, removal of distortion, and determining dimensionality, among others.

Chapter 5 summarizes the results of the 1-D, 2-D and 3-D modeling methods used for the NNGP MT dataset, with more detail given to the 3-D inversion results. The results are presented through isoresistivity maps and resistivity structures along selected profile lines. A discussion on the different initial models used for 3-D inversion and the subsequent selection of the $30 \mathrm{ohm}-\mathrm{m}$ half space as the initial model used for the final 3-D models is also given in this chapter. Comparison of the results between the 1-D, 2-D, and 3-D models, as well as, the results from the different 3-D initial models, show both the consistent and the distinct features of the various models. This enables the determination of the "true" resistivity features from the ones that may be artefacts of the processing algorithms.

Chapter 6 discusses the interpretation of resistivity structure particularly from the 3-D models, in terms its significance in the geothermal resource at NNGP. This is done by correlating the models with the subsurface data, which consists of alteration mineralogy, lithology and measure well temperatures. The delineation of the high temperature resource based on the resistivity structure at NNGP is also presented in this chapter.

Lastly, Chapter 7 gives a summary of the processing techniques applied to the MT data in preparation for 3-D modeling. This chapter also highlights the new findings from 3-D modeling and its significance to the geothermal resource in NNGP. These include the delineation of a shallow moderately resistive body "doming" beneath Pataan sector, which can be associated with the extent of the high temperature resource that was drilled in the area. The 3-D model also suggests the presence of possible high temperature regions beneath Upper Hagdan and Hardin Sang Balo at the southern portion of NNGP. 


\section{Chapter 2}

\section{The basics of Magnetotelluric (MT) method}

The concept of the magnetotelluric method (MT) was first introduced by Tikhonov (1950) and Cagniard (1953). It is a passive electromagnetic (EM) technique that involves measuring fluctuations in the natural electric (E) and magnetic (B) fields in orthogonal directions at the surface of the Earth as a means of determining the conductivity structure of the Earth. Compared to other electrical methods, MT has the advantage to penetrate very deep levels reaching to hundreds of kilometers. In geothermal exploration, this method is effectively used to map low resistivity anomalies, which can be interpreted as hydrothermally altered zones indicating passage of hot fluids. MT is also useful in mapping out resistivity contrasts, which could reveal geologic structures such as faults that could act as pathways for the geothermal fluids. This chapter presents the basic theories behind the MT method, its properties and applications. This section also includes the parameters considered during processing and modeling of the data. Unless otherwise stated, the main basis for this chapter are the notes from lectures and discussions with Dr. M. R. Ingham. 


\subsection{Signal sources}

MT signals have a very wide spectrum ranging from milliseconds to several years. However, signals with periods less than $1 \mathrm{msec}$ do not penetrate very far into the earth while oscillations with periods longer than one day are usually not recorded for MT. Natural sources for these signals above $1 \mathrm{~Hz}$, also known as "sferics", are the lightning activity during thunderstorms, whereas signals below $1 \mathrm{~Hz}$, are caused by micropulsations in the magnetic field of the earth. Between 0.5 to $5 \mathrm{~Hz}$ lies the so called "dead band" wherein the signals have low amplitude. This is usually reflected in the poor data quality at this range in the MT sounding data. The major source for the MT signals is the magnetosphere, which is the region composed of highly charged particles such as the solar wind (Gold, 1959). This zone includes the atmosphere and the ionosphere, which is the high conductivity zone formed essentially through ionization of gases (i. e. oxygen and nitrogen) by ultraviolet rays from the sun (Vozoff, 1991).

\subsection{Maxwell's equations}

The basic theory of electromagnetic induction of the earth is based on Maxwells equations and may be written in terms of magnetic induction $\underline{B}$ as:

$$
\begin{gathered}
\nabla x \underline{B}=\mu_{0} \underline{J}+\mu_{0} \varepsilon_{0} \frac{\partial \underline{E}}{\partial t} \quad\left(\text { Ampere }^{\prime} s \text { Law }\right) \\
\nabla x \underline{E}=-\frac{\partial \underline{B}}{\partial t} \quad(\text { Faraday's Law }) \\
\nabla \cdot \underline{B}=0 \quad(\text { Gauss's Law for Magnetism }) \\
\nabla \cdot \underline{E}=\frac{q}{\varepsilon_{0}} \quad\left(\text { Gauss }^{\prime} \text { s Law }\right)
\end{gathered}
$$

where $\underline{J}$ is the electric current density, $\underline{E}$ is the electric field, $q$ is the volume density of charge, $\mu_{0}$ is the permeability, and $\varepsilon_{0}$ is the permittivity of free space. 
These four equations can be simplified by relating $\underline{J}$ to $\underline{E}$ through the electrical conductivity of the medium, and by noting that in the context of electromagnetic induction in the Earth, the displacement current factor in the first Maxwell equation is negligible. This can be shown by replacing $\underline{J}=\sigma \underline{E}$ (according to Ohm's Law), and assuming that the time variation of the electric field of the form $\exp (-i \omega t)$, which gives the ratio of the magnitudes of the two terms on the right hand side of the 1st equation as $\mu_{0} \sigma / \mu_{0} \varepsilon_{0} \omega$.

Comparing the typical values for $\sigma$ and $\epsilon_{0} \omega$ wherein $\sigma$ within the crust and mantle range from $10^{-4}$ to $1 \mathrm{Sm}^{-1}$ and frequencies which are measured in induction studies range from $1 \mathrm{kHz}$ to $10^{-4} \mathrm{~Hz}$, gives $\varepsilon_{0} \omega$ values ranging from $10^{-6}$ to $10^{-13}$ which is very small compared to the values of $\sigma$. Thus the displacement term on the right side of equation 2.1 can be ignored. Neglecting the displacement current and taking the curl of equation 2.1 gives

$$
\nabla x(\nabla x \underline{B})=\mu_{0} \nabla x \underline{J}
$$

Again, using the fact that $\underline{J}=\sigma \underline{E}$ and assuming the conductivity is uniform, we get

$$
\nabla x(\nabla x \underline{B})=\mu_{0} \sigma \nabla x \underline{E} .
$$

Using equation 2.2 for the curl of $\underline{E}$ now yields

$$
\nabla x(\nabla x \underline{B})=-\mu_{0} \sigma \frac{\partial \underline{B}}{\partial t} .
$$

The vector identity

$$
\nabla x(\nabla x \underline{B})=\nabla(\nabla \cdot \underline{B})-\nabla^{2} \underline{B}
$$

and equation 2.3 yields a second expression for $\nabla x(\nabla x \underline{B})=-\nabla^{2} \underline{B}$ shown as

$$
\nabla^{2} \underline{B}=\mu_{0} \sigma \frac{\partial \underline{B}}{\partial t} .
$$

This shows that in a uniform conductor, $\underline{B}$ satisfies the diffusion equation. 
It is also possible to eliminate $\underline{B}$ rather than $\underline{E}$ from Maxwells equations to deduce that a time varying electric field obeys

$$
\nabla^{2} \underline{E}=\mu_{0} \sigma \frac{\partial \underline{E}}{\partial t}+\nabla \frac{q}{\varepsilon_{0}} .
$$

The second term on the right hand side of the equation arises because the diffusion of an electric field into a conducting medium is modified by the accumulation of charge on the boundaries of the medium. In any situation a measured $\underline{B}$ or $\underline{E}$ field is a complicated function of time, that it may be represented as a Fourier Series (i.e. a summation of signals of different frequencies). As equations 2.9 and 2.10 are linear, the B or E field at any single frequency may be treated separately as obeying the diffusion equation.

\subsection{Skin depth}

Consider a horizontally oscillating B field and a plane with a semi-infinite conductor. If the time variations of the field are the same everywhere in the xy plane, then the field can be represented as a wave of infinite wavelength that strikes the surface of the conductor. Within the conductor the field is a wave with the general form

$$
\underline{B}=\underline{B}_{0} e^{\alpha z} e^{(-i \omega t)} .
$$

Substituting into the diffusion equation

$$
\begin{gathered}
\frac{\partial^{2} \underline{B}}{\partial z^{2}}=\mu_{0} \sigma \frac{\partial \underline{B}}{\partial t} \\
\alpha^{2} \underline{B_{0}} e^{\alpha z} e^{-i \omega t}=\mu_{0} \sigma(-i \omega) \underline{B_{0}} e^{\alpha z} e^{-i \omega t} \\
\alpha^{2}=\mu_{0} \sigma(-i \omega) \\
\alpha= \pm(1-i)\left(\mu_{0} \omega \sigma / 2\right)^{1 / 2}
\end{gathered}
$$


For a physically realistic solution $\underline{B}$ must decrease with depth $z$ into the Earth and thus the positive (+) solution can be ignored leaving:

$$
\underline{B}=\underline{B_{0}} e^{-z / \delta} e^{-i(\omega t-z / \delta)}
$$

where

$$
\delta=\sqrt{\frac{2}{\mu_{0} \sigma \omega}}=\sqrt{\frac{\left(10^{7}\right)(2) \rho T}{(4 \pi)\left(10^{-} 7\right)(2 \pi)}}=503 \sqrt{\rho T} .
$$

Thus, the inverse of the real part of $\alpha$ is known as the skin depth $\delta$ which is defined as the distance over which the initial amplitude decays by a factor of $1 / \mathrm{e}$. As can be seen, the skin depth $\delta$ increases with decreasing frequency (i.e. longer period signals penetrate more deeply) and with decreasing conductivity (i.e. for a given frequency, penetration is greater into a more resistive medium).

\subsection{A 1-D solution to the induction problem: Concept of apparent resistivity and phase}

Electromagnetic induction in the Earth can be analytically solved for a 1-dimensional case, i.e. the electrical conductivity structure varies only with depth. In this case, expressions for the ratio of the internally and externally originating variations in the magnetic field and also for the electric and magnetic fields measured at the surface can be derived. Assuming that the Earth is a plane of uniform half-space with conductivity $\sigma$, the region between the surface of the earth and ionosphere has no currents and sources of magnetic field. Thus, the Earth's external magnetic field $(z<0)$ can be represented by the gradient of a scalar potential

$$
\underline{B}=-\nabla U \text {. }
$$

On the other hand, currents exist within the earth and therefore the internal magnetic field $(z>0)$ can be represented by the curl of a vector 
potential

$$
\underline{B}=\nabla x \underline{A} .
$$

Based on equations 2.3 and 2.18, $U$ must obey Laplace's equation and should satisfy $\nabla^{2} U=0$ where $U$ can be defined as the sum of elliptically polarized waves travelling in the y direction with amplitudes varying with $z$ and is expressed as

$$
U_{(}(y, z)=-\frac{1}{\nu} e^{i \nu y}\left(B_{e} e^{-\nu z}+B_{i} e^{+\nu z}\right) e^{-i \omega t}
$$

where

$\nu$ characterizes the spatial dimension of the wave (i. e. how uniform it is), $B_{e}$ and $B_{i}$ represent the amplitudes associated with the fields that originate externally or internally from the Earth, respectively.

For consistency, the vector potential $\underline{A}$ for the conductor (Earth) is defined as

$$
\underline{A}=A_{x}=F(y)\left(C e^{-\alpha z}+D e^{+\alpha z}\right) e^{-i \omega t}
$$

where $F(y)$ is expressed such that $\underline{A}$ also satisfies the diffusion equation

$$
\nabla^{2} \underline{A}=\frac{\partial^{2} \underline{A}}{\partial x^{2}}+\frac{\partial^{2} \underline{A}}{\partial y^{2}}+\frac{\partial^{2} \underline{A}}{\partial z^{2}}=\mu_{0} \sigma \frac{\partial \underline{A}}{\partial t} .
$$

Expanding and calculating for $F(y)$ as shown

$\frac{\partial^{2} F}{\partial y^{2}}\left(C e^{-\alpha z}+D e^{\alpha z}\right) e^{-i \omega t}+\alpha^{2} F\left(C e^{-\alpha z}+D e^{\alpha z}\right) e^{-i \omega t}=-\mu_{0} \sigma i \omega F\left(C e^{-\alpha z}+D e^{\alpha z}\right) e^{-i \omega t}$

and relating

$$
\frac{\partial^{2} F}{\partial y^{2}}+\left(\alpha^{2}-k^{2}\right) F=0
$$

gives

$$
F(y)=e^{i\left(\alpha^{2}-k^{2}\right)^{1 / 2}} y
$$

where $k^{2}=-i \omega \mu_{0} \sigma$, and

$$
\underline{A}=A_{x}=e^{i\left(\alpha^{2}-k^{2}\right)^{1 / 2} y}\left(C e^{-\alpha z}+D e^{+\alpha z}\right) e^{-i \omega t} .
$$


At the surface of the earth $(z=0)$, the magnetic field must be continuous, thus equating the internal and external magnetic fields at the surface gives:

$$
-\nabla U=\nabla x \underline{A}
$$

Expanding these

$$
-\frac{\partial U}{\partial x} \underline{i}-\frac{\partial U}{\partial y} \underline{j}-\frac{\partial U}{\partial z} \underline{k}=\left(\frac{\partial A_{z}}{\partial y}-\frac{\partial A_{y}}{\partial z}\right) \underline{i}+\left(\frac{\partial A_{x}}{\partial z}-\frac{\partial A_{z}}{\partial x}\right) \underline{j}+\left(\frac{\partial A_{y}}{\partial x}-\frac{\partial A_{x}}{\partial y}\right) \underline{k}
$$

Therefore, at the surface of the earth $(z=0)$

$$
B_{y}=-\frac{\partial U}{\partial y}=\frac{\partial A_{x}}{\partial z}
$$

and

$$
B_{z}=-\frac{\partial U}{\partial z}=\frac{\partial A_{x}}{\partial y}
$$

Applying the boundary condition of continuity of the tangential component of $\underline{B}$ gives

$$
i e^{i \nu y}(B e+B i)=F(y)(-\alpha C+\alpha D)
$$

which means that

$$
F(y)=e^{i \nu y}
$$

Equating

$$
i e^{i \nu y}=e^{i\left(\alpha^{2}-k^{2}\right)^{(12) y}}
$$

gives

$$
\alpha^{2}=\nu^{2}+k^{2}
$$

Equation 2.31 becomes

$$
B_{e}+B_{i}=-\alpha C+\alpha D
$$

Applying the continuity to the $z$ component of $\underline{B}$ yields

$$
B_{e}-B_{i}=i \nu(C+D) .
$$


As $A_{x}$ must go to zero as $z$ goes to infinity it follows that $D=0$ and this yields

$$
B_{e}+B_{i}=-\alpha C
$$

and

$$
B_{e}-B_{i}=i \nu C,
$$

which then yields the ratio of the coefficients of the internal and external magnetic fields to be

$$
\frac{B_{i}}{B_{e}}=\frac{\alpha-\nu}{\alpha+\nu} .
$$

In EM studies, however, the actual ratios of interest are $B z / B y$ and $E x / B y$. Using equation 2.31 to find the $B_{y}$ and $B_{z}$ components at $z=0$, its ratio at the surface of the Earth is given by

$$
\frac{B_{z}}{B_{y}}=\frac{i \nu}{\alpha}=\frac{i \nu}{\left(\nu^{2}+k^{2}\right)^{1 / 2}} .
$$

To obtain $E_{x} / B_{y}$, substitute equation 2.19 into equation 2.2, yields

$$
E=-\frac{\partial A}{\partial t}
$$

and since $E_{x}$ is parallel to the surface of the Earth there is no charge accumulation, which leads to

$$
\frac{E_{x}}{B_{y}}=-\frac{i \omega}{\alpha}=-\frac{i \omega}{\left(\nu^{2}+k^{2}\right)^{1 / 2}} .
$$

Assuming that the inducing field is spatially uniform $(\nu=0)$ yields $\frac{B_{z}}{B_{y}}=0$, implying that over a uniform conducting half space there is no vertical magnetic field and

$$
\frac{E_{x}}{B_{y}}=-\frac{i \omega}{k}=\frac{-i \omega}{\left(-i \omega \mu_{0} \sigma\right)^{1 / 2}},
$$

which means that the ratio of the electric and magnetic field at the surface at any frequency is related to the conductivity of the medium. The latter is usually expressed as the apparent resistivity in the form

$$
\rho_{a}=\frac{\mu_{0}}{\omega} \frac{\left|E_{x}\right|^{2}}{\left|B_{y}\right|}=\frac{\mu_{0}}{\omega} \frac{\omega^{2}}{\omega \mu_{0} \sigma}=\frac{1}{\sigma} .
$$


This indicates that in a homogenous half-space, the apparent resistivity is equal to the true resistivity. The phase relationship $\phi$ between $E_{x}$ and $B_{y}$ is related to the ratio of the real and imaginary parts of $E_{x} / B_{y}$ as shown by

$$
\frac{E_{x}}{B_{y}}=\frac{i \omega}{\left(-i \omega \mu_{0} \sigma\right)^{1 / 2}}=(1-i)\left(\frac{\omega}{2 \mu_{0} \sigma}\right)^{1 / 2}
$$

and

$$
\phi=\tan ^{-1} \frac{\operatorname{Im}}{R e}=\tan ^{-1} 1,
$$

which gives the phase difference between the electric and magnetic fields for a homogeneous half-space equal to $45^{\circ}$.

\subsection{Solution to a 2-dimensional Earth}

Figure 2.1 shows a simple 2-dimensional model with two regions divided by a vertical resistivity boundary extending to infinite depth $(z)$ and striking in the $x$ direction. In this case, the electric current now crosses a boundary but the electric current density must be conserved on both sides. This means that (based on Ohms Law: $\underline{J}=\underline{\sigma E}) \underline{E}$ changes as it crosses the boundary. Furthermore, for a conductive region that depends only on the $y$ and $z$ directions (Figure 2.1), Maxwells equations (assuming a time variation of $e^{-i \omega t}$ and neglecting displacement currents) can be written as $\nabla x E=i \omega \underline{B}$ and $\nabla x \underline{B}=\mu_{0} \sigma(y, z) \underline{E}$. Expressed in component form following the procedure, $\nabla x A=\left(\frac{\partial A_{z}}{\partial y}-\right.$ $\left.\frac{\partial A_{y}}{\partial z}, \frac{\partial A_{x}}{\partial z}-\frac{\partial A_{z}}{\partial x}, \frac{\partial A_{y}}{\partial x}-\frac{\partial A_{x}}{\partial y}\right)$ yields

$$
\begin{gathered}
\frac{\partial B_{z}}{\partial y}-\frac{\partial B_{y}}{\partial z}=\mu_{0} \sigma \underline{E}_{x} \\
\frac{\partial E_{z}}{\partial y}-\frac{\partial E_{y}}{\partial z}=i \omega \underline{B}_{x} \\
\frac{\partial B_{x}}{\partial z}=\mu_{0} \sigma \underline{E}_{y} \\
\frac{\partial E_{z}}{\partial z}=i \omega \underline{B}_{y}
\end{gathered}
$$




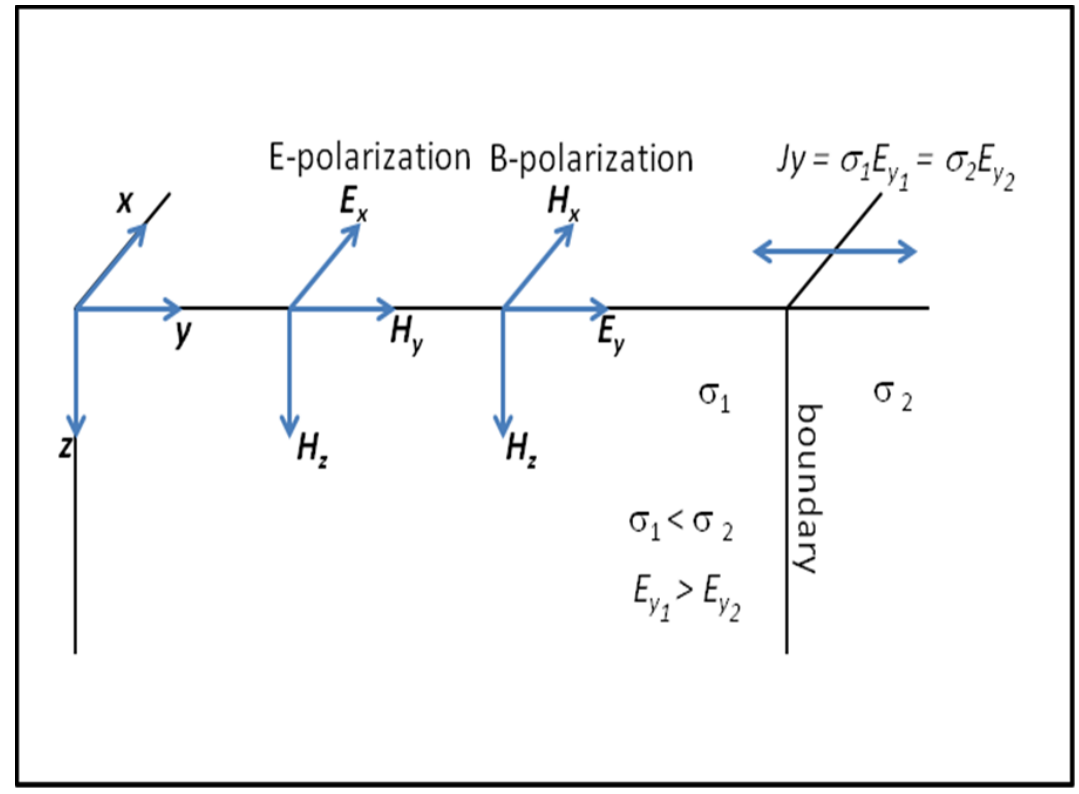

Figure 2.1: A simple 2-D model

$$
\begin{gathered}
-\frac{\partial B_{x}}{\partial y}=\mu_{0} \sigma \underline{E}_{z} \\
-\frac{\partial E_{x}}{\partial y}=i \omega \underline{B}_{z} .
\end{gathered}
$$

It can be noticed that Equations $2.47,2.50$ and 2.51 contain only $\underline{E}_{x}, \underline{B}_{y}$ and $\underline{B}_{z}$ components. Eliminating $\underline{B}_{y}$ and $\underline{B}_{z}$, these equations give

$$
\frac{\partial^{2} \underline{E}_{x}}{\partial y^{2}}-\frac{\partial^{2} \underline{E}_{x}}{\partial z^{2}}=-i \omega \mu_{0} \sigma \underline{E}_{x}
$$

which describe the electric current flowing parallel to the strike direction $(x)$. This is known as the E-polarization or the transverse electric or TE mode of induction. On the other hand, equations 2.48, 2.49 and 2.51 include only $\underline{E}_{y}, \underline{E}_{z}$ and $\underline{B}_{x}$ components. Eliminating $\underline{E}_{y}$ and $\underline{E}_{z}$, these equations lead to

$$
\frac{\partial^{2} \underline{B}_{x}}{\partial y^{2}}-\frac{\partial^{2} \underline{B}_{x}}{\partial z^{2}}-\frac{1}{\sigma}\left(\frac{\partial \sigma}{\partial x} \frac{\partial B_{x}}{\partial y}+\frac{\partial \sigma}{\partial z} \frac{\partial B_{x}}{\partial z}\right)=-i \omega \mu_{0} \sigma \underline{B}_{x}
$$


which describes the magnetic field flowing parallel to the strike direction $(x)$. This is referred to as the B-polarization or $T M$ mode of induction.

As was just shown, induction in a 2-dimensional Earth can be divided into two independent modes represented by two separate equations, which can be resolved using numerical techniques involving matrix calculations.

In general, the $T M$ mode has an advantage in resolving the lateral resistivity boundary while the $T E$ mode is more stable in estimating the variation of resistivity with depth.

\subsection{Solution to a 3-dimensional Earth}

For a 3-dimensional Earth, all the properties of the magnetic and electric fields in all directions are considered. These properties are linked through the concept of the impedance tensor $Z$, which will be discussed in detail in the next section. The solution also needs numerical programs to solve for the matrix calculations involving the impedance. In principle, this can be done the same way like the 2-D case but would consist of much larger matrices and the needed computational requirements would also increase.

\subsection{MT sounding: concept of impedance and tipper}

MT only needs the orthogonal components of $\underline{E}$ and $\underline{H}(B)$, which are the horizontal components along the north $(x)$ and east $(y)$ directions, to estimate the conductivity structure beneath and around the recording site. However, the magnetic field's vertical component $\left(\underline{H}_{z}\right)$ is also usually measured. 
Since the conductivity within the Earth is much greater than that outside the Earth, it can be assumed that for a horizontally layered Earth, all currents and fields are horizontal. Even in situations where conductivity varies laterally, it can be assumed that only the horizontal components of $\underline{H}$ cause induction and the response are the horizontal components of $\underline{E}$.

This can be mathematically represented as the convolution of $\underline{H}$ with a response function of the earth $Z$ to give $\underline{E}$ as a function of time, stated as

$$
\underline{E}(\tau)=\int \underline{Z}(t-\tau) \underline{H}(t) d t .
$$

Through Fourier Transformation this can be further described as a function of frequency and give

$$
\underline{E}(\omega)=\underline{Z}(\omega) \underline{H}(\omega)
$$

where $\mathrm{Z}$ is known as the "impedance tensor". Written in terms of $x$ and $y$ components, this becomes

$$
\begin{aligned}
& \underline{E}_{x}=Z_{x x} \underline{H}_{x}+Z_{x y} \underline{H}_{y} \\
& \underline{E}_{y}=Z_{y x} \underline{H}_{x}+Z_{y y} \underline{H}_{y}
\end{aligned}
$$

respectively. In practice, the impedance tensor $Z_{i j}$ is complex and is usually expressed in terms of an apparent resistivity $\left(\rho_{a}\right)$ where

$$
\rho_{a}=\frac{1}{\mu_{0} \omega}\left|Z_{i j}\right|^{2}
$$

and phase $\left(\phi_{a}\right)$ where

$$
\phi_{a}=\tan ^{-1} \frac{Z_{i}}{Z_{r}}
$$

where $Z_{i}$ and $Z_{r}$ are the imaginary and real parts of $Z_{i j}$.

In a uniform conductor, equation 2.59 would also reflect the true resistivity of the conductor. In a 1-dimensional situation the electric field 
components are related only to the orthogonal magnetic field components. This means that $Z_{x x}=Z_{y y}=0$ and $Z_{x y}=-Z_{y x}$. The minus sign of the off-diagonal components indicates the phase lag.

In a 2-dimensional setting, all the components of the impedance tensor will be non-zero, and will depend on the orientation of the measurements with respect to the strike direction of the conductivity structure. However, when one of the measurement axes is aligned to the strike direction of the conductivity structure, the impedance tensor simplifies to $Z_{\|}$and $Z_{\perp}$ corresponding to the TE and TM modes, respectively. In this case, $\underline{E}_{x}$ is now only associated with $\underline{H}_{y}$ and $\underline{E}_{y}$ to $\underline{H}_{x}$. Assuming that the measurement axes are oriented at an angle $\gamma$ clockwise from the strike direction, the impedances from the measurement axes can be expressed in terms of the strike oriented axis as

$$
\begin{gathered}
Z_{x x}=\left(\frac{Z_{\|}+Z_{\perp}}{2}\right) \sin 2 \gamma \\
Z_{x y}=\left(\frac{Z_{\|}-Z_{\perp}}{2}\right)+\left(\frac{Z_{\|}+Z_{\perp}}{2}\right) \cos 2 \gamma \\
Z_{y x}=-\left(\frac{Z_{\|}-Z_{\perp}}{2}\right)+\left(\frac{Z_{\|}+Z_{\perp}}{2}\right) \cos 2 \gamma \\
Z_{y y}=-\left(\frac{Z_{\|}+Z_{\perp}}{2}\right) \sin 2 \gamma .
\end{gathered}
$$

Evaluating these equations show $Z_{x x}=Z_{y y}=0, Z_{x y}=Z_{\|}$and $Z_{y x}=Z_{\perp}$. Thus, the impedance has only two non-zero components which relates to the TE and TM modes.

In practice, however, the strike direction is unknown and has to be recovered from the measured impedances. Although this was originally done by applying a mathematical rotation to the measured impedances that would result in maximum and minimum values for $Z_{x y}^{\prime}(\theta)$ and $Z_{y x}^{\prime}(\theta)$, which corresponds to the rotated impedances of $Z_{\|}$and $Z_{\perp}$ at an angle $\theta$ (Swift, 1967), more sophisticated techniques for identifying the strike are now widely used often as part of the distortion analysis (Bahr, 1991; Groom and Bailey, 1989; Caldwell et al., 2004). It should be 
noted that the determined strike angle has a $90^{\circ}$ ambiguity since rotating it to $90^{\circ}$ also gives a minimum and maximum value for $Z_{x y}^{\prime}\left(\theta+90^{\circ}\right)$ and $Z_{y x}^{\prime}\left(\theta+90^{\circ}\right)$, but swapping the $Z_{\|}$and $Z_{\perp}$ impedances

In 3-dimensional cases, the impedance elements will be non zero at any orientation. Nevertheless, a certain section over a frequency range may exhibit a 2-dimensional characteristic that enables the calculation of a sensible strike direction. How this is achieved is discussed further in distortion analysis section.

So far, only the horizontal components of the magnetic field $\left(H_{x}, H_{y}\right)$ have been considered. The measured vertical component of the magnetic field $\left(H_{z}\right)$, defines the geomagnetic deep sounding complex transfer functions, which reflect the relationship between the magnitude and phase of the horizontal inducing field and the vertical anomalous field for a given frequency $\omega$. This relationship can be expressed as

$$
H_{z}=A H_{x}+B H_{y}
$$

where A and B are the transfer functions, also known as the Tipper vectors. This relationship is usually represented by the real $|R|$ and imaginary $|I|$ components of the induction arrows whose magnitudes are defined by

$$
\begin{aligned}
& |R|=\left(A_{r}^{2}+B_{r}^{2}\right)^{1 / 2} \\
& |I|=\left(A_{i}^{2}+B_{i}^{2}\right)^{1 / 2} .
\end{aligned}
$$

The real and imaginary directions of the arrows are given by

$$
\begin{gathered}
\theta_{R}=\tan ^{-1}\left(\frac{B_{r}}{A_{r}}\right)+\pi \\
\theta_{I}=\tan ^{-1}\left(\frac{B_{i}}{A_{i}}\right),
\end{gathered}
$$

respectively. The real induction arrow points to regions of high conductance (Parkinson, 1962). 


\subsection{Distortion}

Localized near-surface conductive heterogeneities can cause changes in the magnitude and direction of the electric field because of the accumulation of charges on the conductive boundaries. This result in a distorted electric field measured at a site, independent of frequency. The effect of this distortion can be described by

$$
\underline{E}(\omega)=\underline{E}_{R}(\omega)+\underline{E}_{S}(\omega)
$$

where $\underline{E}$ is the observed electric field, $\underline{E}_{R}$ is the regional electric field and $\underline{E}_{S}$ is the secondary or scattered electric field resulting from the interaction of the regional field and the conductive heterogeneities. However, if the inductive effects are assumed to be negligible and $\underline{E}_{R}$ is spatially uniform over the dimensions of the heterogeneities, $\underline{E}_{S}$ becomes linearly proportional to $\underline{E}_{R}$. The measured electric field can then be written as

$$
\underline{E}(\omega)=D \underline{E}_{R}(\omega)
$$

where $D$ is a real, frequency-independent $2 x 2$ distortion matrix. Similarly, assuming that there is no magnetic distortion,

$$
\underline{H}(\omega)=\underline{H}_{R}(\omega)
$$

where $\underline{H}$ is the measured magnetic field and $\underline{H}_{R}$ is the regional magnetic field. The regional impedance tensor $\underline{Z}_{R}$ as related to the regional electric and magnetic fields is given by

$$
\underline{E}_{R}(\omega)=\underline{Z}_{R} \underline{H}_{R}(\omega) .
$$

Based on the previous equations, it follows that

$$
\underline{E}(\omega)=D \underline{E}_{R}(\omega)=D \underline{Z}_{R} \underline{H}_{R} .
$$

Thus

$$
Z=D \underline{Z}_{R}
$$


The main aim of distortion analysis is to eliminate distortion effects and enables the recovery of the regional impedance from the measured data. One such method is the phase tensor analysis by Caldwell et al. (2004) discussed in the next section.

\subsection{Phase tensor analysis}

As previously stated in equation $2.75, Z=D \underline{Z}_{R}$. Expressing $Z$ into the real and imaginary parts yields

$$
\begin{gathered}
Z=X+i Y \\
Z_{R}=X_{R}+i Y_{R} \\
X=D X_{R} \\
Y=D Y_{R} .
\end{gathered}
$$

The phase tensor $\Phi$ is defined from the ratio of the real and imaginary parts

$$
\Phi=X^{-1} Y=X_{R}^{-1} D^{-1} D Y_{R}=X_{R}^{-1} Y_{R}=\Phi_{R} .
$$

This shows that the observed and regional phase tensors are equal and are thus not affected by the distortion tensor. The phase tensor can be expressed as a matrix in terms of its real and imaginary components:

$$
\left[\begin{array}{ll}
\Phi_{11} & \Phi_{12} \\
\Phi_{21} & \Phi_{22}
\end{array}\right]=\frac{1}{\operatorname{det}(X)}\left[\begin{array}{ll}
X_{22} Y_{11}-X_{12} Y_{21} & X_{22} Y_{12}-X_{12} Y_{22} \\
X_{11} Y_{21}-X_{21} Y_{11} & X_{11} Y_{22}-X_{21} Y_{12}
\end{array}\right]
$$

where $\operatorname{det}(X)=X_{11} Y_{22}-X_{21} Y_{12}$. Three coordinate invariants are used to define the phase tensor: a maximum tensor value $\left(\Phi_{\max }\right)$,a minimum tensor value $\left(\Phi_{\min }\right)$ and the skew angle $(\beta)$. Mathematically,

$\left.\Phi_{\text {max }}=\frac{1}{2}\left[\left(\Phi_{11}+\Phi_{22}\right)^{2}+\left(\Phi_{12}-\Phi_{21}\right)^{2}\right)\right]^{1 / 2}+\frac{1}{2}\left[\left(\Phi_{11}-\Phi_{22}\right)^{2}+\left(\Phi_{12}+\Phi_{21}\right)^{2}\right]^{1 / 2}$ 


$$
\begin{gathered}
\left.\Phi_{\text {min }}=\frac{1}{2}\left[\left(\Phi_{11}+\Phi_{22}\right)^{2}+\left(\Phi_{12}-\Phi_{21}\right)^{2}\right)\right]^{1 / 2}-\frac{1}{2}\left[\left(\Phi_{11}-\Phi_{22}\right)^{2}+\left(\Phi_{12}+\Phi_{21}\right)^{2}\right]^{1 / 2} \\
\beta=\frac{1}{2} \tan ^{-1}\left(\frac{\Phi_{12}-\Phi_{21}}{\Phi_{11}-\Phi_{22}}\right) .
\end{gathered}
$$

Another element of the phase tensor that denotes the dependence of the phase tensor to the coordinate system is

$$
\alpha=\frac{1}{2} \tan ^{-1}\left(\frac{\Phi_{12}+\Phi_{21}}{\Phi_{11}+\Phi_{22}}\right) .
$$

The predominant strike direction is determined by $\alpha-\beta$.

Using these parameters, the phase tensor can be expressed as

$$
\Phi=R^{T}(\alpha-\beta)\left[\begin{array}{cc}
\Phi_{\max } & 0 \\
0 & \Phi_{\min }
\end{array}\right] R(\alpha+\beta)
$$

where $R(\theta)=\left[\begin{array}{cc}\cos \theta & \sin \theta \\ -\sin \theta & \cos \theta\end{array}\right]$ and $R^{T}(\theta)=R^{-1}(\theta)=R(-\theta)$.

The phase tensor can be represented graphically by an ellipse as shown in Figure 2.2. The phase tensor ellipticity is given by

$$
\lambda=\frac{\Phi_{\max }-\Phi_{\min }}{\Phi_{\max }+\Phi_{\min }} .
$$

In 1-D case, the ellipse will reduce to a circle at all periods since $\Phi_{\min }=\Phi_{\max }$. Furthermore, $\beta=\alpha=0$ and $\lambda=0$.

On the other hand, for the 2-D case, when the coordinate axes are rotated parallel or perpendicular to the strike direction, $\Phi_{\min }$ and $\Phi_{\max }$ are equal to the axes' lengths and one of these is aligned to the strike, so $\lambda \neq 0$. Also, $\beta=0$ while $\alpha \neq 0$, making $\alpha-\beta$ constant.

Lastly, for the 3-D case, all of the components of the phase tensor are non-zero $(\beta \neq 0, \lambda \neq 0)$. $\beta$ can then be used as a measure of departure from the 2-D case, the bigger the value of $\beta$, the greater the departure from the 2-D case (i.e. when $|\beta|>\beta_{C}$, where $\beta_{C}$ is some threshold value that indicates 3-dimensionality). Instances with small values of $\beta$ can be approximated similar to 2-D cases without significant errors (Bibby et al., 2005). 


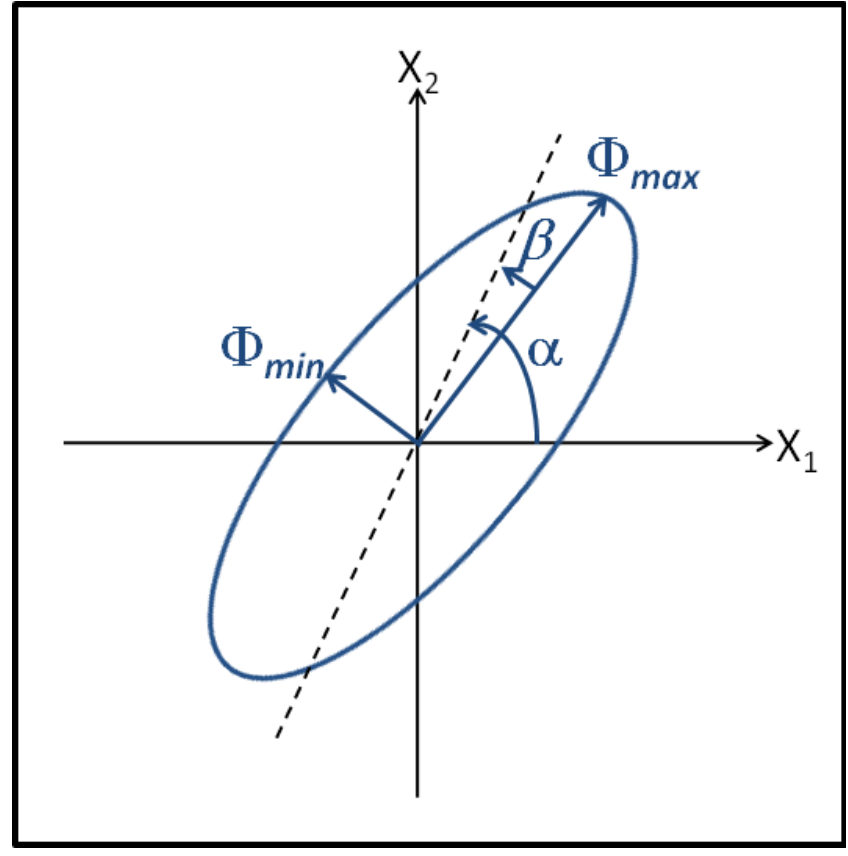

Figure 2.2: The phase tensor ellipse (Caldwell et al., 2004)

\subsection{Static shift}

One of the types of galvanic distortion is the so-called static shift, which creates a shift in the apparent resistivity curves (i.e. TE, TM)relative to each other. This is mainly caused by the build up of electrical charges along a discontinuity separating a conductor from a resistor. This can be illustrated mathematically by treating the distortion tensor as a matrix of four real numbers

$$
D=\left(\begin{array}{ll}
d_{11} & d_{12} \\
d_{21} & d_{22}
\end{array}\right)
$$

making the impedances as

$$
\left(\begin{array}{ll}
Z_{1} & Z_{2} \\
Z_{3} & Z_{4}
\end{array}\right)=\left(\begin{array}{ll}
d_{11} & d_{12} \\
d_{21} & d_{22}
\end{array}\right)\left(\begin{array}{cc}
Z_{x x} & Z_{x y} \\
Z_{y x} & Z_{y y}
\end{array}\right) .
$$

From which

$$
Z_{1}=d_{11} Z_{x x}+d_{12} Z_{y x}
$$




$$
\begin{aligned}
& Z_{2}=d_{11} Z_{x y}+d_{12} Z_{y y} \\
& Z_{3}=d_{21} Z_{x x}+d_{22} Z_{y x} \\
& Z_{4}=d_{21} Z_{x y}+d_{22} Z_{y y} .
\end{aligned}
$$

If the regional structure is 1-dimensional $\left(Z_{x x}=Z_{y y}=0\right.$ and $Z_{x y}=$ $-Z_{y x}$ ), equations 2.90 to 2.93 simplifies to

$$
\begin{gathered}
Z_{1}=-d_{12} Z_{x y} \\
Z_{2}=d_{11} Z_{x y} \\
Z_{3}=-d_{22} Z_{x y} \\
Z_{4}=d_{21} Z_{x y} .
\end{gathered}
$$

The apparent resistivity can then be expressed as multiples of apparent resistivities calculated from $Z_{x y}$, such that

$$
\rho_{a 2}=\frac{1}{\mu_{0} \omega}\left|Z_{2}\right|^{2}=\frac{1}{\mu_{0} \omega} d_{11}^{2}\left|Z_{x y}\right|^{2}=d_{11} \rho_{a x y} .
$$

This leads to

$$
\log \rho_{a 2}=\log d_{11}^{2}+\log \rho_{a x y}=2 \log d_{11}+\log \rho_{a_{x y}} .
$$

Which when shown on a log-log plot of the apparent resisitivty against period, the shift is independent of frequency and the entire resistivity curve is shifted by a constant value equivalent to $2 \log d_{11}$. This shift can either be going up or going down depending on $d_{11}$ either being $>1$ or $<1$, respectively.

Furthermore, as $d_{11}$ is real, $Z_{2}=d_{11} Z_{x y}$, the phase is

$$
\phi_{2}=\tan ^{-1} \frac{\operatorname{Im}\left(Z_{2}\right)}{\operatorname{Re}\left(Z_{2}\right)}=\tan ^{-1} \frac{\operatorname{Im}\left(d_{11} Z_{x y}\right)}{\operatorname{Re}\left(d_{11} Z_{x y}\right)}=\tan ^{-1} \frac{\operatorname{Im}\left(Z_{x y}\right)}{\operatorname{Re}(Z x y)}=\phi_{x y} \text {. }
$$

This demonstrates that static shift does not affect the phase.

In a 2-dimensional case, the impedance elements are computed based on the angle of rotation from the strike direction $(\theta)$. However, when the 
data are rotated parallel or perpendicular to the strike direction the rotated impedance elements $\left(Z^{\prime}\right)$ simplify to

$$
\begin{aligned}
& Z_{1}^{\prime}(\theta)=D_{12} Z_{y x}^{\prime}(\theta)=D_{12} Z_{\perp} \\
& Z_{2}^{\prime}(\theta)=D_{11} Z_{x y}^{\prime}(\theta)=D_{11} Z_{\|} \\
& Z_{3}^{\prime}(\theta)=D_{22} Z_{y x}^{\prime}(\theta)=D_{22} Z_{\perp} \\
& Z_{4}^{\prime}(\theta)=D_{21} Z_{x y}^{\prime}(\theta)=D_{21} Z_{\|} .
\end{aligned}
$$

Similarly by computing the apparent resistivity as simple multiples of the principal impedances shows that the apparent resistivity $\rho_{a}$ is shifted while the phase $\theta$ is not affected.

Static shifts can be corrected using transient electropmagnetic (TEM) data since the magnetic field is relatively unaffected by surface inhomogeneities (Sternberg et al., 1988).

\subsection{Modeling}

Modeling schemes can be classified into two types: forward and inverse. A forward modeling scheme is basically computing for the response (apparent resistivity and phase at the surface) of a given model with known dimensions and properties (i.e. conductivity, thickness). In contrast, an inversion modeling scheme involves the calculation of a model from a given data set until a reasonable fit of the computed response with the measured data is achieved. The main aim of the inversion scheme is to create a real distribution of conductivity $(\sigma)$ in space $(x, y, z)$ from a series of apparent resistivity and phase data based on the impedance tensors. Most of these schemes are based on finding the smoothest model that fits the data but lies within an accepted threshold value. It should be noted however that a certain data set can produce several models that can equally fit it. Extra care should be given to verify if the resulting model is realistic and sensible. One way to do this is 
usually done by comparing the results of the different models produced by 1-D, 2-D and 3-D schemes and check for consistency in the models. The forward model is generally used as the initial model before inversion modeling is performed.

This section gives an overview of the modeling schemes, from 1-D to 3-D, which were used and considered during processing of the data.

\subsubsection{1-dimensional modeling}

The commonly used 1D inversion schemes are the (Bostick, 1977), the 1-D simple layered model and the Occam Inversion (Constable et al., 1987). An overview of these schemes is presented here.

\subsubsection{Bostick inversion}

This is one of the simpler inversion schemes which provide a reasonable first approximation to the true conductivity-depth distribution beneath the recording station (Jones, 1983). This is given in terms of $\rho(h)$, where $h$ is the penetration depth in a half-space medium of resistivity which is equal to the apparent resistivity at a particular period. $h$ is related to the apparent resistivity at period $T$ by

$$
h=\sqrt{\frac{\rho_{a}(T) T}{2 \pi \mu_{0}}}
$$

and the corresponding resistivity at this depth is given by

$$
\rho=\rho_{a}(T) \frac{1+m(T)}{1-m(T)}
$$

where $m$ is the gradient of the $\log \rho_{a}-\log T$ curve at period $T$.

One of the strengths of this inversion scheme is its effective determination of the depth to a conductor. 


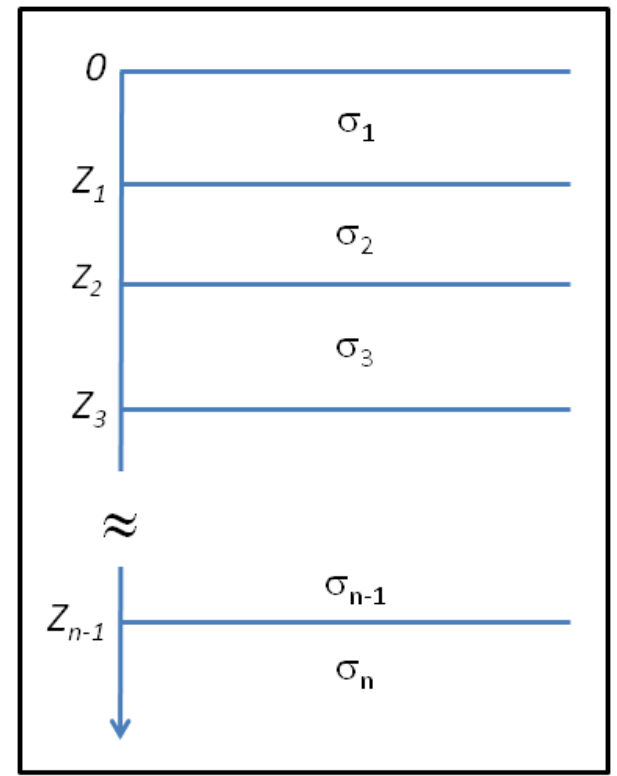

Figure 2.3: Simple 1-D layered model

\subsubsection{Simple layered model}

In the section 2.4, it was shown how the resistivity of a homogeneous half-space can be calculated from the horizontal components of the $\underline{E}$ and $\underline{B}$ fields. This can be extended to a layered half-space where the conductivity only varies with depth along the z-axis (Figure 2.3).

As previously stated, the magnetic field above the surface can be represented by a scalar potential $\underline{B}=-\nabla U$ with $U_{y, z}=-\frac{1}{\nu} e^{i \nu y}\left(B_{e} e^{-\nu z}+\right.$ $\left.B_{i} e^{+\nu z}\right) e^{i \omega t}$. Within each layer, the vector potential $A_{j}$ is used giving the magnetic field along the $\mathrm{y}$-direction $\underline{B}_{j}=\nabla x \underline{A}_{j}$.

From equation 2.21, it can defined that

$$
\underline{A}_{x j}=F(y)\left(C e^{-\alpha z}+D e^{+\alpha z}\right) e^{-i \omega t}
$$

where $\alpha_{j}^{2}=\nu^{2}+k_{j}^{2}$, with $\nu$ again being the spatial wave number of the source field. At the boundary between the $j$ and $(j+1)$ layers $\left(\right.$ at $\left.z_{j}\right)$ both $B_{z}$ and $B_{y}$ must be continuous giving

$$
-\alpha_{j} C_{j} e^{-\alpha_{j} Z_{j}}+\alpha_{j} D_{j} e^{\alpha_{j} Z_{j}}=-\alpha_{j+1} C_{j+1} e^{-\alpha_{j+1} Z_{j}}+\alpha_{j+1} D_{j+1} e^{\alpha_{j+1} Z_{j}}
$$


and

$$
C_{j} e^{-\alpha_{j} Z_{j}}+D_{j} e^{\alpha_{j} Z_{j}}=C_{j+1} e^{-\alpha_{j+1} Z_{j}}+D_{j+1} e^{\alpha_{j+1} Z_{j}} .
$$

Introducing $R_{j}=\frac{C_{j}}{D_{j}}$ and combining these equations yields

$$
R_{j}=e^{2 \alpha_{j} Z_{j}} \frac{R_{j+1}\left(\alpha_{j}+\alpha_{j+1}\right)+\left(\alpha_{j}+\alpha_{j+1}\right) e^{2 \alpha_{j+1} Z_{j}}}{R_{j+1}\left(\alpha_{j}-\alpha_{j+1}\right)+\left(\alpha_{j}+\alpha_{j+1}\right) e^{2 \alpha_{j+1} Z_{j}}} .
$$

At the lowermost layer $(n)$ the field has to go to zero as $z \rightarrow \infty$, which means that $D_{n}=0$. Therefore at the lowermost boundary $z=z_{n-1}$ and

$$
R_{n-1}=e^{2 \alpha_{n-1} Z_{n-1}} \frac{\alpha_{n-1}+\alpha_{n}}{\alpha_{n-1}-\alpha_{n}} .
$$

Given that at the surface, $\nabla x \underline{A}=\nabla \underline{U}$, values for both $B_{i} / B_{e}$ and $E_{x} / B_{y}$ can be calculated using

$$
\frac{E_{x}}{B_{y}}=\frac{-i \omega}{\alpha_{1}} \frac{R_{1}+1}{R_{1}-1} .
$$

These set of equations 2.110 to 2.112 form a recursive scheme, which enables the computation of $E_{x} / B_{y}$ at the surface if all the $z_{j}$ and $\sigma_{j}$ of all layers are given. Starting from the bottommost layer, equation 2.112 allows $R_{n-1}$ to be computed from $Z_{n-1}, \sigma_{n-1}$ and $\sigma_{n}$. Equation 2.110 can then be used repeatedly moving up through all the layers until values of $R_{1}$ is obtained, which can then be used to get the surface ratio of $E_{x} / B_{y}$ from which the apparent resistivities and phase can be calculated.

\subsubsection{Occam inversion}

The Occam inversion finds the smoothest possible model that fits the data within the expected tolerance level, rather than fitting the data as much as possible which then increases the roughness of the model. This method allows the model to be as flexible as possible and yet suppress complexity explicitly. This is done by introducing two main parameters: 
the roughness parameter which is defined as the integrated square of the first or second derivative with respect to depth:

$$
\begin{gathered}
R_{1}=\int(d m / d z)^{2} d z \\
R_{2}=\int\left(d^{2} m / d z^{2}\right)^{2} d z
\end{gathered}
$$

where $m(z)$ refers to resistivity or log resistivity, and the weighted leastsquares parameter, which is an estimation of the misfit:

$$
\left.X^{2}=\sum_{j-1}^{M}\left(d_{j}-F_{j}|m|\right)^{2}\right) / \sigma_{j}^{2}
$$

where $\sigma_{j}$ is the uncertainty in the $j t h$ datum. Rewriting both parameters in terms of simple matrix operations and applying the Lagrange multiplier $\mu^{-1}$ gives

$$
U=\left\|\tilde{\partial} m_{k+1}\right\|^{2}+\mu^{-1}\left\{\left\|\tilde{W}\left(d-F\left[m_{1}\right]+\tilde{J}_{1} m_{1}\right)-\tilde{W} \tilde{J}_{1} m_{k+1}\right\|^{2}-X_{*}^{2}\right\}
$$

where the first term on the right is the roughness and the second term is the misfit weighted by the Lagrange multiplier with $m_{1}$ as the initial model, $m_{k+1}$ is the successive model after the $k$ th iteration that minimizes $U, \tilde{W}$ is the diagonal $M x M$ matrix, and $X_{*}^{2}$ as the desired misfit value of $X^{2}$. Using this scheme, the final model is independent of the initial model and has the least 'roughness' while at the same time matches a specified 'misfit'. The vector $m_{k+1}$ and its misfit value $X_{*}^{2}$ were defined further as

$$
\begin{gathered}
m_{k+1}(\mu)=\left[\mu \tilde{\partial}^{T}+\left(\tilde{W} \tilde{J}_{k}\right)^{T} \tilde{W} \tilde{J}_{k}\right]^{-1}\left(\tilde{W} \tilde{J}_{k}\right)^{T} \tilde{W} \hat{d}_{k} \\
X_{k+1}(\mu)=\left\|\tilde{W} \hat{d}_{k}-\tilde{W} F\left[m_{k+1}(\mu)\right]\right\| .
\end{gathered}
$$

These 1-D modeling schemes enable the computations of the resistivity and phases from a given data set. However, MT data is rarely truly 1-D in a sense that it usually has two sets of curves having different features. Instead of choosing which particular curve to model, it is 


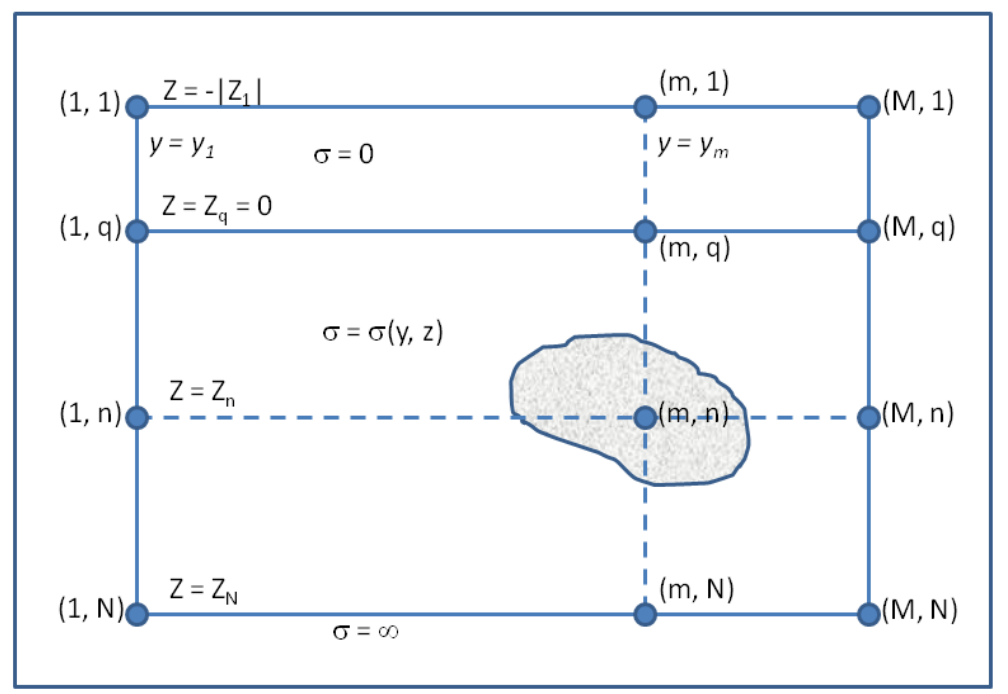

Figure 2.4: 2-D modeling (Brewitt-Taylor and Weaver, 1976)

customary to use $\rho_{a}$ and $\phi_{a}$ derived from impedances that are invariant with respect to the coordinated axes regardless of the dimensionality of the data. The commonly used invariant impedances are the average $\left(Z_{a v}\right)$ and the determinant $\left(Z_{\text {det }}\right)$ which are described as:

$$
Z_{a v}=\frac{1}{2}\left(Z_{x y}-Z_{y x}\right)
$$

and

$$
Z_{\text {det }}=\sqrt{\left(Z_{x x} Z_{y y}-Z_{x y} Z_{y x}\right)} .
$$

\subsubsection{2-dimensional modeling schemes}

An inclusive review of several 2-dimensional modeling techniques was made by Ogawa (2002). The classic 2-D modeling scheme by the finite difference method of Brewitt-Taylor and Weaver (1976) is discussed briefly here.

The structure is defined by a mesh with rectangular elements of varying dimensions and conductivity values (Figure 2.4). Two solutions can be derived, either for the TE or E-polarization mode or for the TM or 
B-polarization mode. The scheme consists of formulating equations to compute for $\underline{E}$ at all sides of the structure (i.e. left, right, top and bottom) taking into account that these should conform to the boundary conditions and diffusion equation. These series of equations can then be expressed as a matrix that allows the computation of $\underline{E}$ (for TE mode solution) at any point when $\underline{E}$ along the nodes have been estimated. Once the value for $\underline{E}$ is found the corresponding $\underline{B}$ can then be calculated using finite difference approximations of the Maxwells equation.

If the TM mode is used, a similar finite difference scheme is applied for $\underline{B}$ along the $y$ axis then $\underline{E}$ can then be derived from Maxwells equations.

\subsubsection{3-dimensional modeling}

Several 3-D inversion algorithms have been developed over the years (i.e. Madden and Mackie (1989); Siripunvaraporn et al. (2005); Sasaki (2001)). A comprehensive review of these methods was made by Siripunvaraporn (2011).

The 3-D code that was used for this project is the WSINV3DMT (Siripunvaraporn et al., 2005). The algorithm is based on the Occam's method (Constable et al., 1987; deGroot Hedlin and Constable, 1990) but considers a data-space scheme (Siripunvaraporn et al., 2005), wherein computation is conducted in a $N$ dimensional data space. This is in contrast with the usual model-space format wherein the computation is conducted in the $M$ dimensional model parameter space. One of the main advantages of using the data-space scheme is that the computational time and hardware requirement is greatly reduced since the number of independent data $N$ is generally less than $M$ (Siripunvaraporn et al., 2005). This makes the software applicable to invert a modest 3-D dataset on a PC. 


\subsection{Instrumentation and data acquisition}

A typical layout for an MT sounding is shown in Figure 2.5. The MT equipment consists of:

1. a receiver,

2. magnetic sensors, which are usually induction coils,

3. electric wires,

4. potential electrodes, which are made up of a porous ceramic base and non-polarising materials such as $\mathrm{Pb} / \mathrm{PbCl}_{2}$ or $\mathrm{Cu} / \mathrm{CuSO}_{4}$.

The wires, which are about 60 to $100 \mathrm{~m}$ in length depending on the flatness of the site, are arranged orthogonal to each other, oriented northsouth and east-west, relative to the magnetic north. These "E-lines" with the potential electrodes attached at the end, measure the voltage drop along the telluric dipole line. These electrodes are buried for better contact with the ground. On the hand, three sets of magnetic coils, oriented north-south, east-west, and vertically, measure the $\underline{H}_{x}, \underline{H}_{y}$, and $\underline{H}_{y}$, respectively. These coils are extremely sensitive to any movement that may be caused by wind, walking, vehicles, that they are buried also under the ground.

The wires and the magnetic sensors are connected to the receiver which is usually placed at the center of the layout. The receiver filters and records the data as time series files. Duration time for data recording is usually a minimum of 10 hours. Usually, by extending the recording time, which means more data are stacked up, improves the data quality.

An ideal site should be located in a relatively flat area about $100 \mathrm{~m}$ x $100 \mathrm{~m}$, and away from possible "noise" sources such as power lines, electrical fences, power plants, etc. 


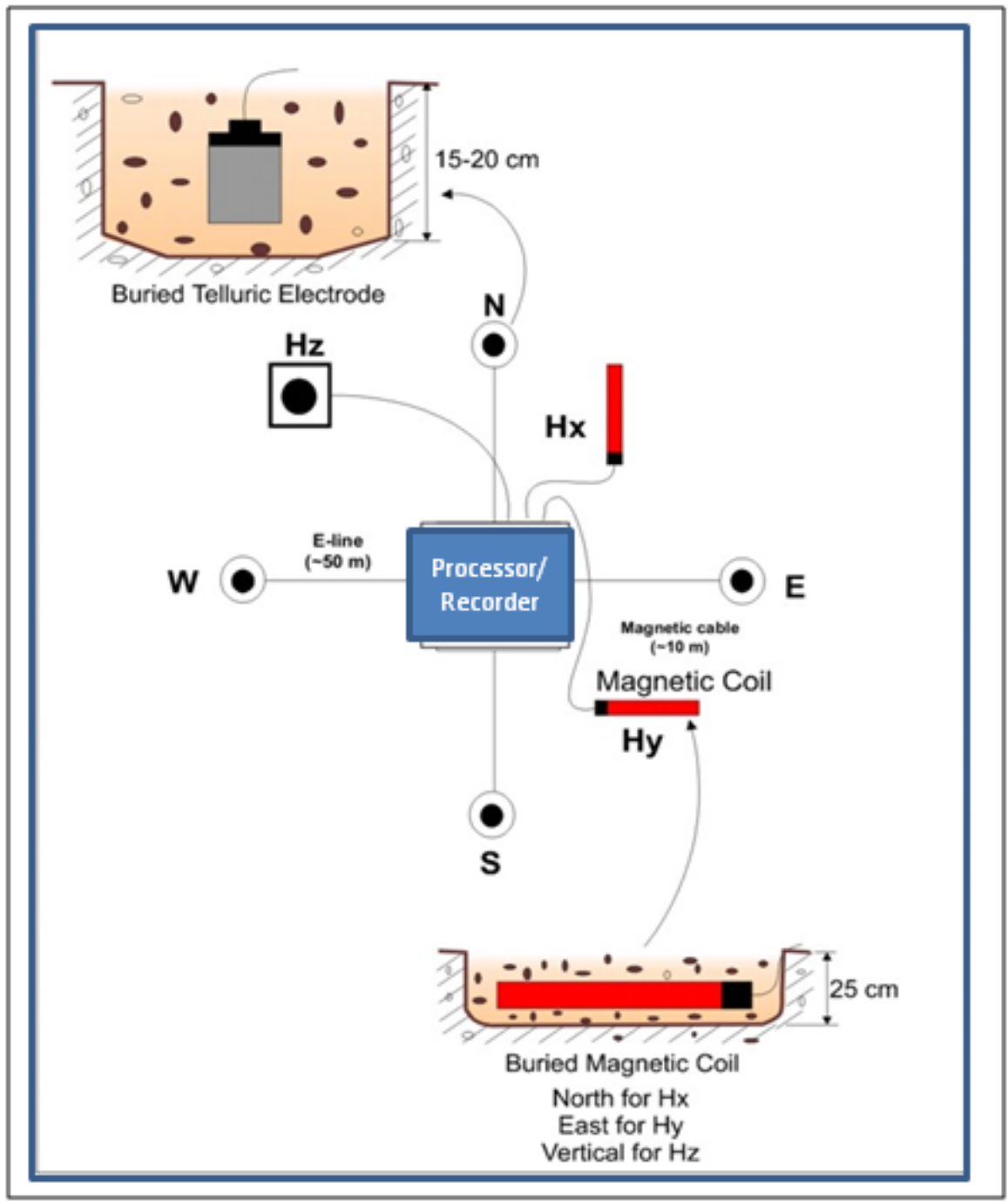

Figure 2.5: Typical MT station layout 


\subsection{Data processing}

A rundown of the general steps during MT data processing is shown in Figure 2.6. The "raw" time series data are converted to Discrete Fourier Transforms (DFT) to become functions of frequency using the software TStoFT (Phoenix Geophysics Ltd., 2005). The DFT's are then converted to "crosspowers" through "Robust" routines which filter out noise and outliers in the data. These softwares are included in the SSMT2000 data processing software (Phoenix Geophysics Ltd., 2005). The crosspower data which contain the impedances are then edited and converted to "EDI" files (Soc. of Expl. Geophysics., 1991) using the "MT editor" software (Phoenix Geophysics Ltd., 2005). The MT data are then analyzed using the phase tensors and "stripped" of distortions. The "stripped" EDI files are the ones used for modeling. The WinGLink software (Geosystem SRL, 2008) was used for 1-D and 2-D modeling, also for further editing of the data, which consist of masking of unwanted data points, curve smoothing (D+), static shift correction, TE and TM mode determination, and rotation of the impedances. 


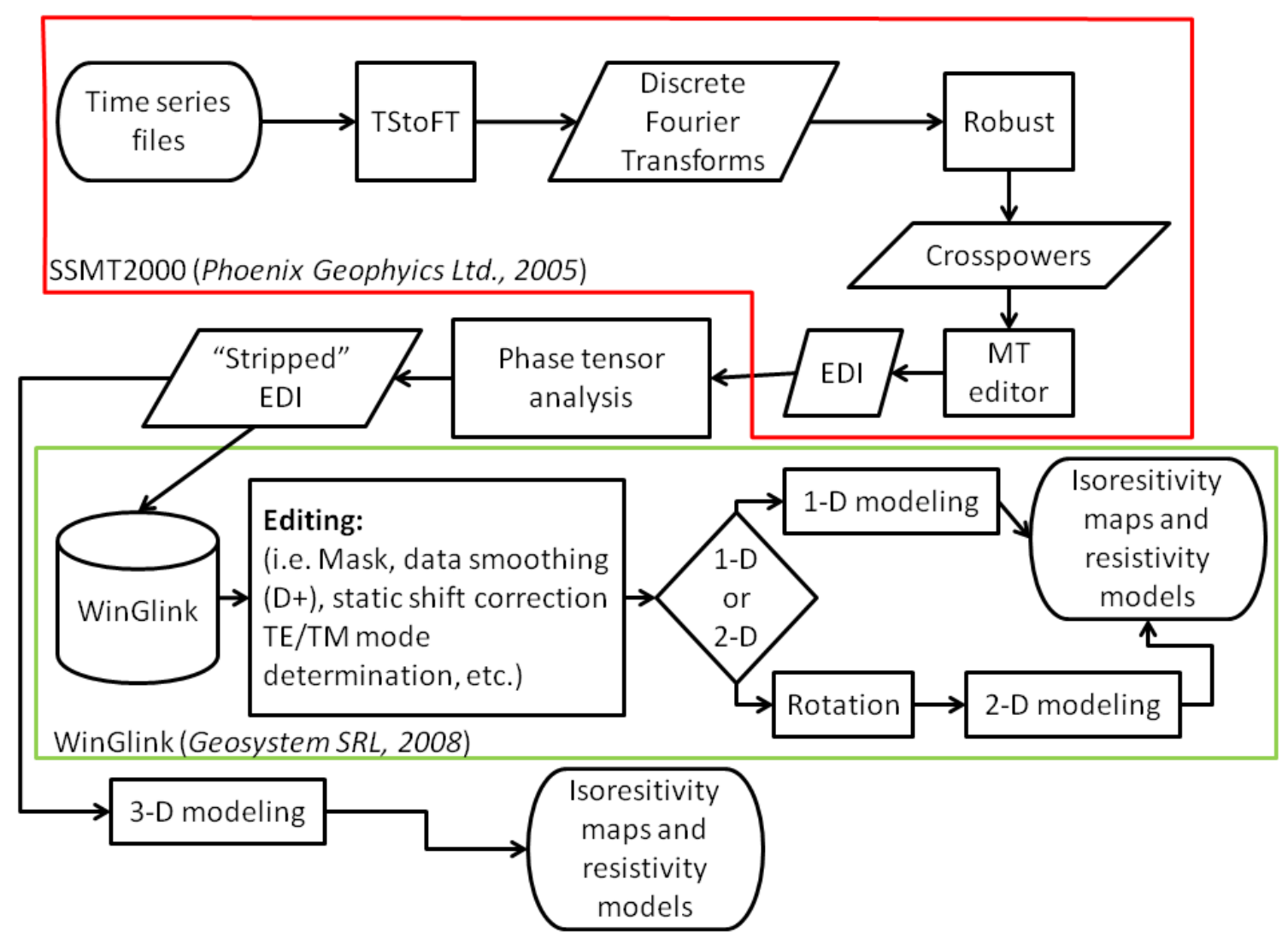

Figure 2.6: MT data processing flowchart 


\section{Chapter 3}

\section{Northern Negros Geothermal Project}

The Northern Negros Geothermal Project (NNGP) is located on the northern portion of the Philippine central island of Negros (Figure 3.1). It lies on the northwestern flank of the active Mt. Canlaon volcano, which is part of the northeasterly aligned cluster of volcanoes that include Mts. Mandalagan and Silay in the north. These volcanoes are associated with the subduction of the Sulu Sea Basin along the Negros Trench reaching depths of about $150 \mathrm{~km}$ (Acharya and Aggarwal, 1980).

Geoscientific studies in the area started in the 1970's when the then Commission on Volcano conducted a reconnaissance survey in Mambucal (Figure 3.2) and found thermal springs in the area (Comm. on Volcanology, 1981). Subsequent studies made by the National Power Corporation and Philippine National Oil Company-Energy Development Corporation (PNOC-EDC) led to the drilling of two exploratory wells MC-1 and MC-2 in 1978-79, which confirmed the existence of near-neutral fluids of almost $200^{\circ} \mathrm{C}$ (Reyes, 1979).

A new round of surveys during the 1980's to early 1990's which include the southern areas of Pataan and Hagdan, led to the drilling of deep exploration wells CT-1D, HG-1D, PT-1D and PT-2D in 1994- 


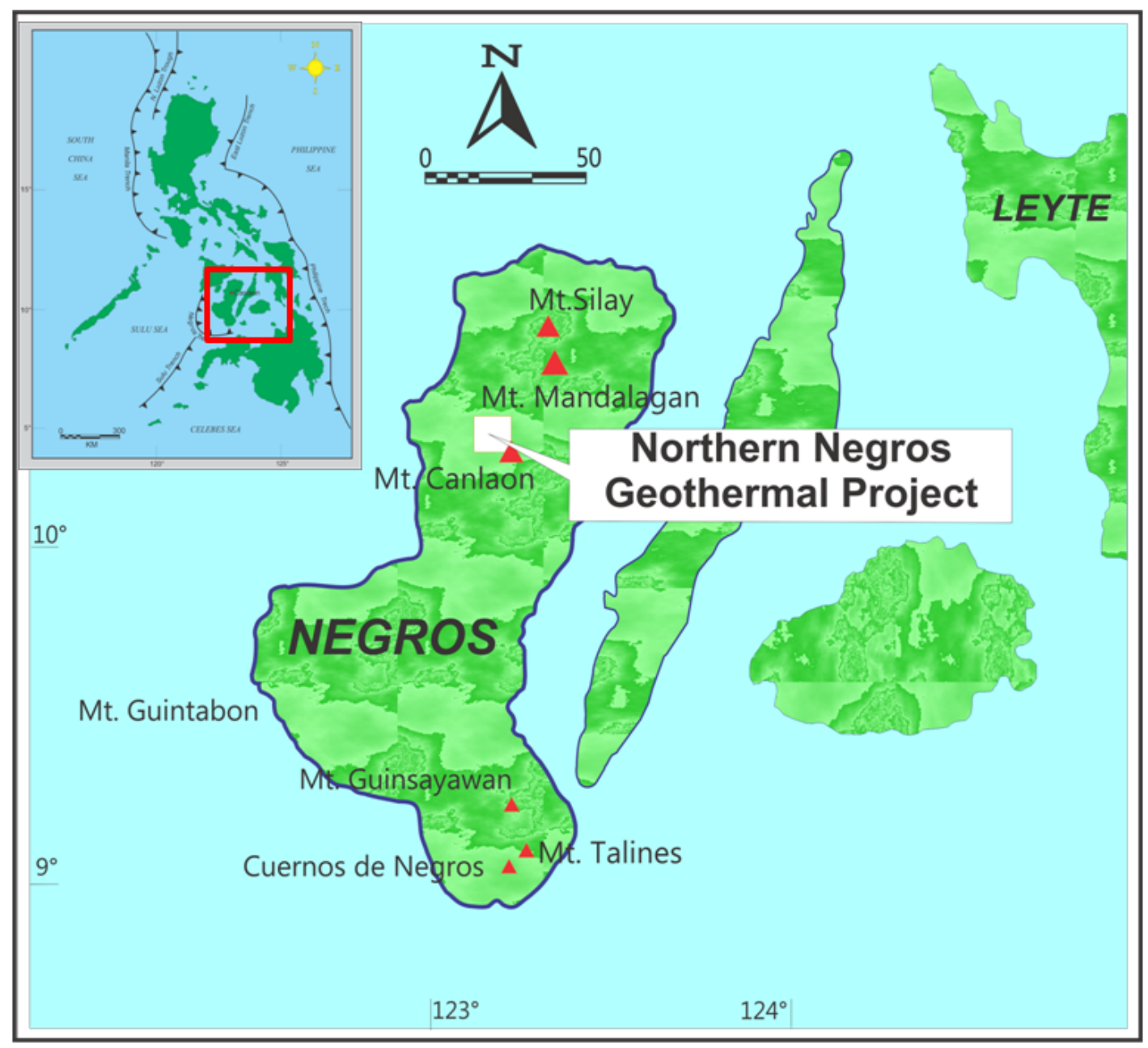

Figure 3.1: Location map of the Northern Negros Geothermal Project (NNGP) 


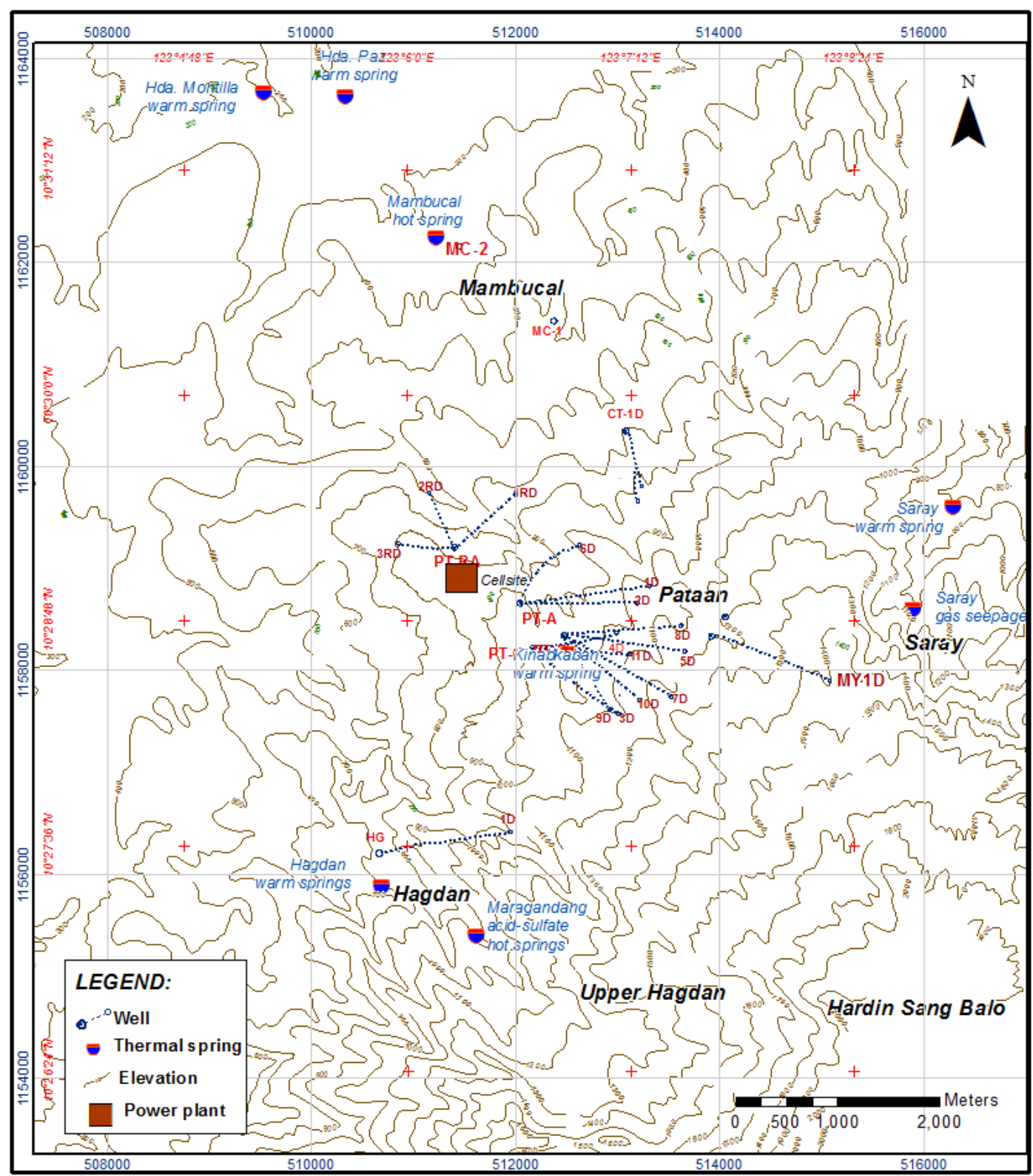

Figure 3.2: Location map of wells and thermal areas in NNGP 
95. High temperatures $>230^{\circ} \mathrm{C}$ were encountered at HG-1D and PT2D but output wellhead pressures were non-commercial. Since then, more studies like magnetotelluric (MT) and Bouguer gravity surveys have been conducted in the area. Nine additional wells (PT3D to PT11D) have also been drilled prior to the commissioning of the 50 MWe power plant in 1997. The latest of these is well MY-1D drilled towards the southeastern portion of Pataan in 2009 (Figure 3.2).

This chapter presents a summary of the main results of the previous studies conducted in NNGP.

\subsection{Geology}

The geologic map within the vicinity of Canlaon volcano is shown in Figure 3.3. Five major stratigraphic units have been identified (Pamatian et al., 1992). The oldest rock is the Cretaceous-Paleocene Basak Formation (Bf) which is made up of very thick interbedded sequences of two-pyroxene basalt lavas and clastic sedimentary rocks composed of mudstones, claystones and granule conglomerates. This is overlain by the Budlasan Volcanics (Blv) which is primarily made up of thick lava flows exposed on the southeast of Mt. Canlaon. This in turn is overlain by the Miocene Talave Formation (Tf) which is composed of interbedded sequence of recrystallized fossiliferous coralline limestone, sandstone, siltstone, claystone, conglomerate and volcaniclastic breccias (Pamatian et al., 1992). On top of this is a sequence of fossiliferous calcisiltites, calcarenites and calcirudites deposited during the Pliocene and collectively termed as the Caliling Formation (Cf). These are exposed with Karstic features in the eastern coast (Pamatian et al., 1992). The youngest unit is the Canlaon Volcanics ( $\mathrm{CnV}$ ) which is composed of Quaternary volcanic deposits erupted from Mt. Canlaon and its different vents during different episodes of eruptions. This unit includes pyroxene andesite lava flows, tuff breccias, and occasional dacites and basaltic flows. Only the 
younger two of these units, namely the $\mathrm{Tf}$ and $\mathrm{CnV}$ were intersected by the drilled wells in NNGP. Furthermore the Tf appears to occur deeper towards the SE and was not encountered by well MY-1D.

The dominant fault structures mapped in NNGP are the northwest/ north-northwest trending ones with minor east-west, north-east and northsouth/ north-northeast strike (Figure 3.4). Panem and Leynes (1996) inferred that the northwest and north-northwest trending structures transect the east-west and north-south faults. The east-west faults are found mainly in the southern portion traversing along ridges and stream channels.

The location of the thermal springs in NNGP is shown in Figure 3.2. These are found mainly in and northwest of Mambucal. Two are sited in Hagdan while only one, the Kinabkaban warm spring can be found within Pataan. A warm spring and gas seepage have also been reported at Saray. The most impressive of these is the hot spring in Hagdan reaching temperatures of $>50^{\circ} \mathrm{C}$. All except the Maragandang acid sulphate hot spring have neutral chloride fluids.

\subsection{Gravity survey}

A Bouguer gravity survey undertaken in 1995-96 detected a prominent gravity high ( $>12$ mgals) enclosing the area of Mt. Canlaon and and its northwestern flank towards Hagdan and Pataan (Figure 3.5 ). A similar gravity high is also exposed within the vicinity of Saray. These were interpreted to be intrusive bodies associated with the Canlaon Volcanic Complex (Rigor and Los Banos, 1997). The decreasing gravity values surrounding the gravity high are attributed to the thickening of pyroclastic materials and sedimentary deposits such as the Basak Formation in the east. 


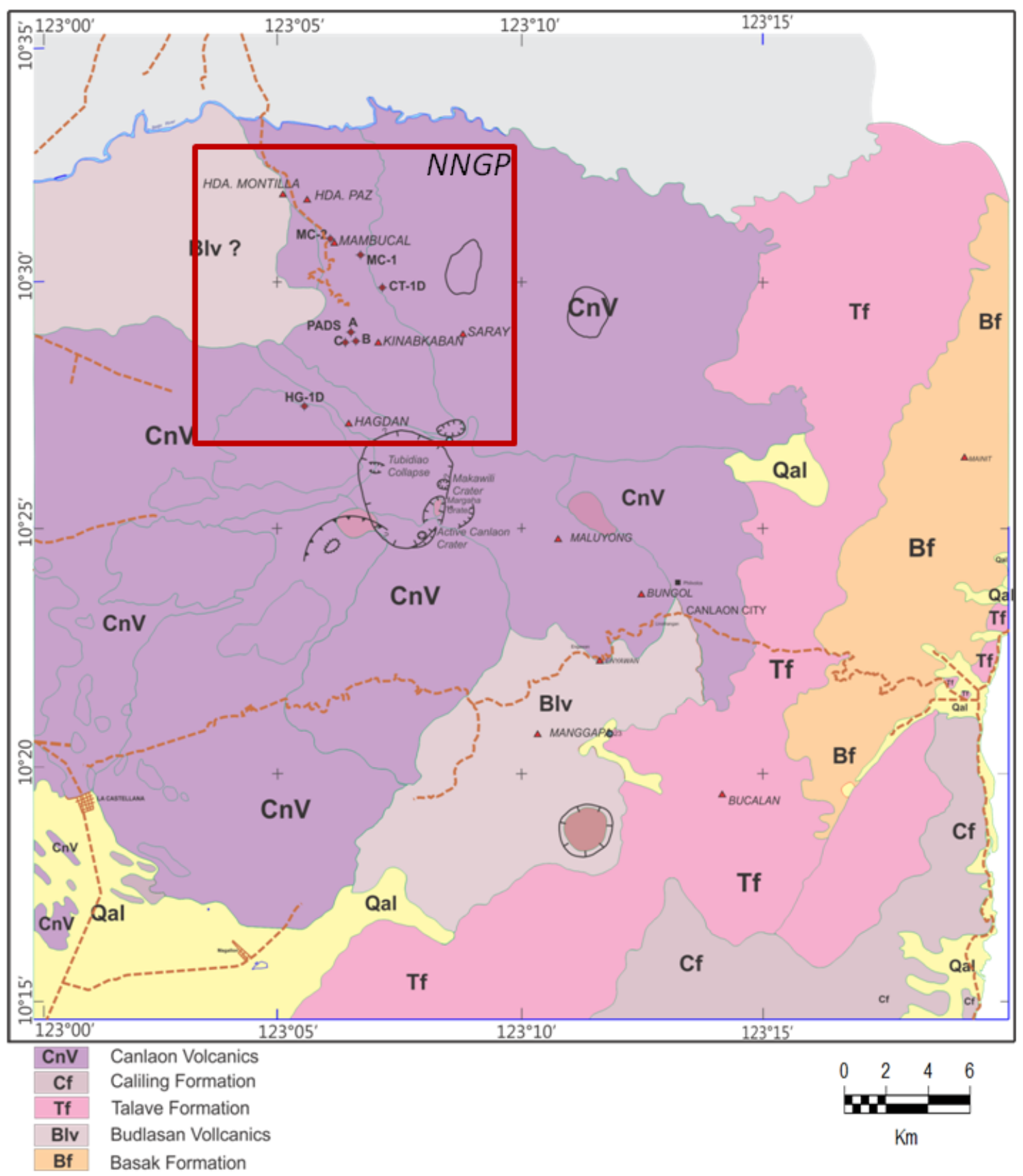

Figure 3.3: Simplified geologic map of NNGP (enclosed in red box) 


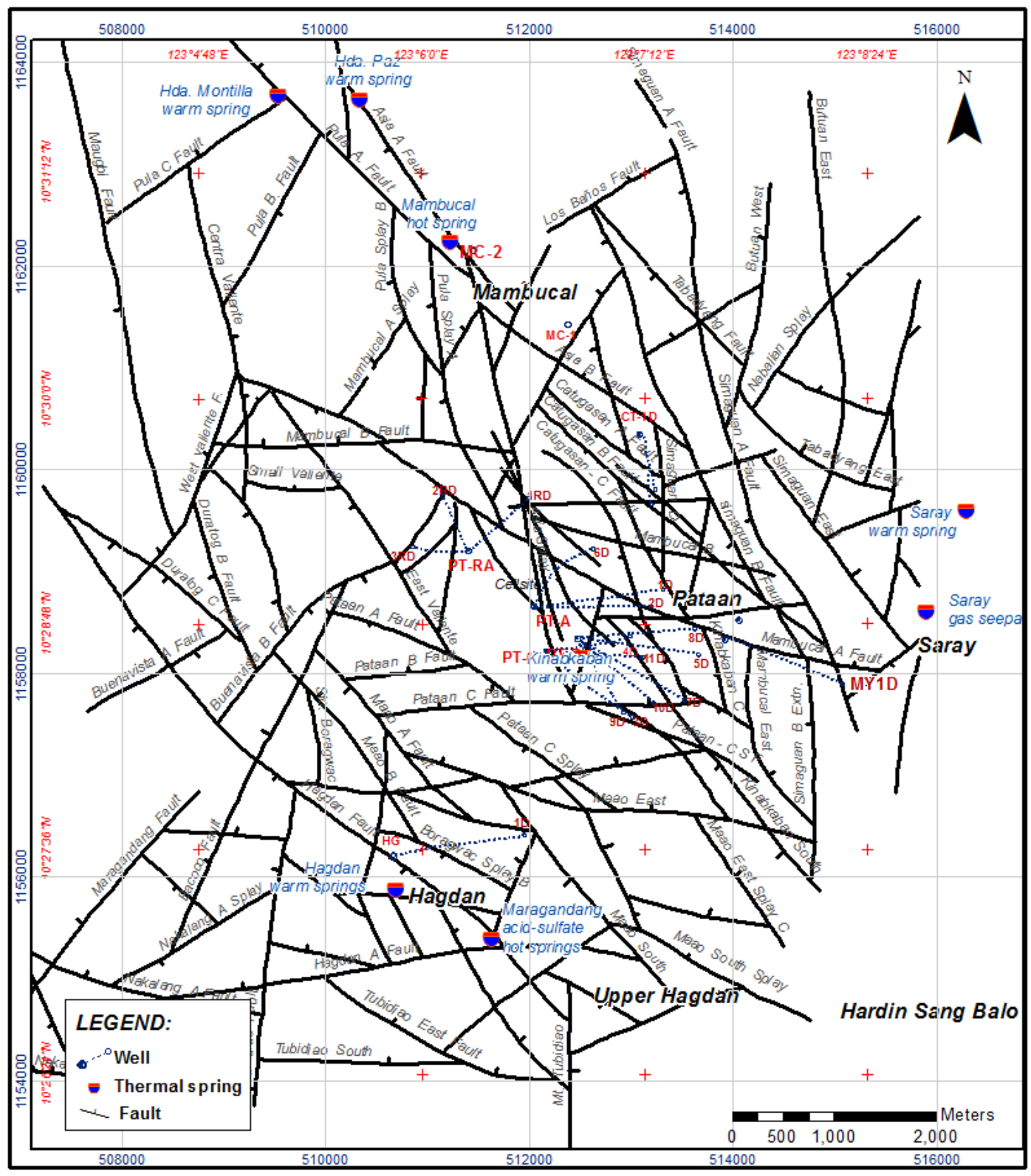

Figure 3.4: Structural map of NNGP 


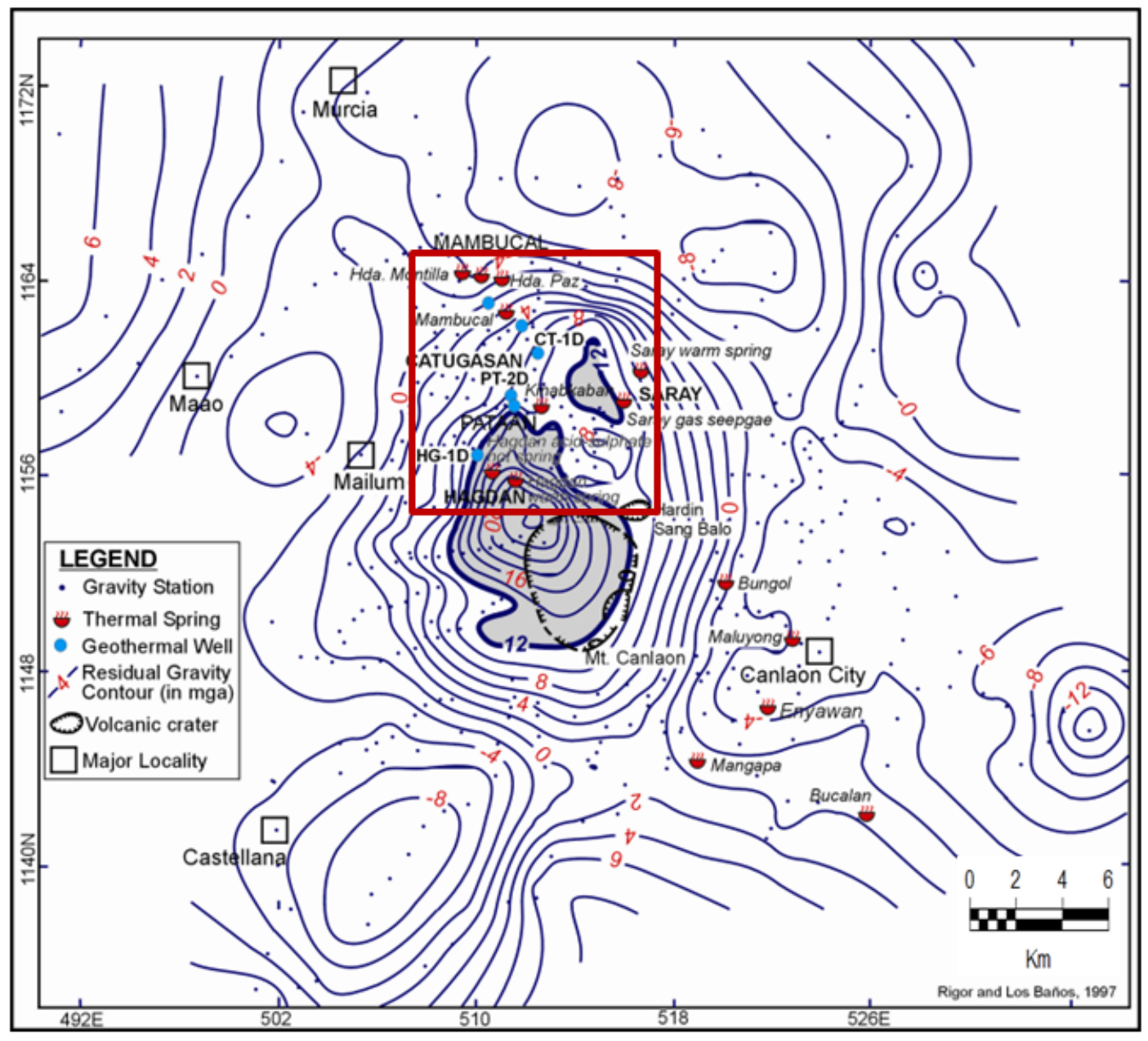

Figure 3.5: Residual Bouguer anomaly map (from Rigor and Los Banos, 1997; NNGP is enclosed by the red box) 


\subsection{5 and $2000 \mathrm{MT}$ surveys}

Previous MT data at NNGP were collected during two survey seasons. The initial one was in 1995 wherein 30 stations were measured by WestJecPhoenix Geophysics, Ltd. and PNOC-EDC personnel using the Phoenix V-5 MT-16 equipment. Five channels were recorded which included the vertical magnetic field component $H_{z}$. The raw time series data were reprocessed using the remote-reference technique (Gamble et al., 1979). The next MT survey was conducted by EDC staff in 2000 where an additional 63 soundings were measured still using the Phoenix V-5 MT system. However, $H_{z}$ in some of the stations was not measured.

The MT data was rotated to $\mathrm{N} 53^{\circ} \mathrm{W}$ and no static shift corrections were applied during processing (Maneja et al., 2001). 1-D layered modeling was then applied using an invariant impedance. The results of the survey shows a northwest-southeast trending conductive zone of $<10 \mathrm{ohm}-\mathrm{m}$ from Sumaguan to Mambucal (Figure 3.6). This conductive zone was correlated with the clay alteration minerals as shown by a simple layered 1-D model running parallel to the conductive zone (Figure 3.7). It was postulated that the more conductive bottom layers beneath Pataan and Sumaguan sectors were caused by hydrothermal fluids flowing towards Mambucal sector.

A 2-D MT model wherein the data was rotated to the principal axis and both the TE and TM modes, as well as static shifts were included in the inversion is shown in Figure 3.8. The 2-D model shows that the increasing resistivity layers with depth correlates well with the transition of alteration minerals with temperature (smectite-illite-epidoteactinolite/biotite) as encountered in the drilled wells including MY-1D (Technical Services Sector, 2010) 


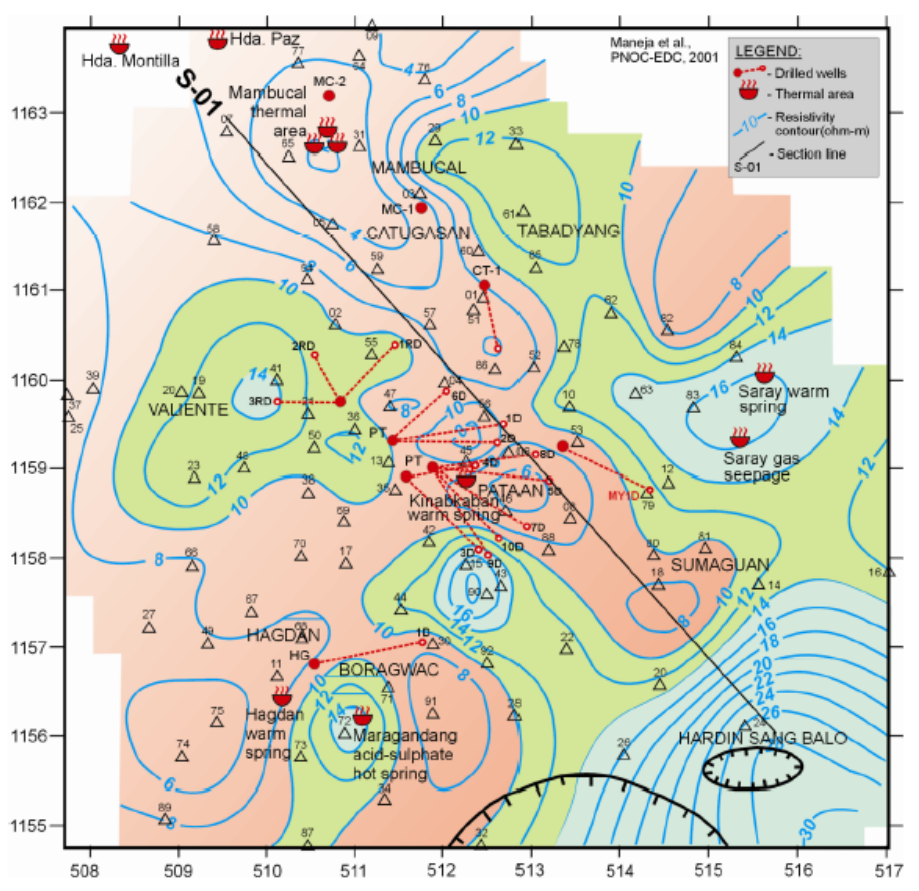

Figure 3.6: Apparent isoresistivity map at 0.33s (from Maneja et al., 2001)

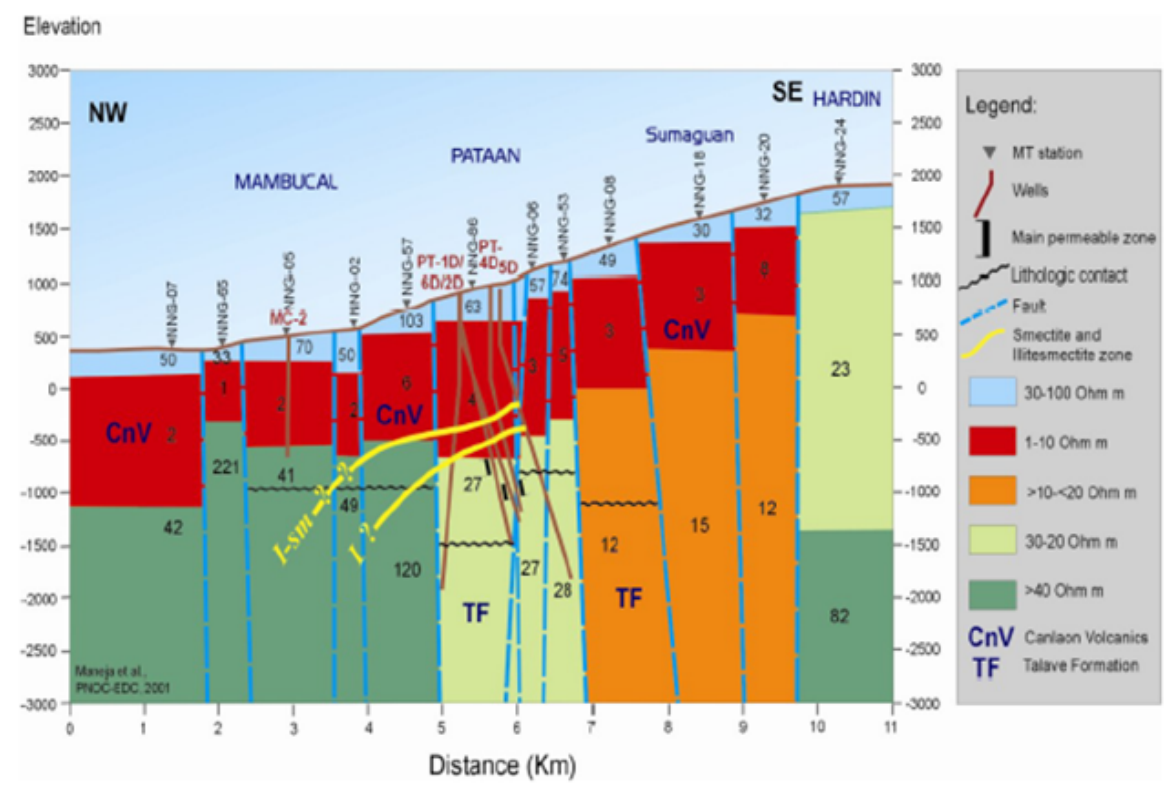

Figure 3.7: 1-D layered model along profile S-01 (from Maneja et al., 2001) 


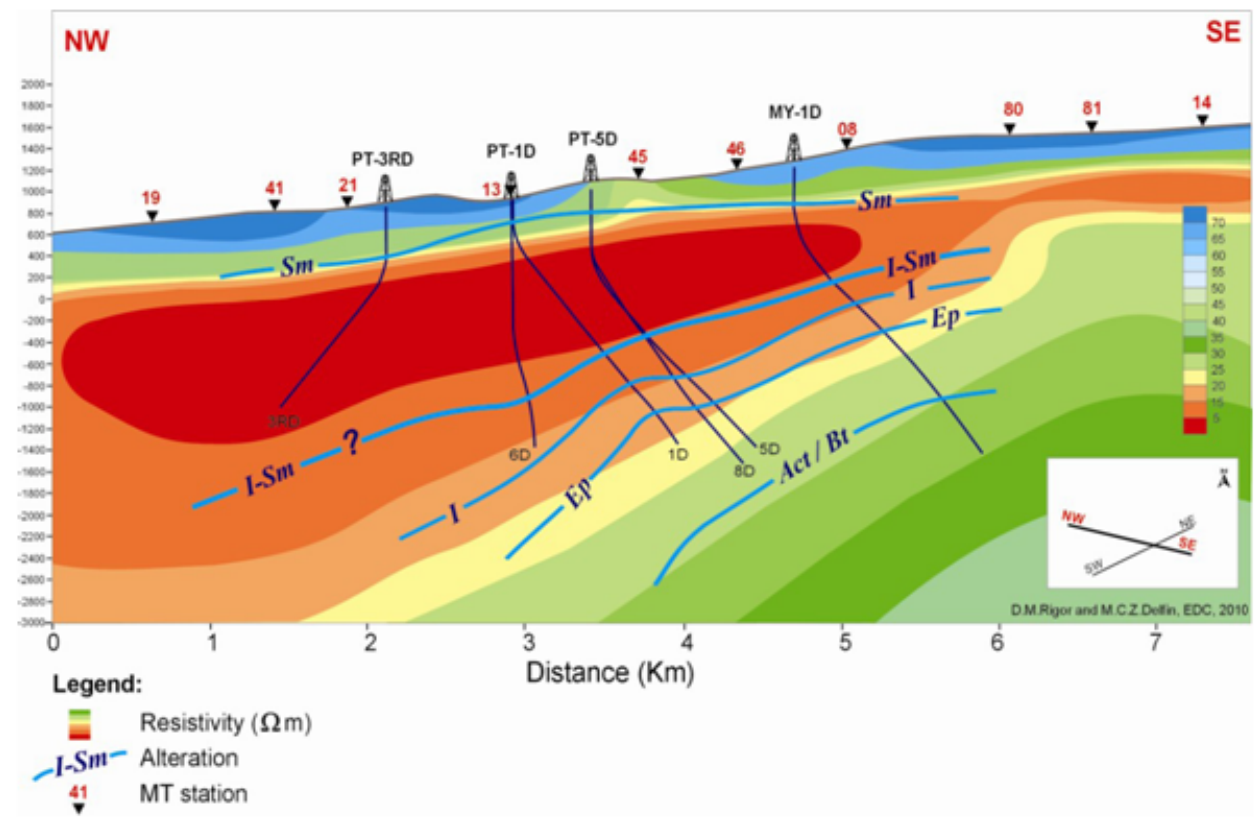

Figure 3.8: 2-D resistivity model (after Technical Services Sector, 2010)

\subsection{Hydrothermal system}

The hottest portion of NNGP is located near PT-5D and PT-7D, in Pataan sector, where $290^{\circ} \mathrm{C}$ fluids have been encountered (Dulce, 2001, 2003). The reservoir is hosted by the Talave Formation (Tf) and capped by the thick sequence of the Canlaon Volcanics (CnV). Permeability is primarily fault-controlled. Two of the more permeable of the faults are the Mambucal-A and Kinabkaban-A Faults (PNOC-EDC, 1998). Minor permeability was also attributed to inter-formation contacts. The main outflow direction is assumed to be towards Mambucal sector in the northwest. On the other hand, the heat source of the system is related to young intrusives associated with the Hardin Sang Balo crater found on the southeast. This is supported by the increasing temperature trend of the alteration minerals towards this direction.

The mineral assemblage intersected by well MY-1D such as secondary 


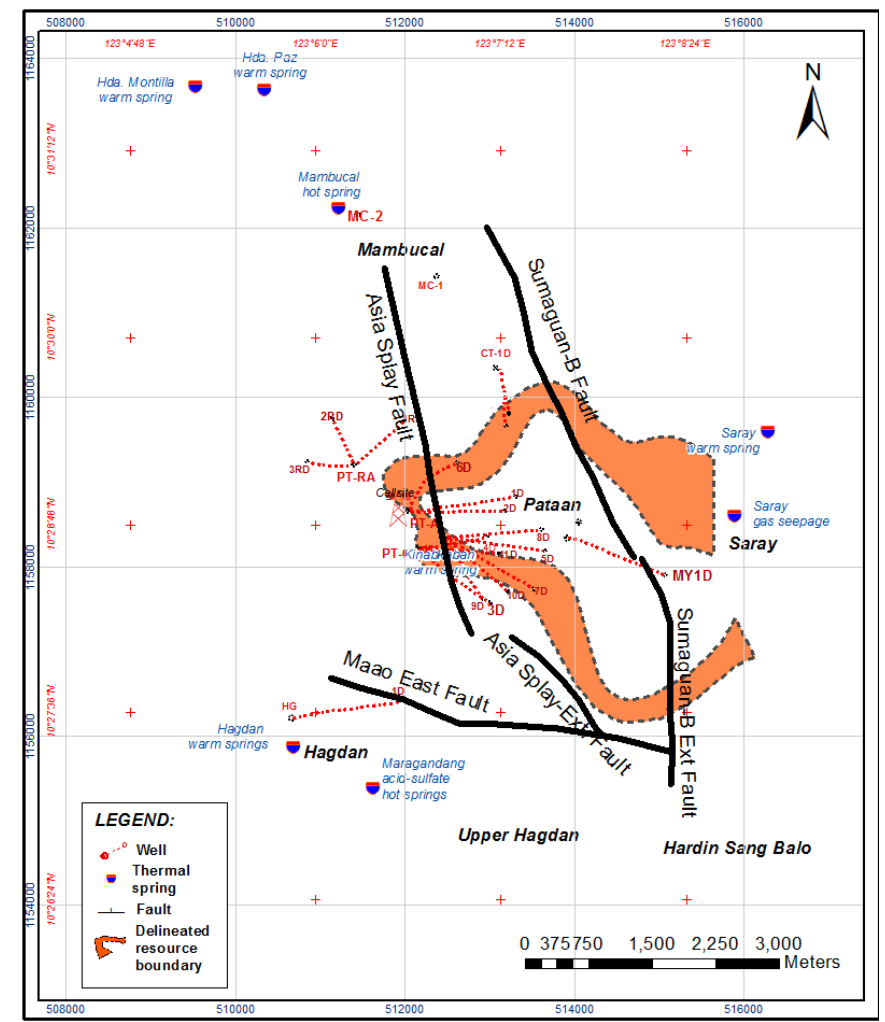

Figure 3.9: Delineated resource area at NNGP (from Maneja et al., 2001)

biotite, actinolite and secondary pyroxene indicate temperatures $>300^{\circ} \mathrm{C}$. This suggests that the area drilled by MY-1D was once hotter than Pataan sector before incursion of peripheral waters cooled it down.

The resource area as delineated by the MT survey and drilled wells is bounded by PT-3D and Asia Splay Fault, Asia Splay Extension Fault to the west, PT-6D in the northwest, well CT-1D on the northeast and MY-1D and Sumaguan-B Extension Fault to the east. The boundary to the south is obscured since no well has yet been drilled and the MT data are scarce in this sector but the contemplated boundary is the Maao East Fault (Figure 3.9). 


\section{Chapter 4}

\section{MT survey}

A recent MT survey was conducted at NNGP from December 2010 to April 2011. Its main objective was to produce a geophysical model using more advanced techniques such as the phase tensor analysis and 3-D modeling to define the resistivity structure with a higher resolution in terms of depth and size. This will also refine the resource boundary in the area particularly in the southern portion where previous data were scarce or noisy. A total of 66 new soundings were measured making the total MT stations occupied at NNGP to 158. The later model MTU-5A system by Phoenix Geophysics, Ltd., was used during the survey. This has a higher data (more than double) frequency sampling rate than the previous V-5 MT-16 units. All five channels were recorded over frequencies ranging from 320-0.0014 $\mathrm{Hz}$. Improving data quality in the latest survey was a challenge since aside from the noise brought about by the bad weather conditions (i.e. strong rain and wind), a lot of cultural noise sources such as a cell-site tower, power plant, drilled wells and electric lines that did not exist during the earlier surveys are now present. One of the steps taken to improve the data quality recording period was to extend the recording time for each MT station between 40-60 hours.

Processing of the MT data was done using the SSMT2000 software (Phoenix Geophysics Ltd., 2005). This included the transformation of 
the time series files to DFT's, which in turn is translated to cross-power functions through the "Robust" processing scheme. A remote reference site in the town of Hinigaran, about 50 kilometers away from the study area was used during the "Robust" processing. The cross-power data were eventually edited using the "MT editor" software by Phoenix Geophysics, Ltd.

A Transient Electromagnetic (TEM) survey was also conducted at some of the new MT station locations. The distribution of the MT and TEM stations is shown in Figure 4.1.

\subsection{Data quality and description}

Out of the total 158 stations from the three MT survey seasons, only 138 were used during processing. The rest were too noisy and or had data that were too scattered to give reliable results. Examples of these are data from stations 123 and 124 (Figure 4.2), which were sited near to a cell-site tower near PT-A pad (4.1). All the apparent resistivity and phase curves that were used are shown in Appendix I while a detailed description of each data curve is presented in Appendix II. In general, noisy data are common in the dead band range (about $2 \mathrm{~s}$ to $20 \mathrm{~s}$ ). Most data show static shifts ranging from slight shifts (i.e. 07, 11, 66, 81) to very large ones (i.e. $8,25,120,142$ ). Typical apparent resistivity curves in NNGP show moderately resistive values $(>20 \mathrm{ohm}-\mathrm{m})$ at short periods then decrease to $<20 \mathrm{ohm}-\mathrm{m}$ starting at the mid period range from 0.1 to about $10 \mathrm{~s}$ then rise up again to $>20 \mathrm{ohm}-\mathrm{m}$ on the longer periods (Appendix I). Data from stations in Mambucal sector (i.e. 3, 61, 76, 77) show a conductor with $<10 \mathrm{ohm}-\mathrm{m}$ as the apparent resistivity curve drops well below the $10 \mathrm{ohm}-\mathrm{m}$ line. Similar observations can be said of the stations north (i.e. 51, 85, 86), west (i.e. 25, 37) and south (42, $43,137)$ of Pataan sector. However, stations towards Saray in the east $(83,84)$ as well as stations in the southeast $(96,106,109)$ of Pataan, indi- 


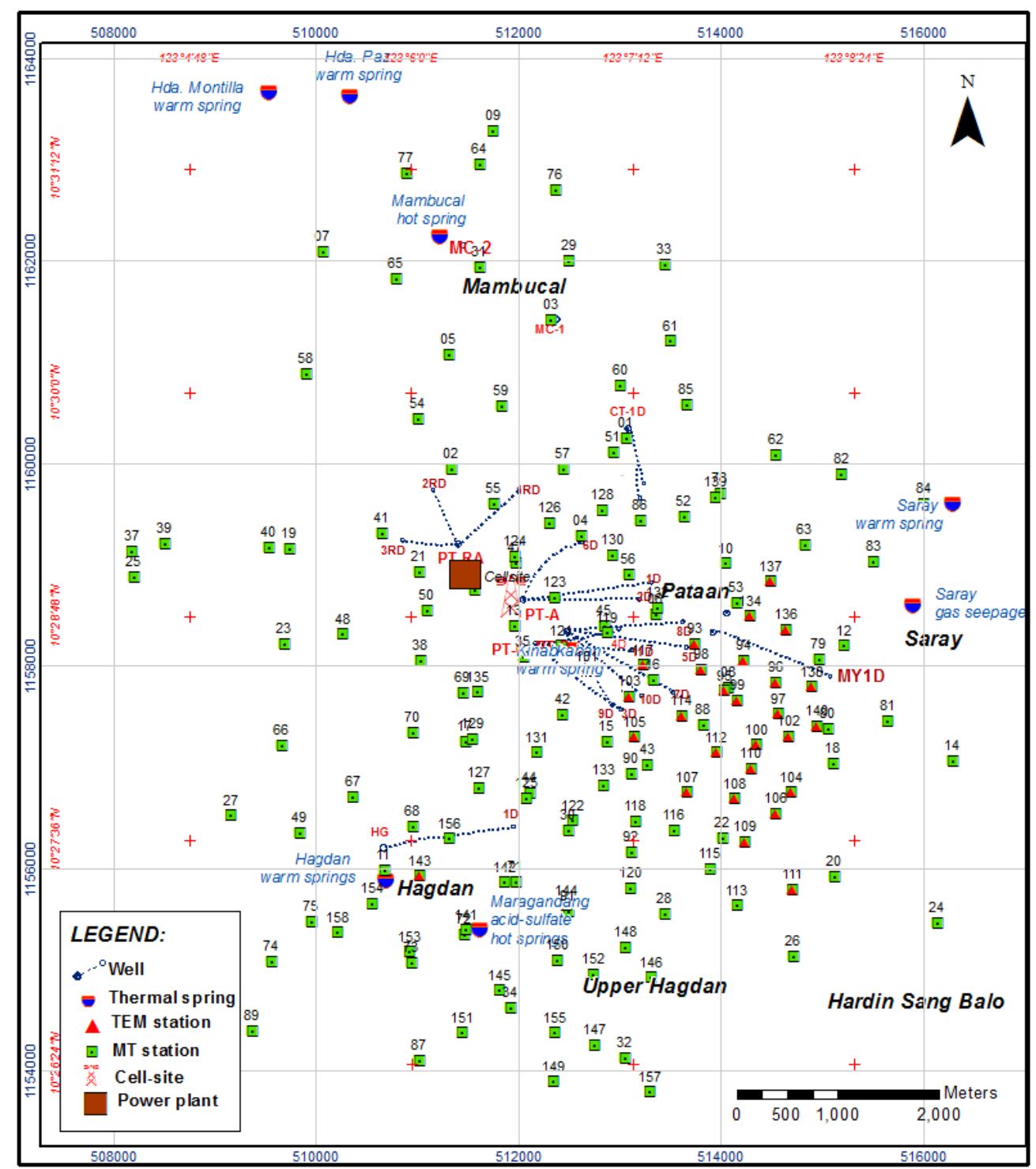

Figure 4.1: MT and TEM stations location map 
Table 4.1: Summary of data types based on quality

\begin{tabular}{cccc}
\hline Total number of MT stations & Type 1 & Type 2 & Type 3 \\
\hline 138 & 73 & 33 & 32 \\
$\%$ & 53 & 24 & 23 \\
\hline
\end{tabular}

cated a conductor with a slightly higher resisitivity since values barely go down to $10 \mathrm{ohm}-\mathrm{m}$. MT data in the vicinity of Hagdan sector also shows a conductor with $<10 \mathrm{ohm}-\mathrm{m}$ values $(67,143,145)$ but towards the south, stations indicate a slight increase in the resistivity value (147, 149, 157). The quality of the data is ranked into three types (Appendix II), which are coded as:

1. Type 1: reliable data only up to about $2 \mathrm{~s}$

2. Type 2: good data up to about $100 \mathrm{~s}$ but with patches of scattered and noisy data

3. Type 3: smooth data curves extending to $>100 \mathrm{~s}$

Based on the concept of skin depth, given the resistivity value of the conductor, which is $\sim 10 \mathrm{ohm}-\mathrm{m}$, Type 1 data can only penetrate up to depths of about 1-2 kms, while Types 2 and 3 data can penetrate depths $>5 \mathrm{kms}$. Table 4.1 gives a summary of the data type according to quality rank. This shows that $53 \%$ of the data are of the Type 1 , while only about $23 \%$ can be considered as Type 3 .

\subsection{Phase tensor analysis}

The phase tensor analysis scheme by Caldwell et al. (2004) was used to determine the dimensionality of the data and its associated properties. Analysis of the data indicate 1-D characteristics at periods $<1 \mathrm{~s}$ while 2-D and 3-D effects are notable in the longer period range. Among the 


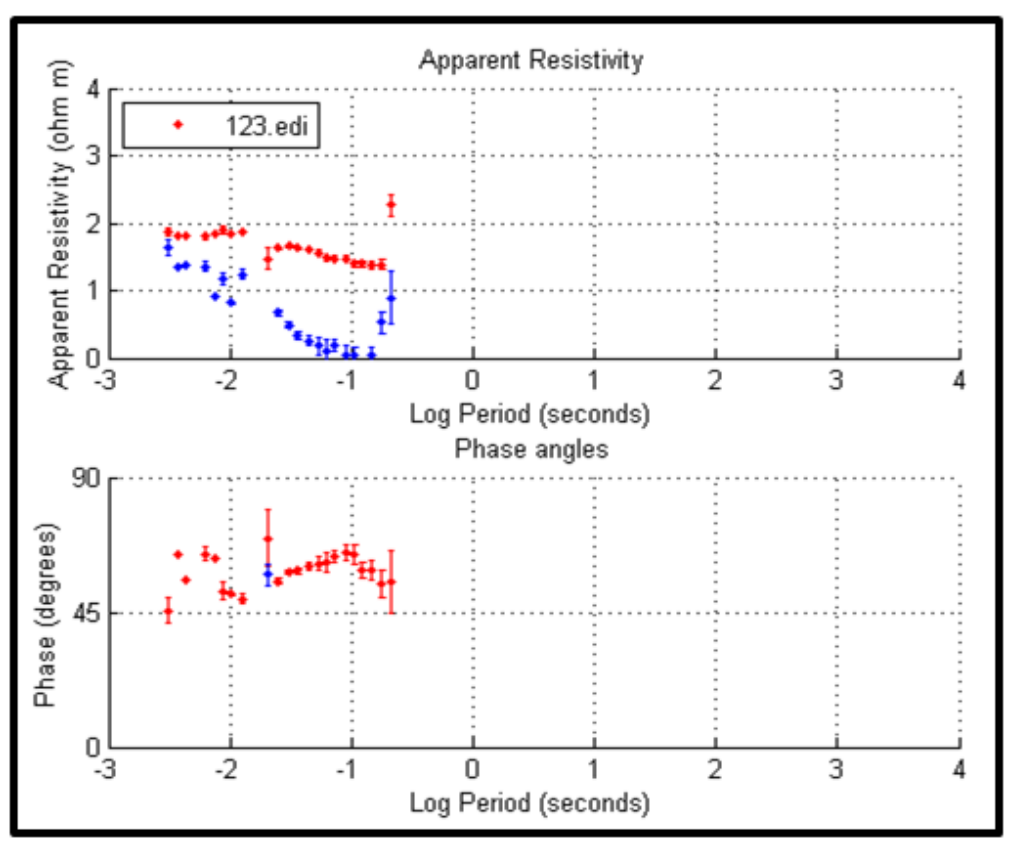

(a) MT station 123

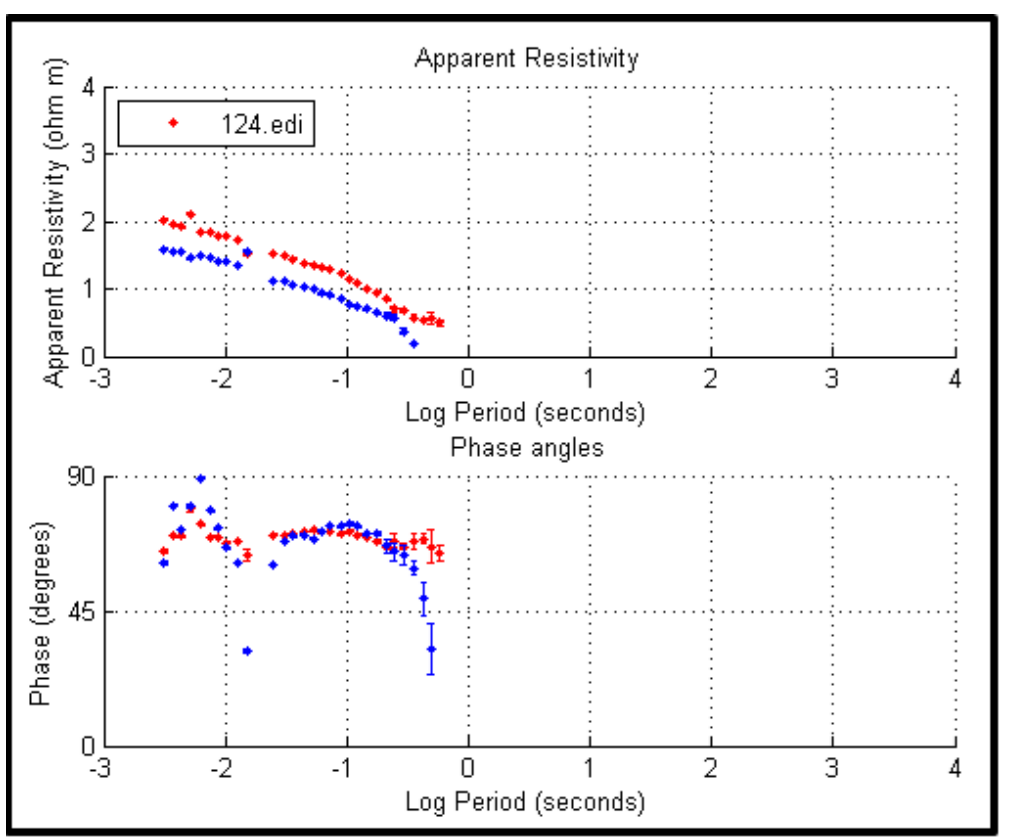

(b) MT station 124

Figure 4.2: Samples of extremely noisy MT data 
data curves that show this observation are stations \# 3,10,23, 67, 84, 96, 106, 108, 111, 134, 137, 145, 154 (Appendix I). The dominant and consistent semi-major axis angle $(\alpha-\beta)$ at periods where 2-D and 3-D character are observed, usually at periods of $>1 \mathrm{~s}$, was chosen for each station to determine the prominent strike direction in the area. Plotting these angle orientations show that majority of the MT stations within Mambucal (29, 60, 85, 62, 63), Pataan (94, 99, 04, 86, 99, 107, 43, 104, $106,107)$ and Saray $(63,81,18,104,106)$ sectors show a dominant strike orientation in a northwest-southeast or almost east-west direction (Figure 4.3). The other stations have either northeast-southwest (83, 84, 12, $138,100)$ or almost north-south $(98,88,97,15)$ orientation. On the other hand, the stations in Hagdan and Upper Hagdan sectors in the south, show mixed strike angle directions which include northeast-southwest $(149,147,111,141,67,27)$, north-south $(48,32)$ and northwest-southeast directions $(142,120,143,49)$.

A summary of the frequency of the semi-major angles $(\alpha-\beta)$ is shown through a rose diagram in Figure 4.4. This indicates that the dominant strike in the MT stations as determined by the phase tensor analysis is a slightly northwest-southeast/almost east-west direction. However, it should be noted that the there is a $90^{\circ}$ ambiguity as mentioned in Section 2.7, so another possible principal strike direction is the slightly north-east-southwest/almost north-south. Secondary strike directions indicated by the phase tensors are the northwest-southeast and southwest-northeast. This variation in strike directions is reflective of the numerous faults that cuts across the project area (Figure 3.4)

The phase tensor was also used to remove the galvanic effects in all the MT site data. This was done using the "strip and rewrite" matlab script by Dr. H. Bibby, wherein a 1-D section of the of the MT data was identified to estimate the real and frequency independent galvanic distortion and used to remove the distortion from all the periods in the data set (Bibby et al., 2005). Strictly speaking, a 1-D characteristic should 


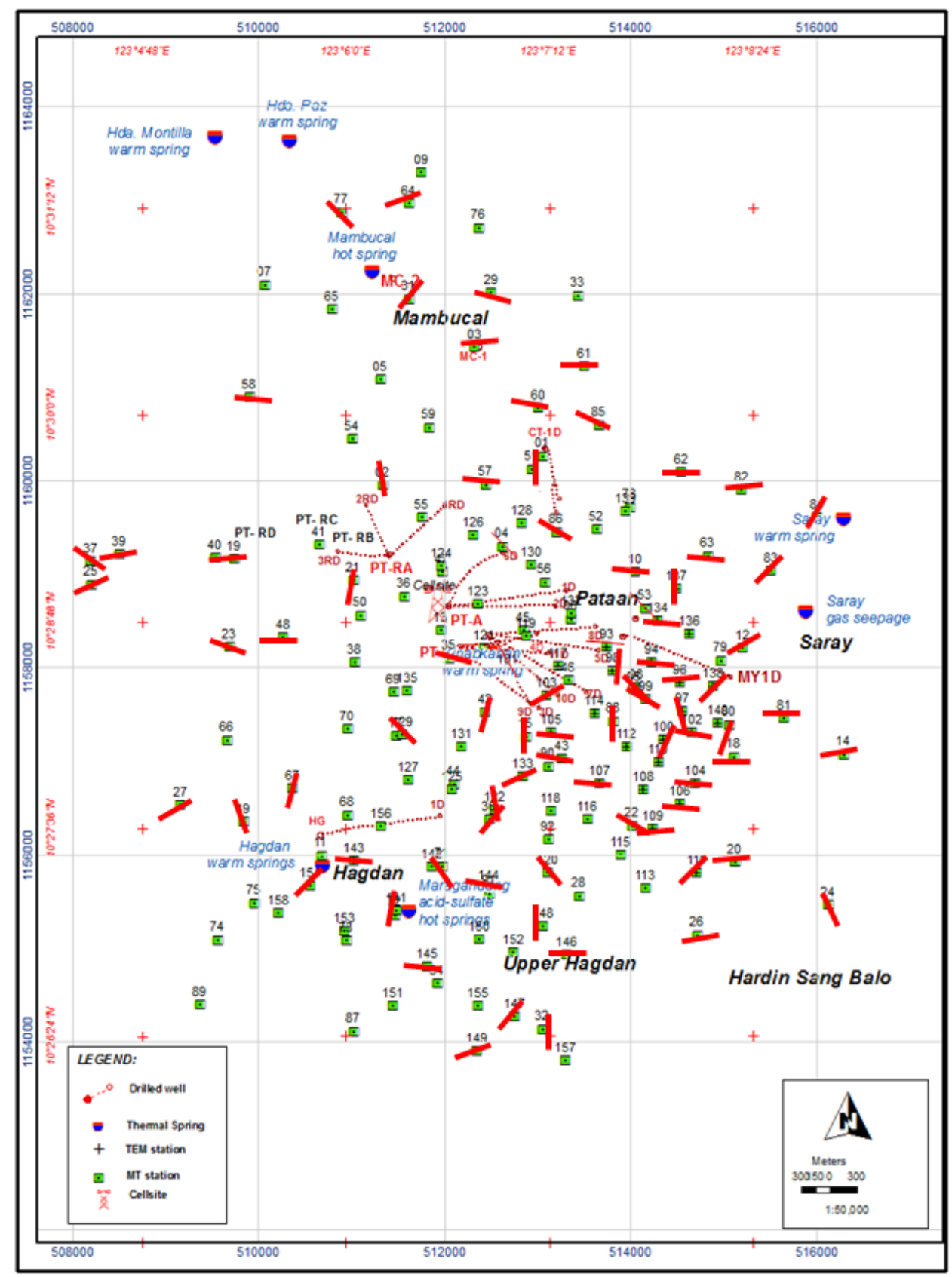

Figure 4.3: Strike directions of MT stations based on phase tensor (red lines are oriented according to the strike direction) 


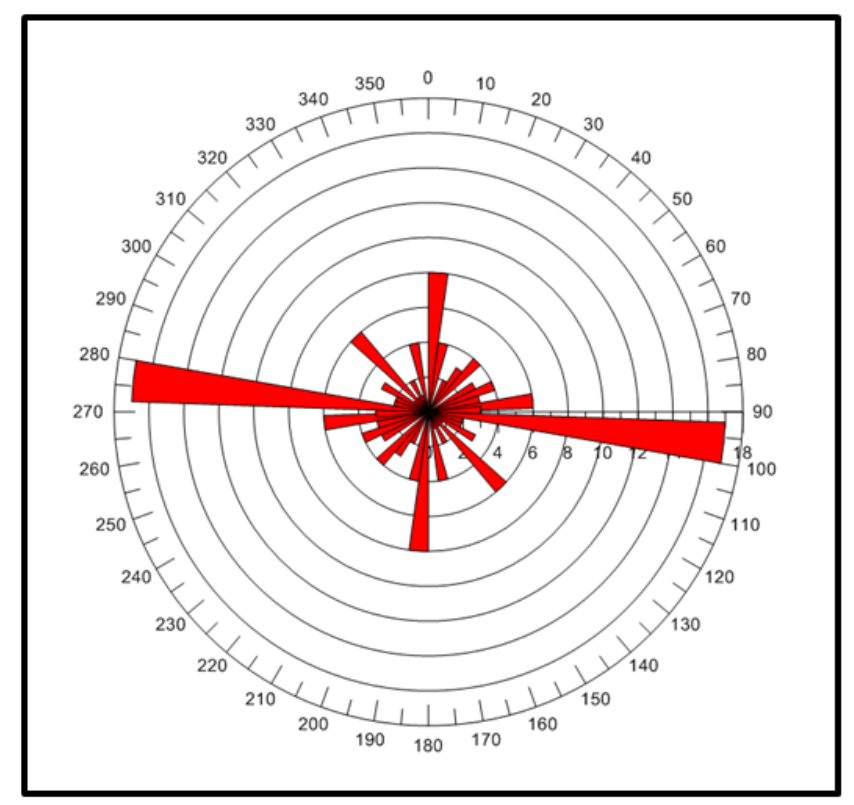

Figure 4.4: Dominant strike directions of the MT data based on the phase tensor

have $\phi_{\min }=\phi_{\max }, \beta=0$ and $\alpha$ cannot be determined (Section 2.9). However, for this study, the parameters considered for determining the 1-D segment include: $\lambda$ or $(\max -\min ) /(\max +\min )$ should be $<0.2$, $\beta$ should be $\leq \pm 5$ and there should no $\alpha-\beta$ value. The "1-D" section selected for each station is shown as the area enclosed by the loop in the plots in Appendix I. The "stripped" data curves were then used during modeling.

The phase tensor ellipses for each Type 3 station were plotted at different periods (Figure 4.5). At short periods (0.007 s, $0.01 \mathrm{~s})$, most stations have an almost circular ellipse indicating 1-D characteristic (Figures 4.5(a) and 4.5(b)). But at longer periods ( $>0.056 \mathrm{~s})$, the ellipses show elongation in a certain direction, either in a northwest-southeast $(0.222$ s, $2.667 \mathrm{~s}$ ) or southwest-northeast directions (1.778 s, $3.555 \mathrm{~s})$ ) or both $(7.112 \mathrm{~s})$ (Figures $4.5(\mathrm{~d})$ to $4.5(\mathrm{~h})$ ). The complexity of the resistivity structure is apparent from these plots and that 3-D effects, as indicated by the 
higher degree of ellipticity of the phase tensors, are more pronounced at longer periods which corresponds to deeper levels. 

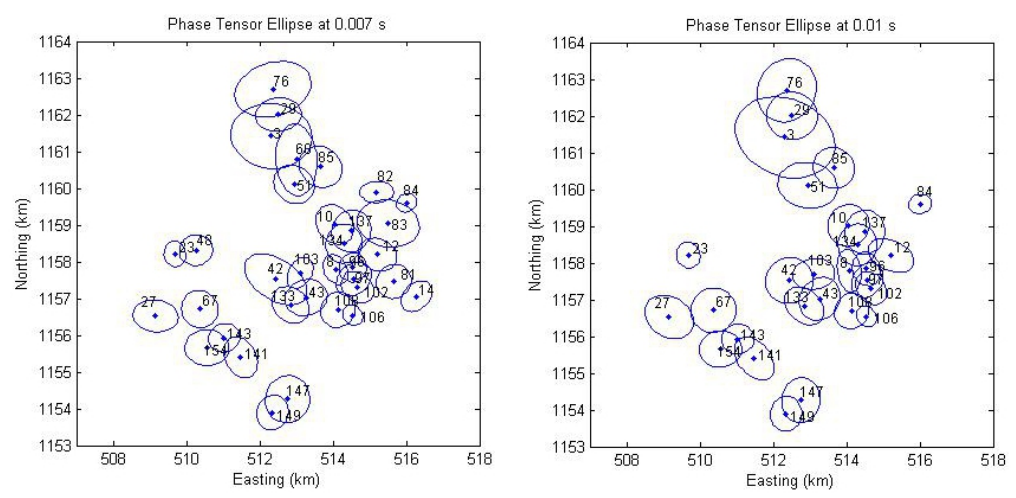

(a) Phase tensor ellipse at $0.007 \mathrm{~s}$

(b) Phase tensor ellipse at $0.01 \mathrm{~s}$
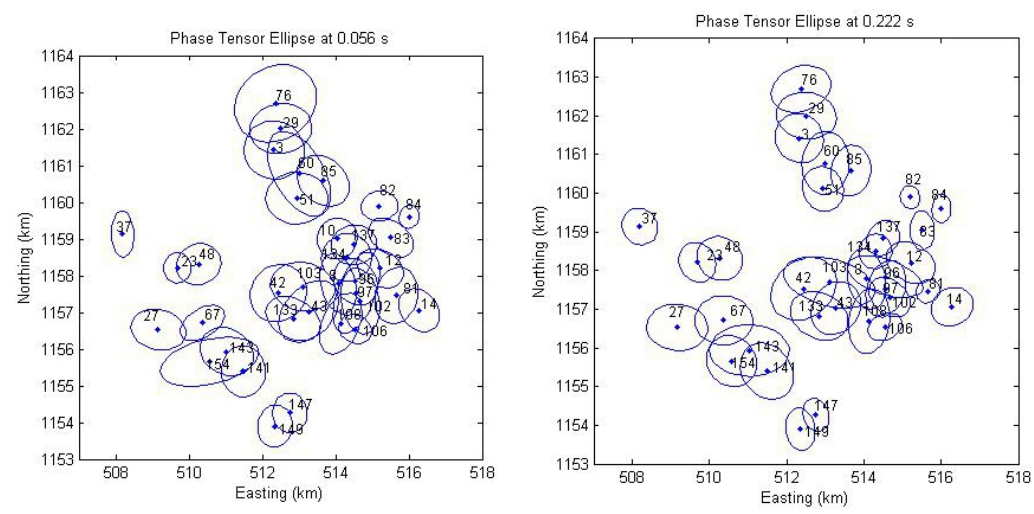

(c) Phase tensor ellipse at $0.056 \mathrm{~s}$

(d) Phase tensor ellipse at $0.222 \mathrm{~s}$
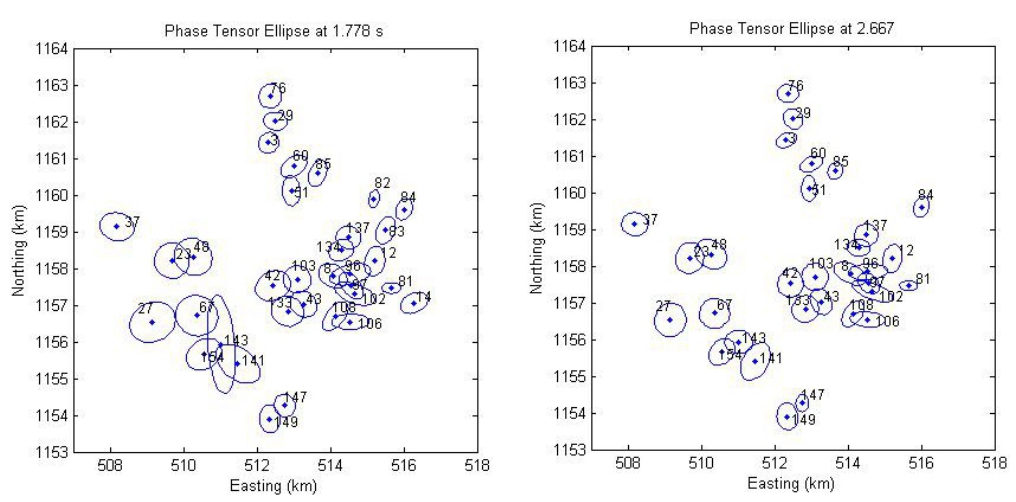

(e) Phase tensor ellipse at $1.778 \mathrm{~s}$

(f) Phase tensor ellipse at $2.667 \mathrm{~s}$
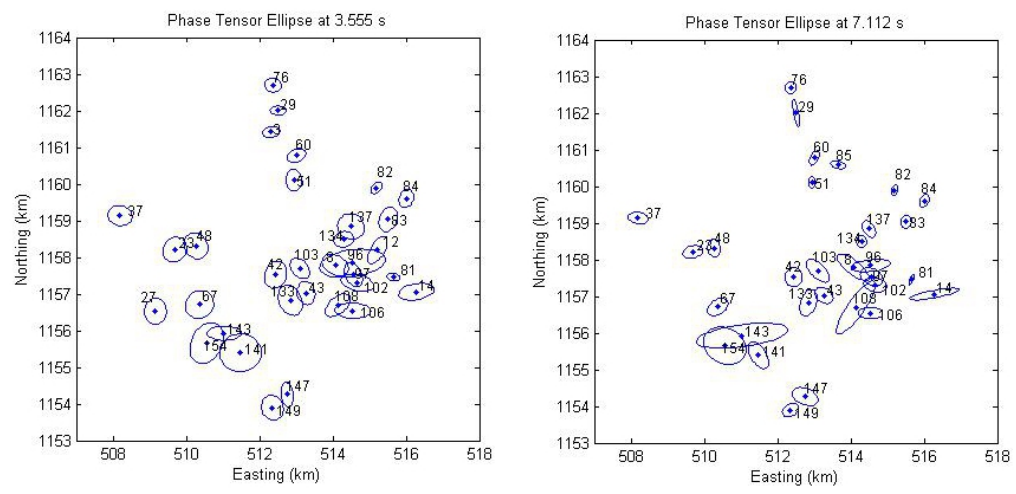

(g) Phase tensor ellipse at $3.555 \mathrm{~s} \mathrm{(h)} \mathrm{Phase} \mathrm{tensor} \mathrm{ellipse} \mathrm{at} 7.112 \mathrm{~s}$

Figure 4.5: Phase tensor ellipse at different periods 


\subsection{Induction arrows}

To have a general idea where the possible conductors are located, the induction arrows from the latest MT survey were plotted.

At frequency $>300 \mathrm{~Hz}$, the real component of the induction arrows generally point towards the west-northwest indicating a major conductive body towards that direction (Figure 4.6). This behavior persists until $10 \mathrm{~Hz}$ (Figure 4.7). At $1 \mathrm{~Hz}$, the real induction arrows (shown as red) of the stations on the southwestern section point towards the east while those on the eastern and southeast portion of Pataan point towards the northeast and southeast (Figure 4.8). At deeper levels $(0.1 \mathrm{~Hz})$, the real induction arrows now point towards the southeast (Figure 4.9). At 0.01 $\mathrm{Hz}$, the real component of the induction arrows points towards the north and northeast (Figure 4.10). At frequencies $<0.001 \mathrm{~Hz}$, the induction arrows point to the northeast and northwest (Figure 4.11). The directions indicated by the induction arrows are generally consistent with the principal strike directions determined from the phase tensors (Figure 4.4)

\subsection{Static shift correction}

As mentioned in section 2.10, near surface galvanic distortions such as a thin conductor layer at or near the surface can result into the so called "static shift" phenomenon. One of the methods to correct for this is by using TEM data, which are not affected by static shifts. This is achieved by doing a 1-D inversion modeling of the TEM data then using the model fit curve as the true level of the high frequency portion of the MT data curves. This can be done in WinGLink (Geosystem SRL, 2008). For NNGP, only 29 MT stations have TEM data, most of these are the stations located east and southeast of Pataan (Figure 4.1). For the other stations in Pataan, Saray, Hagdan and Upper Hagdan sectors which do not have TEM data, the MT data were adjusted based on the 


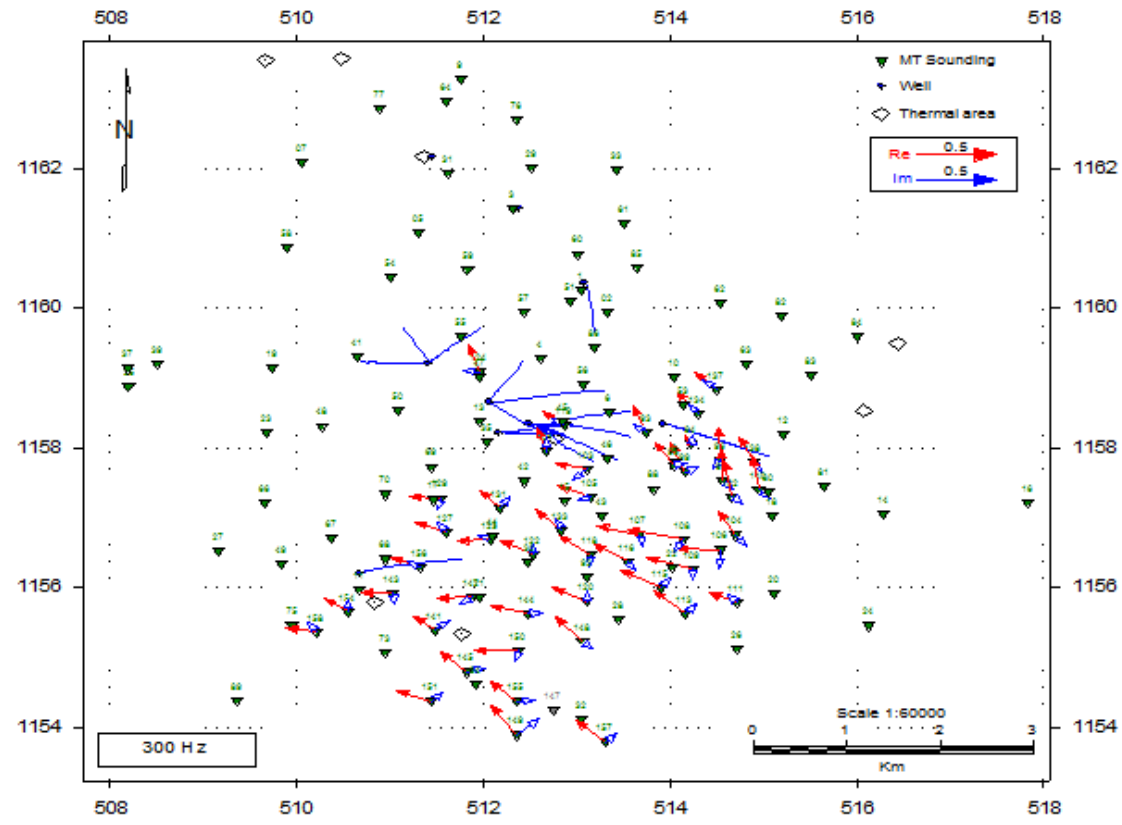

Figure 4.6: Induction arrows at $300 \mathrm{~Hz}$

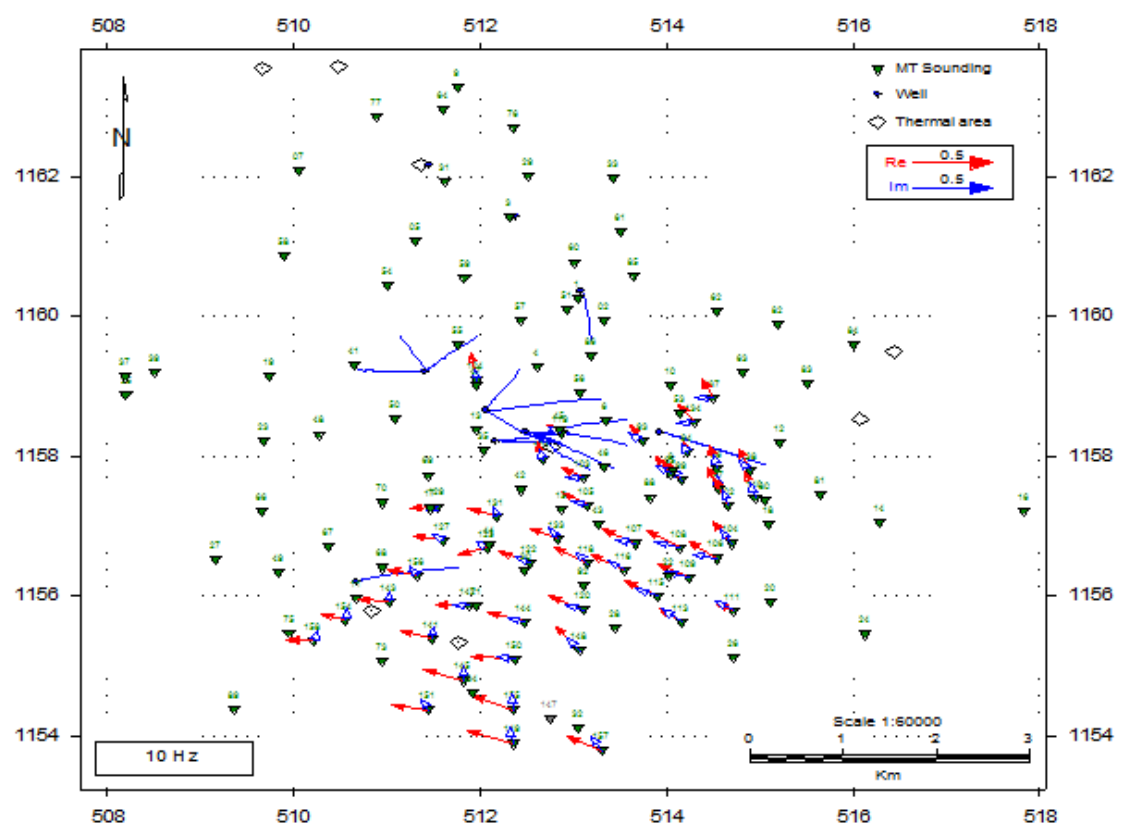

Figure 4.7: Induction arrows at $10 \mathrm{~Hz}$ 


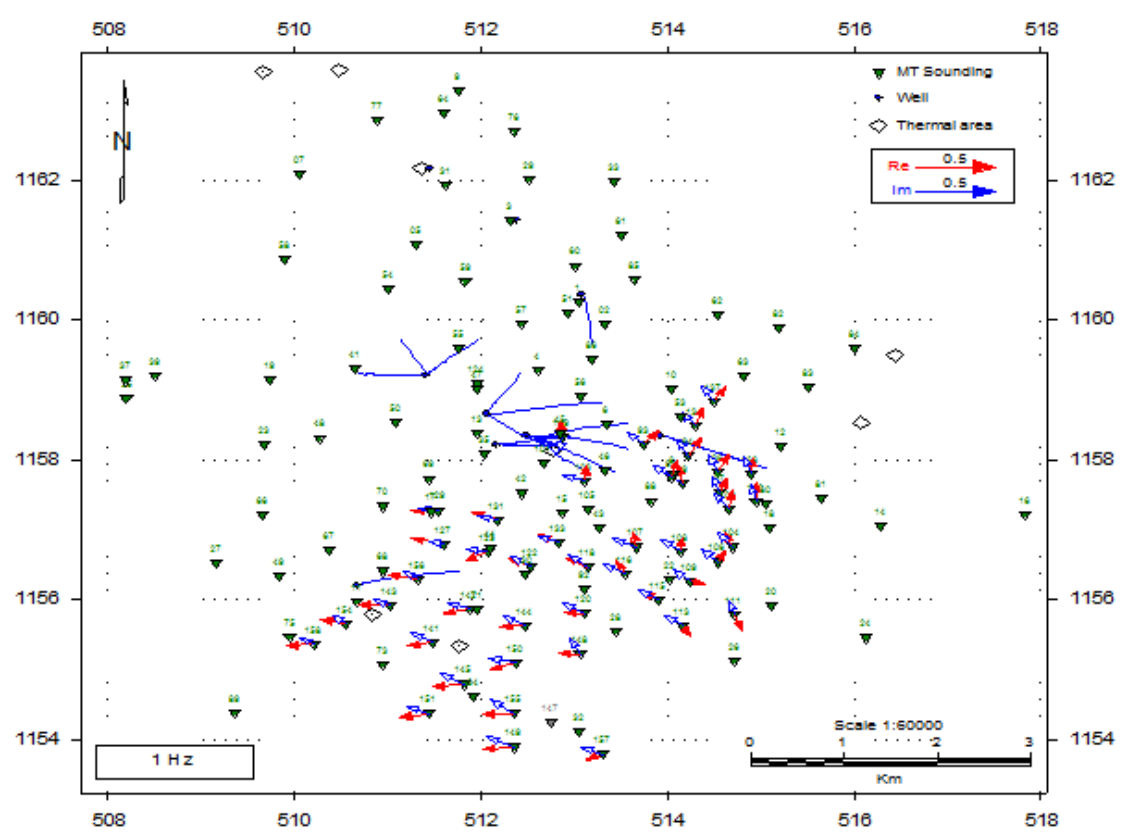

Figure 4.8: Induction arrows at $1 \mathrm{~Hz}$

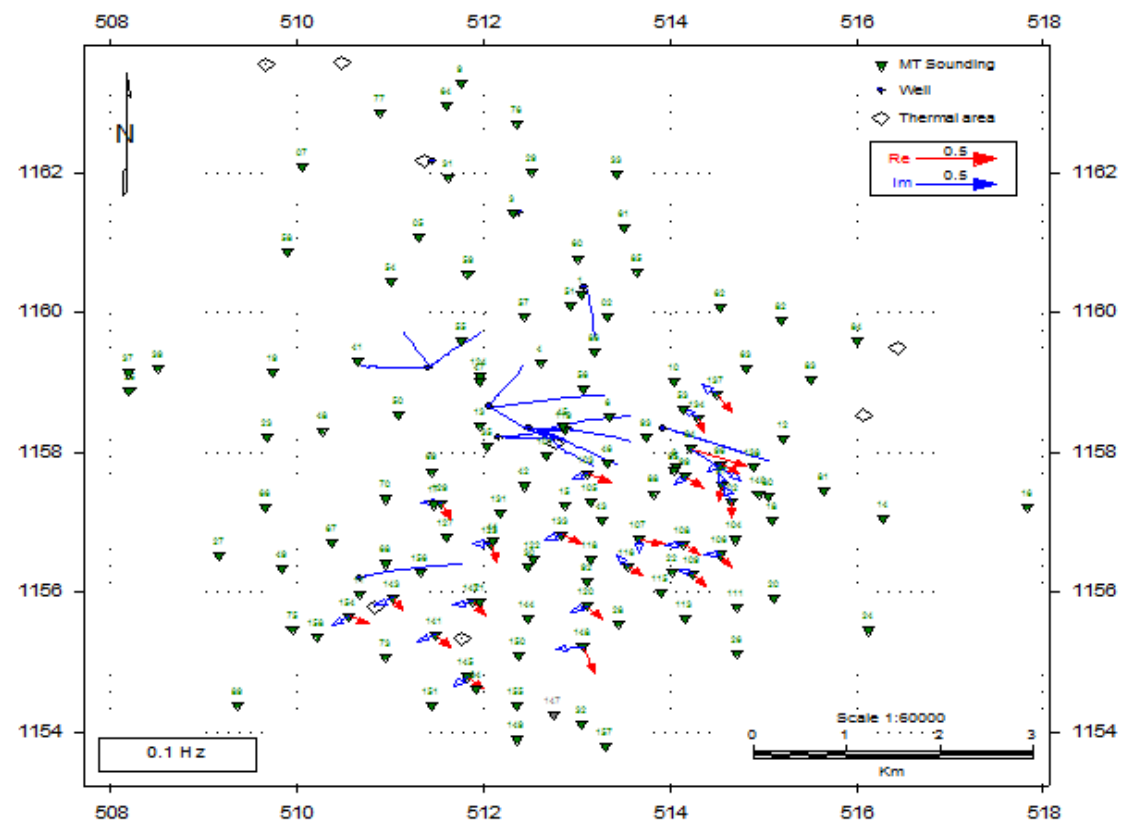

Figure 4.9: Induction arrows at $0.1 \mathrm{~Hz}$ 


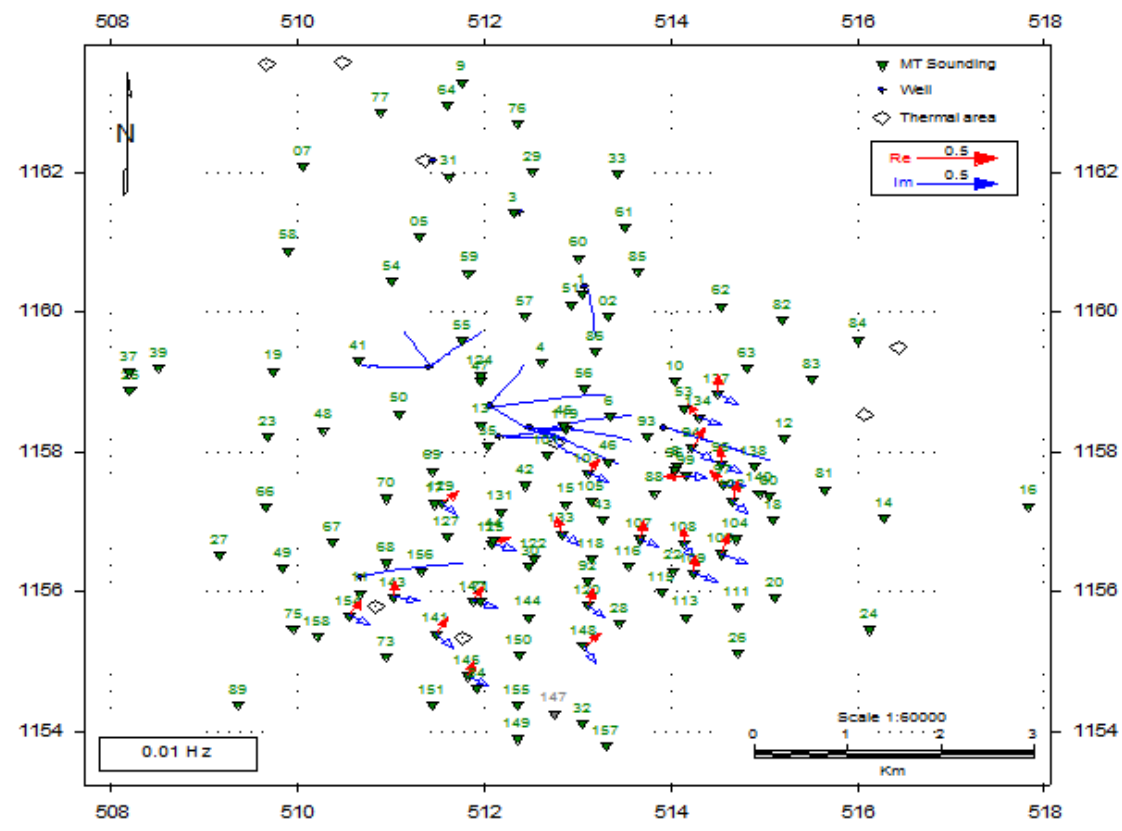

Figure 4.10: Induction arrows at $0.01 \mathrm{~Hz}$

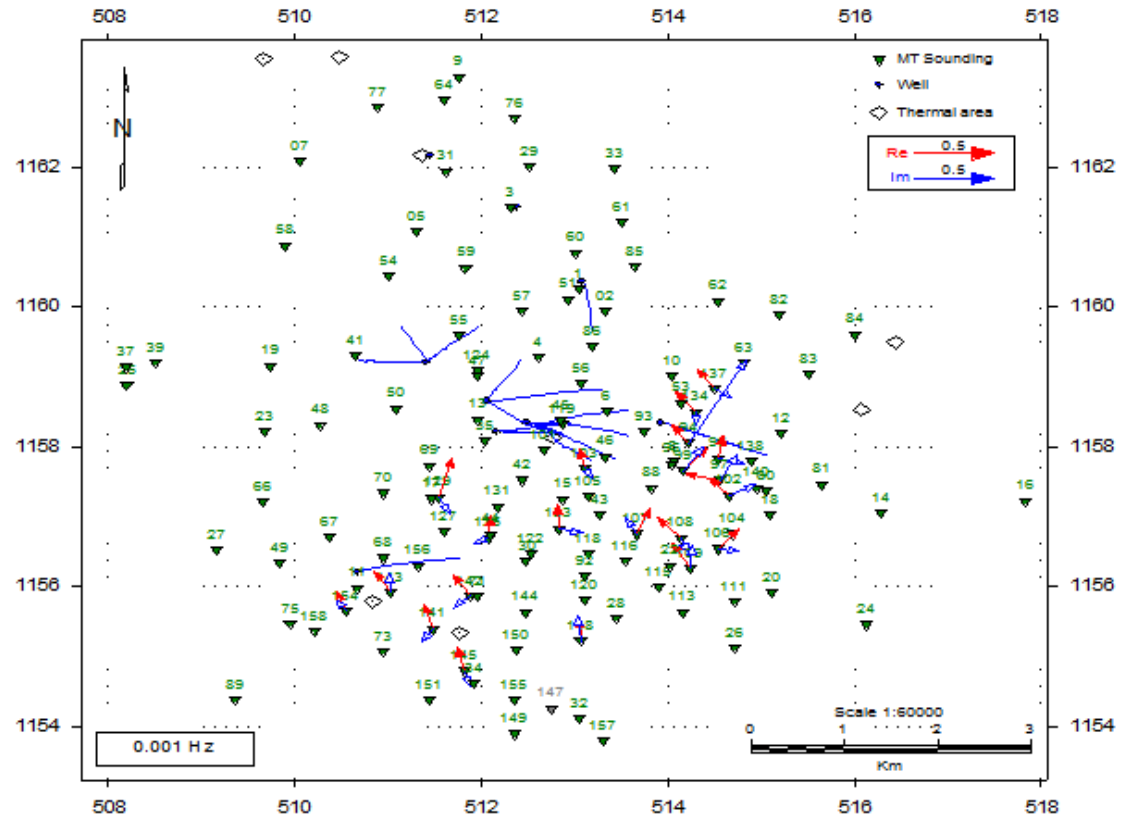

Figure 4.11: Induction arrows at $0.001 \mathrm{~Hz}$ 
nearest TEM station available (i.e. for station 18, TEM data 140 was used).Using the TEM computed models show that even after stripping the data by using the phase tensor decomposition technique (Caldwell et al., 2004), a shift is still evident. It can be observed however that most of the stations have only minimal shifts applied (Appendix III). Only about 15 stations have notable shifts corrected by a factor $>2.0$. These stations are located within and south of Pataan suggesting that this block has higher levels of resistivity at the surface compared to the surrounding areas.

For the stations in the Mambucal sector in the north and area east of Pataan, no shifts were applied. Comparing these stations with those nearest them which were shifted show no significant difference in the resistivity levels. 


\section{Chapter 5}

\section{Modeling}

This chapter gives the results of the various modeling schemes applied to the MT data. This include 1-D, 2-D and finally 3-D modeling. The results for each model are first presented through isoresistivity maps then cross-sections along selected profile lines were compared to show the similar and different features of each model.

\subsection{1-D inversion modeling}

1-D modeling was carried out mainly by using the Occam inversion scheme included in the WinGLink software (Geosystem SRL, 2008)). The determinant mode of the impedance (Equation 2.120) was used during the inversion modeling.

\subsubsection{Isoresitivity maps}

Isoresistivity maps were created to show the variation of resistivity at different depths.

The greater part of the project area including the Pataan, Saray, Hagdan and Hardin Sang Balo sectors, is mainly covered by moderate to high resistivity values ( $>30 \mathrm{ohm}-\mathrm{m}$ ), shown by green and blue colours, 


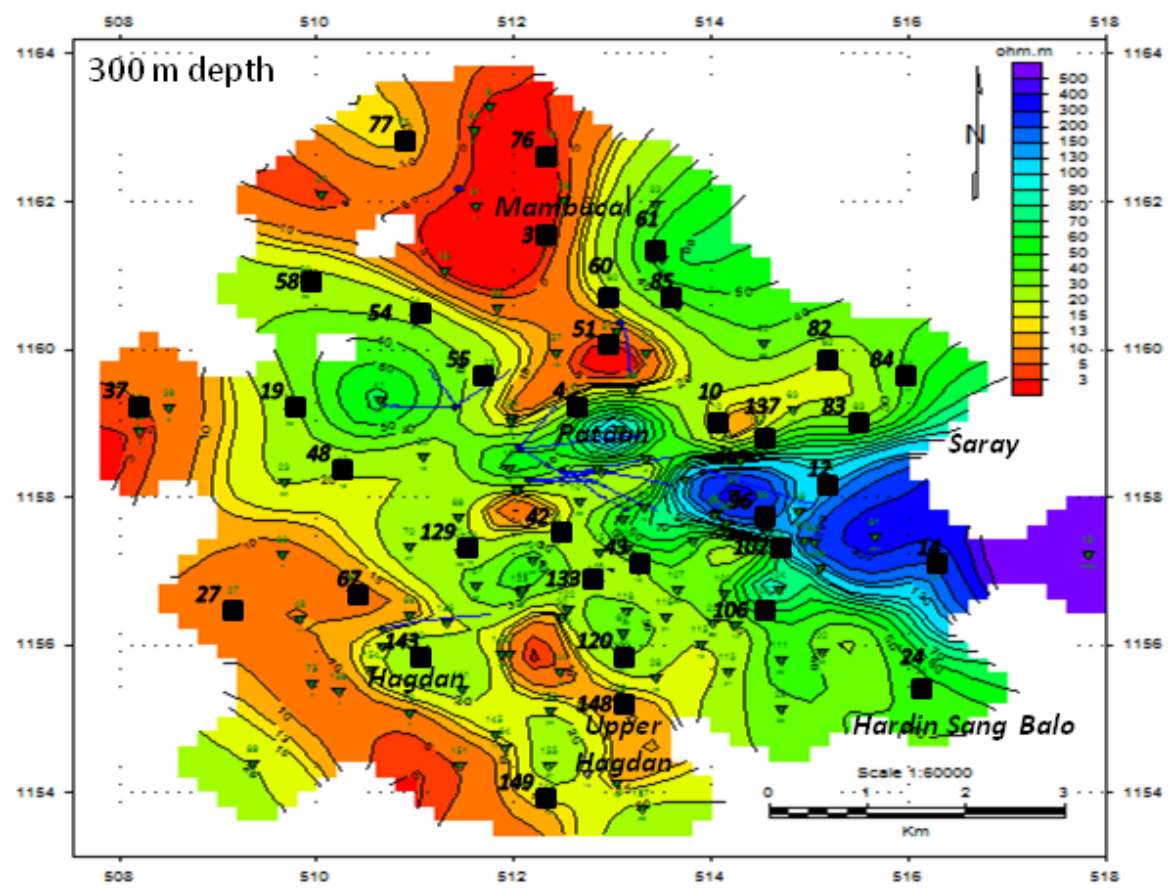

Figure 5.1: 1-D isoresistivity map at $300 \mathrm{~m}$ depth

at $300 \mathrm{~m}$ depth (Figure 5.1). However, a conductive zone enclosed by $<10$ ohm-m, represented by red and orange colours, can be found within Mambucal area in the northwest. At $1000 \mathrm{~m}$ depth, more than half of NNGP is now covered by low resistivity values $<10 \mathrm{ohm}-\mathrm{m}$ which include Pataan and Hagdan (Figure 5.2). At this depth, the resistive zone is now confined to the eastern and southern portions of Saray, Upper Hagdan and Hardin Sang Balo. At $2000 \mathrm{~m}$ depth, a resistive block is delineated southwest of Pataan (Figure 5.3)

\section{$5.2 \quad 2-D$ inversion modeling}

The 2D inversion was carried out using the non-linear conjugate gradient (NLCG) based 2D inversion algorithm (Rodi and Mackie, 2001) that is also included in the WinGLink suite. The modeling software inverts 


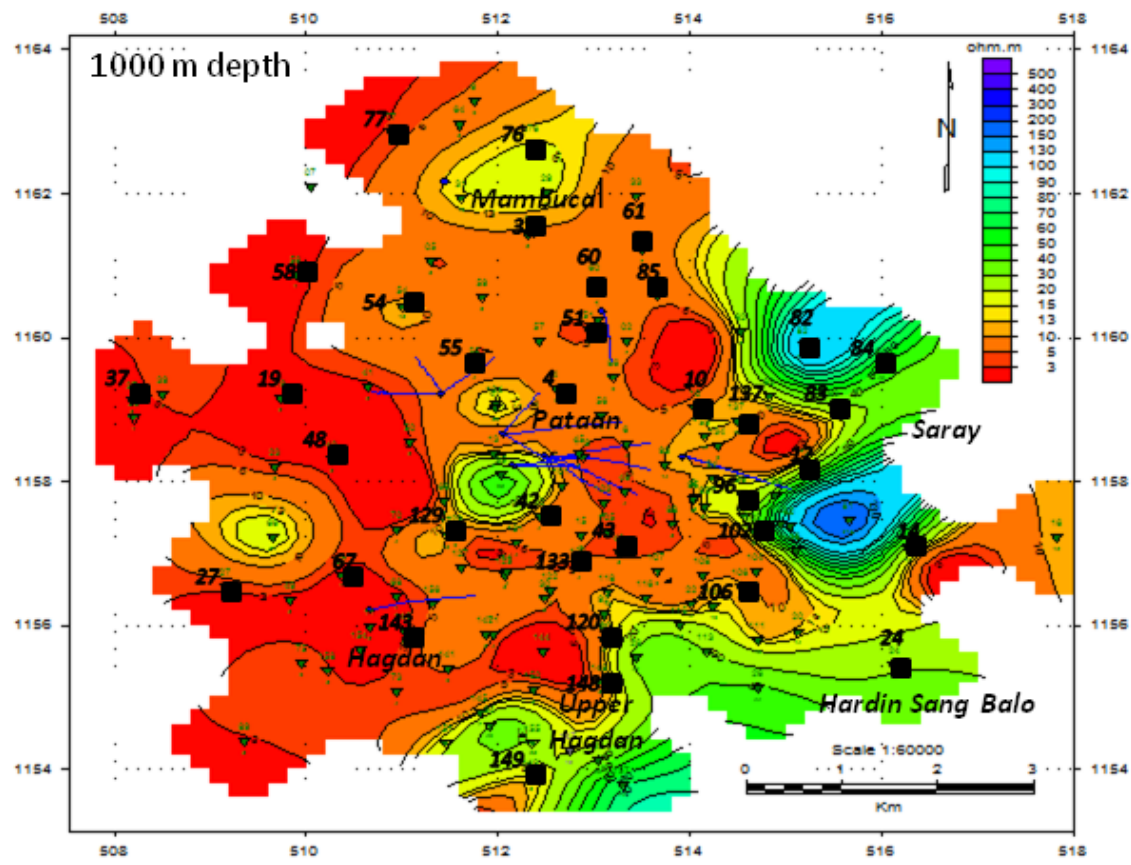

Figure 5.2: 1-D isoresistivity map at $1000 \mathrm{~m}$ depth

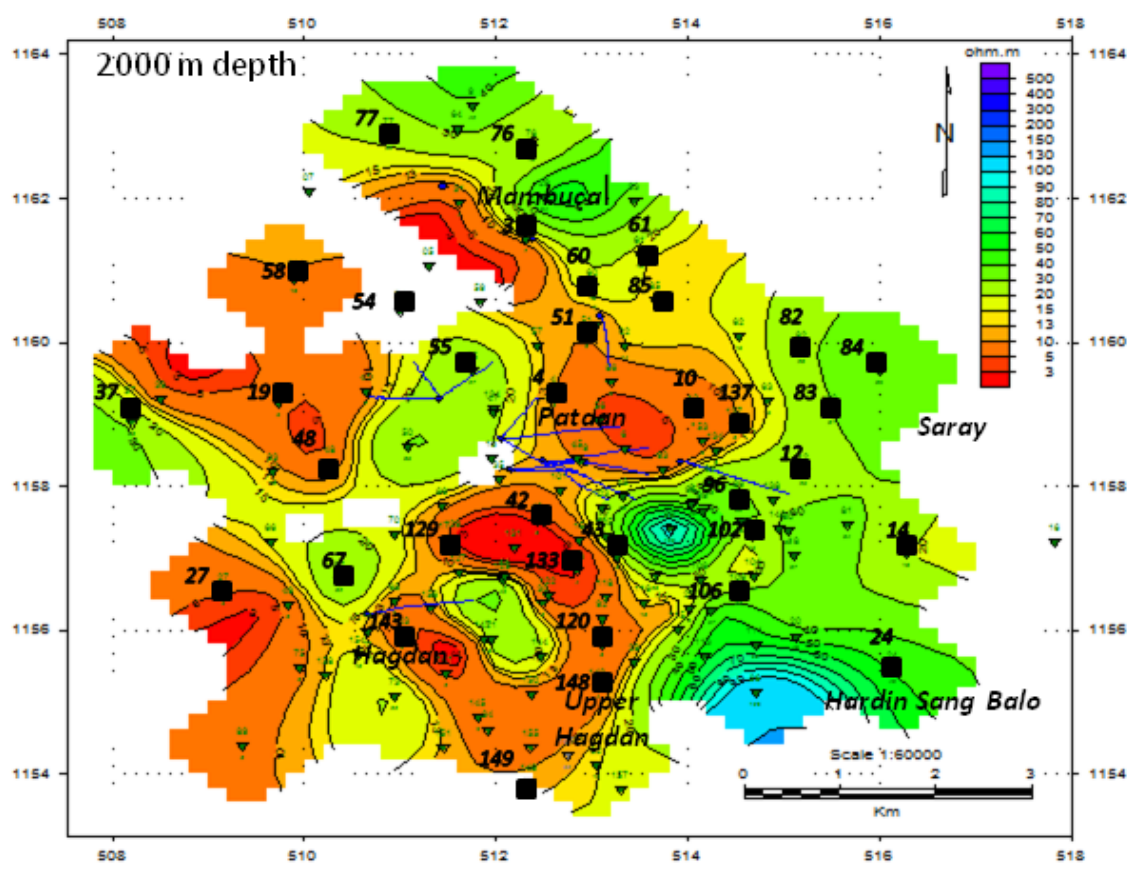

Figure 5.3: 1-D isoresistivity map at $2000 \mathrm{~m}$ depth 
using a user-defined finite-difference mesh of resistivity blocks extending laterally and downwards beyond the study area (Geosystem SRL, 2008).

As seen from Figure 4.4 and considering the ambiguous characteristic of the strike, possible strike directions are either $\mathrm{N}^{\circ} 5^{\circ} \mathrm{W}$ or $\mathrm{N}^{\circ} \mathrm{E}$. Profiles perpendicular to both of these possible strike orientations were created and 2-D models were run for each profile. As implied by the phase tensor analysis (Appendix I and Figure 4.5) the MT data shows 2 -D characteristic only at the lower period $<1 \mathrm{~s}$ ) range. It has been suggested that for situations like this, it is better to use the TM mode during 2-D inversion to give a more accurate resistivity structure because this mode may only be affected by galvanic effects unlike the TE mode wherein it may influenced by both galvanic and inductive effects (Ledo, 2005). Furthermore, the TE mode does not consider boundary changes that it may give false features in resulting model (Wannamaker et al., 1984). The TM mode was then solely used during inversion.

The starting model used was a mesh with half space of $100 \mathrm{ohm}-\mathrm{m}$. The smoothed curves, wherein a smooth curve was generated from the data curves using D+ smoothing algorithm, was selected during inversion. The other settings during the inversion included the setting of data errors for the "Rho" at 10\% while for the phase at 5\% . Static shift was not included in the inversion since this was already corrected for using the TEM data in most of the stations. The relaxation parameter $\tau$, which controls the smoothness of the model was set at 10 and the number of iterations made for each model is at least 100 . Topography was included in the inversion.

\subsubsection{Isoresistivity maps}

The 2-D isoresistivity maps were generated by compiling the 2-D resistivity models along profiles lines, that are mainly oriented NW-SE. These profiles were chosen to be able to model the resistivity from the 


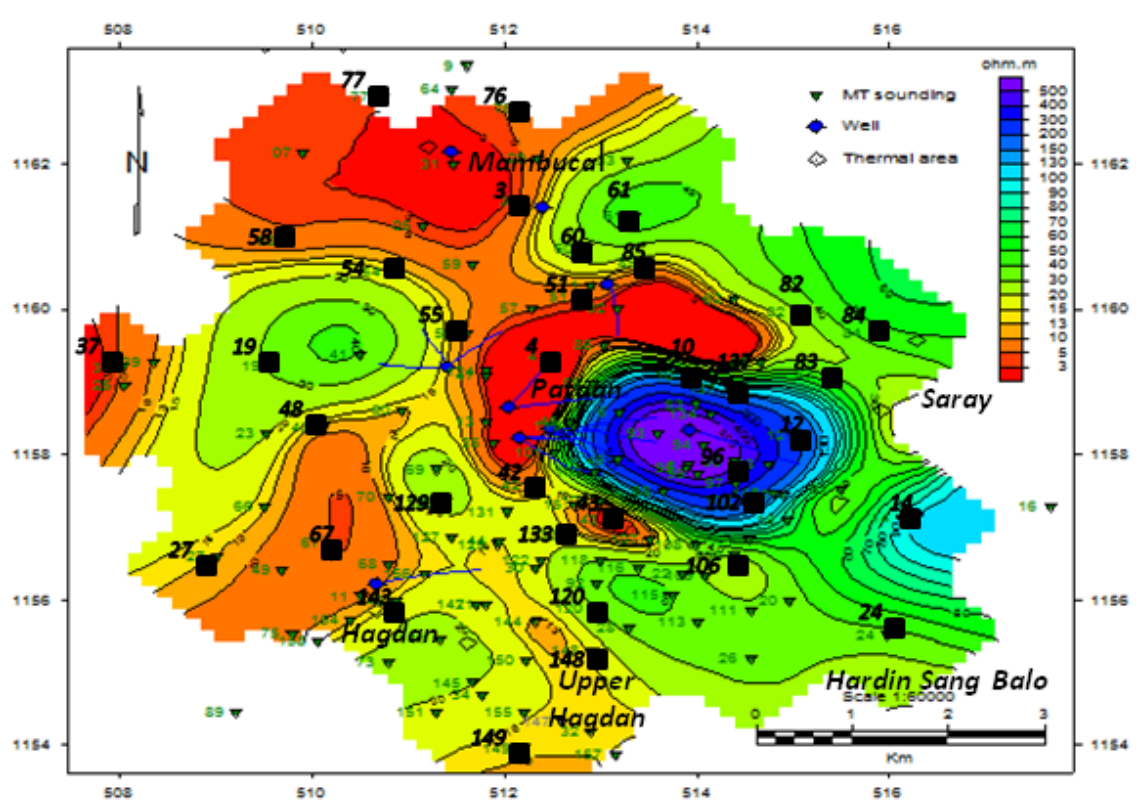

Figure 5.4: 2-D isoresistivity map at $300 \mathrm{~m}$ depth

postulated heat source in the southeast to the outflow zone in the northwest. Some of these profiles will be presented in Section 5.5.

At $300 \mathrm{~m}$ depth, moderate to high resistivity values covers most of NNGP particularly east and south of Pataan where $>100 \mathrm{ohm}-\mathrm{m}$ can be found (Figure 5.4). A broad conductive zone of $<10 \mathrm{ohm}-\mathrm{m}$ was detected at Mambucal sector extending towards the north-northwestern portion of Pataan. At $1000 \mathrm{~m}$ depth, the conductive zone now occupies more than half of the project area including Hagdan, Upper Hagdan and west of Pataan (Figure 5.5). The resistive region is confined to east and southeast of Pataan and Saray sectors. At $2000 \mathrm{~m}$ depth, a resistive block is still detected east and southeast of Pataan (Figure 5.6). Similar resistive regions are detected in Hardin Sang Balo and Saray. Hagdan and Upper Hagdan are enclosed within the moderately resistive zone. Then again, Mambucal is set apart by high conductivity values $<10 \mathrm{ohm}-\mathrm{m}$. A conductive strip was also detected between Upper Hagdan and Hardin Sang Balo (Figure 5.6). 


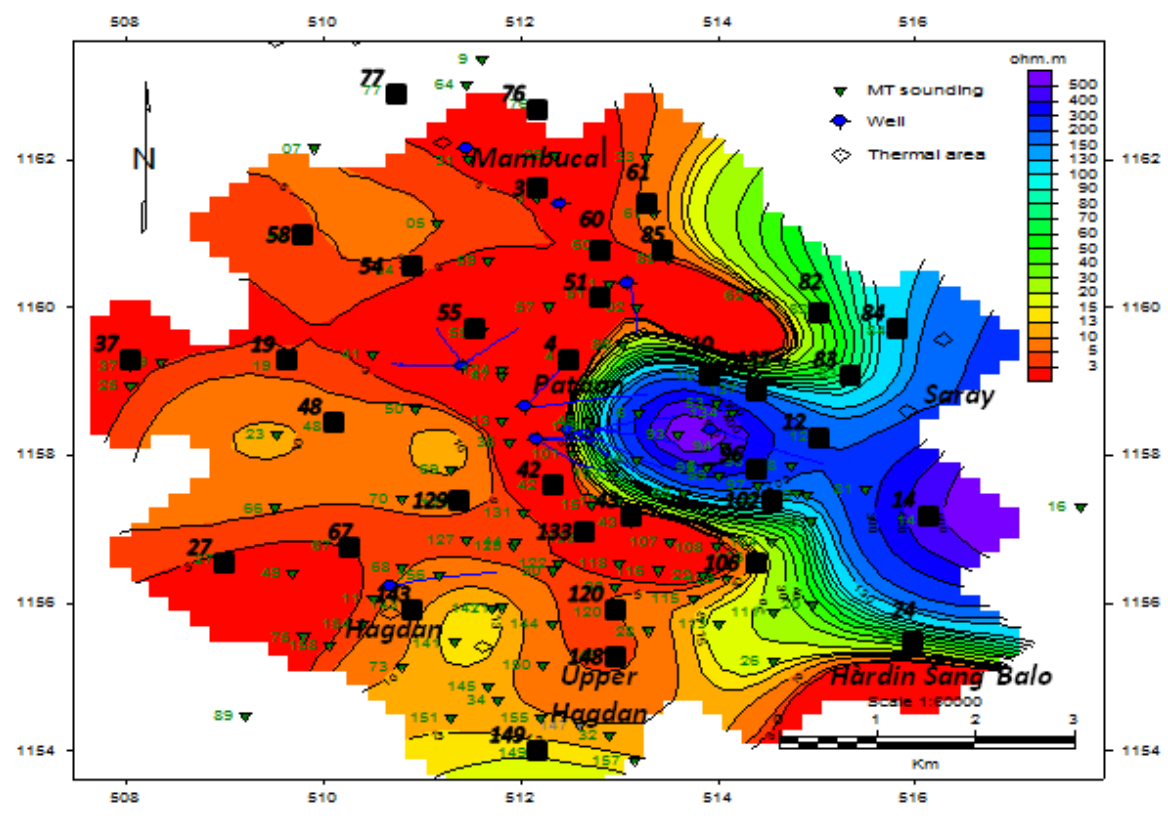

Figure 5.5: 2-D isoresistivity map at $1000 \mathrm{~m}$ depth

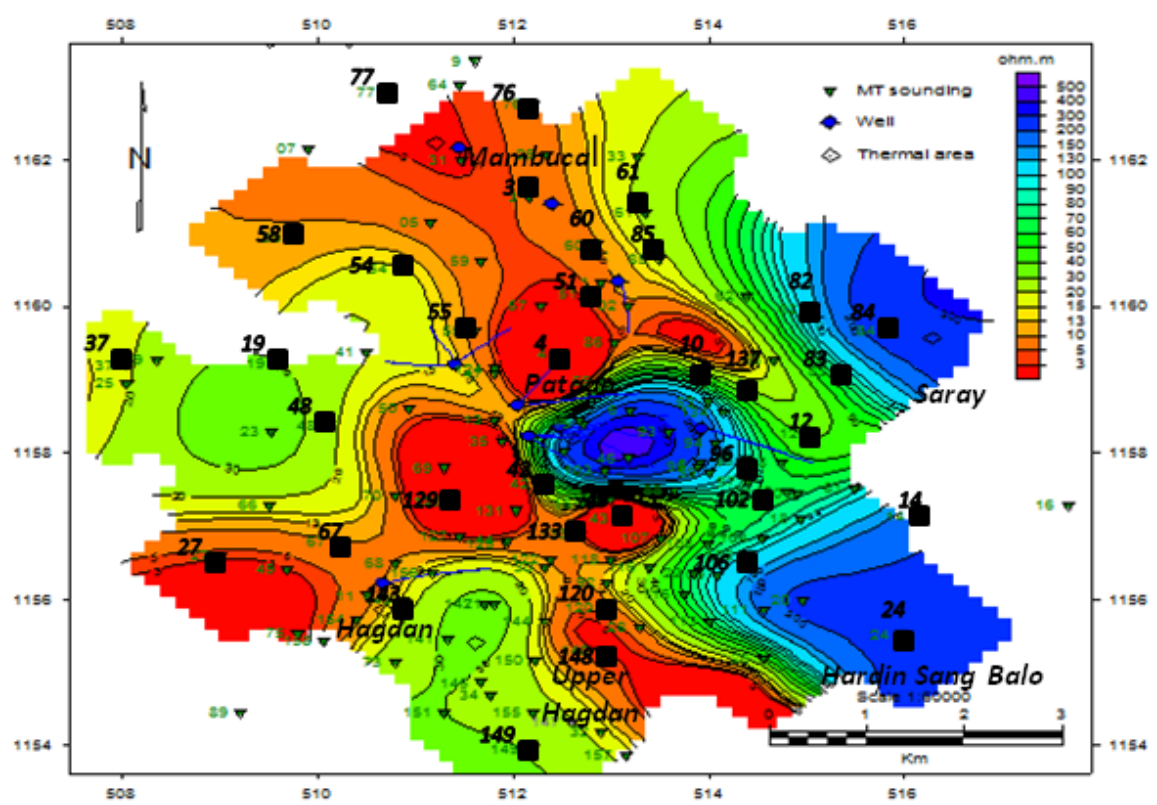

Figure 5.6: 2-D isoresistivity map at $2000 \mathrm{~m}$ depth 


\subsection{3-D inversion modeling}

The 3D inversion modeling software used is the WSINV3DMT (Siripunvaraporn et al., 2006). The MT data that were classified as "Type 3" (Appendix II) or those that has good quality data extending to periods of 100 s or longer were used in the 3D inversion. However, some of the data that were ranked as "Type 2" were also used to fill up the gaps between the "Type 3" stations for better coverage during inversion. A total of 37 MT stations, which are represented as black squares in the isoresistivity maps, were included during 3-D inversion. Moreover, 14 periods were used ranging from $0.007 \mathrm{~s}$ to $170 \mathrm{~s}$, which is equivalent to skin depths of about $100 \mathrm{~m}$ to $>5 \mathrm{kms}$. All eight impedance elements of the MT data which consisted of the real and imaginary components of $Z_{x x}, Z_{x y}, Z_{y x}$ and $Z_{y y}$ were included in the inversion.

The MT stations were located using a grid system wherein " $\mathrm{X}$ " denotes the north-south direction while " $Y$ " refers to the east-west axis. The $\mathrm{X}$ and $\mathrm{Y}$ origin $(0,0)$ is located at the center and the value increase towards the north in the $X$ axis and to the east in the $Y$ direction. Depth is represented by the "Z" axis and it increases from the surface down.

The grid was designed in a manner that it is sufficient to compute the resistivity value at the center of each grid square at the same time as considering the capability of the PC used. A $28 \times 28 \times 28$ grid was used with the $X$ and $Y$ axis having a minimum spacing of $500 \mathrm{~m}$ within the first $9 \mathrm{~km}$ which encloses the geothermal project site and gradually increases to $20 \mathrm{~km}$ further away. The total area coverage in both $X$ and $Y$ directions extended to 55 kilometers, which is much more than the skin depth of the longest period. For the depth $(Z)$, the starting level was the surface ( 0 meters) then gradually increasing until reaching depths of 45 $\mathrm{km}$. The exact grid values used can be seen in the first sections of the input data file (Appendix IV). 


\subsubsection{Comparison of initial models}

Several 3-D inversions were run using different starting models to determine the features which can be attributed to the MT data from those that could be artefacts of the modeling software. A comparison of three starting models will be presented here, namely:

1. Model A: layered model with $100 \mathrm{ohm}-\mathrm{m}$ for the first $100 \mathrm{~m}$, underlain by $10 \mathrm{ohm}-\mathrm{m}$ until the bottom

2. Model B: half-space of $10 \mathrm{ohm}-\mathrm{m}$

3. Model C: half-space of $30 \mathrm{ohm}-\mathrm{m}$

The minimum RMS/misfit achieved during iterations for models A, B and C were 36.289, 28.281 and 19.029, respectively. All models were processed with at least 15 iterations. It should be noted that Model A was one of the first inversions run and it had only 35 MT stations incorporated during inversion. The inclusion of the additional two stations within Pataan will be explained in the succeeding sections.

Figures 5.7, 5.8 and 5.9 show the isoresistivity maps for the three models at $300 \mathrm{~m}$ depth. The prominent features that can be observed for all three models include:

1. Mambucal sector is enclosed by a broad conductive region with resistivity values of $<10 \mathrm{ohm}-\mathrm{m}$. However, on its eastern portion specifically stations 6 and 85, there are moderately resistive values (>15 ohm-m).

2. A moderately resistive ( $>30 \mathrm{ohm}-\mathrm{m})$ zone is detected at Saray centered on station 12. For Model A, this resistive zone includes the Pataan sector all the way to the south. On the other hand, Models $\mathrm{B}$ and $\mathrm{C}$ detected a highly conductive $(<10 \mathrm{ohm}-\mathrm{m})$ zone within Pataan. This difference can be attributed to the additional MT stations namely, 46 and 93 that were added in this sector. This conductive zone is connected to the one in Mambucal. 
3. Station 24 near Hardin Sang Balo is characterized by resistivity values $>15 \mathrm{ohm}-\mathrm{m}$. All the different models show this resistive zone extending towards the south although the resistivity signature towards the southeastern end differs for the models: Models A and B show $<10$ ohm-m while Model C indicates $>20$ ohm-m. This could be due to the lack of MT stations in this region that the resistivity values are not well constrained.

4. Hagdan sector, specified by stations 143 and 67 is enclosed by moderately resistivity values ( $>15 \mathrm{ohm}-\mathrm{m}$ ) while Upper Hagdan, which is the area between stations 148 and 149 is surrounded by $<10$ ohm-m.

5. Another moderately resistive zone is delineated in the western portion bounded by stations 58,19 and 48 . This moderately resistive zone is connected to the resistive zone in Hagdan in Models B and $\mathrm{C}$.

Figures 5.10, 5.11 and 5.12 show the isoresistivity maps at $2 \mathrm{~km}$ depth for Models A, B and C, respectively. Among the characteristics noted include:

1. A broad $<10 \mathrm{ohm}$-m conductive region was detected in Pataan and Hagdan. The eastern portion of Pataan are covered by moderately resistive values of $>20 \mathrm{ohm}-\mathrm{m}$ as shown by Models $\mathrm{A}$ and $\mathrm{C}$ even when stations 46 and 93 (in Pataan) were not present in Model A. However, this feature cannot be clearly distinguished by Model B at this depth but this moderately resistive layer was indicated at 1 km depth (Figure 5.13).

2. The Mambucal sector (stations 3 and 6 ) is enclosed by $>20 \mathrm{ohm}-\mathrm{m}$ resistivity values. This resistive zone extends to stations 77 and 76 in the north in Models B and C. 


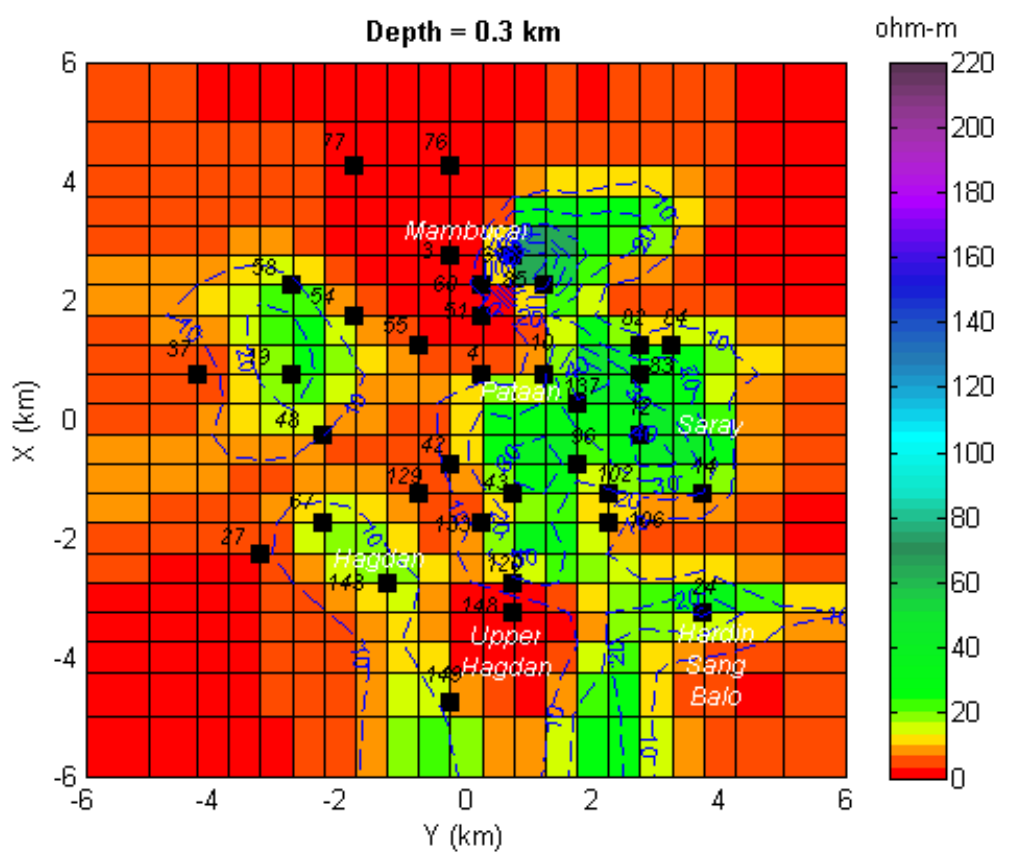

Figure 5.7: Model A isoresistivity map at $300 \mathrm{~m}$ depth

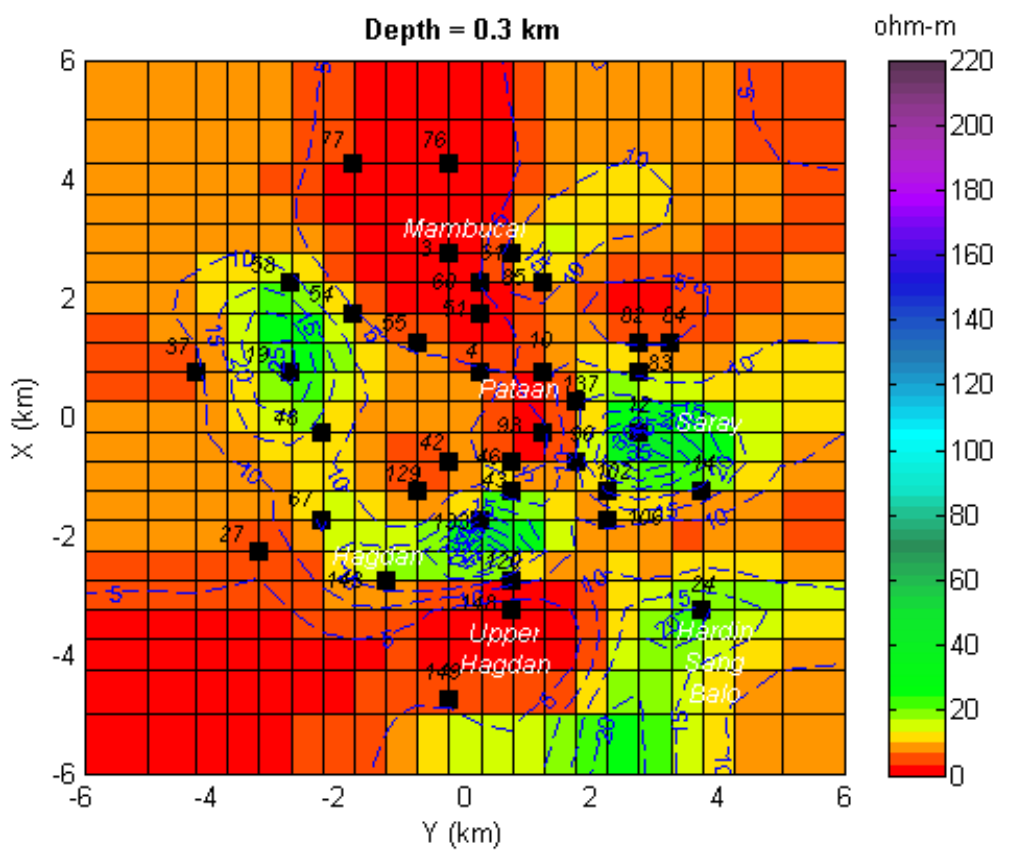

Figure 5.8: Model B isoresistivity map at $300 \mathrm{~m}$ depth 


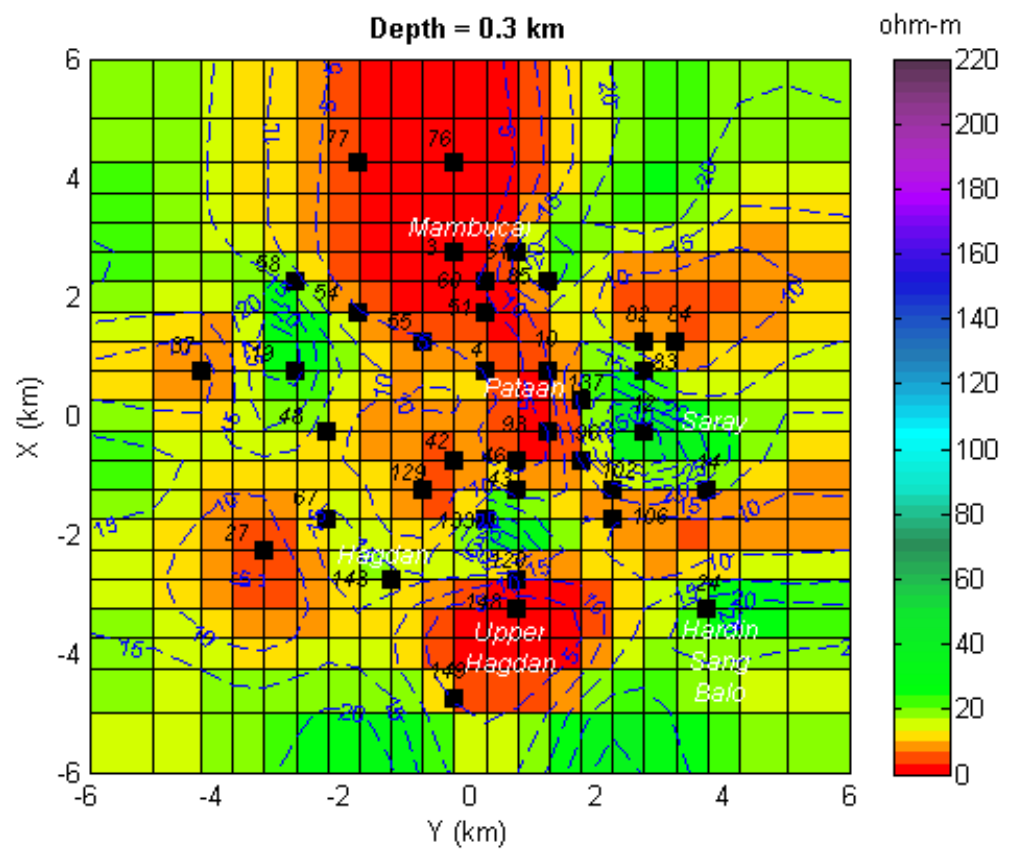

Figure 5.9: Model C isoresistivity map at $300 \mathrm{~m}$ depth

3. The Saray sector, east of station 12 , is moderately resistive $(>20$ ohm-m) in Models B and C, while it is mainly conductive in Model A.

4. The Upper Hagdan sector in the south is also resistive as shown by station 149 .

5. Resistive zones were detected west of Pataan, beneath stations 67, 48 and 54.

The isoresistivity maps of the different models shows similar resistivity patterns where there are sufficient MT data available. The inclusion of two more stations in the Pataan sector proves that shallow moderately resistive body beneath Pataan is not just an artefact of the inversion process. Major differences are observed further from the centre where there were no MT stations. This can be further illustrated through 


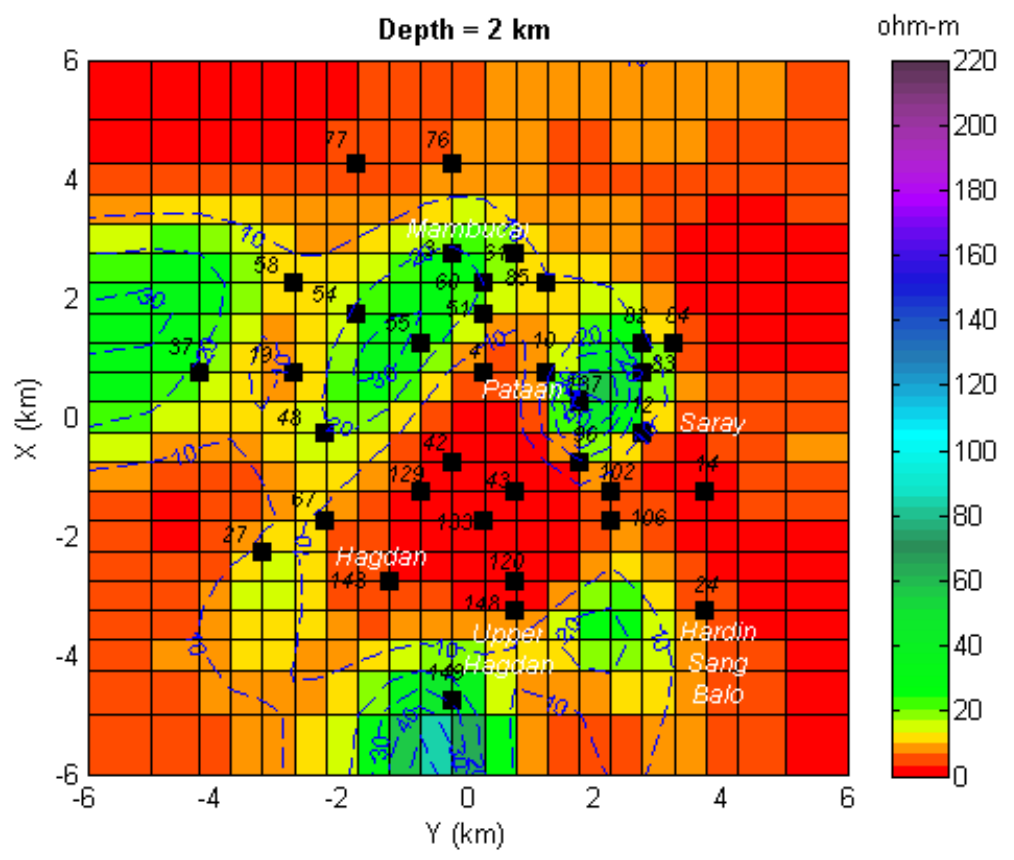

Figure 5.10: Model A isoresistivity map at $2000 \mathrm{~m}$ depth

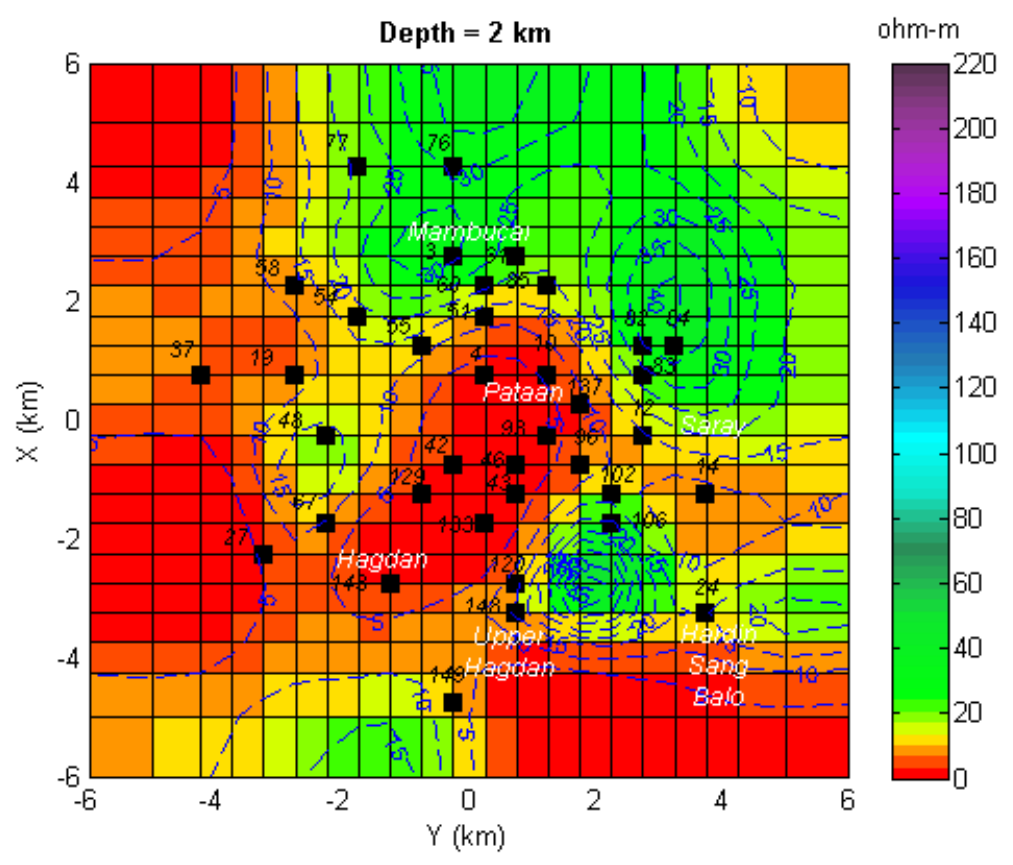

Figure 5.11: Model B isoresistivity map at $2000 \mathrm{~m}$ depth 


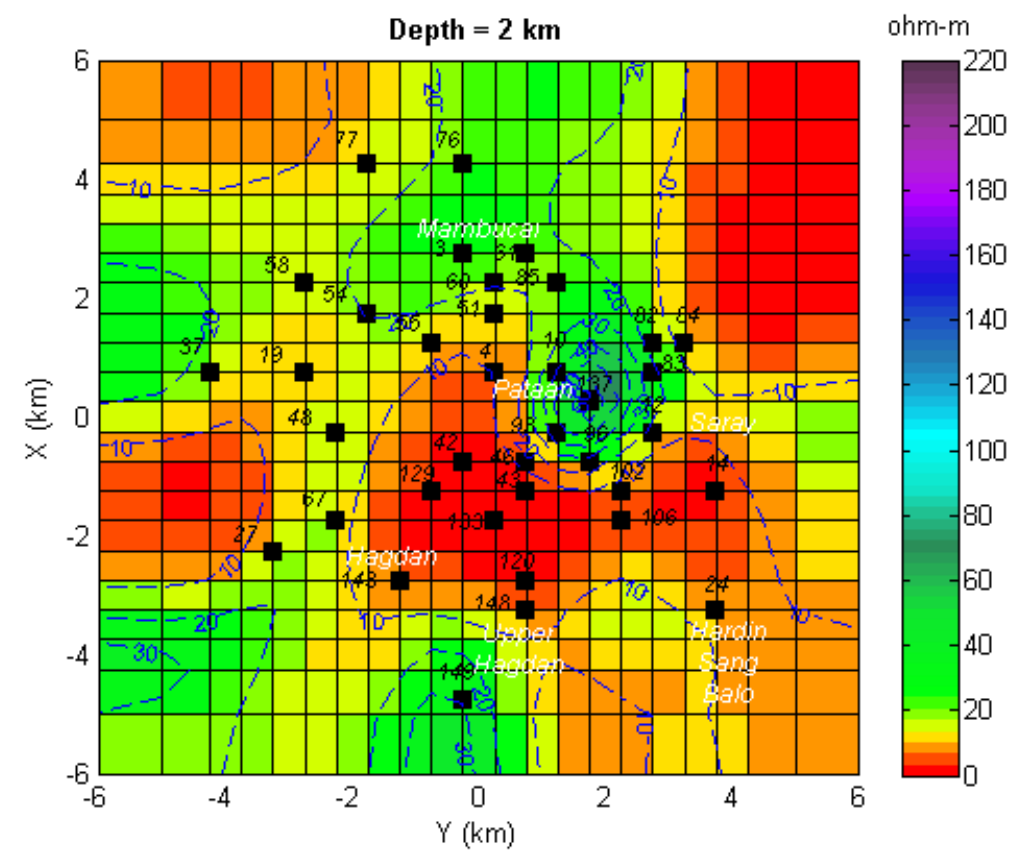

Figure 5.12: Model C isoresistivity map at $2000 \mathrm{~m}$ depth

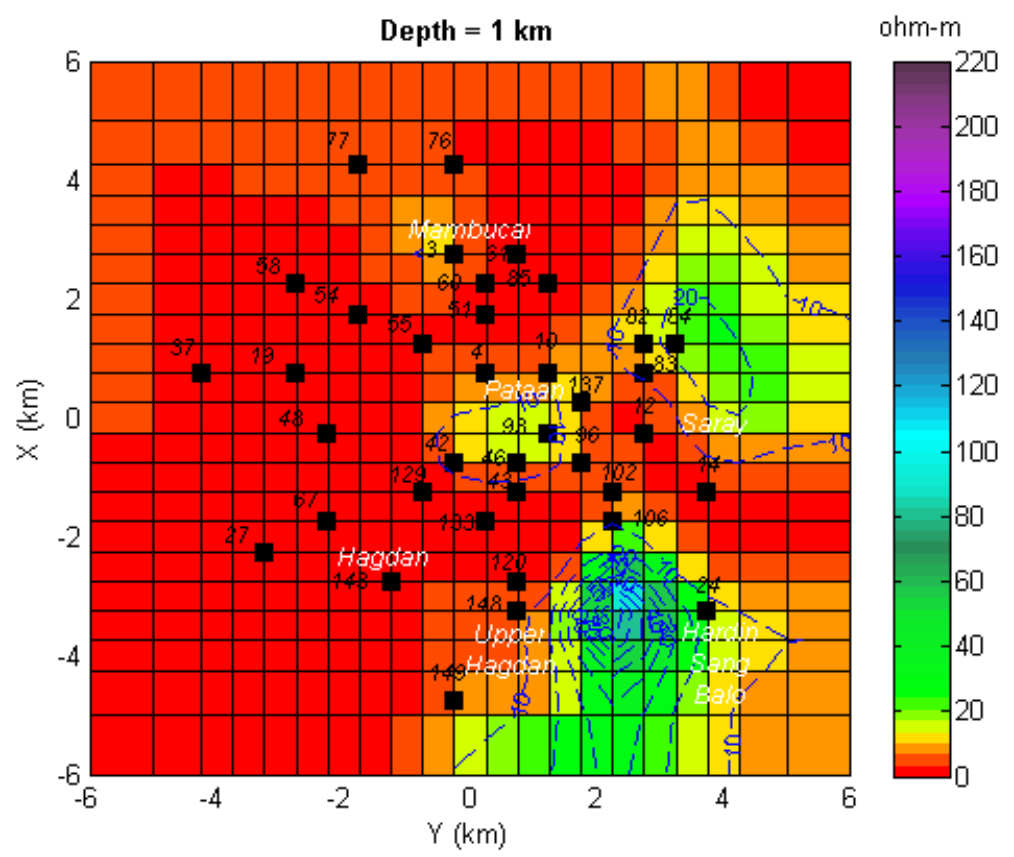

Figure 5.13: Model B isoresistivity map at $1000 \mathrm{~m}$ depth 


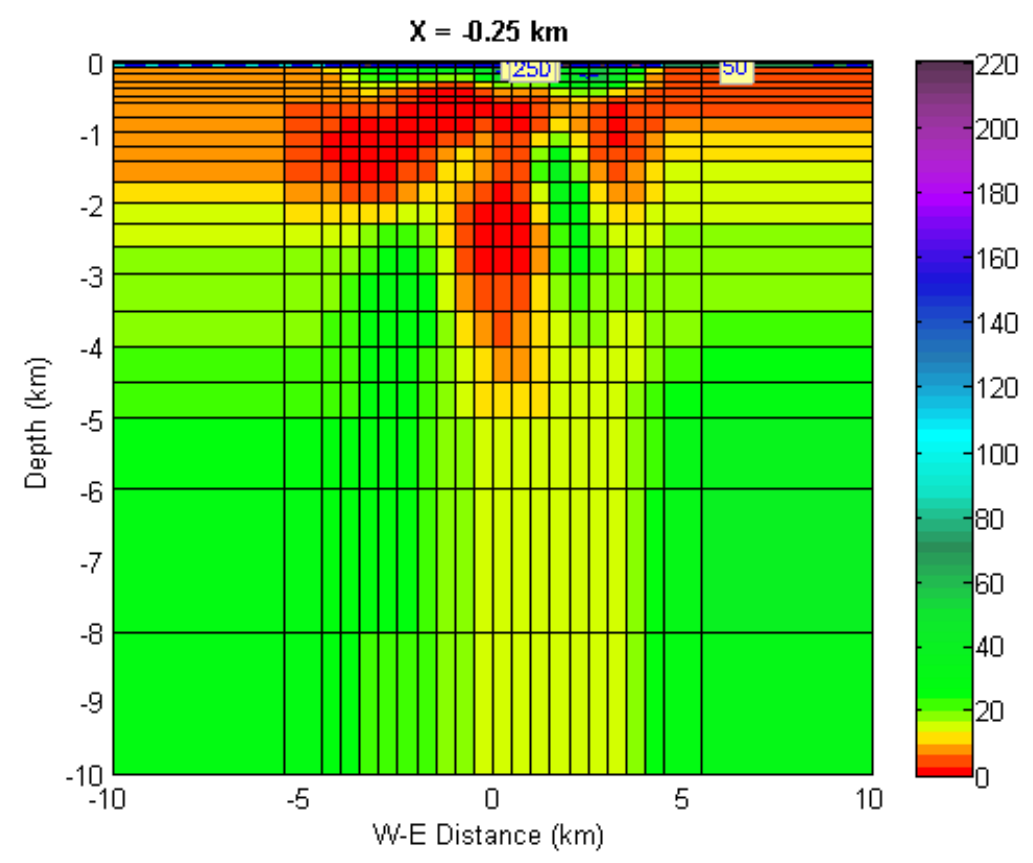

Figure 5.14: Model A profile line $X=-0.25 \mathrm{~km}$

the cross sections that cut across the middle of the project area namely lines $X=-0.25 \mathrm{~km}$ and $Y=0.75 \mathrm{~km}$.

Profile line $X=-0.25 \mathrm{~km}$ traverses the Pataan sector in a west-east direction. It shows similar characteristics in Models $\mathrm{A}, \mathrm{B}$ and $\mathrm{C}$, such as a resistive cap (>50 ohm-m) layer from 0 to about $300 \mathrm{~m}$ depth (Figures $5.14,5.15$ and 5.16). This is followed by a highly conductive layer $(<10$ ohm-m) which extends to as deep as about $4.5 \mathrm{~km}$ in the middle $(0 \mathrm{~km})$. This is underlain by a bottom layer with increasing resistivity values ( $>10$ ohm-m) with depth. Slightly lower resistivity values for this layer are found in Model A. The more resistive bottom layer can be found beneath Pataan sector protruding upwards to depth of about $1 \mathrm{~km}$. This feature can be clearly seen in Models A and C while only a portion can be discerned in Model B.

On the other hand, different features among the models can also be observed. These included the resistive layer detected in the eastern end 


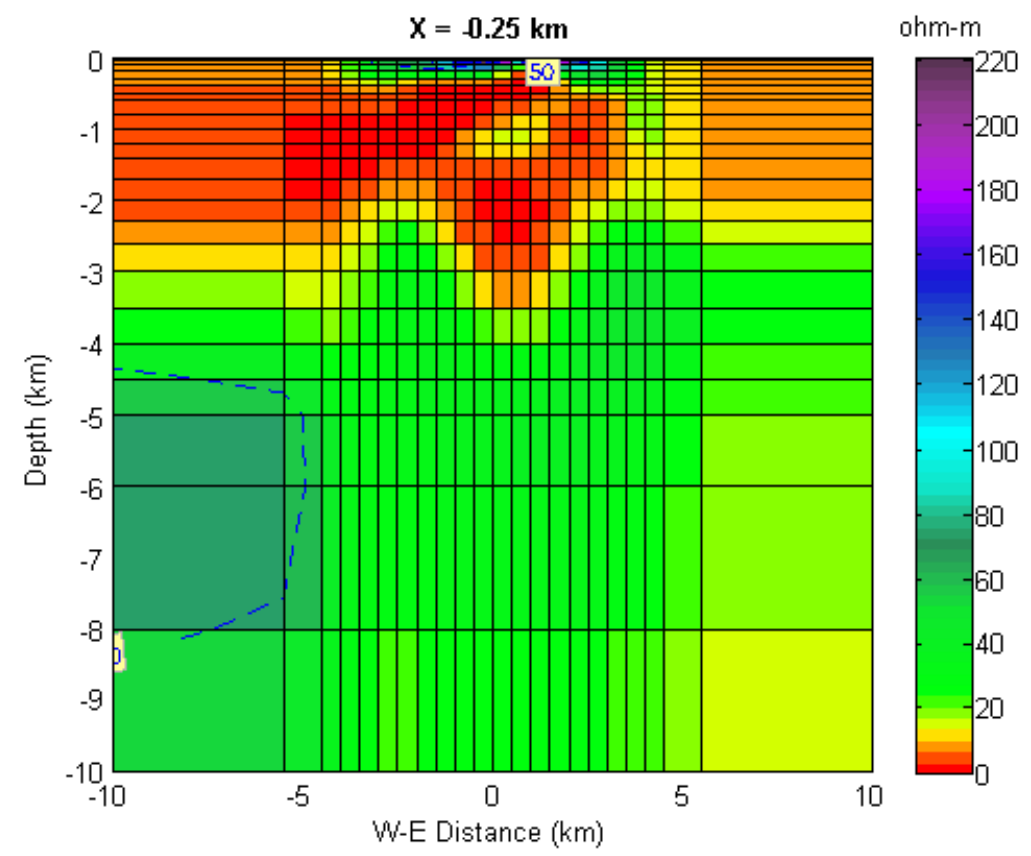

Figure 5.15: Model B profile line $X=-0.25 \mathrm{~km}$

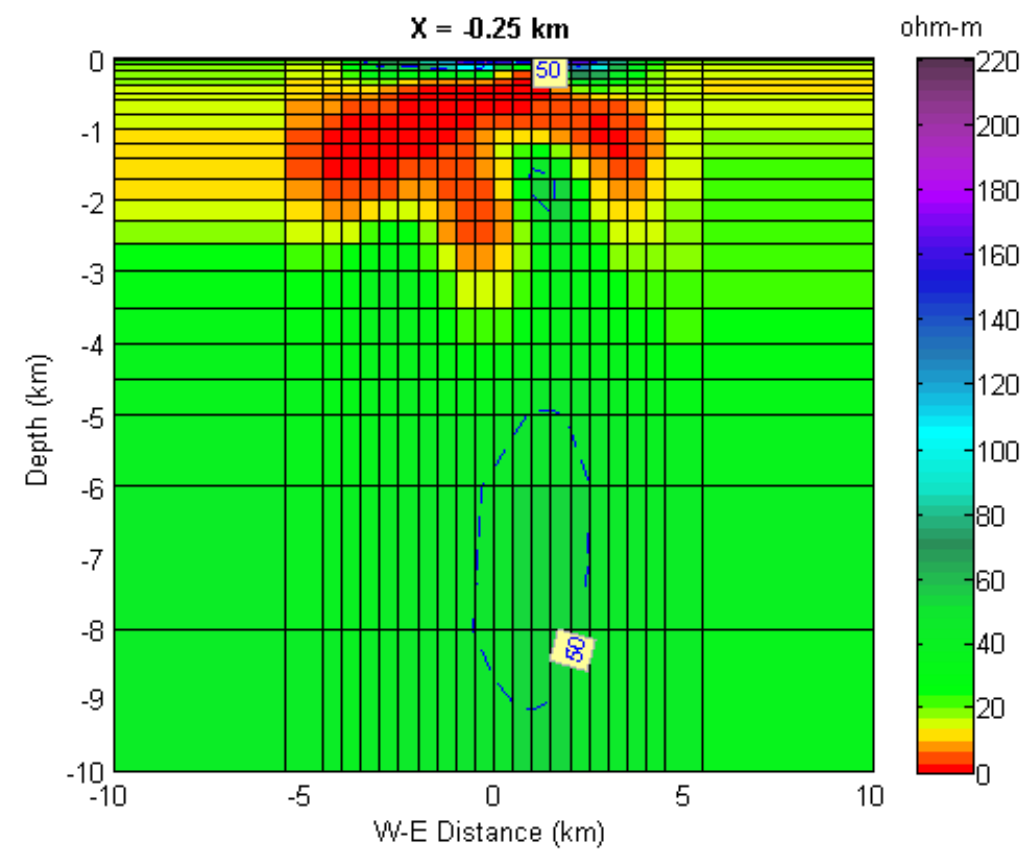

Figure 5.16: Model C profile line $X=-0.25 \mathrm{~km}$ 
of Model C specifically in the $5 \mathrm{~km}$ to $10 \mathrm{~km}$ range compared to a conductive layer in Models A and B. Again, differences in the depth extent of this conductive layer can be noted. It reaches depths of about $2 \mathrm{~km}$ depth in Model B and only about $1 \mathrm{~km}$ depth in Model A. On the western edge $(-5 \mathrm{~km}$ to $-10 \mathrm{~km})$, a conductive layer is detected starting from about $100 \mathrm{~m}$ depth in Models A and B while a more resistive layer is detected in Model $\mathrm{C}$. The extent of the conductive layer also varies, it reaches about depths of about $1.5 \mathrm{~km}$ and $2.5 \mathrm{~km}$ for Models A and B, respectively. These differences correspond to those seen in the isoresistivity maps in the regions where there are few MT sites, outside the central area.

Profile line $\mathrm{Y}=0.75 \mathrm{~km}$ also traverses the Pataan sector but in a southnorth direction. The cross sections are shown in Figures 5.17, 5.18 and 5.19. A similar resistive ( $>30 \mathrm{ohm}-\mathrm{m})$ layer is detected from surface to about $300 \mathrm{~m}$ depth. This is underlain by a $<10 \mathrm{ohm}-\mathrm{m}$ layer extending at its deepest to about $4.5 \mathrm{~km}$. Below this conductive layer, resistivity values increase with depth. As shown in line $X=-0.25 \mathrm{~km}$, the resistivity values of the bottom layer is slightly lower in Model A. Also, just as in the previous cross section, a shallower portion of the resistive bottom layer exists beneath the Pataan sector at depths ranging from of about 1 to $1.5 \mathrm{~km}$. This can be seen in Models A and C while in Model B higher resistivity occurs as an isolated region at about $1 \mathrm{~km}$ depth. The resistivity values and extent of the layers on the southern and northern edges also varies for the models. For Model A, the conductive layer persists to the southern and northern edges until about $2 \mathrm{~km}$ depth while for Model B this is thinner on the northern tip while going deeper on the southern portion reaching depths of about $4 \mathrm{~km}$. On the other hand for Model C, only the northern edge is conductive from depths of about 300 $\mathrm{m}$ to about $1.5 \mathrm{~km}$ while the southern portion is resistive. Again, these differences occur in regions of low site density where the grid spacings are increased. 


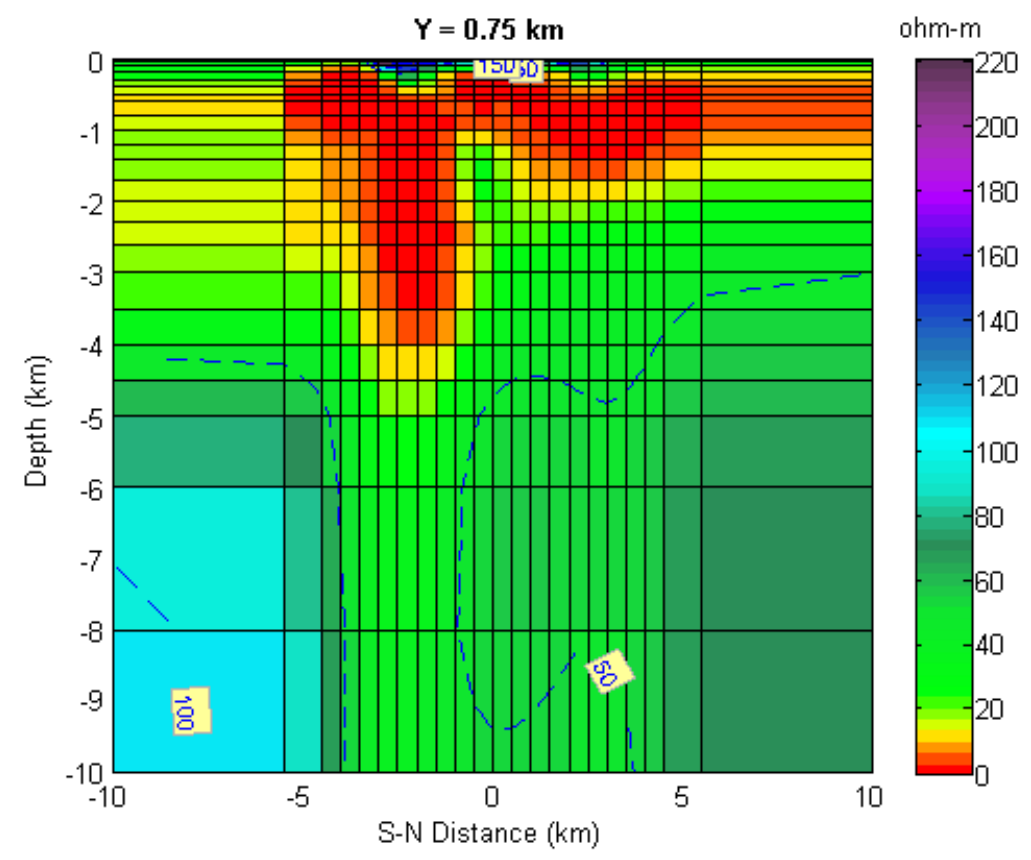

Figure 5.17: Model A profile line $Y=0.75 \mathrm{~km}$

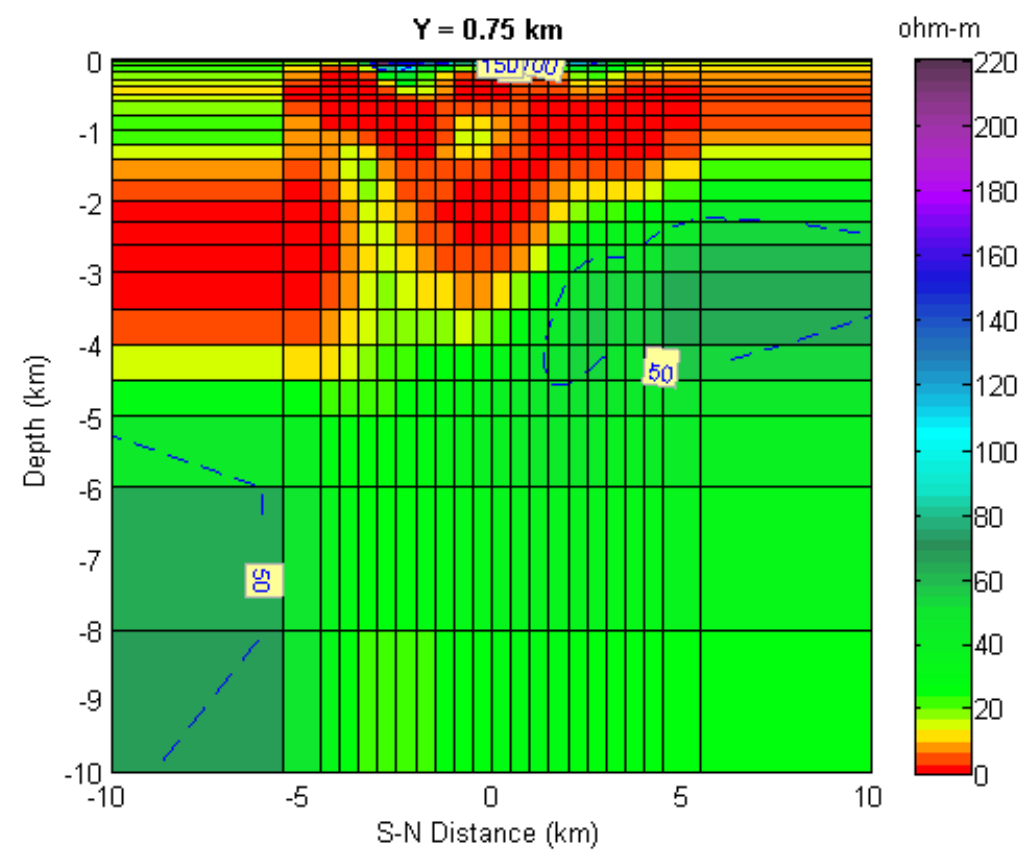

Figure 5.18: Model B profile line $Y=0.75 \mathrm{~km}$ 


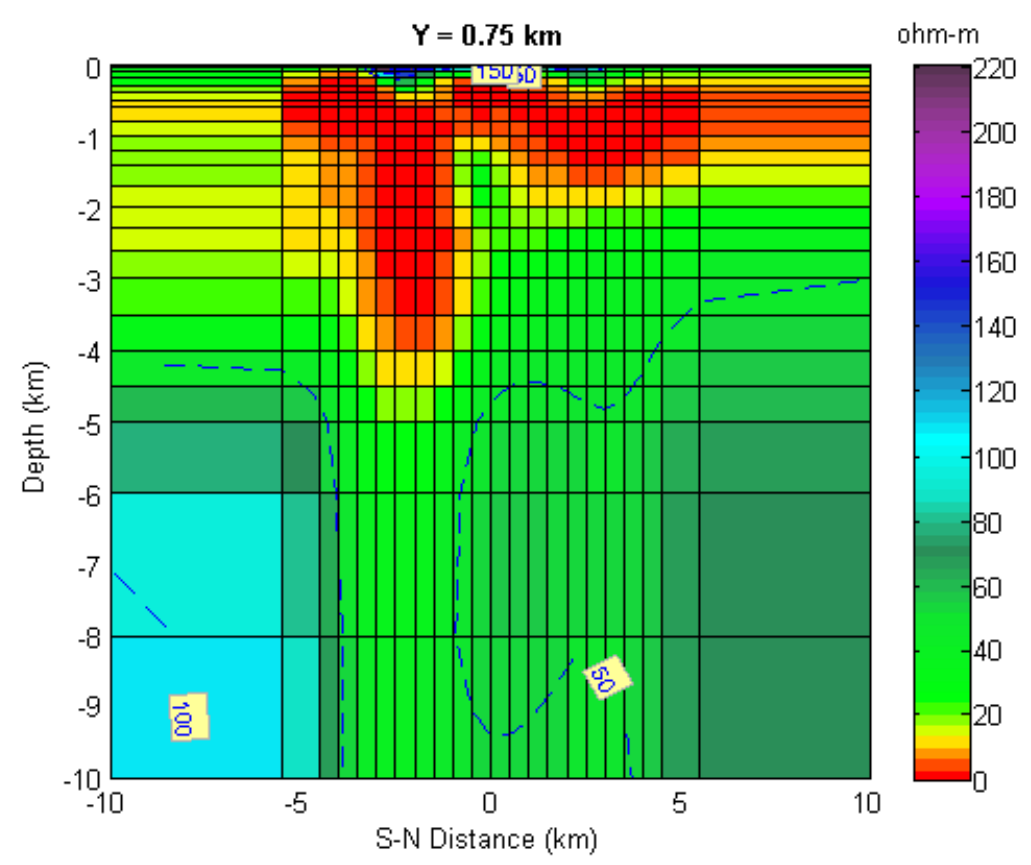

Figure 5.19: Model C profile line $Y=0.75 \mathrm{~km}$

A lower RMS is achieved with the model that has a starting model with the higher initial resistivity value at depth of $30 \mathrm{ohm}-\mathrm{m}$ (Model C). Compared to Models A and B, the calculated curves have a smoother fit to the apparent resistivity and phase data especially in the long period range. Examples to illustrate this are at stations 4 and 14 (Figures 5.20 and 5.21). 

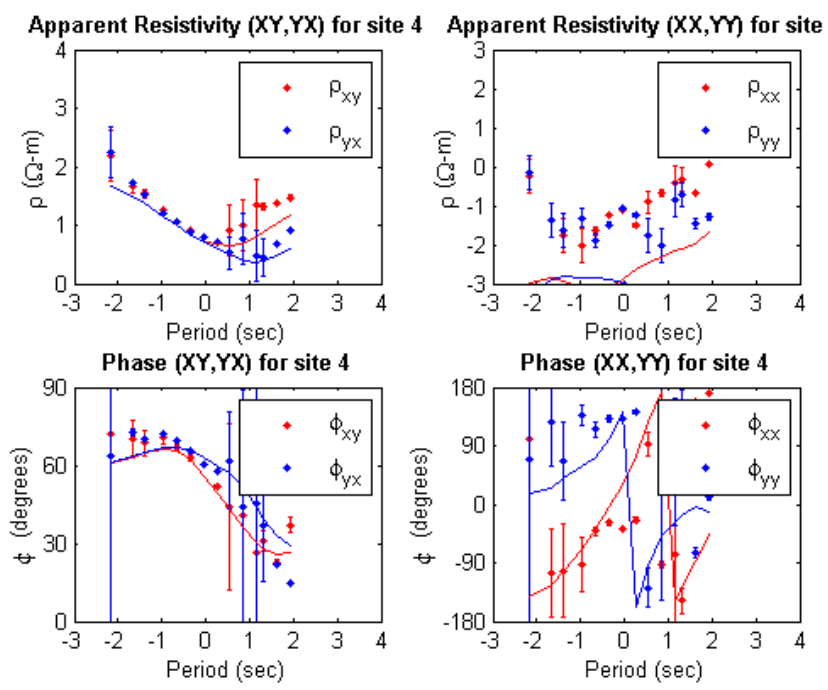

(a) Model A
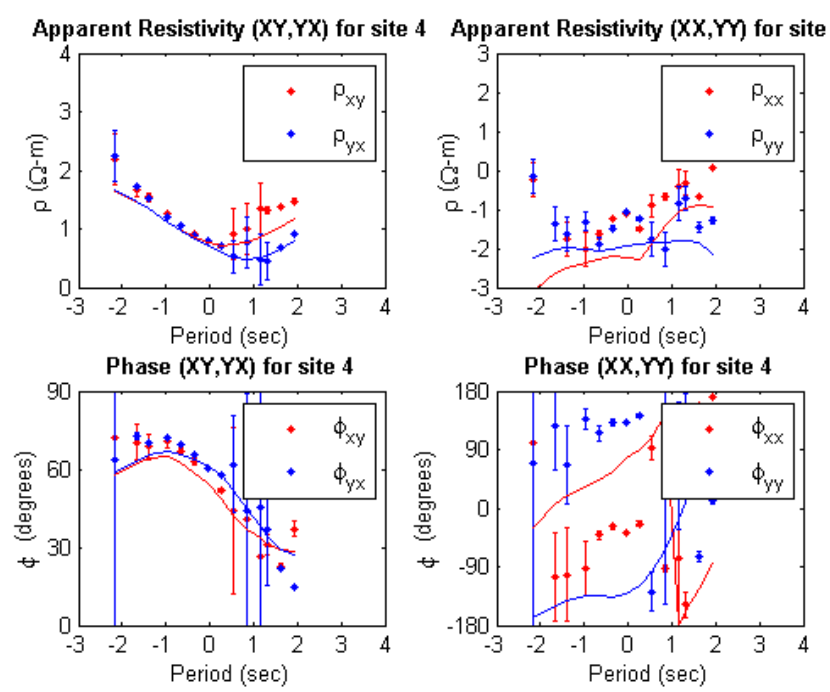

(b) Model B
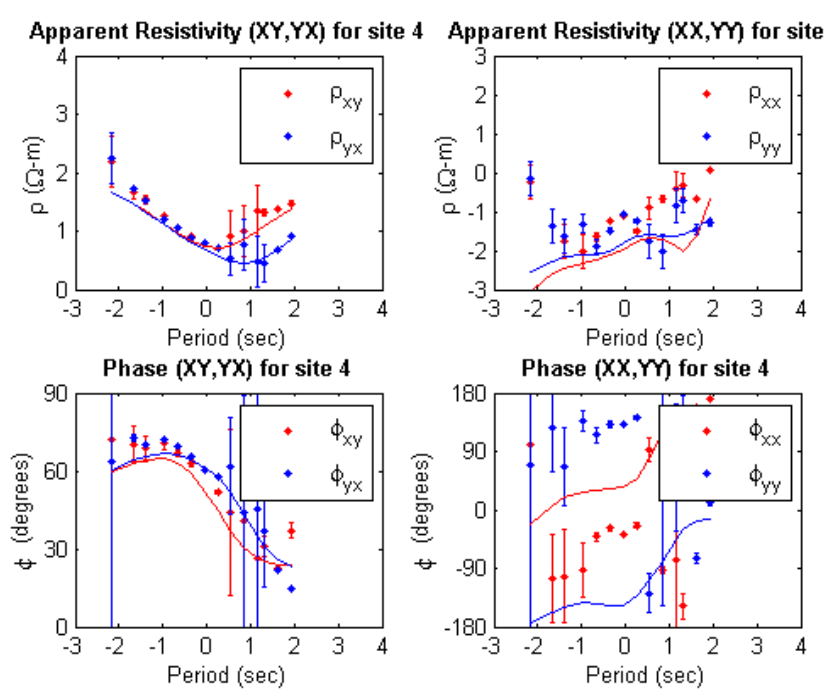

(c) Model C

Figure 5.20: Curve fit of model vs data of MT station 4 

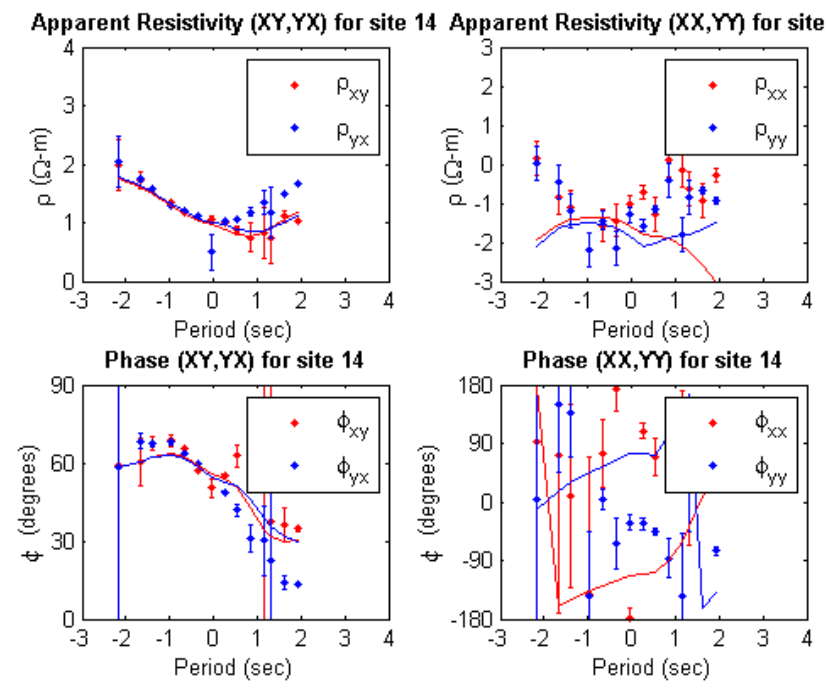

(a) Model A
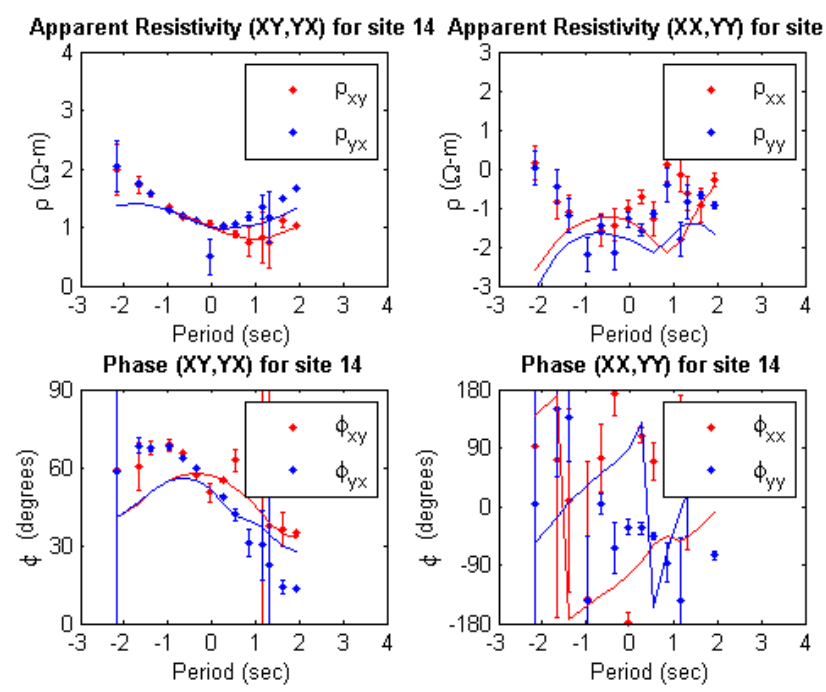

(b) Model B

Apparent Resistivity (XY,YX) for site 14 Apparent Resistivity (XX, M for site 14
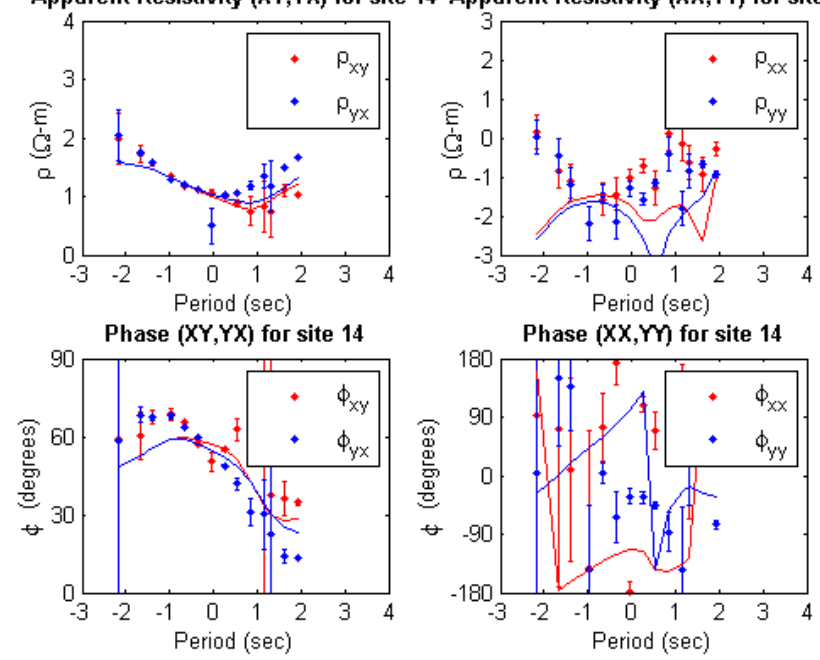

(c) Model C

Figure 5.21: Curve fit of model vs data of MT station 14 


\subsection{3-D inversion results}

The results of the 3-D inversion using Model C as the initial model (with $30 \mathrm{ohm}-\mathrm{m}$ half space) will be presented here to describe the resistivity structure of NNGP in more detail.

\subsubsection{MT data curves}

The MT data curves and fit of the calculated model are shown in Appendix V. The lowest RMS achieved was 19.029 in the 15 th iteration.

In general, most of the calculated curves match the station data curves very well, namely the apparent resistivities and phases of both $Z_{x y}$ and $Z_{y x}$ (i.e. stations $3,4,10,12,19,27,42,46,48,58,67,77,82,85,93,96$, $106,129)$. At some sites, the calculated curves only fit either the $Z_{x y}$ or $Z_{y x}$ curve (i.e. $37,43,51,60,76,83,102,120$ ). There are also a few data curves that are poorly fitted (i.e.24,54,61,55,84) either due to poor data quality or the possible presence of additional static shifts not accounted for. It can also be observed that the $Z_{x x}$ and $Z_{y y}$ components of the station data tend to be poorly matched by the calculated model curves. However, considering that these elements have values at least an order of magnitude less than the $Z_{x y}$ and $Z_{y x}$, this is not crucial to the overall misfit.

\subsubsection{Isoresistivity maps}

Several isoresistivity maps were produced to show the variation of resistivity with depth.

The isoresistivity map at $10 \mathrm{~m}$ depth shows a massive $>50 \mathrm{ohm}-\mathrm{m}$ resistivity body extending from Upper Hagdan in the south towards Mambucal in the north (Figure 5.22 ). This resistive body was subdivided into three smaller blocks within the areas of Pataan, Saray and Hagdan at $100 \mathrm{~m}$ depth (Figure 5.23 ). Hardin Sang Balo, located in the 
southeast is covered by resistivities $>20 \mathrm{ohm}-\mathrm{m}$. Meanwhile, the Upper Hagdan and Mambucal sectors are now covered by $<10 \mathrm{ohm}-\mathrm{m}$ resistivity contours. At 300 m, Hagdan, Saray and Hardin Sang Balo are still enclosed by moderately resistive values $>20 \mathrm{ohm}-\mathrm{m}$, while Pataan is now included in the conductive zone that continues to the north of Mambucal (Figure 5.24) . Likewise, the conductive zone within Upper Hagdan is now larger. At $500 \mathrm{~m}$ depth, most of the region including Mambucal, Pataan, Hagdan and Upper Hagdan, is now highly conductive (Figure 5.25). The sectors of Saray and Hardin Sang Balo are still moderately resistive. At $1 \mathrm{~km}$ depth, the conductive zone becomes larger, now extending towards Saray in the east (Figure 5.26). A portion of Pataan is now slightly resistive while Hardin Sang Balo is still resistive. At $2 \mathrm{~km}$ depth, Pataan all the way to the northwest in Mambucal, as well Upper Hagdan in the south, is now enclosed by moderate resistivity $>20 \mathrm{ohm}-$ $\mathrm{m}$ (Figure 5.27). Saray, east of Pataan is slightly resistive. A $<10 \mathrm{ohm}-\mathrm{m}$ conductive zone which includes Hagdan, extends toward Hardin Sang Balo sector. Deeper down at $3 \mathrm{~km}$ depth, the region is mostly resistive (>30 0m-m) except for the conductive zone comprising Hagdan and Hardin Sang Balo (Figure 5.28). The conductive zone in Hagdan and Hardin Sang Balo are now separated at $4 \mathrm{~km}$ depth (Figure 5.29). At 5 $\mathrm{km}$ depth, only the Hagdan sector is slightly conductive(Figure 5.30). At $8 \mathrm{~km}$ depth, almost the entire region is covered by resistivity $>40 \mathrm{ohm}-$ $m$ (Figure 5.31). Upper Hagdan and Hardin Sang Balo in the south have higher resistivities $>80 \mathrm{ohm}-\mathrm{m}$.

\subsubsection{Resistivity profiles}

The lateral variation in the resistivity of NNGP is shown through the resistivity profiles created along the $\mathrm{X}$ and $\mathrm{Y}$ axes, which extend to 10 kilometers. The MT stations and sector names that were intersected by the cross-section lines are plotted on the profiles for reference. 


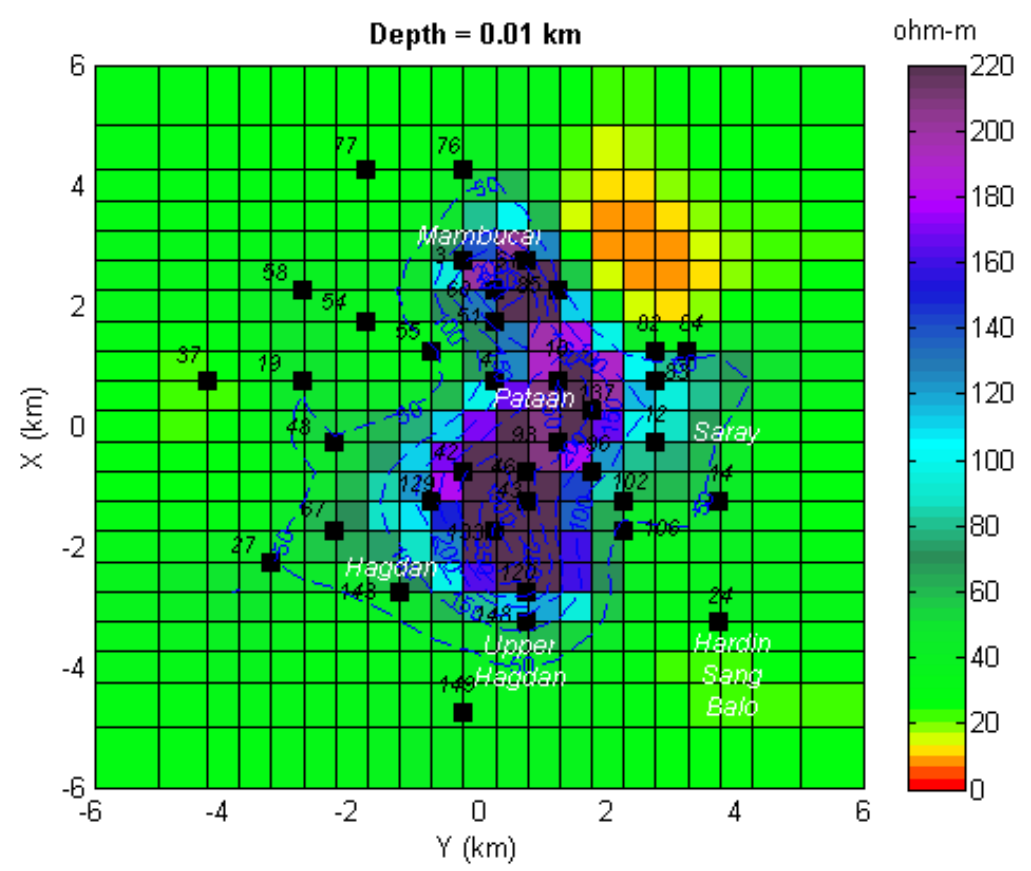

Figure 5.22: Isoresistivity map at $10 \mathrm{~m}$ depth

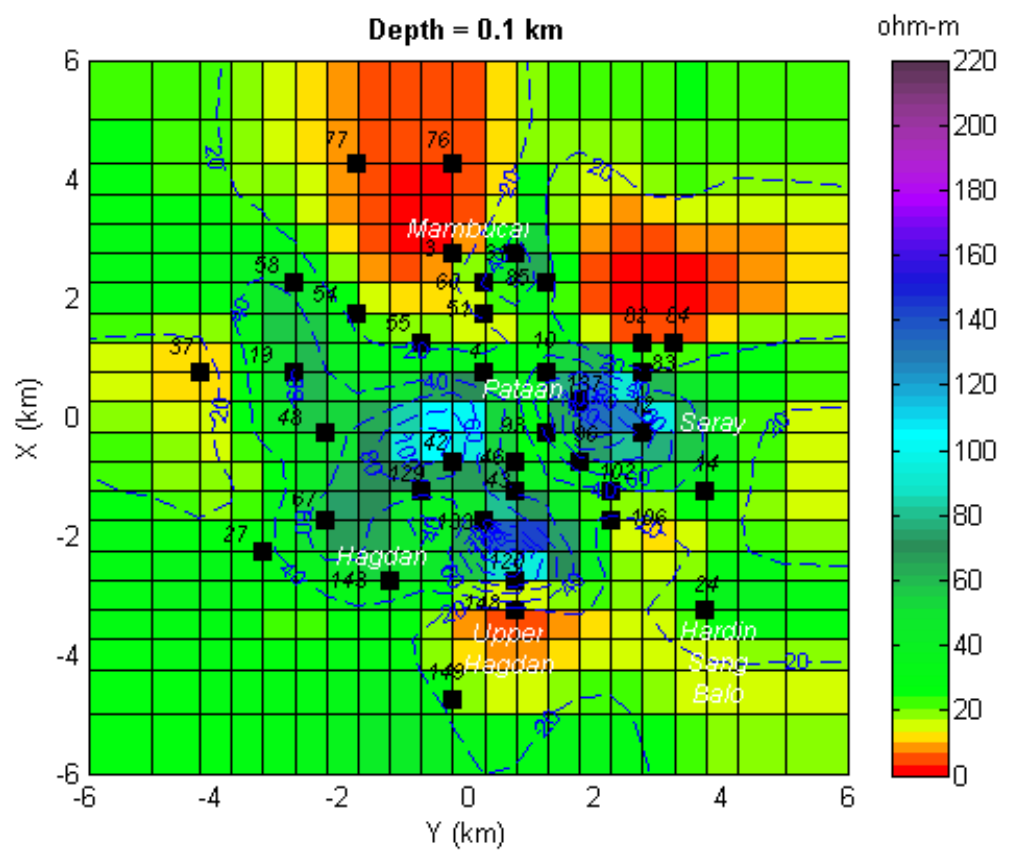

Figure 5.23: Isoresistivity map at $100 \mathrm{~m}$ depth 


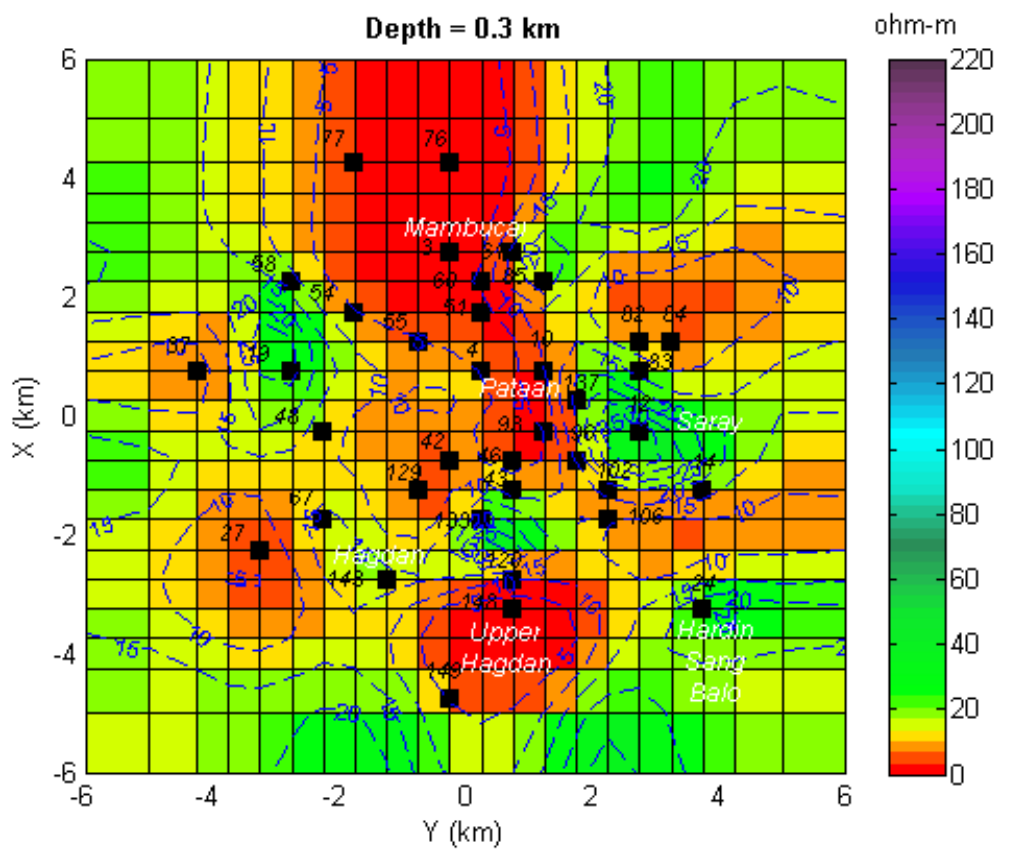

Figure 5.24: Isoresistivity map at $300 \mathrm{~m}$ depth

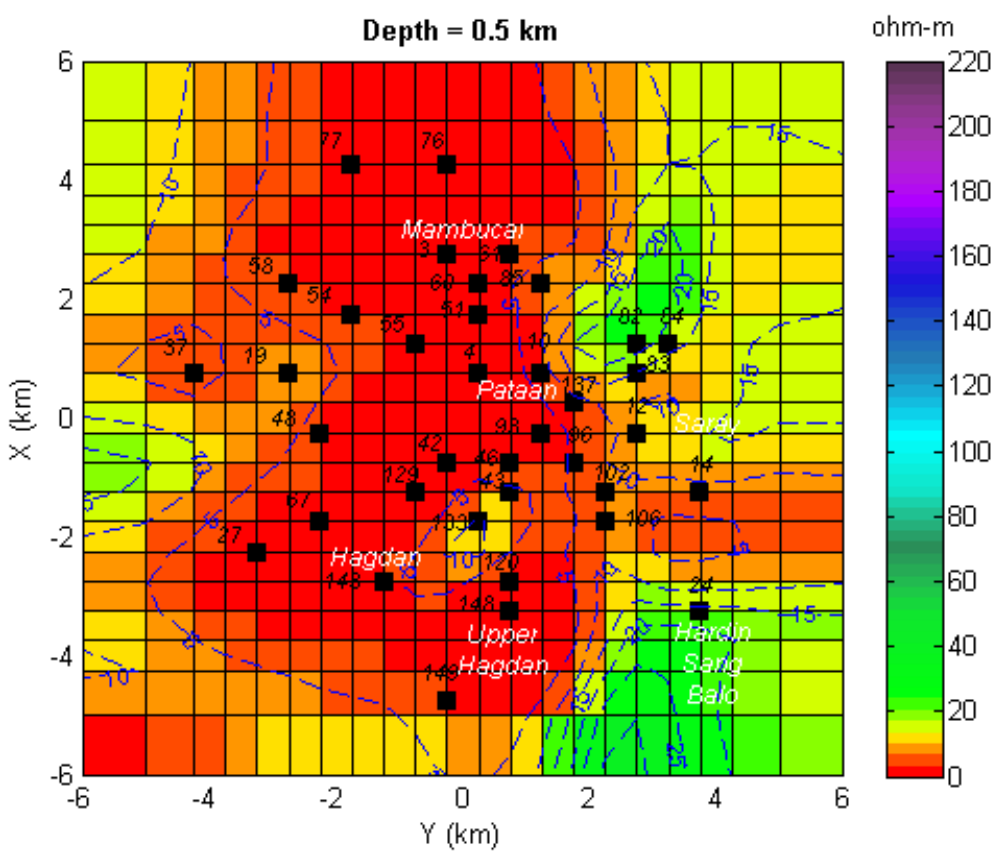

Figure 5.25: Isoresistivity map at $500 \mathrm{~m}$ depth 


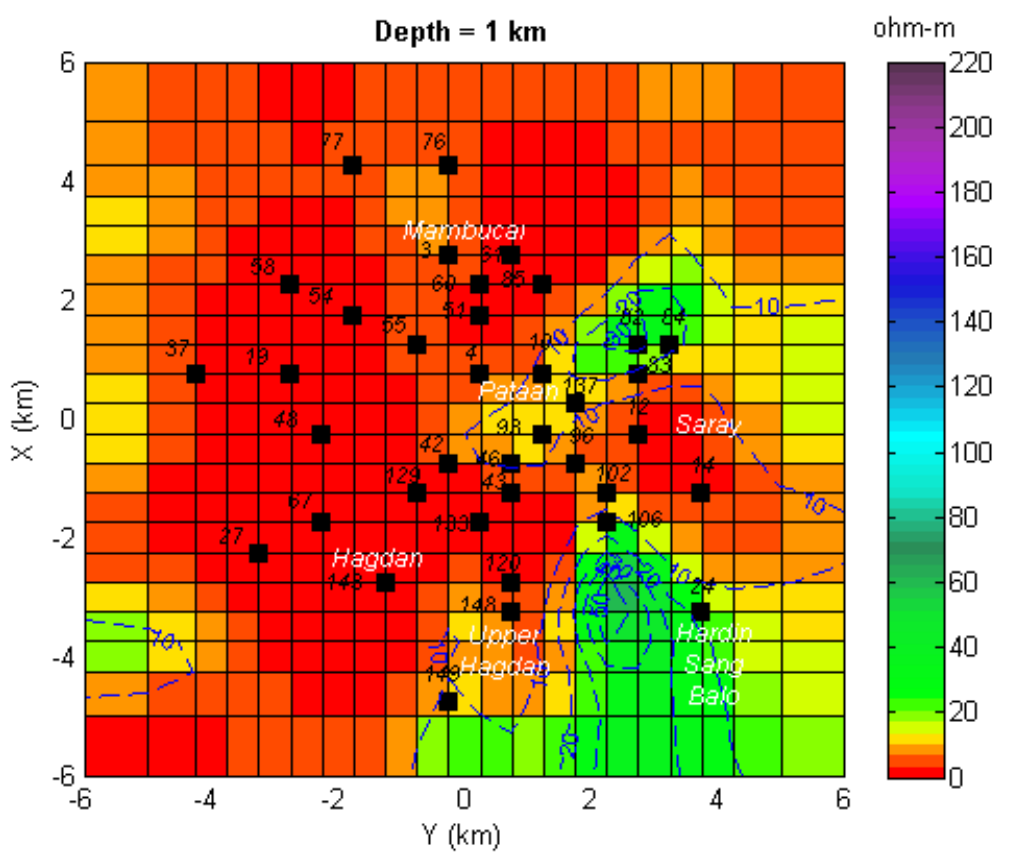

Figure 5.26: Isoresistivity map at $1 \mathrm{~km}$ depth

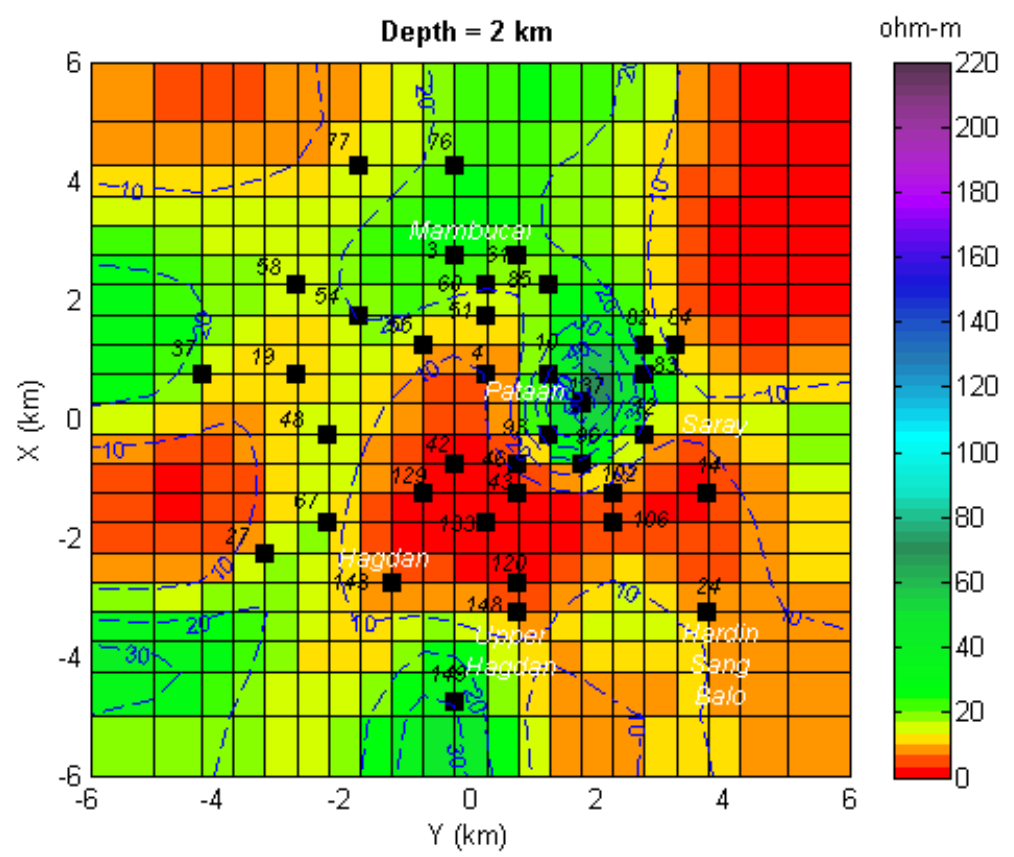

Figure 5.27: Isoresistivity map at $2 \mathrm{~km}$ depth 


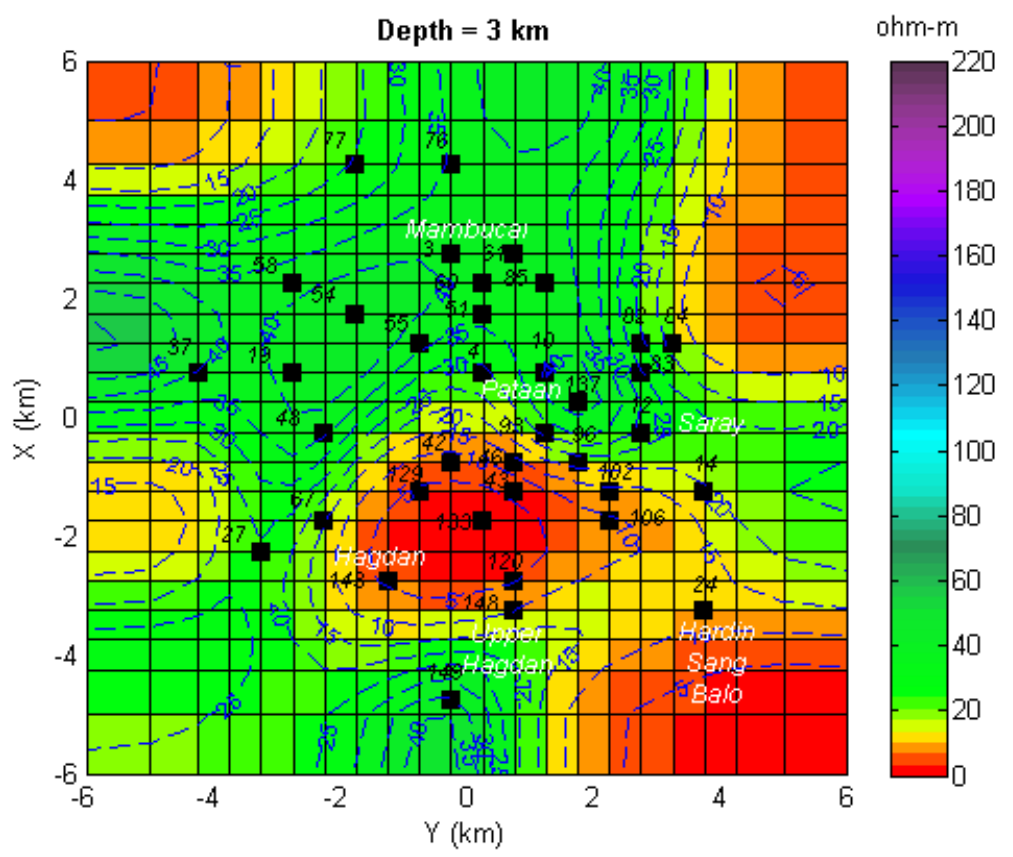

Figure 5.28: Isoresistivity map at $3 \mathrm{~km}$ depth

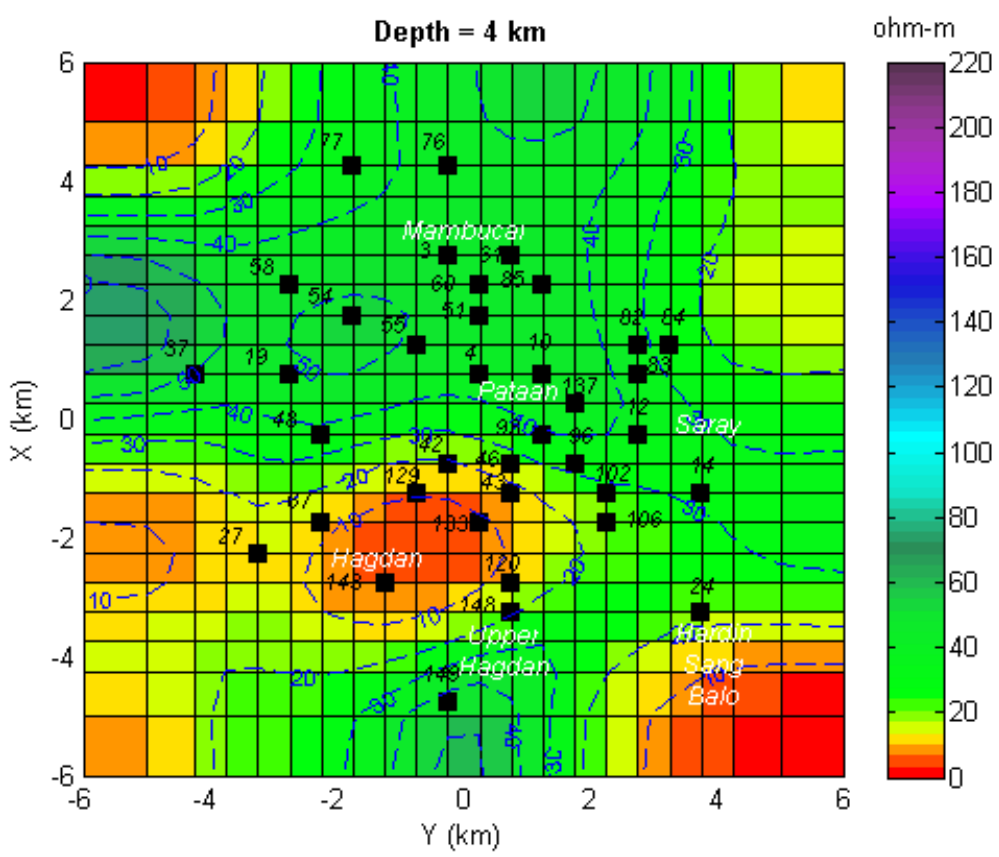

Figure 5.29: Isoresistivity map at $4 \mathrm{~km}$ depth 


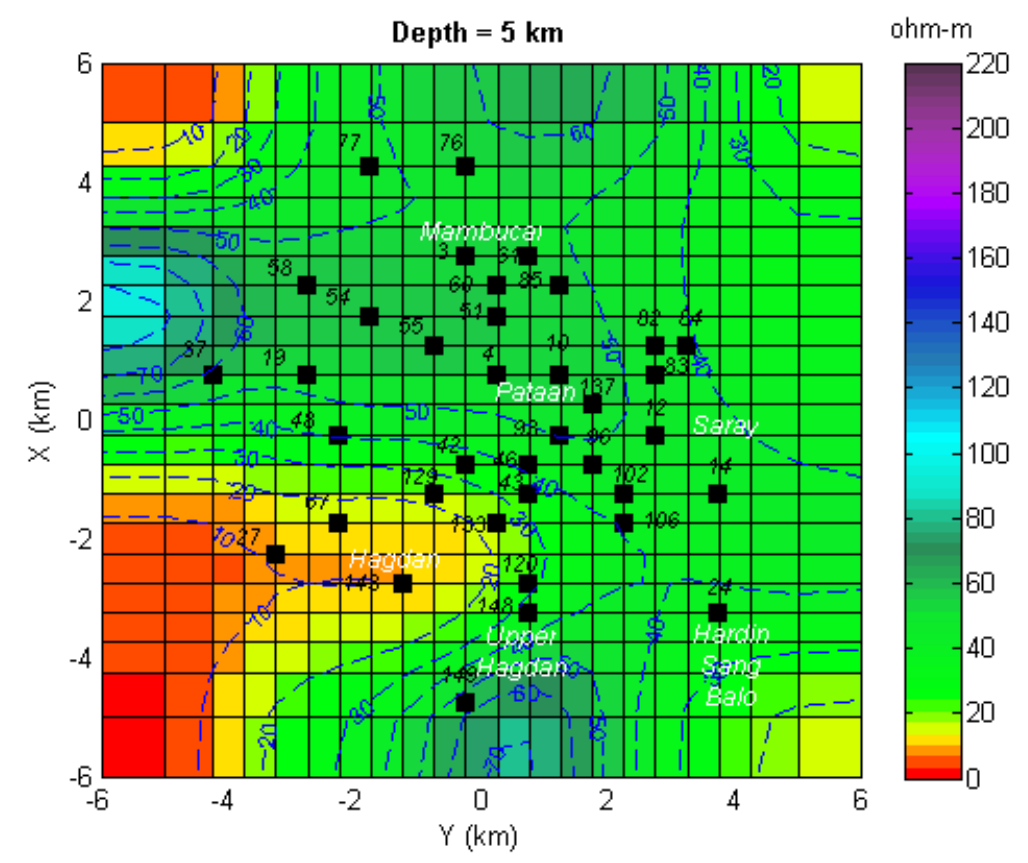

Figure 5.30: Isoresistivity map at $5 \mathrm{~km}$ depth

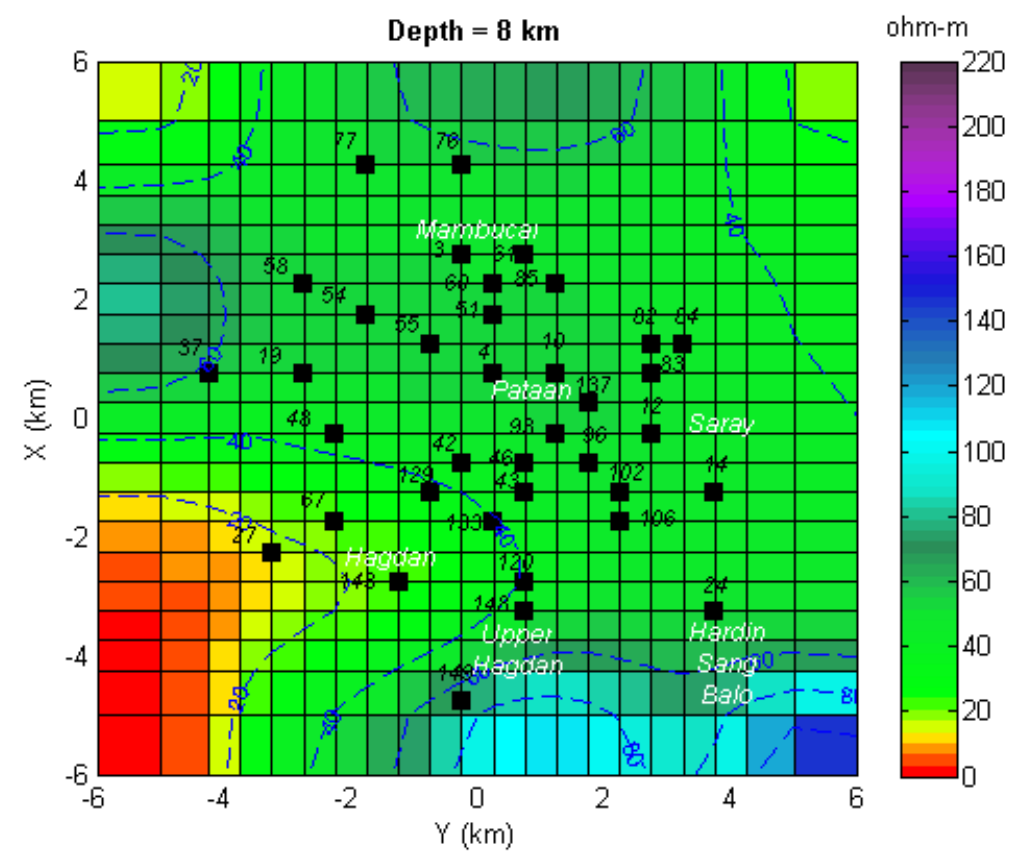

Figure 5.31: Isoresistivity map at $8 \mathrm{~km}$ depth 


\subsubsection{YZ slices}

The west-east profiles, which were made by taking the $\mathrm{YZ}$ slices from the 3D models, are shown in Figure 5.32 to 5.39 to a depth of $5 \mathrm{~km}$. The resistivity structure at NNGP can be simplified as made up of three main layers:

1. A top layer with resistivity $>50 \mathrm{ohm}-\mathrm{m}$

2. A middle layer with $<10 \mathrm{ohm}-\mathrm{m}$ and

3. A bottom layer with resistivity $>20 \mathrm{ohm}-\mathrm{m}$, which increases with depth.

The resistivity structure specifically of the different sectors of NNGP will be described starting from the southernmost to the northernmost portion.

Looking at profile lines $X=-4.25 \mathrm{~km}$ (Figure 5.32) and $X=-3.75 \mathrm{~km}$ (Figure 5.33), respectively, the topmost resistive layer can be found from the surface down to about $50 \mathrm{~m}$ in Upper Hagdan but extends to about $2 \mathrm{~km}$ beneath Hardin Sang Balo in the east. The highly conductive $(<10$ ohm-m) middle layer is delineated to about $1.1 \mathrm{~km}$ depth near Hagdan but deepens to $>3 \mathrm{~km}$ depth towards Hardin Sang Balo. It follows that the resistive ( $>20 \mathrm{ohm}-\mathrm{m}$ ) third layer likewise deepens beneath Hardin Sang Balo.

Meanwhile, profile lines $X=-2.75 \mathrm{~km}$ (Figure 5.34)and $X=-2.25 \mathrm{~km}$ (Figure 5.35) show that the topmost resistive layer goes from the surface down to about $400 \mathrm{~m}$ depth at Hagdan sector. This is underlain by the conductive layer which reaches depths of about $2.5 \mathrm{~km}$ in the east but goes beyond $5 \mathrm{~km}$ depth beneath Hagdan. However, aside from the resistive bottom layer on the east, shallow resistive blocks can be observed on the western portion of Hagdan at depths starting from about $2 \mathrm{~km}$ and about $1 \mathrm{~km}$ in the eastern side. 


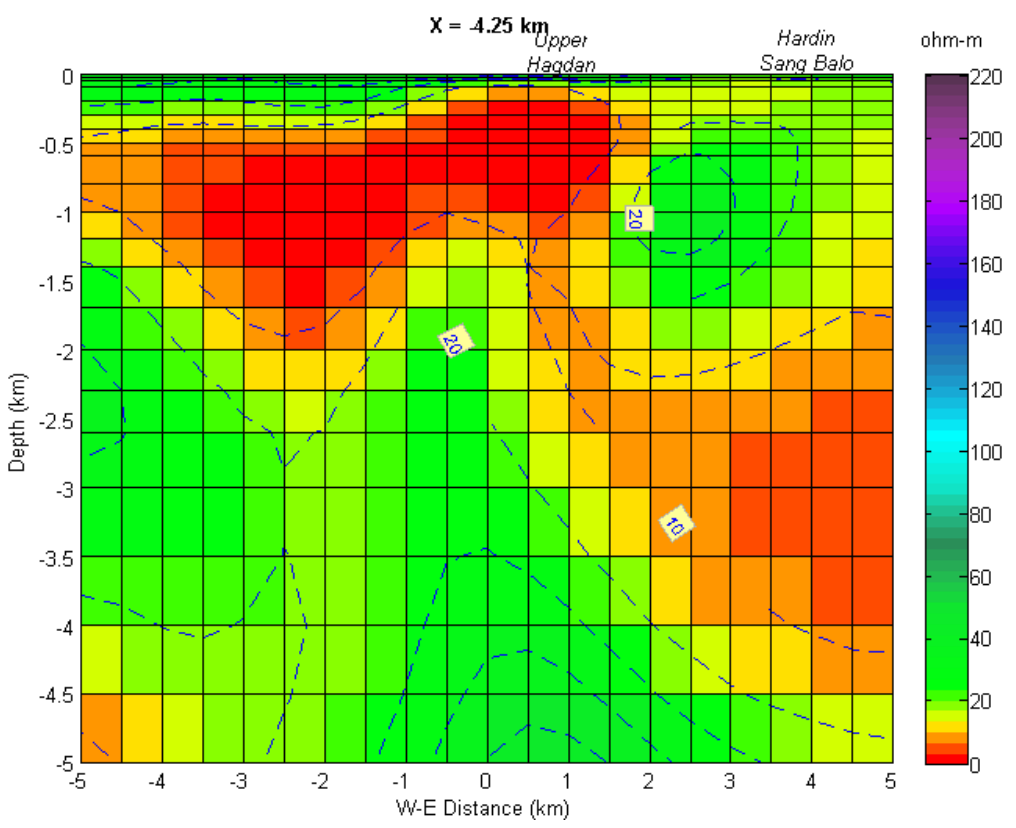

Figure 5.32: Resistivity profile along $X=-4.25 \mathrm{~km}$

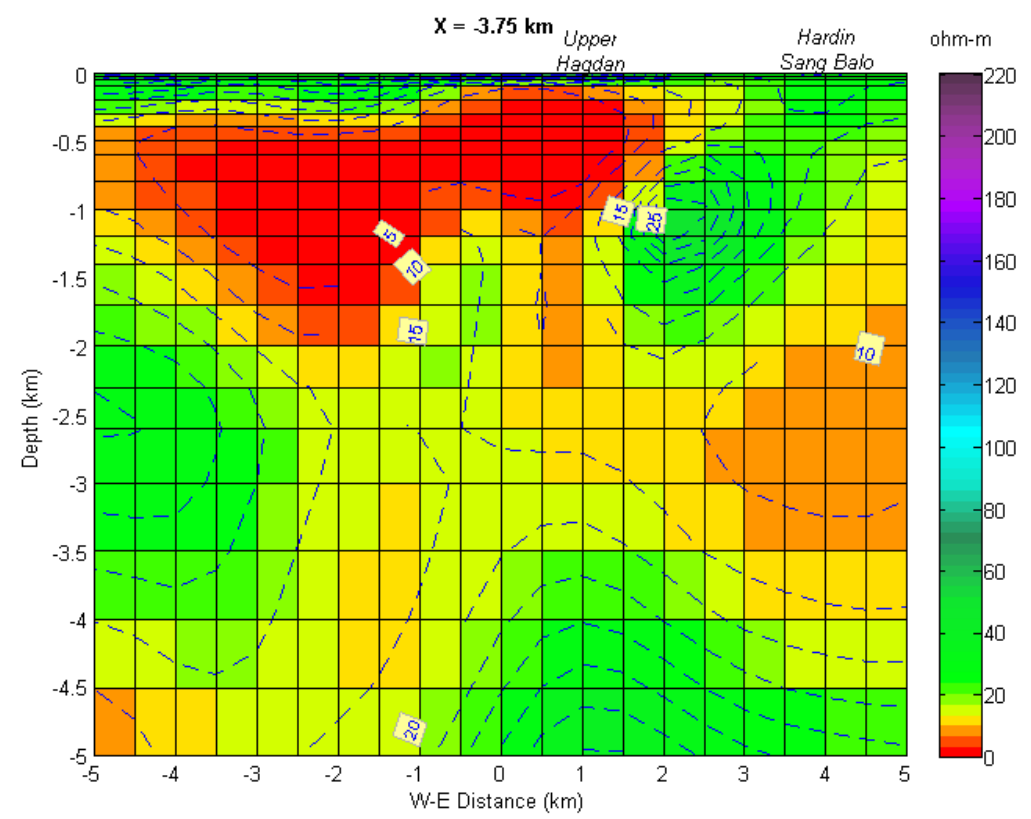

Figure 5.33: Resistivity profile along $X=-3.75 \mathrm{~km}$ 


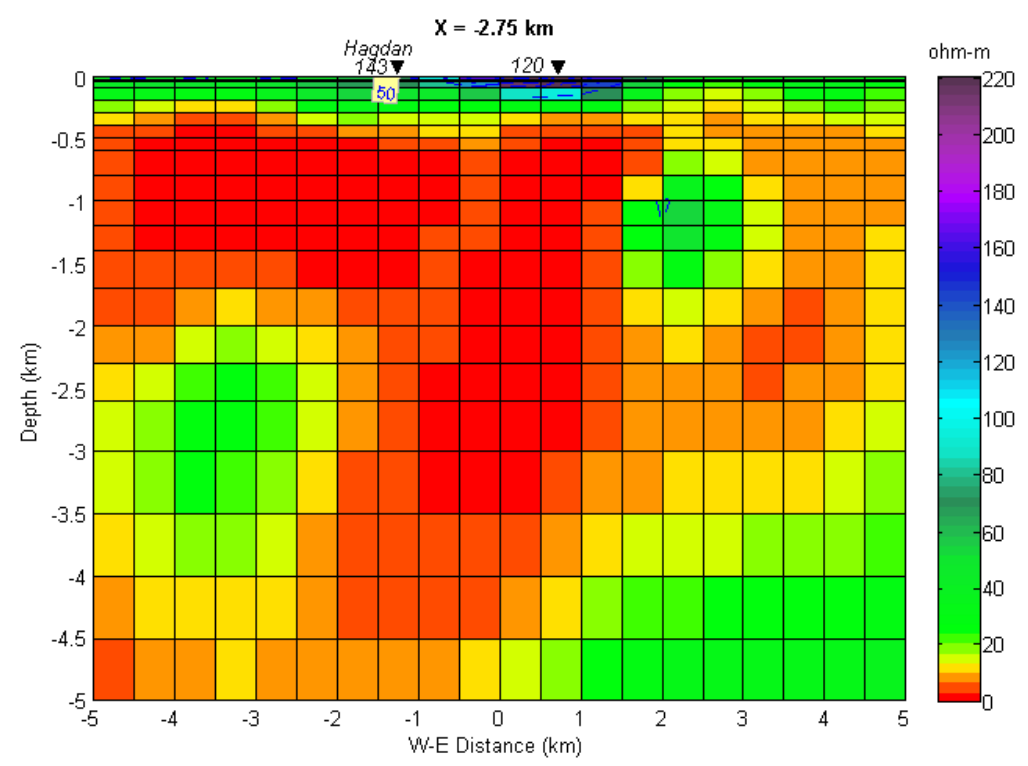

Figure 5.34: Resistivity profile along $X=-2.75 \mathrm{~km}$

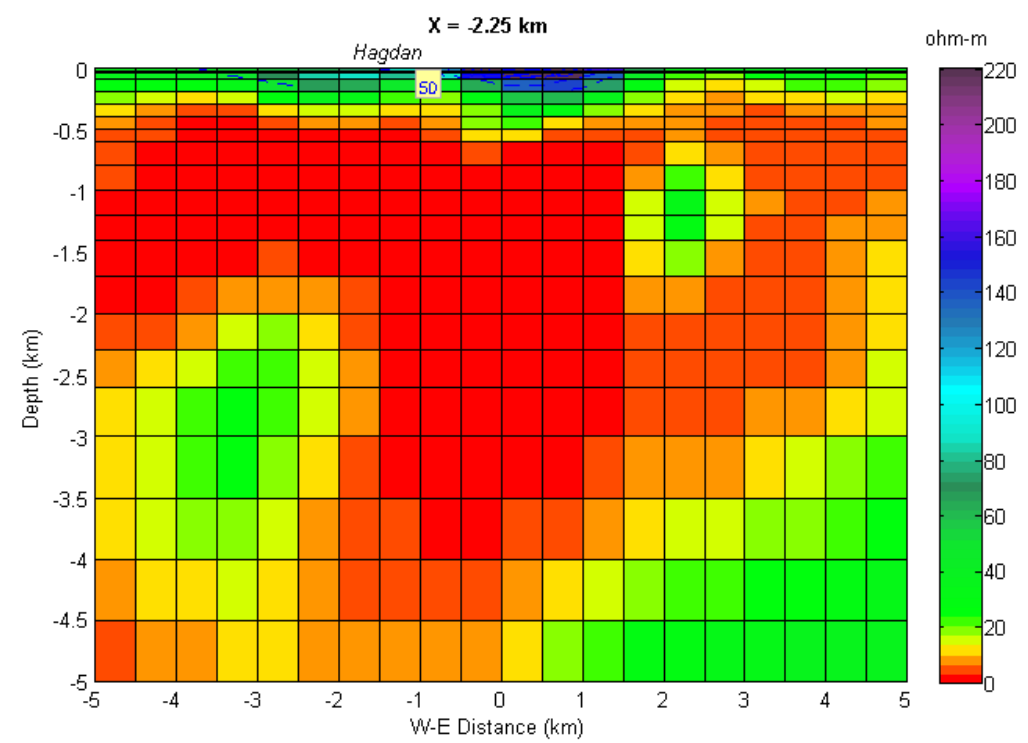

Figure 5.35: Resistivity profile along $X=-2.25 \mathrm{~km}$ 


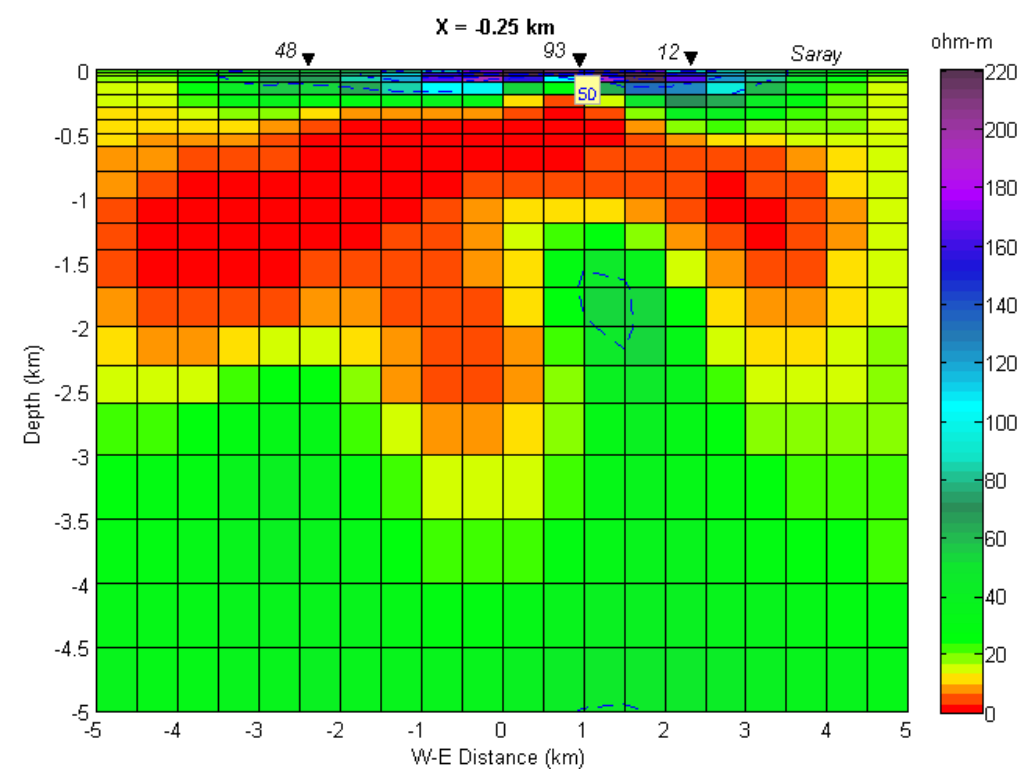

Figure 5.36: Resistivity profile along $X=-0.25 \mathrm{~km}$

Profile lines $X=-0.25 \mathrm{~km}$ (Figure 5.36) and $X=0.25 \mathrm{~km}$ (Figure 5.37) illustrates the resistivity structure beneath Pataan and Saray. The resistive cap layer can be found from surface until about $400 \mathrm{~m}$ depth in Pataan and about $500 \mathrm{~m}$ depth in Saray while the conductive middle layer goes to only up to about $1 \mathrm{~km}$ depth beneath Pataan but extends deeper beneath Saray at depths $>2 \mathrm{~km}$. This goes even deeper on the western portion of Pataan reaching depths $>3 \mathrm{~km}$. A prominent feature that can be identified from this profile is the resistive body protruding beneath Pataan.

Going farther north in the vicinity of Mambucal, through profile lines $X=2.75 \mathrm{~km}$ (Figure 5.38) and $X=3.25 \mathrm{~km}$ (Figure 5.39), show that the highly resistive top layer is thinnest beneath Mambucal reaching depths of only about 100 meters but deepens to about $500 \mathrm{~m}$ on the western and eastern portions. The conductive middle layer extends to depths of about $1.5 \mathrm{~km}$ beneath Mambucal but dips towards the east to $>4 \mathrm{~km}$ depth. 


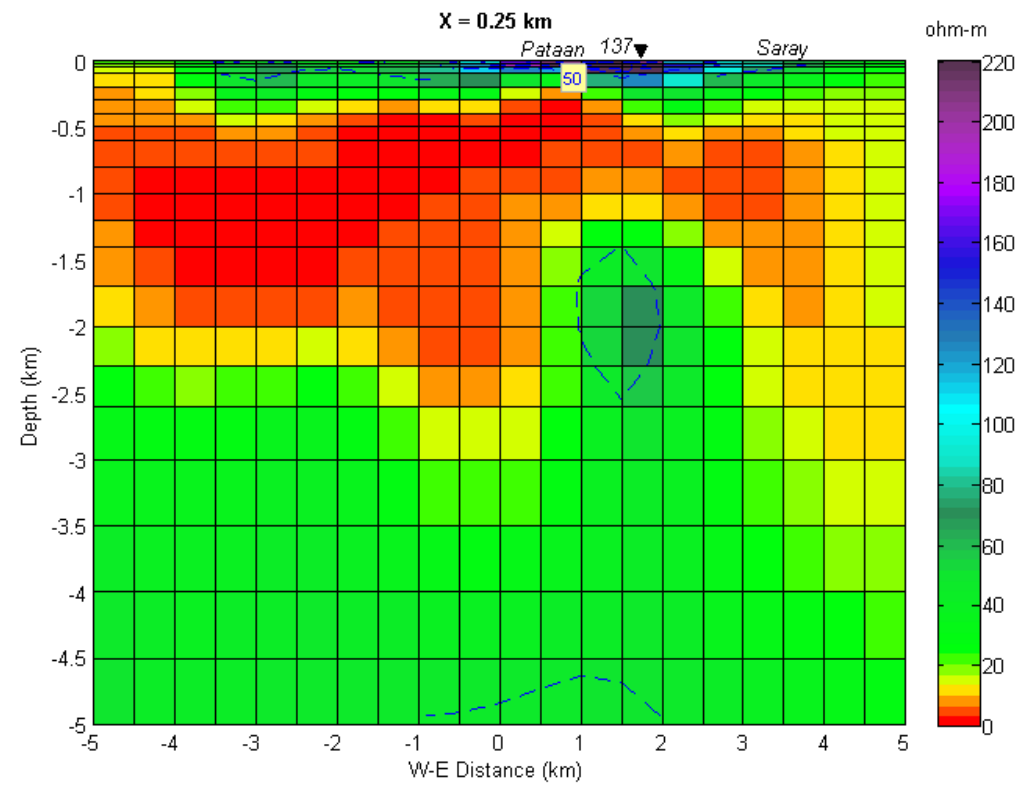

Figure 5.37: Resistivity profile along $X=0.25 \mathrm{~km}$

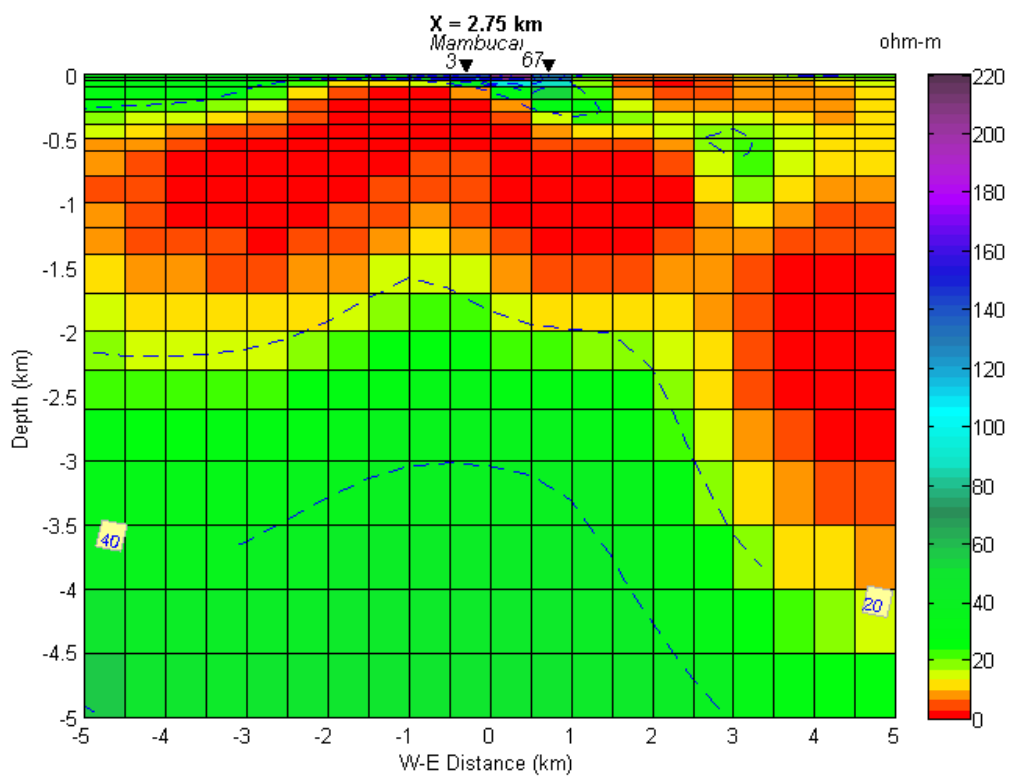

Figure 5.38: Resistivity profile along $X=2.75 \mathrm{~km}$ 


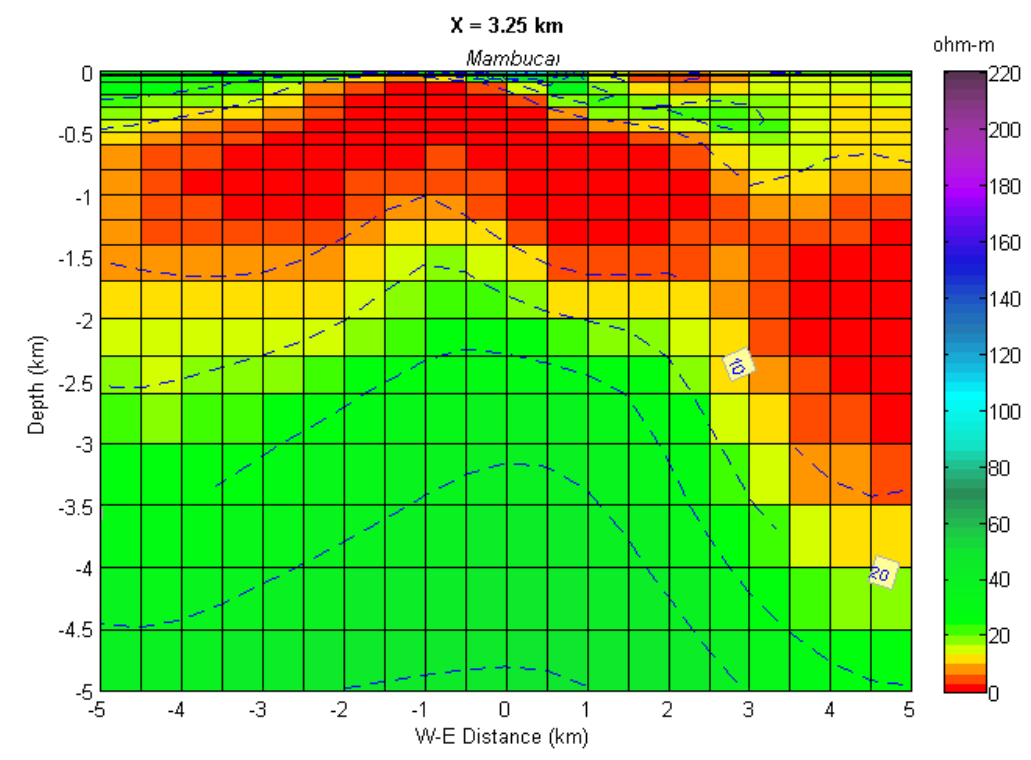

Figure 5.39: Resistivity profile along $X=3.25 \mathrm{~km}$

\subsubsection{XZ slices}

This section presents the south-north profile lines that were created by taking the $\mathrm{XZ}$ slices of the $3 \mathrm{D}$ resistivity model. The resistivity structure is described starting from the westernmost towards the easternmost sector. Representative profiles lines west and within Hagdan, namely $\mathrm{Y}=-$ $2.75 \mathrm{~km}$ (Figure 5.40) and $Y=-1.75 \mathrm{~km}$ (Figure 5.41), show a resistive cap layer from the surface to about $400 \mathrm{~m}$ depth that thins out towards the northern portion. This is underlain by the highly conductive middle layer until depths of about $1.5 \mathrm{~km}$ in most areas except beneath Hagdan where it extends beyond $5 \mathrm{~km}$ depth. This in turn is underlain by a $>20$ ohm-m bottom layer which becomes more resistive with depth.

Going towards the midsection of NNGP, as shown by slices $Y=-0.75$ $\mathrm{km}$ (Figure 5.42), $\mathrm{Y}=0.75 \mathrm{~km}$ (Figure 5.43) and $\mathrm{Y}=1.25 \mathrm{~km}$ (Figure 5.44), the resistive cap layer can be found from the surface to about $400 \mathrm{~m}$ depth. The $<10 \mathrm{ohm}-\mathrm{m}$ conductive layer extends to about $1 \mathrm{~km}$ depth beneath Upper Hagdan but plunges to $>4 \mathrm{~km}$ depths on its southern 


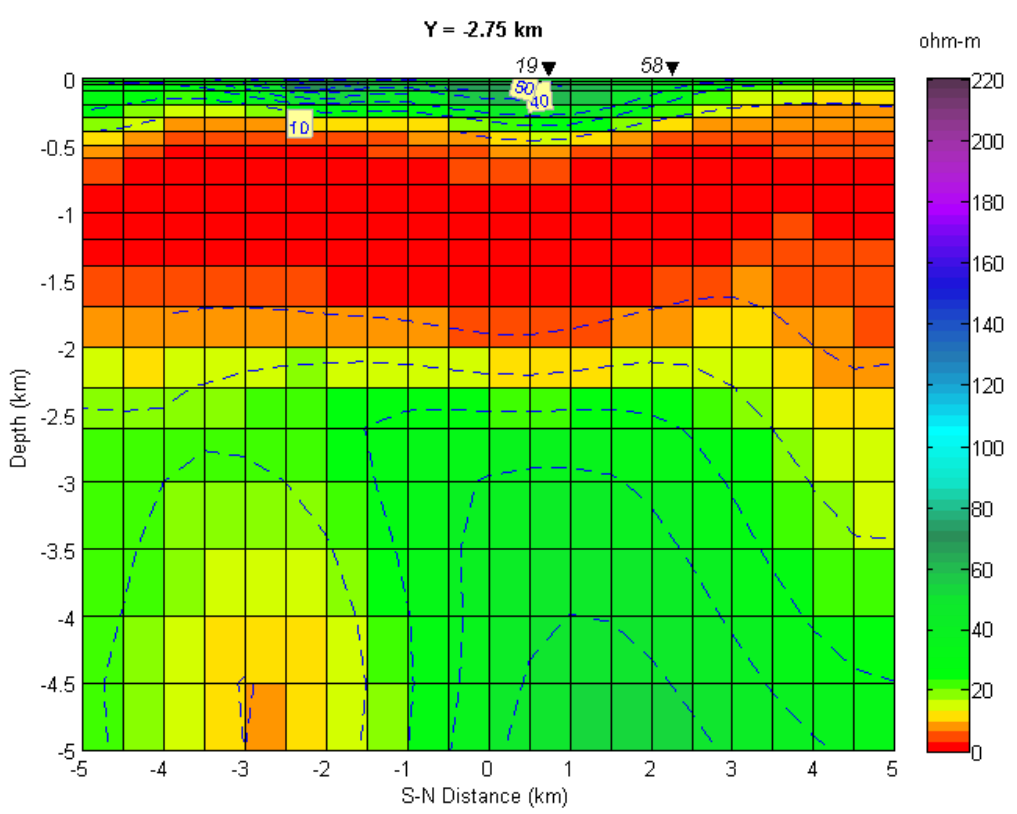

Figure 5.40: Resistivity profile along $\mathrm{Y}=-2.75 \mathrm{~km}$

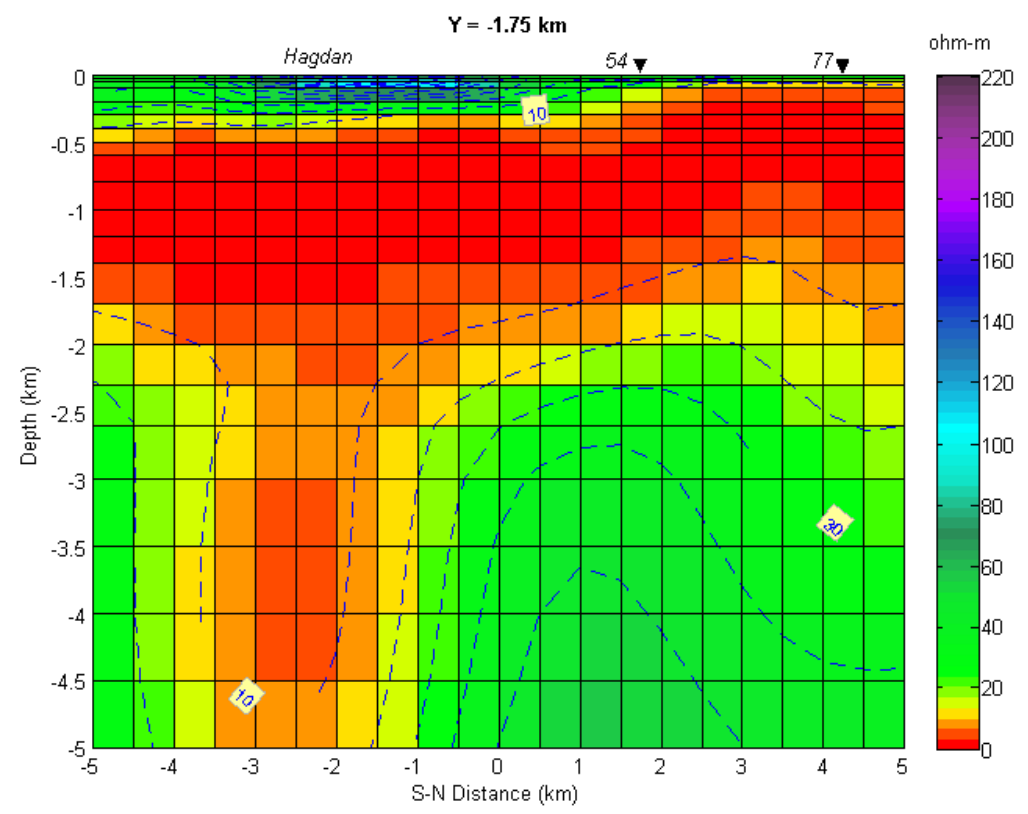

Figure 5.41: Resistivity profile along $Y=-1.75 \mathrm{~km}$ 


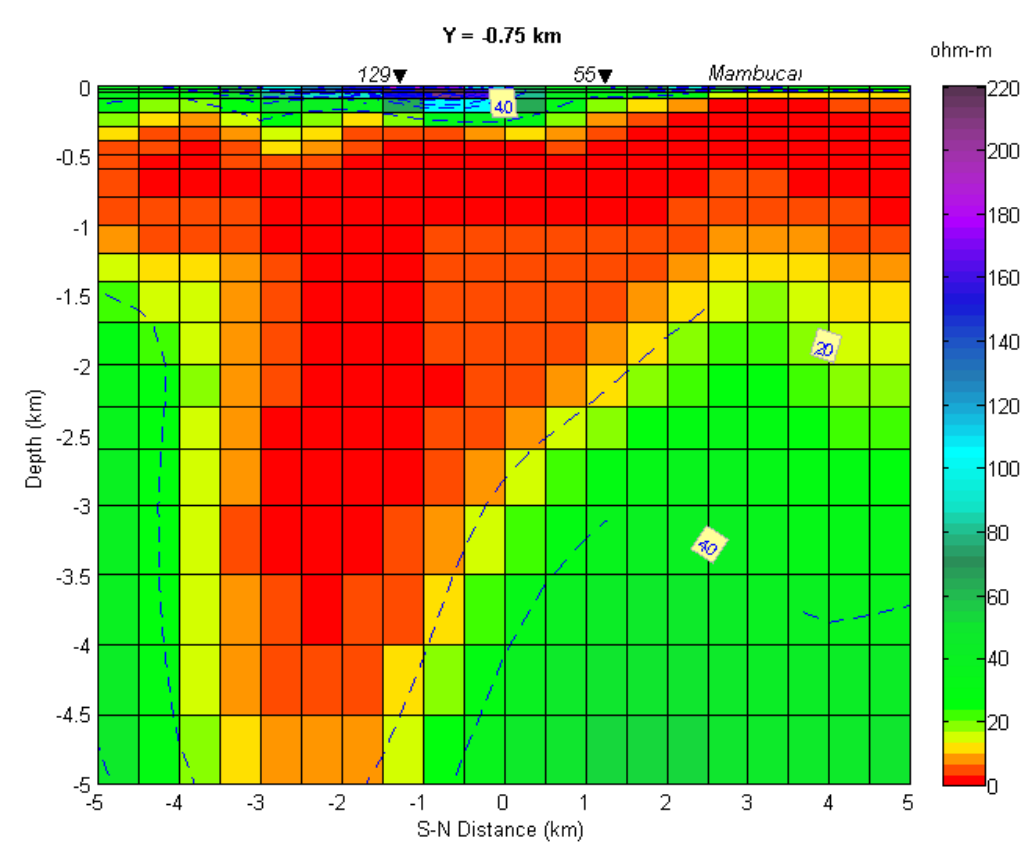

Figure 5.42: Resistivity profile along $Y=-0.75 \mathrm{~km}$

portion then shallows up again towards Mambucal in the south. A prominent feature would be the protruding portion of the bottom resistive layer to depths of about $1 \mathrm{~km}$ beneath Pataan (Figures 5.43 and $5.44)$.

Farther east in the vicinity of Hardin Sang Balo and Saray as shown by profile lines $Y=3.75$ (Figure 5.45) and $Y=4.25 \mathrm{~km}$ (Figure 5.46), the three respective resistivity layers namely the resistive cap layer, middle conductive layer and the bottom resistive layer extend to deeper depths on the southern portion beneath Hardin Sang Balo. The resistive cap layer reaches to $1.5 \mathrm{~km}$ depth while the $<10 \mathrm{ohm}-\mathrm{m}$ middle layer goes beyond $3 \mathrm{~km}$ depth. On the other hand, the resistive cap layer reaches only about $400 \mathrm{~m}$ depth beneath Saray and the resistive bottom is also shallower in this area having been detected at about $2 \mathrm{~km}$ depth. Towards the north, the resistivity layers again extends deeper similar to the southern side. 


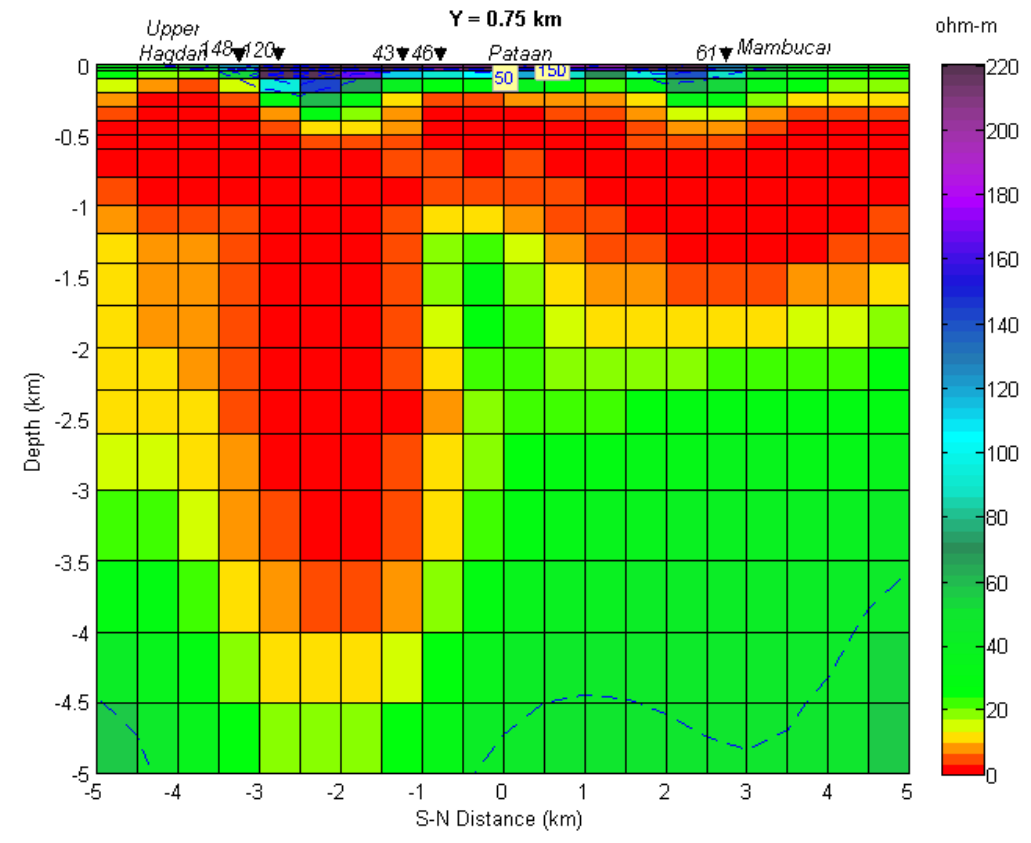

Figure 5.43: Resistivity profile along $Y=0.75 \mathrm{~km}$

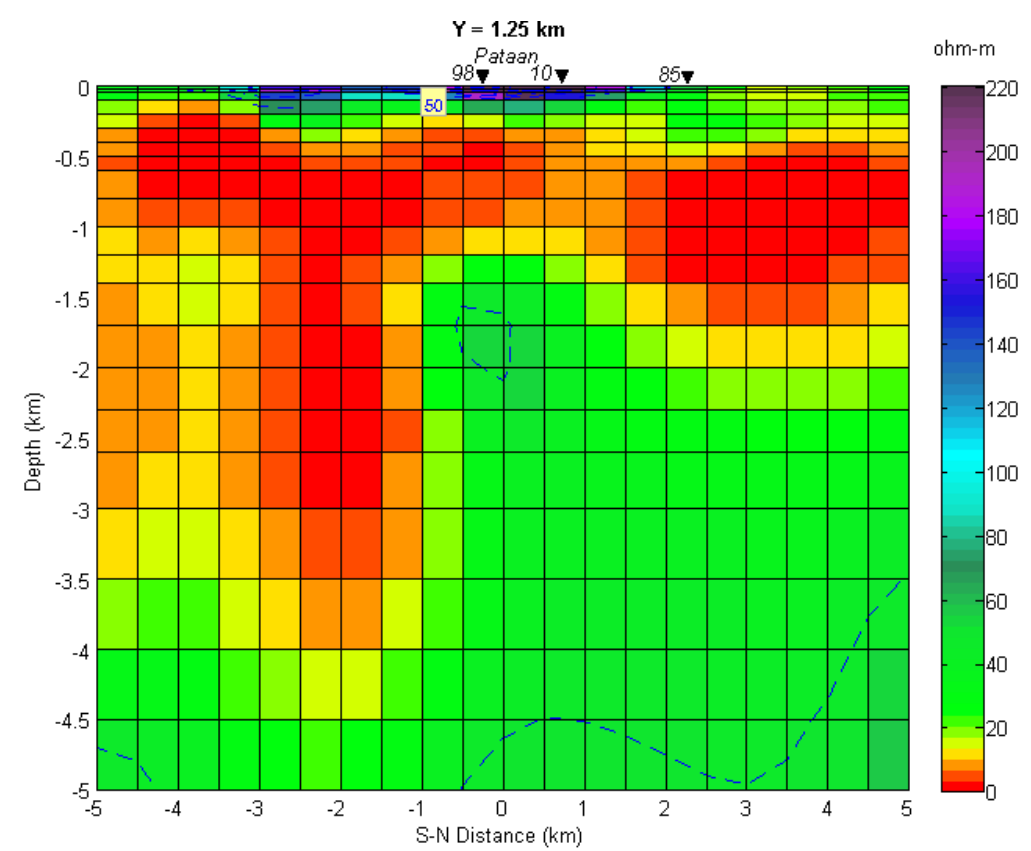

Figure 5.44: Resistivity profile along $Y=1.25 \mathrm{~km}$ 


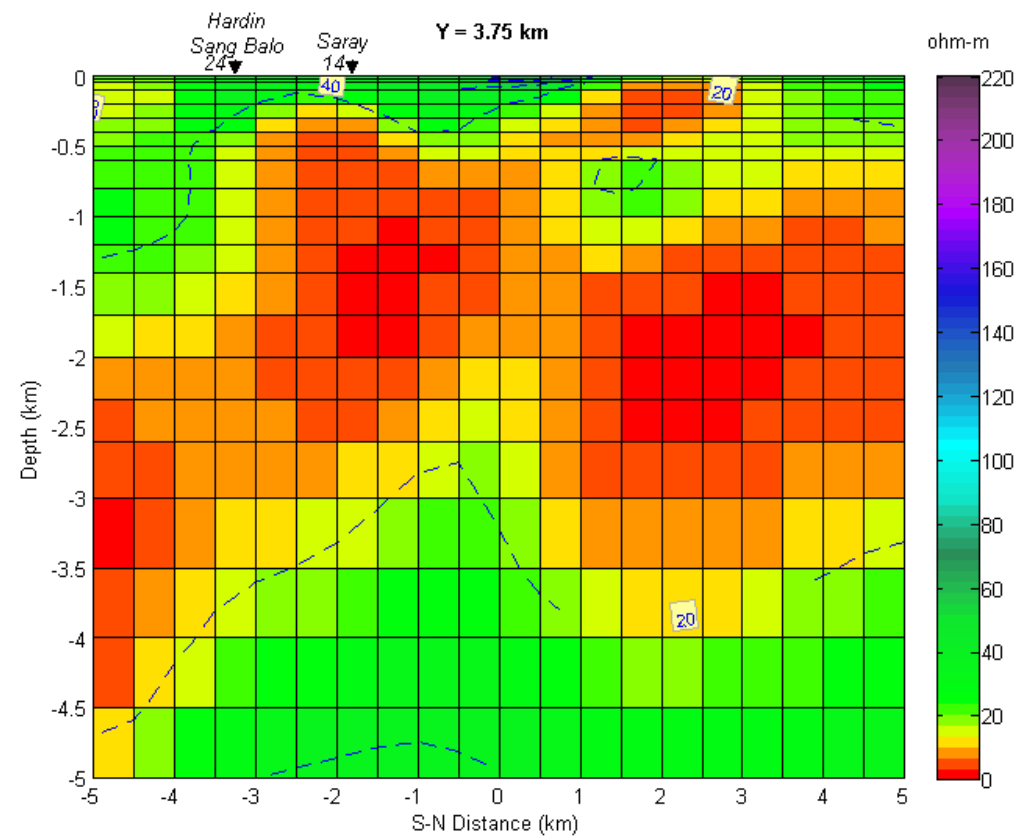

Figure 5.45: Resistivity profile along $Y=3.75 \mathrm{~km}$

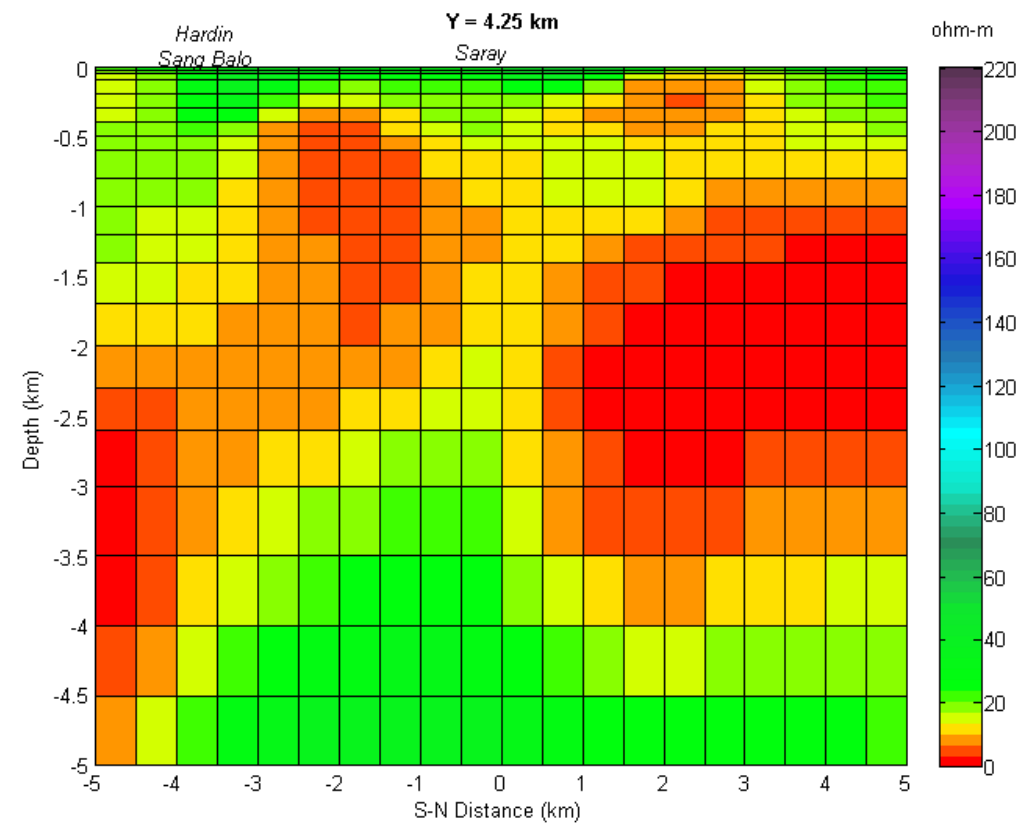

Figure 5.46: Resistivity profile along $\mathrm{Y}=4.25 \mathrm{~km}$ 


\subsection{Comparison of 1-D, 2-D and 3-D models}

\subsubsection{Isoresistivity maps}

The features that were observed among the isoresistivity maps from 1D, 2-D and 3-D models include:

1. High resistivity blankets the study area at shallow levels. As shallow as $100 \mathrm{~m}$ depth, a conductive zone within Mambucal was detected which broadens towards Pataan at $300 \mathrm{~m}$ depth (Figures 5.1, 5.4 and 5.24 ).

2. From $500 \mathrm{~m}$ to $1000 \mathrm{~m}$ depth, NNGP is mostly covered by low resistivities $<10 \mathrm{ohm}-\mathrm{m}$ particularly the western portion, which includes Mambucal, Hagdan and Upper Hagdan. In the 1-D isoresistivity map, Pataan is included in the broad conductive zone but in the 2-D and 3-D isoresistivity maps, only the western portion of Pataan is conductive (Figures 5.2, 5.5, 5.25 and 5.26). The eastern portion, which include Saray and Hardin Sang Balo are enclosed by moderate to high resistivities $>50 \mathrm{ohm}-\mathrm{m}$.

3. At $2000 \mathrm{~m}$ depth, the 2-D and 3-D maps show moderate to highly resistive zones in Upper Hagdan and the east-southeastern portion of Pataan, which are separated by a conductive zone elongated towards the southeast (Figures 5.6 and 5.27). On the other hand, the 1-D model shows the resistive body more to the southeast of Pataan, which extends towards Hardin Sang Balo (Figure 5.3).

4. At $3000 \mathrm{~m}$ depth, NNGP is mostly covered by moderate resistivities $>30 \mathrm{ohm}-\mathrm{m}$. Conductive zones located south and southeast of Pataan which extends to Hardin Sang Balo were observed (Figure 5.28). 
5. At $5000 \mathrm{~km}$ depth, NNGP is now covered by mostly by high resistivity values $>50 \mathrm{ohm}-\mathrm{m}$ (Figure 5.30 ).

\subsubsection{Profile lines}

Profiles lines for all models were created to show the resistivity structure with depth. Three lines (NW-SE lines) were oriented almost parallel to the dominant strike direction indicated from the phase tensor analysis which is $-85^{\circ}$ while one cross-section line (NE-SW) is made almost perpendicular to the other three lines (Figure 5.47). The profile lines cut through the different sectors of NNGP. As mentioned in the previous section, the Occam model was used for the 1-D model while the TM mode was considered for the 2-D models. Moreover, topography was included in the 2-D inversions. The stations that were used for the 3-D models are indicated by the red font colour. The resistivity structure can be generalized into three main layers:

1. A resistive cap layer with resistivity $>50 \mathrm{ohm}-\mathrm{m}$

2. A conductive middle layer with $<10 \mathrm{ohm}-\mathrm{m}$ and

3. A bottom layer with resistivity $>20 \mathrm{ohm}-\mathrm{m}$ and increases with depth.

Profile NW-SE1 goes from Mambucal in the northwest towards the southeast cutting across the wells MC-1 and MC-2 (Figure 5.47). All three models show consistent features such as a thick conductive middle layer that extends as deep as $>3000 \mathrm{~m}$ depth in the 2-D model (Figure 5.48). Another prominent feature that can be observed from the models is the shallowing of the resistive bottom layer towards the southeast. It can also be seen that wells MC-1 and MC-2 intersected mainly the thick conductive middle layer. Moreover, the resistivity structure of the 2-D and 3-D models is almost identical which indicates topography has no sig- 


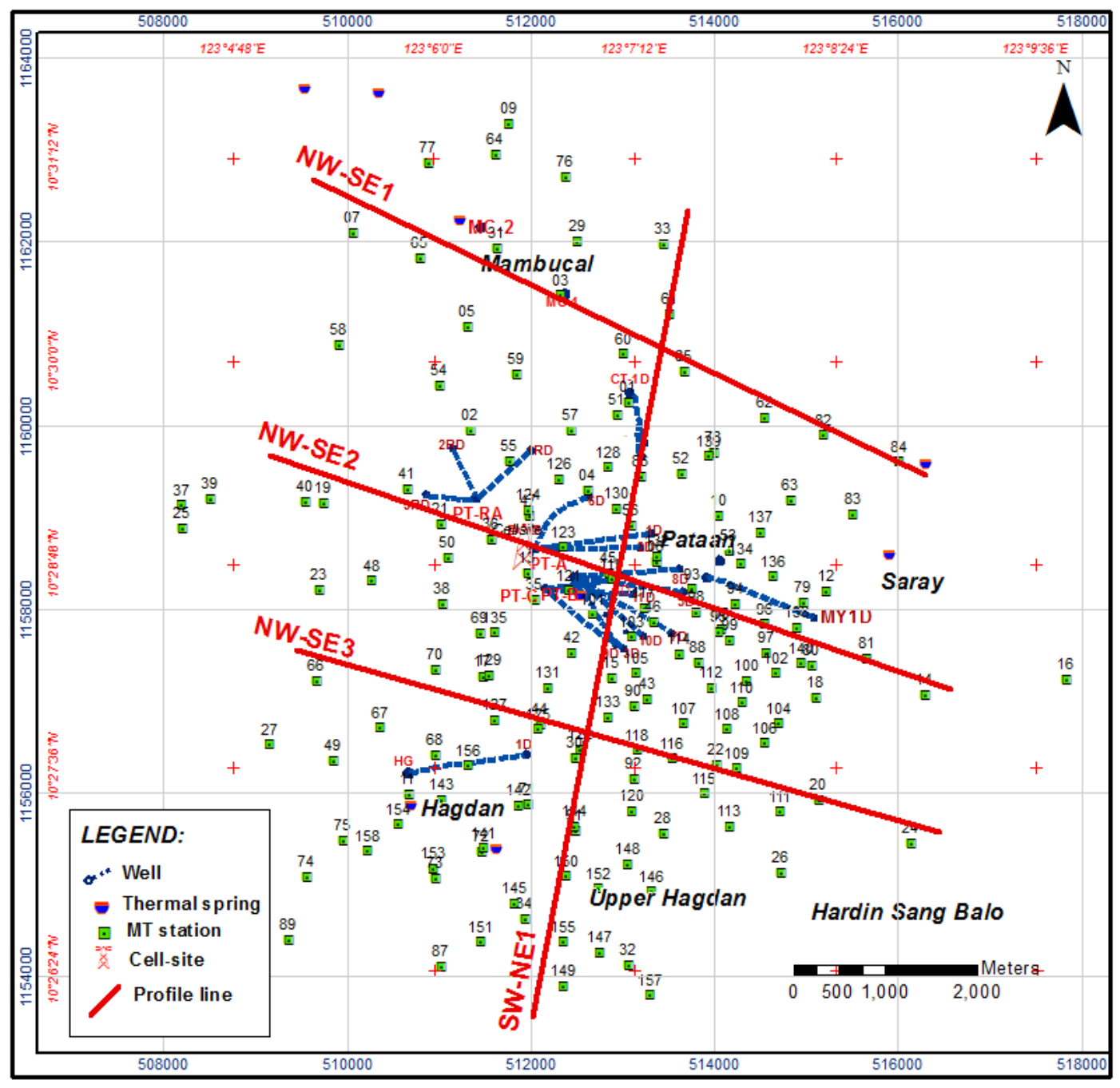

Figure 5.47: Profile lines location map 
nificant effect on the resistivity structure except for an offset of a few hundred meters in terms of vertical displacement (Figure 5.48). 


\subsection{COMPARISON OF 1-D, 2-D AND 3-D MODELS}

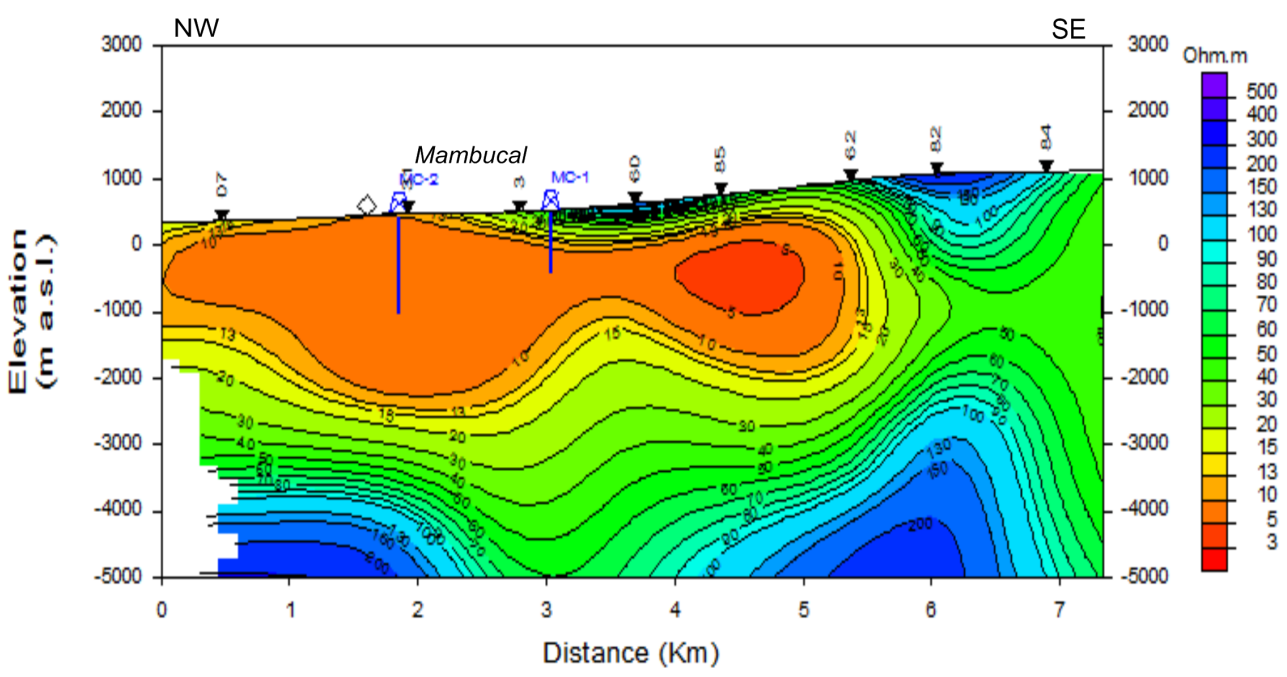

(a) 1-D model along line NW-SE1

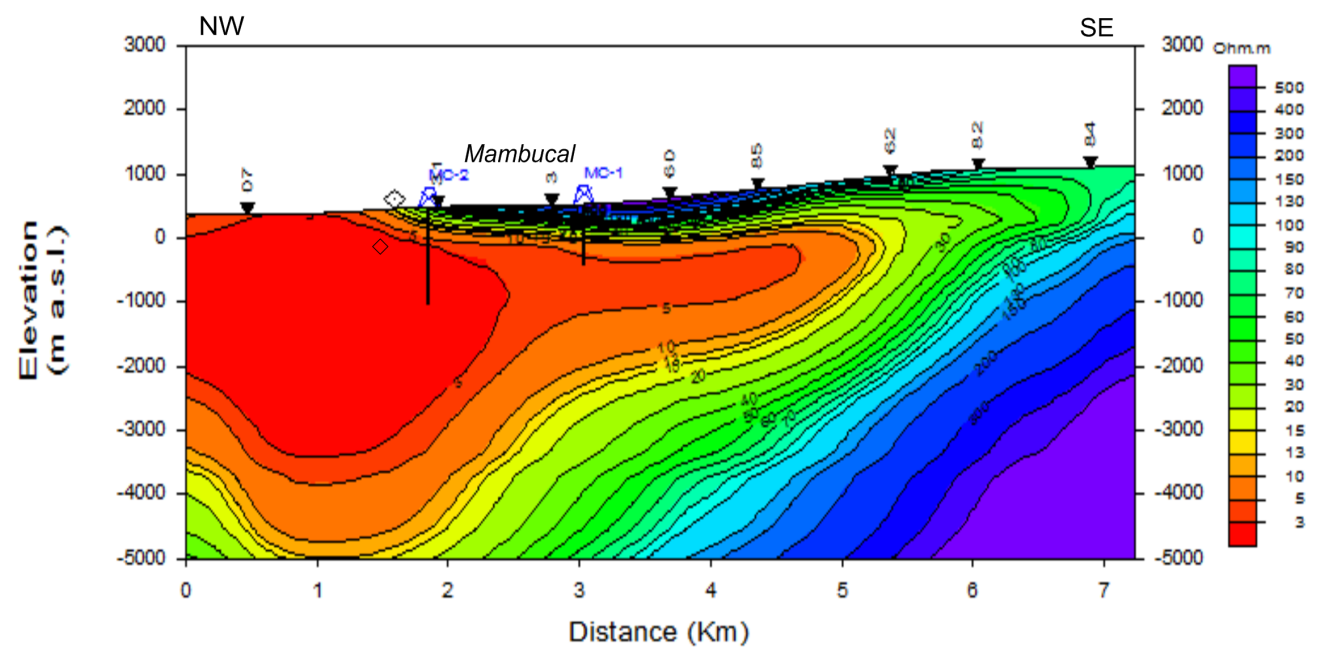

(b) 2-D model along line NW-SE1; RMS=1.328

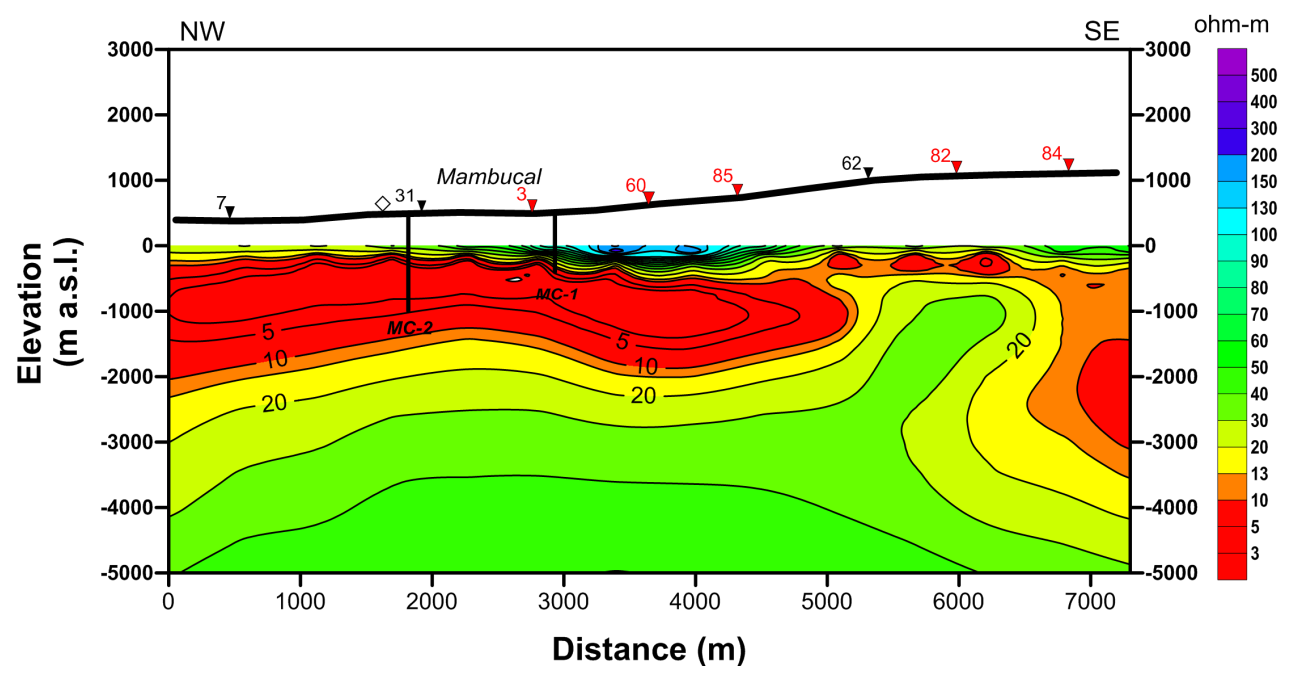

(c) 3-D model along line NW-SE1

Figure 5.48: Profile line NW-SE1 
Profile NW-SE2 cuts across the Pataan sector which is the main production zone at NNGP (Figure 5.47). Similar features that can be observed from the three models include the thick conductive middle layer on the western portion that goes beyond $3000 \mathrm{~m}$ depth on the 2-D model and the moderate to highly resistive block ( $>20 \mathrm{ohm}-\mathrm{m}$ ) beneath Pataan (Figure 5.49). PT-3RD was drilled into the middle conductive layer while wells PT-3D, PT-4D, PT-7D, PT-10D and PT-11D were drilled into the resistive bottom layer. Well MY-1D was also drilled into the resistive zone in the 1-D and 2-D models. However in the 3-D model, MY-1D intersected the conductive layer, which extends towards southeast. Again, the similarity of the resistivity layers of the 2-D and 3-D models particularly on the western portion, suggest a minimum topography effect other than an offset in the vertical displacement (Figure 5.49). 


\subsection{COMPARISON OF 1-D, 2-D AND 3-D MODELS}

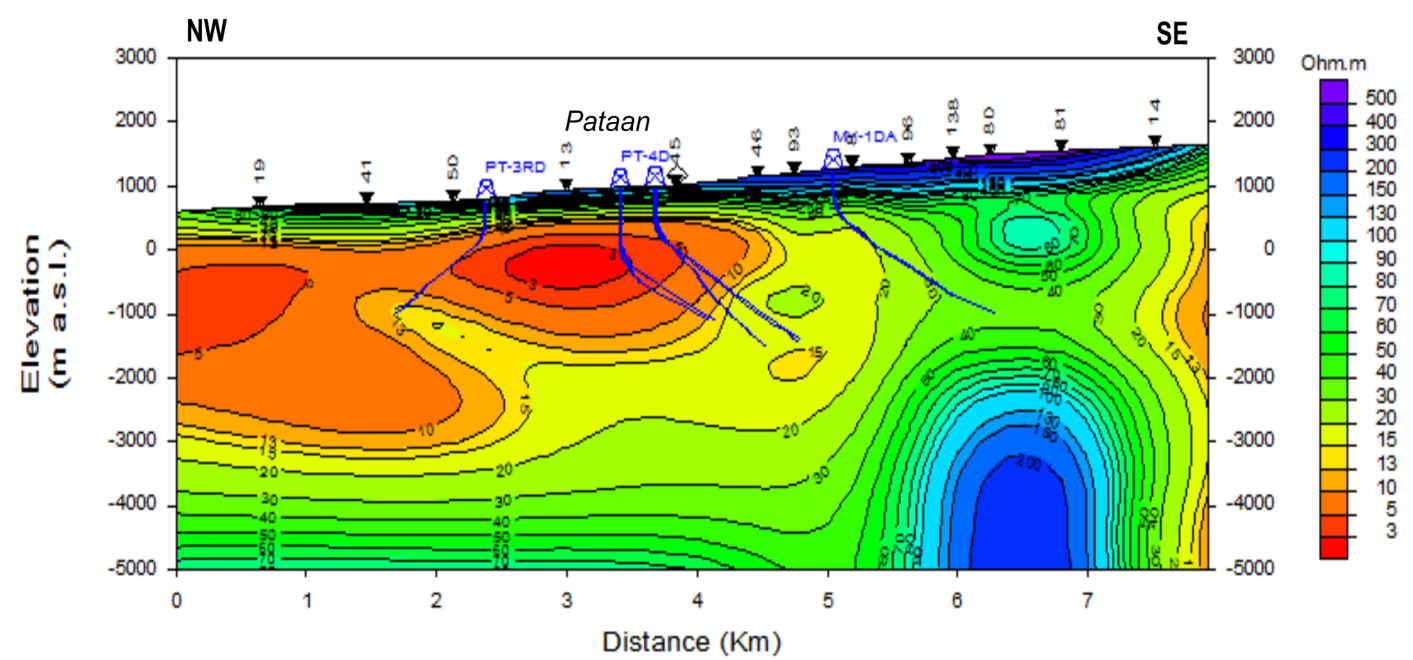

(a) 1-D model along line NW-SE2

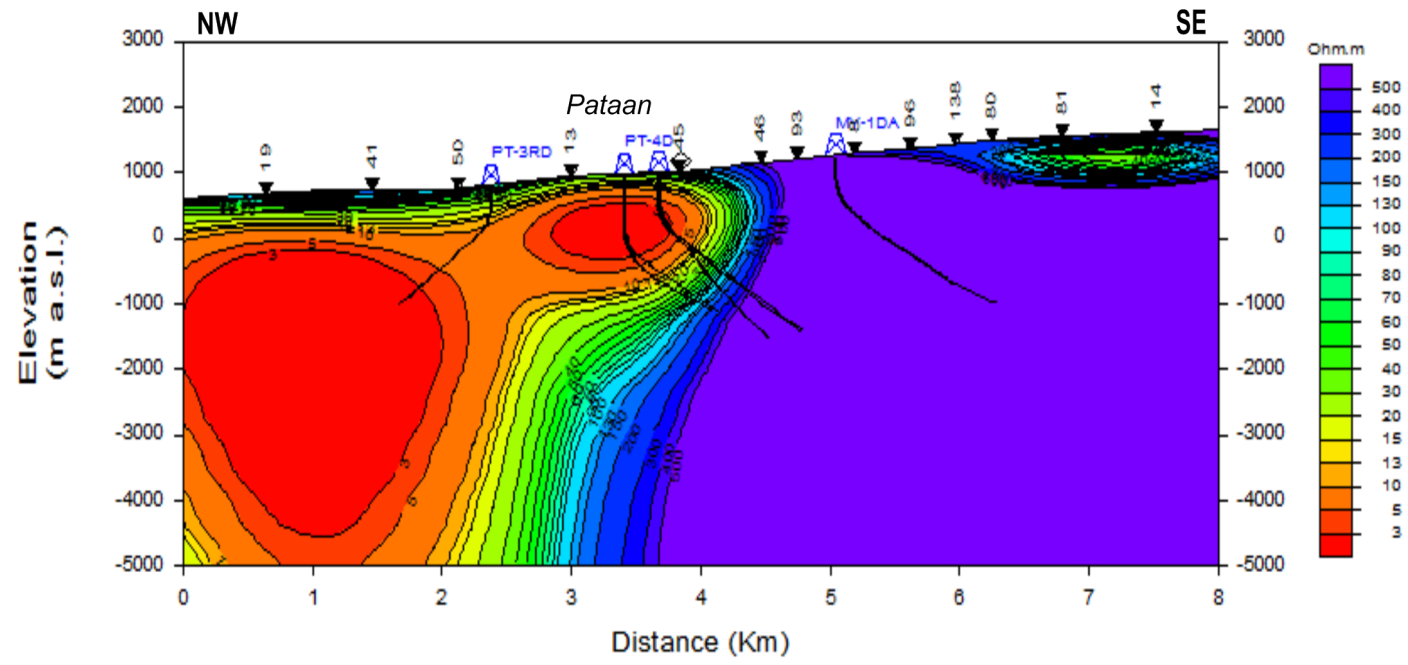

(b) 2-D model along line NW-SE2; RMS=3.006

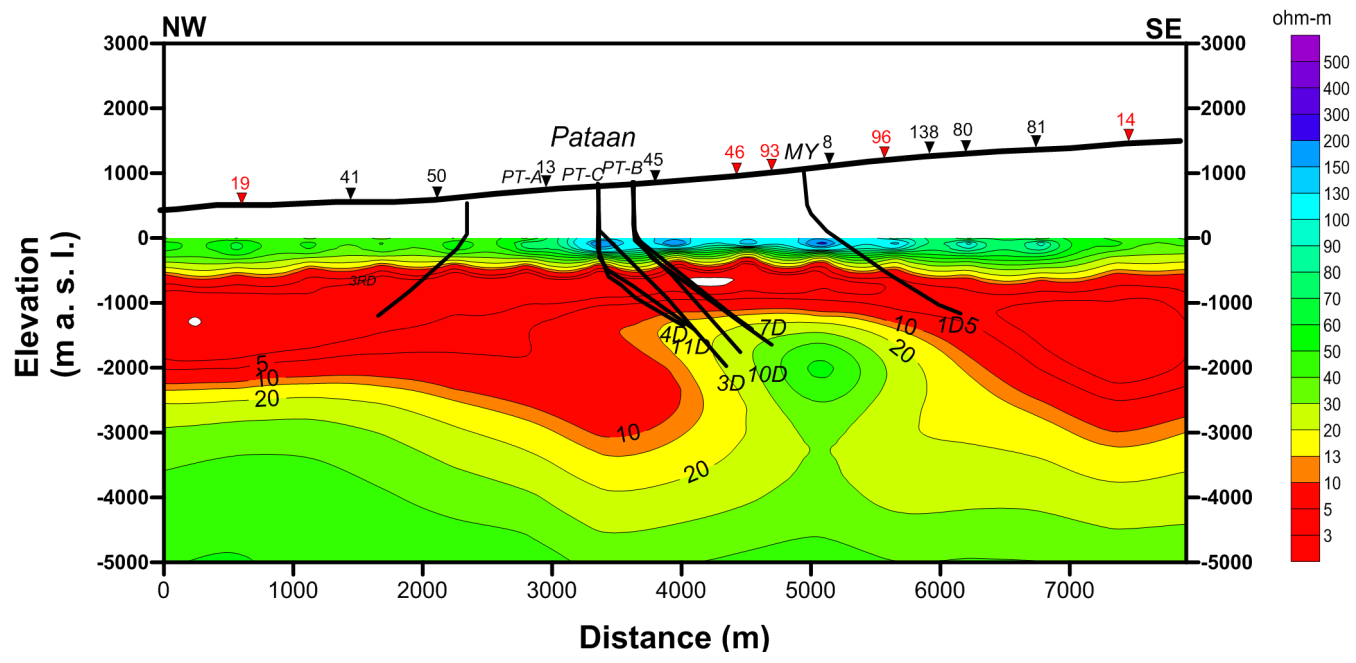

(c) 3-D model along line NW-SE2

Figure 5.49: Profile line NW-SE2 
Profile NW-SE3 extends across the southern portion of NNGP, passing through the Hagdan sector towards Hardin Sang Balo (Figure 5.47). A thick highly conductive layer $(<10 \mathrm{ohm}-\mathrm{m})$ is modeled beneath a resistive cap layer which extends to $>4000 \mathrm{~m}$ depth in 1-D and 3-D models (Figure 5.50). The 1-D model shows that well HG-1D was drilled into the underlying resistive third layer at about $1000 \mathrm{~m}$ depth while in the 2-D and 3-D models, this well was drilled into the thick conductive layer. The 1-D and 2-D models also show that the entire section of Hardin Sang Balo on the southeast is underlain by a resistive layer while the 3-D model exhibited a thick conductive zone beneath a $\sim 1500 \mathrm{~m}$ thick resistive cap layer. Comparing the resistivity structures of the 2-D and 3-D models particularly the topmost layers, it is apparent that at lower elevations $(<1000 \mathrm{~m})$, the topography has no significant effect on the 3D model. However, as the elevation reaches about $2000 \mathrm{~m}$ (i.e. on the southeastern portion), there seem to be an effect in the resistivity structure of the 3-D model as indicated by the resistive body beneath Hardin Sang Balo, which should have occupied the large elevation difference in the southeastern region (Figure 5.50). 


\subsection{COMPARISON OF 1-D, 2-D AND 3-D MODELS}

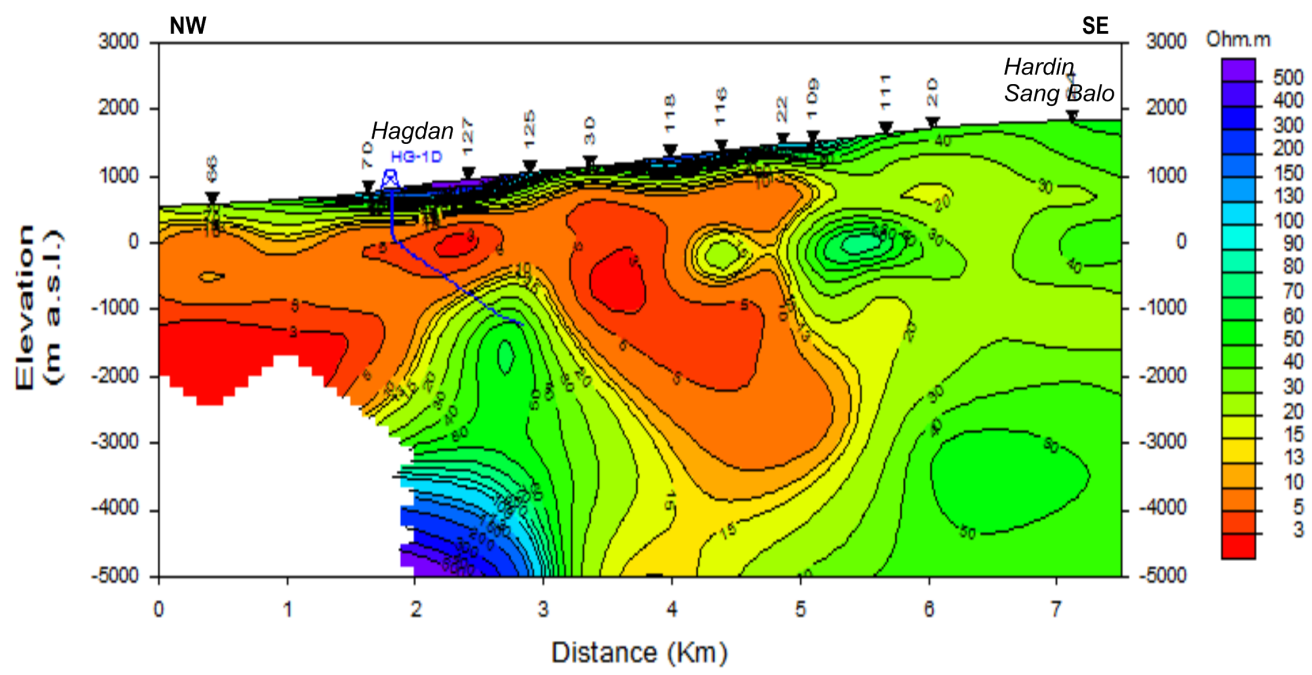

(a) 1-D model along line NW-SE3

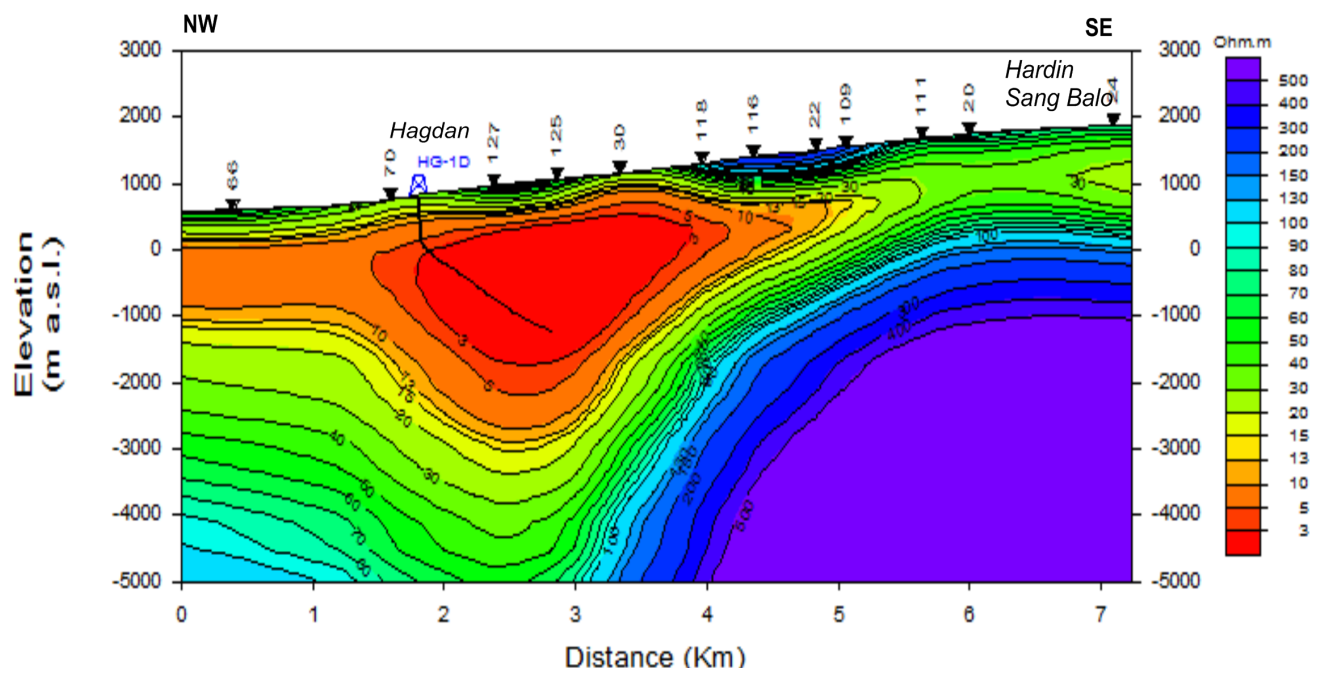

(b) 2-D model along line NW-SE3; RMS=1.627

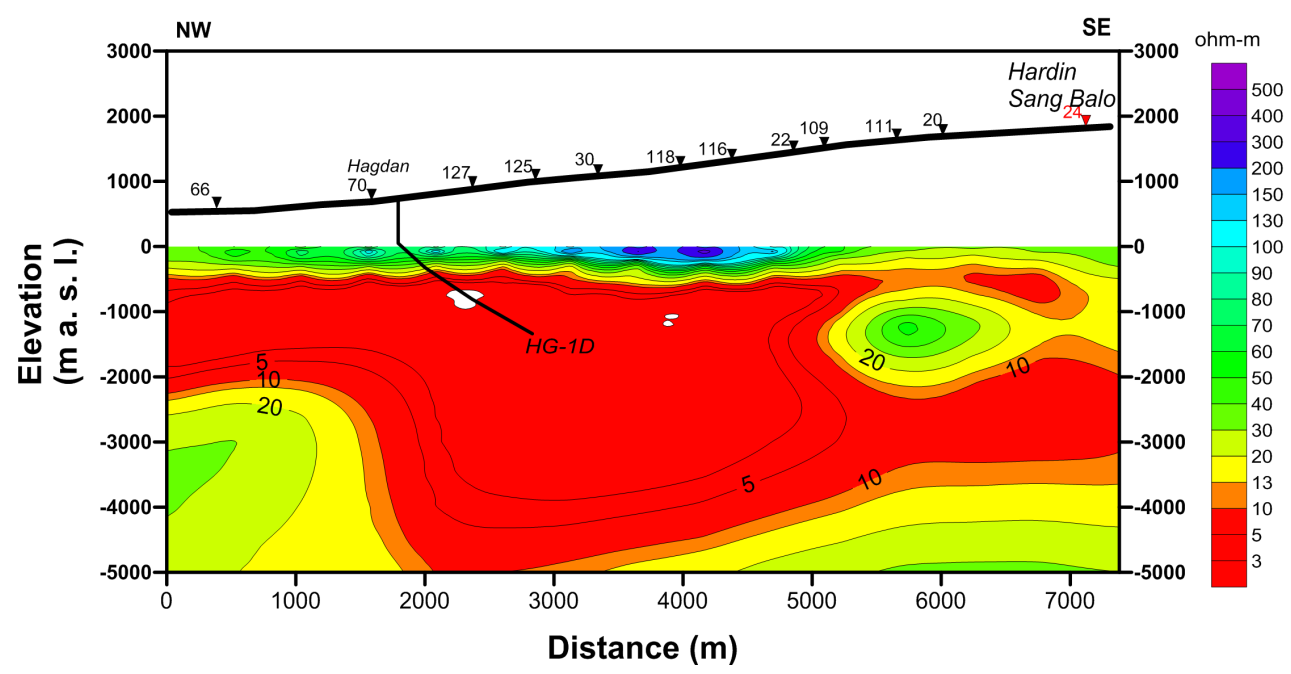

(c) 3-D model along line NW-SE3

Figure 5.50: Profile line NW-SE3 
Profile SW-NE1 goes from Upper Hagdan in the south towards Mambucal in the north (Figure 5.47). A resistive top layer is detected in all models with thickness ranging from $300 \mathrm{~m}$ to $500 \mathrm{~m}$ (Figure 5.51). This is underlain by the $(<10 \mathrm{ohm}-\mathrm{m})$ conductive layer which is thinnest beneath Pataan and thickens towards the southern and northern portions reaching depths $>5000 \mathrm{~m}$ in the 2-D. A prominent feature is the resistive lump beneath Pataan intersected by wells PT-1D, PT-3D, PT-4D, PT-5D, PT-7D, PT-10D and PT-11D (Figure 5.51). Well CT-1D is situated on the edge of the resistive block. Another resistive block can be observed beneath Upper Hagdan at a similar depth to the resistive body beneath Pataan in the 3-D model. Upon comparison again of the 2-D and 3-D models show no significant consequence when topography was not included in the 3-D inversion except for an offset in terms of the vertical depth (Figure 5.51).

In general, the 1-D, 2-D and 3-D models show good agreement. The main differences occur in the southeast portion of lines NW-SE2 and NW-SE3 where the 2-D models show significantly higher resistivity than, in particular, the 3-D model. The 1-D structures fall between these extremes. These differences may partly reflect the lack of topography in the 3-D model, but may also reflect the limitations of 2-D modeling in an inherently 3-D environment. 


\subsection{COMPARISON OF 1-D, 2-D AND 3-D MODELS}

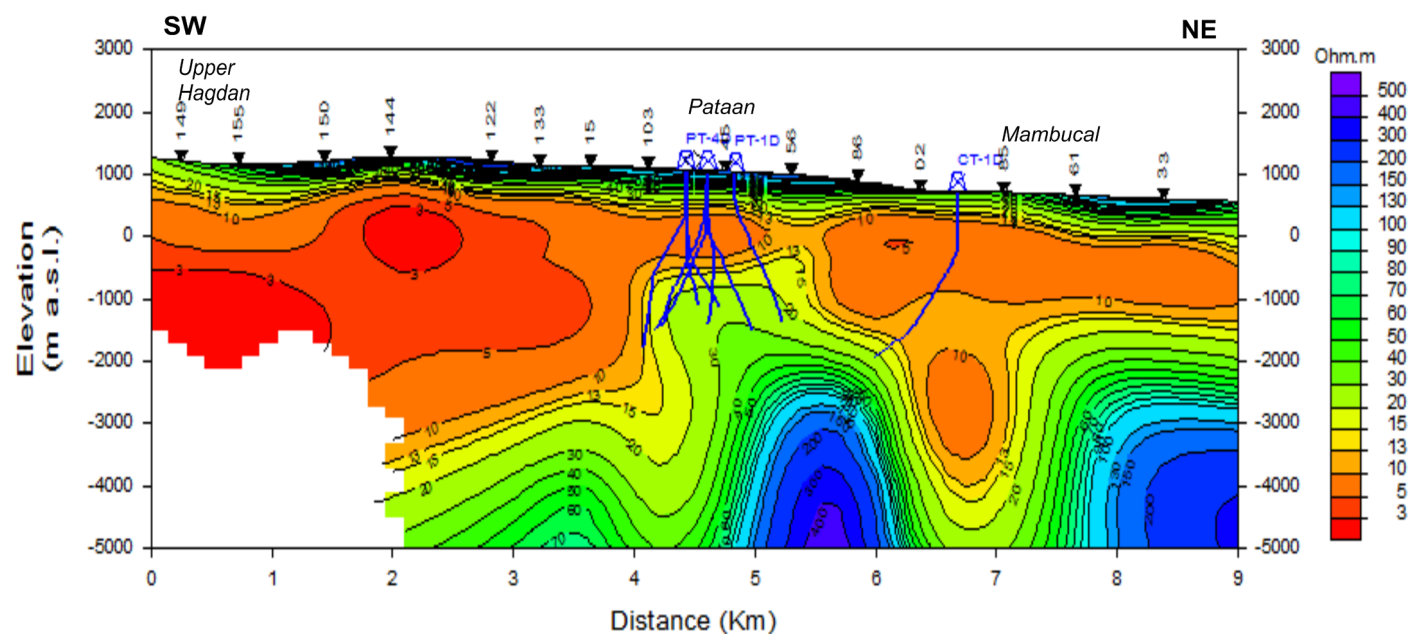

(a) 1-D model along line SW-NE1

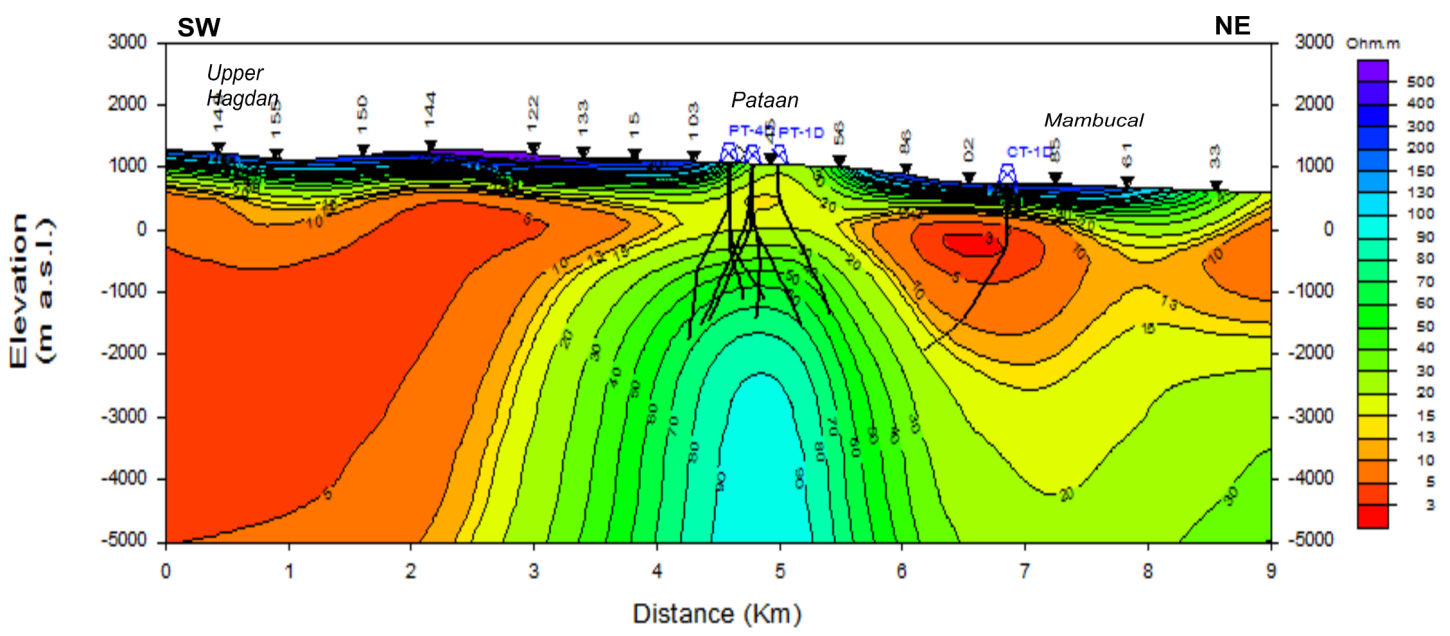

(b) 2-D model along line SW-NE1; RMS=1.657

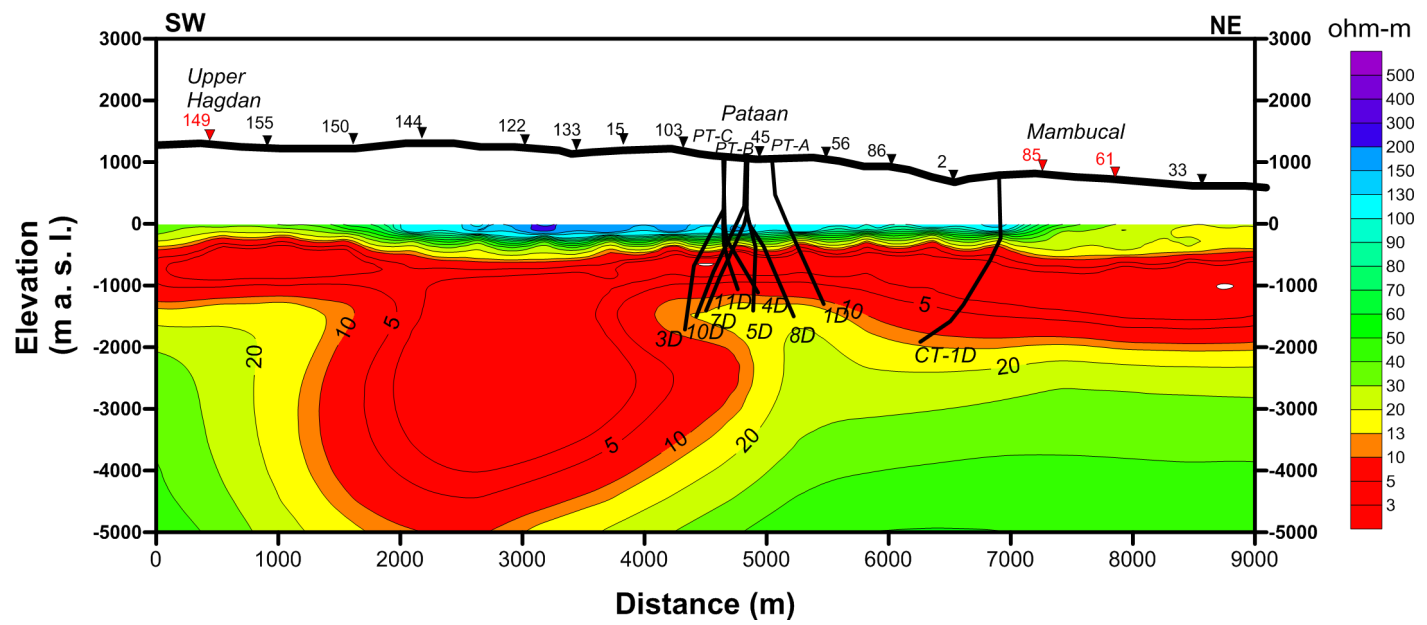

(c) 3-D model along line SW-NE1

Figure 5.51: Profile line SW-NE1 


\section{Chapter 6}

\section{Discussion and interpretation}

\subsection{Resistivity structure of NNGP}

The resistivity models show that NNGP is covered by high resistivity values from the surface down to about $400 \mathrm{~m}$ depth. This is underlain by a highly conductive layer which extends to as deep as $>3000 \mathrm{~m}$ depth in some regions such as Hagdan, Upper Hagdan and Hardin Sang Balo. This in turn is underlain by a bottom layer, which has resistivity of $>20 \mathrm{ohm}-\mathrm{m}$. A prominent feature of this layer is its "doming" beneath Pataan where it is detected at $1000 \mathrm{~m}$ depth (Figures 5.26 and 5.27).

The location of the conductive zones is consistent with the direction of the "real" induction arrows where the arrows of the higher frequency range of $300 \mathrm{~Hz}$ to $10 \mathrm{~Hz}$ (Figures 4.6 and 4.7) point to the northwest and western regions, which coincides with the conductive zones detected with-in Mambucal and Hagdan at $100 \mathrm{~m}$ to $500 \mathrm{~m}$ depth (Figures 5.23 to 5.25). The induction arrows at $1 \mathrm{~Hz}$ (Figure 4.8) points towards the conductive zones of Hagdan in the southwest and Saray in the east as delineated from the isoresistivity maps of $1000 \mathrm{~m}$ and $2000 \mathrm{~m}$ depths (Figures 5.26 and 5.27). Furthermore, the induction arrows at frequencies of $0.1 \mathrm{~Hz}$ and lower (Figures 4.9 to 4.11 ) point mainly towards the southeast, where the conductive zones at the southern portion of Pataan 
Table 6.1: Common mineral geothermometers in Philippine geothermal areas

\begin{tabular}{ll}
\hline \hline Minerals & Temperature of stability $\left({ }^{\circ} \mathrm{C}\right)$ \\
\hline Clays & \\
Smectite & ambient to 180, may reach 200 \\
Illite-smectite & $180-220$ \\
$\quad$ Illite & $\geq 220$ \\
Biotite & $\geq 280$ \\
Actinolite & $\geq 260$ \\
Epidote & \\
Incipient & 180 \\
Anhedral & $180-200$ \\
Subhedral & $200-240$ \\
Euhedral & $\geq 240$ \\
\hline
\end{tabular}

and Hardin Sang Balo were detected at $>3 \mathrm{~km}$ depth (Figure 5.28).

\subsubsection{Correlation with alteration, temperature and lithol- ogy}

In a geothermal system, changes in resistivity are attributed to the interplay of temperature, porosity and fluid chemistry (Heise et al., 2008). This interaction can be reflected through the alteration minerals and temperatures encountered in the wells. A typical progradation hydrothermal alteration mineral suite used to predict temperature regimes in a geothermal field is shown in Table 6.1. To show the relationship between clay alteration minerals, measured temperatures, lithology and the resistivity structure at NNGP, several plots along selected profiles lines were made.

Figure 6.1 shows the plot of the alteration minerals intersected by the wells against the resistivity structure along Line NW-SE2. The resis- 


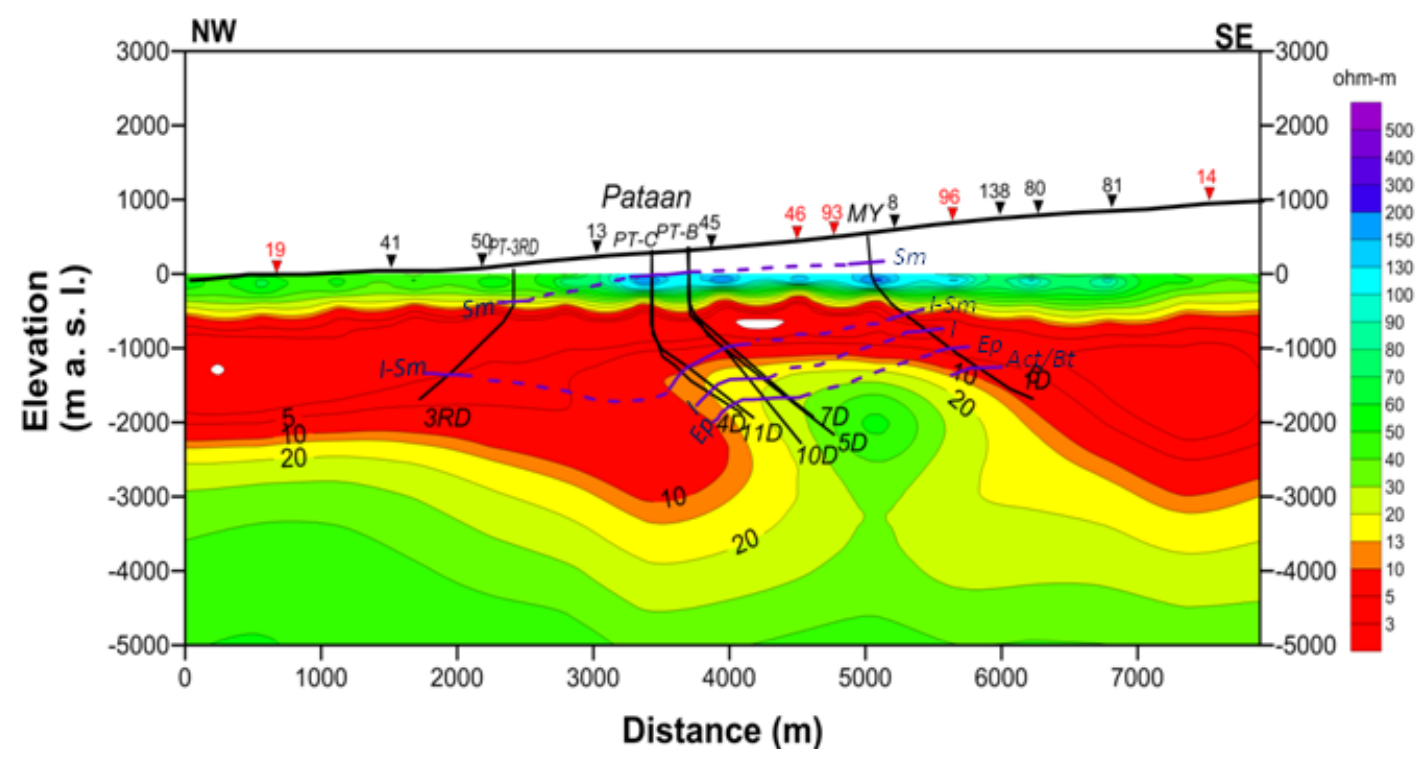

Figure 6.1: Resistivity model vs. alteration minerals along NW-SE2

tivity profile has been shifted to surface level to partly compensate for the offset in depth of the resistivity structure, as a result of not including the topography in the inversion. It is shown that the smectite (Sm) and illite-smectite (Il-Sm) zones, which form at temperatures $<220^{\circ} \mathrm{C}$ (Table 6.1), coincides with the thick highly conductive layer. The onset of the higher temperature alteration minerals particularly illite (Il) and epidote (Ep) overlaps with the doming of the moderately resistive bottom layer beneath Pataan. However, the alteration minerals in MY-1D were intersected at a shallower level. Occurrence of actinolite and biotite (Act/Bt) were also reported (Technical Services Sector, 2010).

Figure 6.2 shows the plot of the temperature measured in the wells against the resistivity structure along Line NW-SE2. Beneath Pataan, the $180^{\circ} \mathrm{C}$ to $200^{\circ} \mathrm{C}$ temperature contours lie within the lower portion of the conductive layer while $>220^{\circ} \mathrm{C}$ coincides with the shallower portion of the moderately resistive bottom layer. The measured temperature reaches $290^{\circ} \mathrm{C}$ in wells PT-5D and PT-7D (Dulce, 2001, 2003) as it goes towards the center of the resistive dome structure. The tempera- 


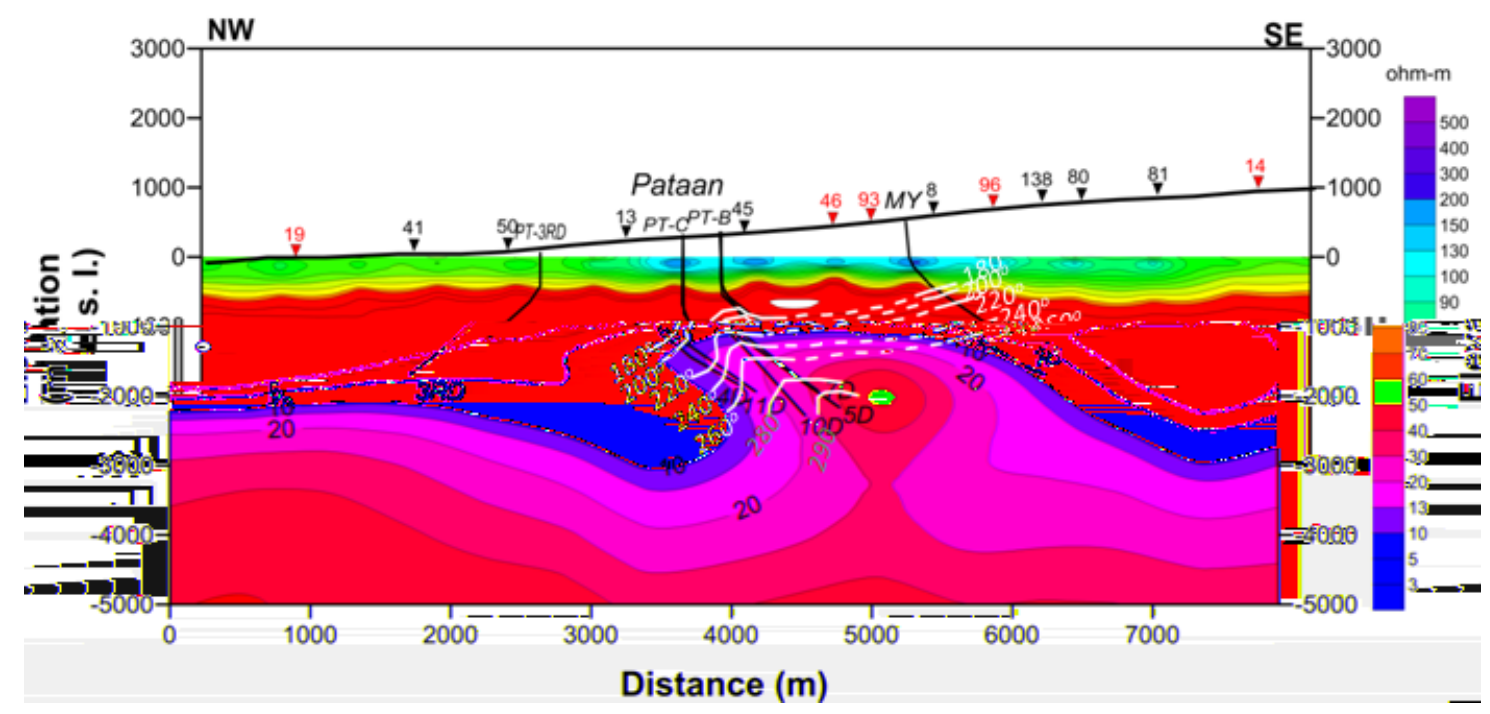

Figure 6.2: Resistivity model vs. measured temperatures along NW-SE2

ture contours do not extend to well PT-3RD because it only achieved a maximum measured temperature of $150^{\circ} \mathrm{C}$ at $1900 \mathrm{mMD}$ (Austria et al., 2009). The steep decline of the temperature contours in wells PT-4D and PT-11D matches the steep resistivity gradient towards the northwest. On the other hand, the temperature contours in MY-1D are again found at an elevated level but the maximum temperature measured by this well is only $269^{\circ} \mathrm{C}$ at $2600 \mathrm{mMD}$ (Austria et al., 2009).

It could be argued that if the resistivity structure is made to follow the ground level everywhere including the southeastern portion (i. e. by tilting the model), the wells, particularly where the higher temperatures were recorded would penetrate into the higher resistivities. The "doming" moderately resistive layer would also closely follow the pattern of the alteration minerals and elevated temperatures from MY-1D.

Figure 6.3 displays the main rock units intersected by the wells along NW-SE2 line. The contact between the volcanic breccias and hornblende andesite lavas of the Canlaon Volcanic Complex $(\mathrm{CnV})$ and the sedimentary breccias intercalated with calcareous-carbonaceous siltsone, lime- 


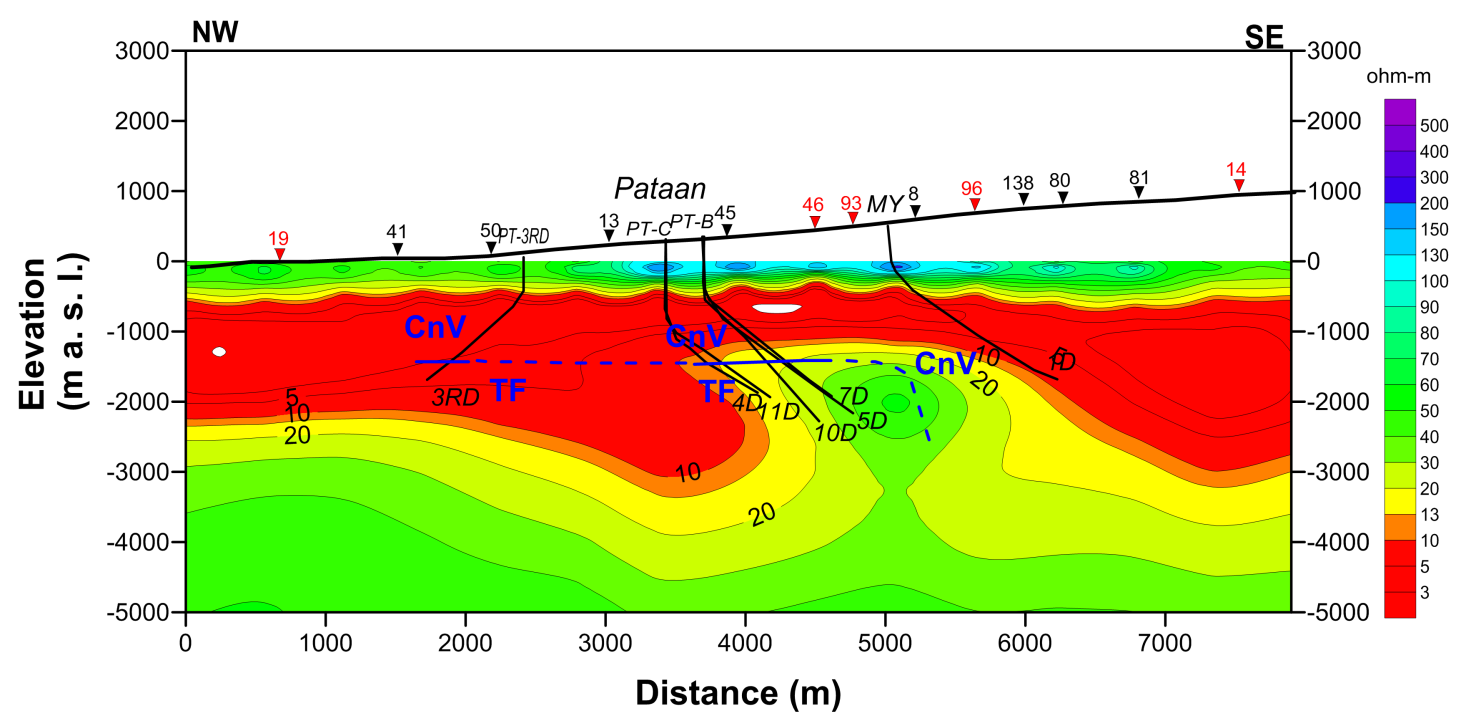

Figure 6.3: Resistivity model vs. lithology along NW-SE2

stone and lavas of the Talave Formation (TF) lies within the thick conductive layer in PT-3RD but coincides within the moderately resistive body beneath Pataan. In MY-1D, only the $\mathrm{CnV}$ was encountered which was composed of completely altered rocks of dacitic composition thought to be caused by thermal metamorphism by intrusion of dikes (Jara, 2010).

Figures 6.4, 6.5 and 6.6 show the plot of the clay alteration minerals, measured temperatures, and intersected lithologies, respectively, as correlated with the resistivity structure along profile line SW-NE1. As previously, the resistivity section has been shifted to make up for the exclusion of topography during the 3-D inversion.

The greater part of the smectite zone overlaps with the highly conductive layer (Figure 6.4). The illite-smectite (Il-Sm), illite (Il) and epidote (Ep) zones delineated from the PT (Pataan) wells coincide with the moderately resistive layer while the illite-smectite (Il-Sm) and illite (Il) zones in well CT-1D plots within the conductive layer. This could be due to the reported cool inflow at depths below $1631 \mathrm{mMD}$ in well CT$1 \mathrm{D}$ as manifested by the reappearance of smectite (Pamatian and Camit, 


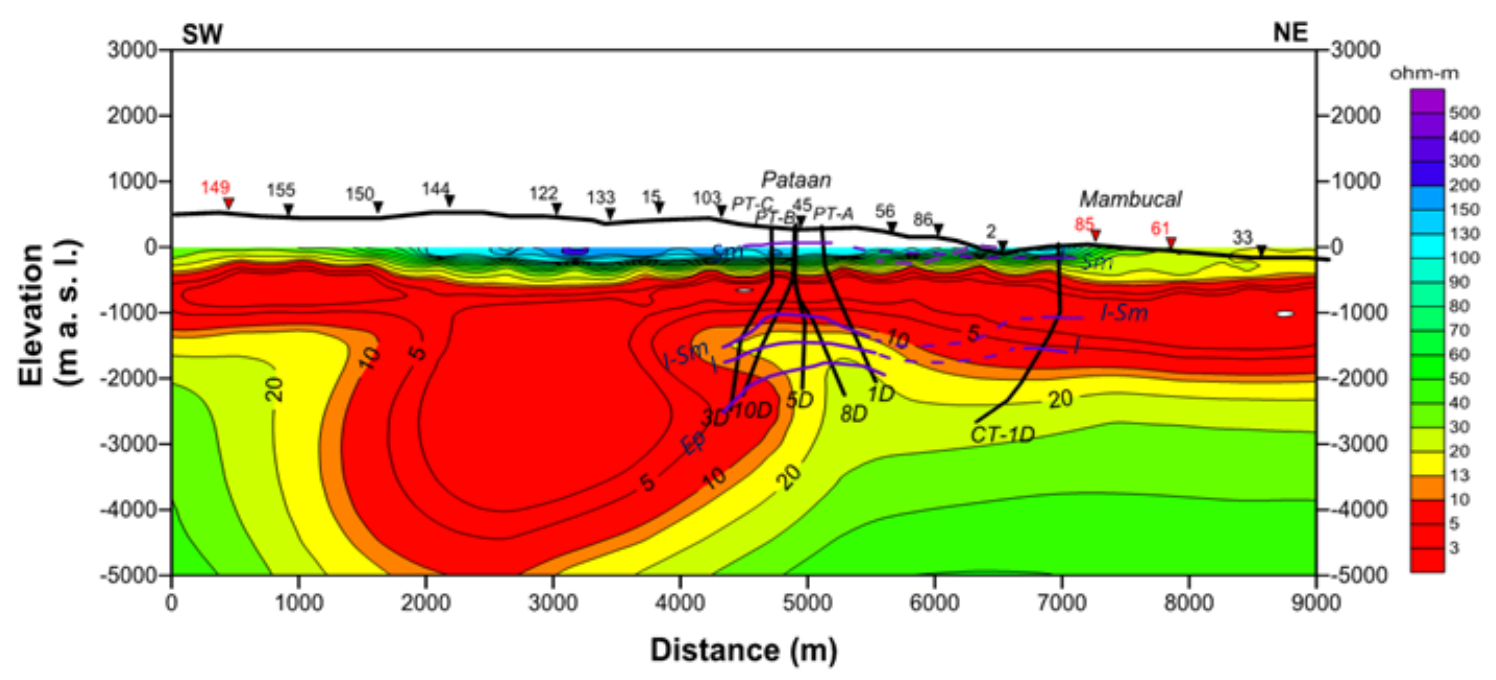

Figure 6.4: Resistivity model vs. alteration minerals along SW-NE1

1995).

The high temperatures measured in the Pataan wells particularly PT$5 \mathrm{D}$ and PT-8D which reaches $>280^{\circ} \mathrm{C}$ coincide with the doming moderately resistive bottom layer (Figure 6.5). The decreasing temperature gradient in PT-3D and CT-1D matches the steep resistivity gradient towards the southwest and northeast, respectively.

The topmost level of $\mathrm{CnV}$ which is composed of relatively fresh volcanic lavas and tuffs coincides with the resistive cap layer (Figure 6.6 ). The contact of the $\mathrm{CnV}$ and TF lies within the conductive zone in PT-3D and CT-1D while it is be found within the resistive "dome" in PT-10D and PT-5D. Only the CnV was intersected by wells PT-1D and PT-8D (Pamatian, 1994; Esperidion et al., 2002)

These correlations agree with the observations in the other studied geothermal fields wherein the $<10 \mathrm{ohm}$-m conductive layers are associated with the low temperature minerals (i.e. smectite) while increasing resistivity with depth can be correlated with the higher temperature anhydrous minerals (i.e. illite, epidote) (Johnston et al., 1992; Anderson et al., 1999). Furthermore, the only relationship that can be established 


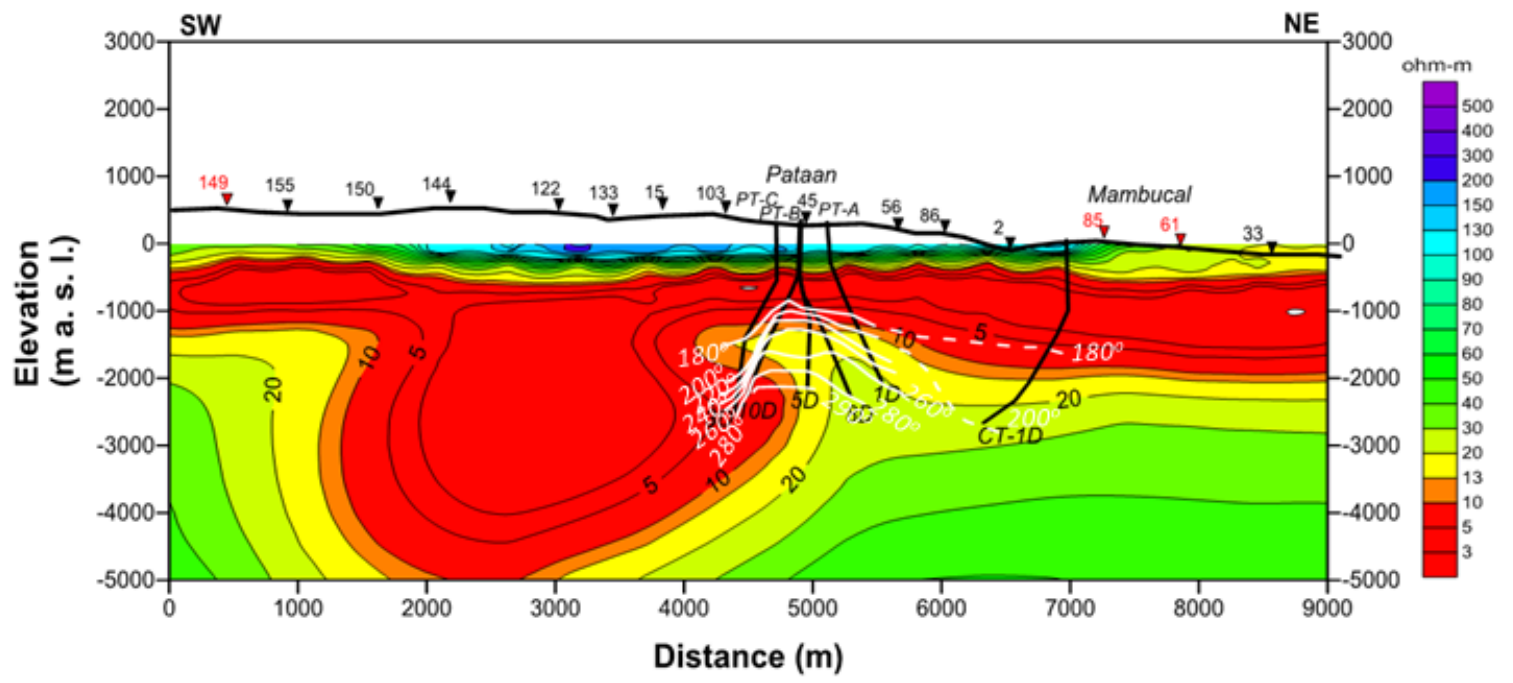

Figure 6.5: Resistivity model vs. measured temperatures along SW-NE1

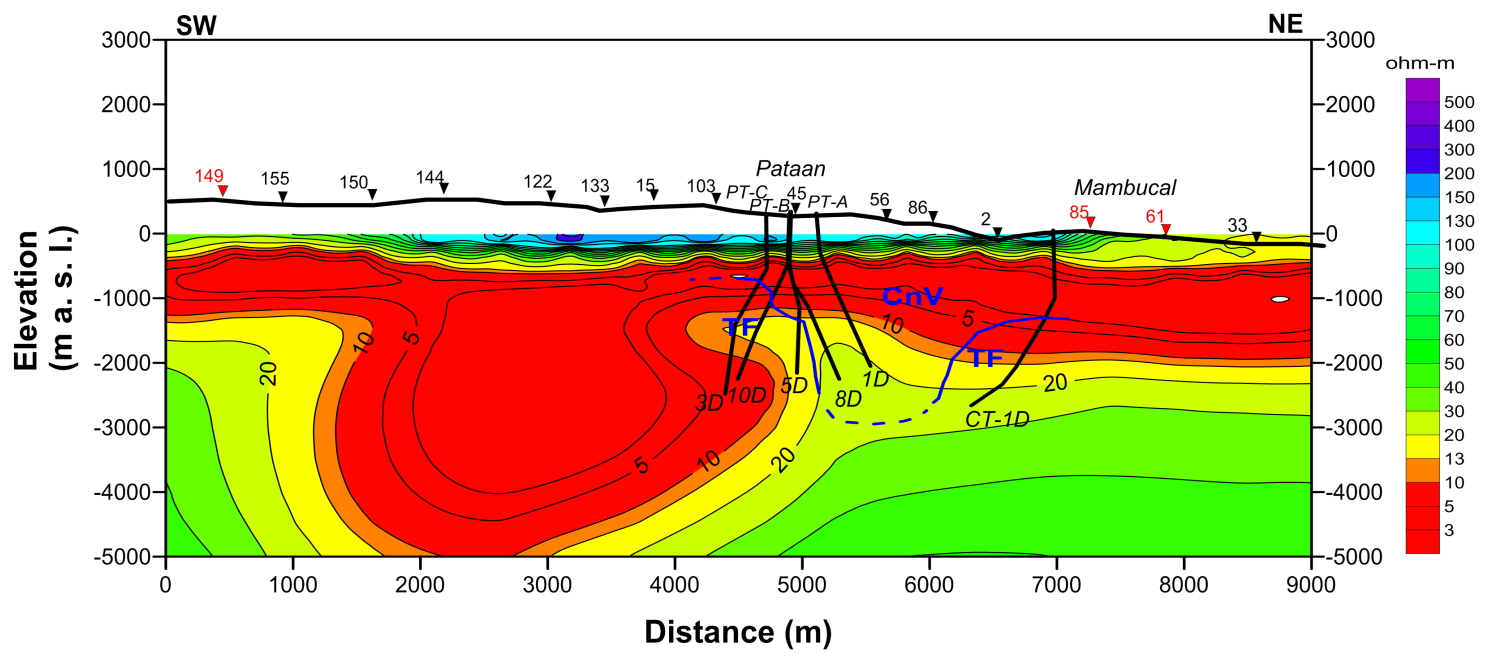

Figure 6.6: Resistivity model vs. lithology along SW-NE1 
between the lithology and resistivity would be the agreement of the relatively unaltered to weakly altered portion of $\mathrm{CnV}$ to the resistive cap layer. The deeper portion of $\mathrm{CnV}$ which consists of the either the highly altered portion of the $\mathrm{CnV}$ and / or metamorphosed dacitic rock overlaps both the conductive and high resistivity zones. Likewise, the occurrence of the Talave Formation also encompasses both the conductive and resistive layers.

\subsection{Geothermal resource area}

The high temperature resource of NNGP is associated with the occurrence of a shallow bottom resistive layer beneath Pataan. The core was intersected by wells PT-5D and 7D where $>290^{\circ} \mathrm{C}$ were measured (Figure 6.5). This is consistent with the model where the upflow zone is the area drilled by PT-5D and PT-7D. The area drilled by well MY-1D lies in the southeastern boundary. It is thought to be the hotter portion of NNGP, reaching temperatures $>300^{\circ} \mathrm{C}$, as indicated by the elevated measured temperatures as well as the shallower onset of the higher temperature alteration minerals (i.e. illite, epidote, actinolite) but has now cooled due to inflow of peripheral waters (Technical Services Sector, 2010). On the other hand, the steep decline of the temperature gradients in wells PT-3D and PT-4D mark the southwestern and western boundaries, respectively, of the resource.

To determine the boundary of the Pataan resource area particularly to the northeast, profile SW-NE2, which follows the delineated moderate resistivity zone at $1 \mathrm{~km}$ depth (Figure 5.26), was created (Figure 6.7). It shows that the moderately doming resistive block in Pataan extends towards station 82 (Figure 6.8). Assuming that resistivity reflects the possible temperature in that region, this could indicate the northeastern boundary of the geothermal resource in Pataan. The delineated boundaries of the high temperature resource are marked by the dashed lines, 


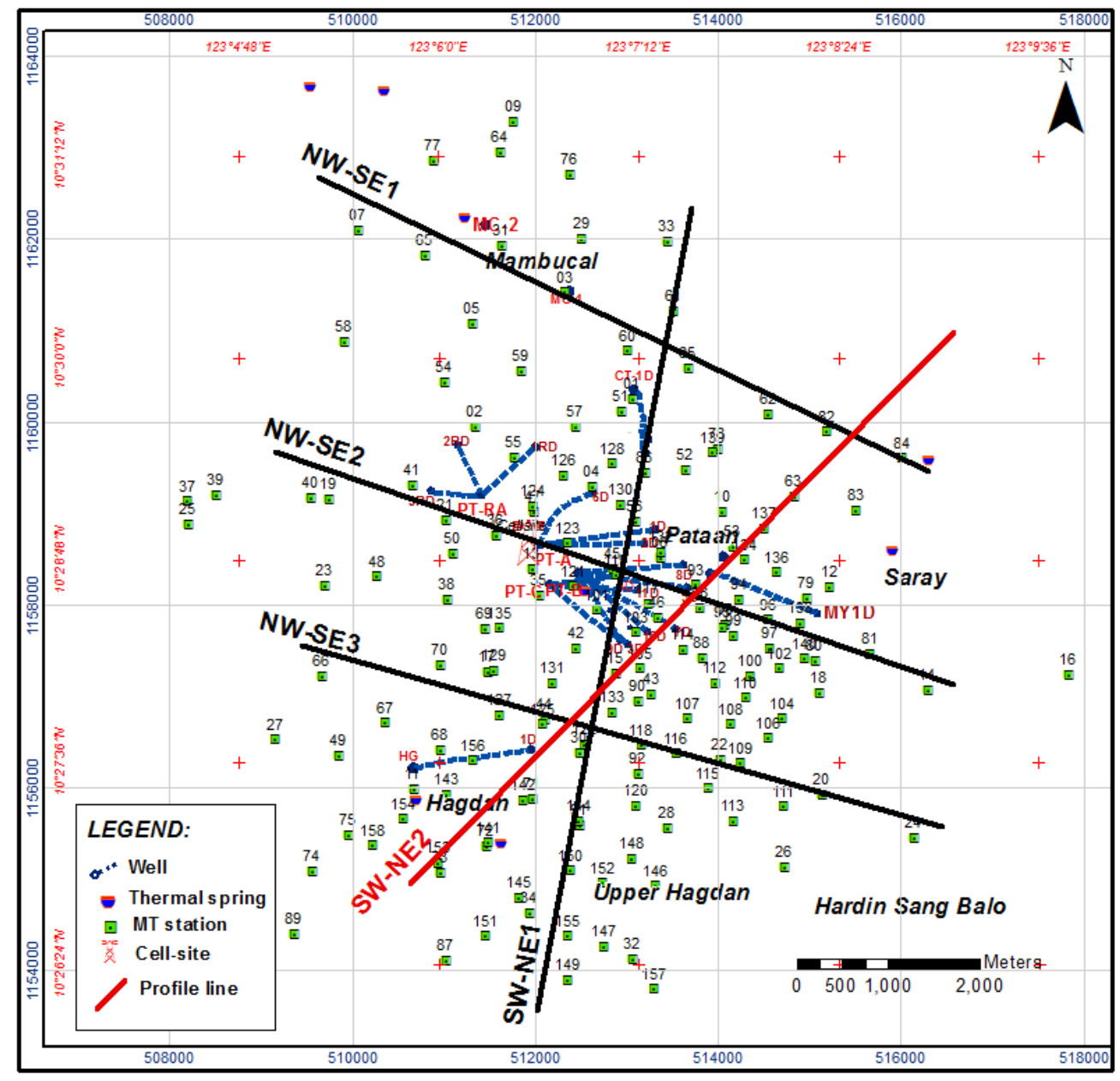

Figure 6.7: Profile line SW-NE2 location map

red representing the inner boundaries while the purple lines indicating the outer boundaries (Figure 6.8).

The high temperature resource area in Pataan based on the resistivity structure as delineated from the profile lines and isoresistivity maps is shown in Figure 6.9. The dashed line represents the possible maximum area while the ellipse is the most likely areal extent of the high temperature resource of $>240^{\circ} \mathrm{C}$. The area of the ellipse is about three $\mathrm{km}^{2}$ while the maximum possible area is about seven $\mathrm{km}^{2}$. The boundaries of the delineated resource is marked by well PT-1D on the west, PT-3D on the 


\subsection{GEOTHERMAL RESOURCE AREA}

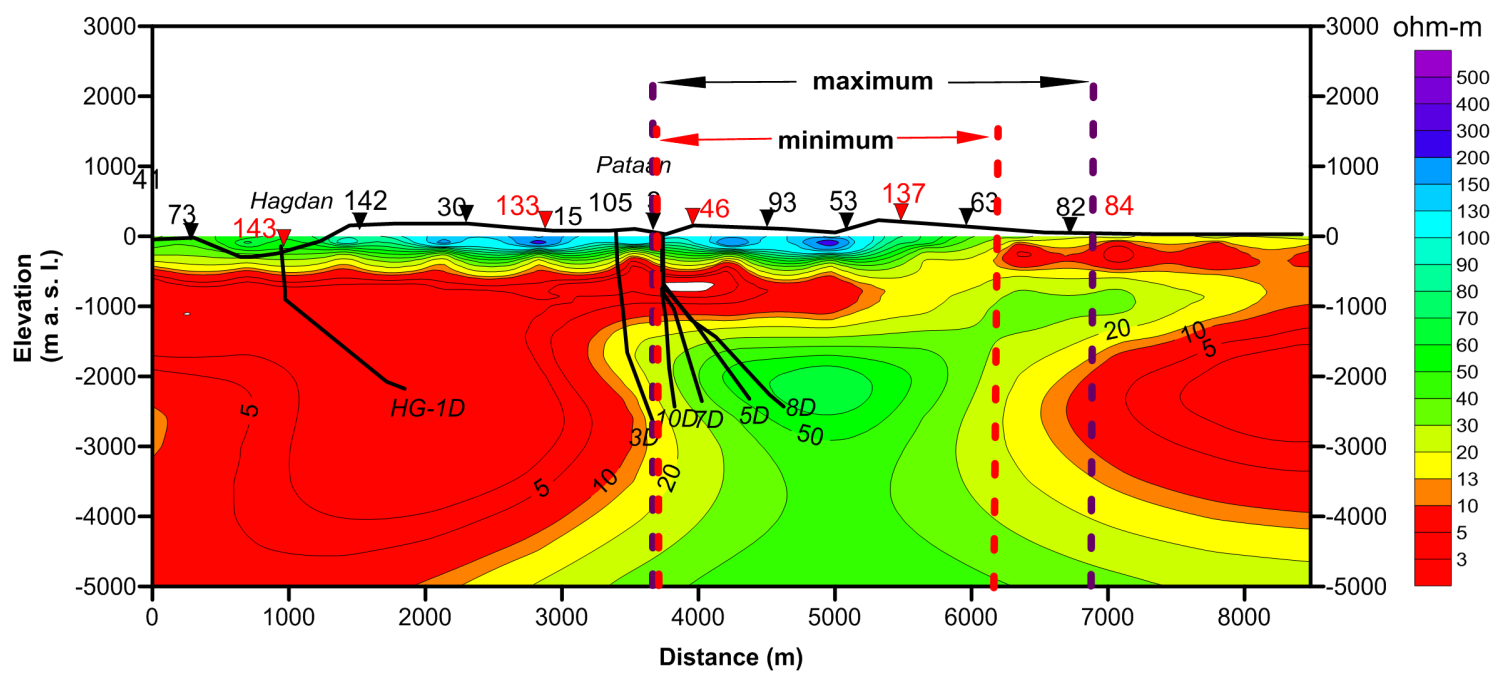

Figure 6.8: Resistivity model along SW-NE2

southwest, MY-1D on the east, and station 63 on the northeast.

Profile SW-NE2, also shows that well HG-1D where measured temperatures only reach $235^{\circ} \mathrm{C}$ at about $2100 \mathrm{mVD}$ lies within the thick conductive layer (Figure 6.8). This further suggests that there is no hotter region in the Hagdan sector that can be deduced from the resistivity structure.

Another possible area where high temperatures may be encountered would be Upper Hagdan sector as indicated by the shallow resistive bottom layer in profile NW-SE3 (Figure 5.5.2) and at $1 \mathrm{~km}$ and $2 \mathrm{~km}$ depth maps (Figures 5.26 and 5.27). It should be noted however, that resolution of resistivity at deeper levels in the southern areas of Hagdan, Upper Hagdan and Hardin Sang Balo may not be well resolved mainly because of the low station density in these areas. Additionally, possible effects of topography may be included in the resistivity structure modelled particularly within the vicinity of Hardin Sang Balo due to its high elevation difference with the majority of the stations. 


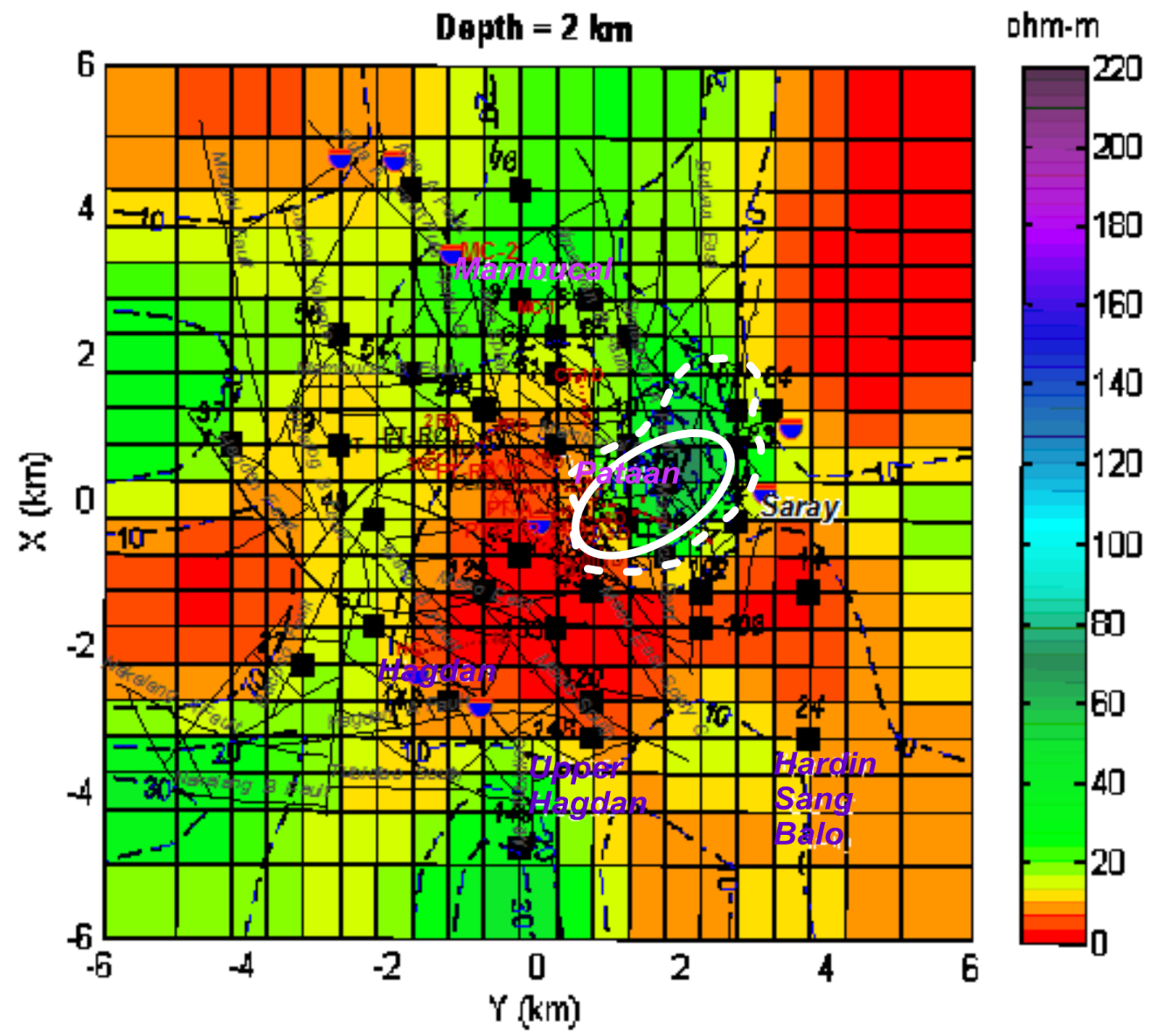

Figure 6.9: Delineated resource area in NNGP based on 3-D inversion 


\section{Chapter 7}

\section{Summary and Conclusions}

To realize a 3-D resistivity model for NNGP, additional stations were occupied during the survey season of December 2010 to April 2011. To overcome the possible noise sources such as the power plant, power lines and other installations, as well as the rainy and windy weather conditions, recording time was extended to $40-60$ hours. A remote reference site, which is situated about $50 \mathrm{kms}$ away, was also employed to improve the data quality. 66 new MT stations were added making the total available MT stations in NNGP to 158. Although only about half of the stations have data exceeding periods $>100 \mathrm{~s}$, data coverage in the vicinity of Pataan, which is the main producing zone at NNGP is sufficient.

One improvement applied during data processing is the removal of the distortion through the phase tensor analysis method by Caldwell et al. (2004). The dimensionality of the MT data were also determined using this method. It showed that 1-dimensionality of the data is observed only on the short period range ( $<1 \mathrm{~s})$ but becomes 3 -D at the longer periods. Another development is the application of static shift correction using TEM data, which was conducted in some of the MT stations during the latest survey. The MT stations which show the bigger shifts are mainly the ones within Pataan and Saray. 
The 1-D, 2-D and 3-D isoresistivity maps consistently delineated conductive zones at Mambucal, Pataan, Saray, Hagdan and Upper Hagdan sectors at shallower depths. The locations of these conductive zones were consistent with the directions of the real component of the induction arrows at high frequencies.

The 1-D, 2-D, and 3-D models also shows a resistivity structure made up of a top $>100 \mathrm{ohm}-\mathrm{m}$ resistive layer, which extends from surface to depths of about $400 \mathrm{~m}$. This is underlain by a highly conductive $<10$ ohm-m layer, which reaches $>4000 \mathrm{~m}$ depth in some sectors. This is underlain in turn by a bottom moderately resistive layer of $>20 \mathrm{ohm}-\mathrm{m}$ and increases with depth. Moreover, the models consistently detected a "doming" portion of the bottom resistive layer beneath Pataan.

Correlating the 3-D resistivity structure with the subsurface data, which was obtained primarily from the drilled wells showed that the conductive layer overlaps with the low-temperature clay alteration mineral smectite while the moderately resistive layer coincide with the higher temperature $\left(>200^{\circ} \mathrm{C}\right)$ alteration minerals such as illite and epidote. This agrees with the highest temperatures $\left(>290^{\circ} \mathrm{C}\right)$ measured in the wells drilled within the moderately resistive layer namely PT-5D and PT-7D. Correlation of the resistivity structure with lithology shows that the topmost highly resistive layer corresponds with relatively fresh volcanic deposits of the Canlaon Volcanics. However, no clear correlation can be seen within the middle and bottom resistivity layers with lithology as these coincide with both the Canlaon Volcanics and the Talave Formation. This could be due to the fact that the deeper portion of the Canlaon Volcanics is highly altered that no major contrast can be made with the sedimentary Talave Formation.

The high-temperature resource drilled in NNGP correlates to the "doming" structure of the bottom moderately resistive layer beneath Pataan (Figure 7.1). It is bounded on the west by well PT-1D, on the southwest by PT-3D and Pataan-C Splay Fault, and on the east by MY- 
1D. This delineated resource area is found to be elongated towards the northeast and covers an area of about three to seven $\mathrm{km}^{2}$. The highly permeable Mambucal-A and Kinabkaban-A Faults, as well as Asia-B and Sumaguan Faults cut through the resource. These faults could be the channel of the hot fluids from the upflow zone at Pataan towards the outflow zone in Mambucal and PT-A sectors giving rise to the thermal springs of Mambucal, Hda. Paz, Hda. Montinolla and Kinabkaban, in the northwest and west.

Looking further at the 3-D resistivity structure, another possible hightemperature area may be present beneath Upper Hagdan at the southern portion of NNGP, where a similar shallow portion of the moderate resistive layer was detected. The hot springs in Hagdan sector may be associated with this inferred Upper Hagdan resource through Hagdan Fault acting as the conduit. Another area of interest would be Hardin Sang Balo in the southeast. However, model resolution in both of these areas are not well defined due to the limited MT stations in this region. To fully resolve the resistivity structure, more MT stations are needed in this area. 


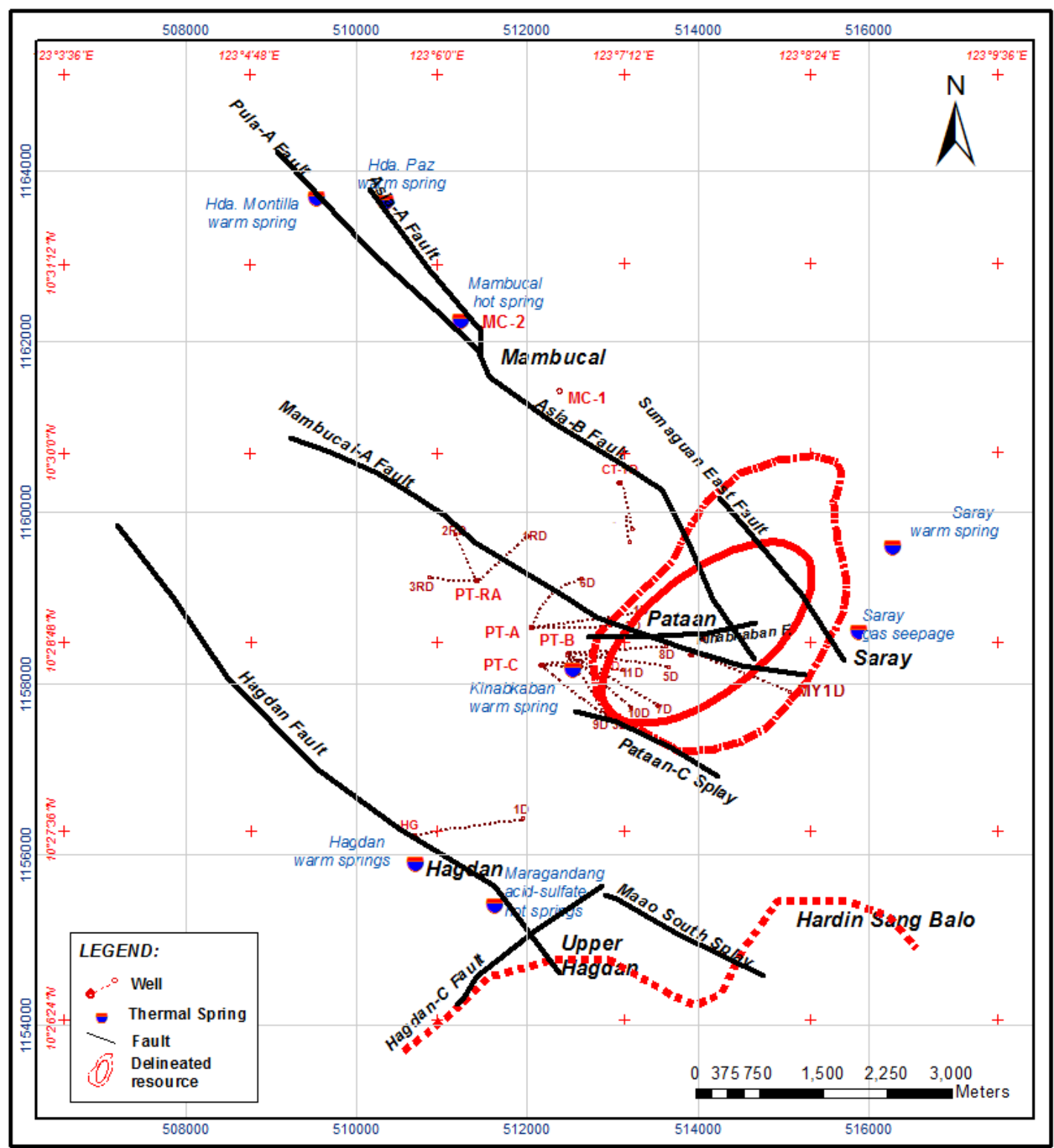

Figure 7.1: Delineated resource area at NNGP 


\section{References}

Acharya, H. K. and Aggarwal, Y. P., 1980, Seismicity of the Philippine Island. J. Geophys. Res., 85(B6):3239-3250

Anderson, E., Crosby, D. and Ussher, G., 1999, As plain as the nose on your face: Geothermal systems revealed by deep resistivity. Proceedings, 21st New Zealand Geothermal Workshop (1999), Univ. of Auckland, Geothermal Institute, 107-112

Austria, J. J. C., Omagbon, J. B. and O'Sullivan, M. J., 2009, Threedimensional reservoir simulation of Northern Negros Geothermal Reservoir, Philippines. Technical Report, EDC, Philippines

Bahr, K., 1991, Geological noise in magnetotelluric data: A classification of distortion types. Phys. Earth Planet. Int., 66:2438

Bibby, H. M., Caldwell, T. G. and Brown, C., 2005, Determinable and non-determinable parameters of galvanic distortion in magnetotellurics. Geophys. J. Int, 163:915-930

Bostick, F. X., 1977, A simple almost exact method of MT analysis Workshop on Electrical Methods in Geothermal Exploration, U.S. Geol. Surv., Contract No. 14080001-8-359

Brewitt-Taylor, C. R. and Weaver, J. T., 1976, On the finite difference solution of two-dimensional induction problems. Geophys. J. R. Astr. Soc., 47:375-396 
Cagniard, L, 1953, Basic theory of the magnetotelluric method of geophysical prospecting. Geophysics, 18:605-635.

Caldwell, T. G., Bibby, H. M. and Brown, W., 2004, The magnetotelluric phase tensor. Geophys. J. Int., 158:457-469.

Commission on Volcanology, 1981, Catalogue of Philippine volcanoes and solfataric areas, Technical report, Comvol, Quezon City, Philippines.

Constable, S. C., Parker, R. L. and Constable, C. G., 1987, Occam's inversion: A practical algorithm for generating smooth models from em sounding data. Geophysics, 52:289-300.

Cumming, W., Nordquist, G. and Astra, D., 2000, Geophysical exploration for geothermal resource: An application for combine MTTDEM 70th Ann. International Mtg., Soc. of Expl. Geophys., 1071-1074

deGroot-Hedlin, C. and Constable, S., 1990, Occam's inversion to generate smooth, two-dimensional models from magnetotelluric data. Geophys., 55(12):1613-1624

Dulce, R. G, 2001 Petrologic summary of well PT-5D. Technical Report, PNOC-EDC, Philippines

Dulce, R. G, 2003 Petrology of well PT-7D. Technical Report, PNOC-EDC, Philippines

Esperidion, J. A., Bien, O. C. and Camit, R. A., 2002, Well geology report PT-8D, Northern Negros Geothermal Project. Technical Report, PNOCEDC, Philippines

Gamble, T. D., Goubau, W. M. and Clarke, J., 1979, Magnetotellurics with a remote magnetic reference. Geophysics, 44:53-68

Geosystem SRL, 2008, User's guide to WinGLink, Release 2.20.02.01, Milan, Italy 
Gold, T., 1959, Motions in the magnetosphere of the earth. J. Geophys. Res., 64(9):1219-1224

Groom, R. W. and Bailey, R.C, 1989, Decomposition of magnetotelluric impedance tensors in the presence of local three-dimensional galvanic distortion. J. Geophys. Res., 94(B2):1913-1925

Heise, W., Caldwell, T. G., Bibby, H. M. and Bannister, S. C., 2008, Threedimensional modeling of magnetotelluric data from the Rotokawa Geothermal Field, Taupo Volcanic Zone, New Zealand, Geophys. J. Int., 173:740-750

Ingham, M. R., Bibby, H. M., Heise, W., Jones, K. A., Cairns, P., Dravitzki, S., Bennie, S. L. , Caldwell, T. G. and Ogawa, Y., 2005, A magnetotelluric study of Mount Ruapehu Volcano, New Zealand. Geophys. J. Int., 179:887-904

Jara, M. P., 2010, Geology of MY-1D. Technical Report, EDC, Philippines

Johnston, J. M., Pellerin, M. and Hohmann, G. W., 1992, Evaluation of electromagnetic methods for geothermal reservoir detection. Geothermal Resource Council Transactions, 16:241-245

Jones, A.G., 1983, On the equivalence of the Niblett and Bostick transformations in the magnetotelluric method. J. Geophys, 53:72-73

Ledo, J., 2005, 2-D vs. 3-D magnetotelluric data interpretation. Surveys in Geophys., 26:511-543

Madden, T. R. and Mackie, R. L., 1989, Three-dimensional magnetotelluric modeling and inversion. IEEE, 77(2): 318-330

Maneja, F. C., Los Banos, C. F., Layugan, D. B., Apuada, N. A. and Rigor, D. M., Jr., 2001, Magnetotelluric survey in the Northern Negros Geothermal Field, Central Philippines. Technical report, PNOC-EDC, Philippines 
Ogawa, Y, 2002, On two-dimensional modeling of magnetotelluric field data, Surveys in Geophysics, 23(2-3):251-273

Pamatian, P. I., 1994, Geology of well PT-1D, Northern Negros Geothermal Prospect, Mt. Canlaon, Negros Occidental, Technical report, PNOC-EDC, Philippines

Pamatian, P. I. and Camit, R. A., 1995, Geology of well CT-1D, Northern Negros Geothermal Prospect, Mt. Canlaon, Negros Occidental, Technical report, PNOC-EDC, Philippines

Pamatian, P. I., Salonga, N. D. and Tebar, H. J., 1992, The geology of Northern Negros Geothermal Prospect, Mt. Canlaon, Negros Occidental, Technical report, PNOC-EDC, Philippines

Panem, C. C. and Leynes, R. D. C., 1996, Faults and lineaments in Northern Negros Geothermal Area, Technical report, PNOC-EDC, Philippines

Parkinson, W. D., 1962, The influence of continents and oceans on geomagnetic variations, Geophys. Journal of the Royal Astronomical Society, 6:441-449

Phoenix Geophysics Limited, 2005, Data processing user guide V. 3.0, Toronto, Canada

PNOC-EDC, 1998, Northern Negros Geothermal Project-resource assessment update, Technical report, PNOC-EDC, Philippines

Reyes, A. G., 1979, Geology of Mambucal-1 exploratory well, Mambucal, Murcia, Negros Occidental. Technical report, PNOC-EDC, Philippines

Rigor, D. M., Jr. and Los Banos, C. F., 1997, Regional gravity survey in the Northern Negros Geothermal Project, Mt. Canlaon, Central Philippines. Technical report, PNOC-EDC, Philippines 
Rodi, W. and Mackie, R. L., 2001, Nonlinear Conjugate Gradients algorithm for 2-D magnetotelluric inversion. Geophysics, 66(1):174-187

Sasaki, Y., 2001, Full 3D inversion of electromagnetic data on PC. J. Appl. Geophys., 46:4554.

Siripunvaraporn, W., Egbert, G. and Lenbury, Y. and Uyeshima, M., 2005, Three-dimensional magnetotelluric inversion: data-space method, In: Physics of the Earth and Planetary Interiors, 150:3-15

Siripunvaraporn, W., Egbert, G., Uyeshima, M., 2006, WSINV3DMT version 1.0.0 for single processor machine, Bangkok, Thailand

Siripunvaraporn, W., 2011, Three-dimensional magnetotelluric inversion: An introductory guide for developers and users, Surv. Geophys.,33:5-27

Society of Exploration Geophysics, 1991, MT/EMAP data interchange standard

Sternberg, B. K., Washburne, J. C. and Pellerin, L., 1988, Correction for the static shift in magnetotellurics using transient electromagnetic soundings, Geophysics,53:1459-1468

Swift, C. M. Jr, 1967, A magnetotelluric investigation of an electrical conductivity anomaly in the Southwestern United States, PhD thesis, Mass. Inst. of Technology

Technical Services Sector, 2010, Reassessment of Northern Negros Geothermal Resource. Technical report, EDC, Philippines

Tikhonov, A. N, 1950, The determination of the electrical properties of deep layers of the earths crust. Dokl. Acad. Nauk. SSR, 73:295-297

Uchida, T., 2005, Three-dimensional magnetotelluric investigation in geothermal fields in Japan and Indonesia. Proceedings, World Geothermal Congress 2005, Antalya, Turkey 
Wannamaker, P. E., Hohmann, G. W. and Ward, S. H., 1984, Magnetotelluric responses of three-dimensional bodies in layered earths, Geophys., 49(9):1517-1533

Vozoff, K., 1991, The magnetotelluric method, In: Electromagnetic methods in applied geophysics II (ed.) M. N. Nabighian, Soc. of Explo. Geophys., V.2 


\section{Appendix I: Data curves and phase tensor analysis}


NNG-01
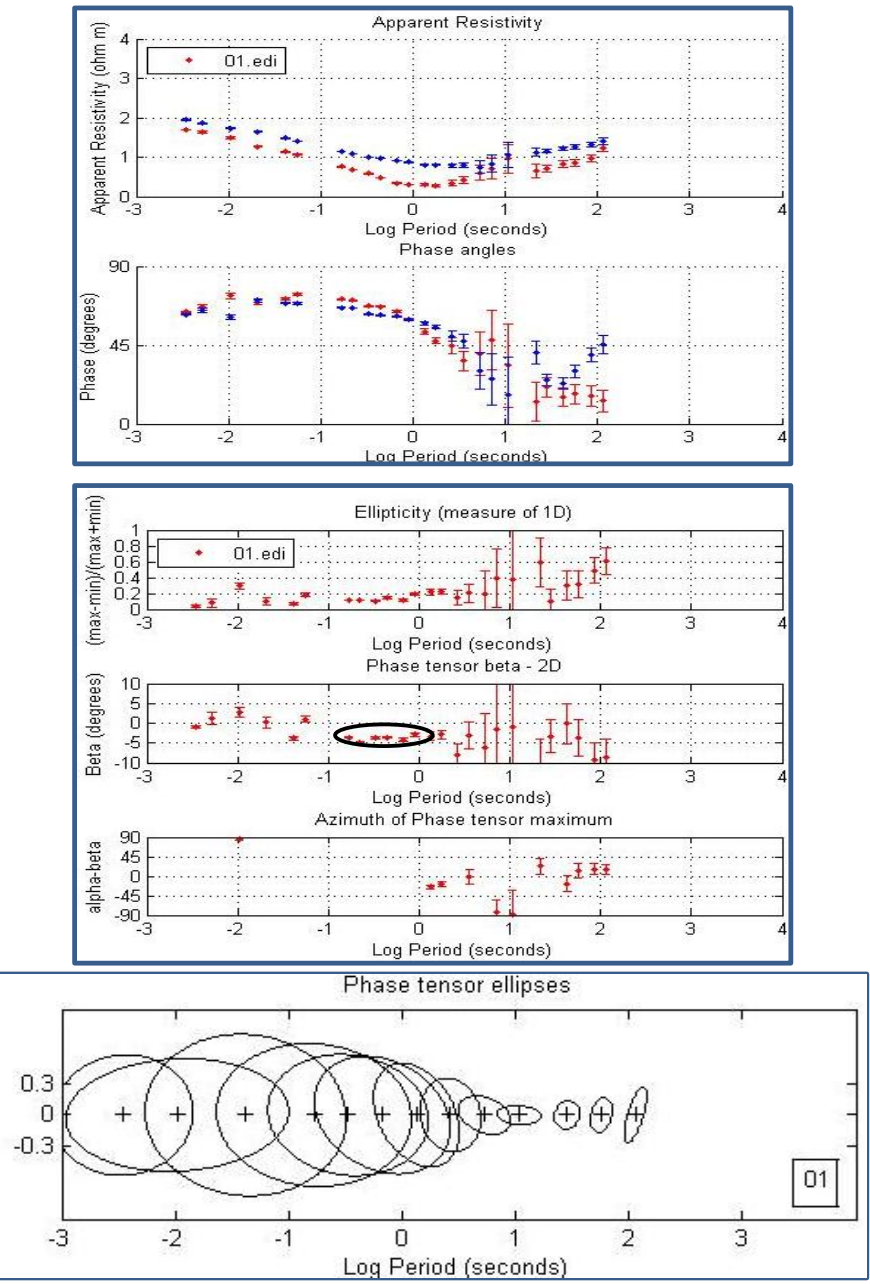

NNG-03
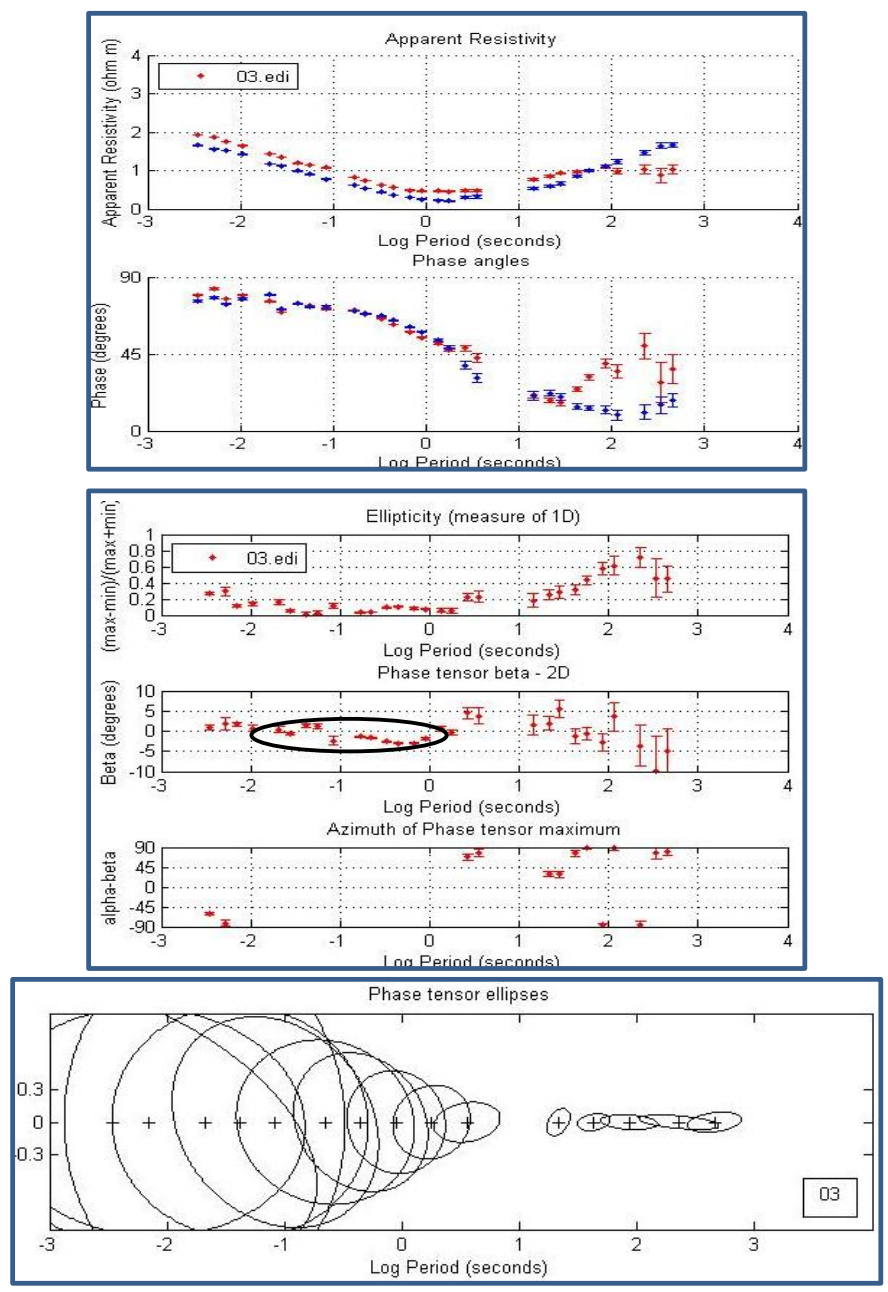

NNG-02
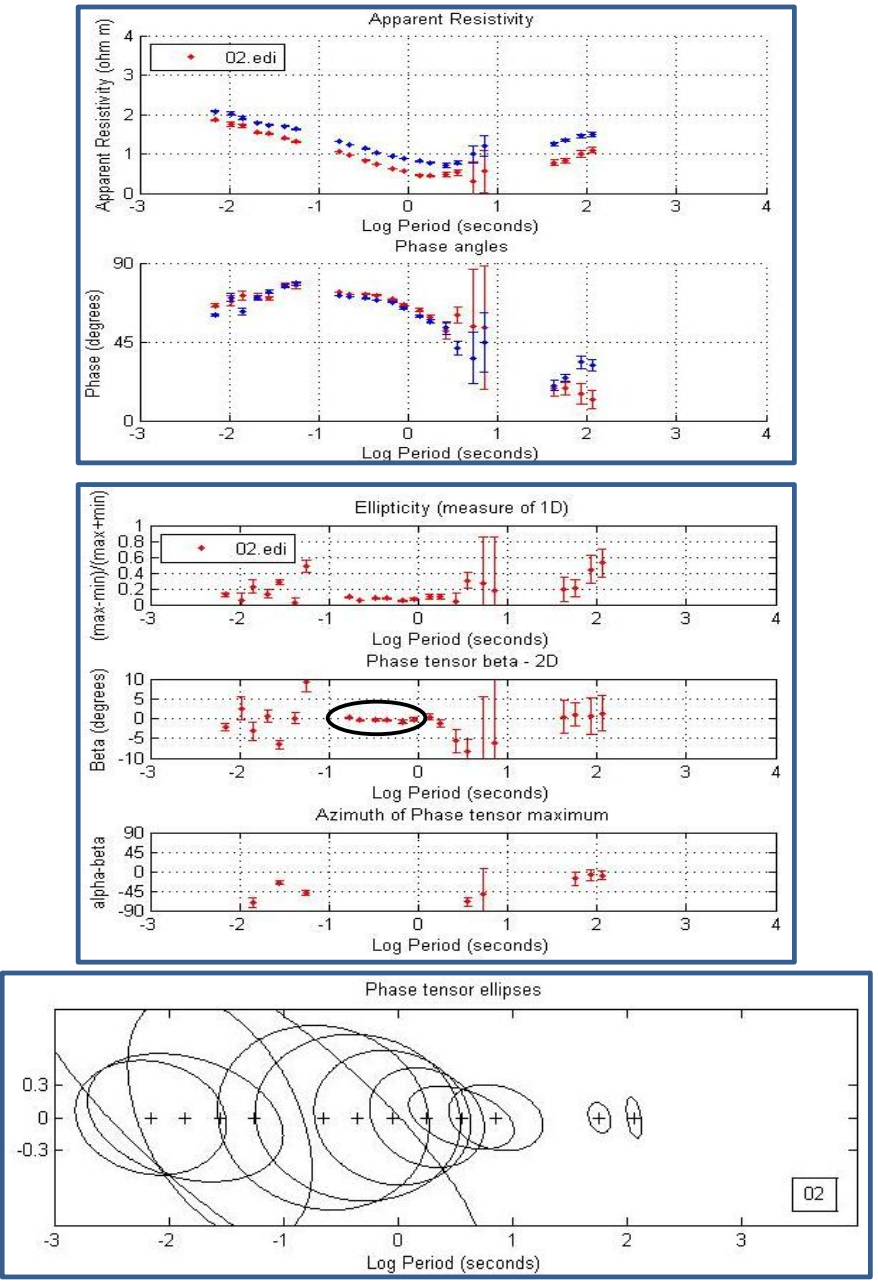

NNG-04
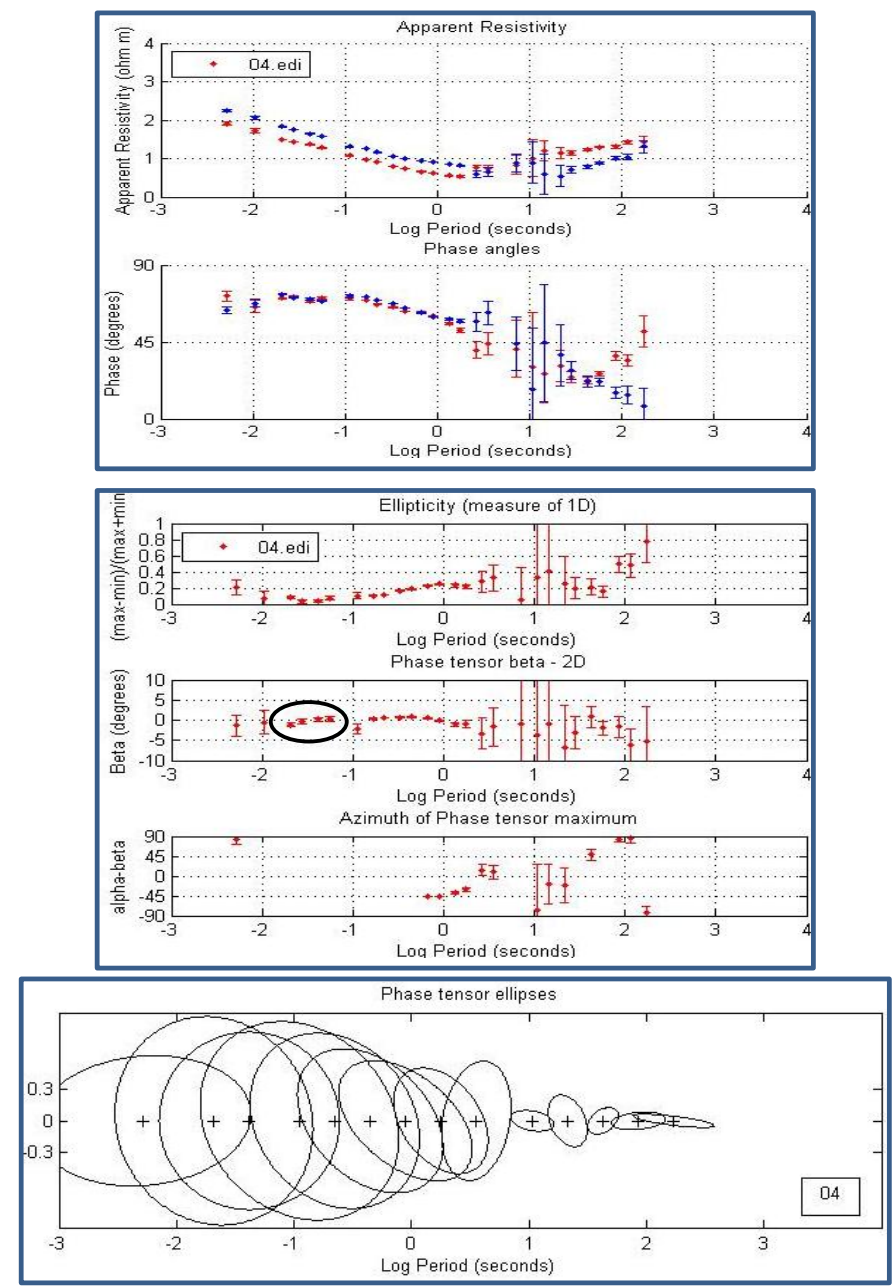
NNG-05
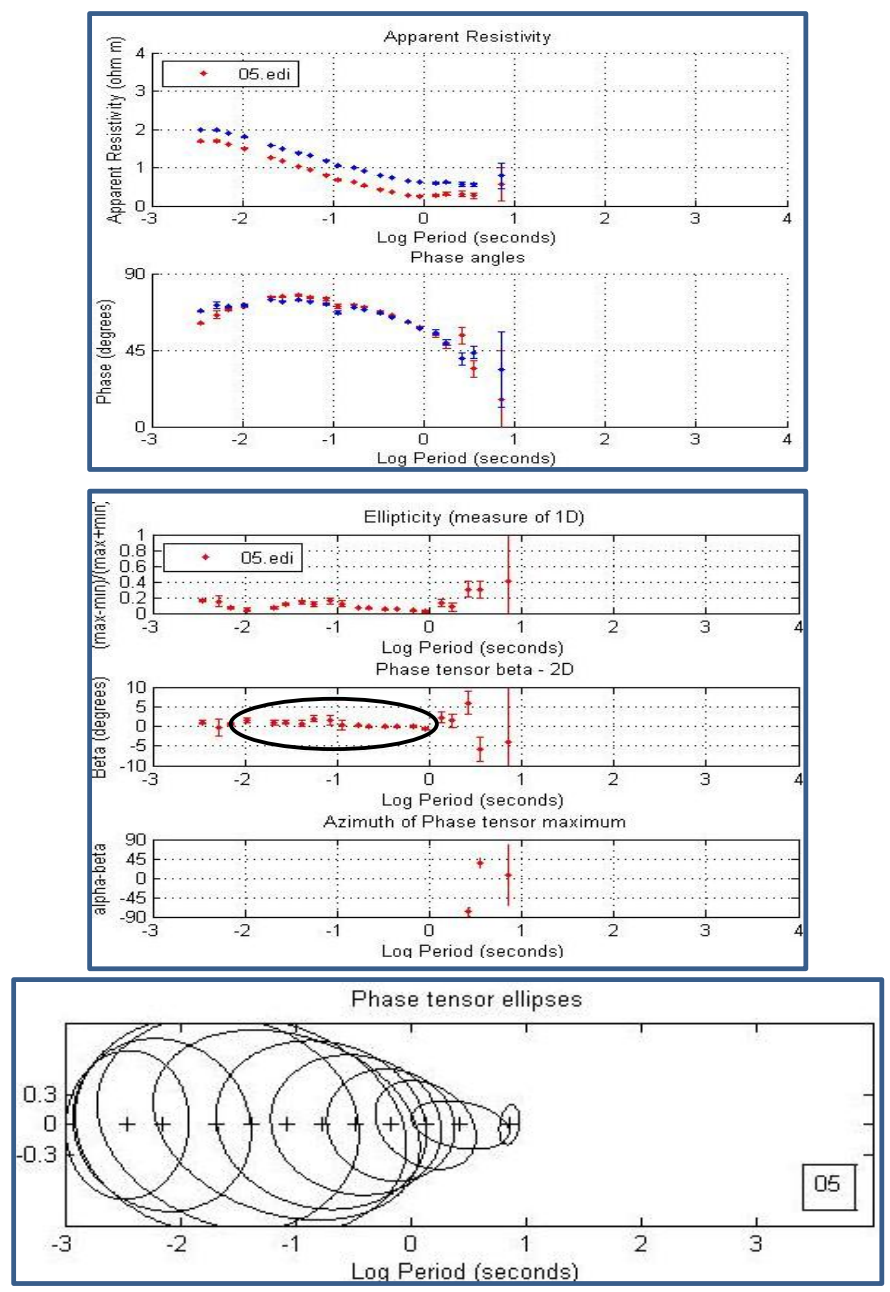

NNG-07
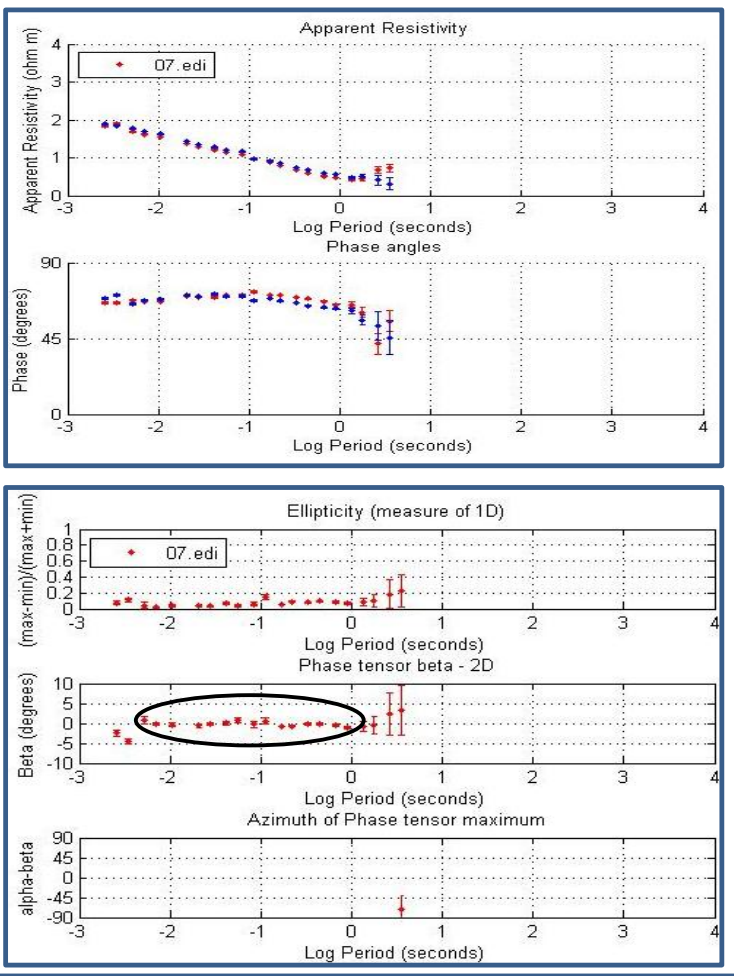

Phase tensor ellipses

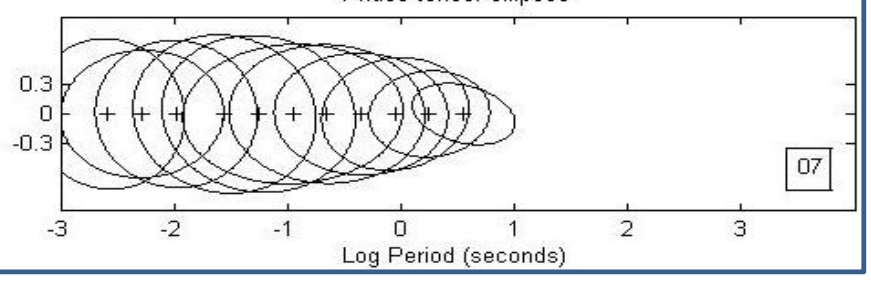

NNG-06
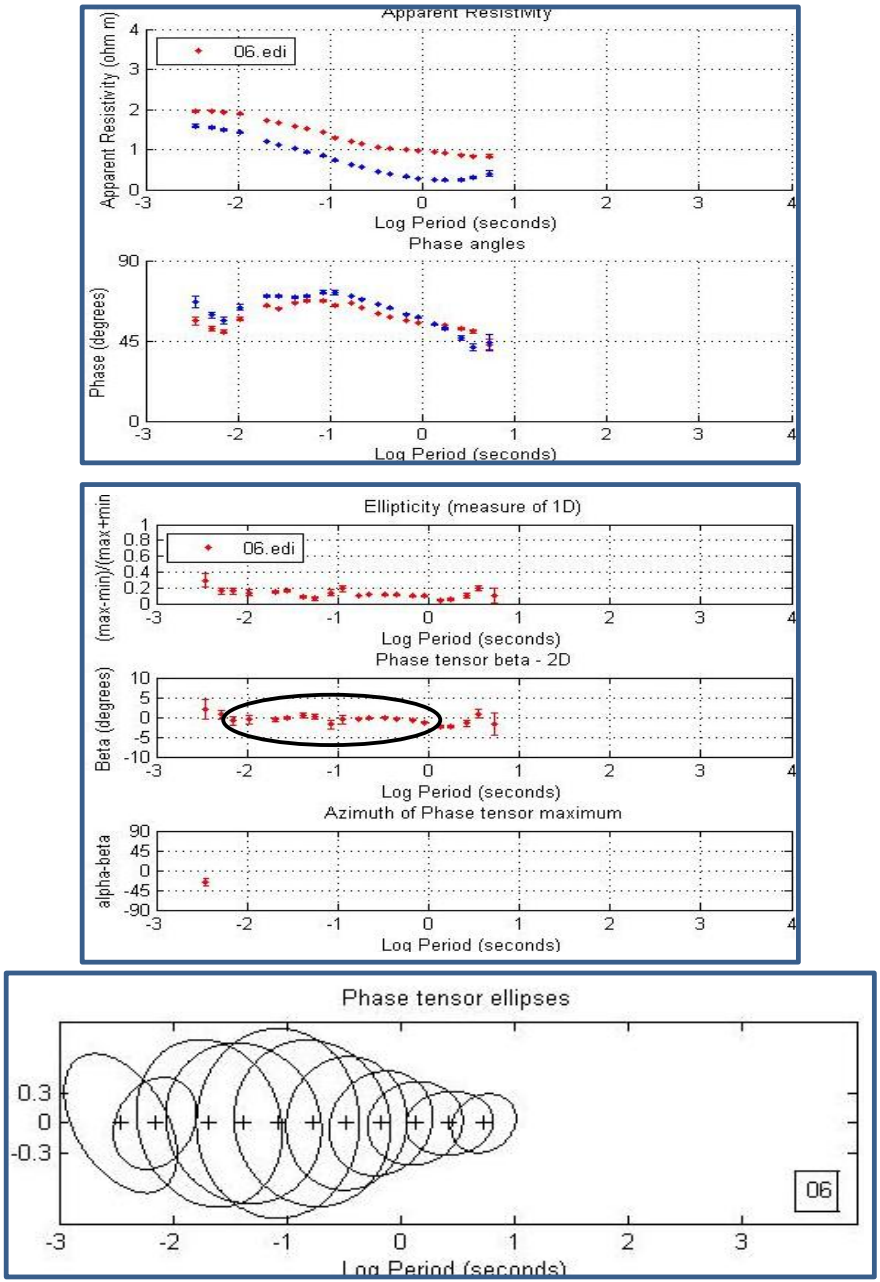

NNG-08
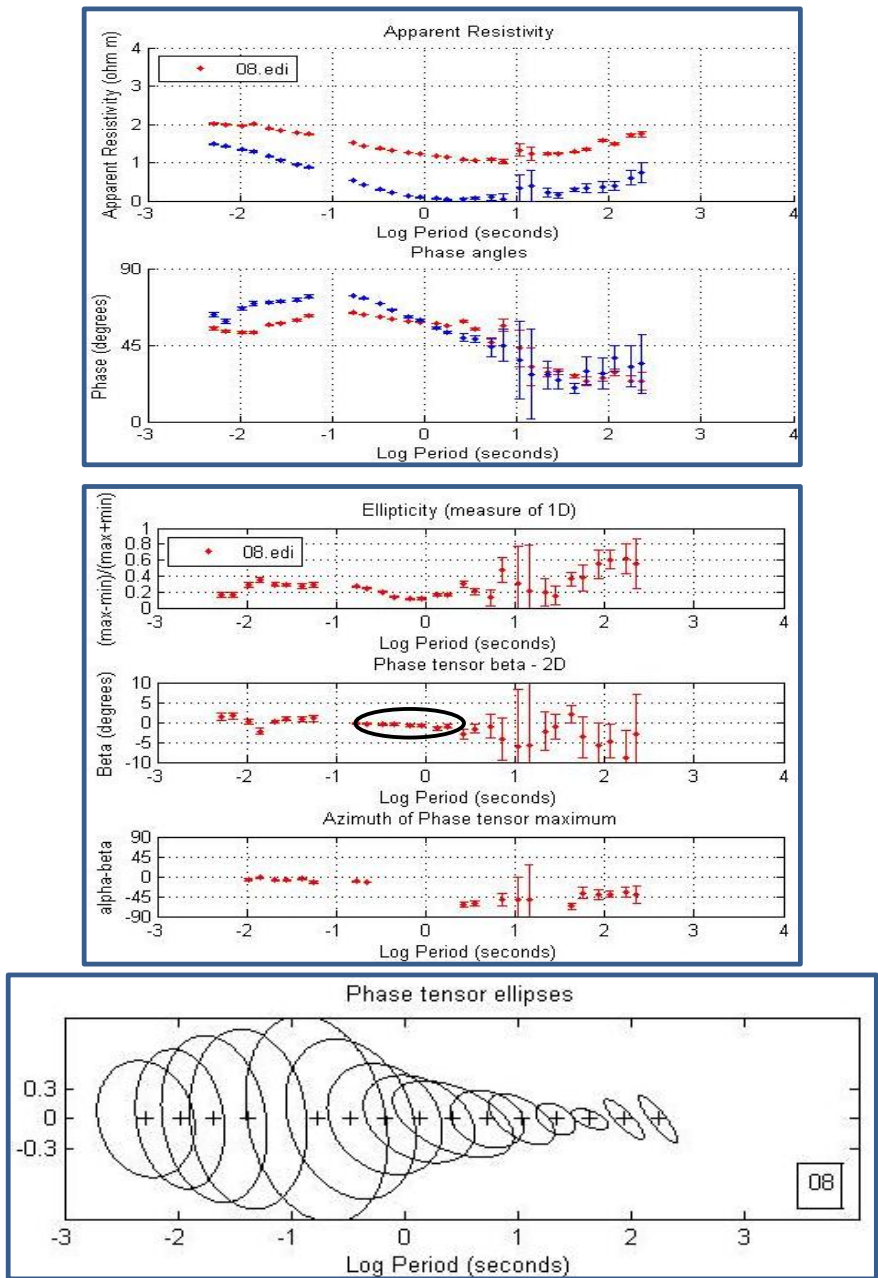
NNG-09
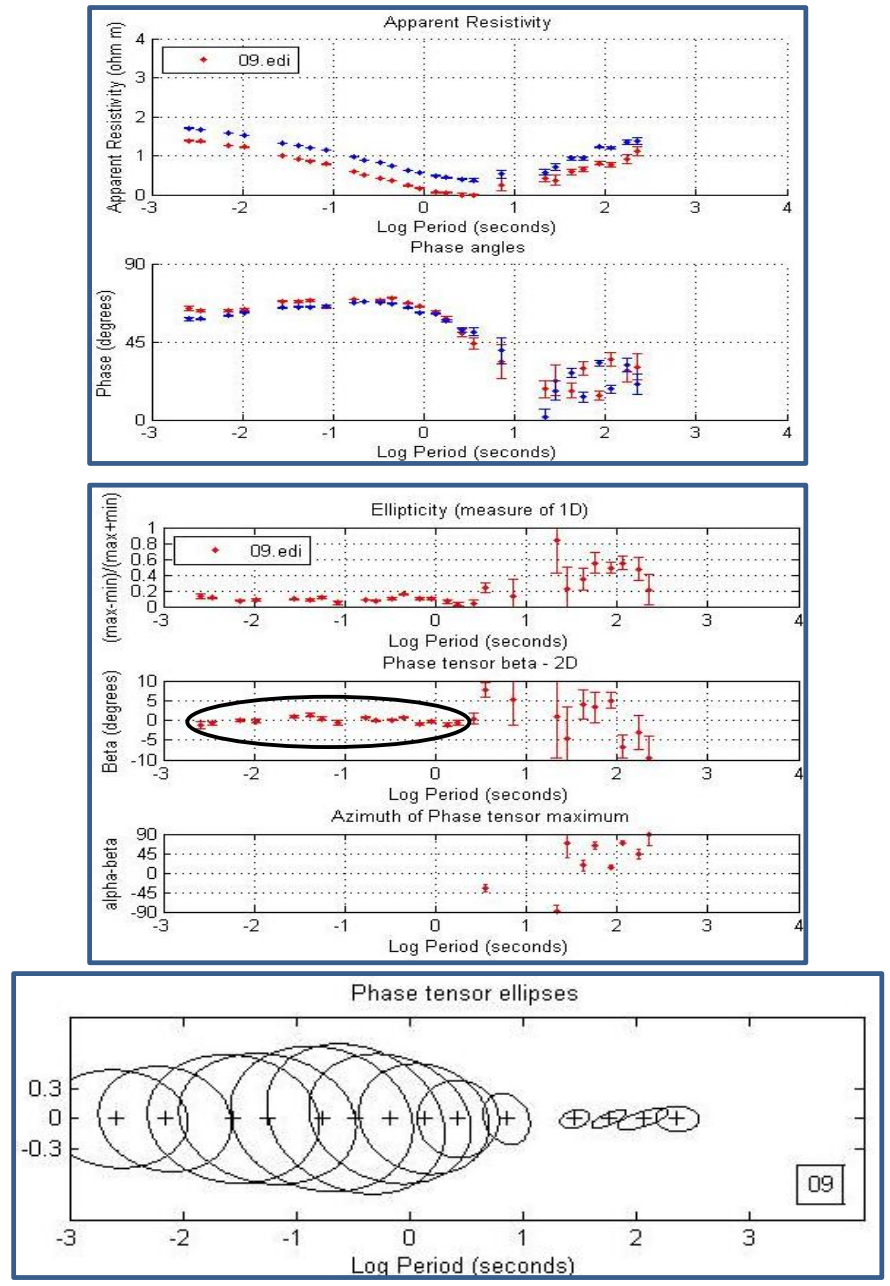

NNG-11
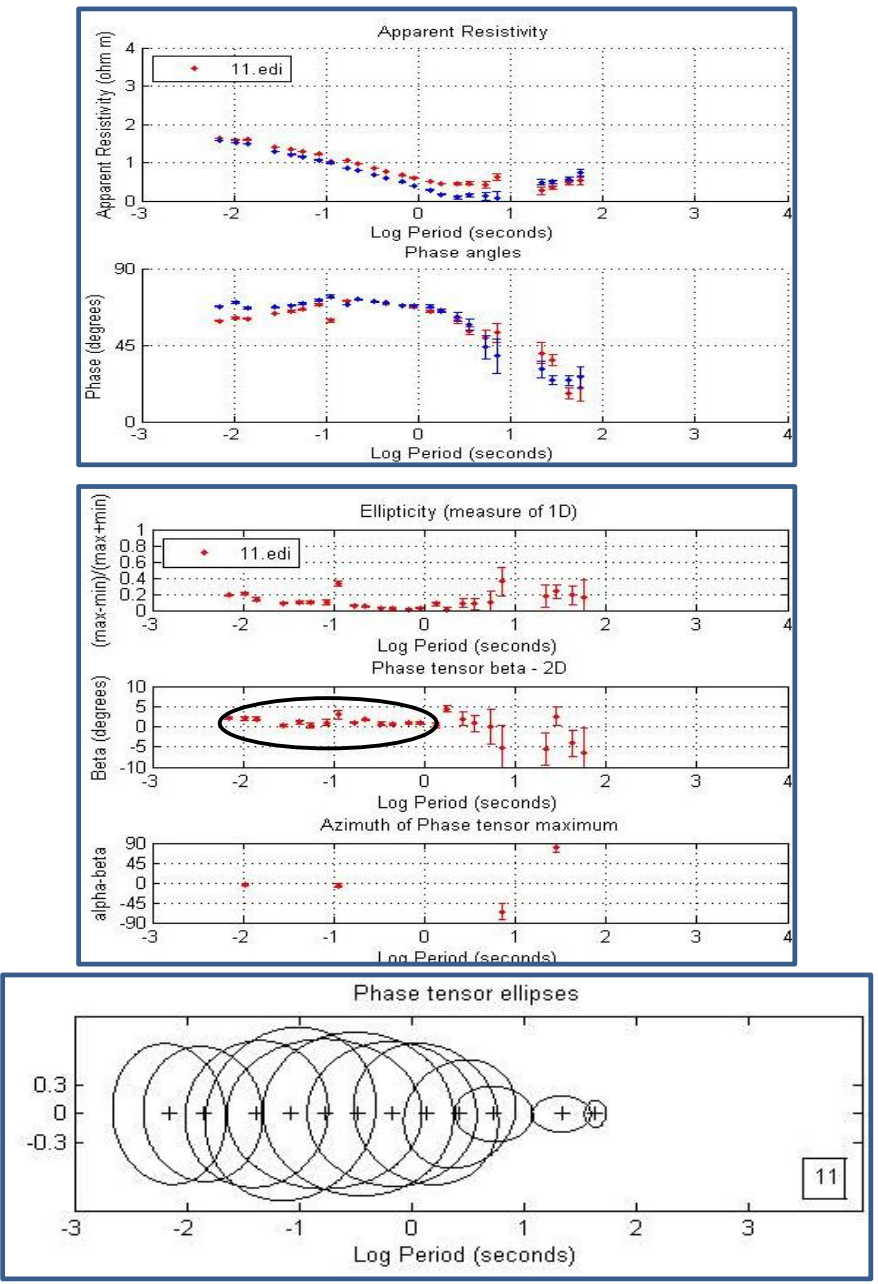

NNG-10
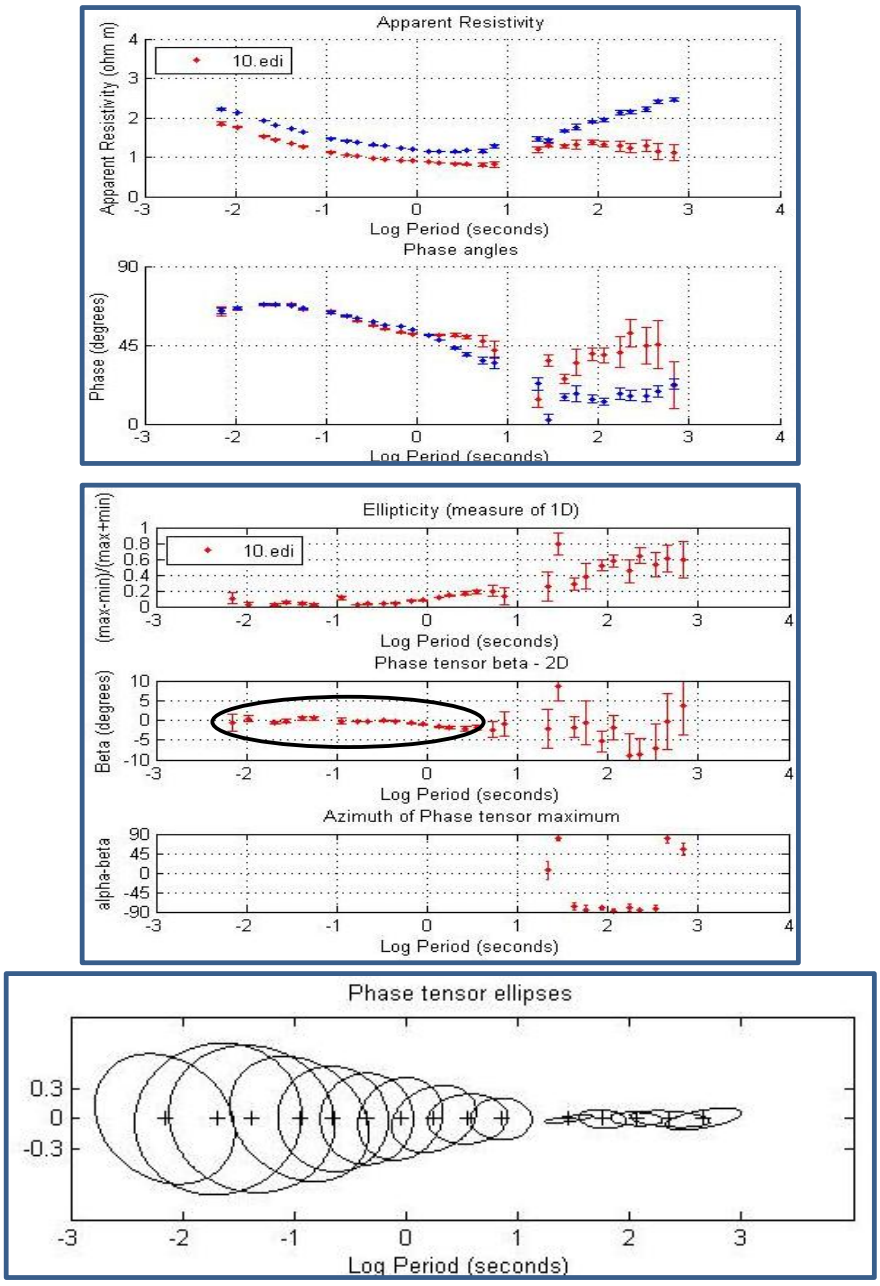

NNG-12
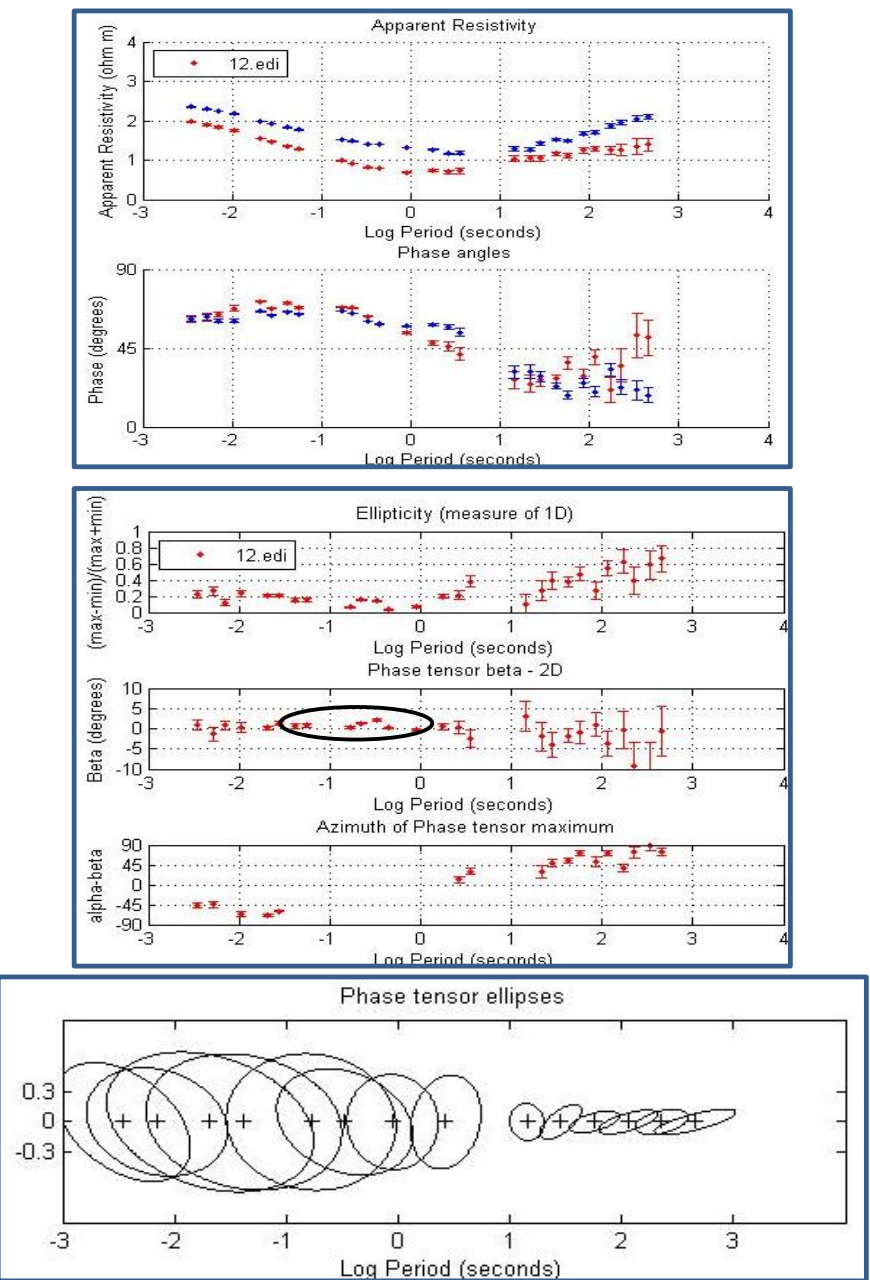
NNG-13
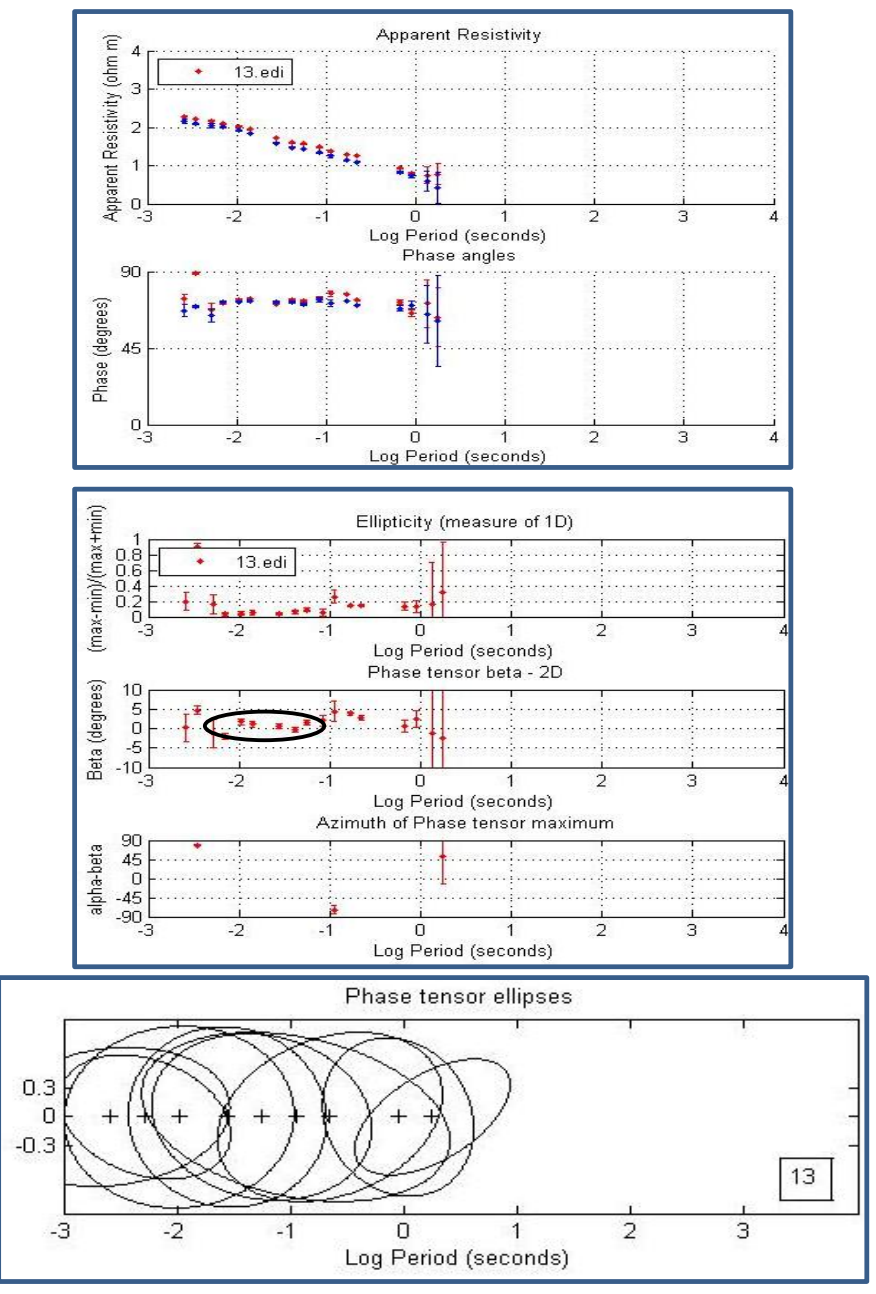

NNG-15
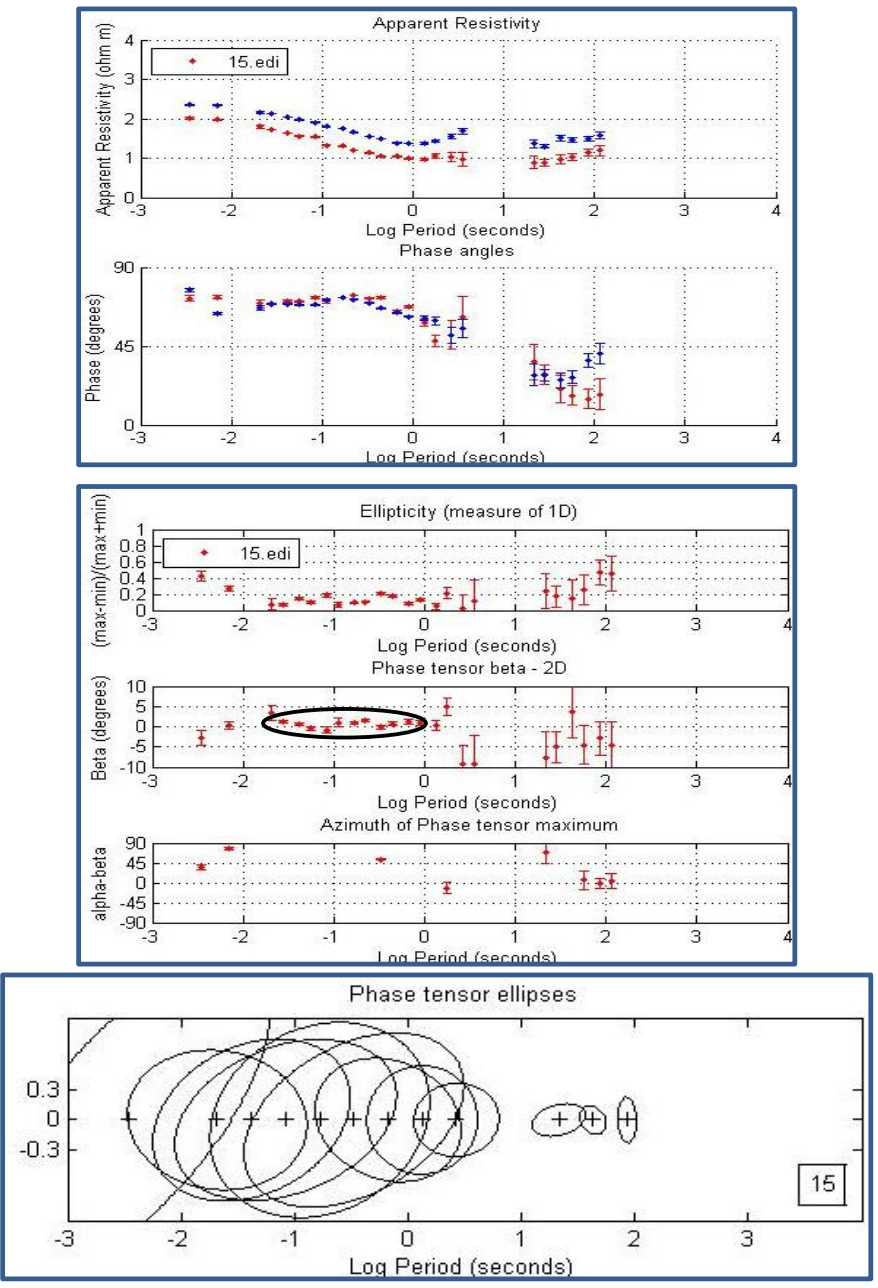

NNG-14
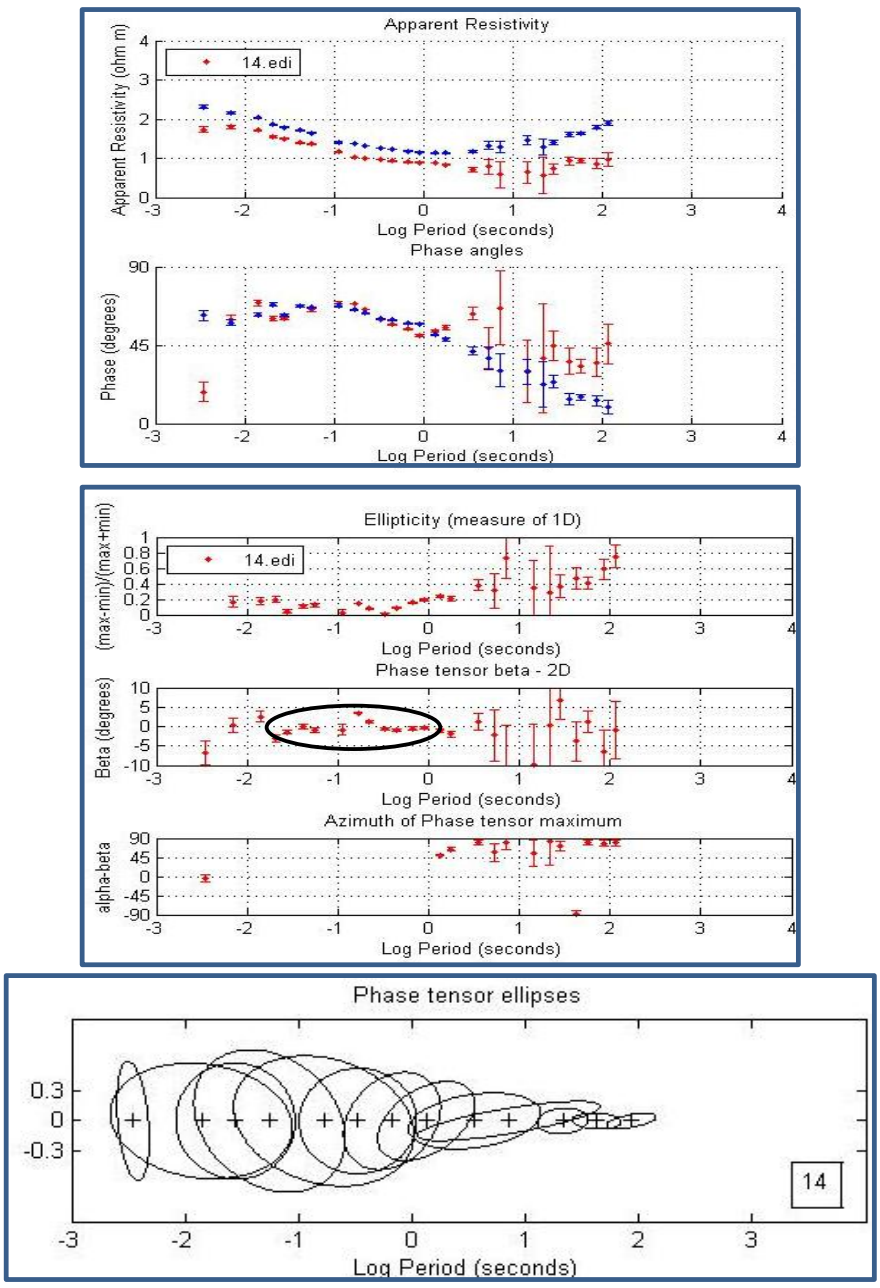

NNG-16
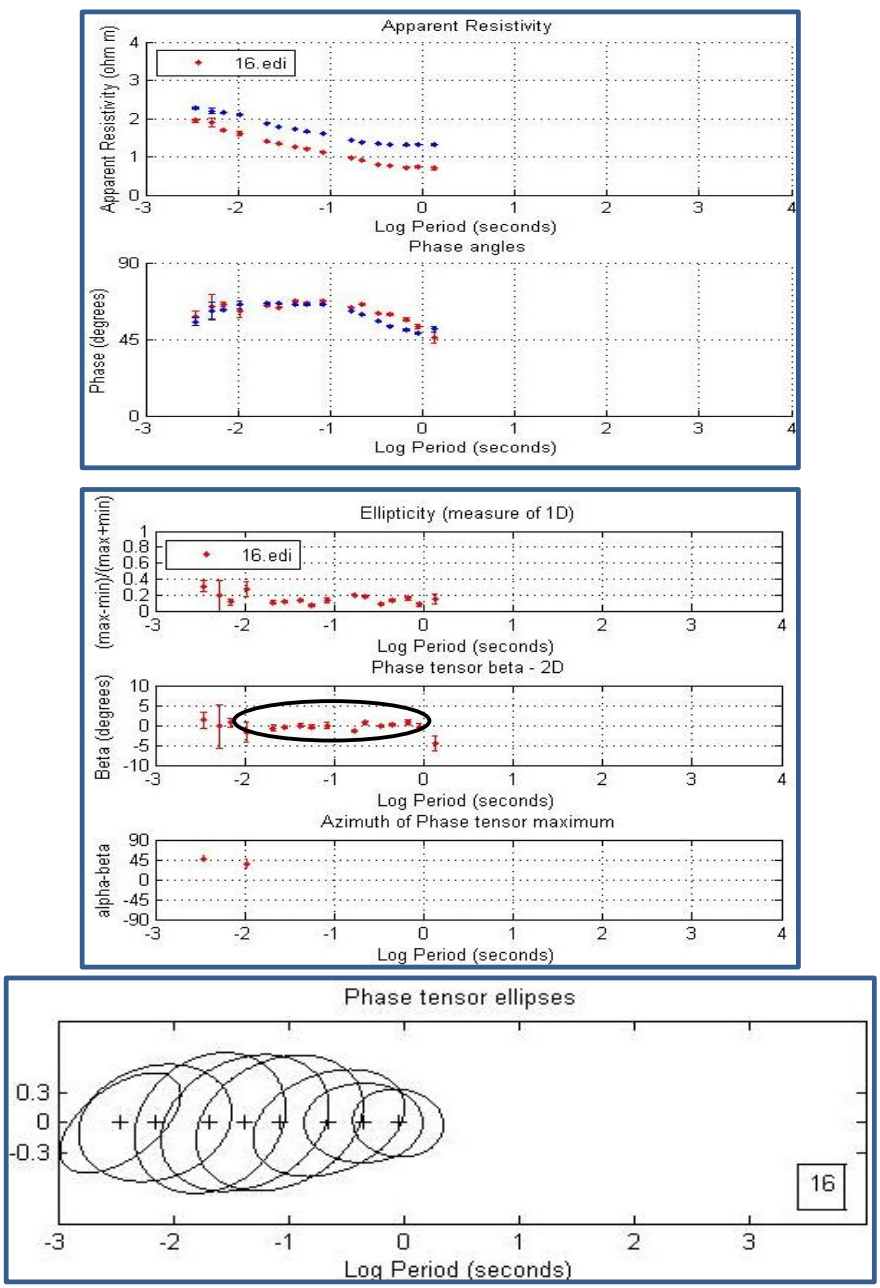
NNG-17
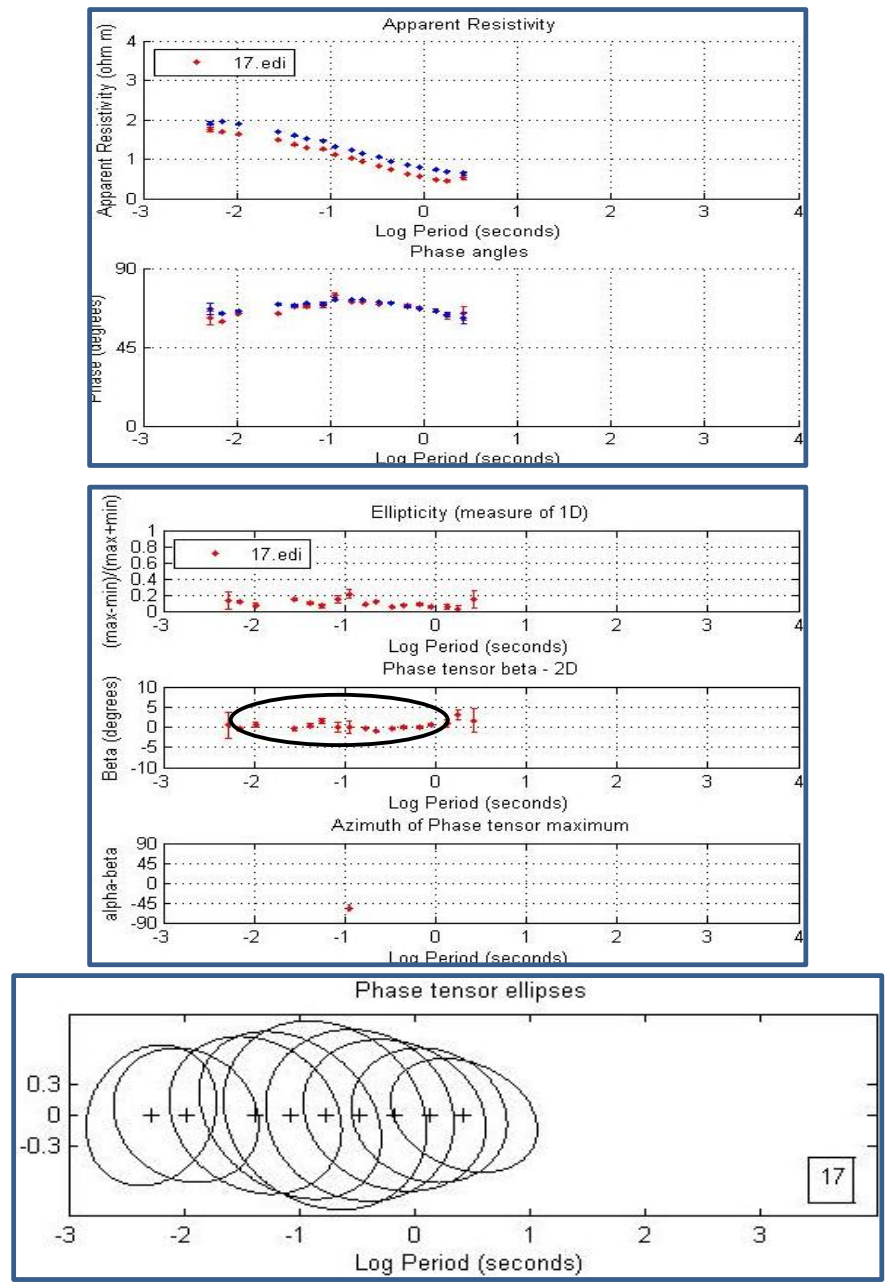

NNG-19
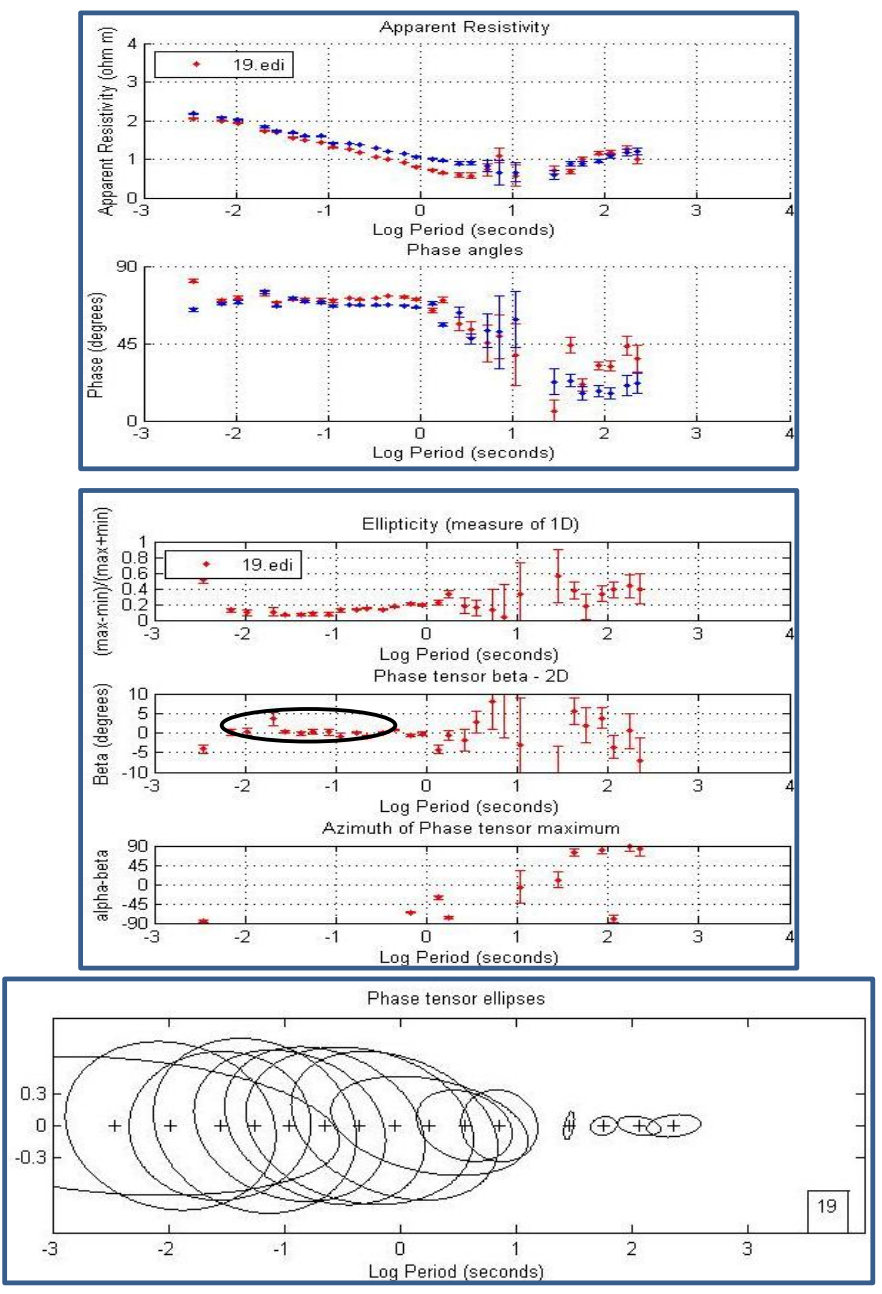

NNG-18
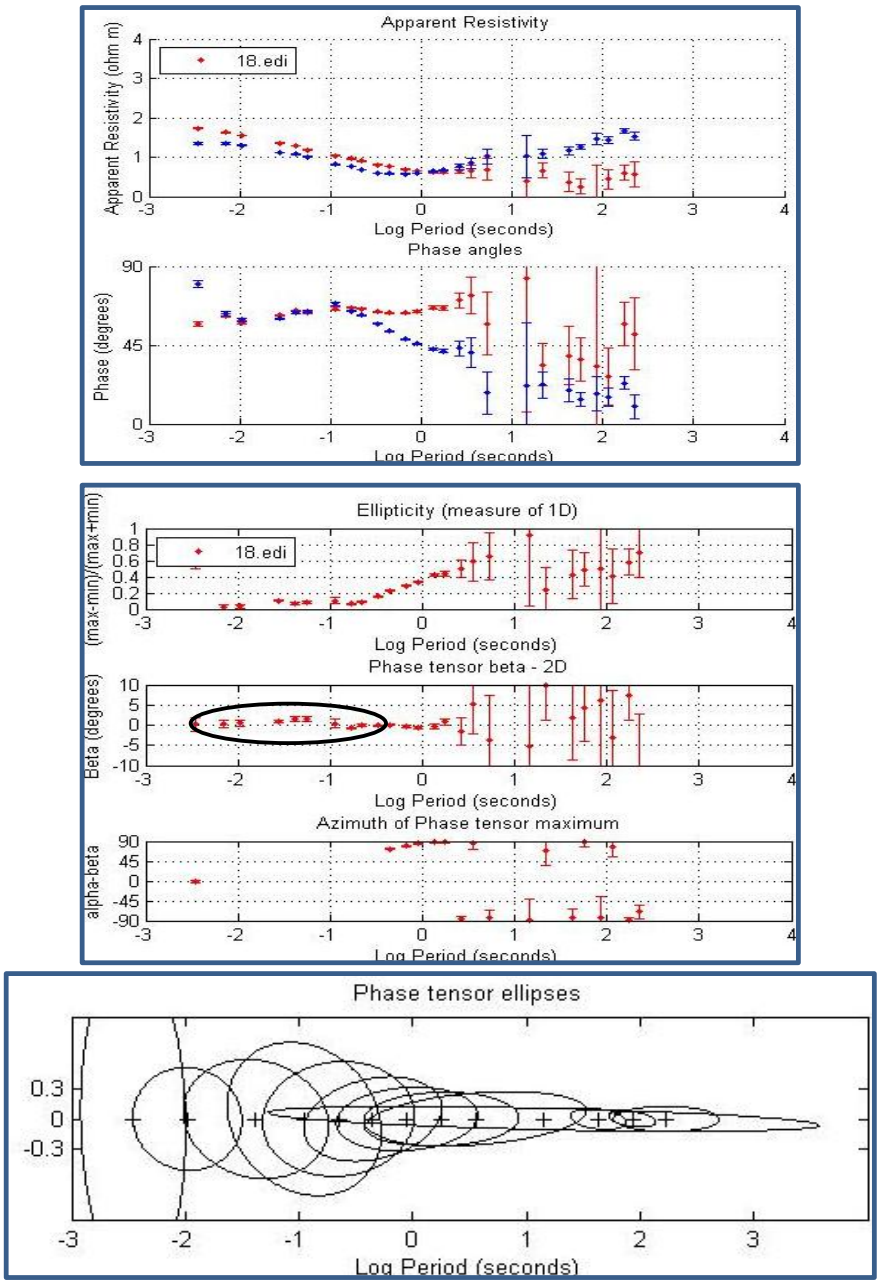

NNG-20
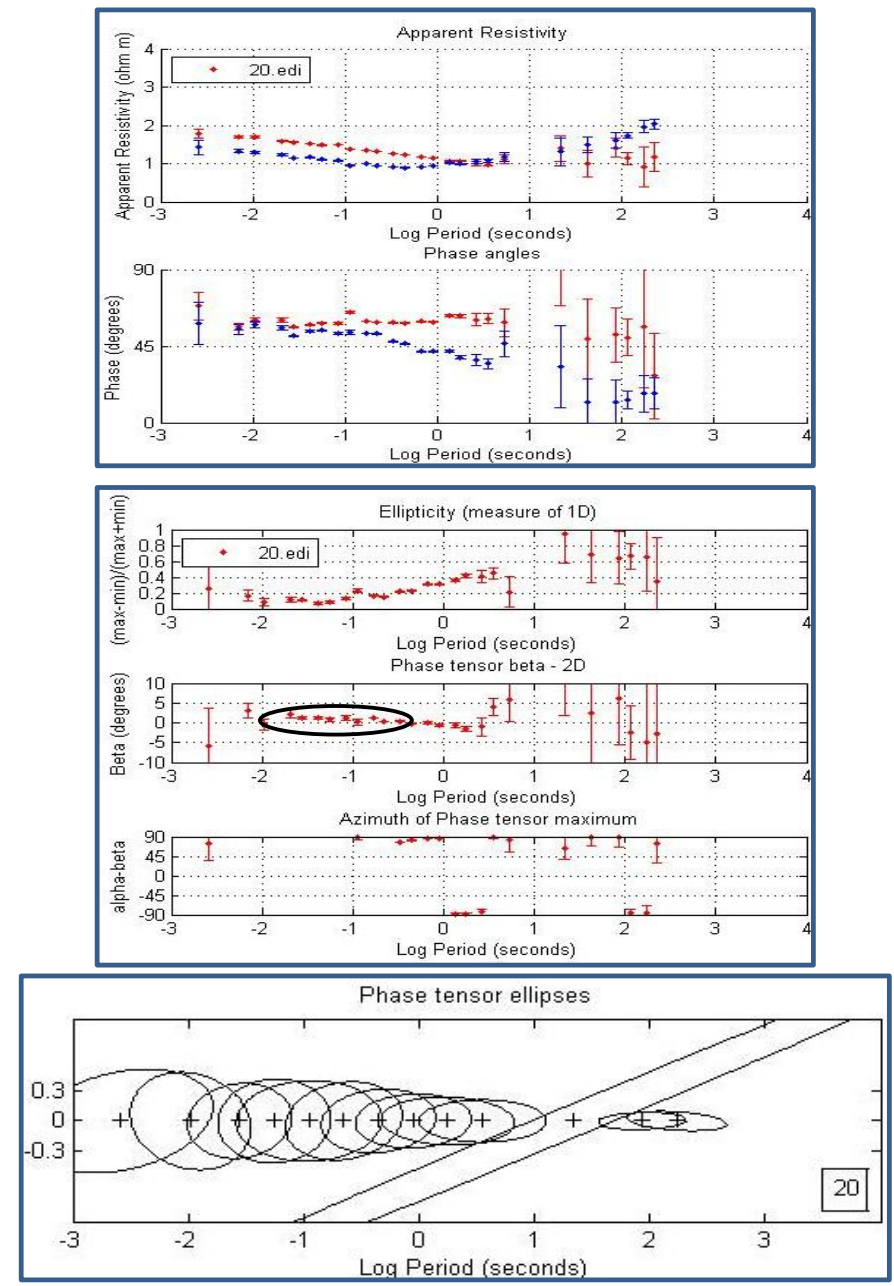
NNG-21
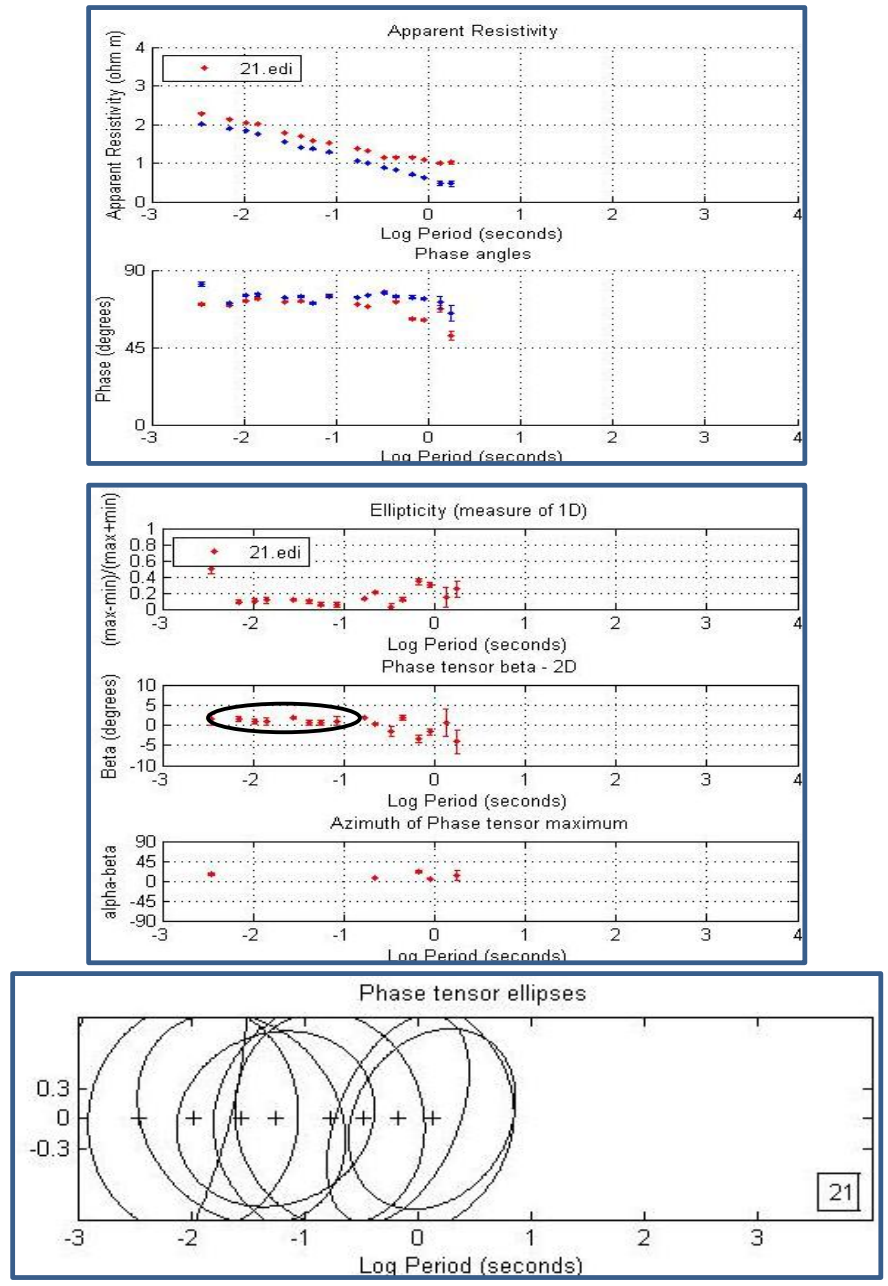

NNG-23
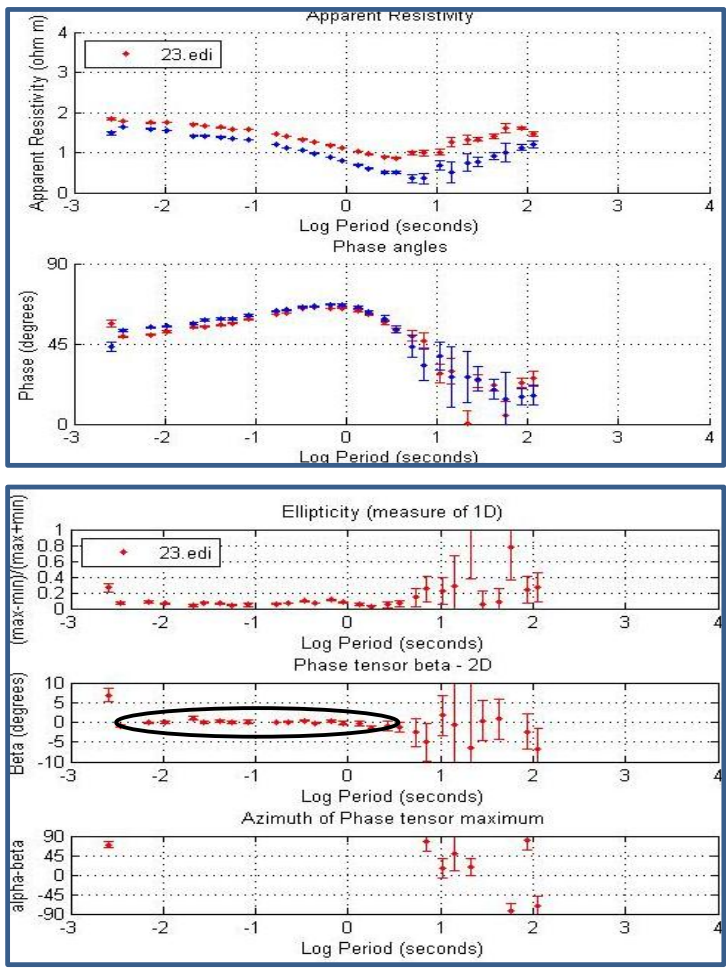

Phase tensor ellipses

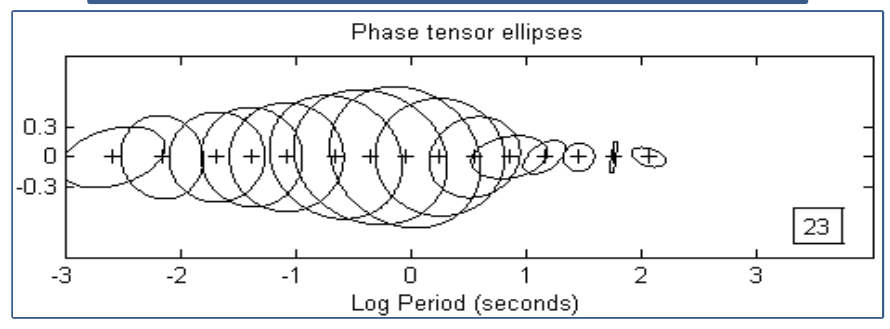

NNG-22
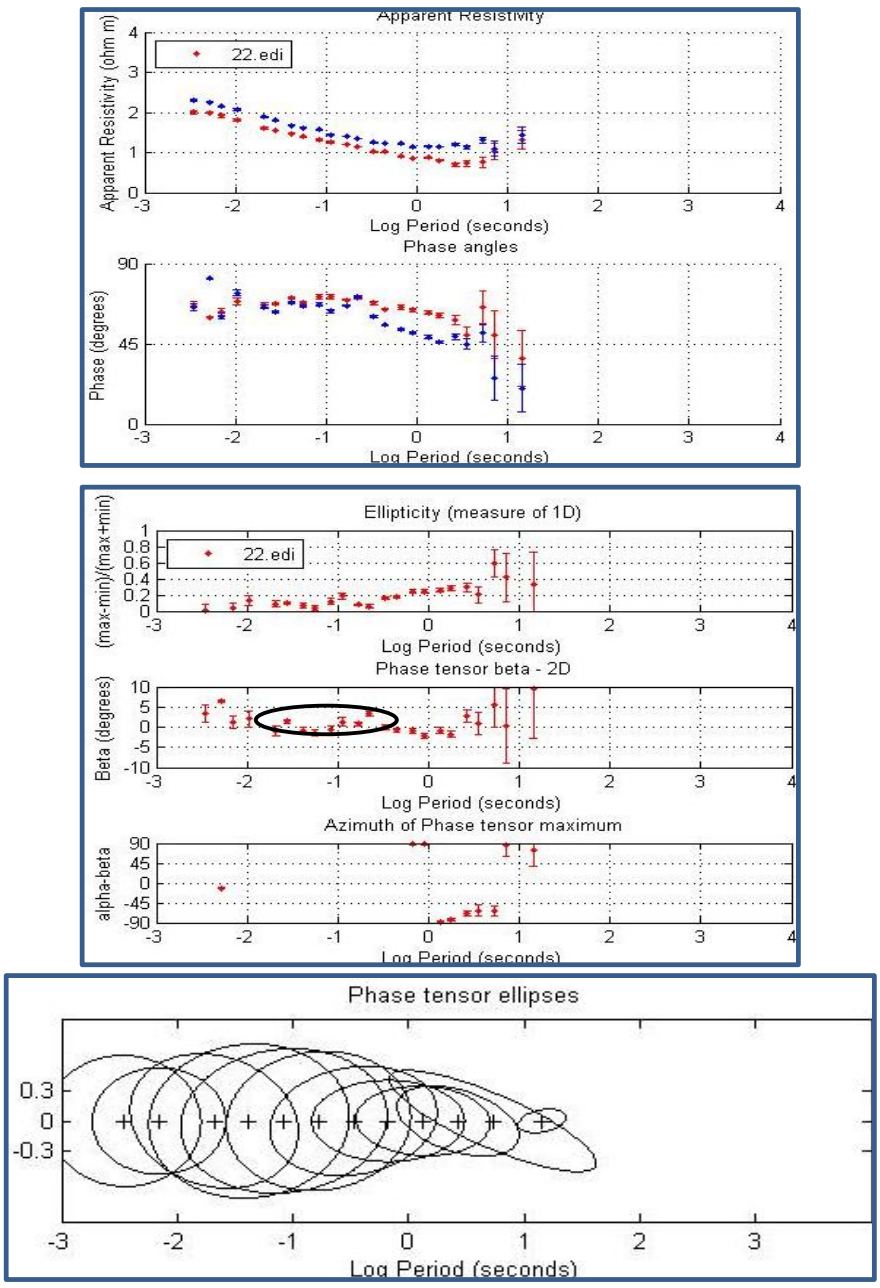

NNG-24
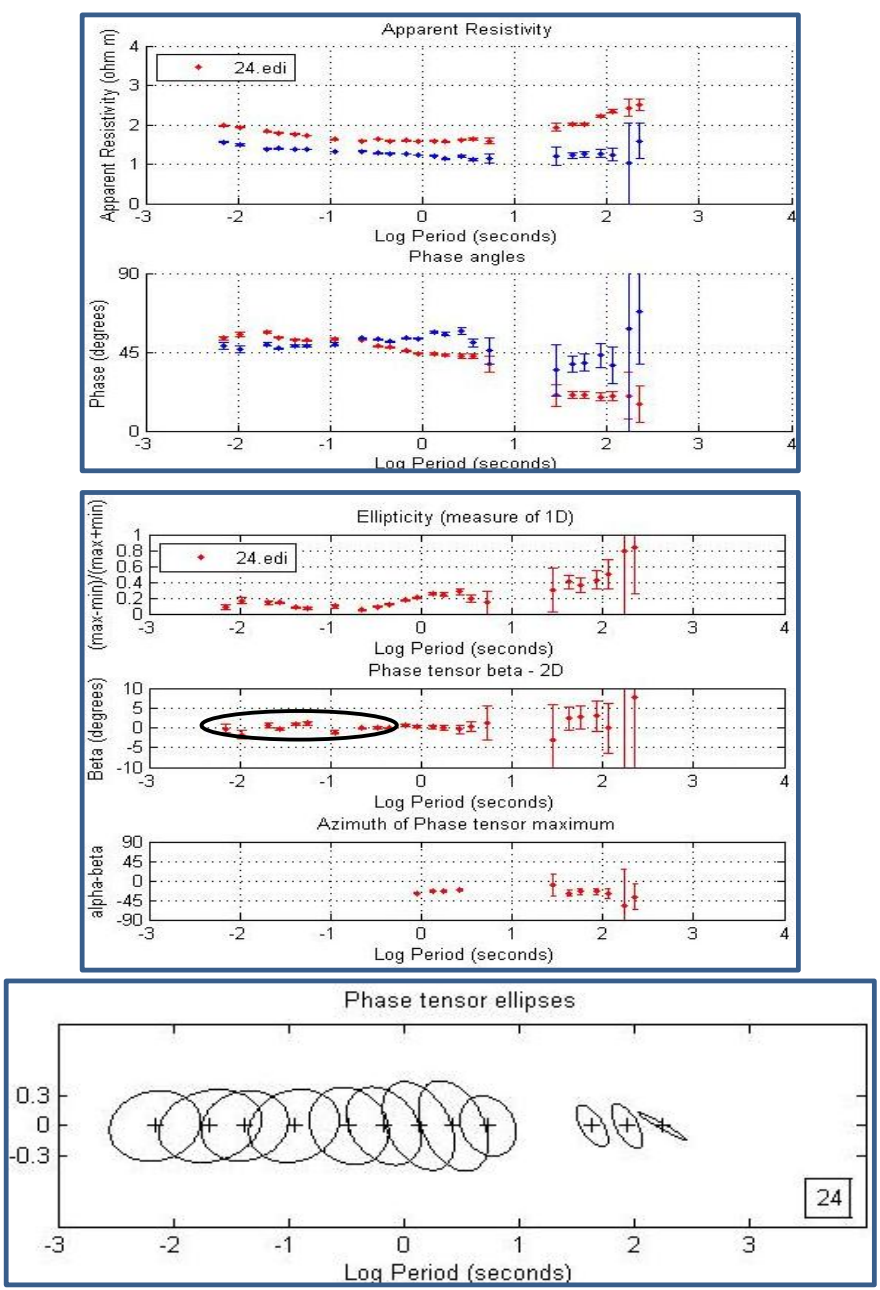
NNG-25
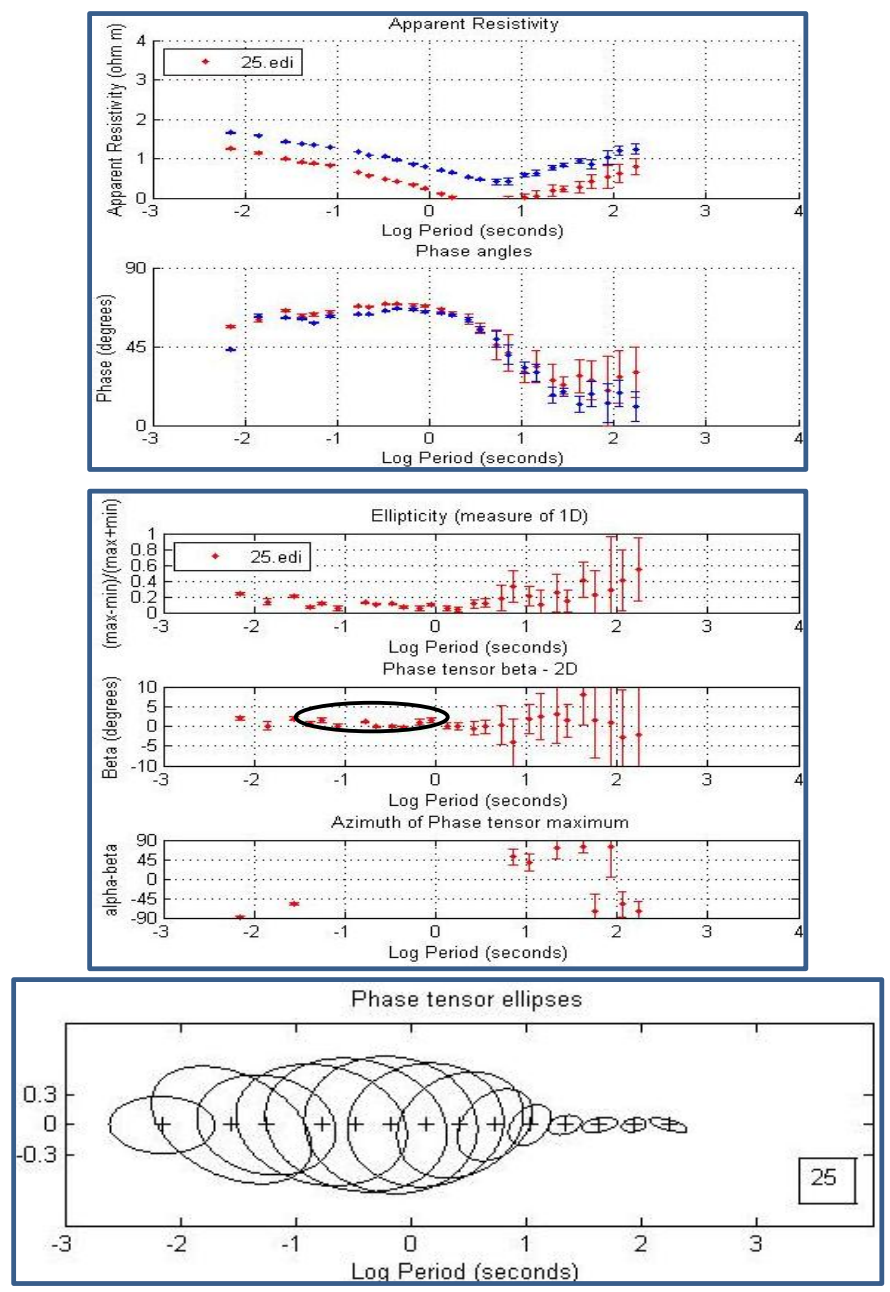

NNG-27
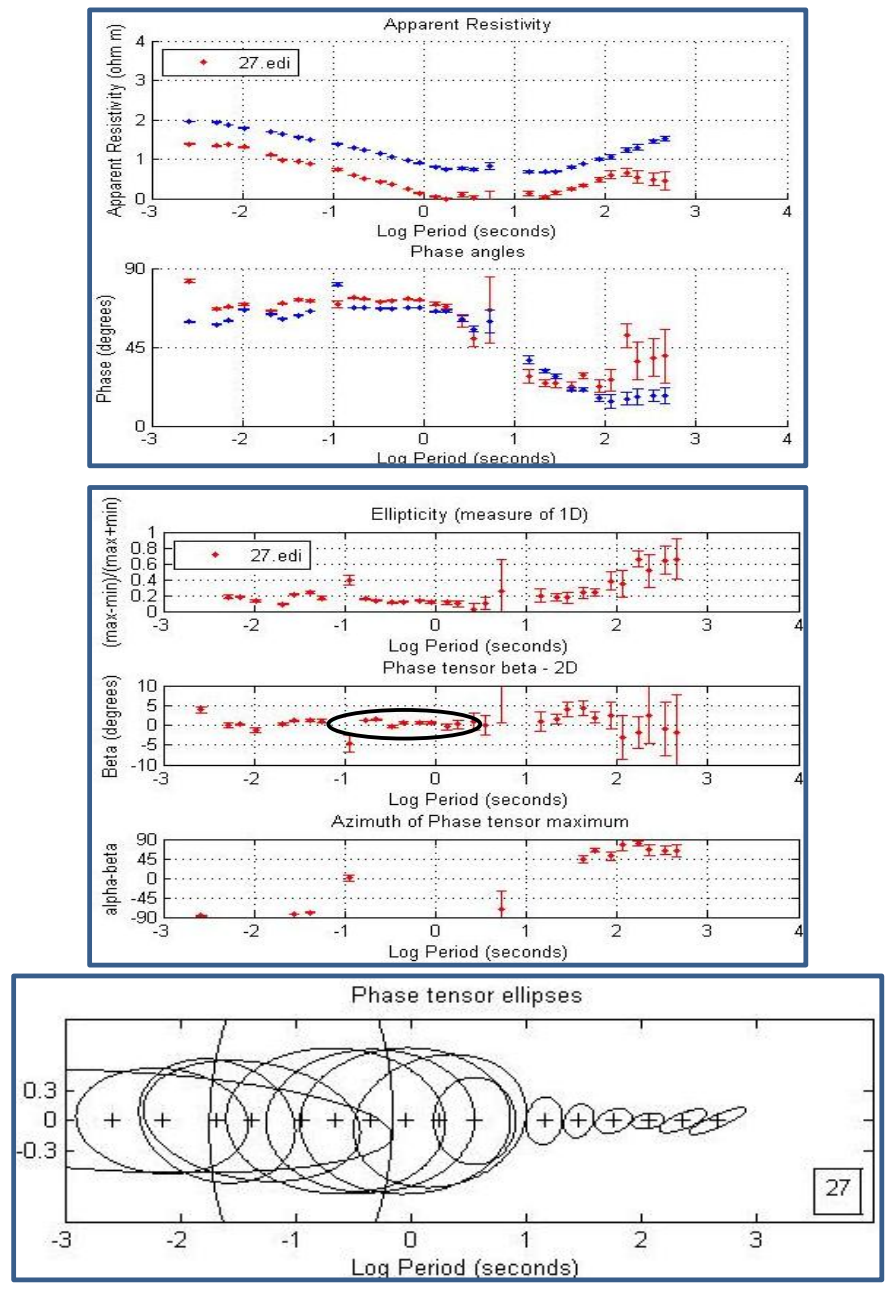

NNG-26
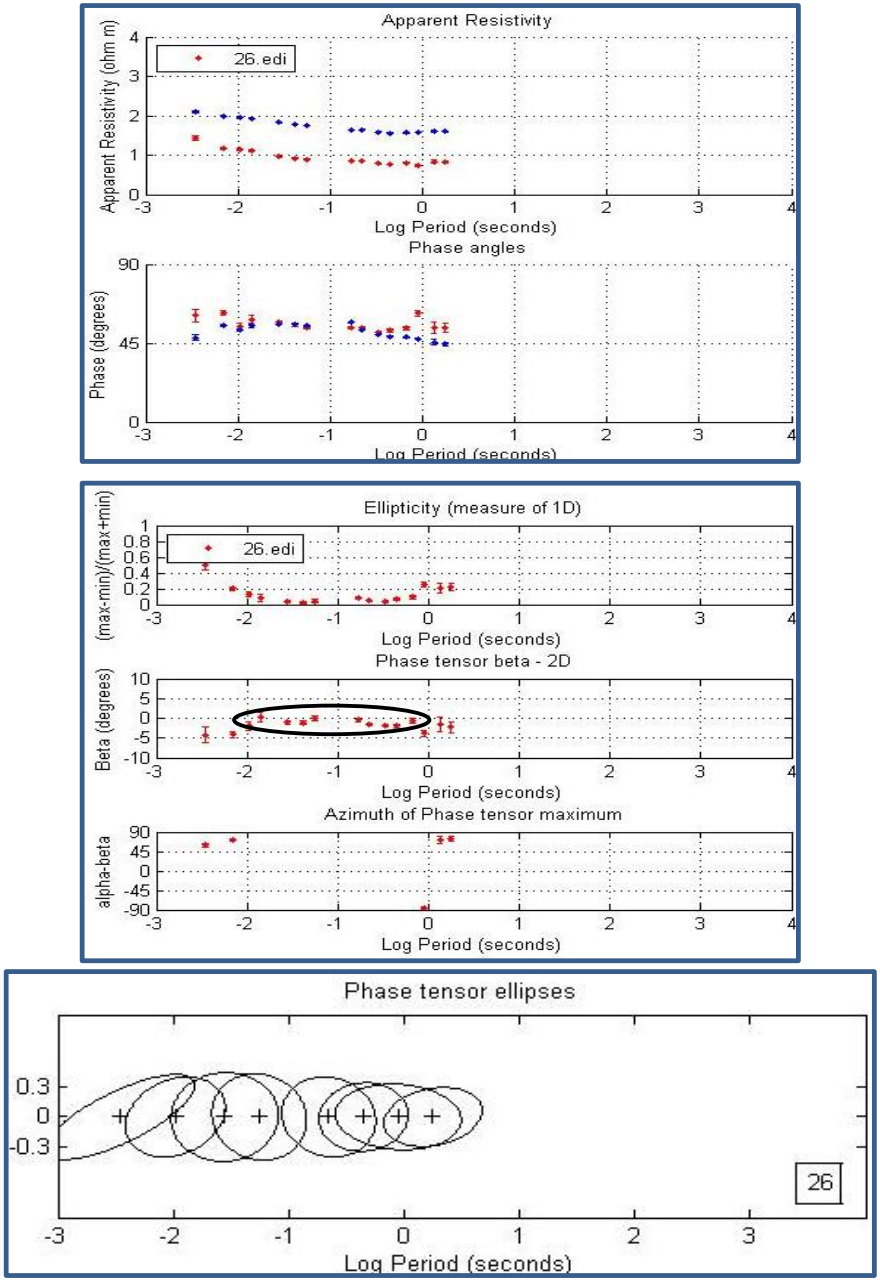

NNG-28
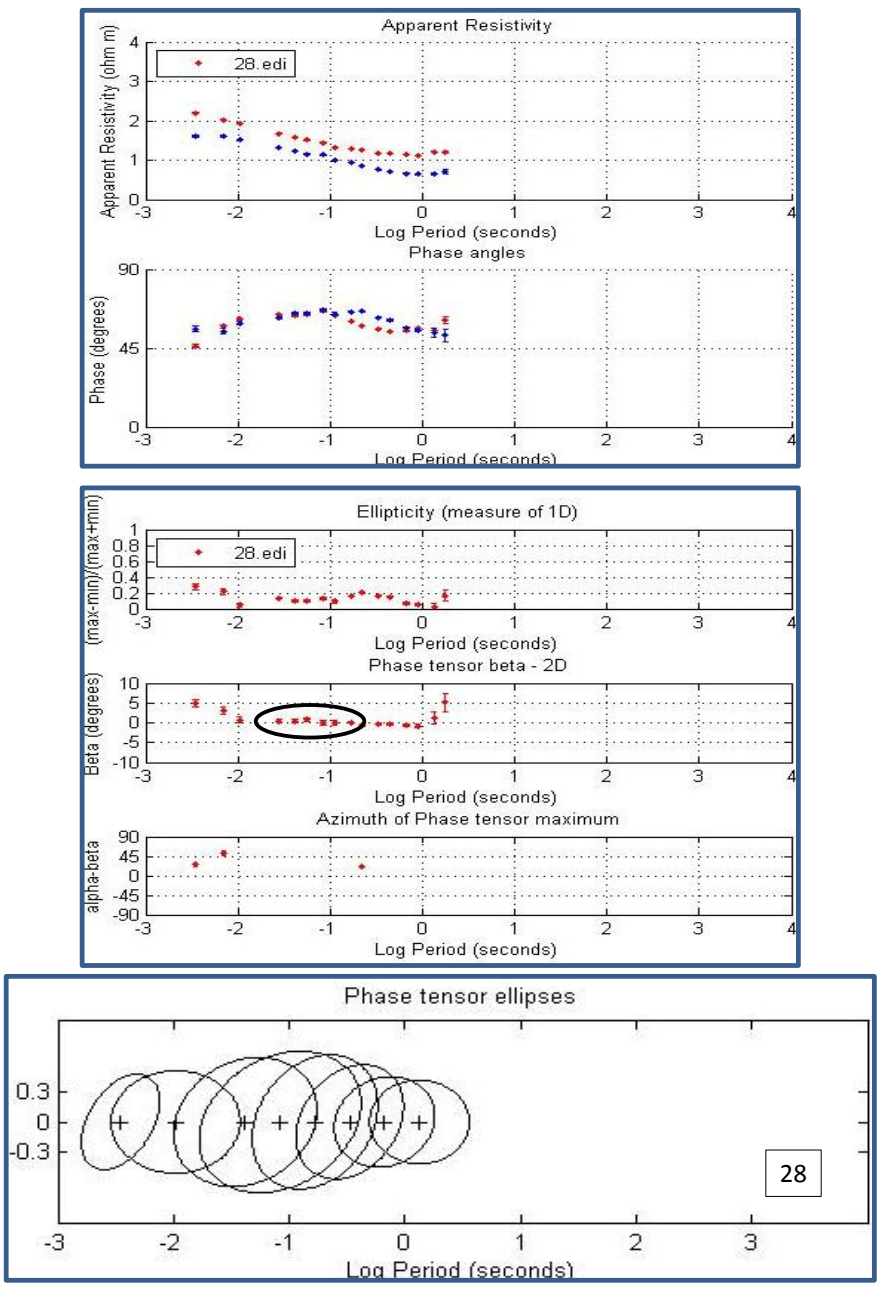
NNG-29
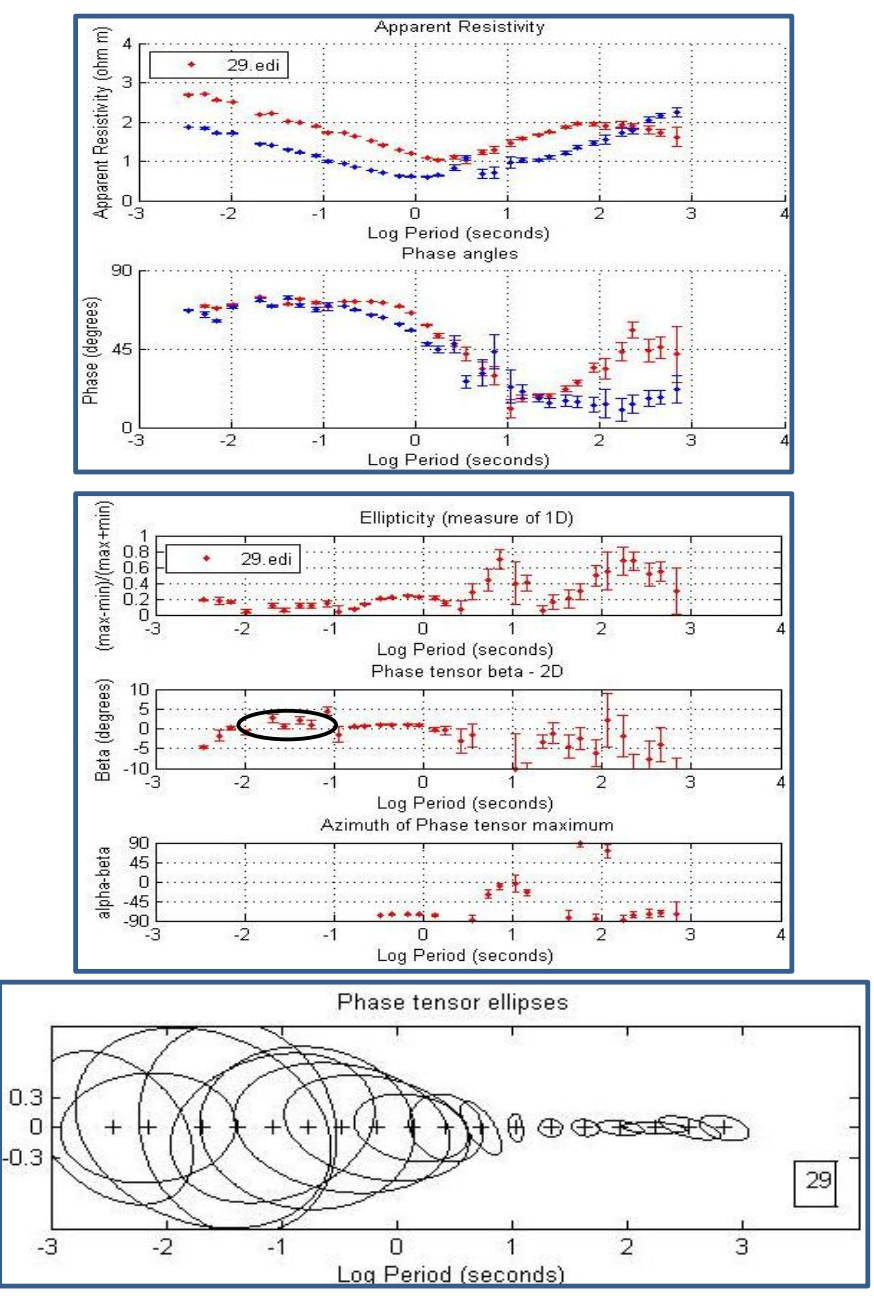

NNG-31
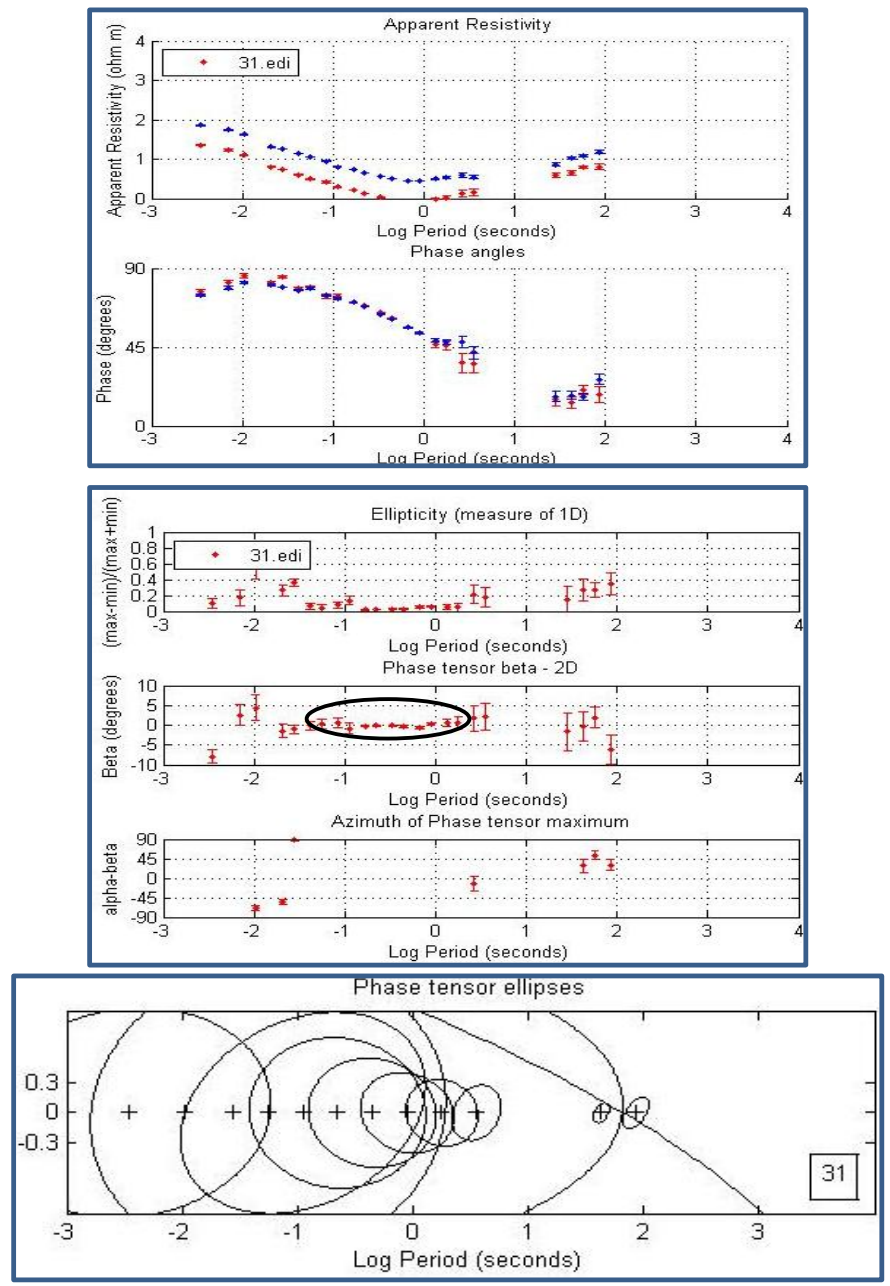

NNG-30
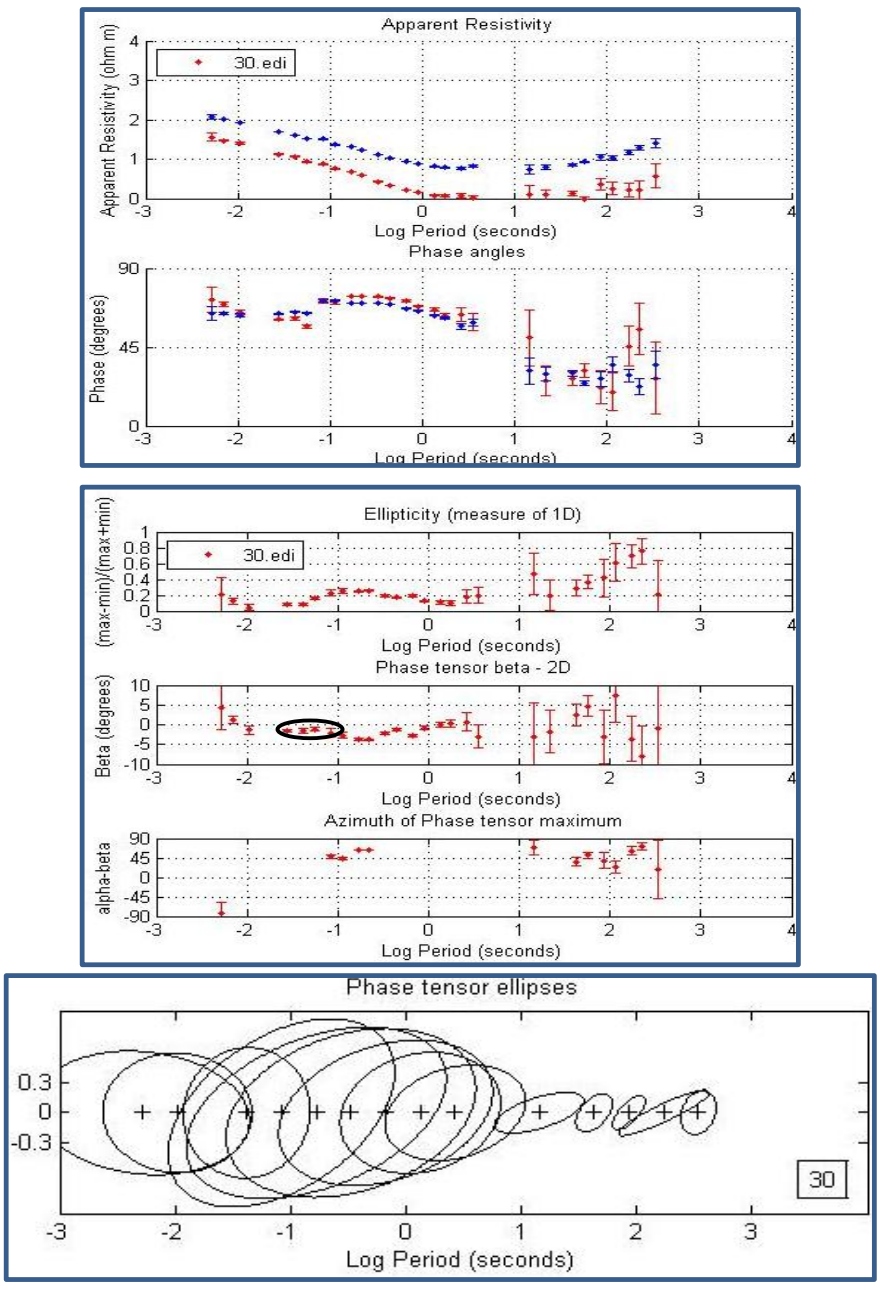

NNG-32
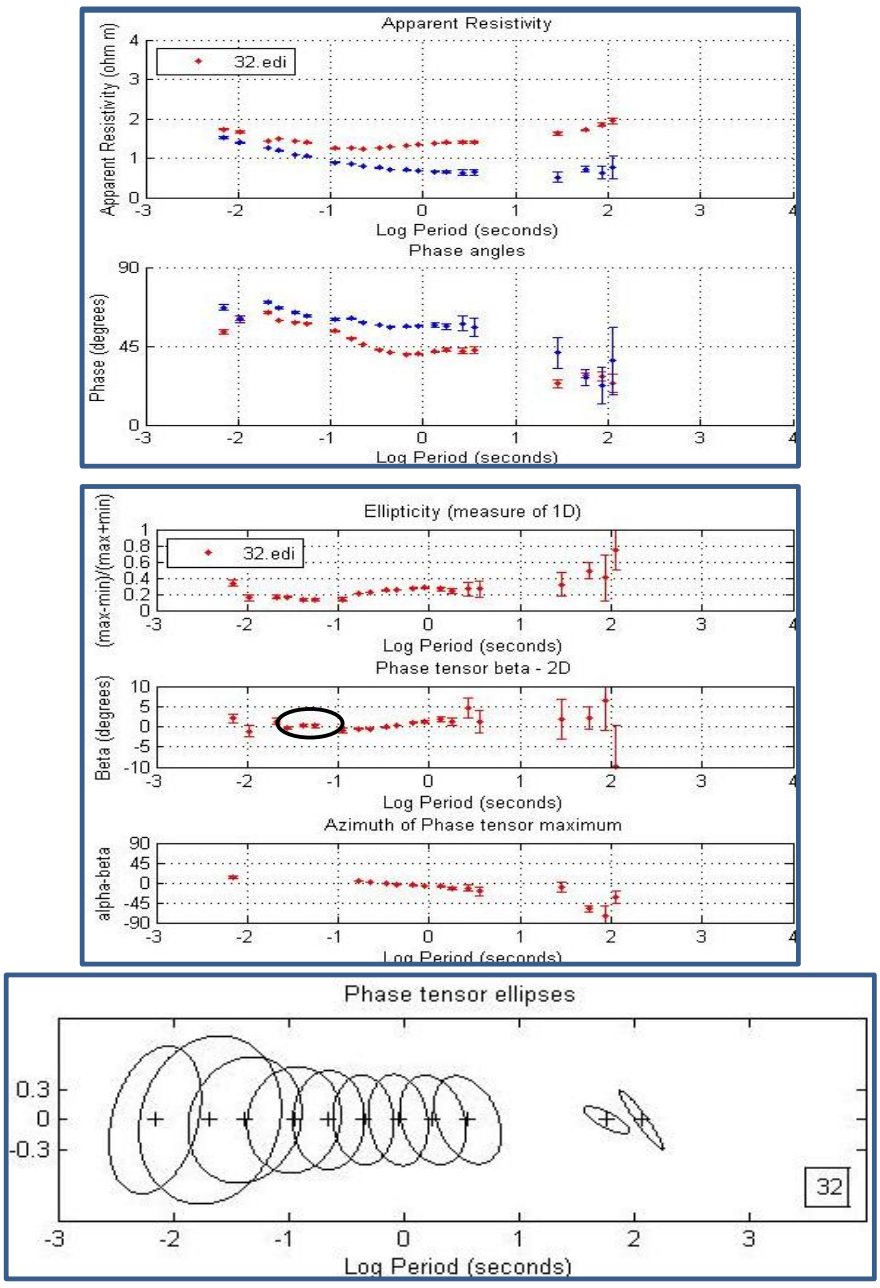
NNG-33
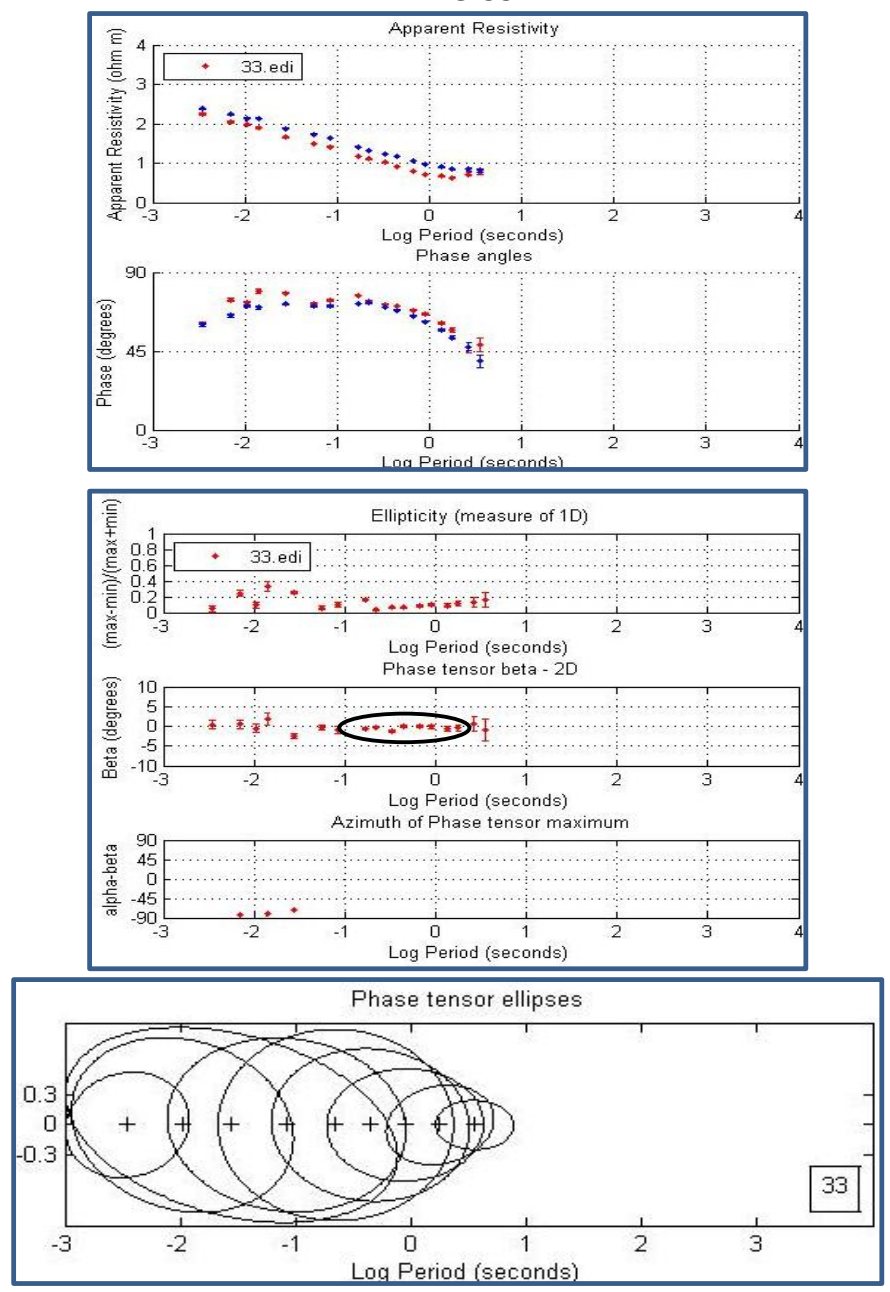

NNG-35
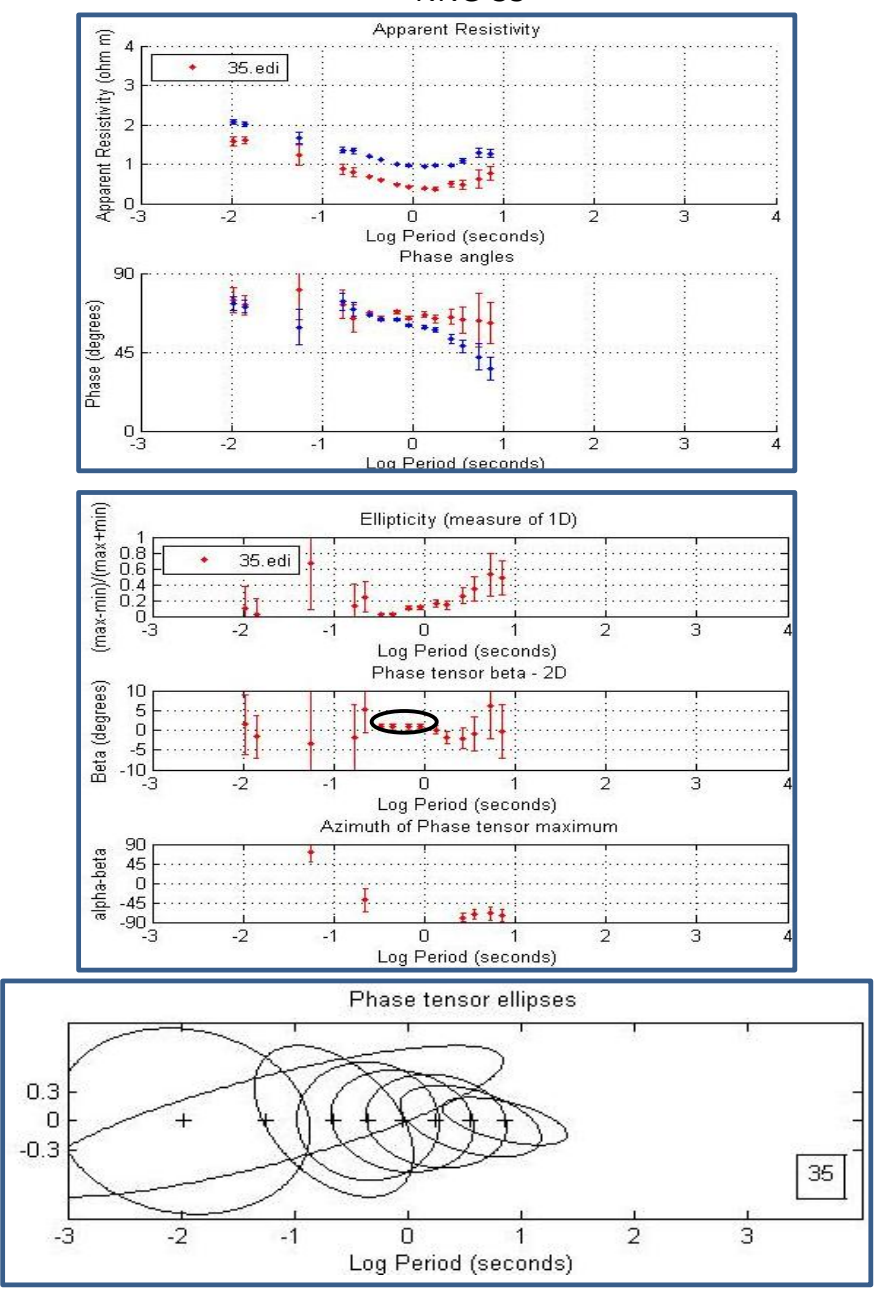

NNG-34
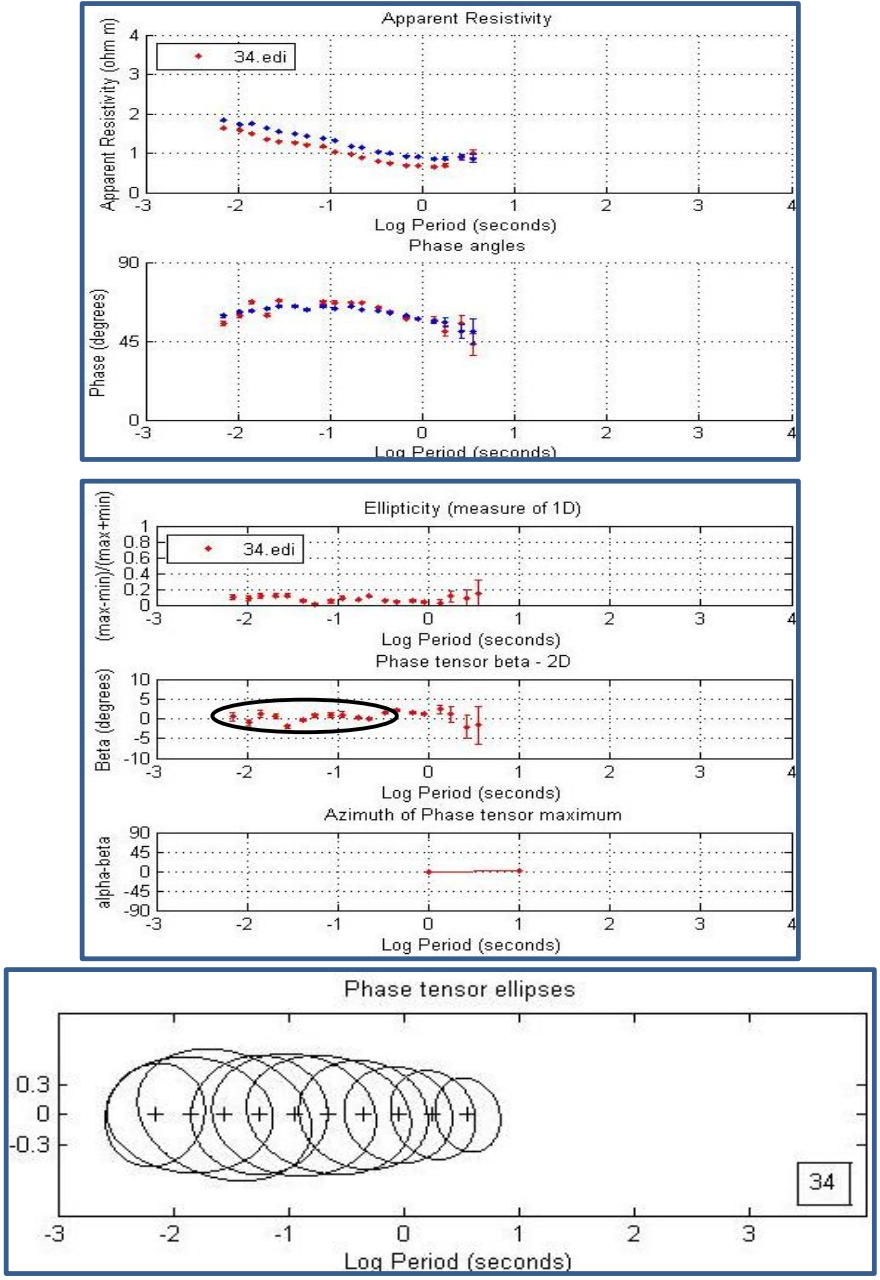

NNG-37
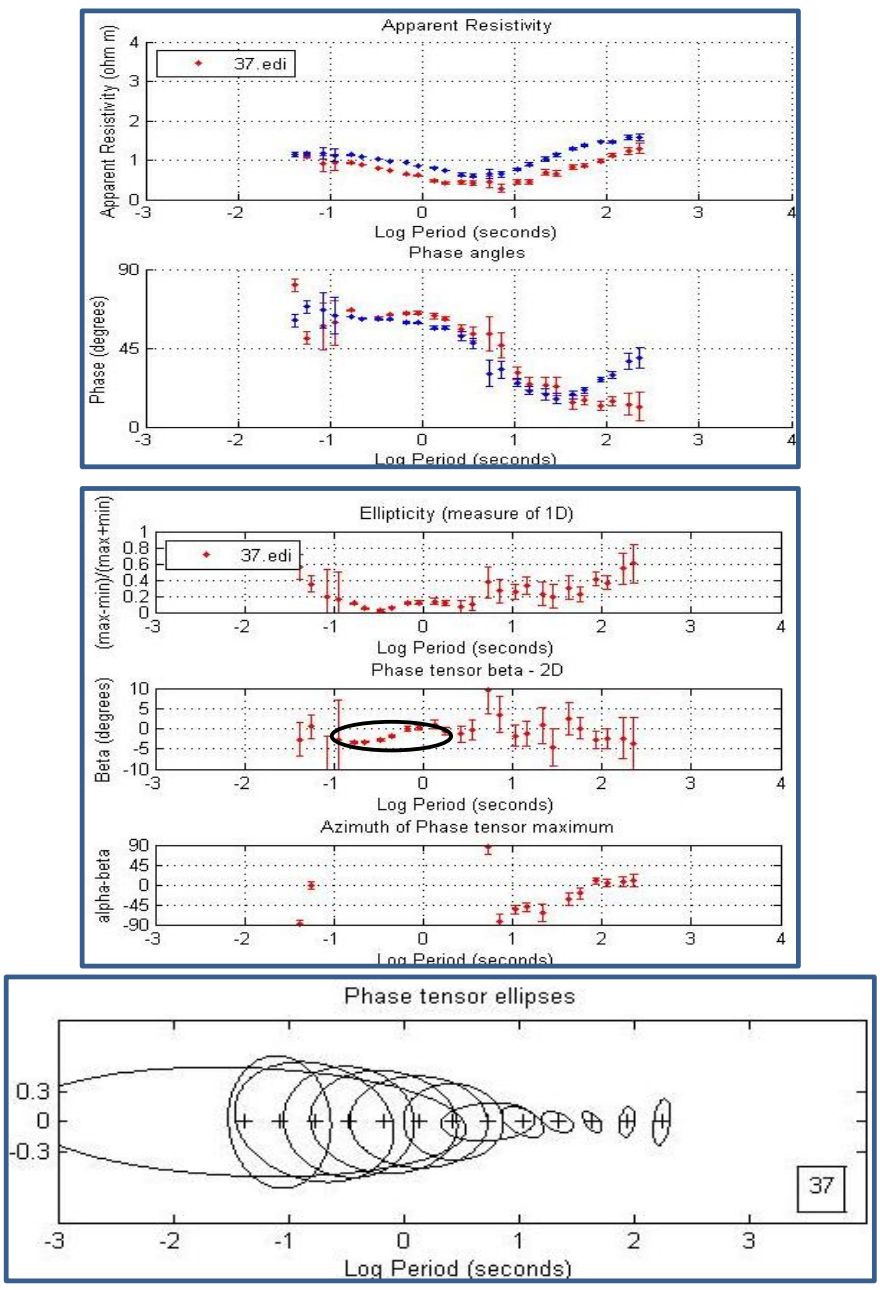
NNG-39
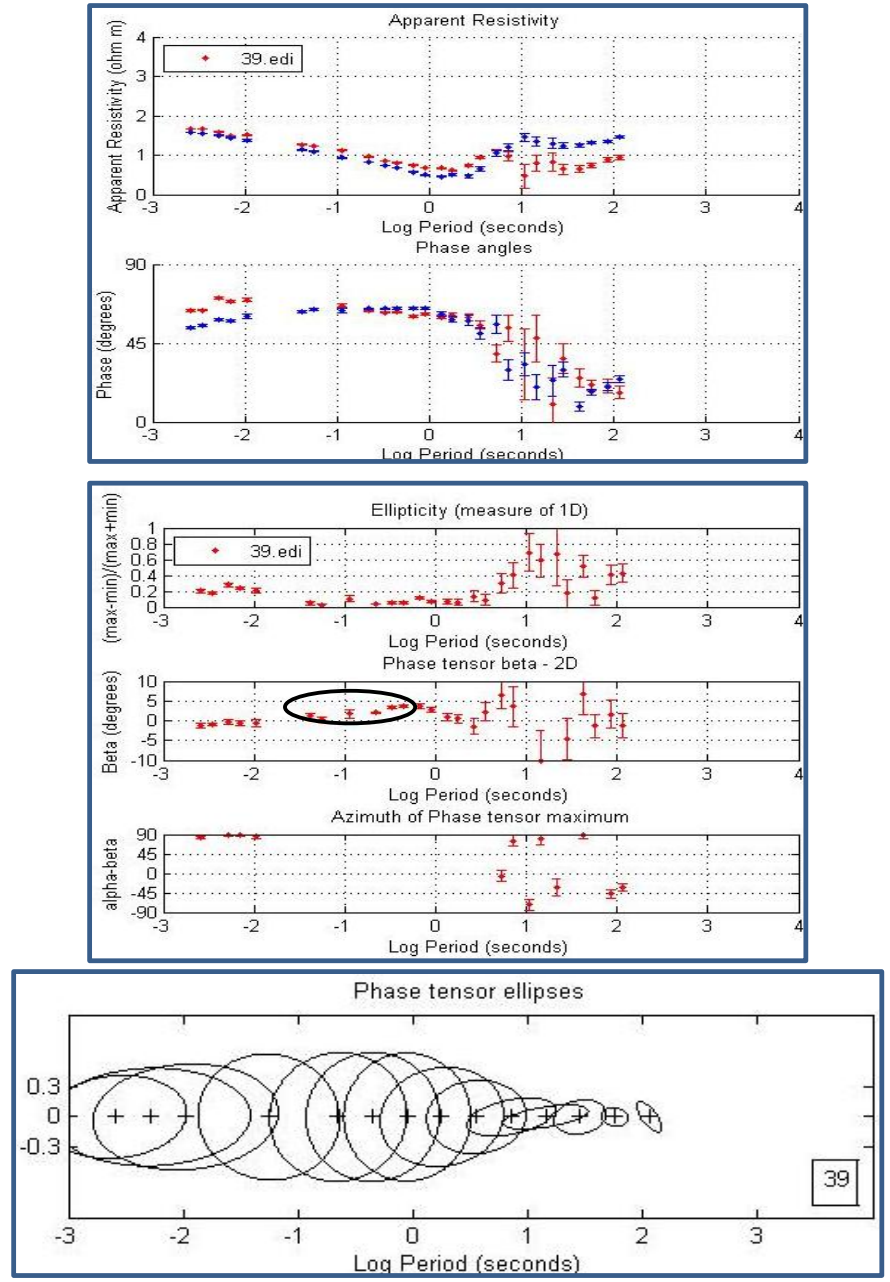

NNG-42
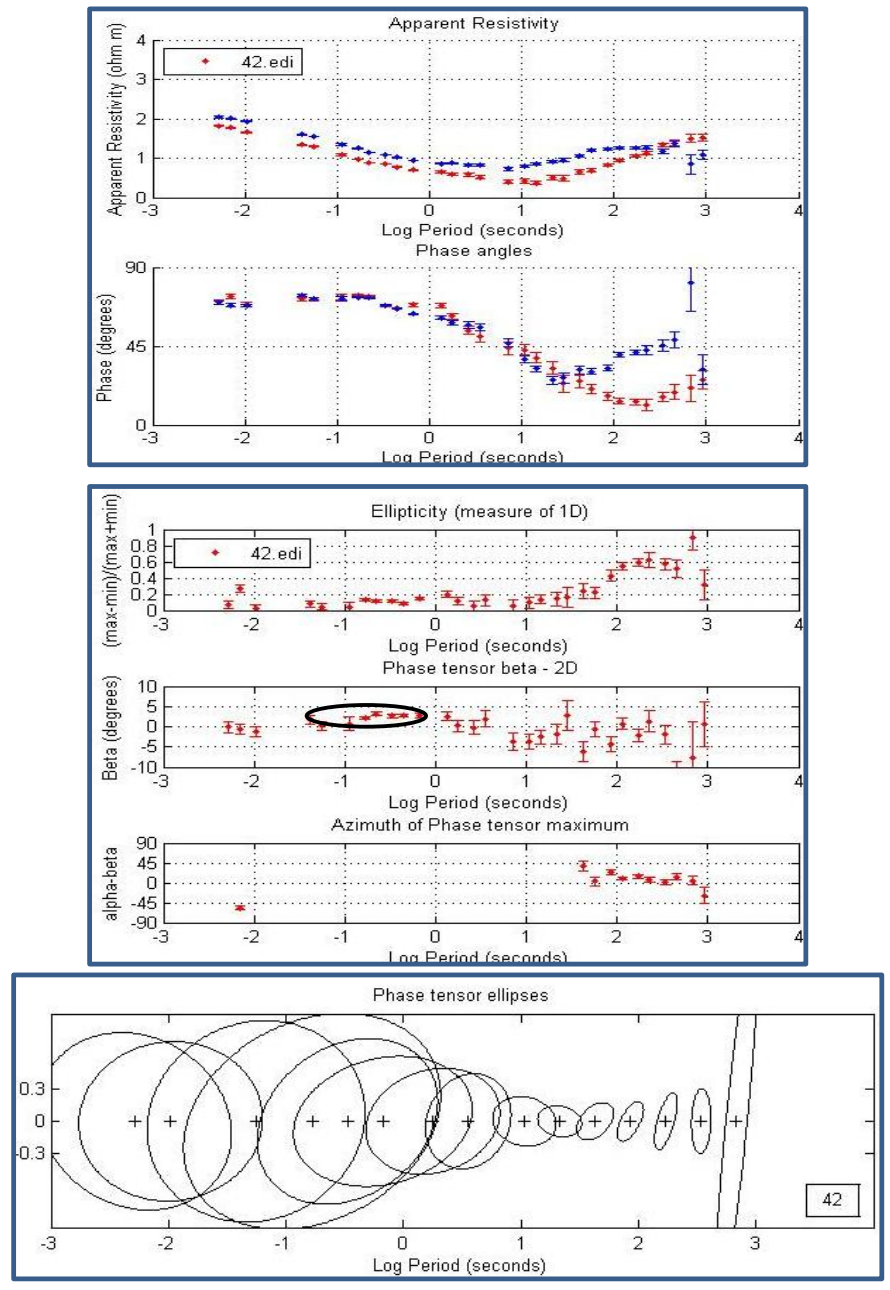

NNG-41
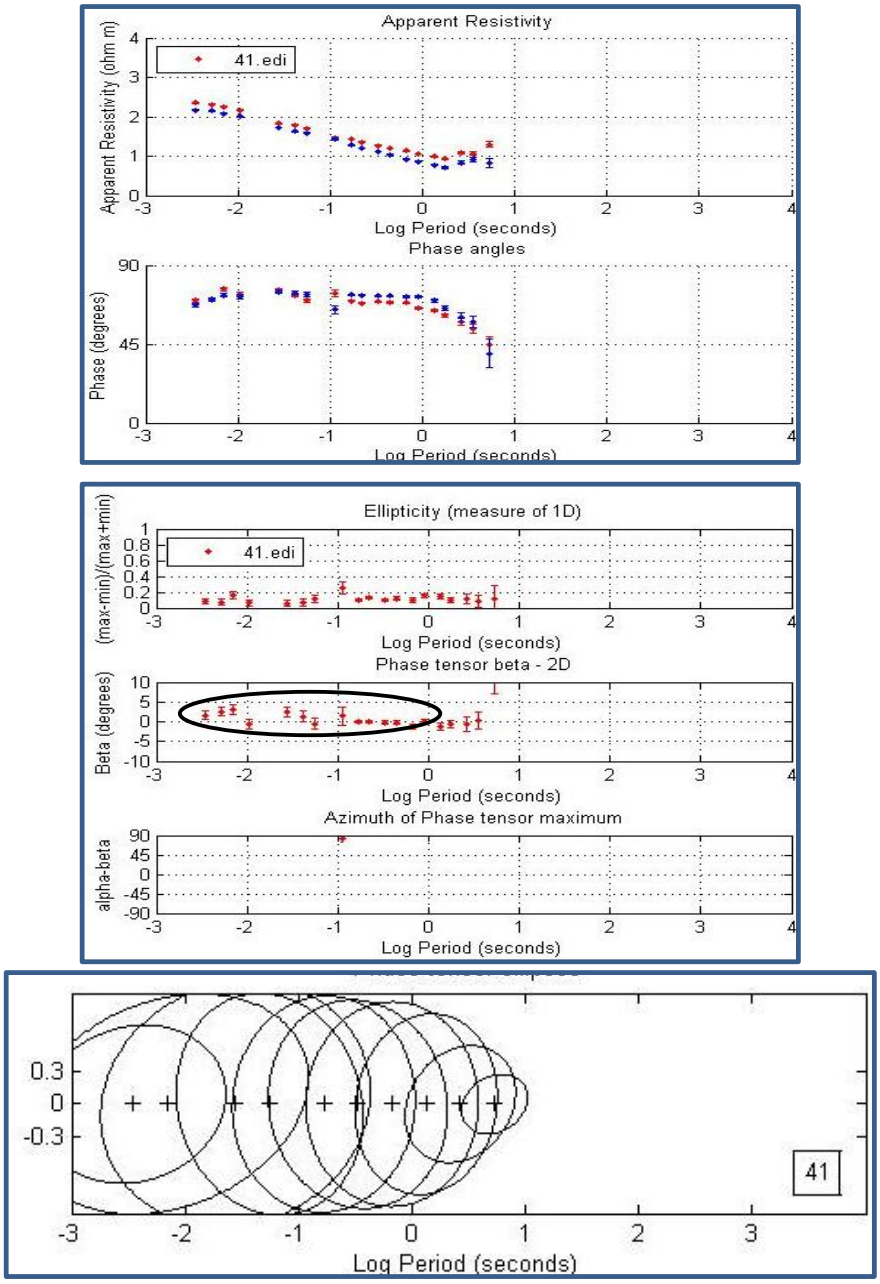

NNG-43
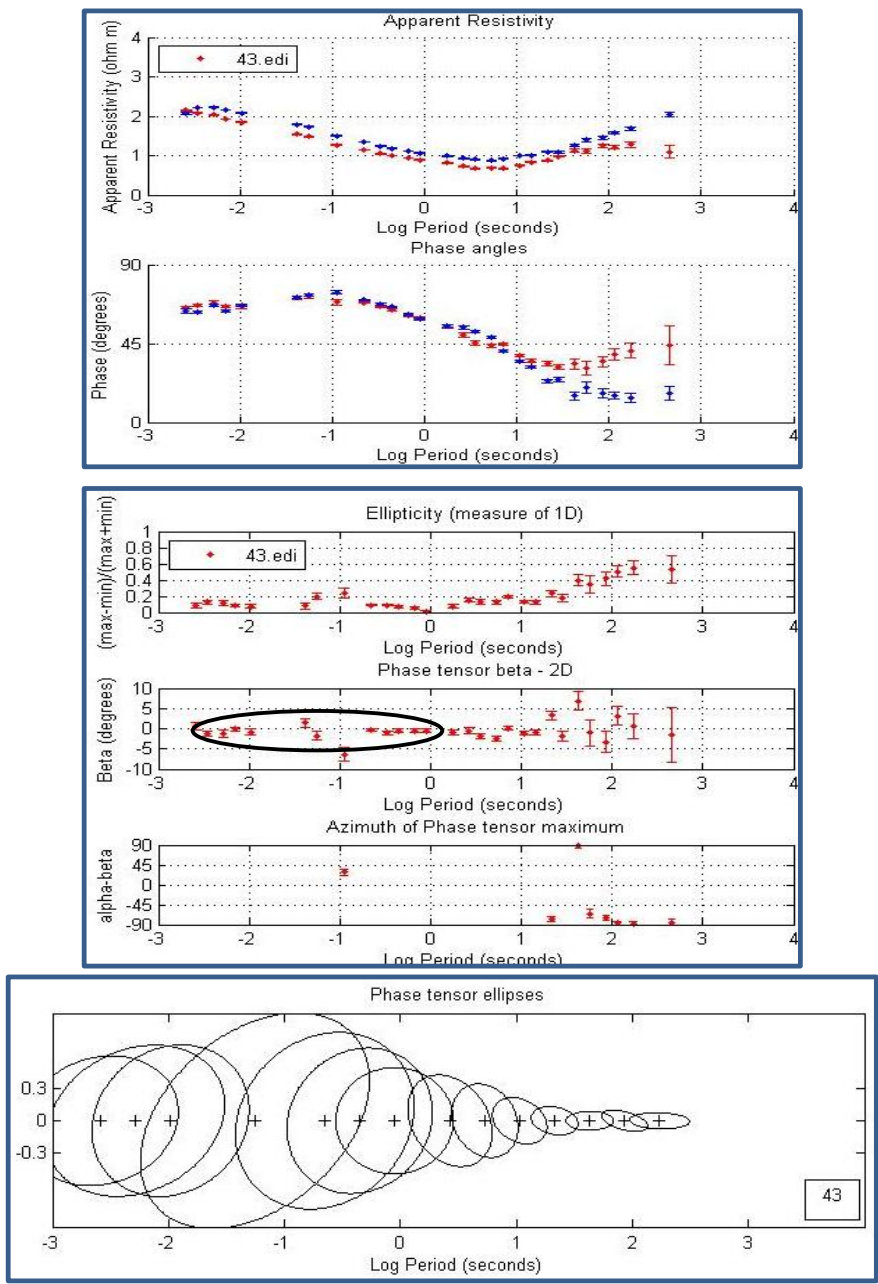
NNG-44
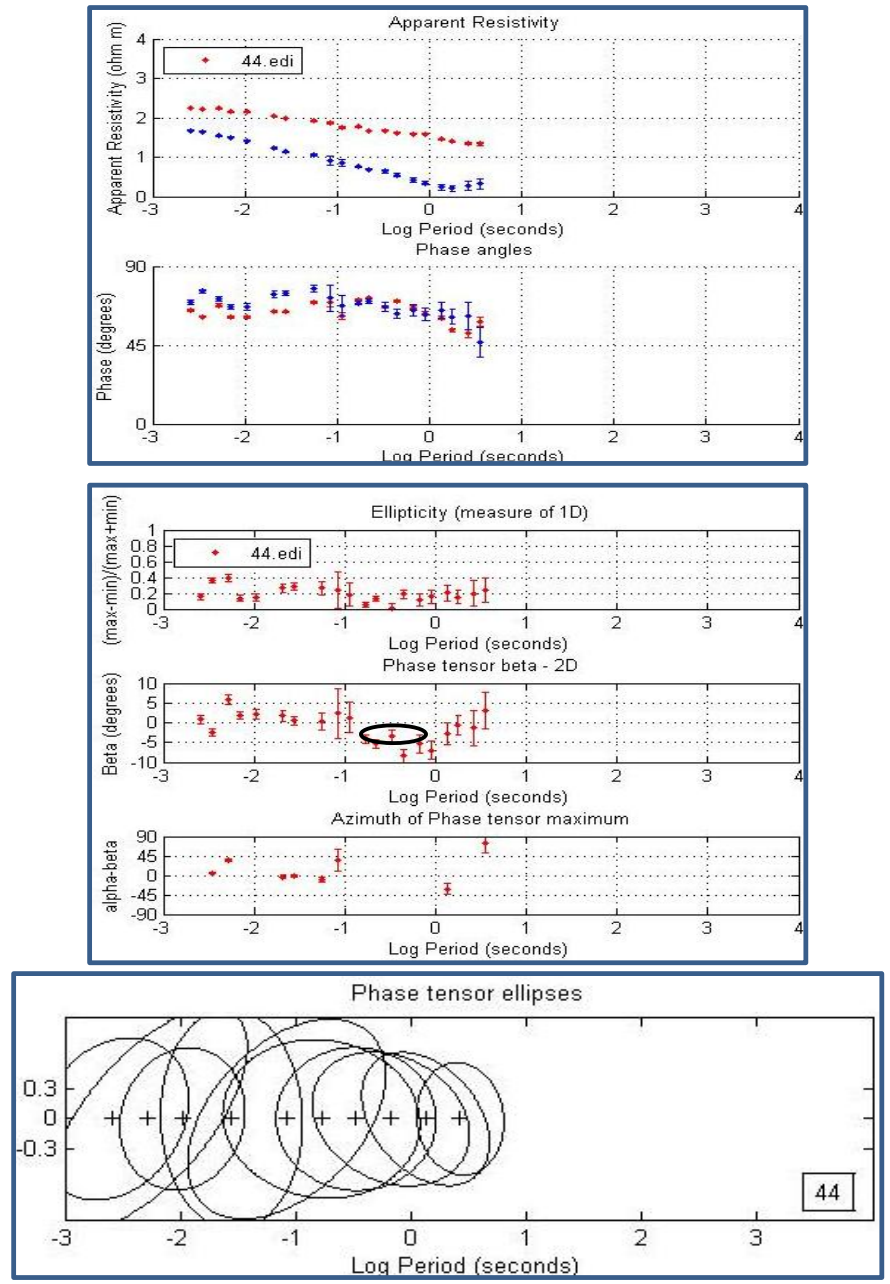

NNG-46
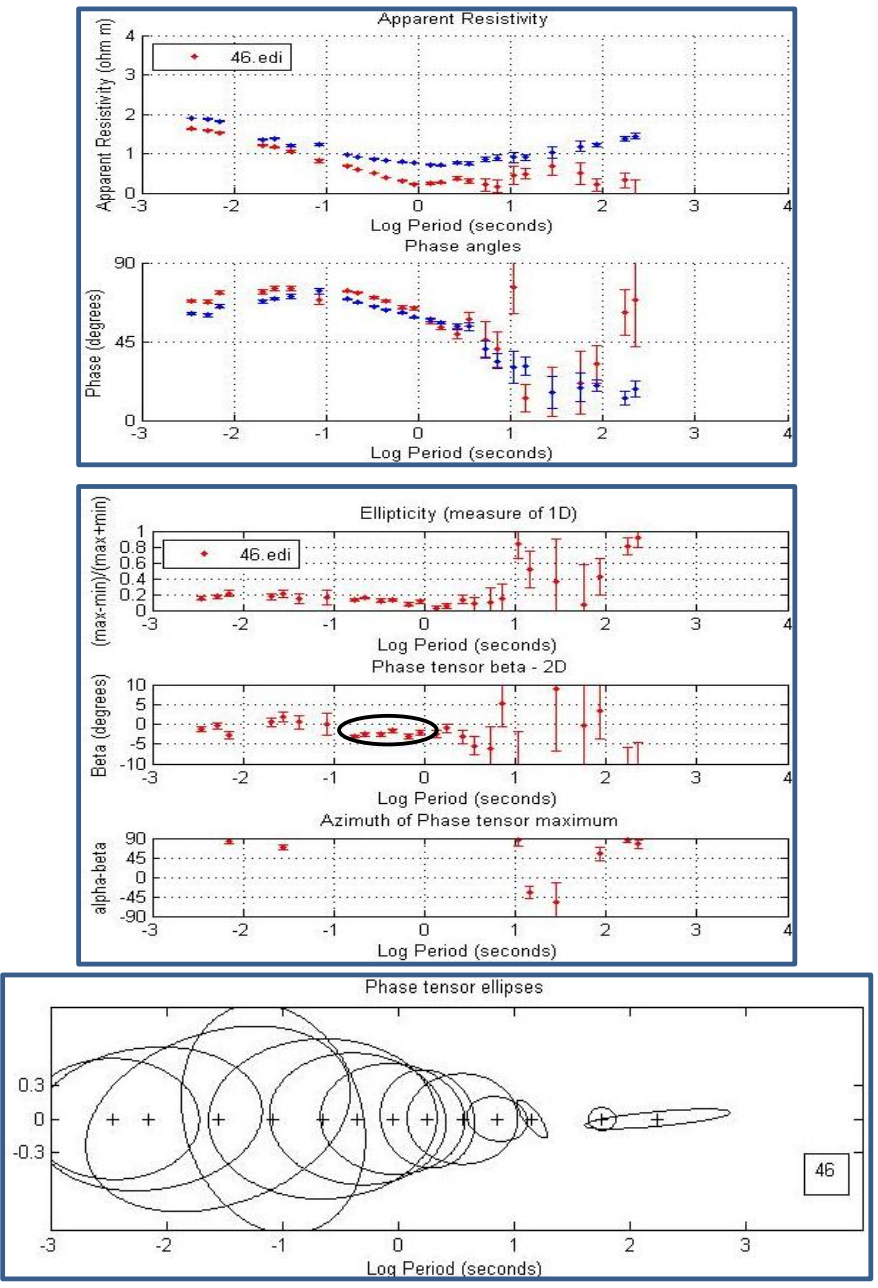

NNG-45
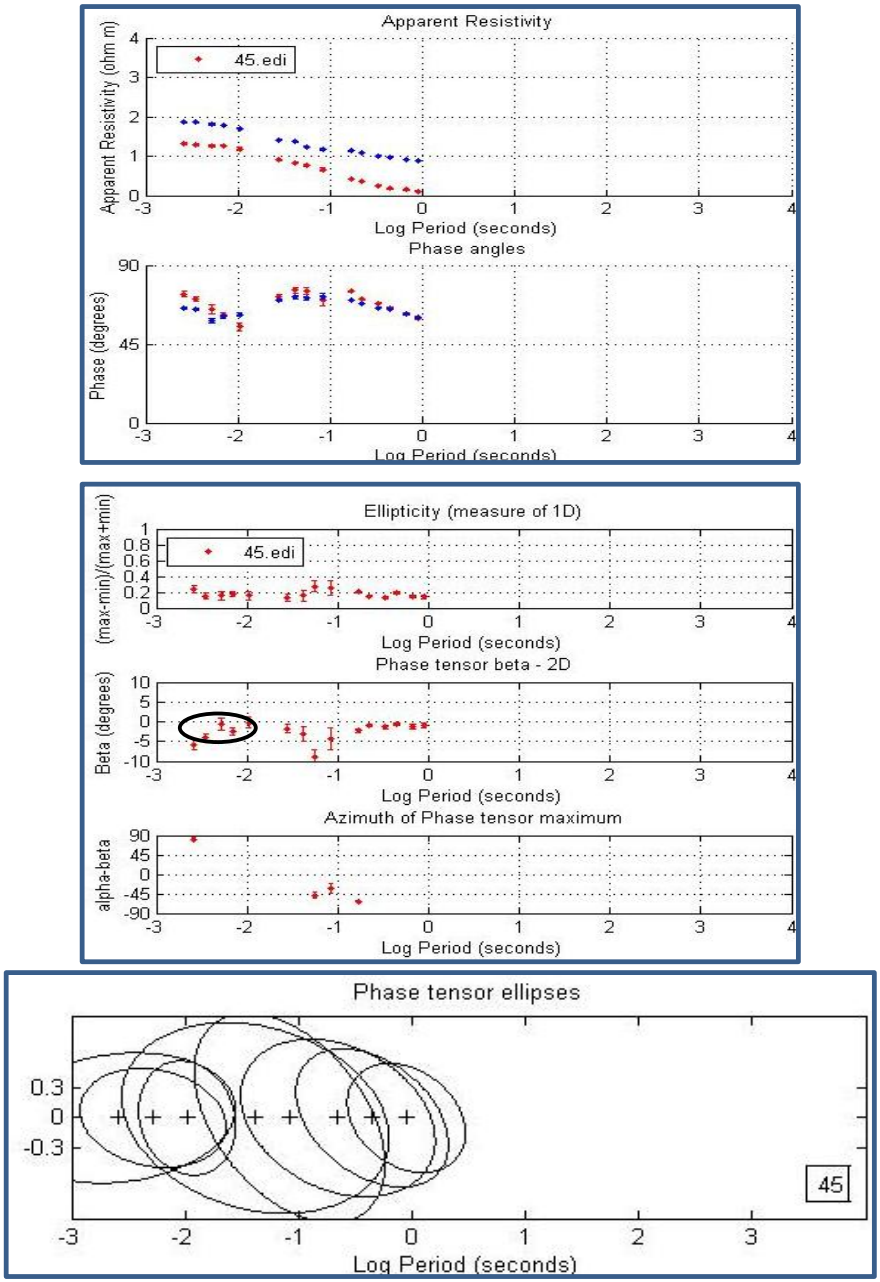

NNG-47
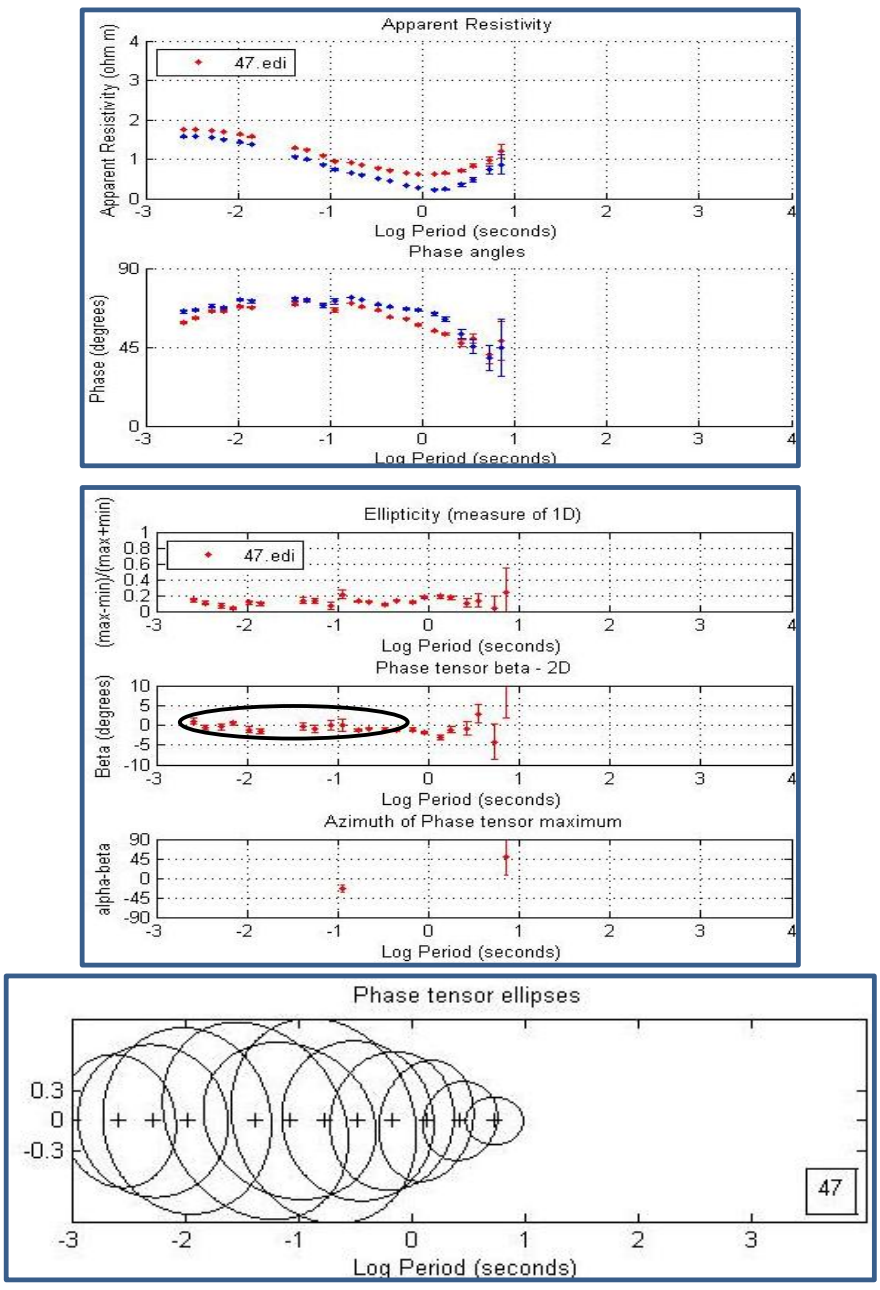
NNG-48
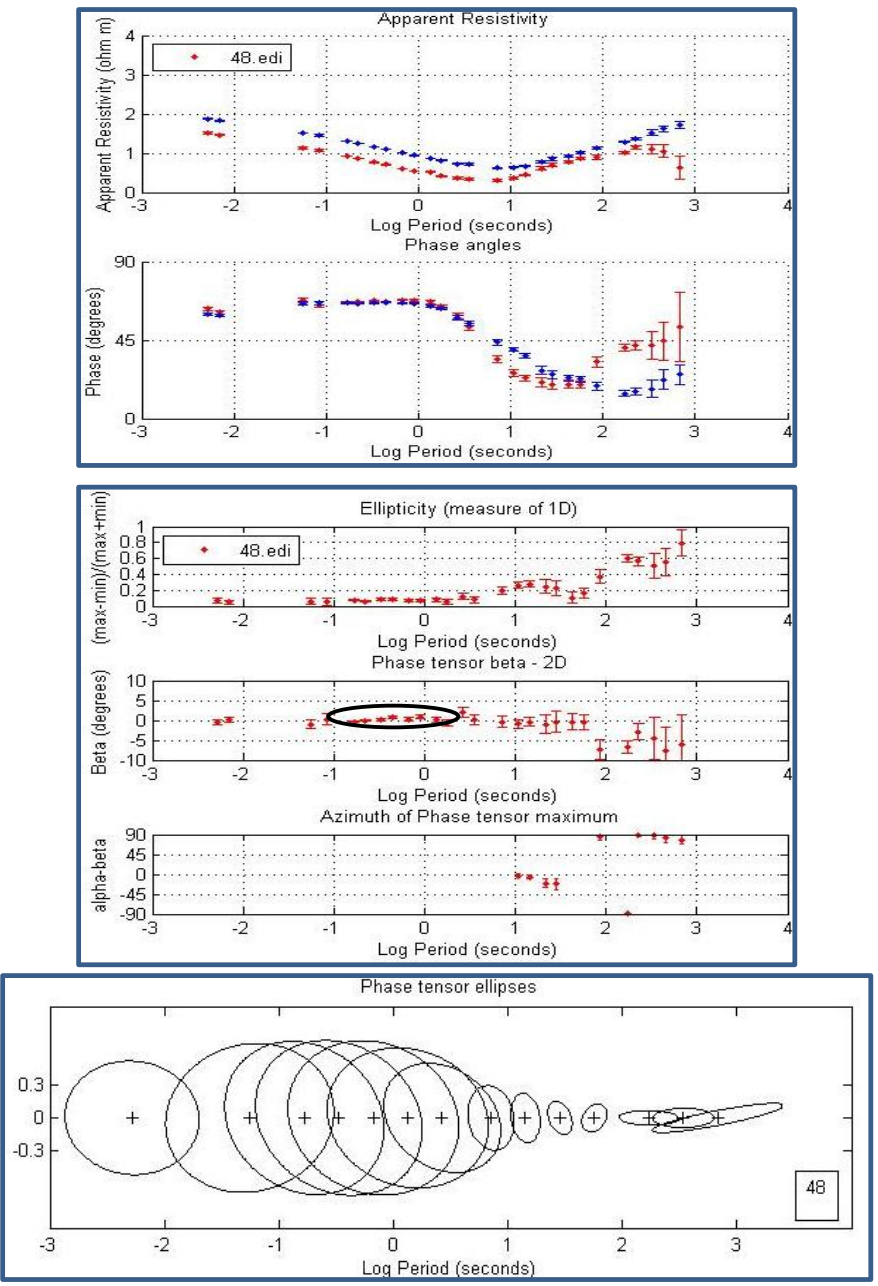

NNG-50
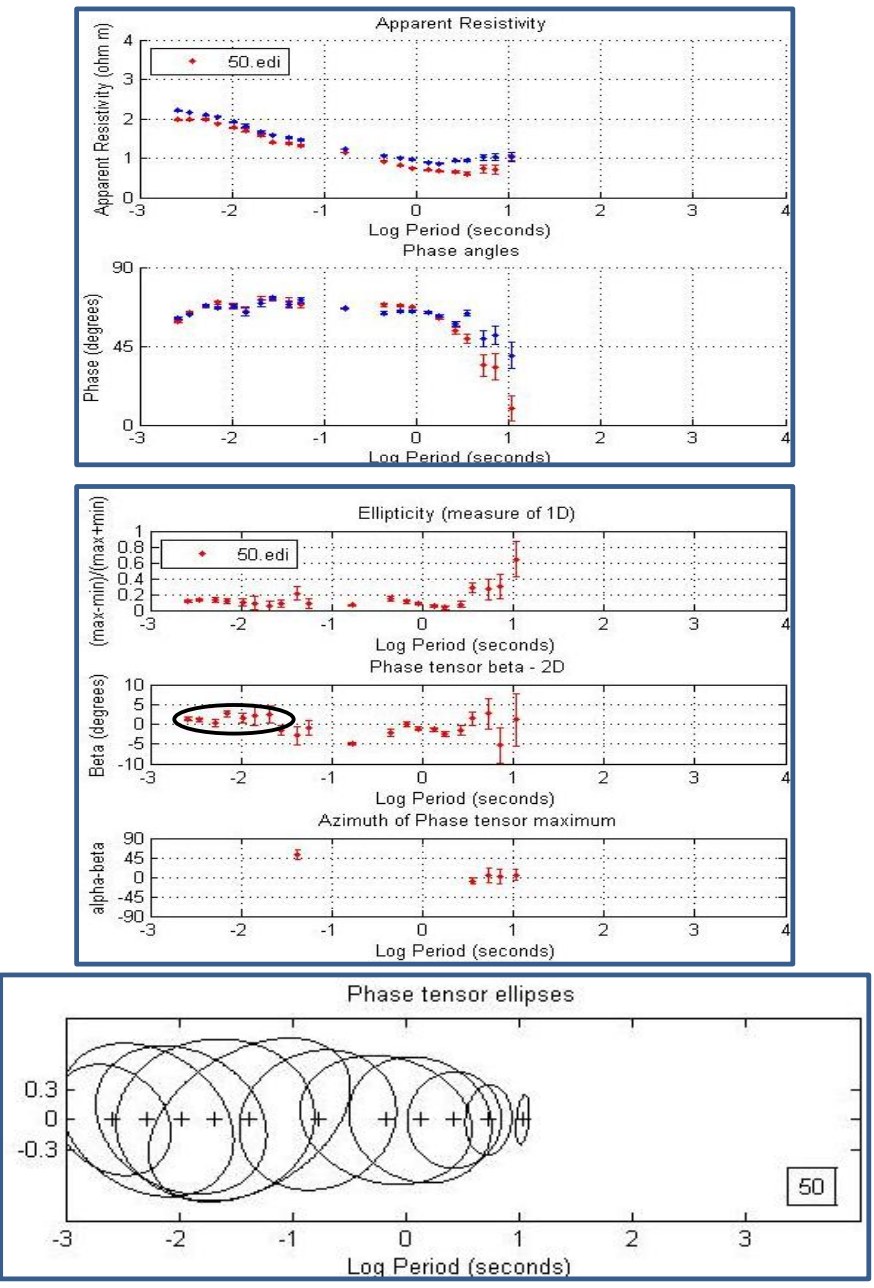

NNG-49
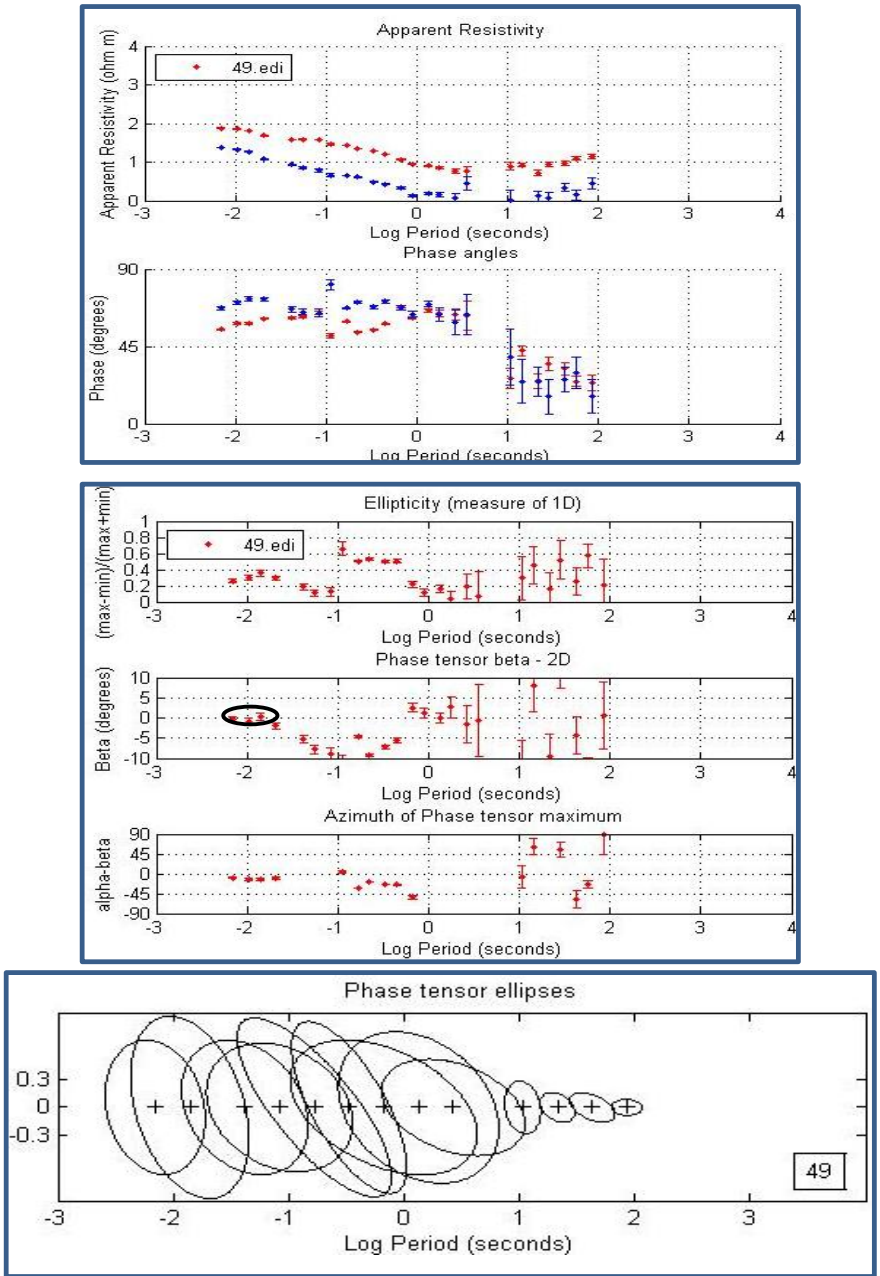

NNG-51
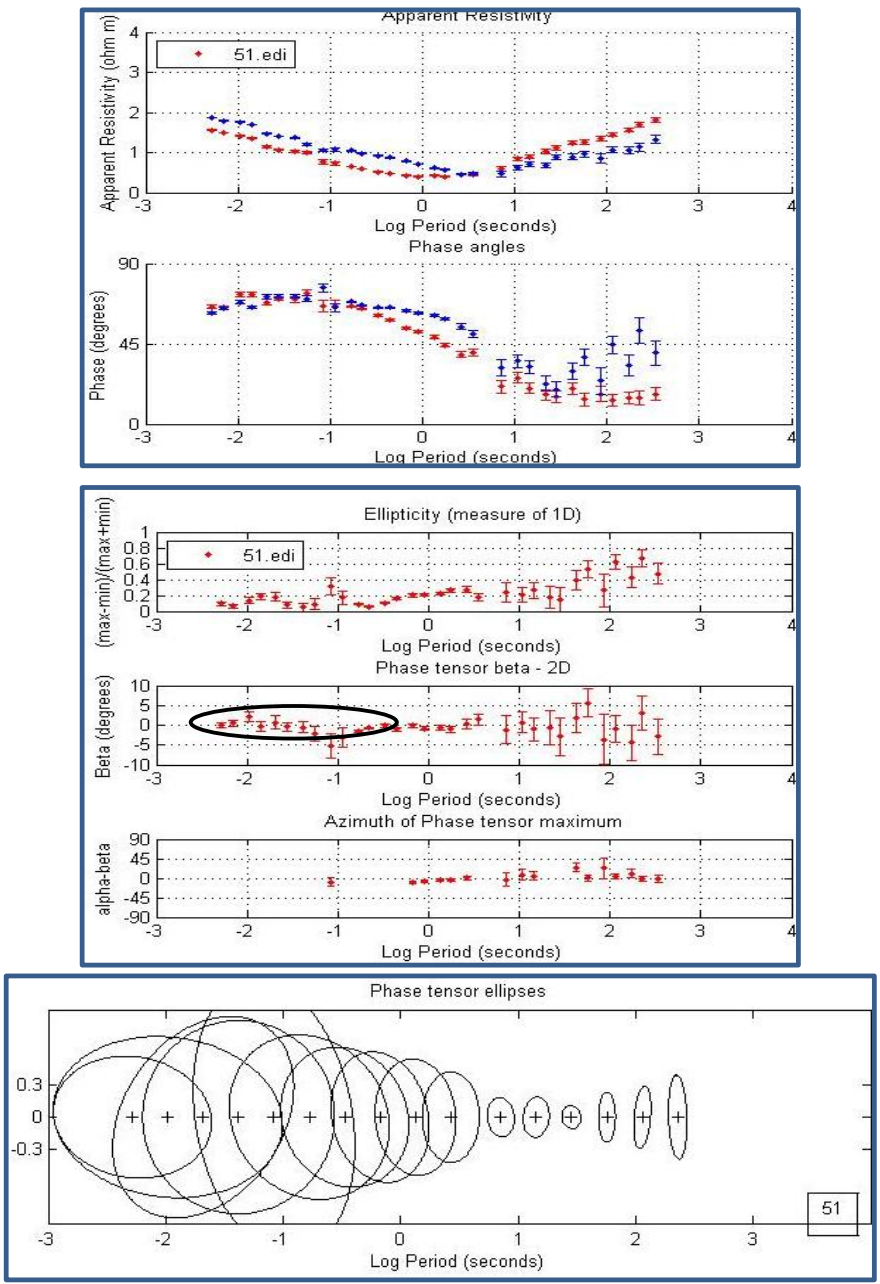
NNG-53
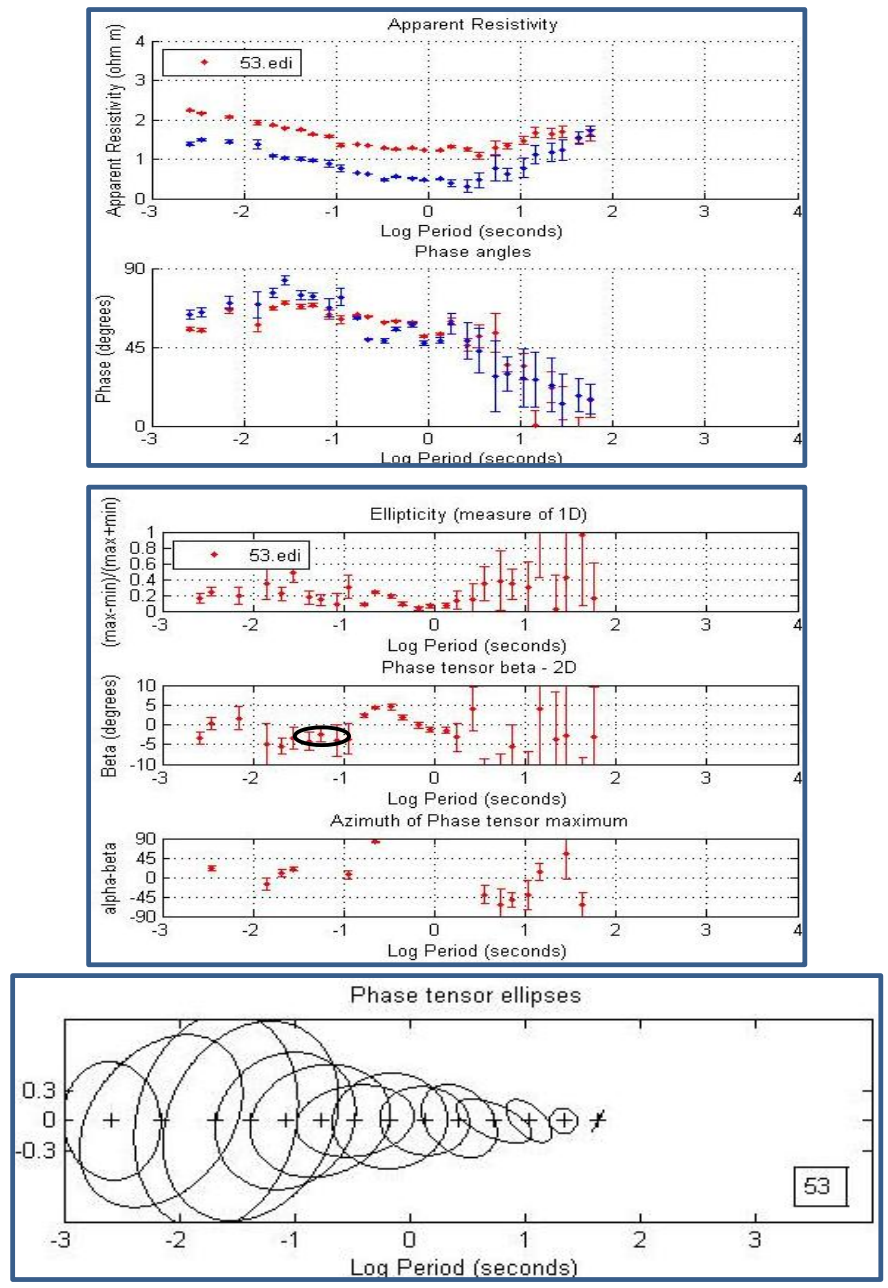

NNG-55
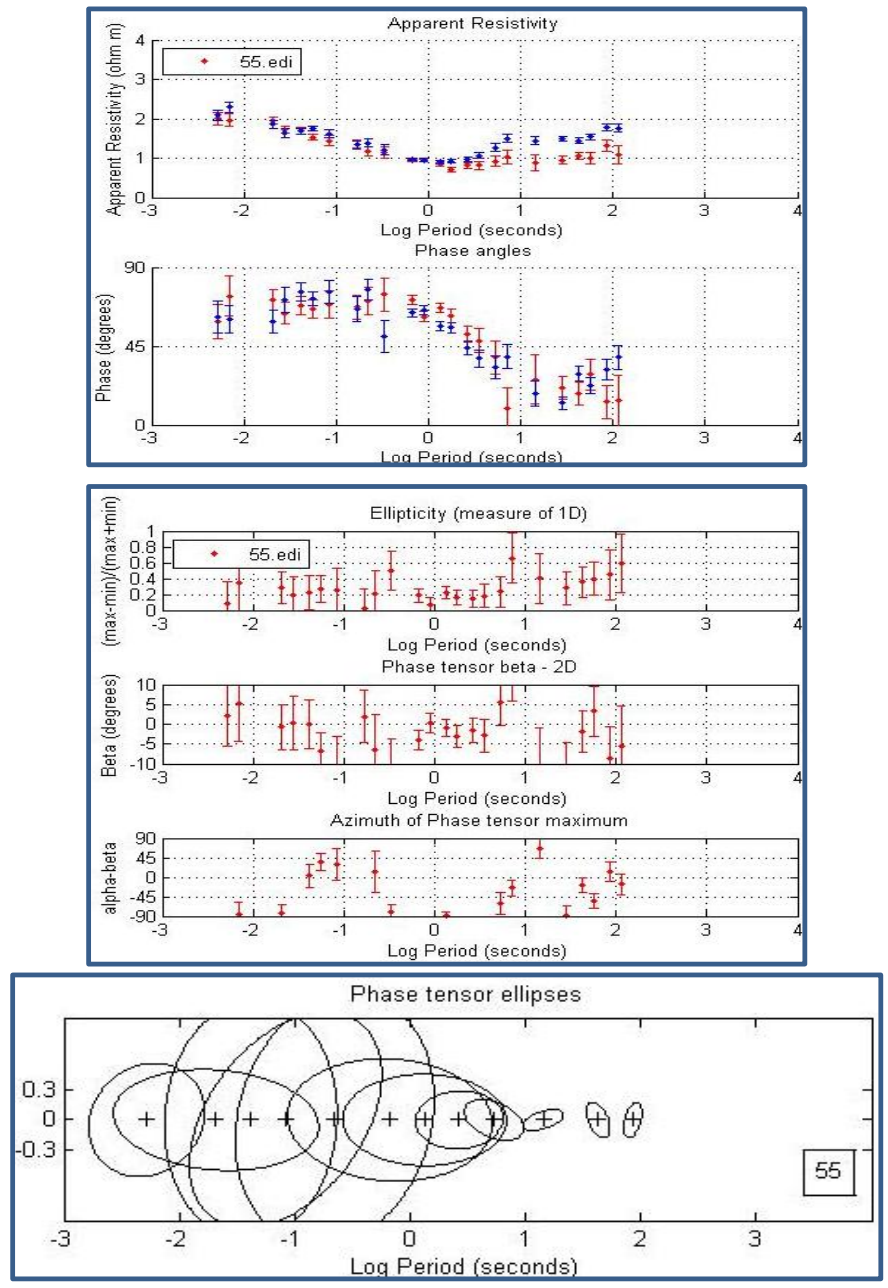

NNG-54
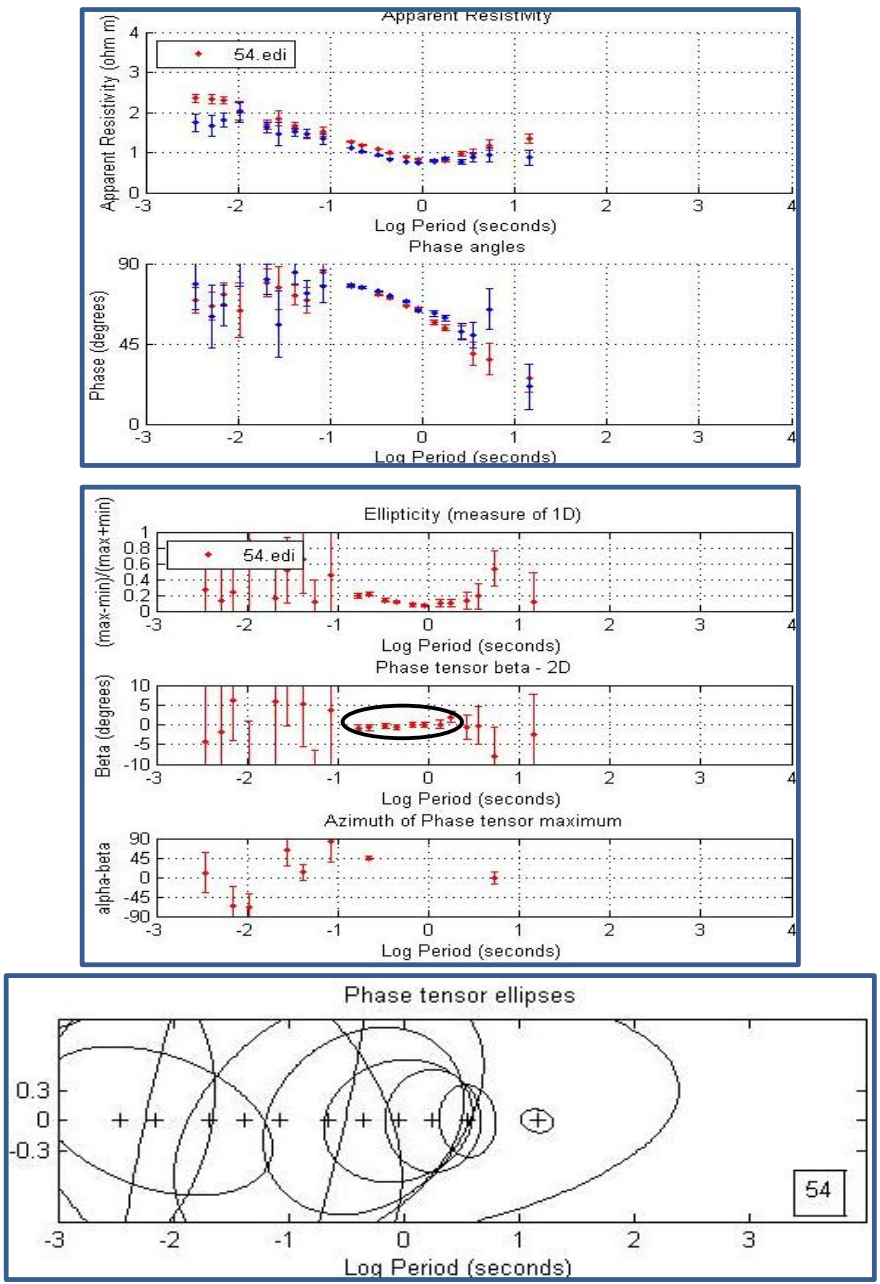

NNG-56
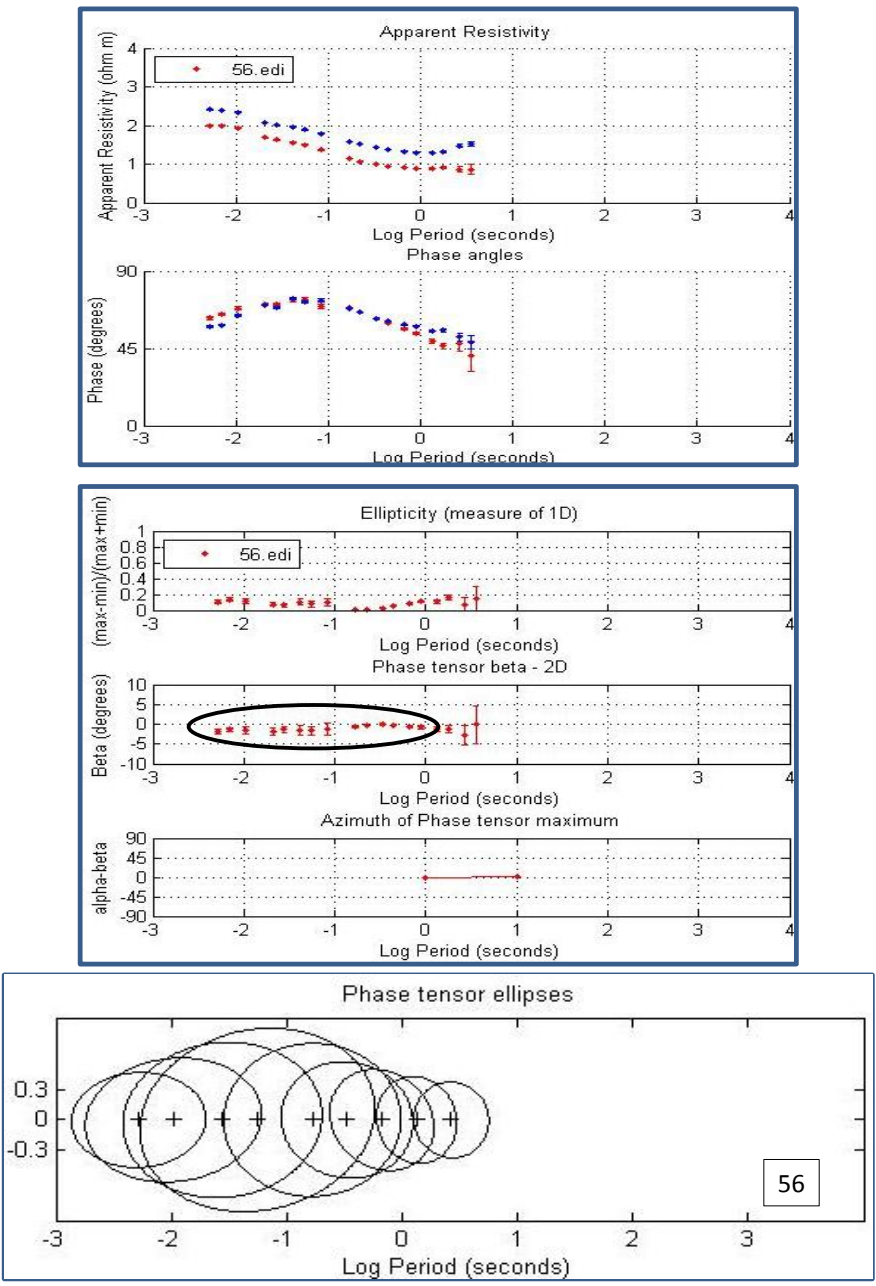
NNG-57
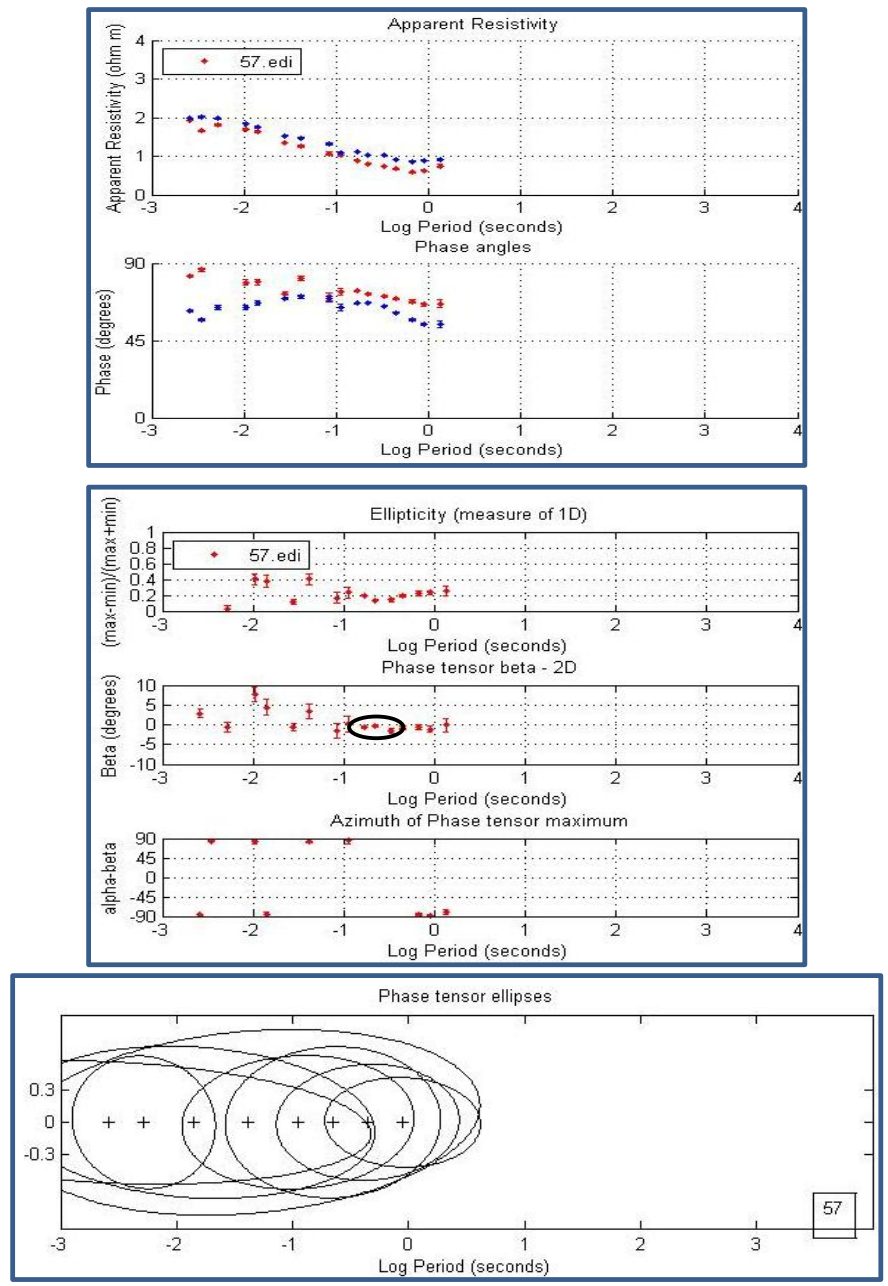

NNG-59
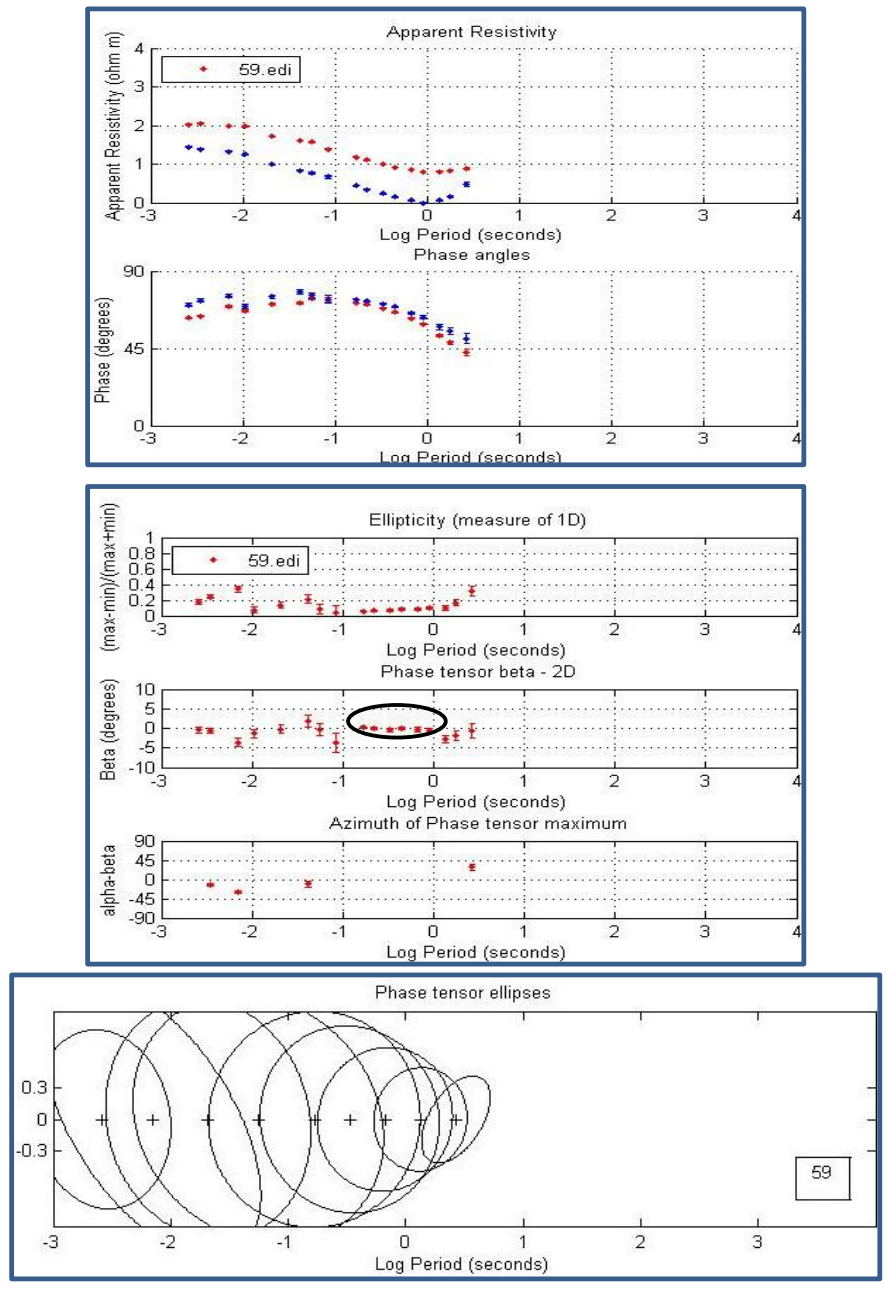

NNG-58
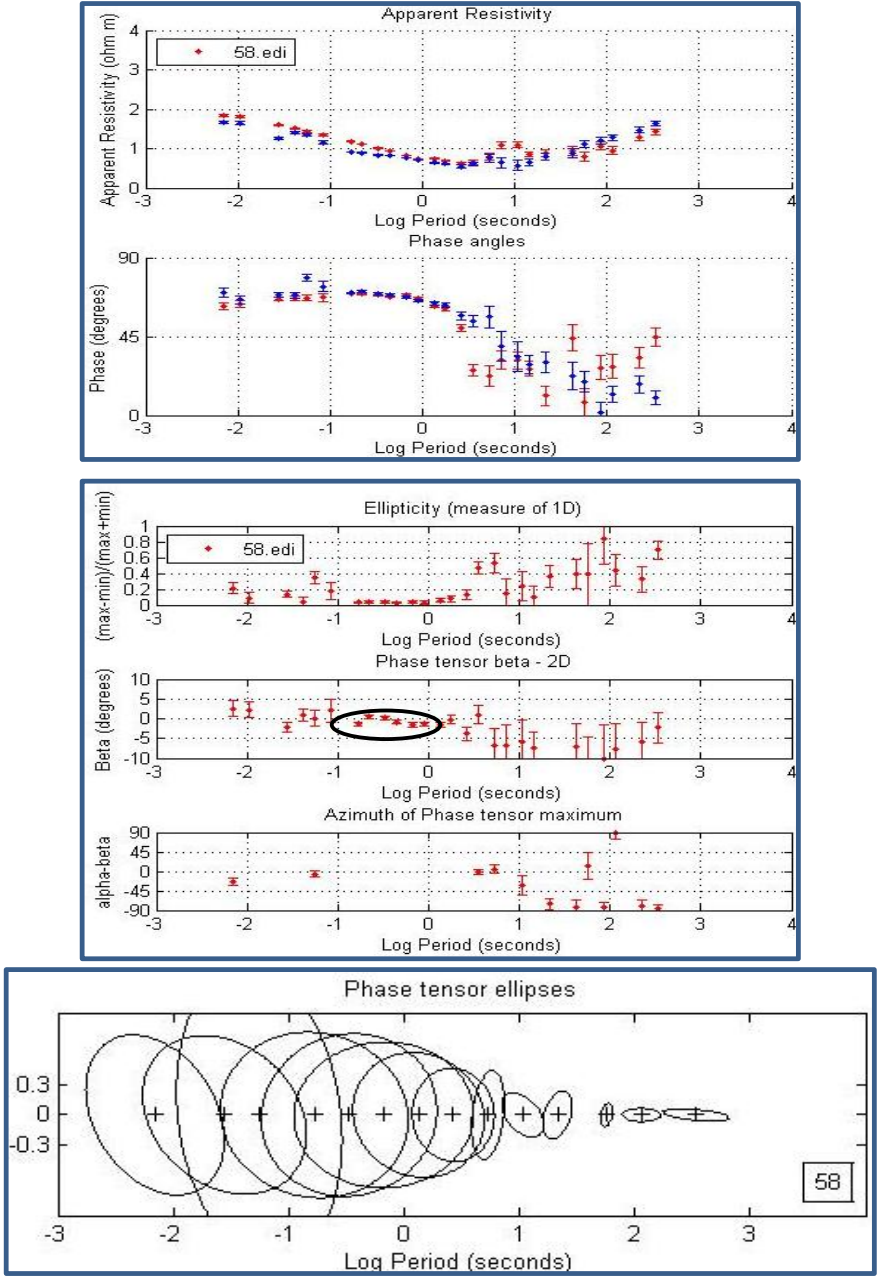

NNG-60
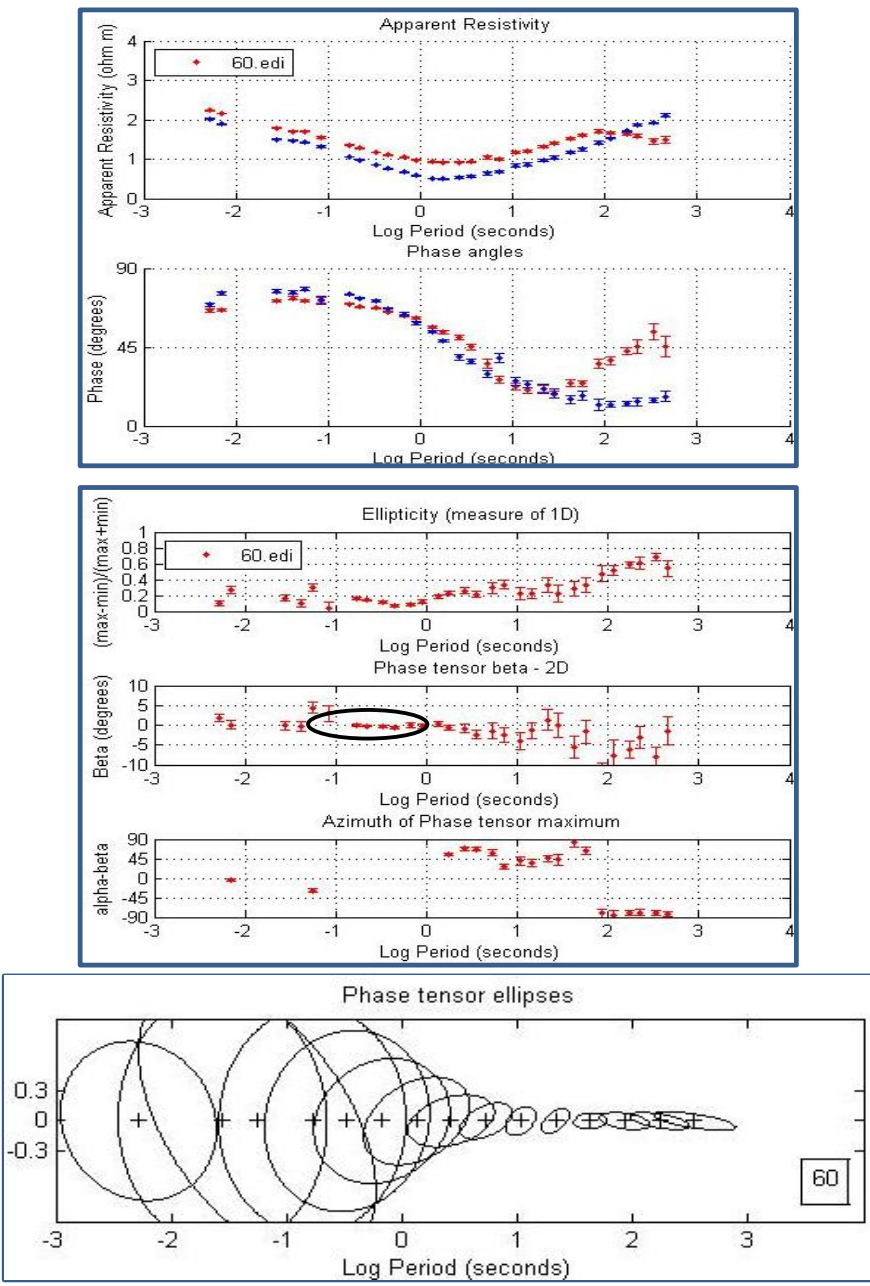
NNG-61
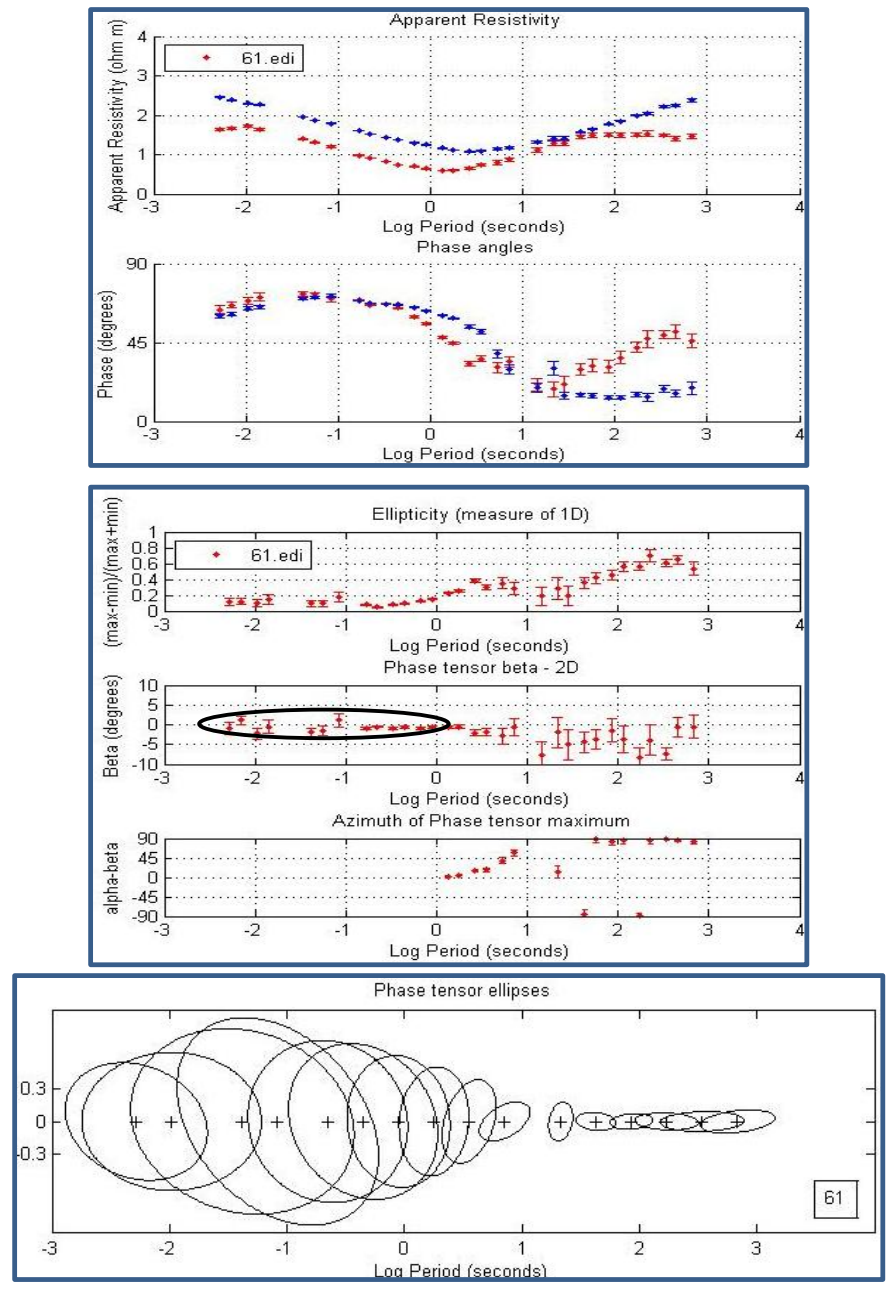

NNG-63
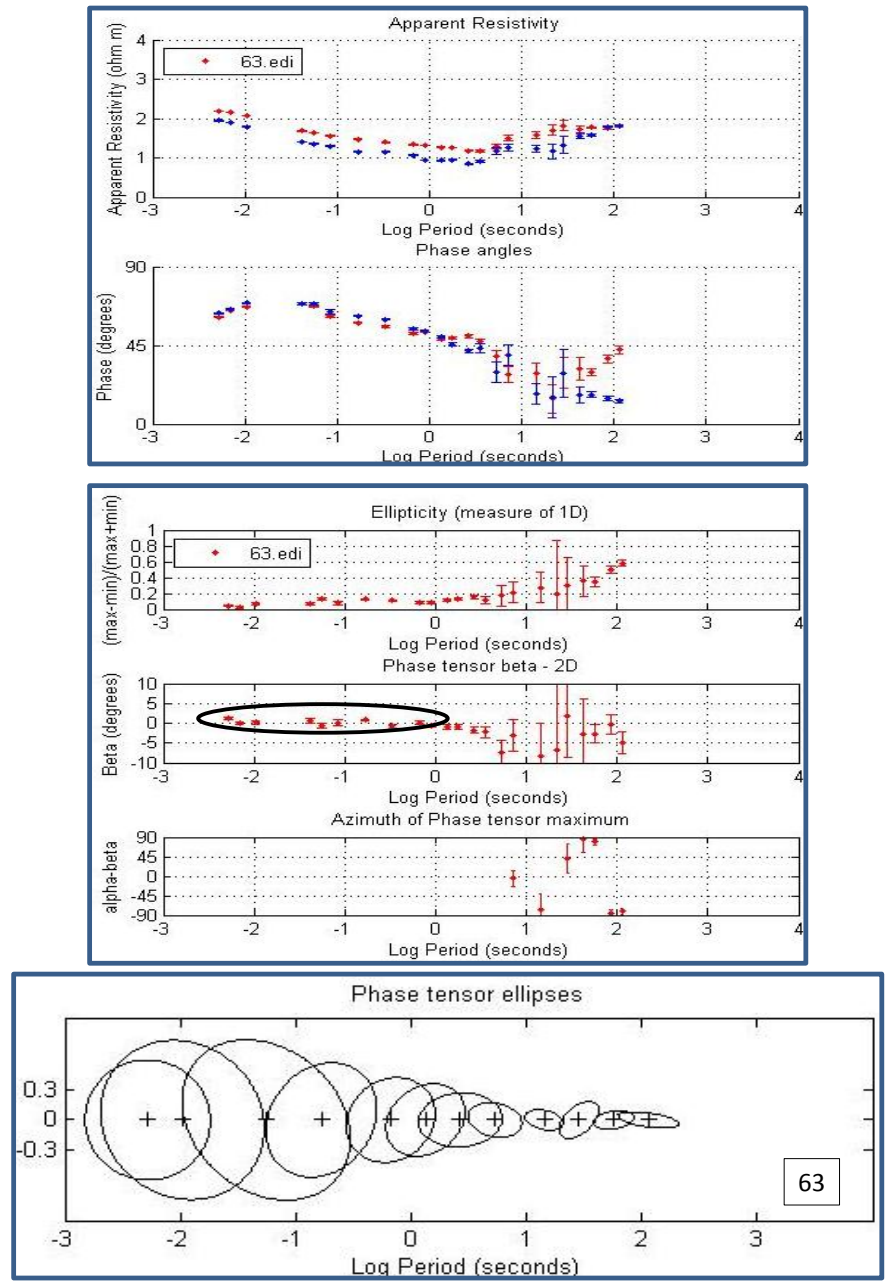

NNG-62
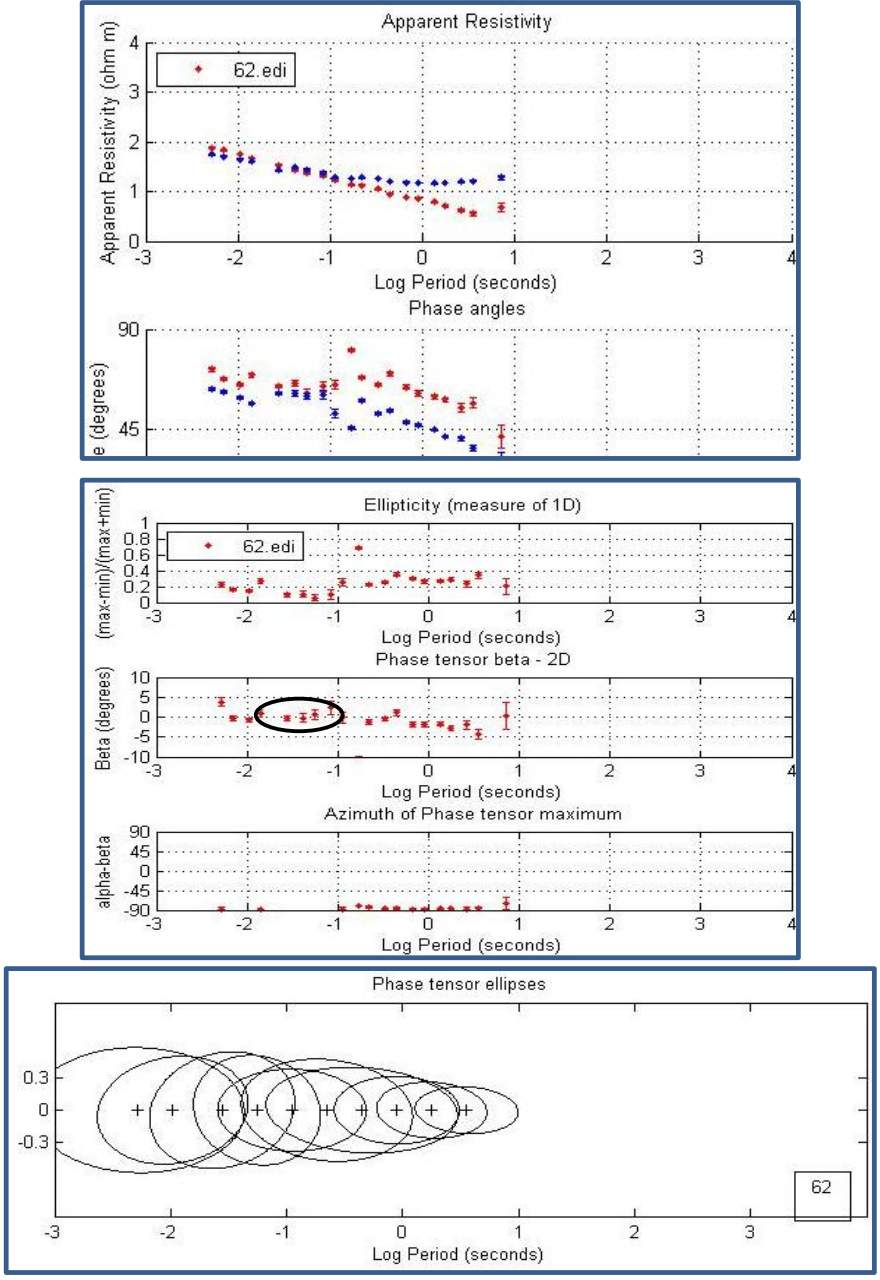

NNG-64
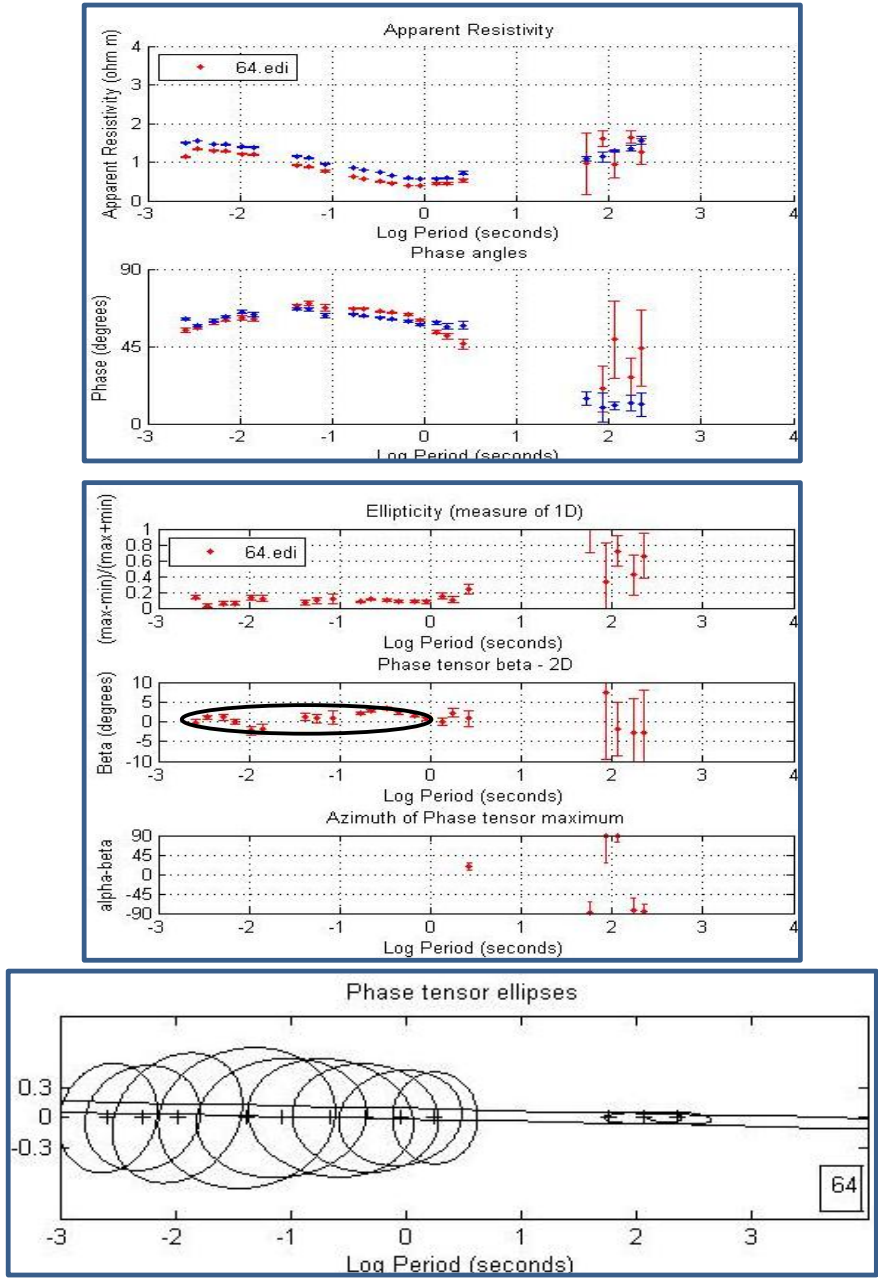
NNG-66
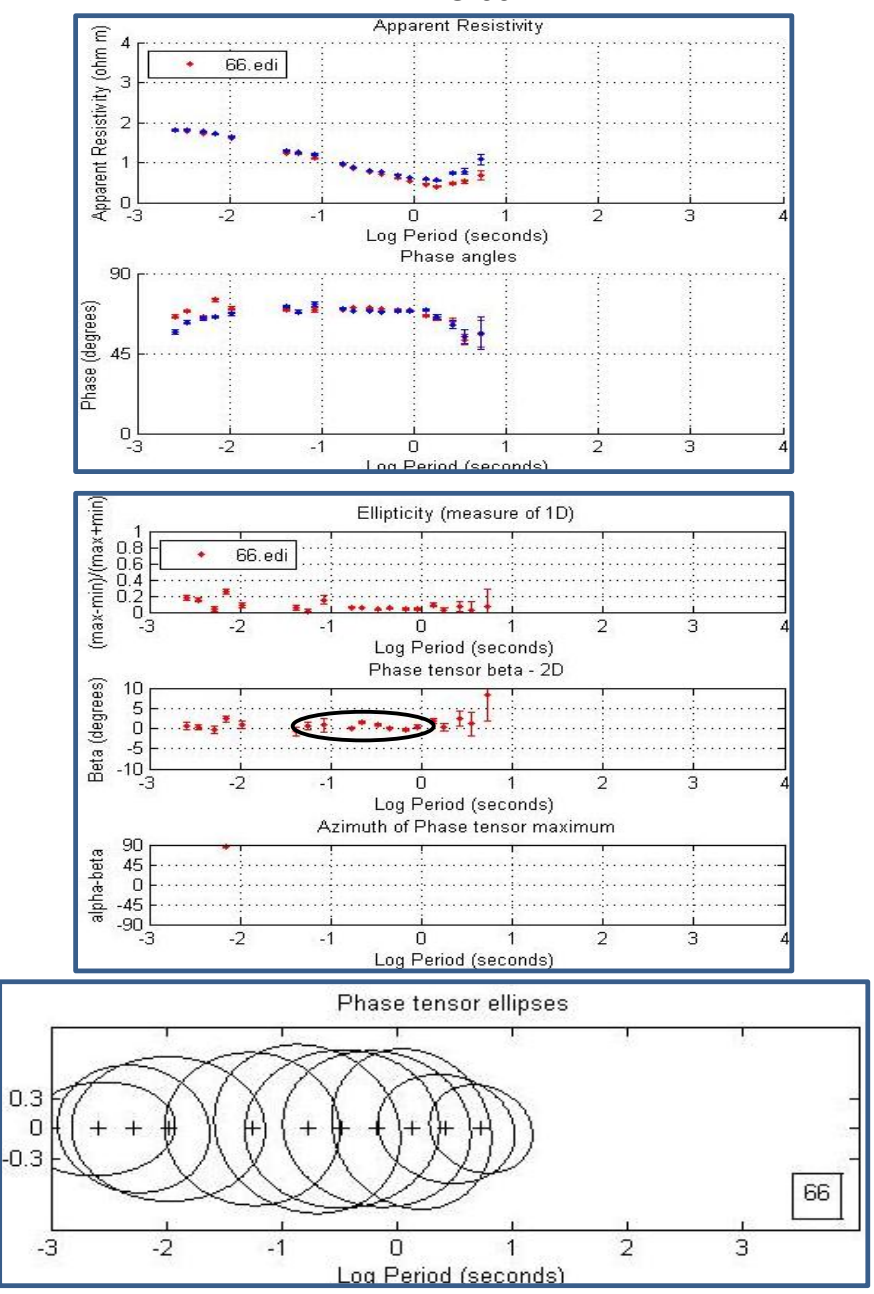

NNG-68
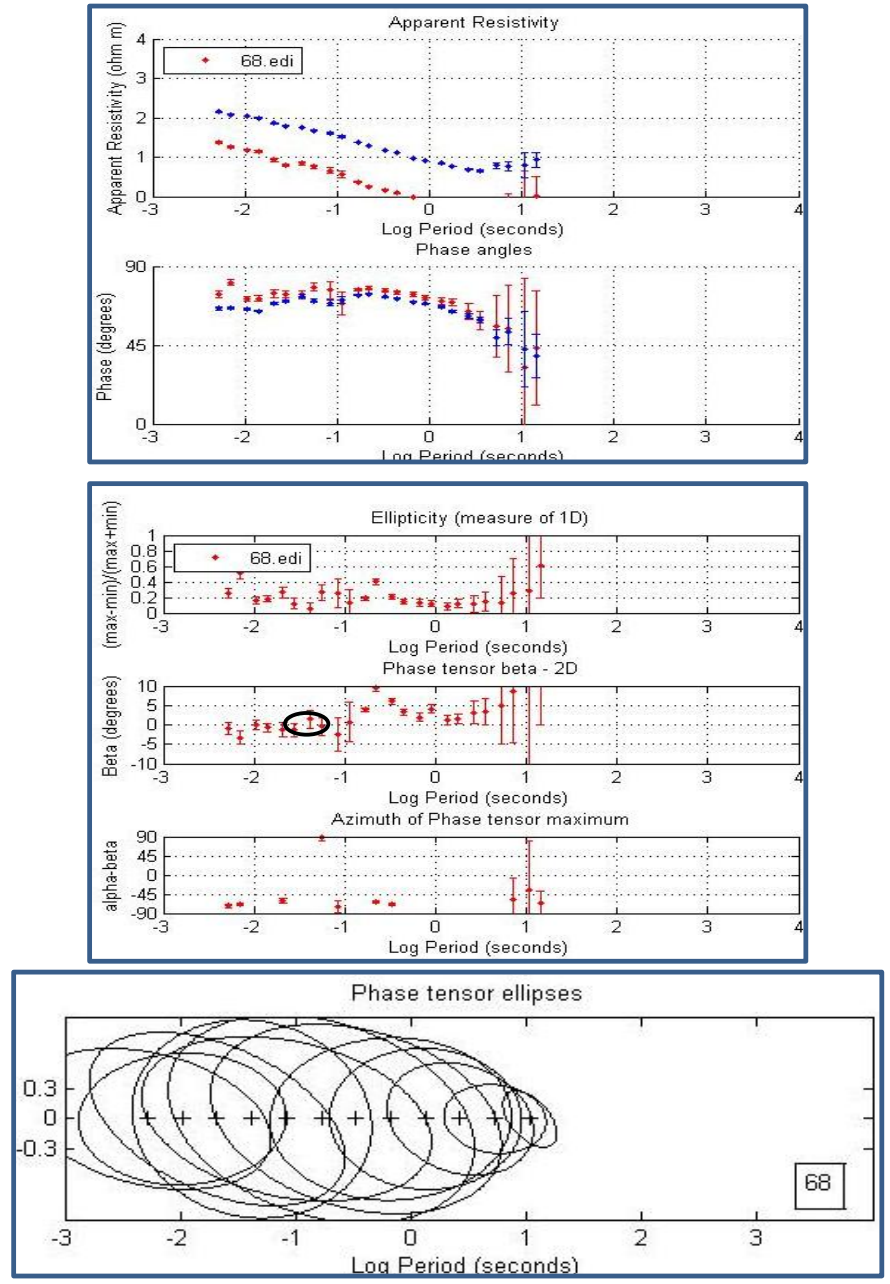

NNG-67
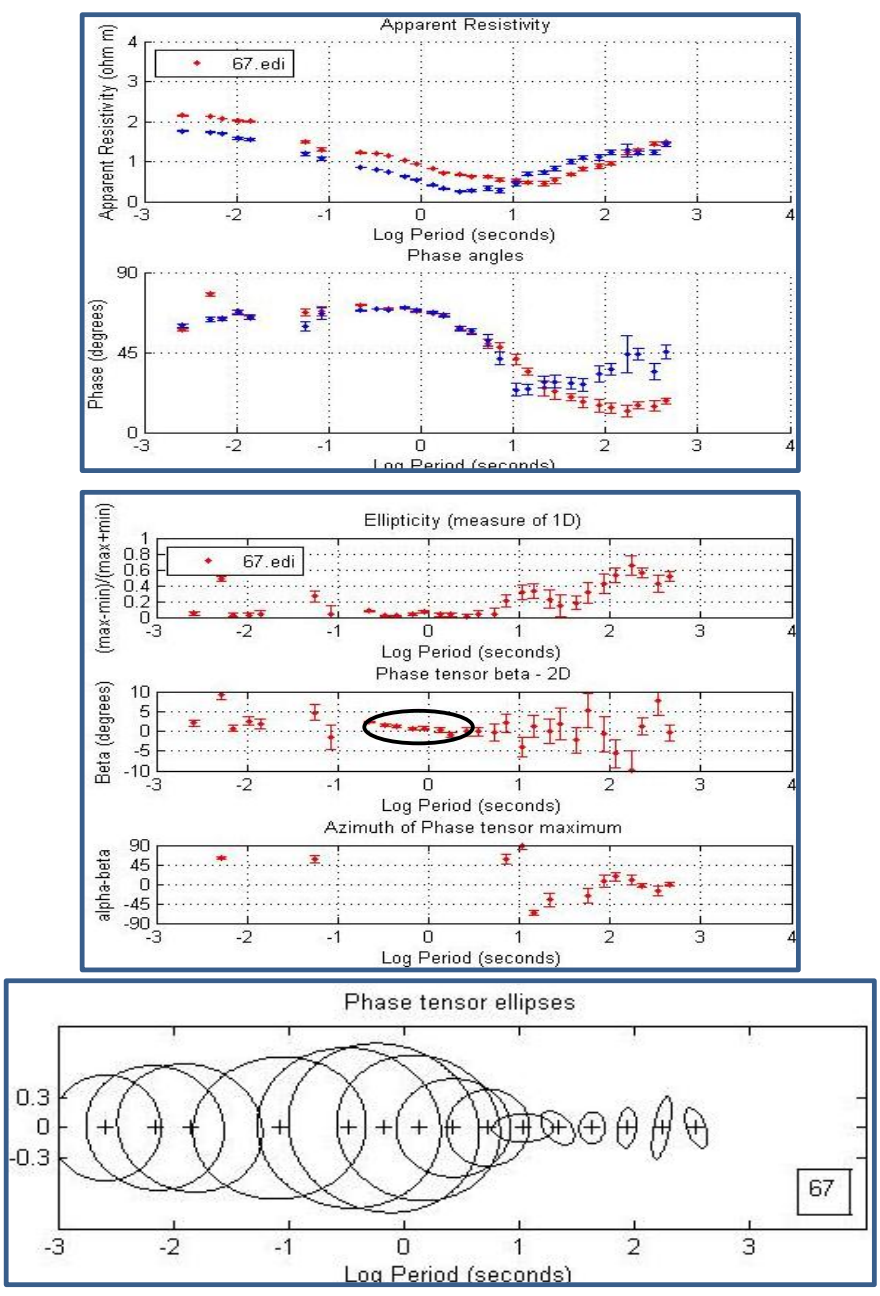

NNG-69
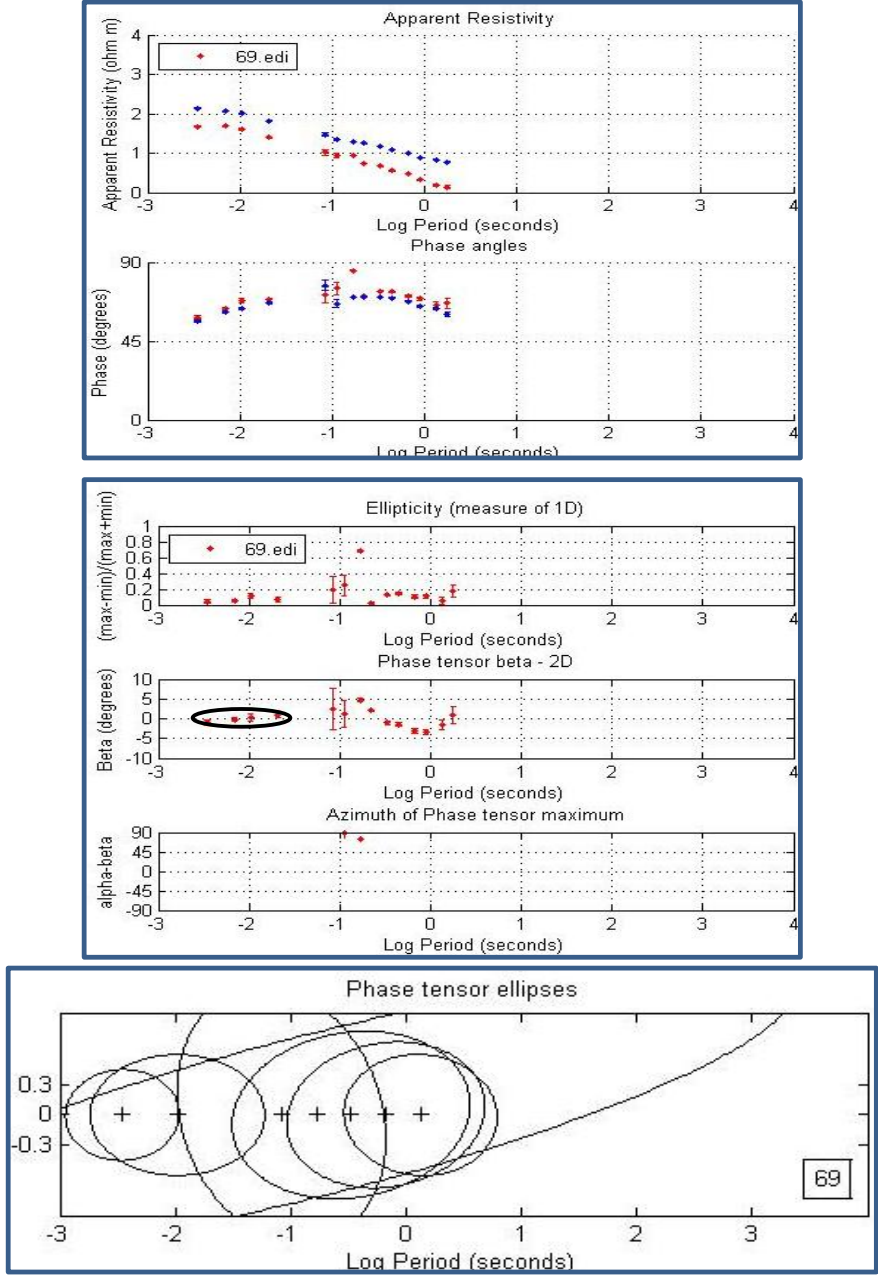

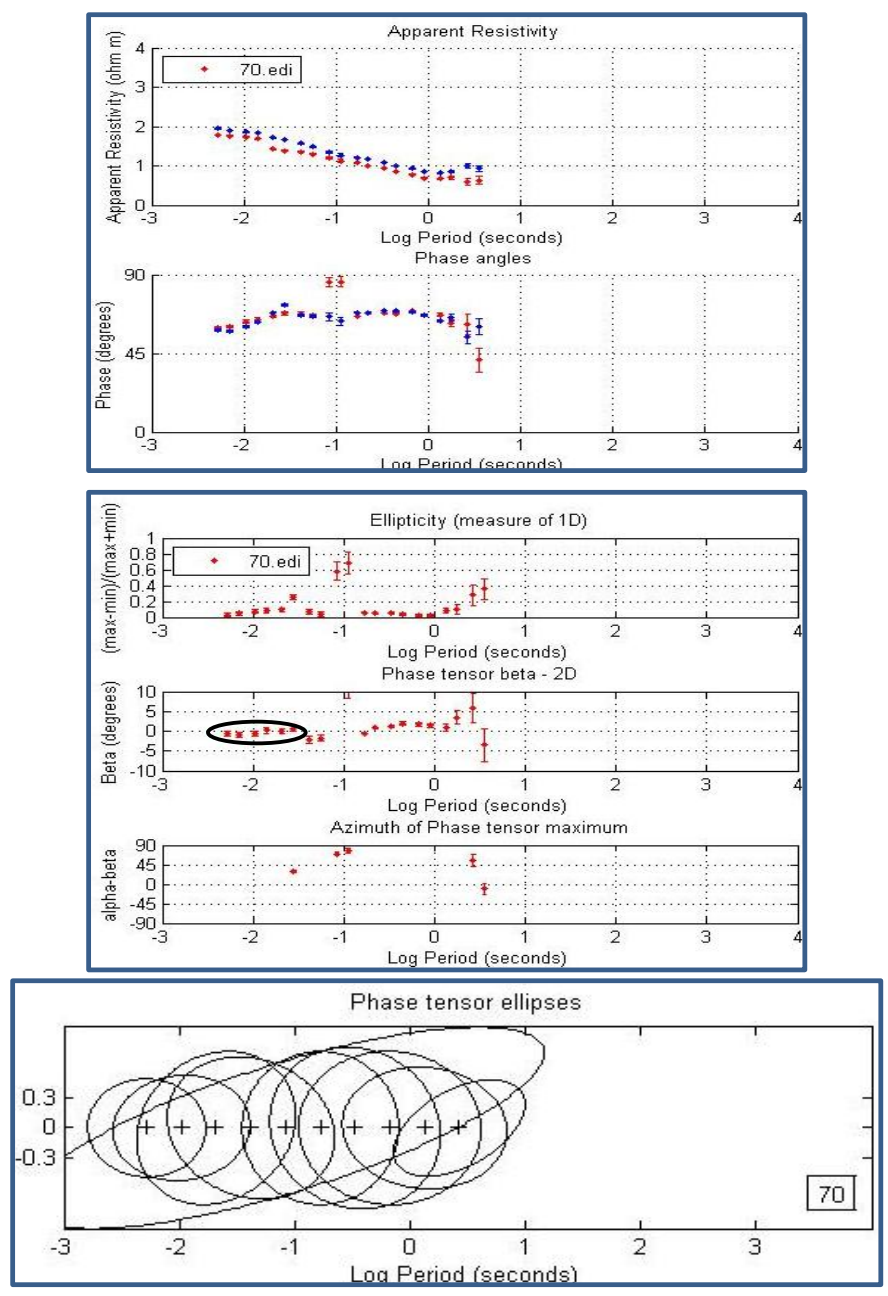

NNG-73
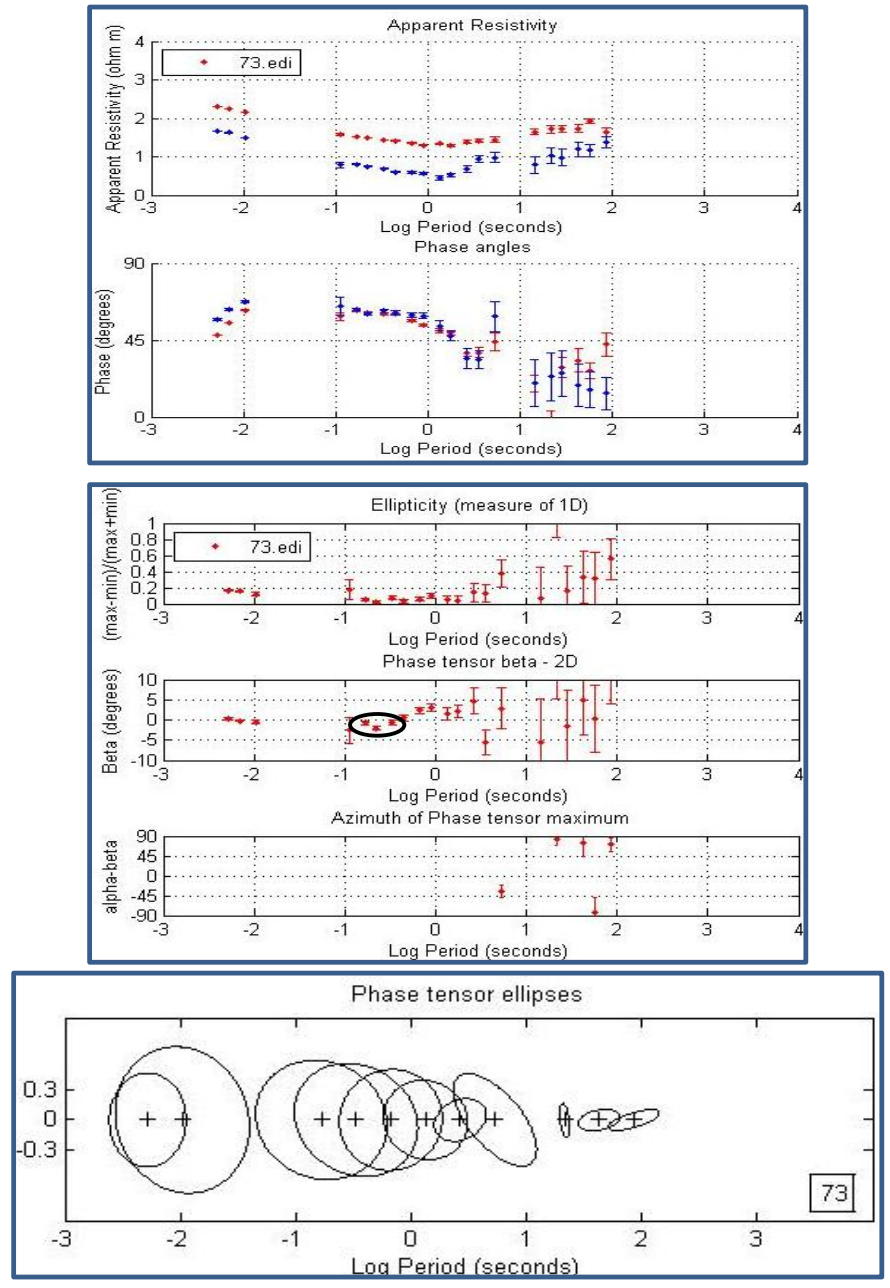
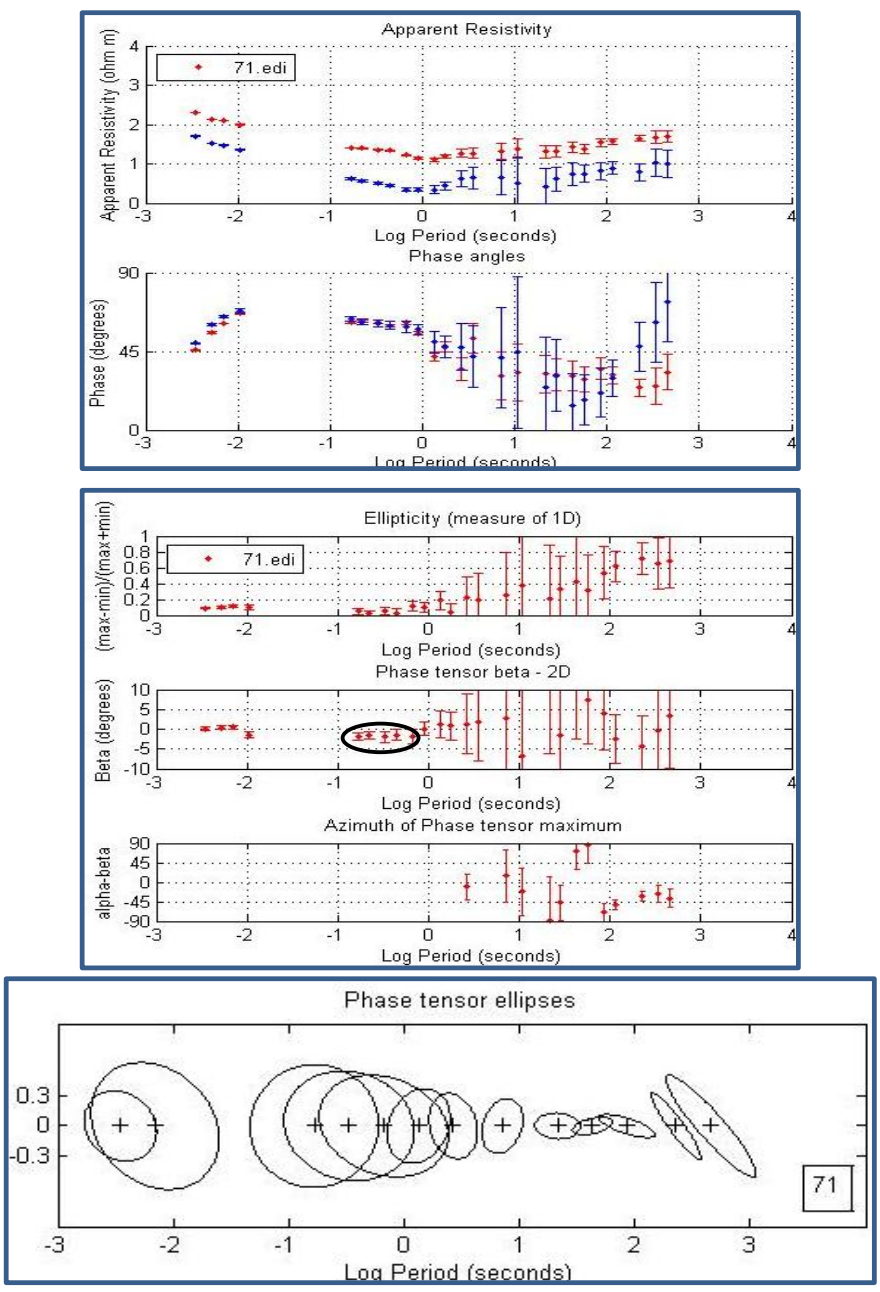

NNG-75
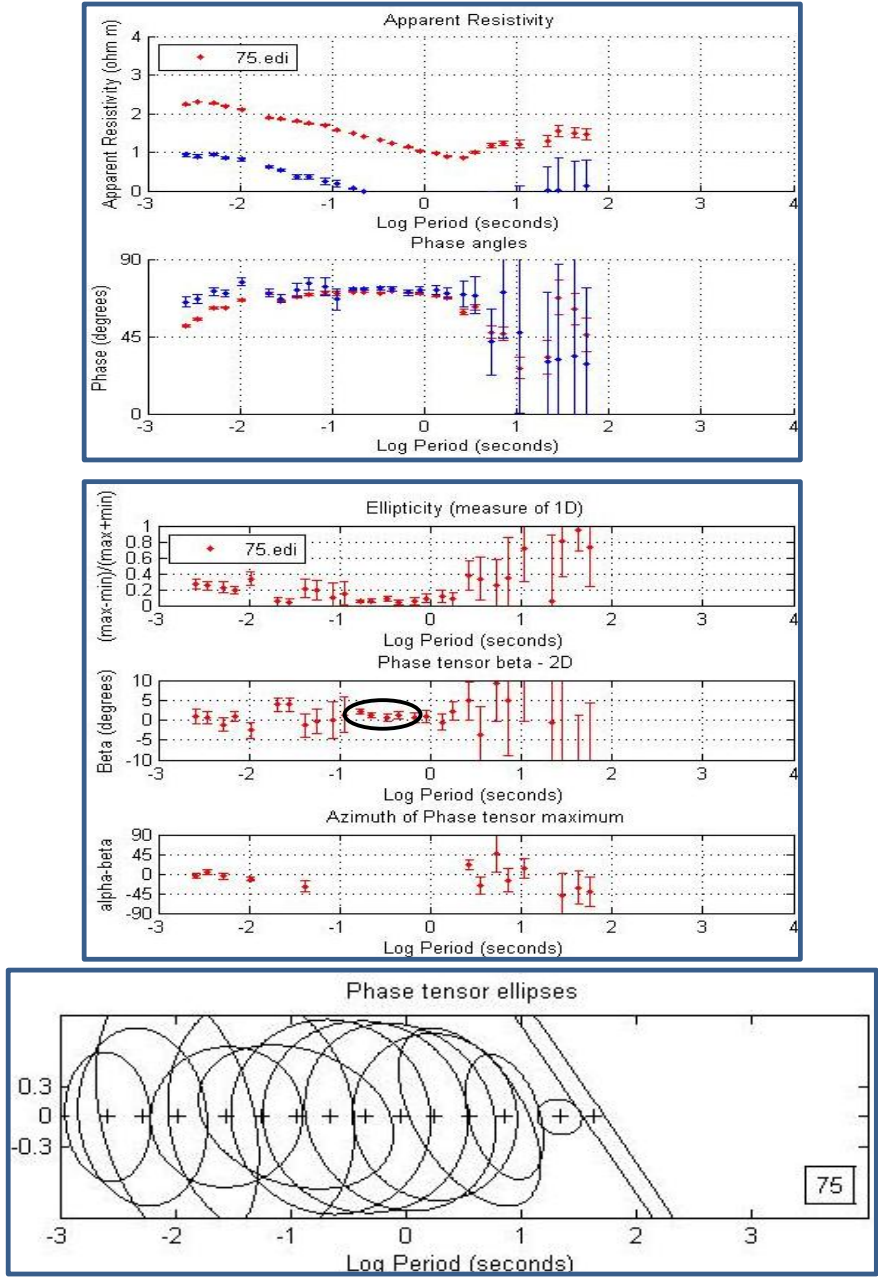

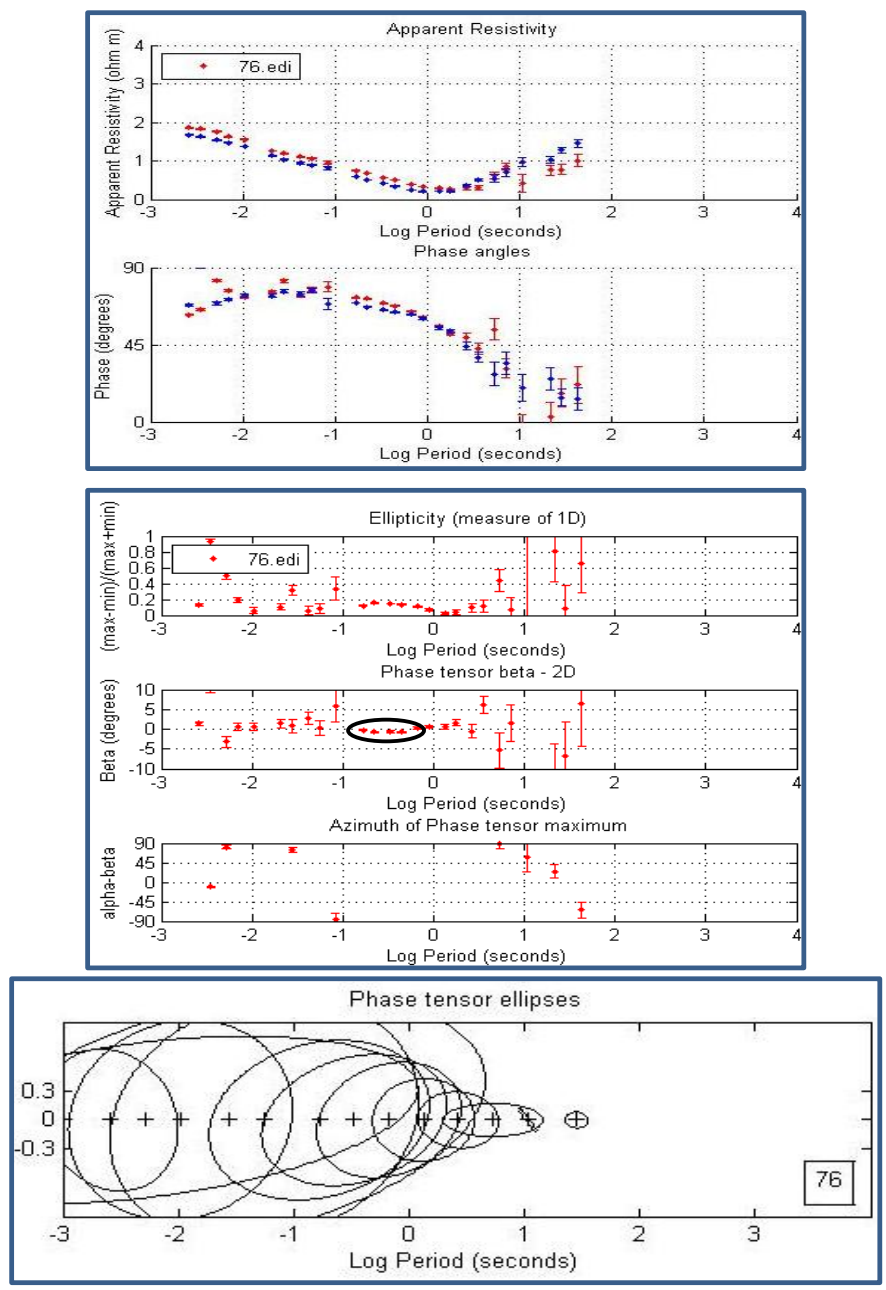

NNG-80
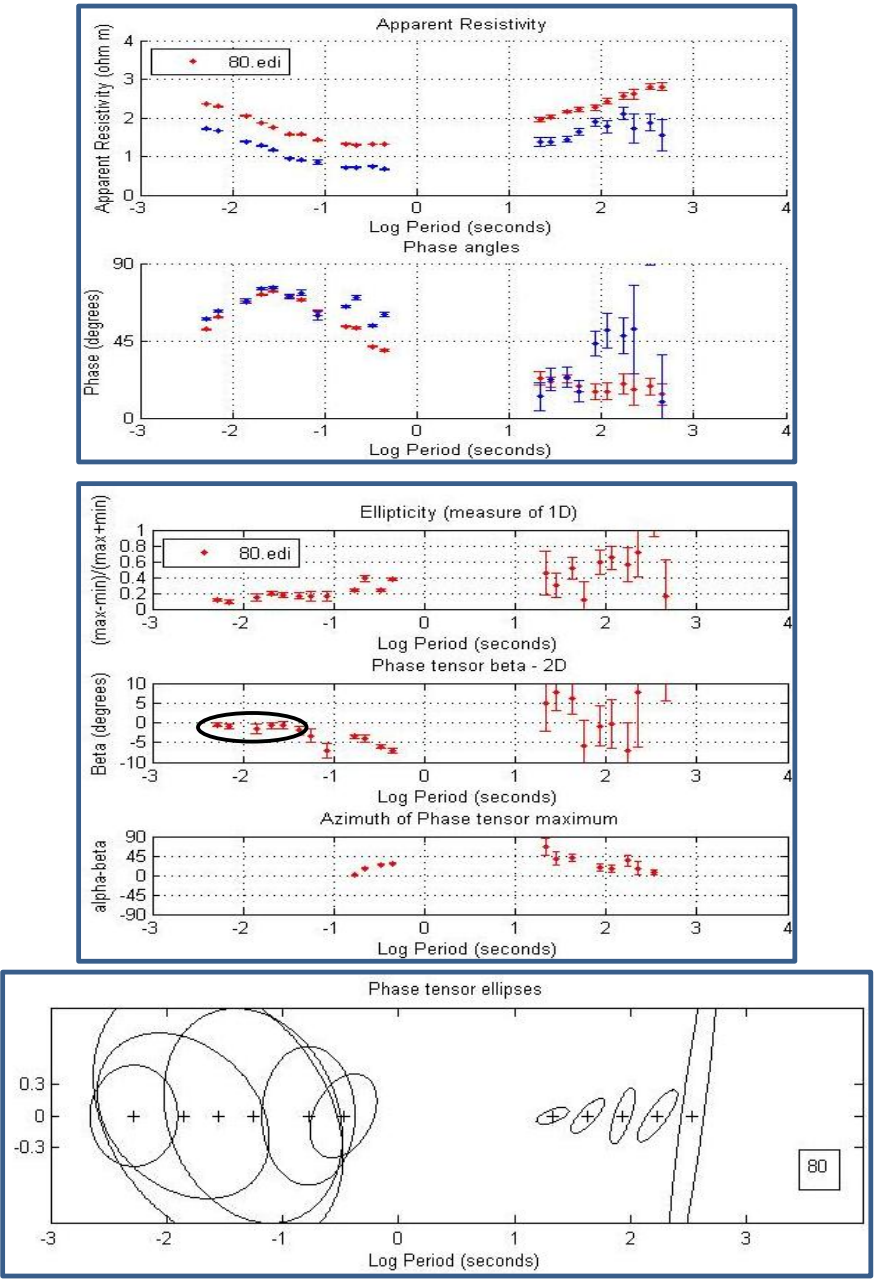
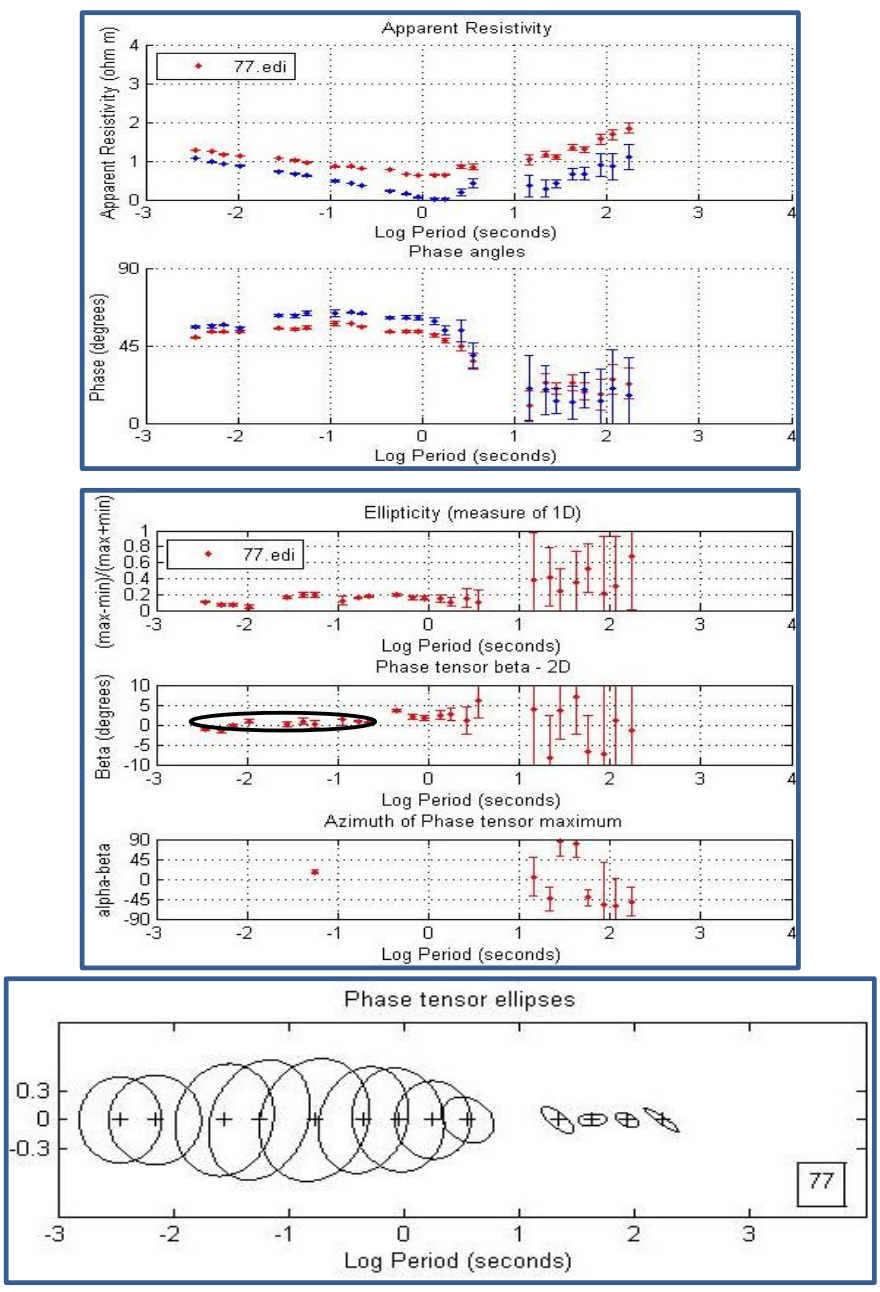

NNG-81
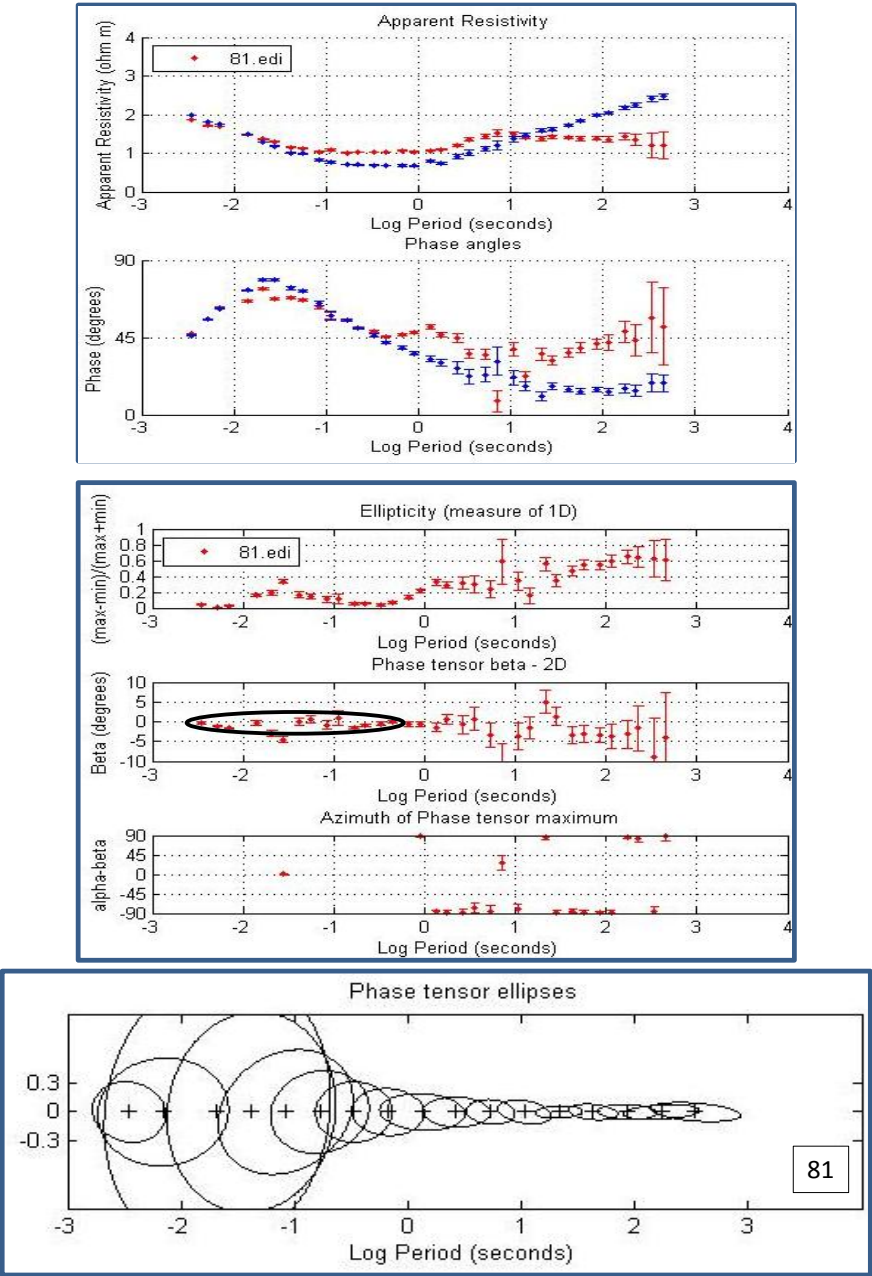

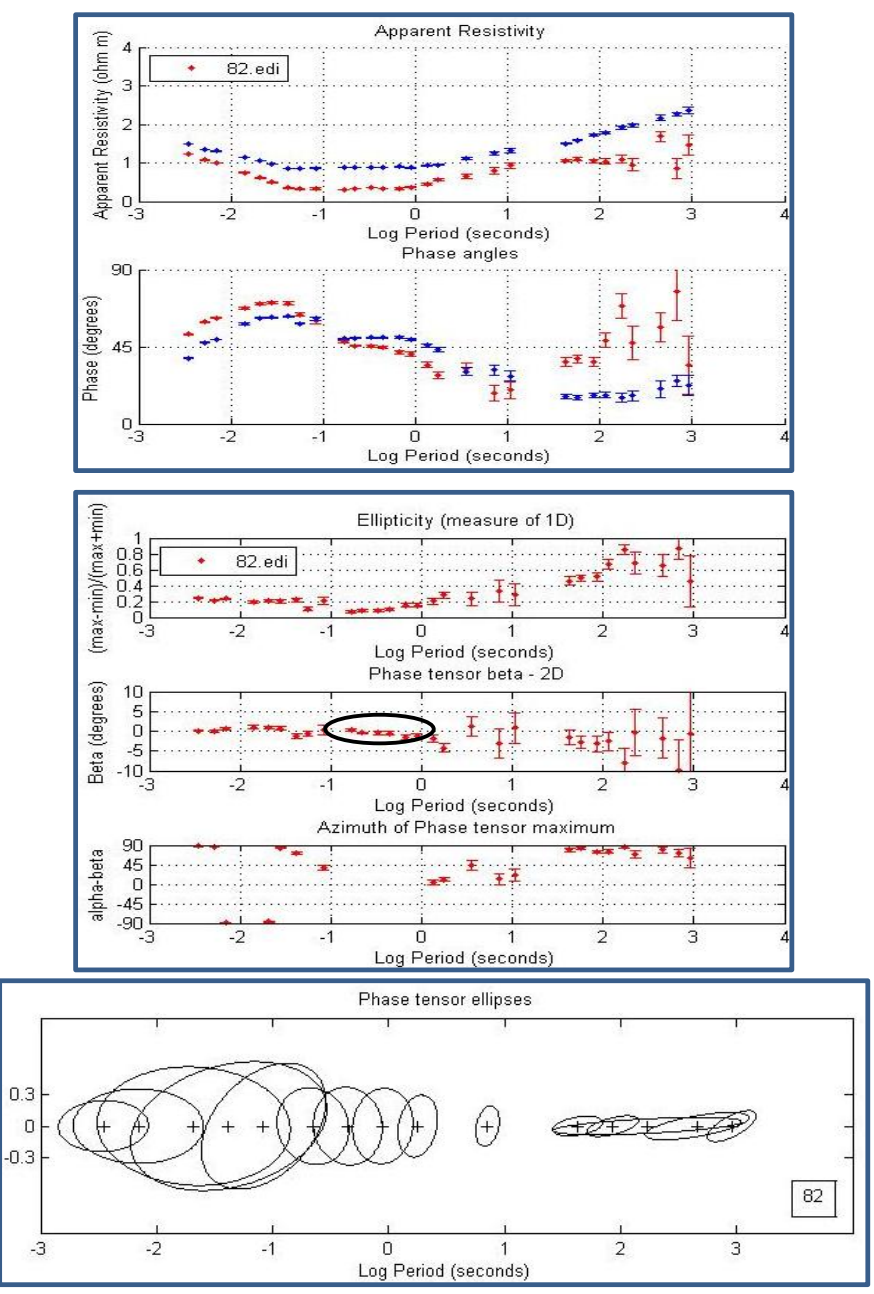

NNG-84
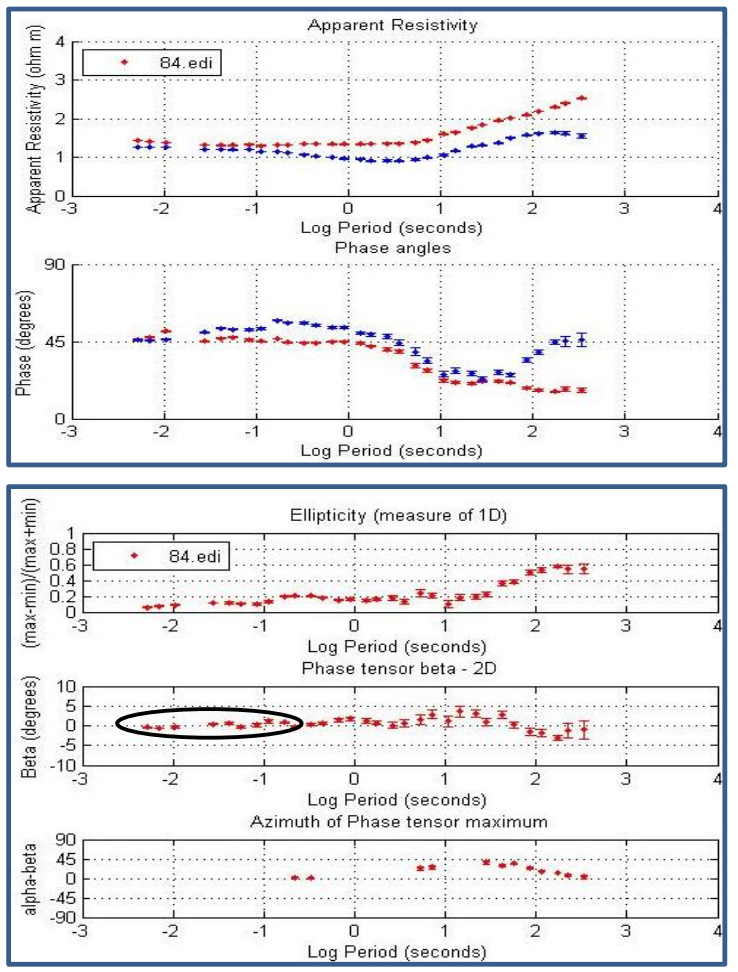

Phase tensor

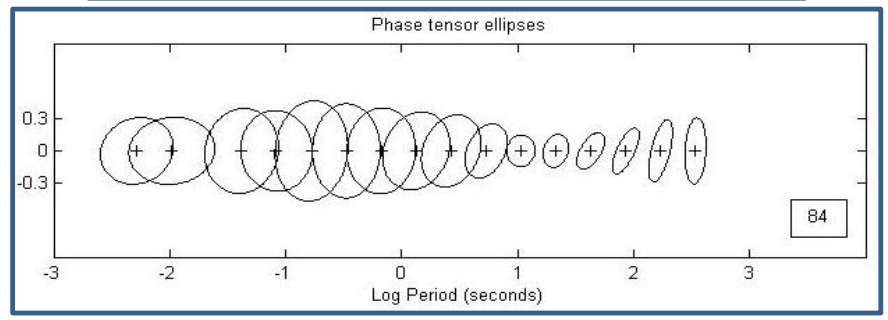

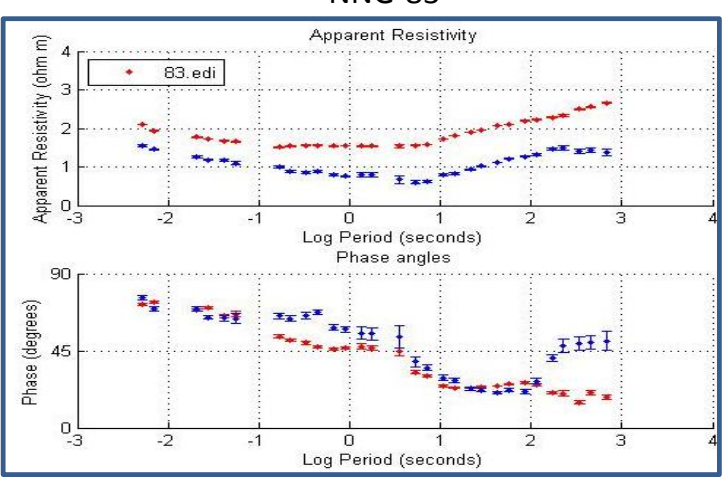
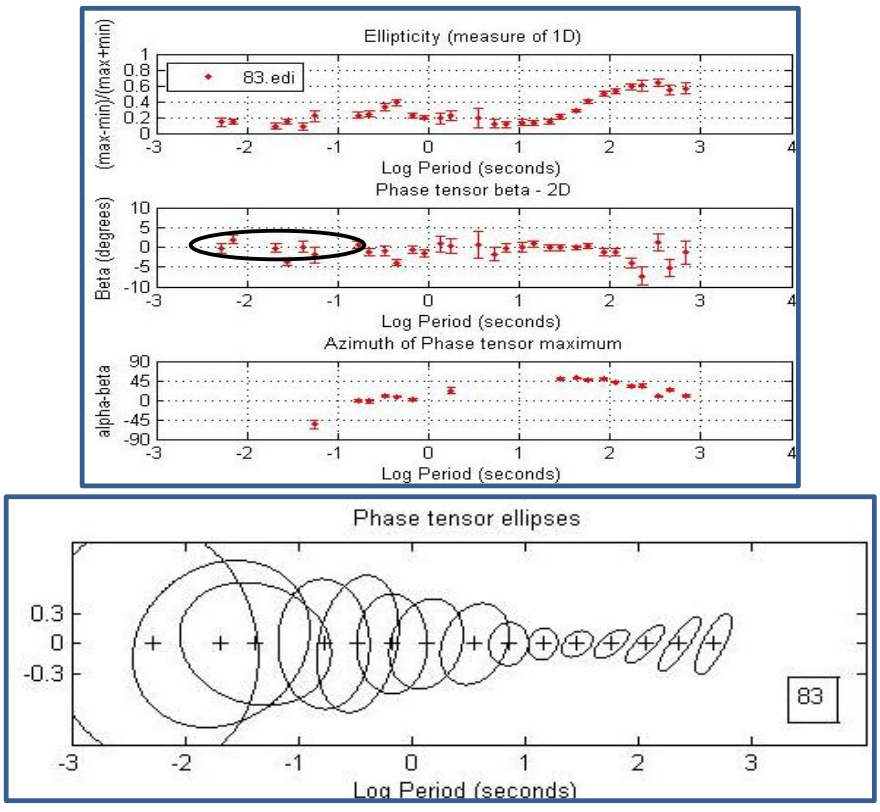

NNG-85
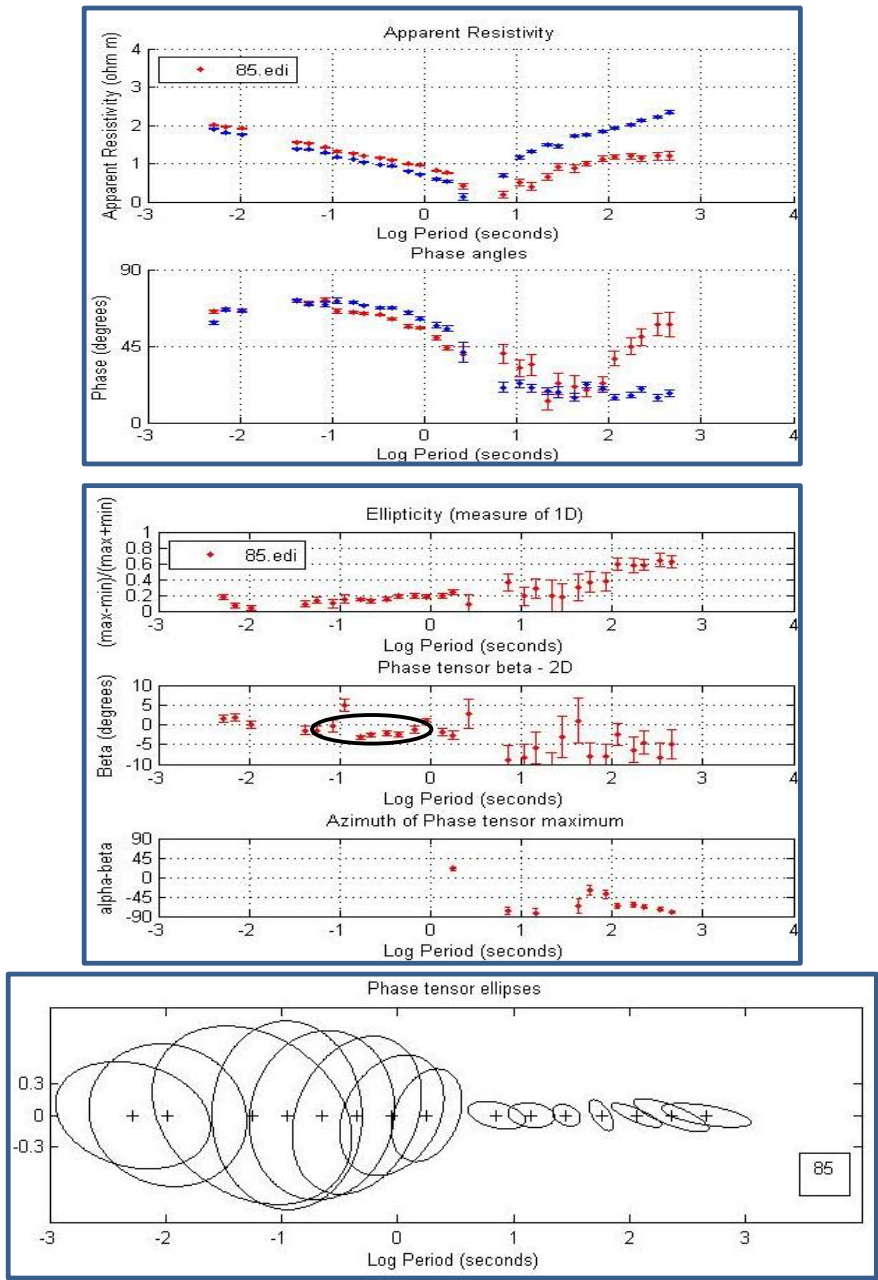

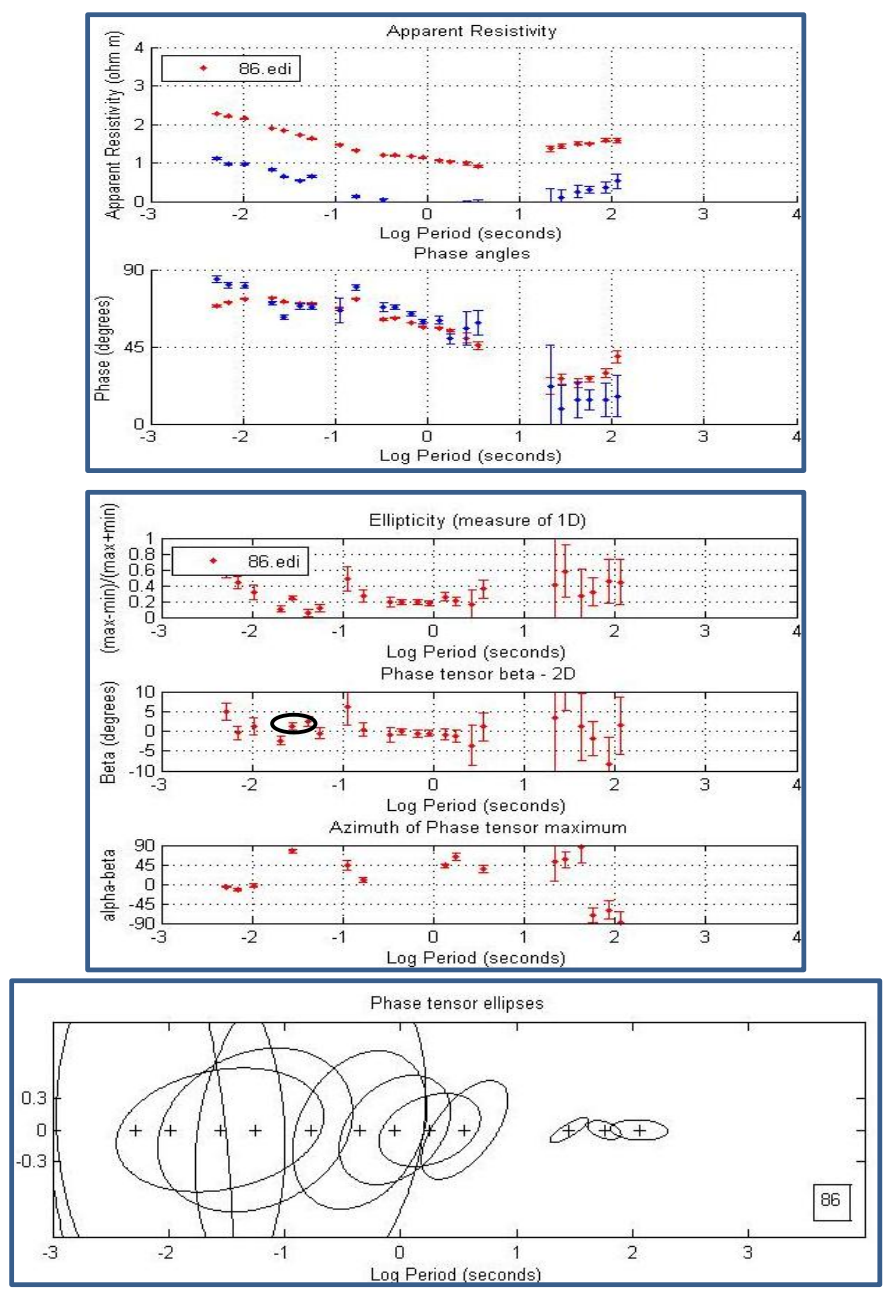

NNG-89
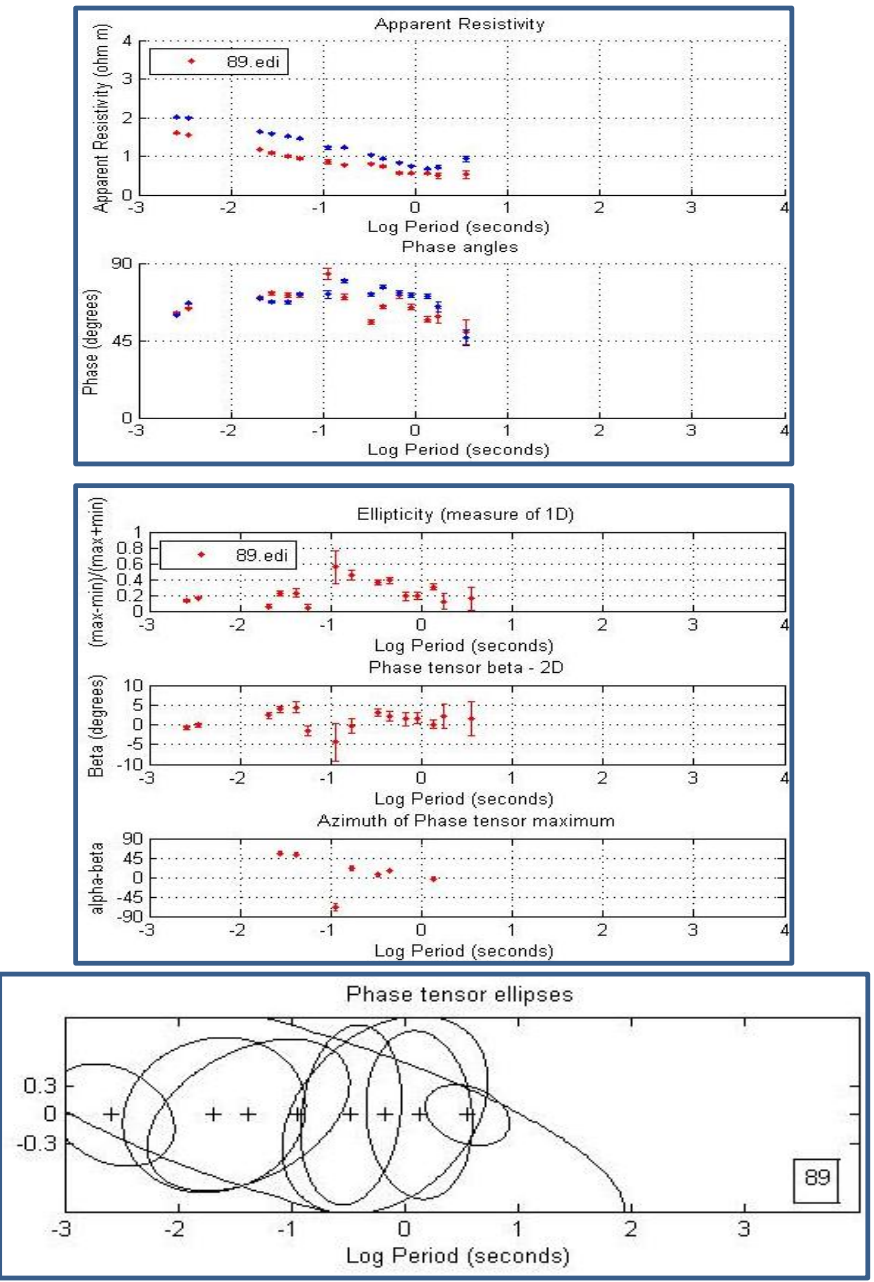

Apparent Resistivity
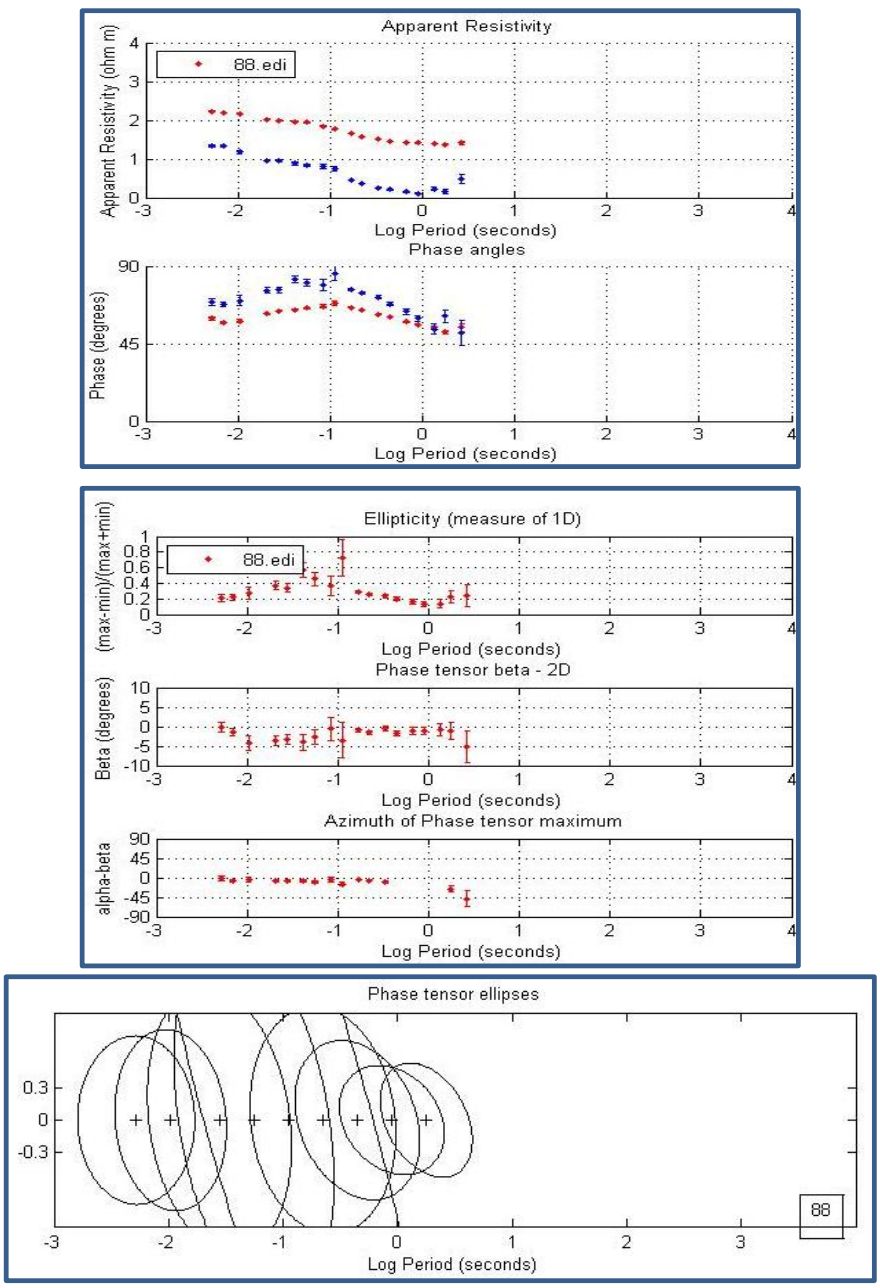

NNG-91
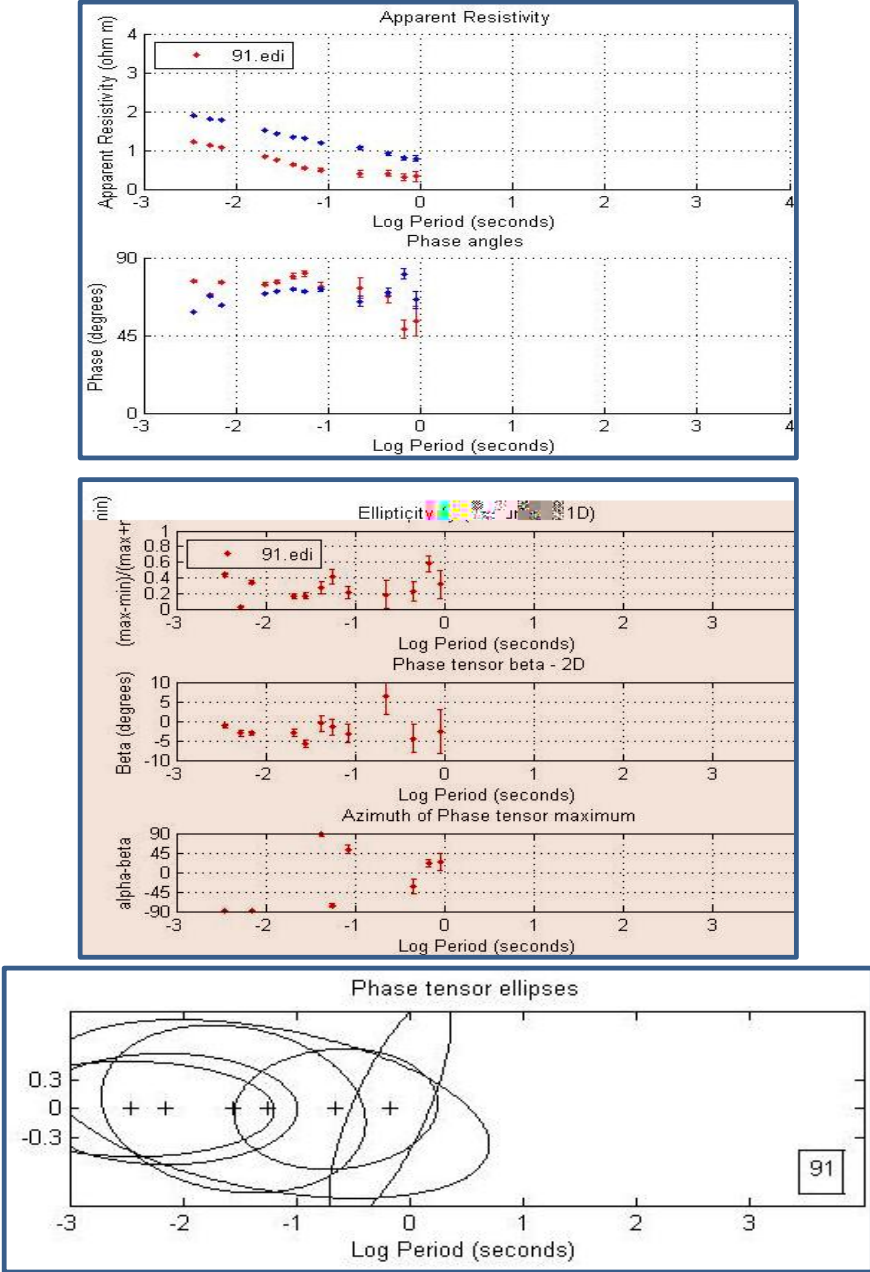

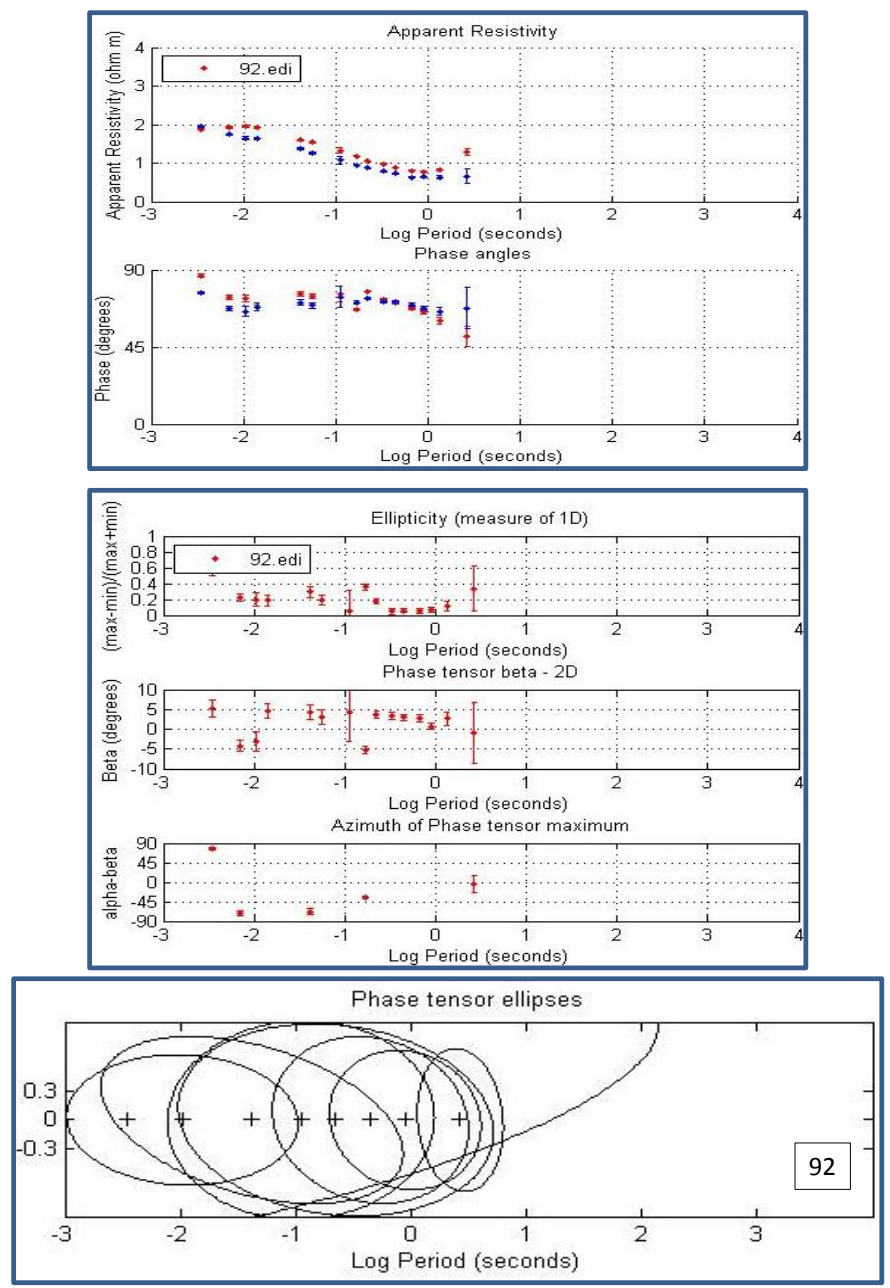

NNG-94
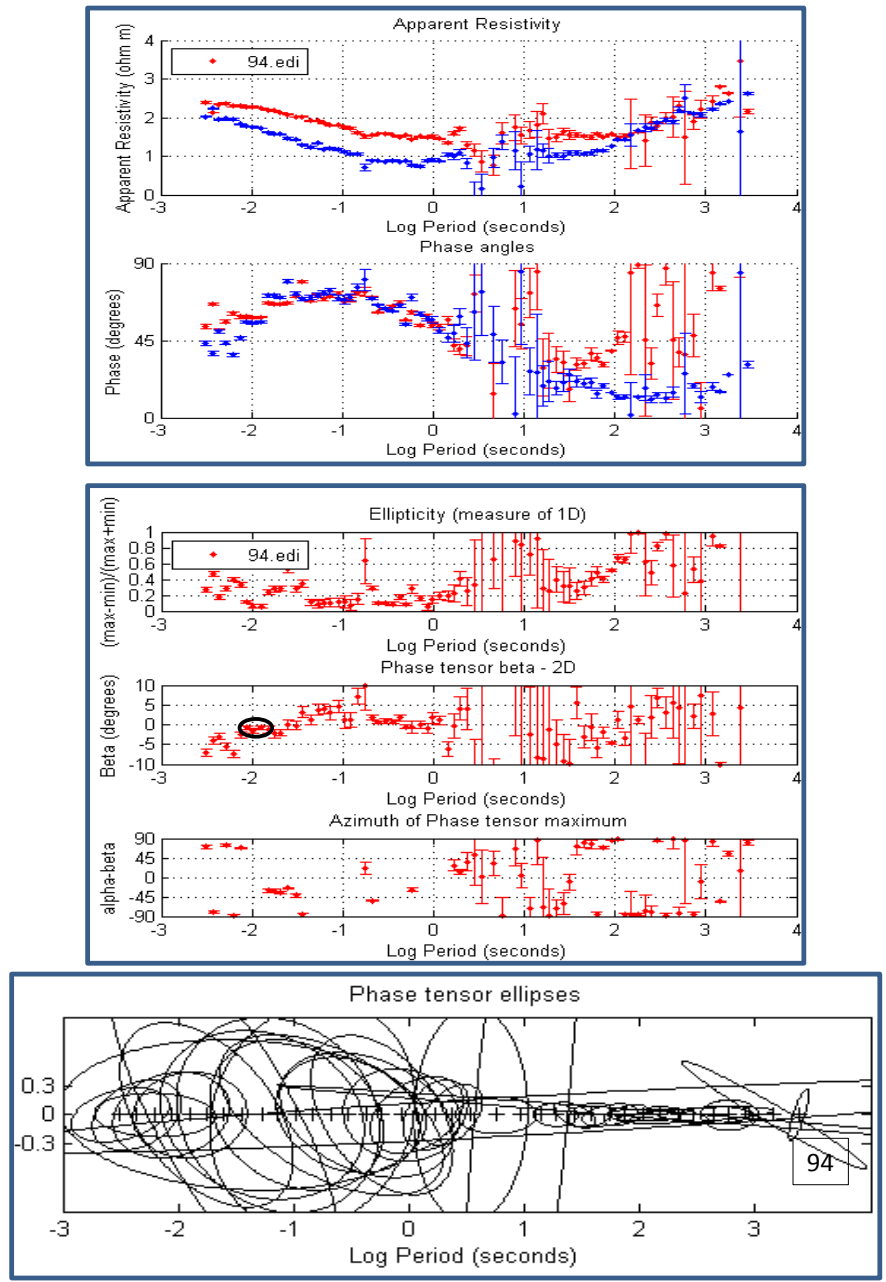
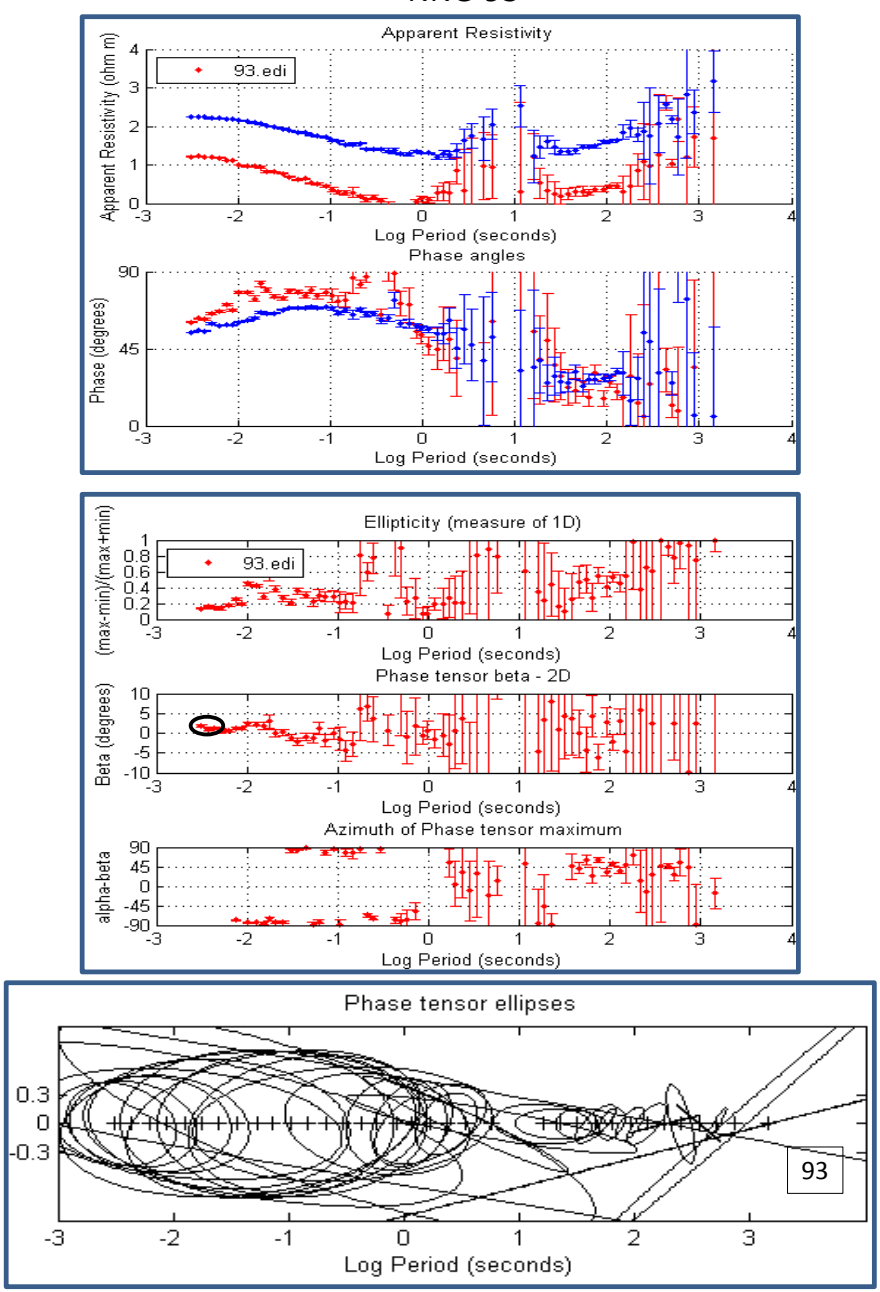

NNG-95
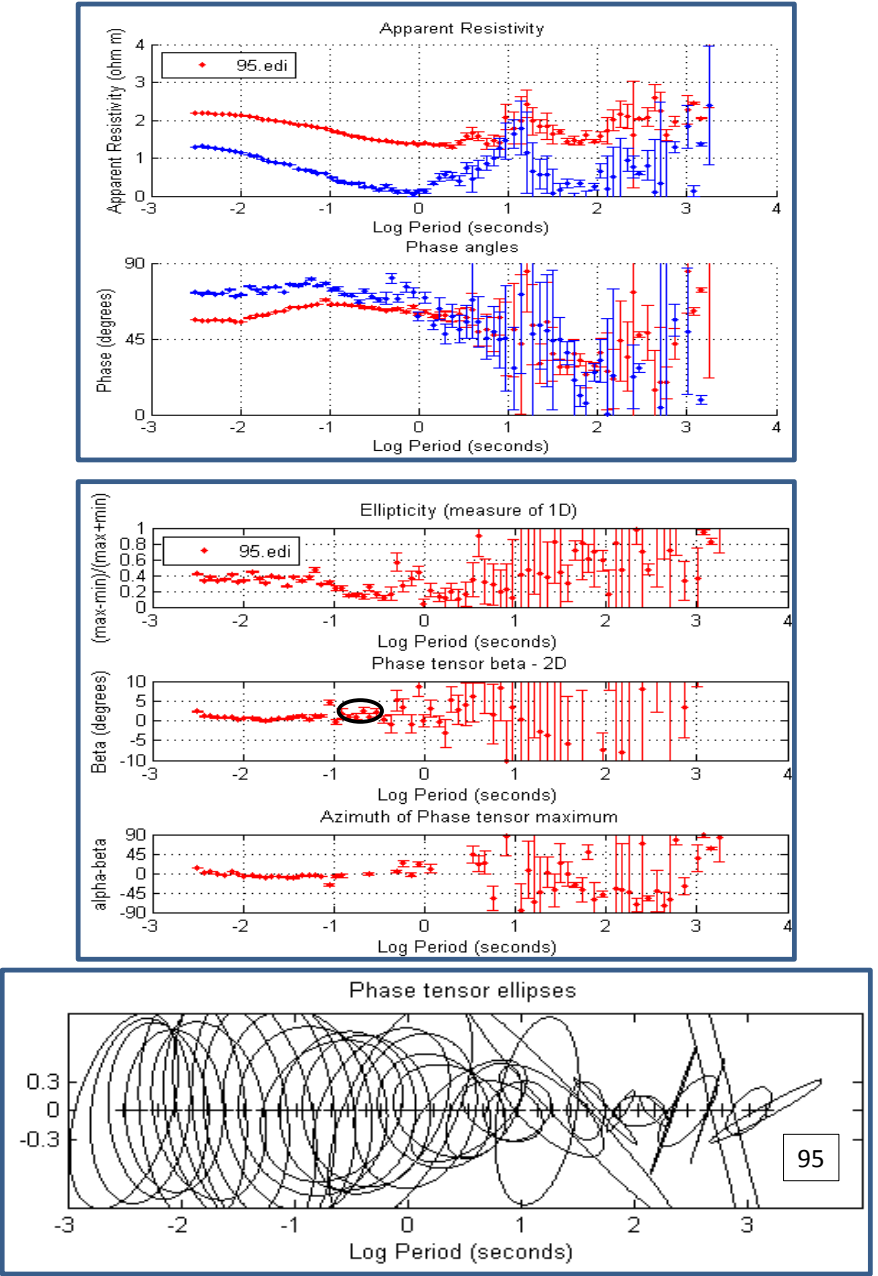
NNG-96
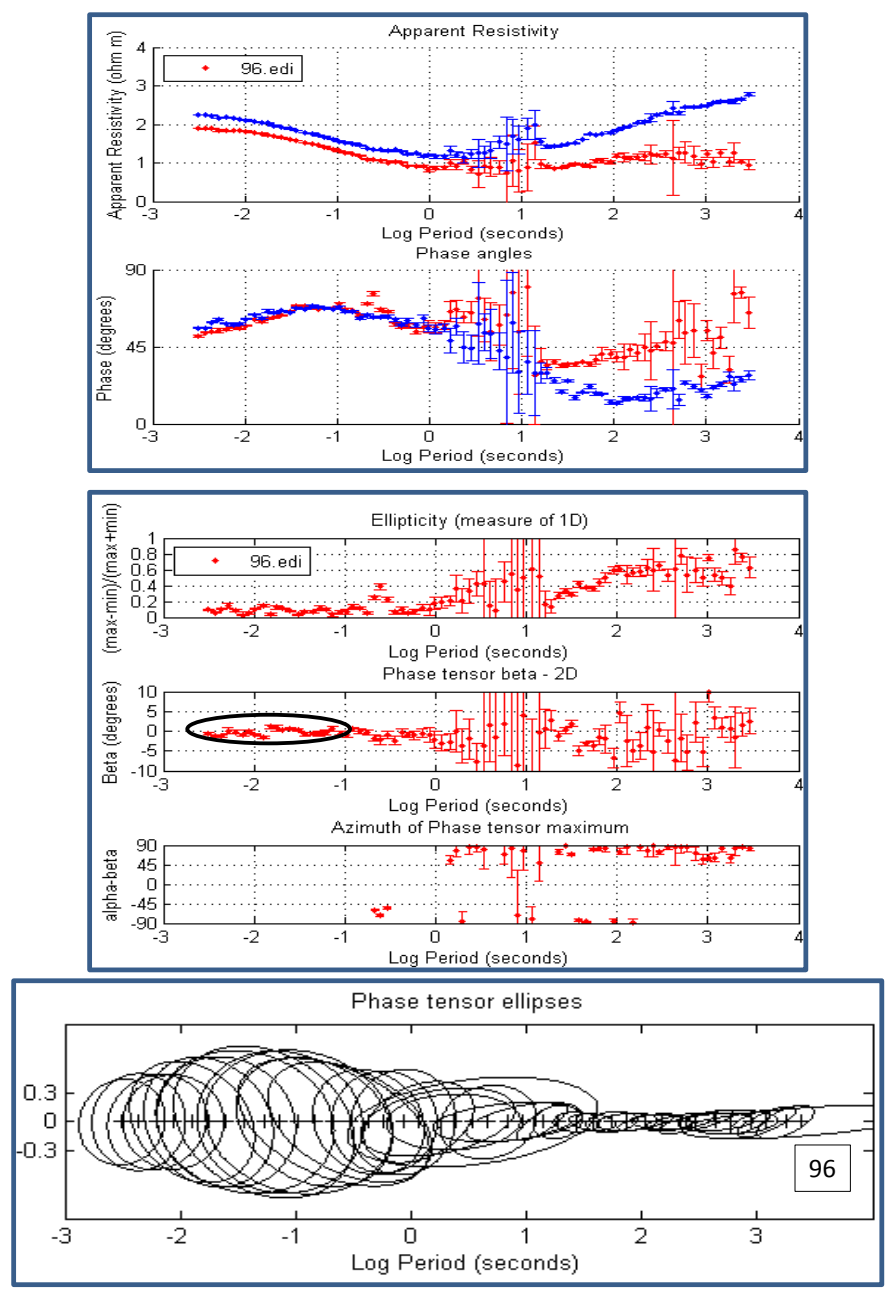

NNG-98
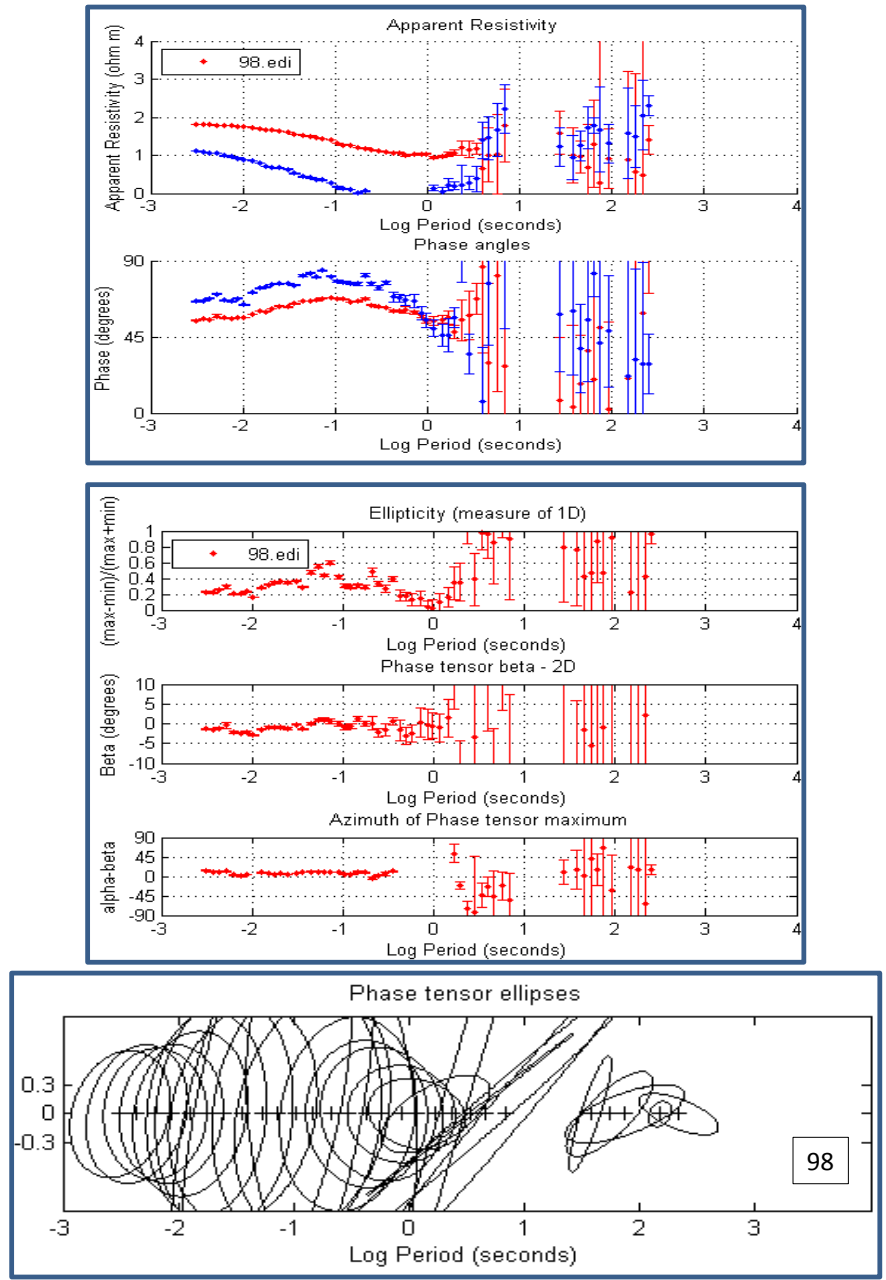

NNG-97
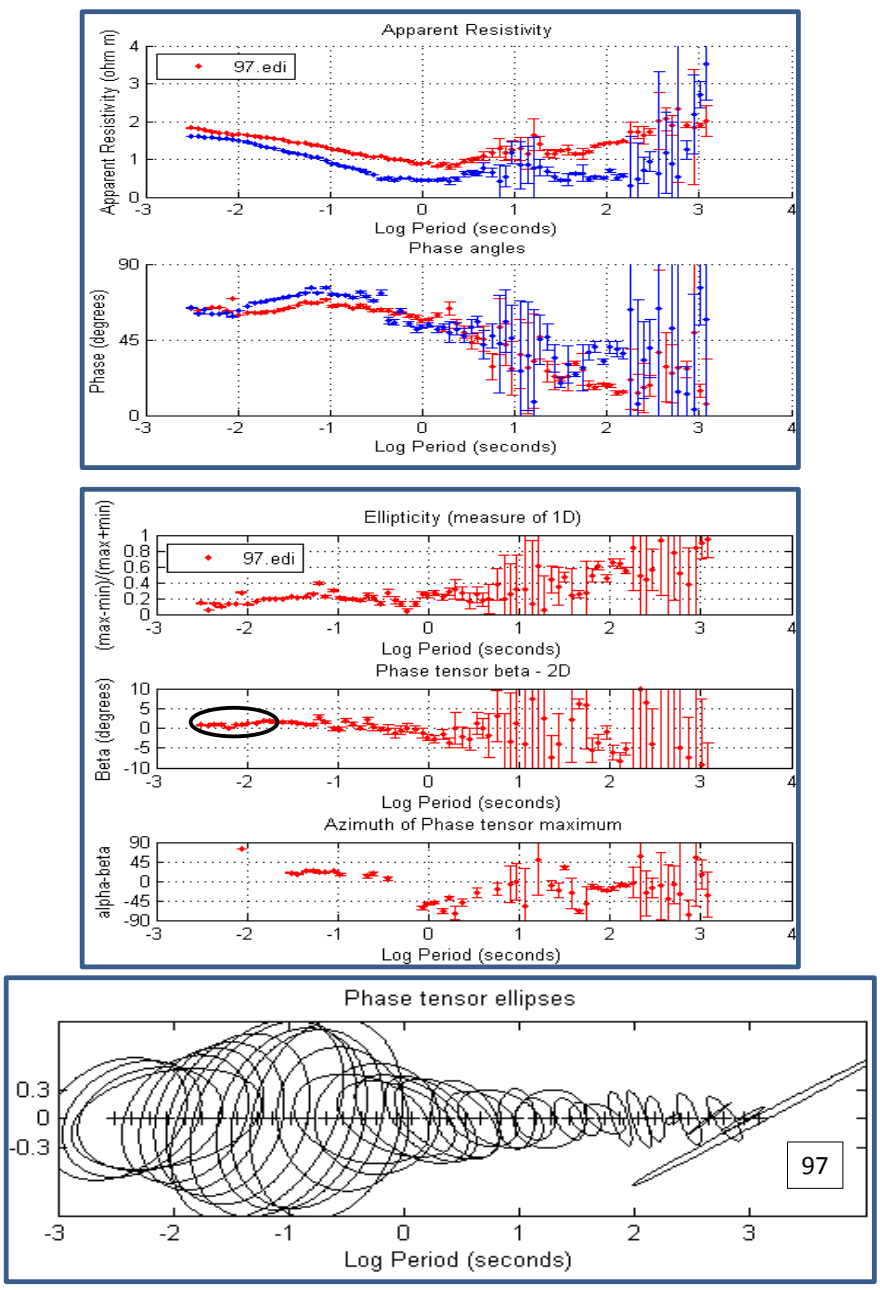

NNG-99
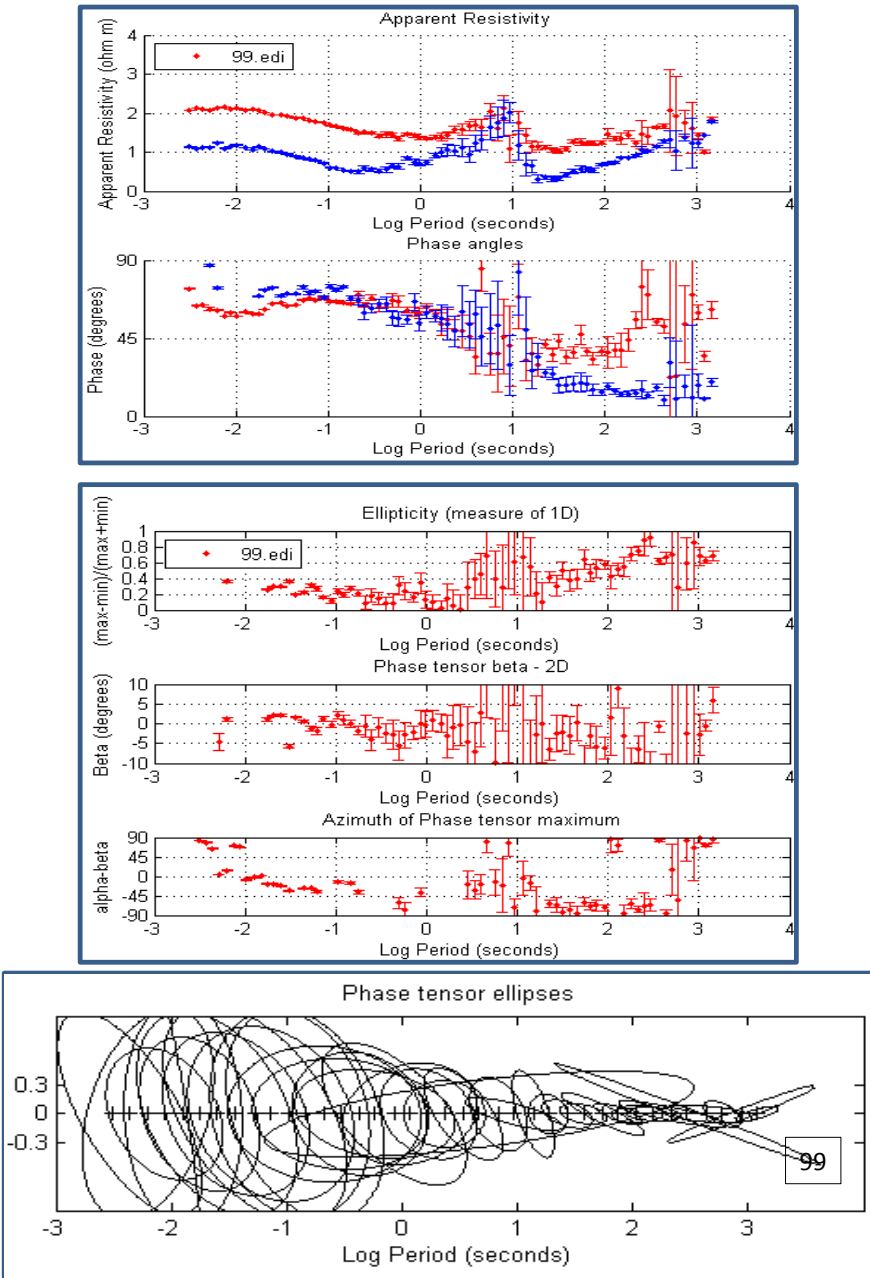
NNG- 100
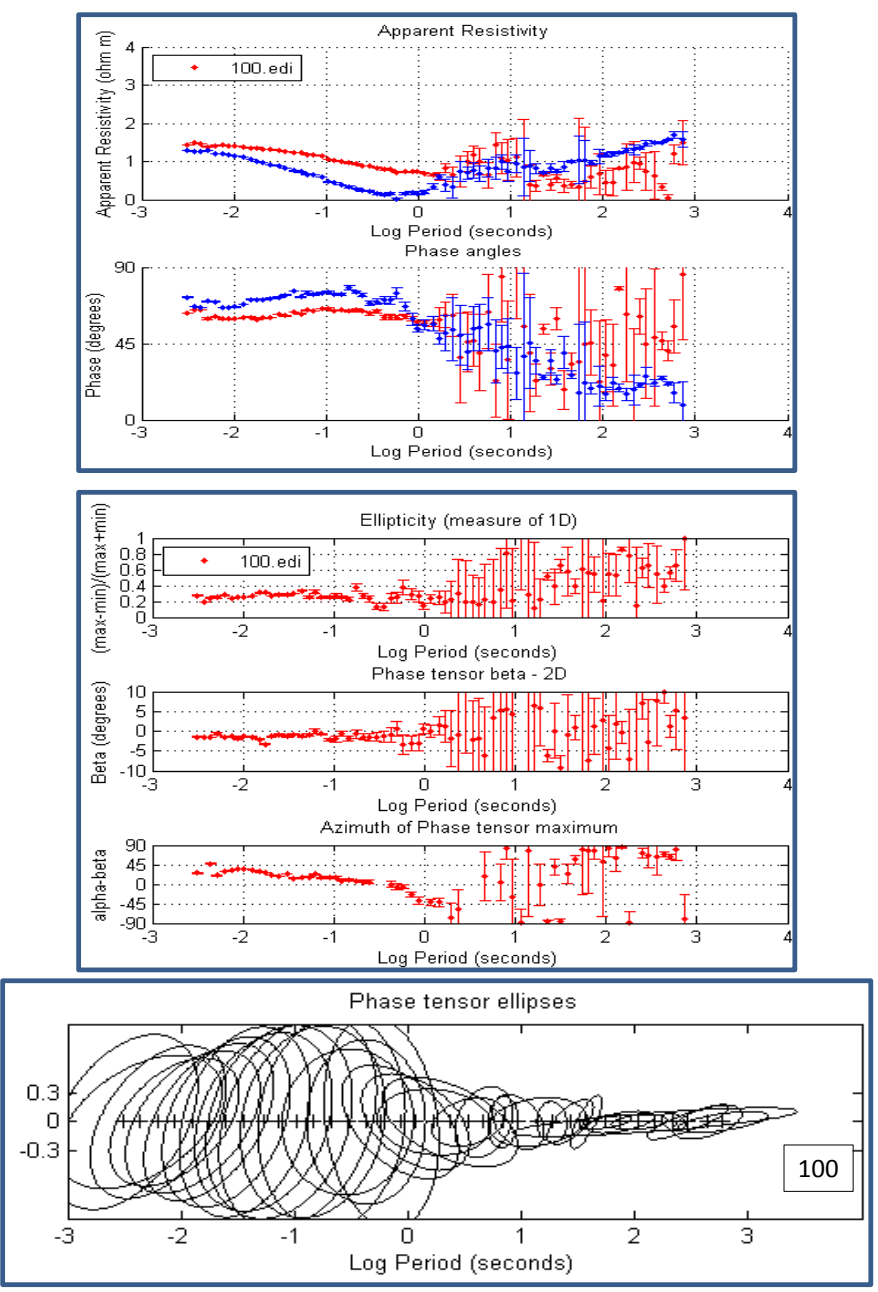

NNG-102
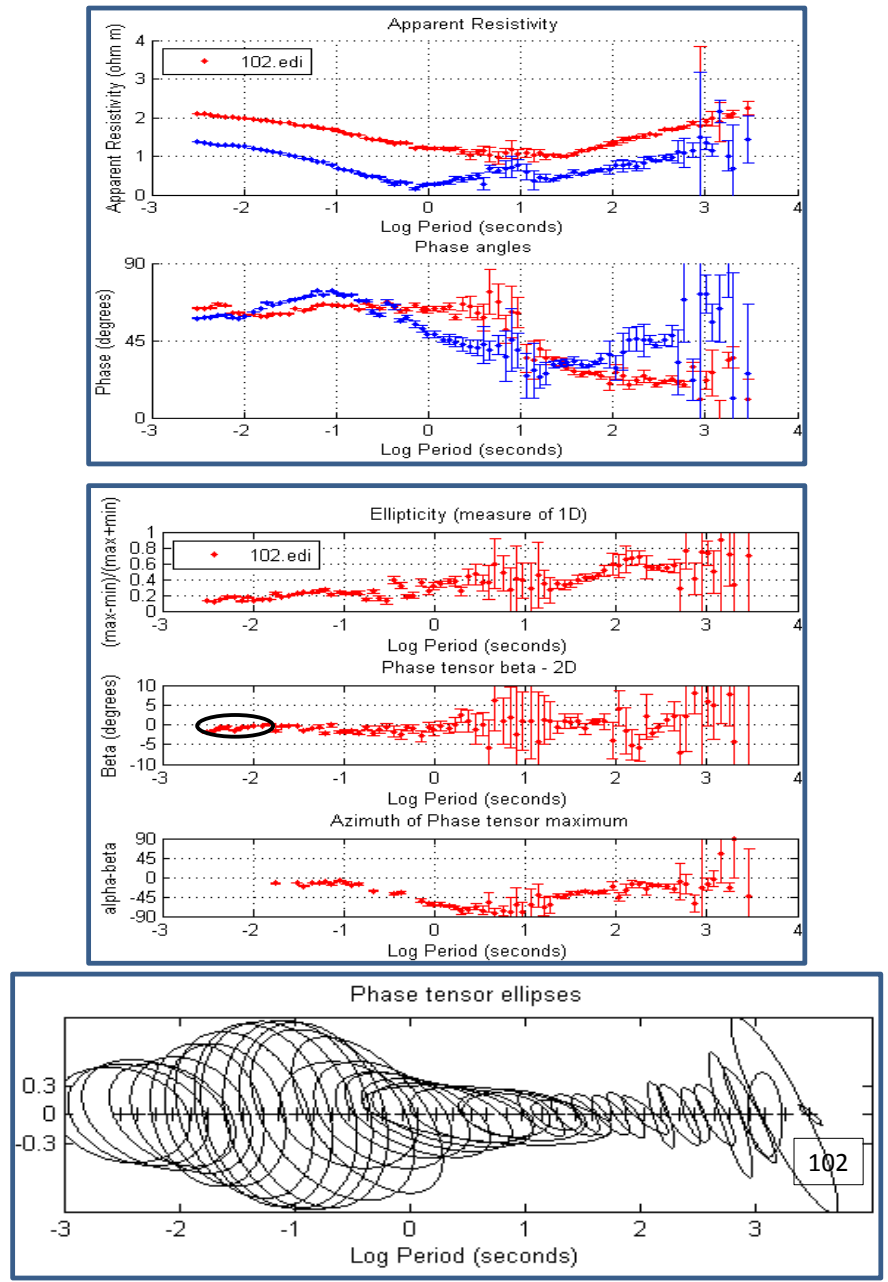

NNG-101
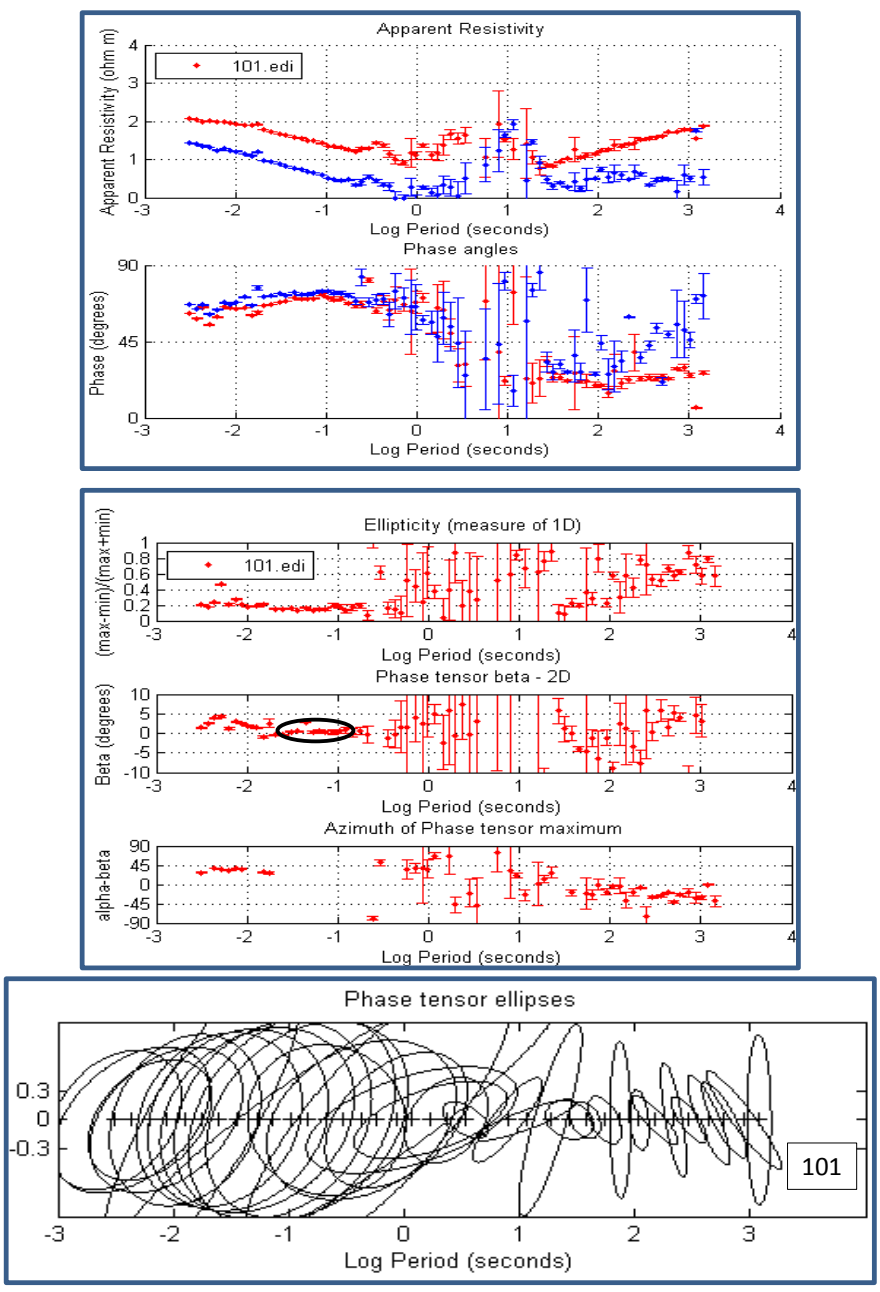

NNG-103
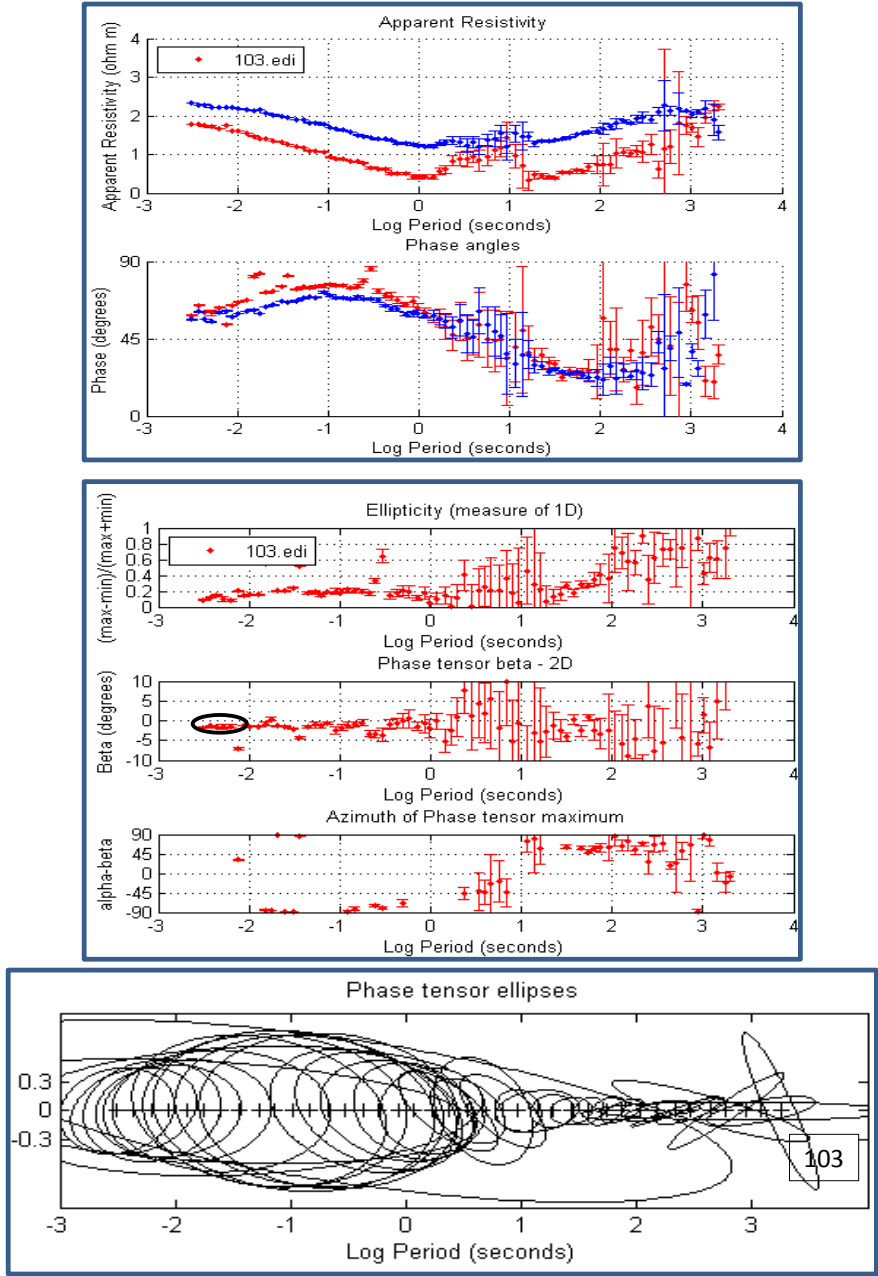
NNG-104
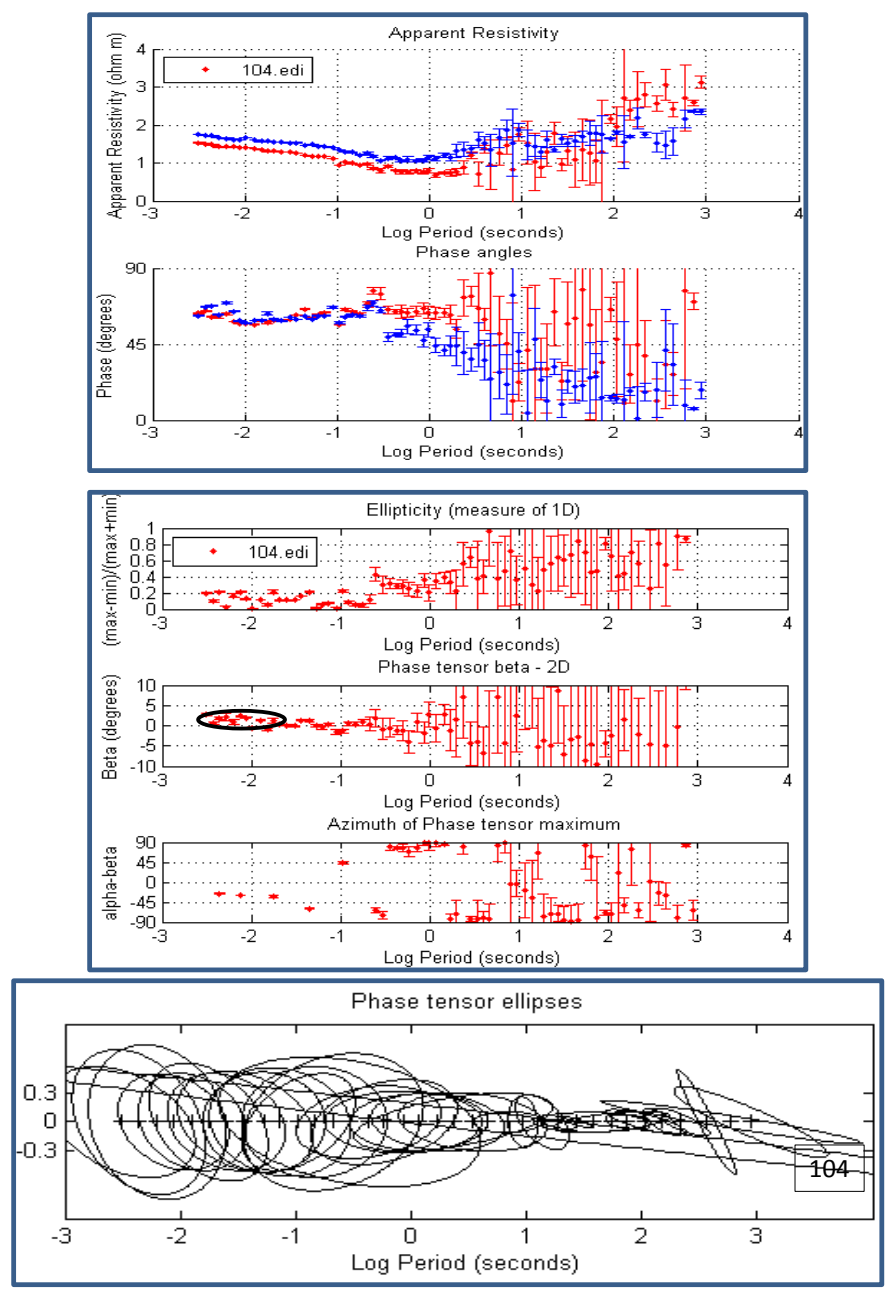

NNG-106
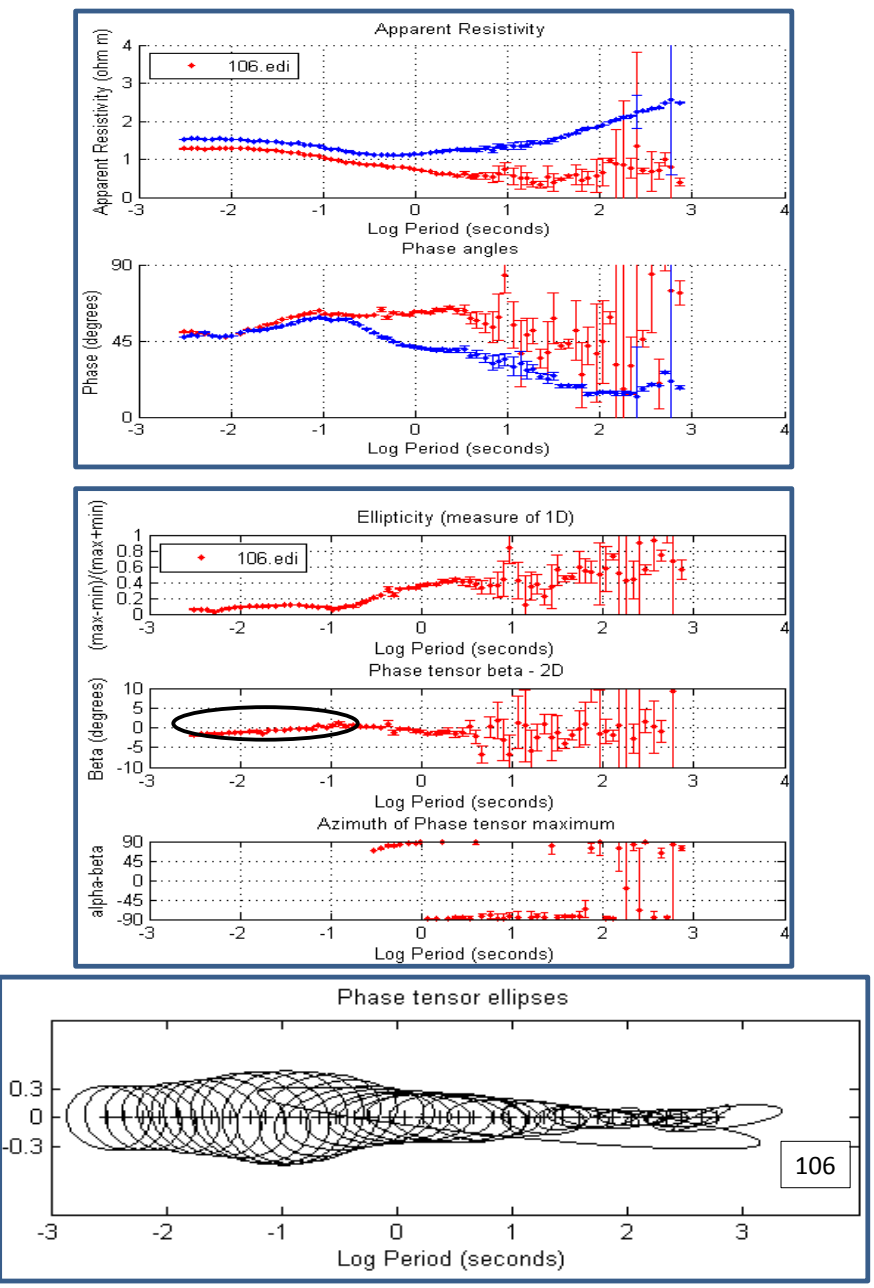

NNG-105
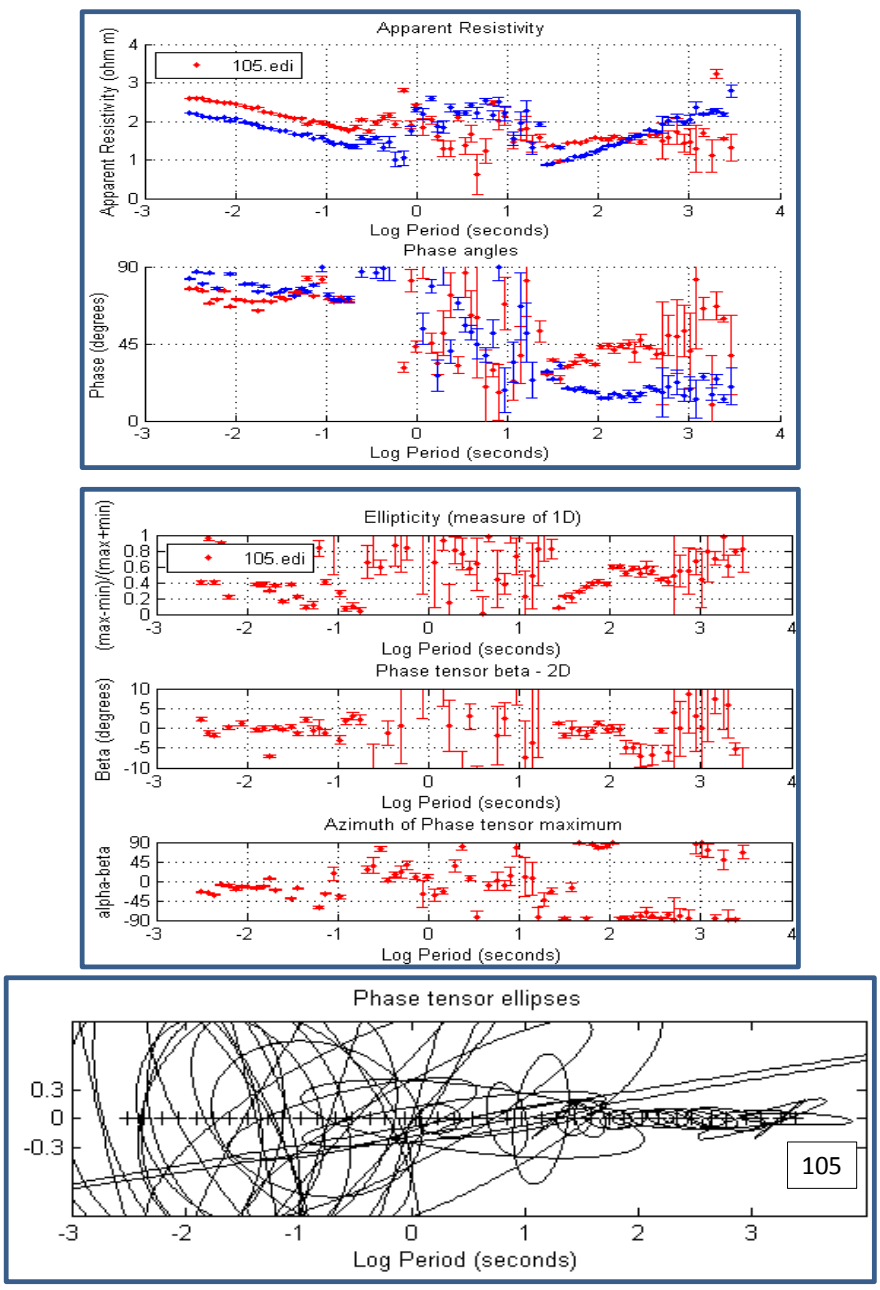

NNG-107
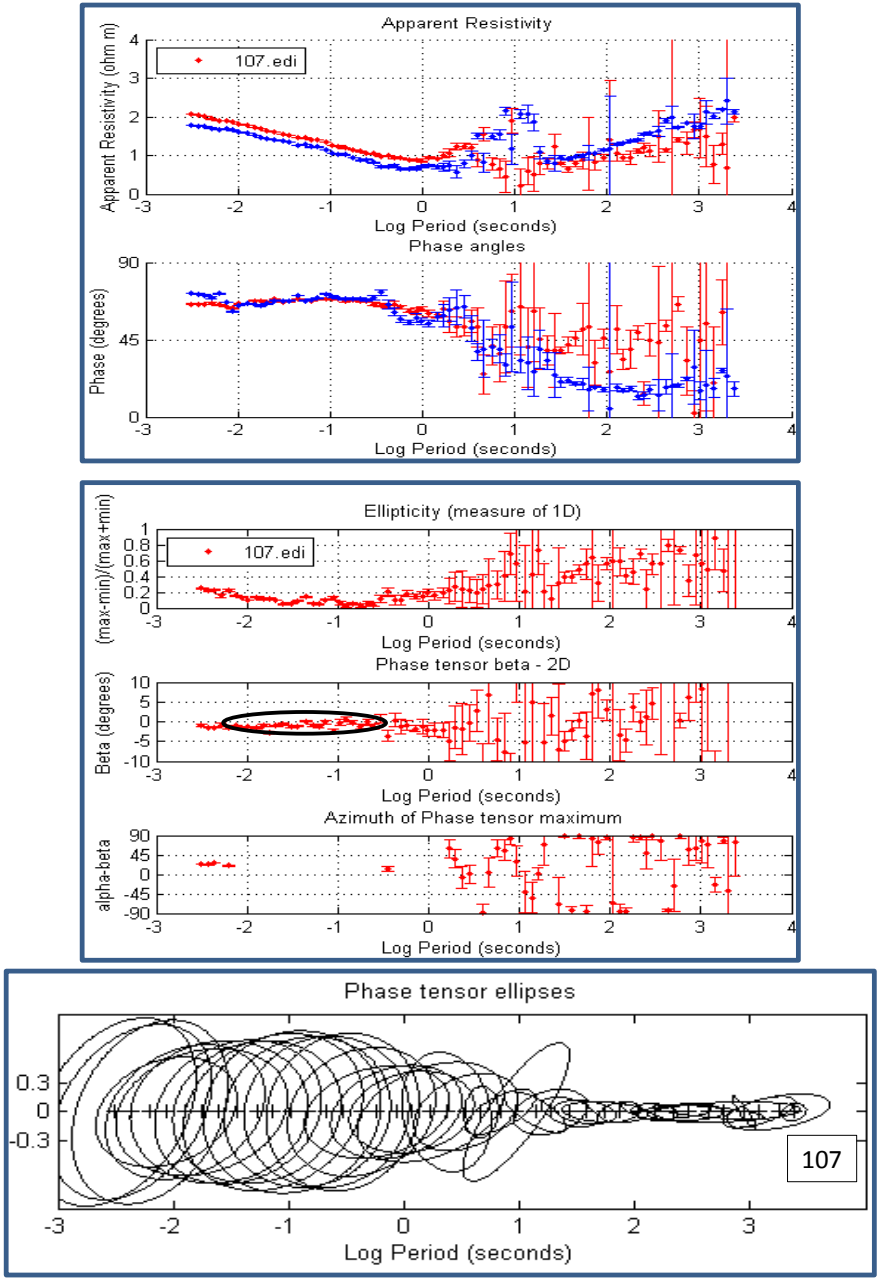
NNG-108
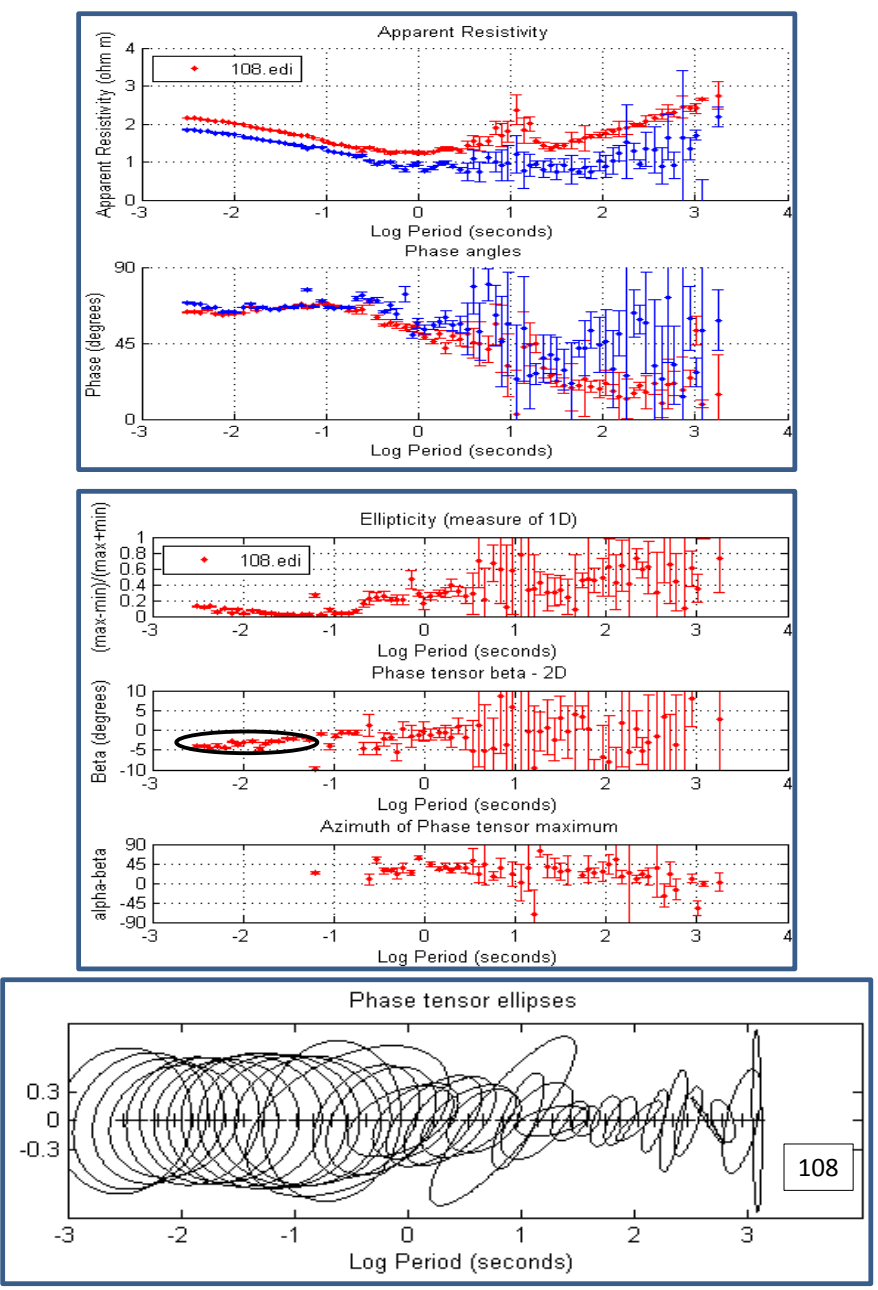

NNG-110
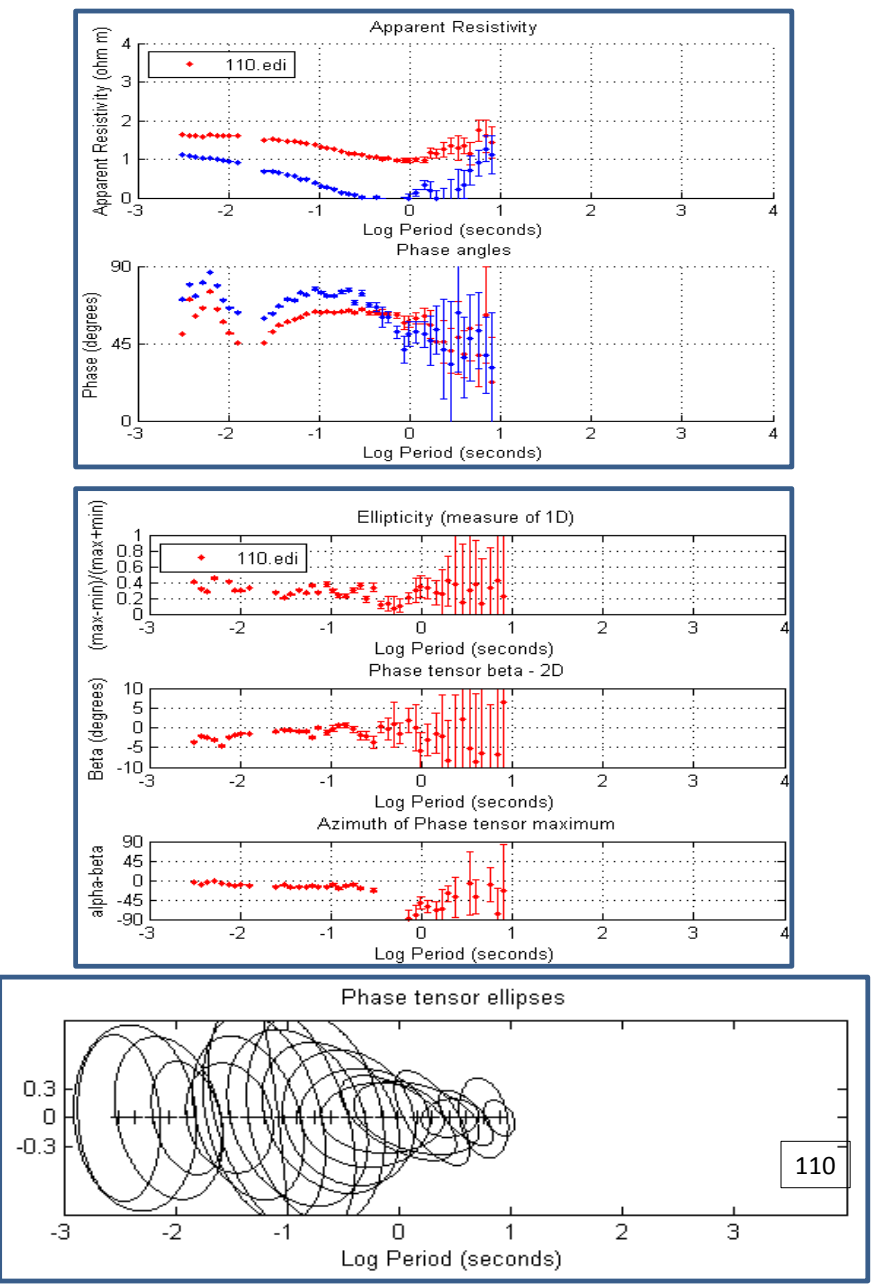

NNG-109
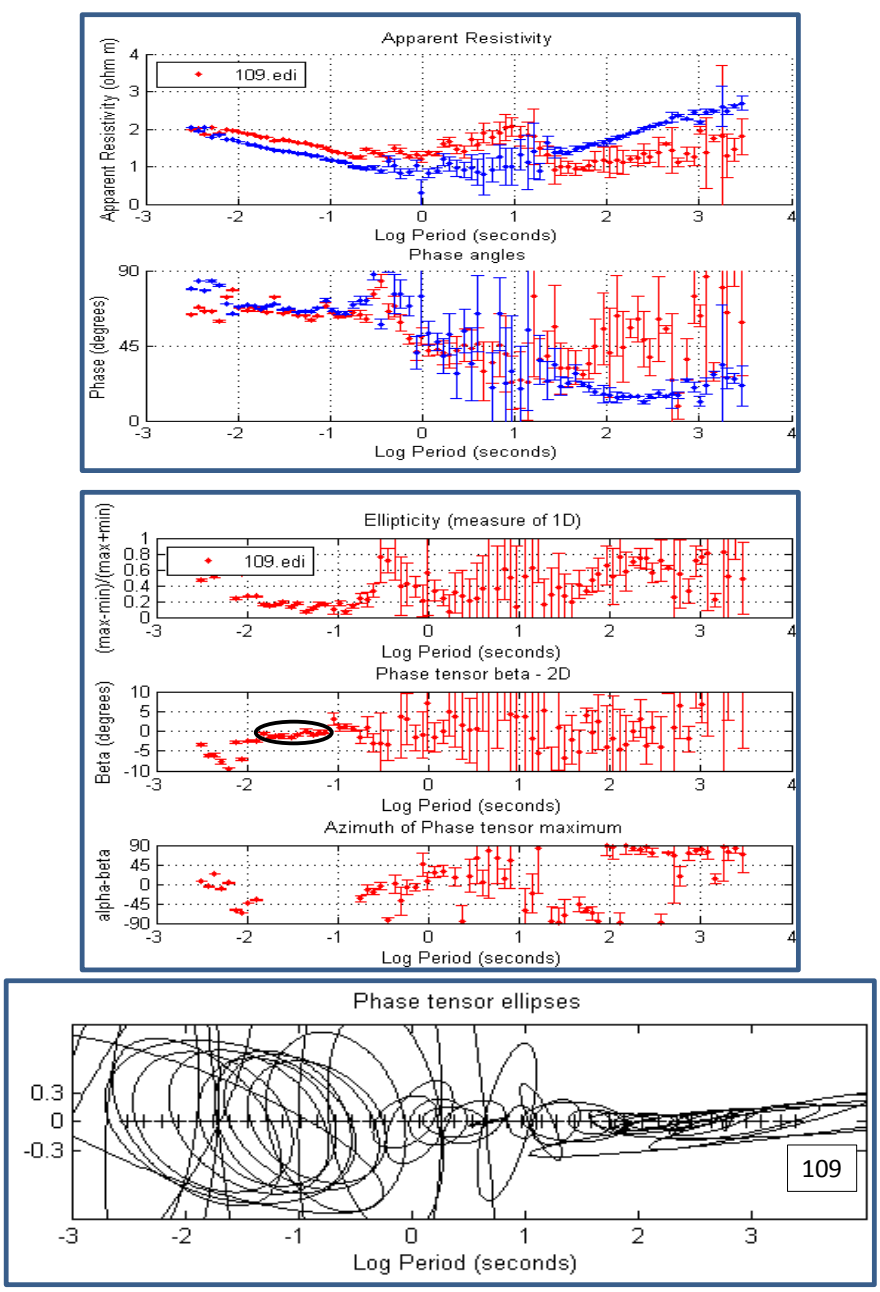

NNG-111
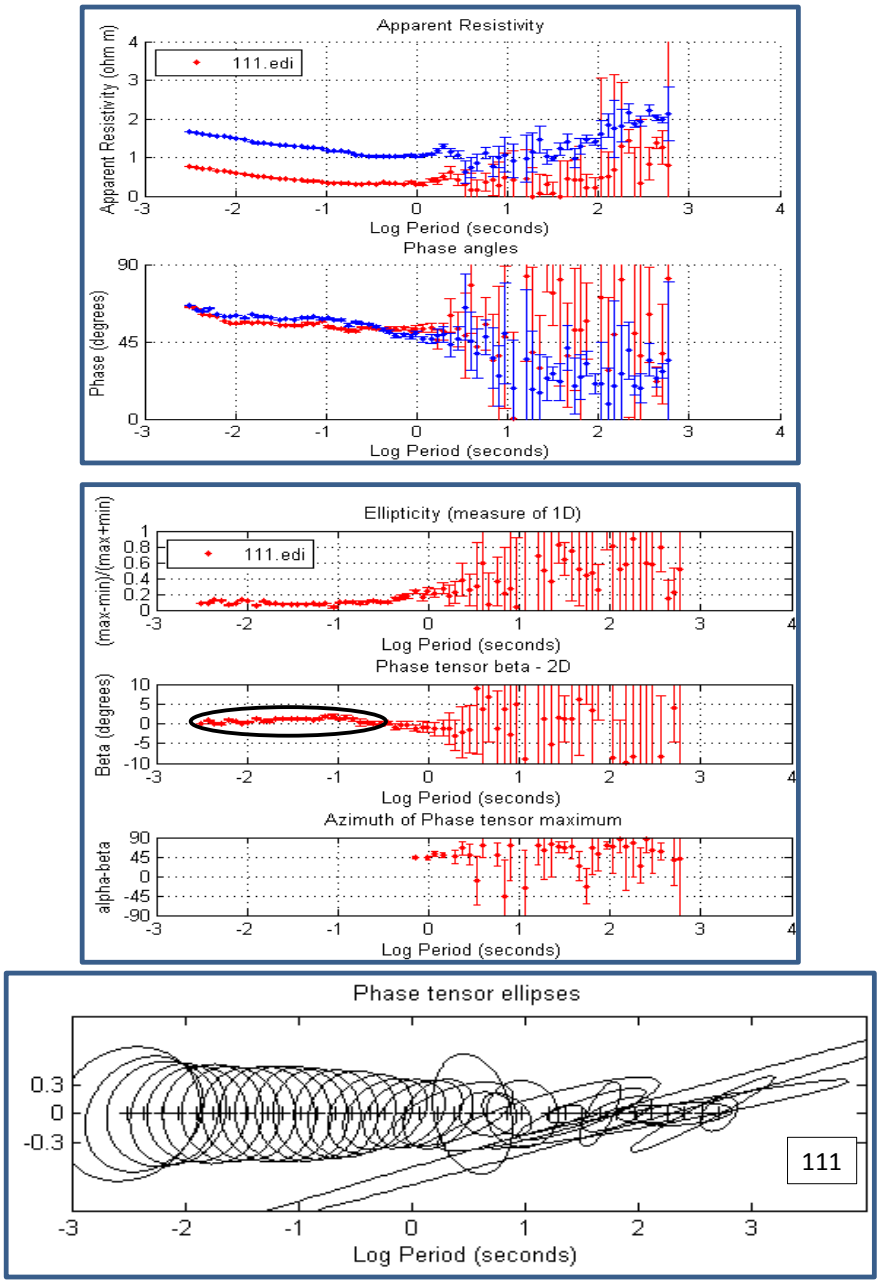
NNG-112
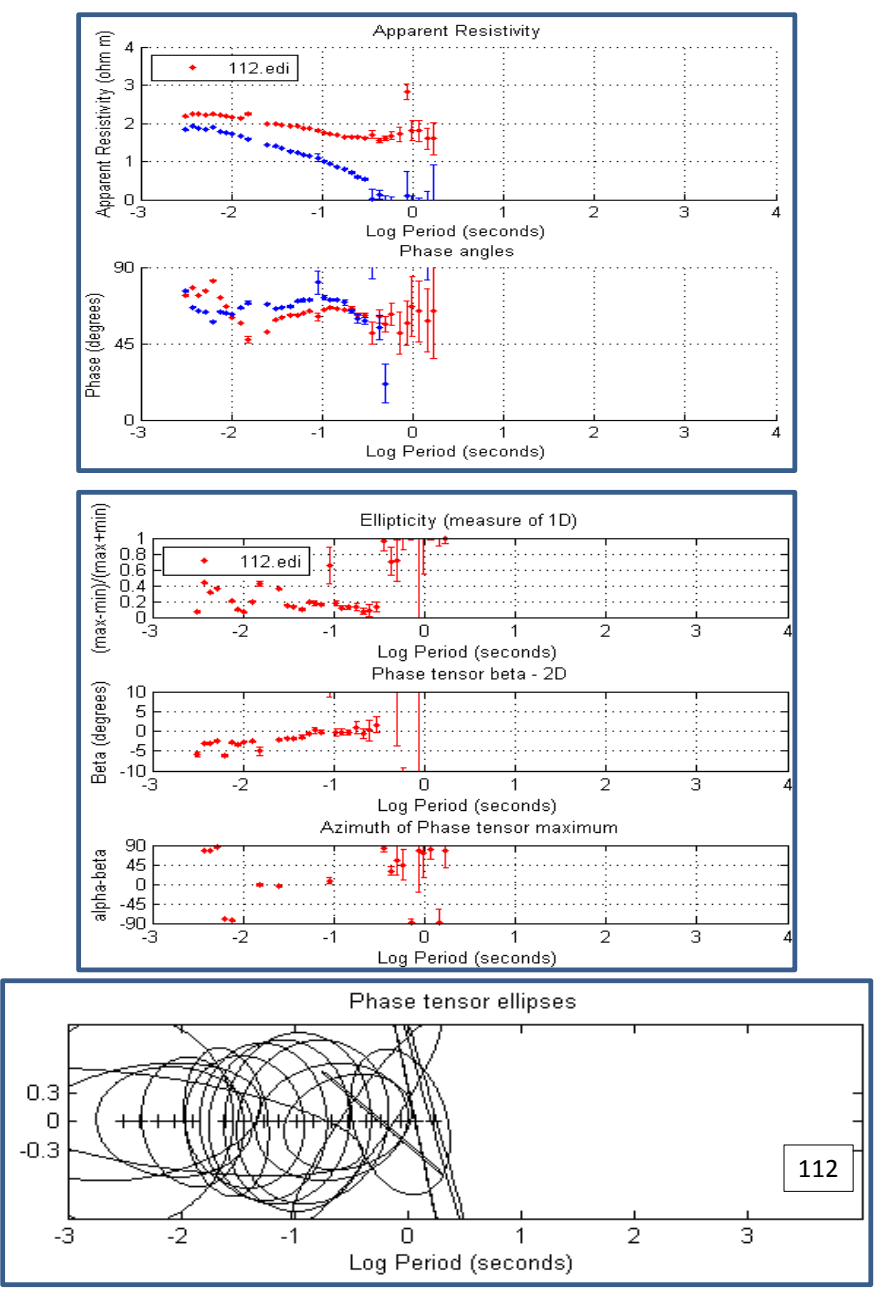

NNG-115
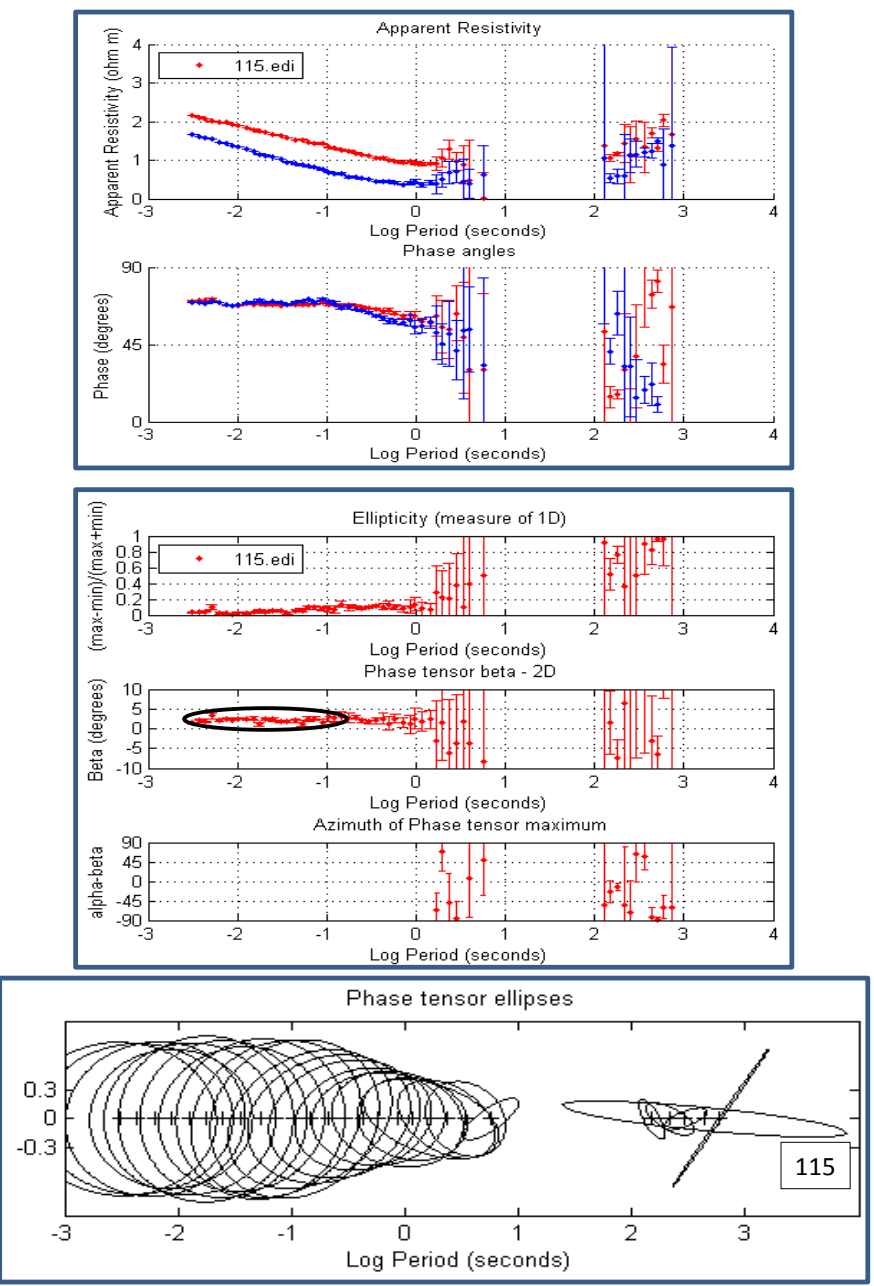

NNG-113
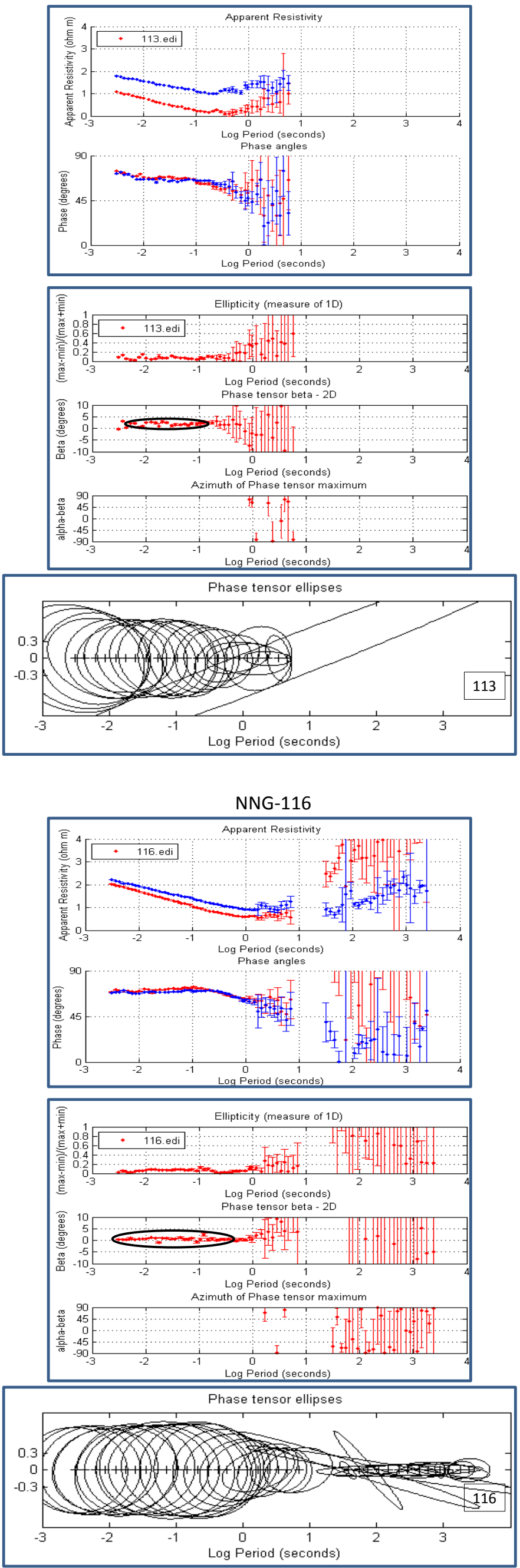
NNG-118
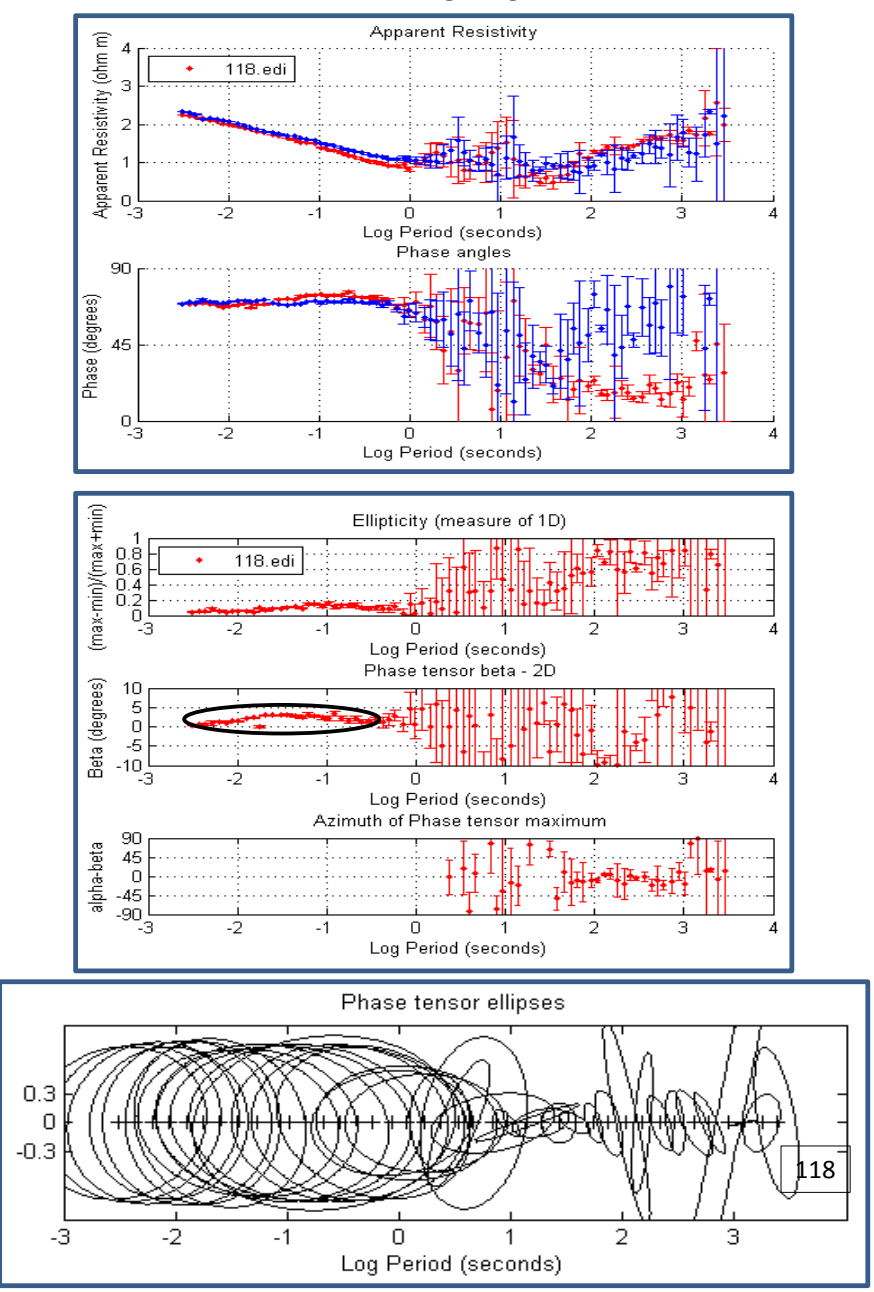

NNG-120
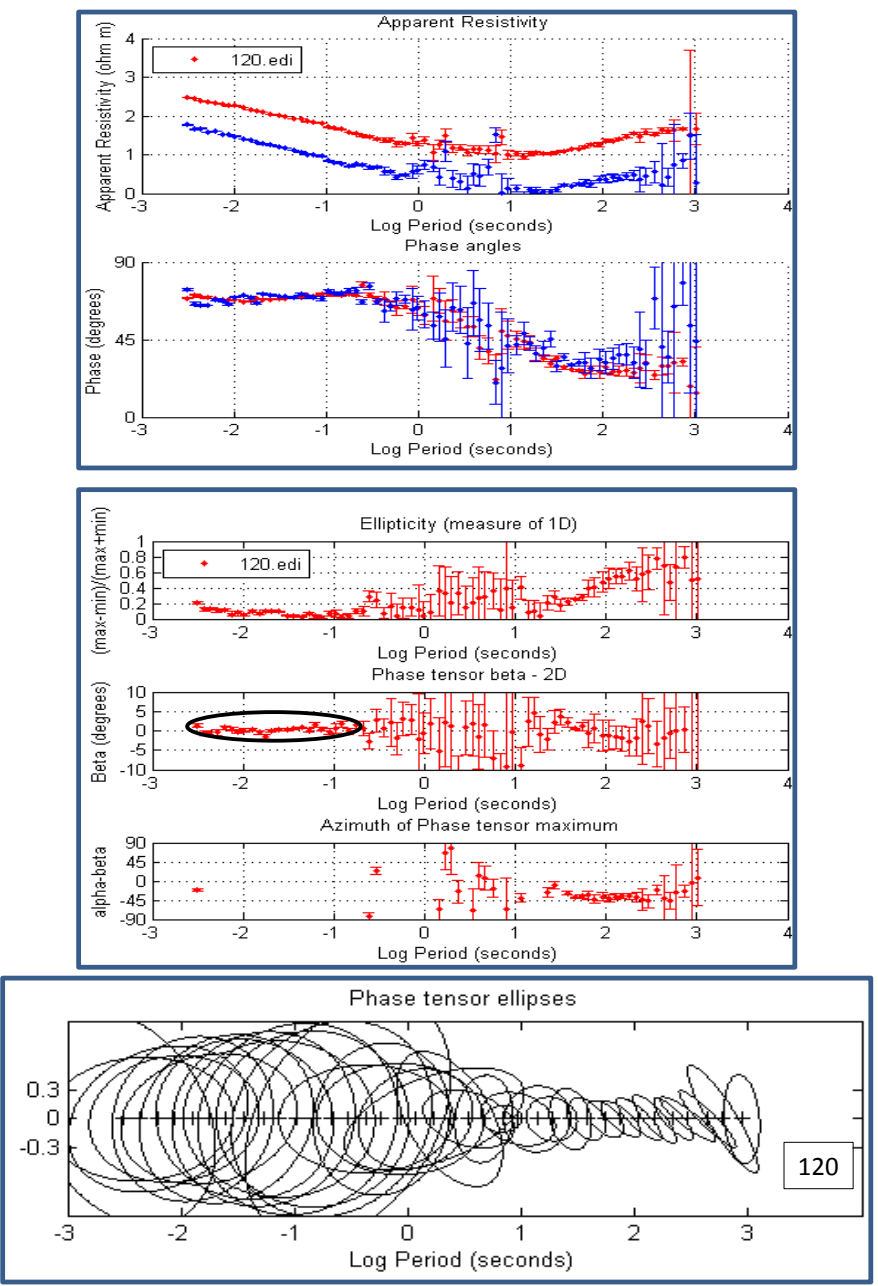

NNG-119
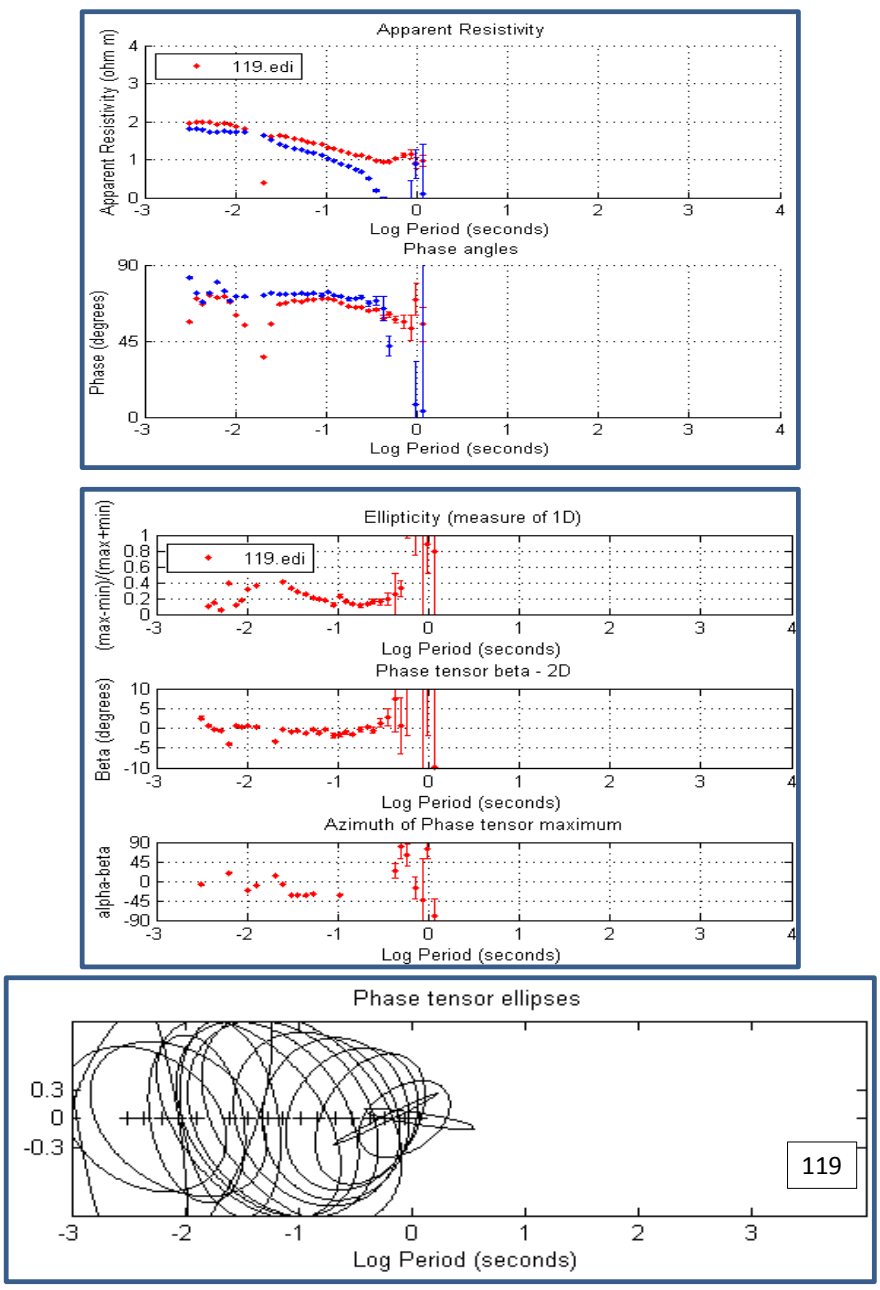

NNG-122
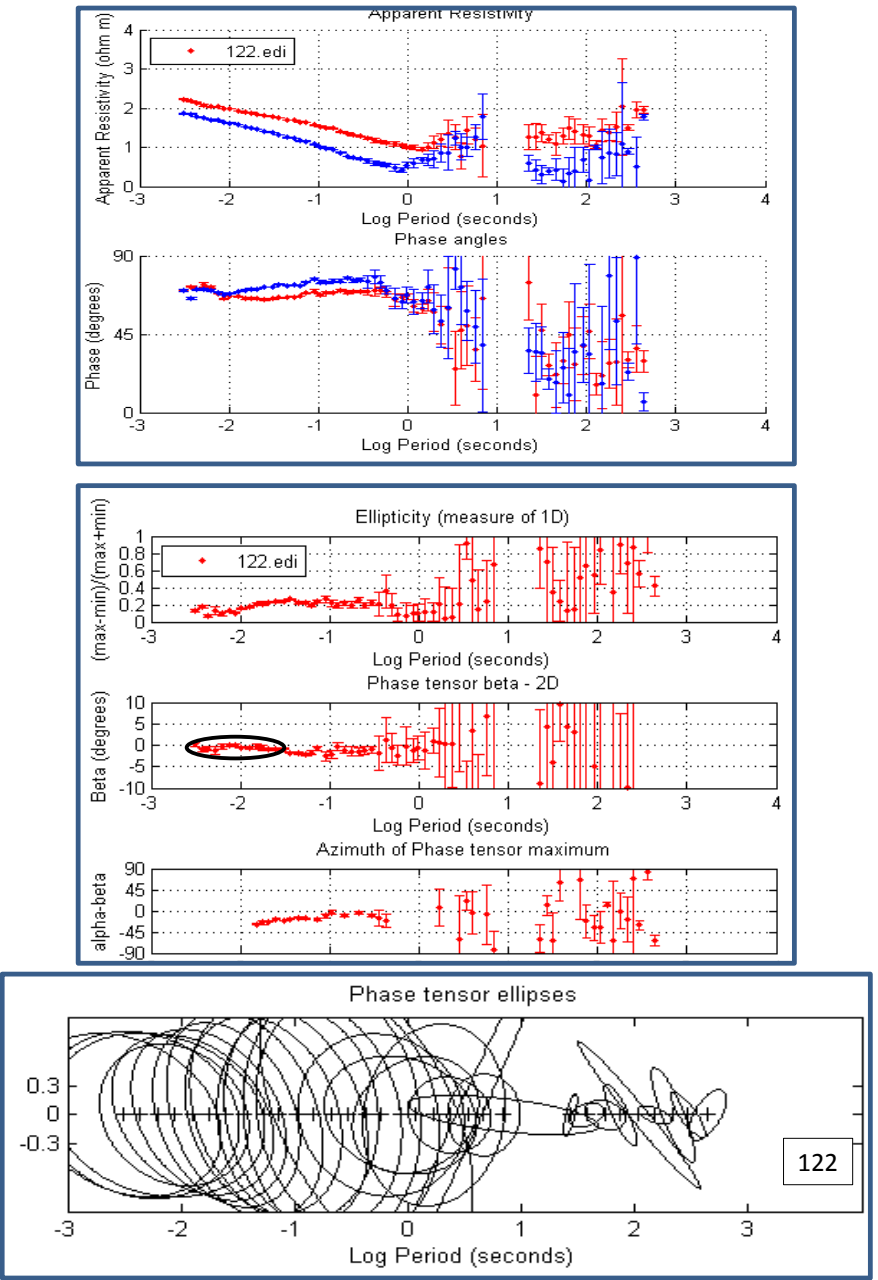
NNG-123
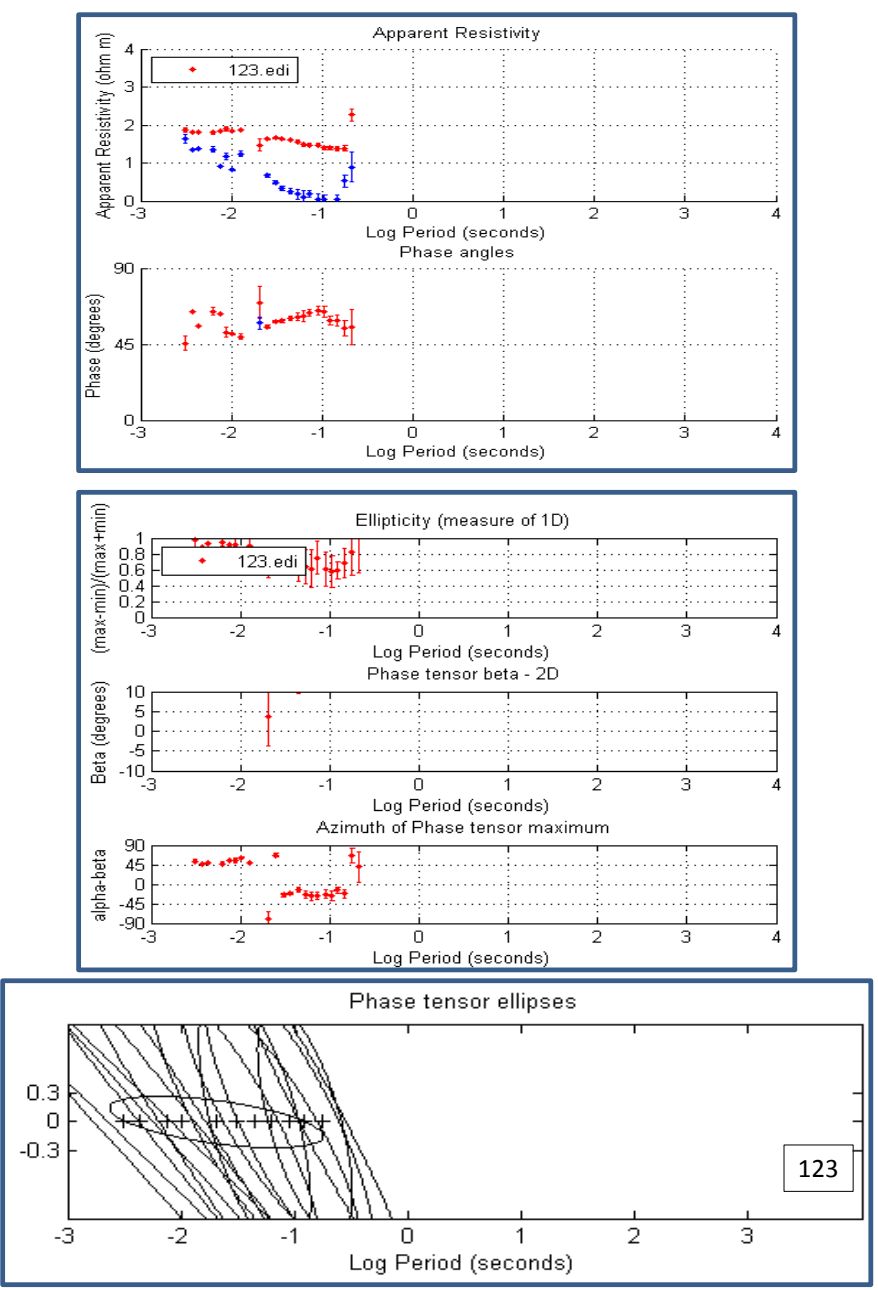

NNG-125
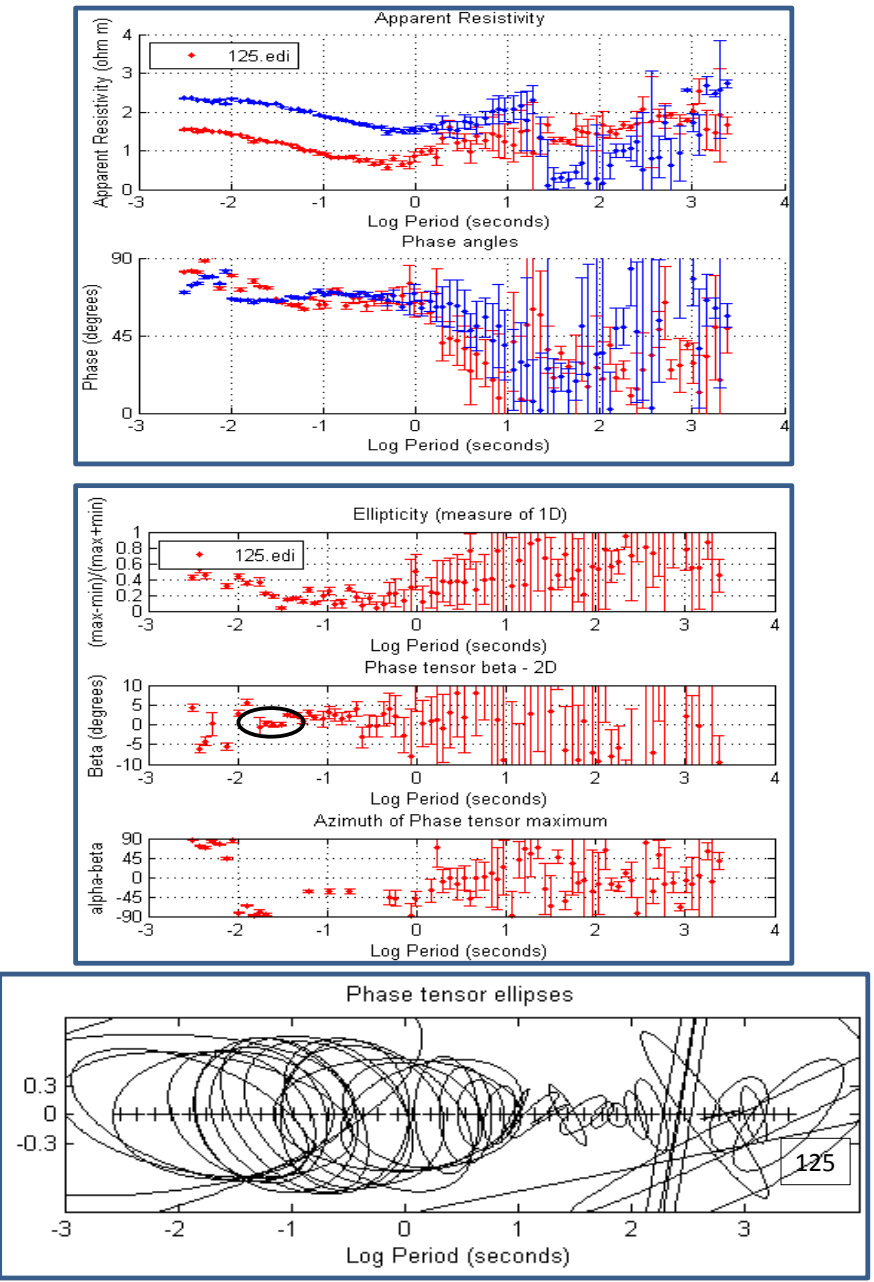

NNG-124
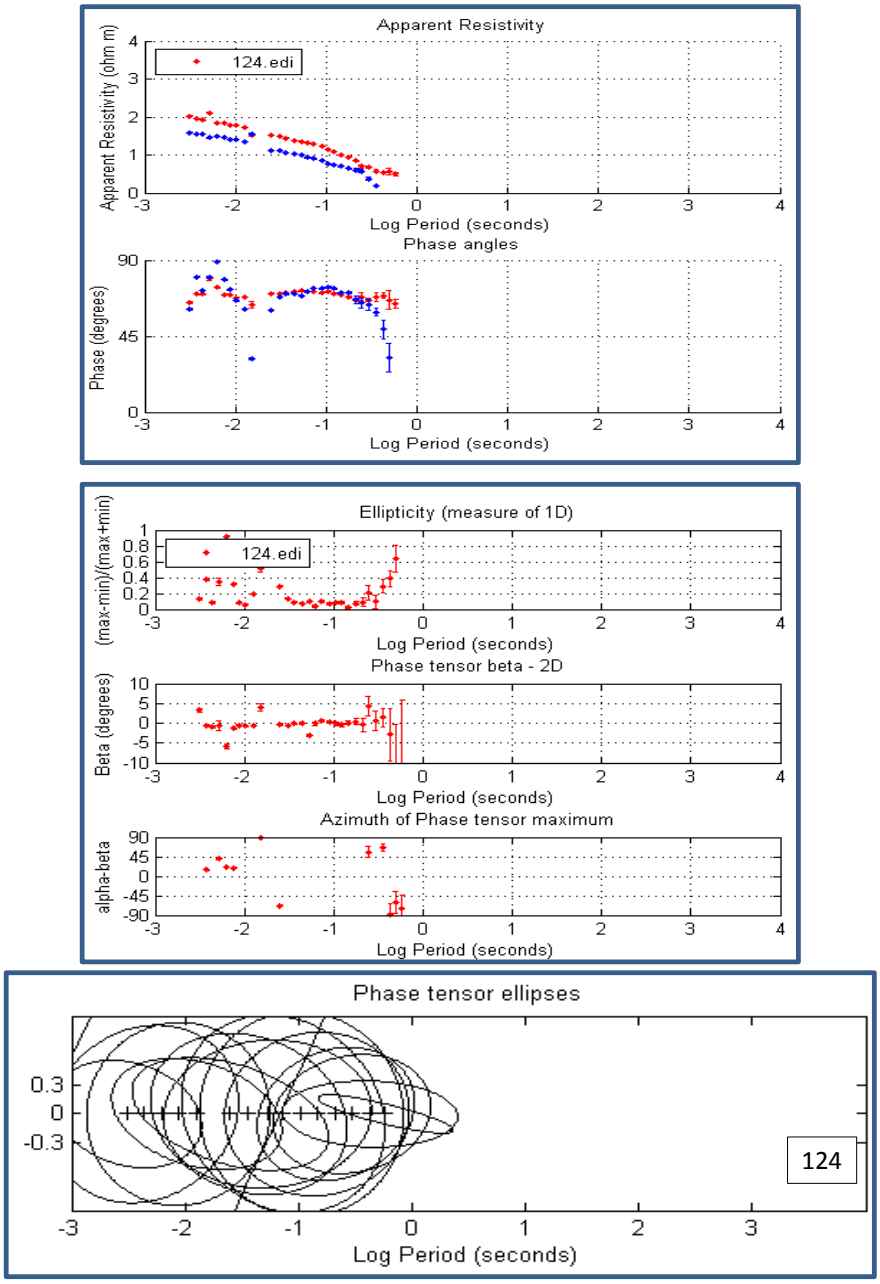

NNG-127
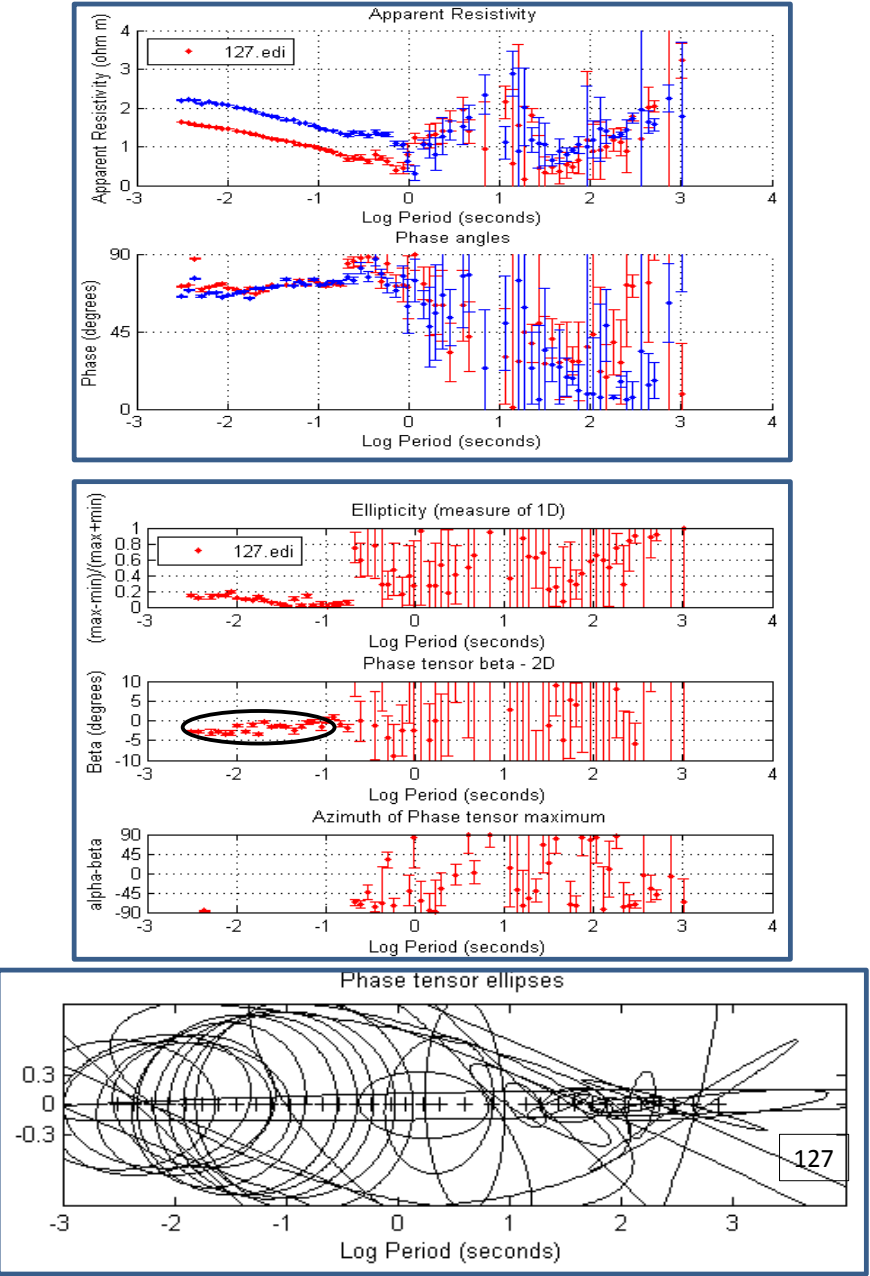
NNG-129
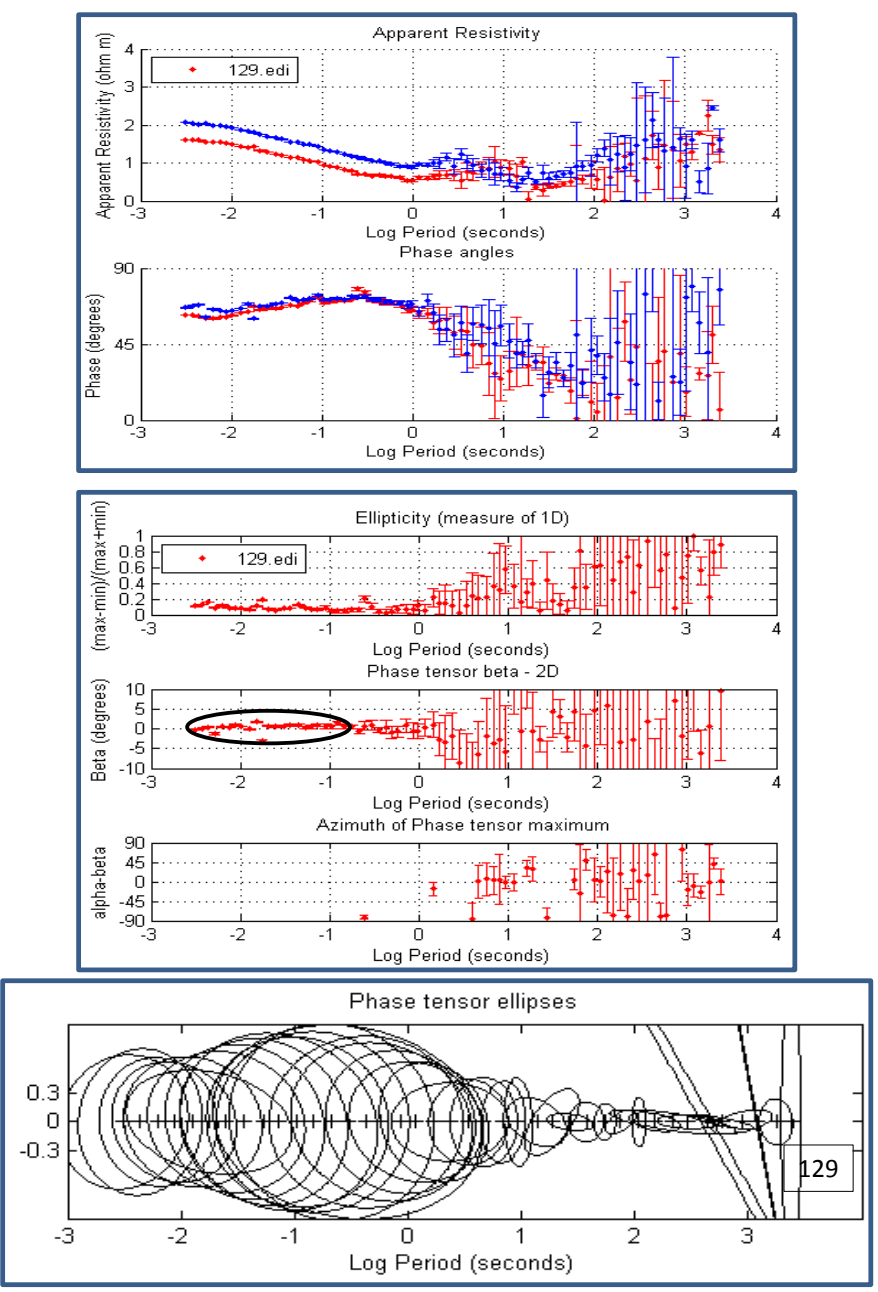

NNG-133
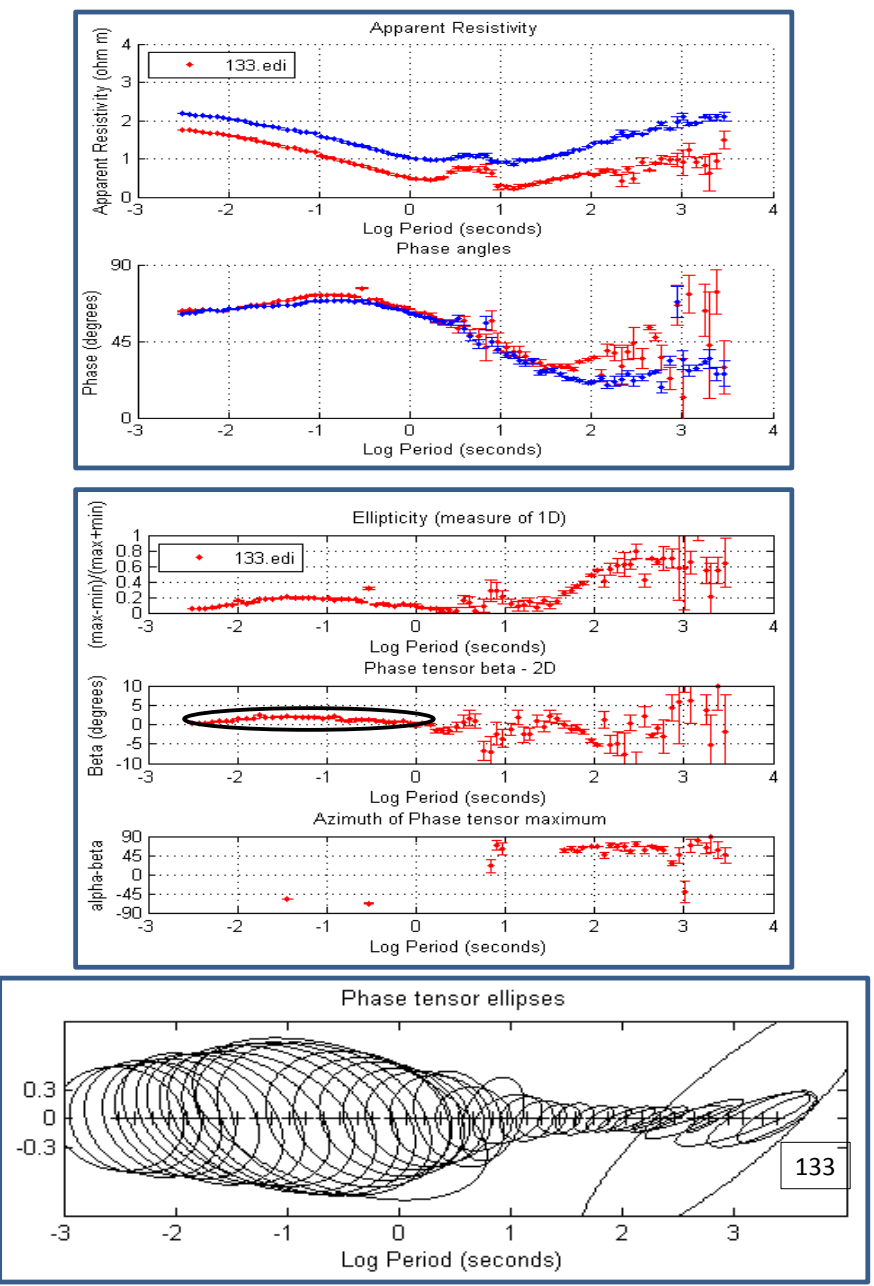

NNG-131
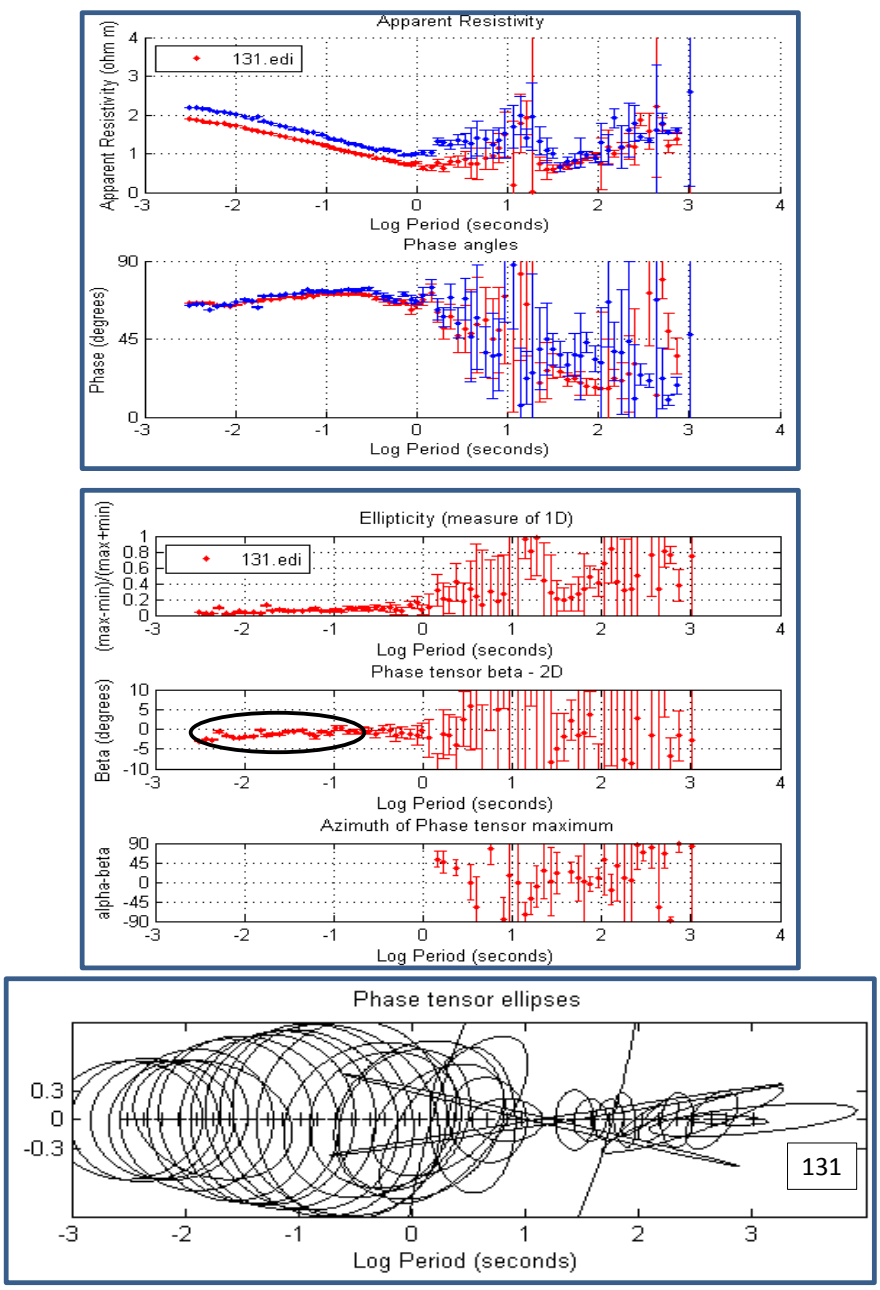

NNG-134
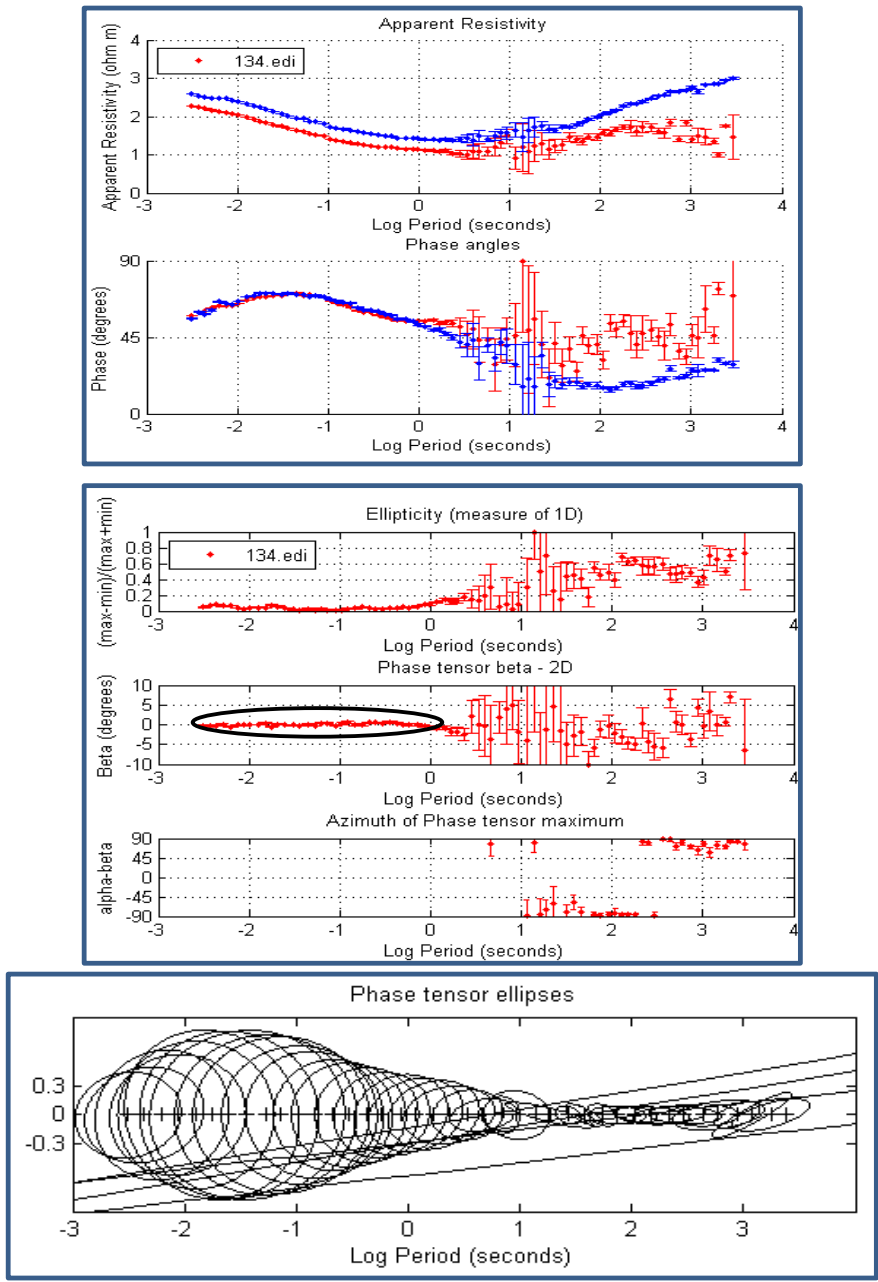
NNG-137
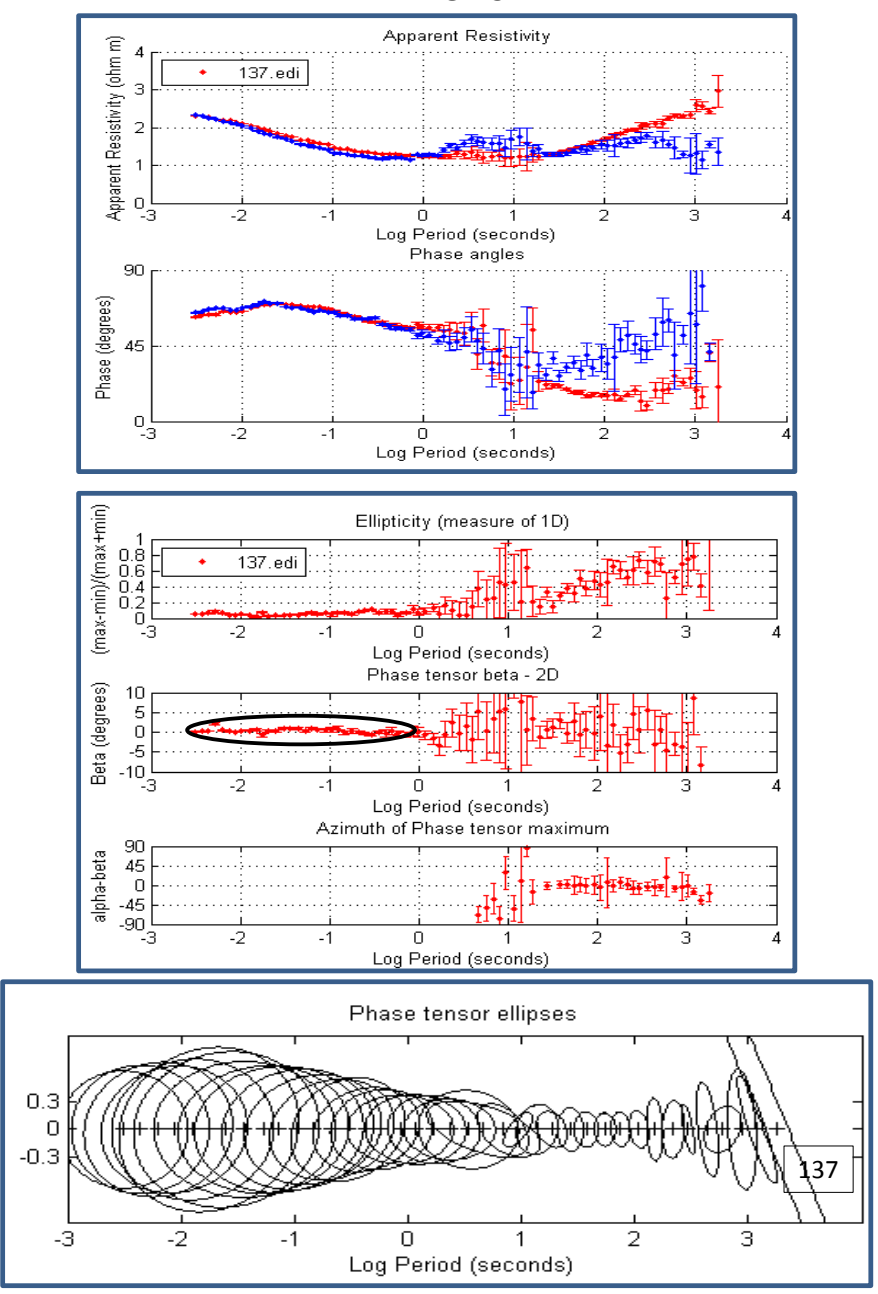

NNG-140
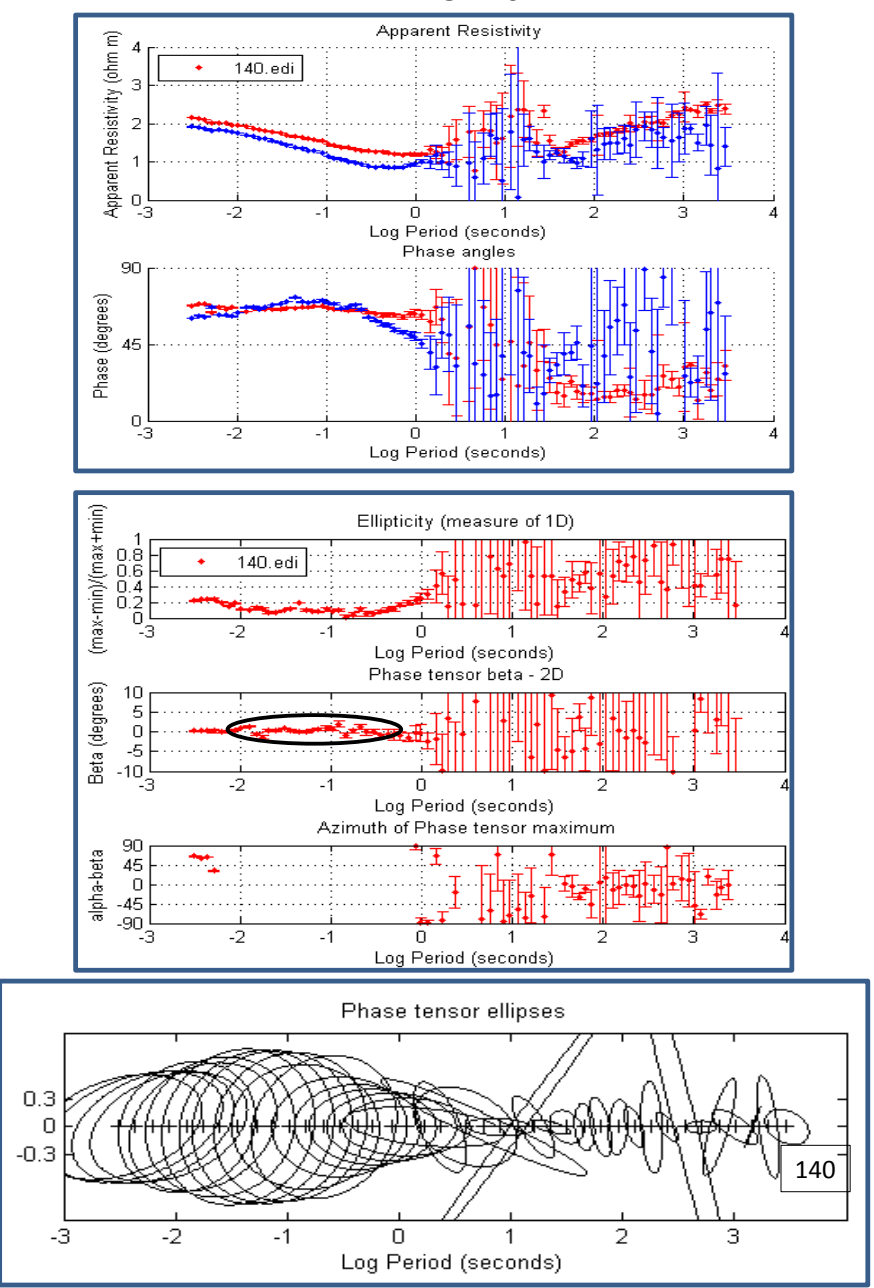

NNG-138
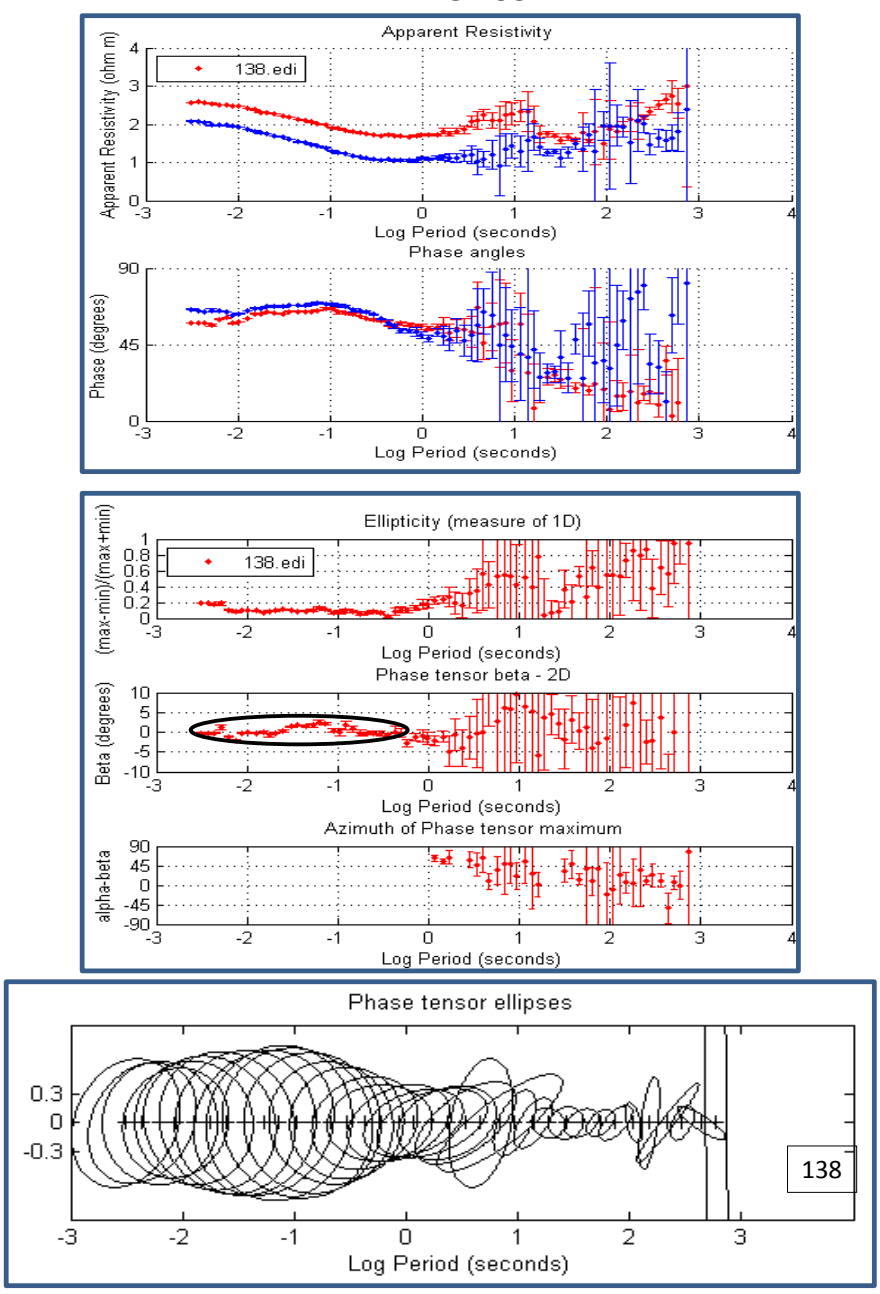

NNG-141
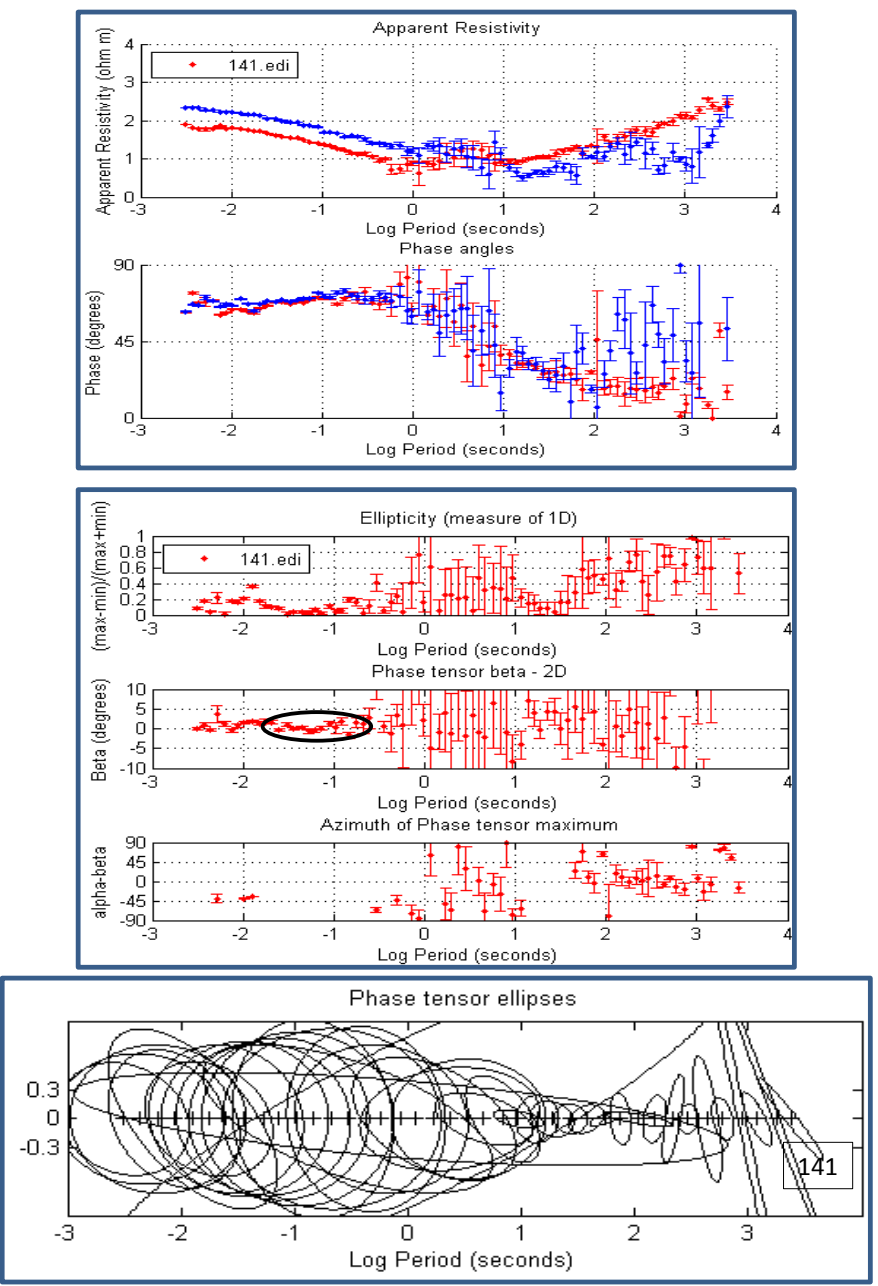
NNG-142
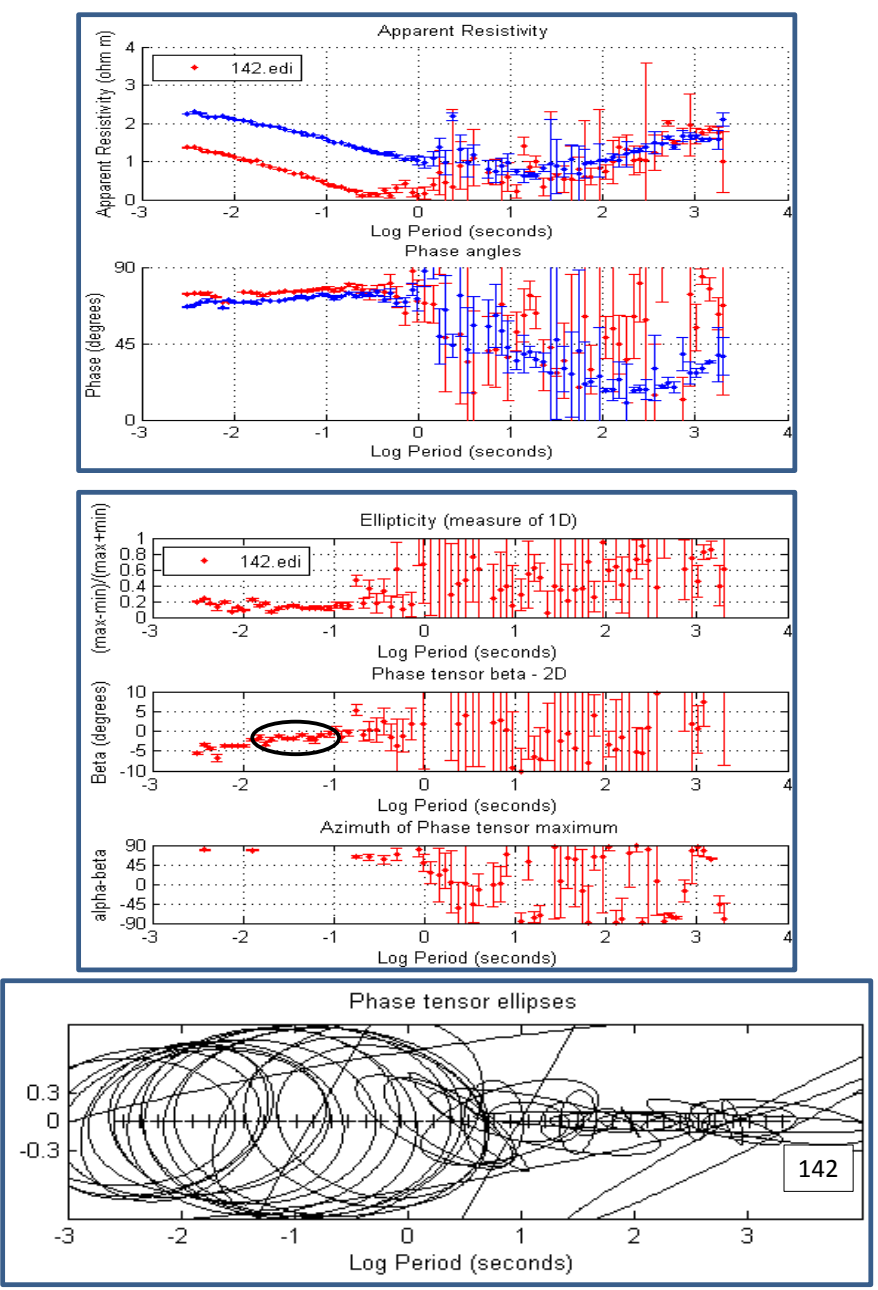

NNG-144
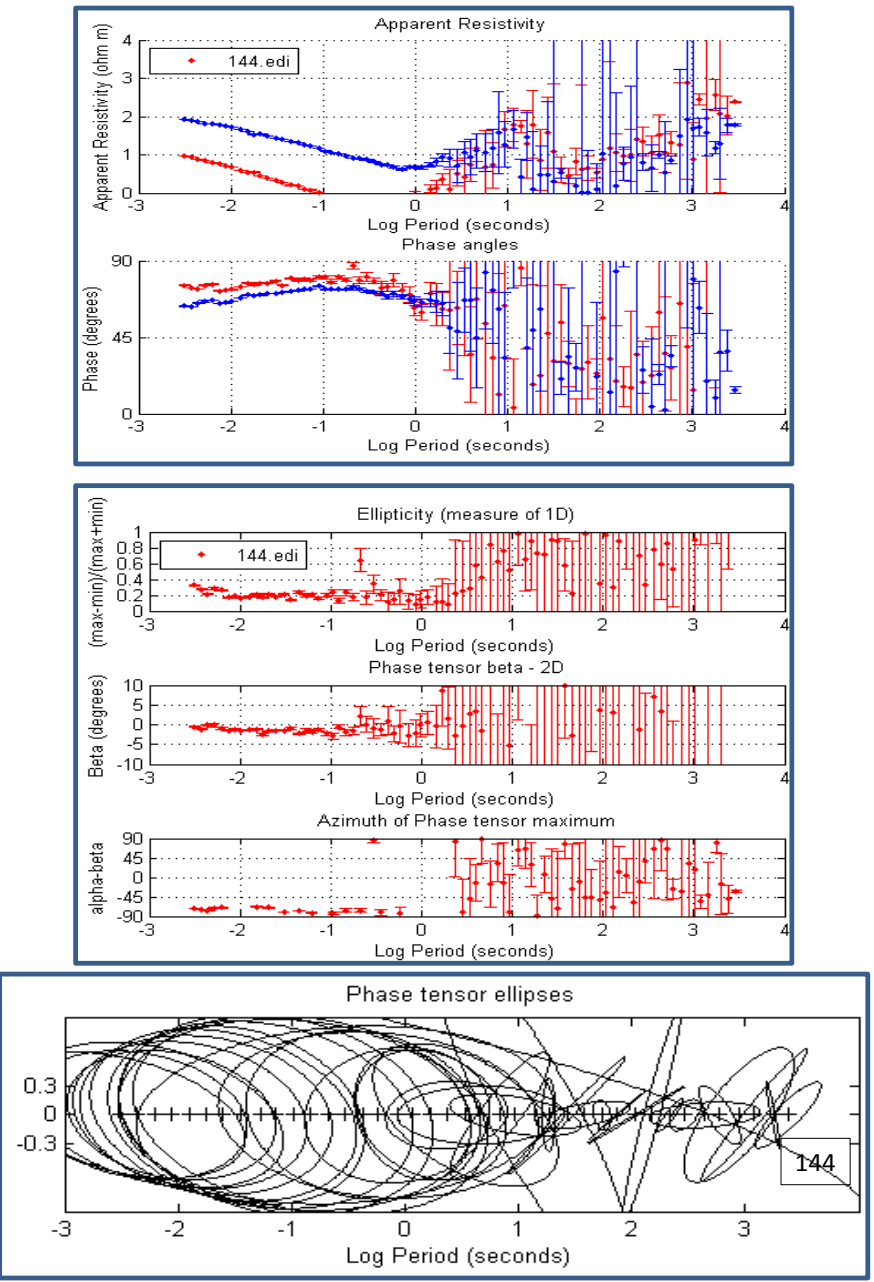

NNG-143
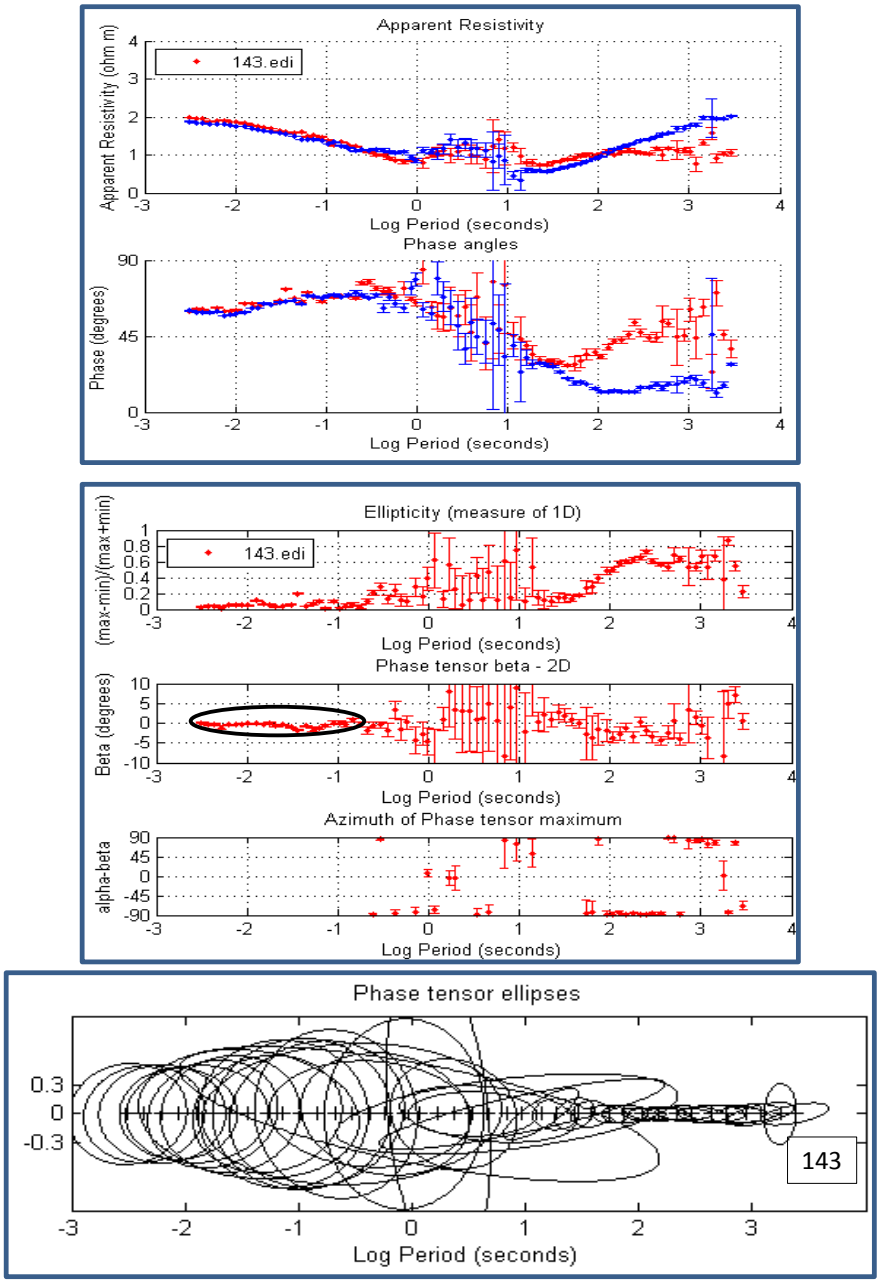

NNG-145
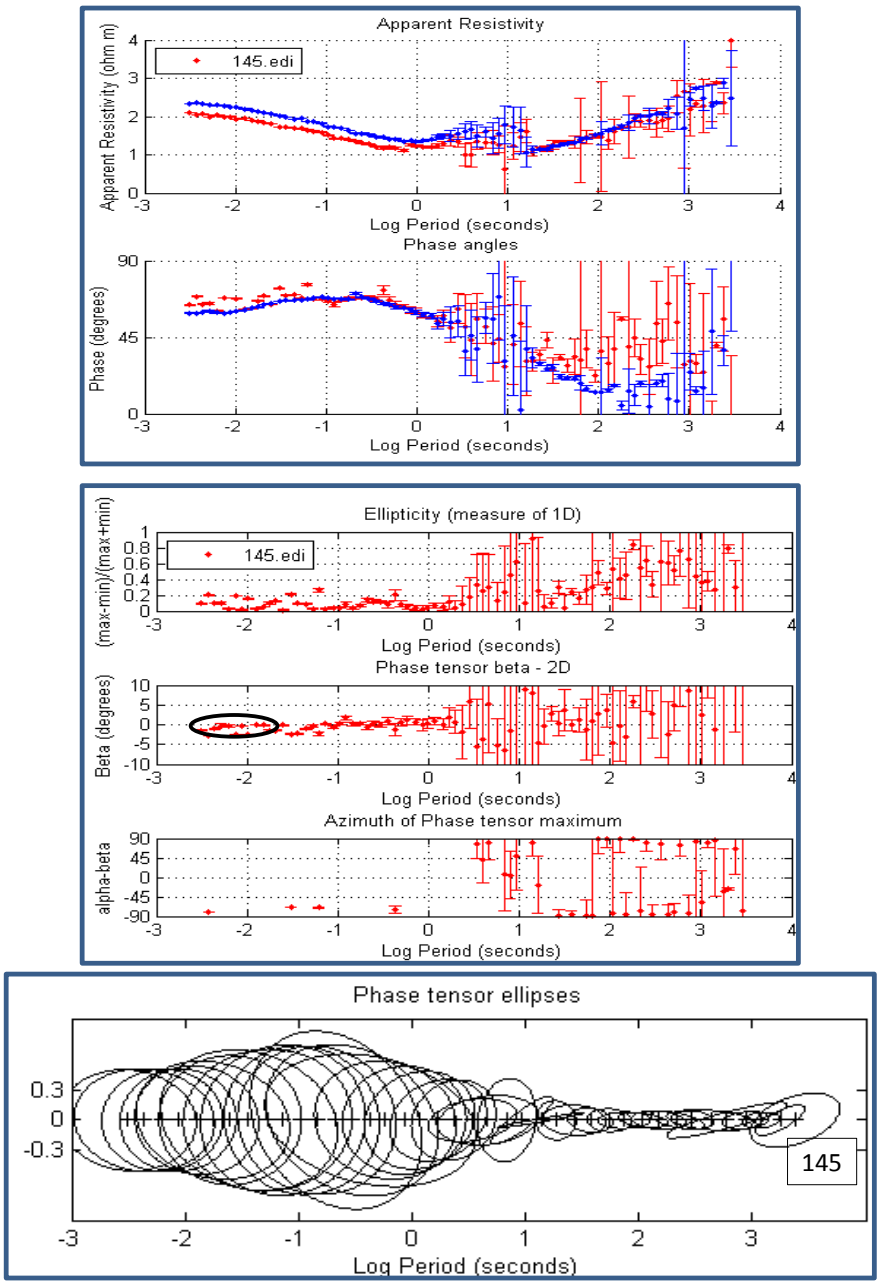
NNG-146
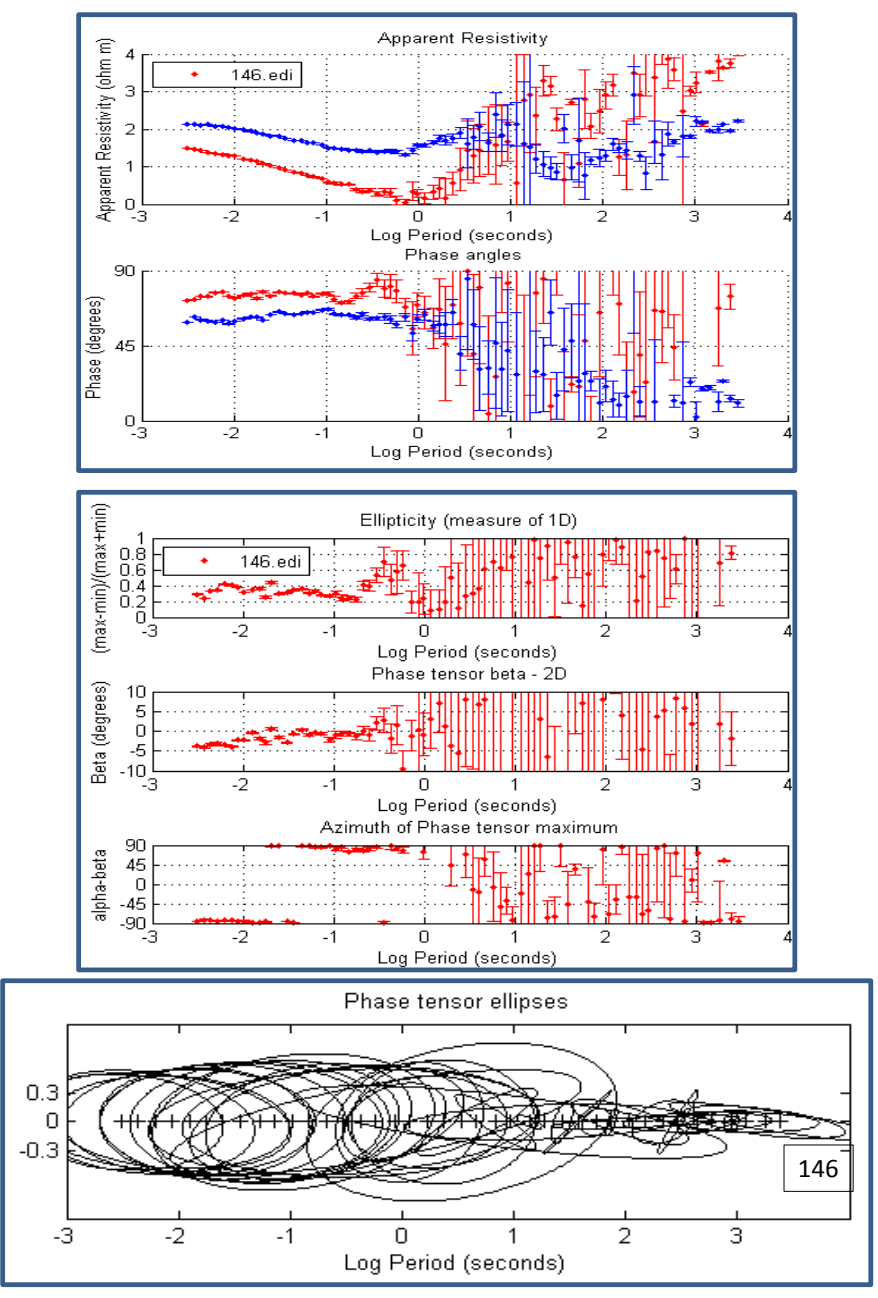

NNG-148
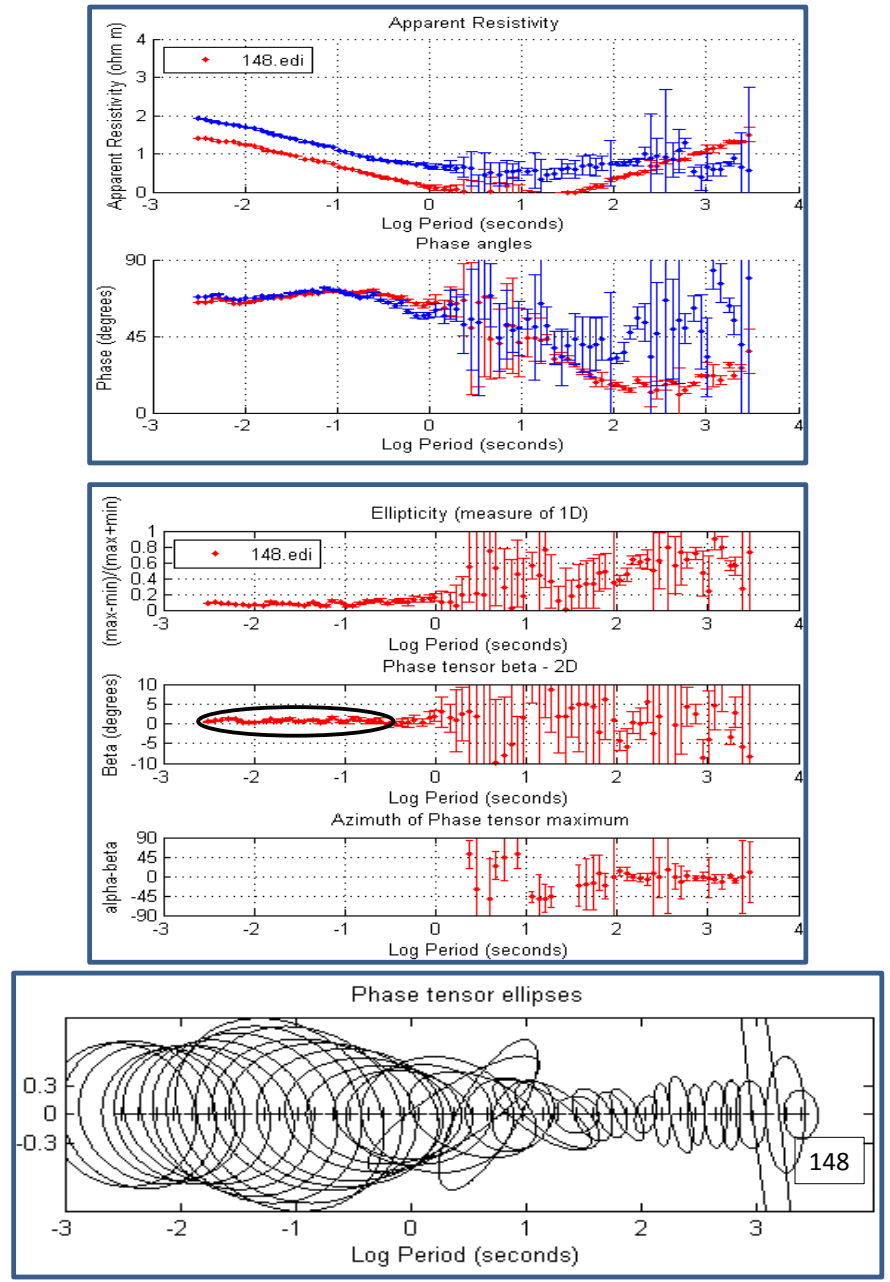

NNG-147
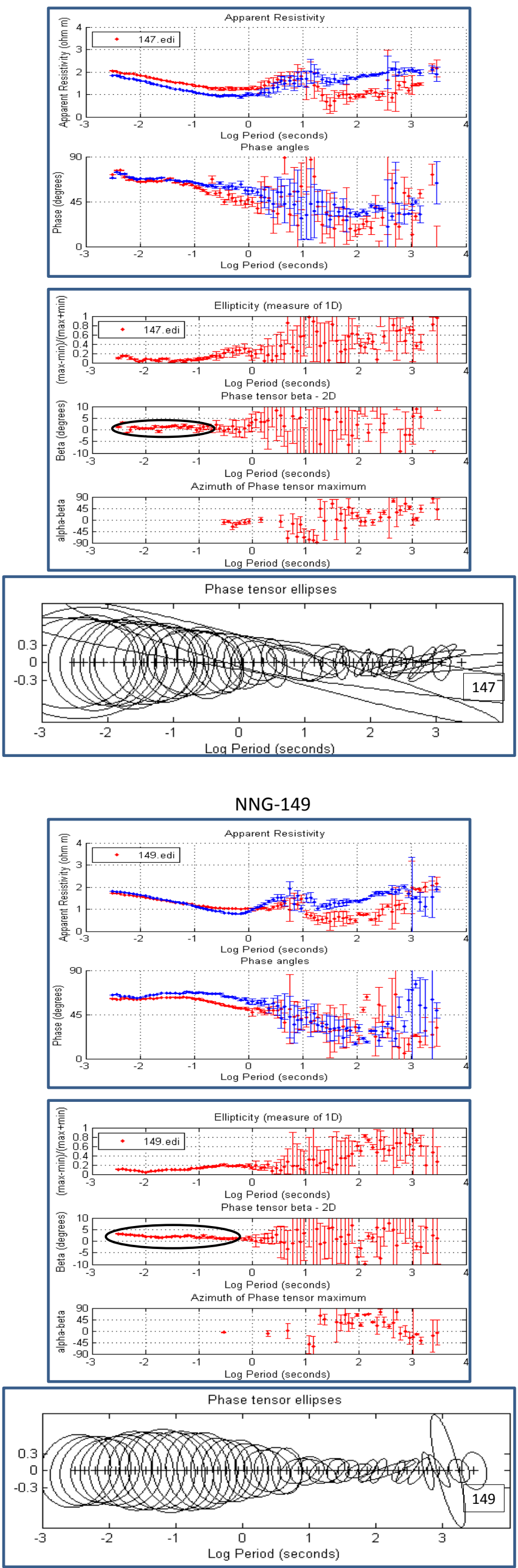
NNG-150
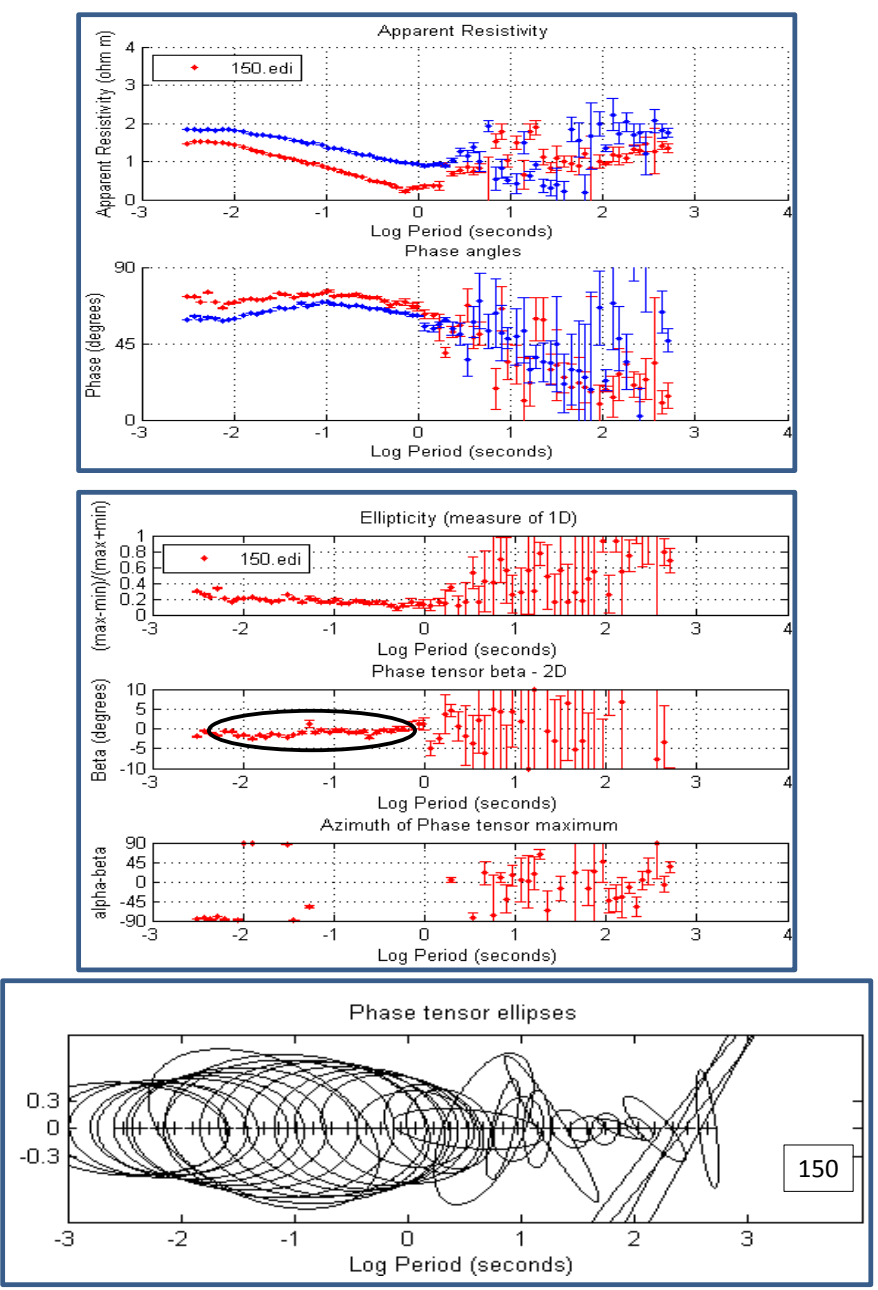

NNG-153
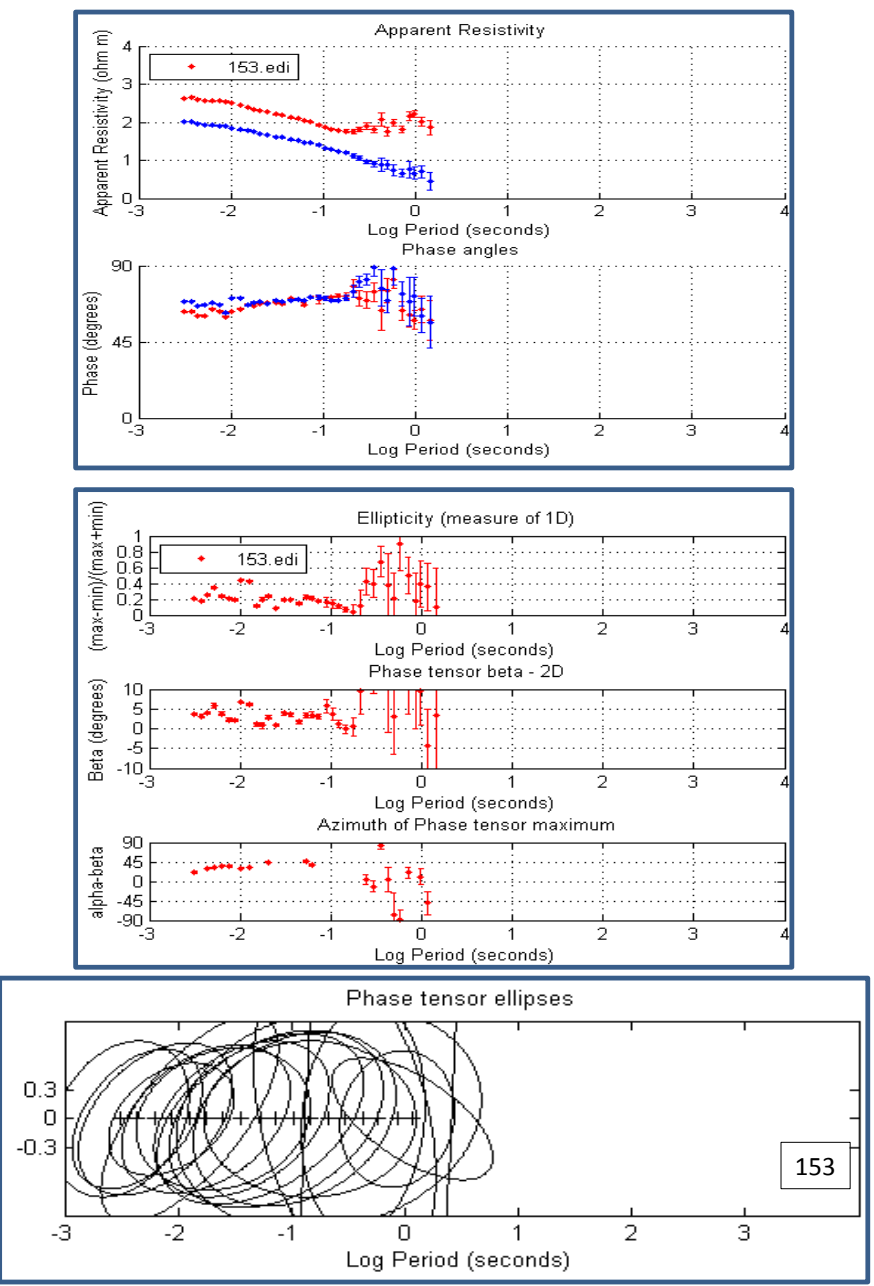

NNG-151
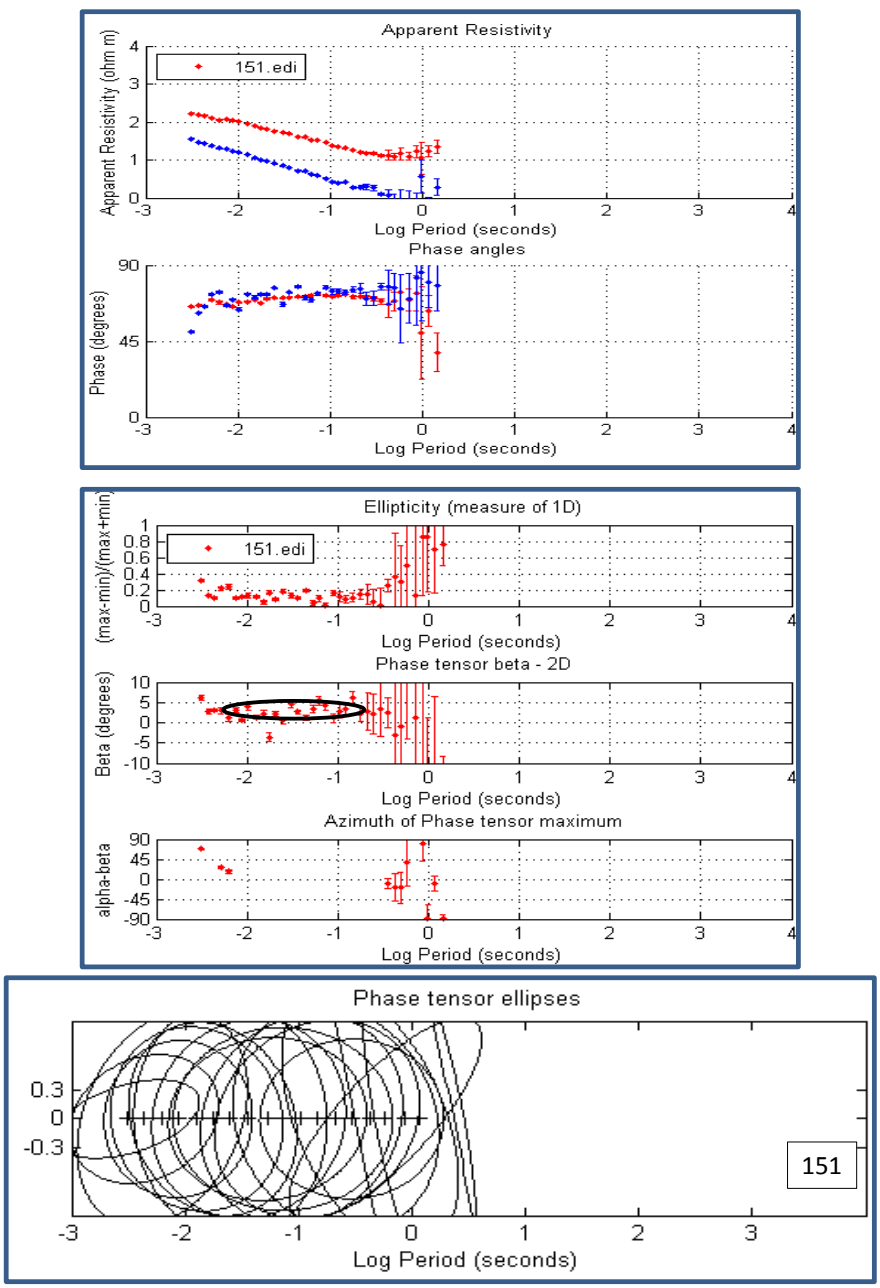

NNG-154
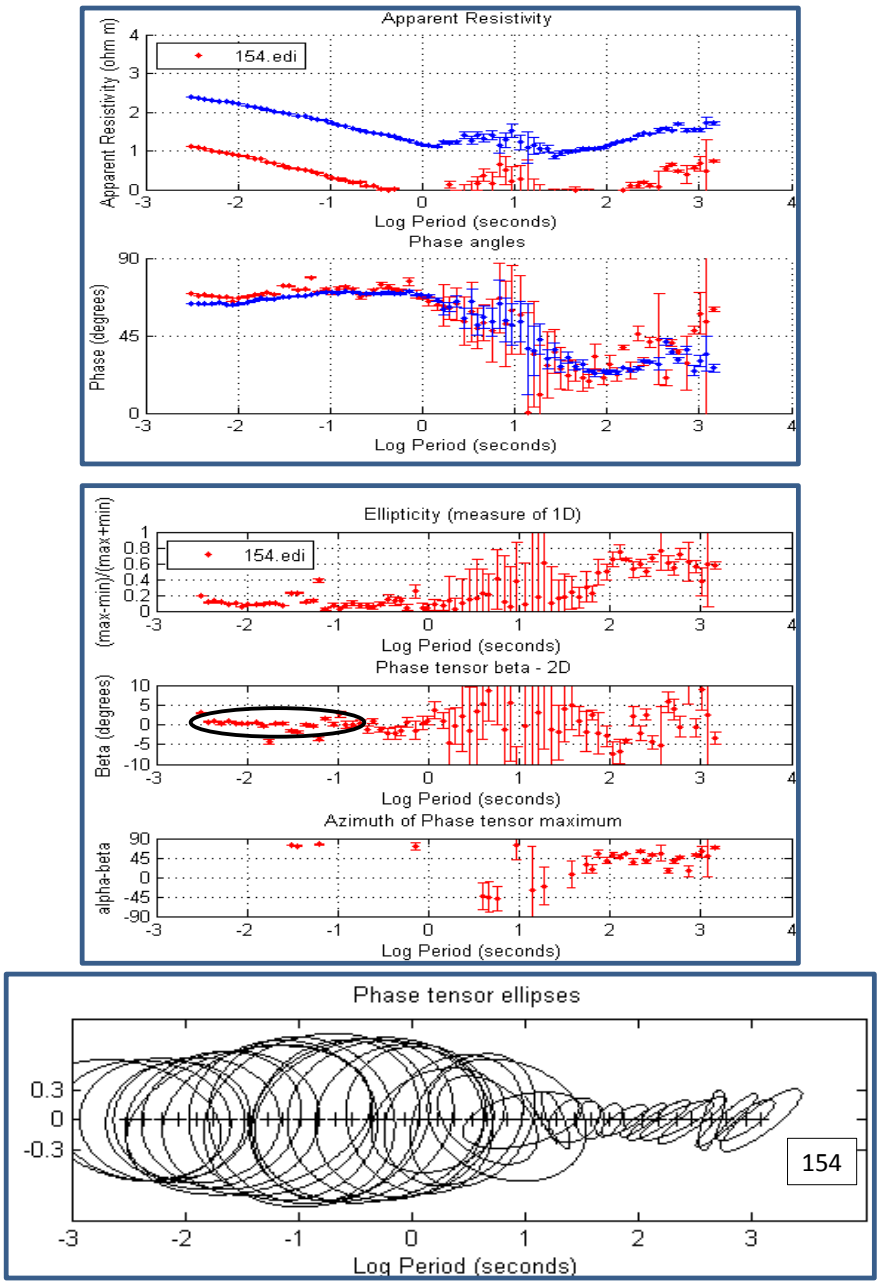
NNG-155
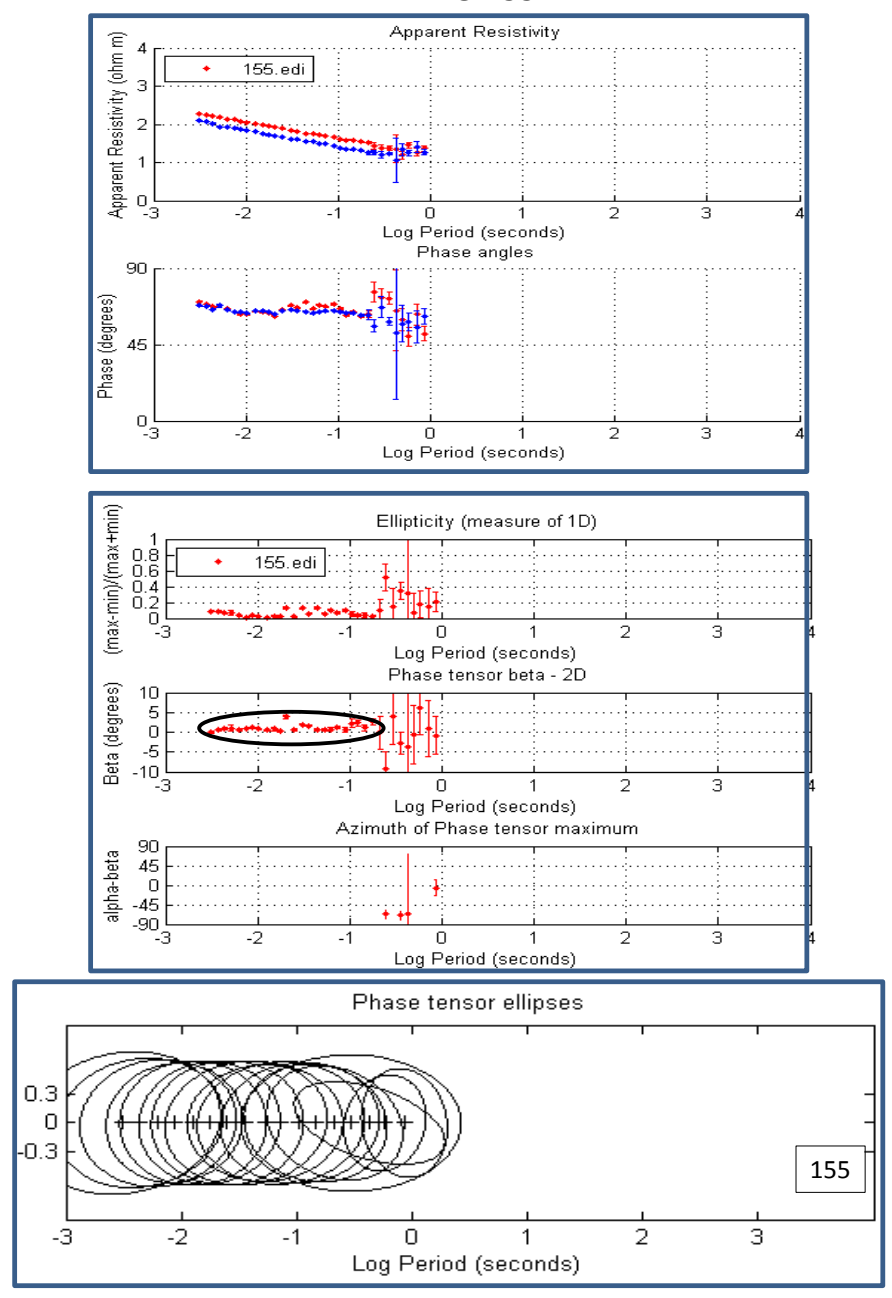

NNG-157
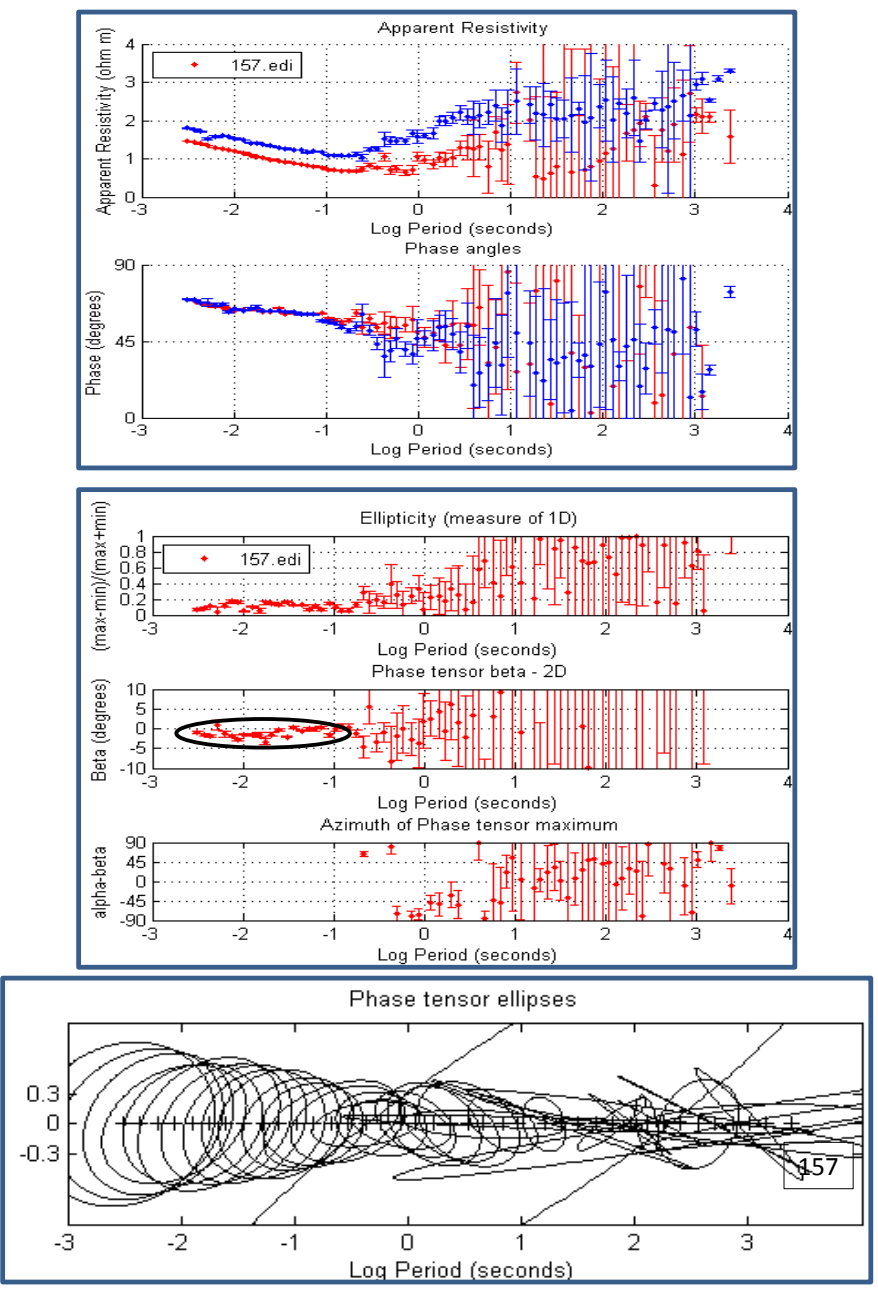

NNG-156
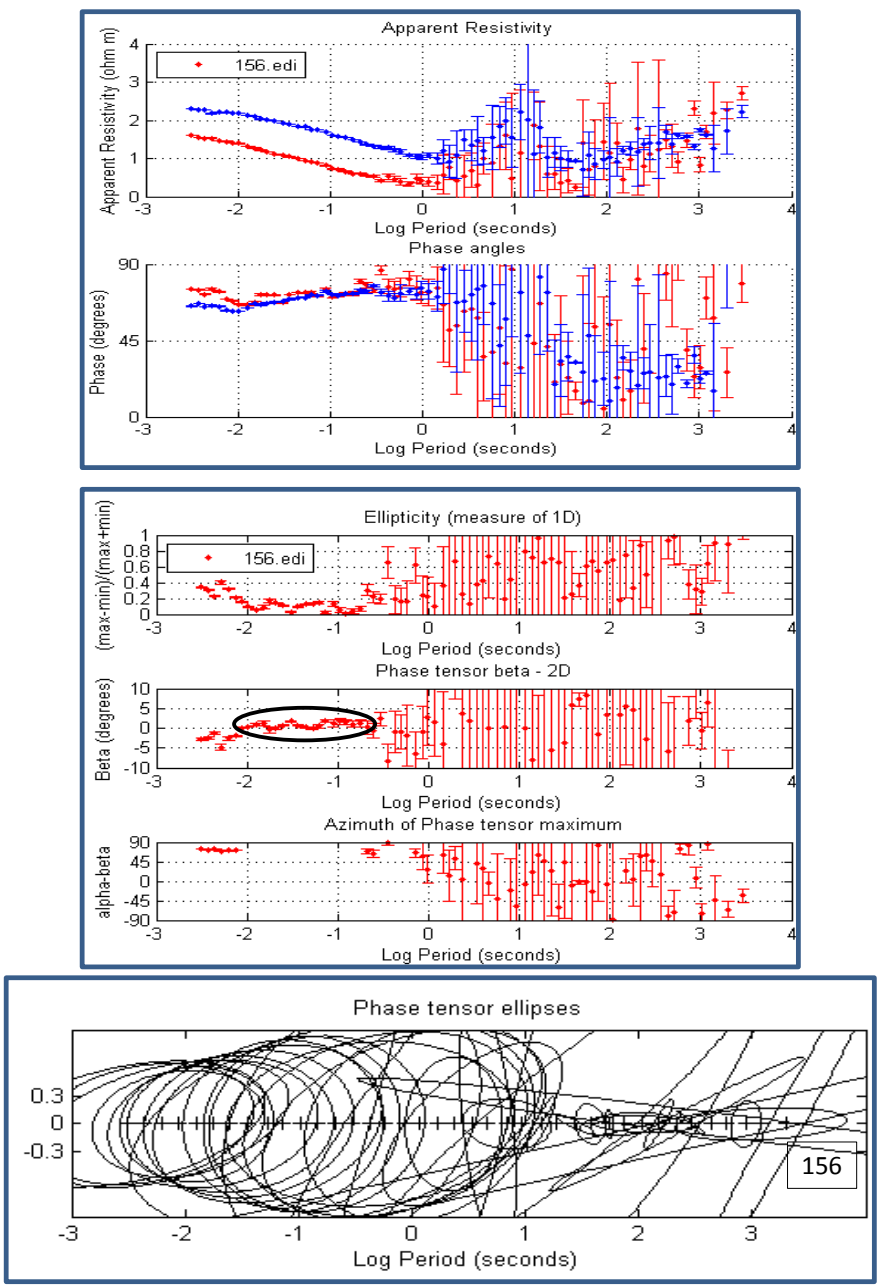

NNG-158
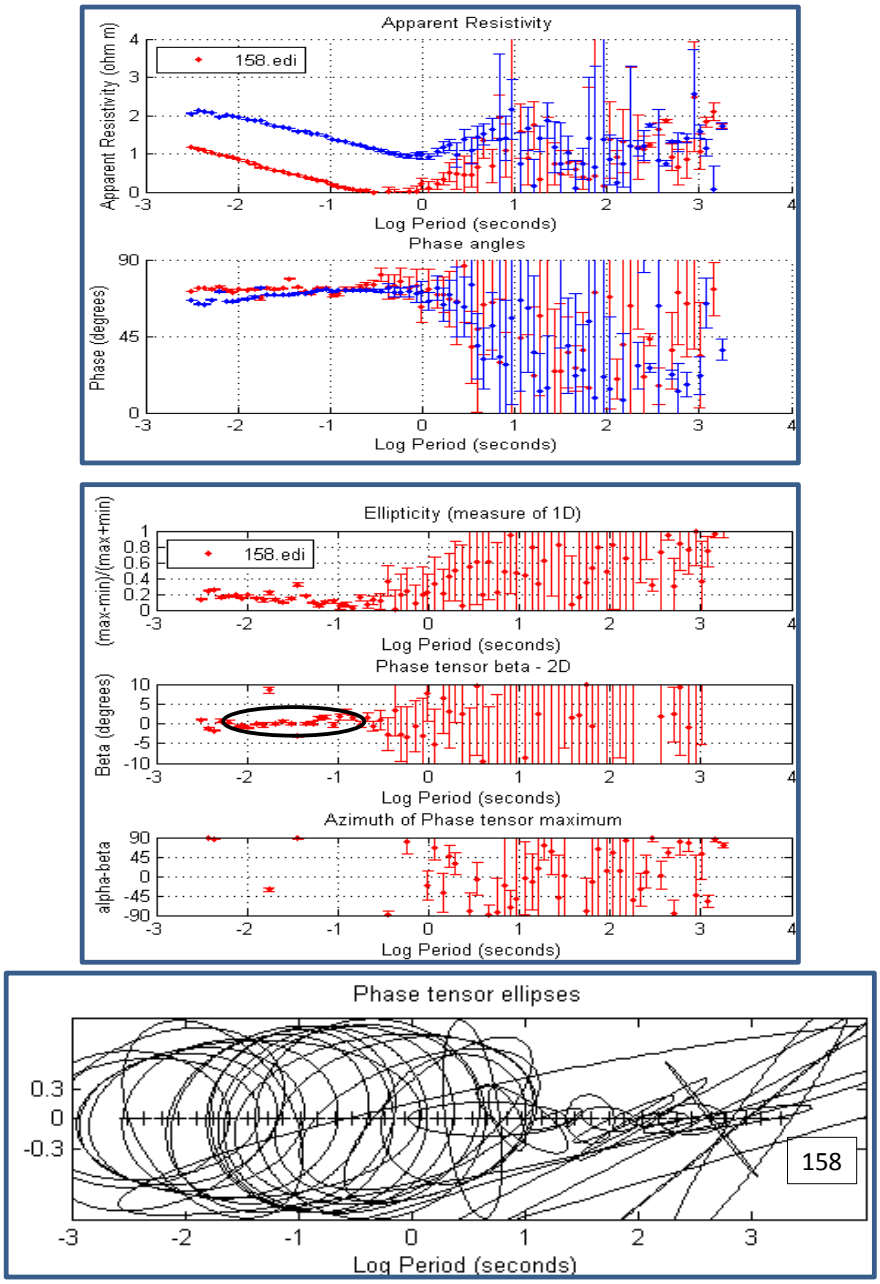


\title{
Appendix II: MT data description
}

\author{
Station Data description and analysis \\ Rank Semi-major \\ ID \\ angle (deg) \\ $1 \quad$ Reliable data up to $100 \mathrm{~s}$ but missing data points \\ 2 \\ between 7 to $20 \mathrm{~s}$; very small shift between TE \\ and TM curves \\ 2 Data up to $100 \mathrm{~s}$ but reliable data is only until \\ $1 \quad-10$ \\ $0.8 \mathrm{~s}$; TE and TM curves have minimal shift and \\ show 1-D characteristic at short periods and 2-D \\ at longer period \\ 3 Fair data up to $400 \mathrm{~s}$ but xy phase data is noisy \\ $3 \quad 85$ \\ from $100 \mathrm{~s}$; almost no shift between curves but \\ they split at about $100 \mathrm{~s} ; 3-\mathrm{D}$ at long periods \\ 4 Data reaches up to about $200 \mathrm{~s}$ but contaminated \\ $2-45$ \\ by noise esp the phase between 2 to $20 \mathrm{~s}$; TE and \\ TM curves show minimum shift and show 1-D \\ characteristic at periods less than 1 s then 2-D at \\ $>10 \mathrm{~s}$ \\ 5 Reliable data only up to about 4s; TE and TM \\ curves show minimum shift and 1D characteris- \\ tic
}




\begin{tabular}{|c|c|c|c|}
\hline $\begin{array}{l}\text { Station } \\
\text { ID }\end{array}$ & Data description and analysis & Rank & $\begin{array}{l}\text { Semi-major } \\
\text { angle (deg) }\end{array}$ \\
\hline 6 & $\begin{array}{l}\text { Noisy data }<0.01 \mathrm{~s} \text { but reliable data up to } 7 \mathrm{~s} ; \mathrm{TE} \\
\text { and TM curves have large static shift and show } \\
\text { 1-D characteristic }\end{array}$ & 1 & \\
\hline 7 & $\begin{array}{l}\text { Reliable data up to } 2 \mathrm{~s} \text {; No shift between TE and } \\
\text { TM curves; } 1 \text {-D characteristic }\end{array}$ & 1 & \\
\hline 8 & $\begin{array}{l}\text { Good data up to } 200 \mathrm{~s} \text { but with noise in between } \\
5 \mathrm{~s} \text { to } 20 \mathrm{~s} \text {; TE and TM curves show large shift; } \\
\text { shows 2-D characteristics at short period and 3- } \\
\text { D at longer period }\end{array}$ & 3 & -45 \\
\hline 9 & $\begin{array}{l}\text { Data up to } 200 \mathrm{~s} \text { but distorted from }>9 \mathrm{~s} \text {; minimal } \\
\text { shift between curves; 1-D at short periods }<1 \mathrm{~s} \\
\text { but 3-D at }>10 \mathrm{~s}\end{array}$ & 2 & 70 \\
\hline 10 & $\begin{array}{l}\text { Good quality data up to }>400 \mathrm{~s} \text { with some miss- } \\
\text { ing and noisy data points between } 7 \mathrm{~s} \text { to } 30 \mathrm{~s} ; \mathrm{TE} \\
\text { and TM curves show minimum shift and splits } \\
\text { at } 40 \mathrm{~s} ; 1 \text {-D at }<1 \mathrm{~s} \text { and } 3 \text {-D at }>10 \mathrm{~s}\end{array}$ & 3 & -85 \\
\hline 11 & $\begin{array}{l}\text { Data up to } 50 \mathrm{~s} \text { but reliable data only up to about } \\
4 \mathrm{~s} \text { since data }>4 \mathrm{~s} \text { is either missing or noisy } \\
\text { (phase); TE and TM curves show very minimum } \\
\text { shift and 1-D characteristic }\end{array}$ & 1 & \\
\hline 12 & $\begin{array}{l}\text { Fair data up to }>400 \mathrm{~s} \text { with gaps in between } 0.05 \\
\mathrm{~s} \text { to } 0.1 \mathrm{~s} \text { and } 3 \mathrm{~s} \text { to } 14 \mathrm{~s} \text {, and noisy phase data } \\
>200 \mathrm{~s} \text {; TE and TM curves have small static shift } \\
\text { and show } 1-\mathrm{D} \text { characteristic at short period, 2-D } \\
\text { at }>10 \mathrm{~s} \text { then } 3-\mathrm{D} \text { at }>100 \mathrm{~s}\end{array}$ & 2 & 60 \\
\hline 13 & $\begin{array}{l}\text { Reliable data only up to } 1 \mathrm{~s} \text {; Almost no shift be- } \\
\text { tween TE and TM curves; } 1 \text {-D characteristic }\end{array}$ & 1 & \\
\hline
\end{tabular}




\begin{tabular}{|c|c|c|c|}
\hline $\begin{array}{l}\text { Station } \\
\text { ID }\end{array}$ & Data description and analysis & Rank & $\begin{array}{l}\text { Semi-major } \\
\text { angle (deg) }\end{array}$ \\
\hline 14 & $\begin{array}{l}\text { Fair data up to } 100 \mathrm{~s} \text { but phase curve has some } \\
\text { noise at }<0.1 \mathrm{~s} \text { and in between } 7 \mathrm{~s} \text { to } 20 \mathrm{~s} \text {; TE and } \\
\text { TM curves show small shift; show } 1 \text {-D character- } \\
\text { istic at }<1 \mathrm{~s} \text { then } 3 \text {-D at longer periods }\end{array}$ & 2 & 80 \\
\hline 15 & $\begin{array}{l}\text { Data up to } 100 \mathrm{~s} \text { but data is missing from } 4 \mathrm{~s} \text { to } \\
20 \mathrm{~s} \text { and phase data has large error bars }>40 \mathrm{~s} \text {; } \\
\text { minimal shift between curves; } 3-\mathrm{D} \text { at }>10 \mathrm{~s}\end{array}$ & 1 & 0 \\
\hline 16 & $\begin{array}{l}\text { Fair data up to } 1 \mathrm{~s} ; \mathrm{TE} \text { and TM curves show small } \\
\text { shift and slightly 2-D characteristic }\end{array}$ & 1 & \\
\hline 17 & $\begin{array}{l}\text { Fair data up to } 2 \mathrm{~s} \text {; TE and TM curves show min- } \\
\text { imum shift and 1-D characteristic }\end{array}$ & 1 & \\
\hline 18 & $\begin{array}{l}\text { Data up to }>200 \mathrm{~s} \text { with gap in between } 5 \mathrm{~s} \text { to } 14 \\
\mathrm{~s} \text { and noisy phase data }>5 \mathrm{~s} \text {. TE and TM curves } \\
\text { have small static shift but splits at } 0.4 \mathrm{~s} ; 3 \text {-D char- } \\
\text { acteristic at }>2 \mathrm{~s}\end{array}$ & 2 & 90 \\
\hline 19 & $\begin{array}{l}\text { Data extends to } 200 \mathrm{~s} \text { but with gap or noisy phase } \\
\text { data between } 6 \mathrm{~s} \text { to } 40 \mathrm{~s} \text {; Almost no shift between } \\
\text { TE and TM curves; } 1 \text {-D characteristic at short pe- } \\
\text { riods but 3-D at longer periods }\end{array}$ & 2 & 85 \\
\hline 20 & $\begin{array}{l}\text { Reliable data only up to } 7 \mathrm{~s} \text { since phase data is } \\
\text { scattered }>7 \mathrm{~s} \text {; TE and TM curves show small } \\
\text { shift; shows 2-D characteristic }\end{array}$ & 1 & 85 \\
\hline 21 & $\begin{array}{l}\text { Data up to } 2 \mathrm{~s} \text { only; small shift between TE and } \\
\text { TM mode curves; shows 2-D characteristic }\end{array}$ & 1 & 10 \\
\hline 22 & $\begin{array}{l}\text { Reliable data only from } 0.02 \mathrm{~s} \text { to about } 3 \mathrm{~s} \text { due to } \\
\text { noise which is seen in phase data at }<0.02 \mathrm{~s} \text { and } \\
>3 \mathrm{~s} \text {; small shift between TE and TM curves; } 2-\mathrm{D} \\
\text { at }>1 \mathrm{~s}\end{array}$ & 1 & -60 \\
\hline
\end{tabular}




\begin{tabular}{|c|c|c|c|}
\hline $\begin{array}{l}\text { Station } \\
\text { ID }\end{array}$ & Data description and analysis & Rank & $\begin{array}{l}\text { Semi-major } \\
\text { angle (deg) }\end{array}$ \\
\hline 23 & $\begin{array}{l}\text { Good data up to } 5 \mathrm{~s} \text { with some scattering in the } \\
\text { phase }>5 \mathrm{~s} \text { to } 100 \mathrm{~s} \text {; small shift between TE and } \\
\text { TM curves; } 1 \text {-D characteristic at }<1 \mathrm{~s} \text { range then } \\
\text { 2-D at longer period }\end{array}$ & 3 & -70 \\
\hline 24 & $\begin{array}{l}\text { Data up to } 200 \mathrm{~s} \text { but with gap from } 5 \mathrm{~s} \text { to } 30 \mathrm{~s} \text { and } \\
\text { noisy data }>100 \mathrm{~s} \text {; has a significant shift between } \\
\text { the TE and TM curves; 2-D at }>20 \mathrm{~s}\end{array}$ & 2 & -25 \\
\hline 25 & $\begin{array}{l}\text { Reliable data up to about } 200 \text { s with some noise } \\
\text { at the lower end; significant shift between TE } \\
\text { and TM curves; } 1-\mathrm{D} \text { at short periods then 2-D at } \\
\text { longer periods }\end{array}$ & 3 & 65 \\
\hline 26 & $\begin{array}{l}\text { Data only up to } 2 \mathrm{~s} \text {; large shift between TE and } \\
\text { TM mode curves; shows 2-D characteristic }\end{array}$ & 1 & 80 \\
\hline 27 & $\begin{array}{l}\text { Reliable data up to } 400 \mathrm{~s} \text { with gap from } 3 \mathrm{~s} \text { to } 14 \mathrm{~s} \\
\text { and some noise shown by the phase at the lower } \\
\text { end; small static shift between the TE and TM } \\
\text { curves; 2-D characteristic esp at longer periods }\end{array}$ & 3 & 60 \\
\hline 28 & $\begin{array}{l}\text { Data only up to about } 2 \mathrm{~s} \text { with small shift be- } \\
\text { tween TE and TM curves; Almost 1-D character- } \\
\text { istic }\end{array}$ & 1 & \\
\hline 29 & $\begin{array}{l}\text { Good data up to } 400 \mathrm{~s} \text { with some noise from } 2 \\
\mathrm{~s} \text { to } 10 \mathrm{~s} \text { range; large shift between TE and TM } \\
\text { curves that split at } 20 \mathrm{~s} \text {; } 3 \text {-D feature at }>100 \mathrm{~s}\end{array}$ & 3 & -75 \\
\hline 30 & $\begin{array}{l}\text { Data up to } 300 \mathrm{~s} \text { but with gap from } 3 \mathrm{~s} \text { to } 10 \mathrm{~s} \text { and } \\
\text { noisy data }>100 \mathrm{~s} \text {; has a significant shift between } \\
\text { the TE and TM curves; } 2 \text {-D at }>10 \mathrm{~s}\end{array}$ & 2 & 40 \\
\hline
\end{tabular}




\begin{tabular}{|c|c|c|c|}
\hline $\begin{array}{l}\text { Station } \\
\text { ID }\end{array}$ & Data description and analysis & Rank & $\begin{array}{l}\text { Semi-major } \\
\text { angle (deg) }\end{array}$ \\
\hline 31 & $\begin{array}{l}\text { Data up to about } 80 \mathrm{~s} \text { with gap in between } 3 \mathrm{~s} \text { to } \\
30 \mathrm{~s} \text {; significant shift between TE and TM curves; } \\
\text { thicker conductive layer compared to other data; } \\
\text { 2-D feature }\end{array}$ & 2 & 40 \\
\hline 32 & $\begin{array}{l}\text { Data up to about } 100 \mathrm{~s} \text { with gap between } 3 \mathrm{~s} \text { to } \\
13 \mathrm{~s} \text { and noise esp. in the phase data at }>13 \mathrm{~s} \text {; TE } \\
\text { and TM mode curves has small shift and splits } \\
\text { at about } 0.5 \mathrm{~s} \text {; } 2 \text {-D characteristic even at short pe- } \\
\text { riod }\end{array}$ & 1 & 0 \\
\hline 33 & $\begin{array}{l}\text { Data only up to } 3 \mathrm{~s} \text {; very small static shift be- } \\
\text { tween the TE and TM curves; Almost 1-D char- } \\
\text { acteristic all throughout }\end{array}$ & 1 & \\
\hline 34 & $\begin{array}{l}\text { Similar to stn } 33 \text {; data only up to } 3 \text { s; very small } \\
\text { static shift between the TE and TM curves; Al- } \\
\text { most 1-D characteristic }\end{array}$ & 1 & \\
\hline 35 & $\begin{array}{l}\text { Relatively poor data all throughout with gaps at } \\
\text { low period and noise in the phase data at }>1 \text { s; } \\
\text { large shift between TE and TM curves; 2-D char- } \\
\text { acteristic }\end{array}$ & 1 & -75 \\
\hline 37 & $\begin{array}{l}\text { Good data up to } 200 \mathrm{~s} \text { but with some scatter- } \\
\text { ing in the low period range }<0.1 \mathrm{~s} ; \mathrm{TE} \text { and TM } \\
\text { curves has very small shift and splits at } 3 \mathrm{~s} ; 2-\mathrm{D} \\
\text { characteristic }\end{array}$ & 3 & -55 \\
\hline 39 & $\begin{array}{l}\text { Data up to } 100 \mathrm{~s} \text { with gap in between } 0.01 \mathrm{~s} \text { to } \\
0.04 \mathrm{~s} \text { and noise }>2 \mathrm{~s} \text {; TE and TM curves hav a } \\
\text { very small shift but splits at about } 1 \mathrm{~s} ; 3-\mathrm{D} \text { at }>8 \\
\mathrm{~s}\end{array}$ & 2 & 80 \\
\hline
\end{tabular}




\begin{tabular}{|c|c|c|c|}
\hline $\begin{array}{l}\text { Station } \\
\text { ID }\end{array}$ & Data description and analysis & Rank & $\begin{array}{l}\text { Semi-major } \\
\text { angle (deg) }\end{array}$ \\
\hline 41 & $\begin{array}{l}\text { Curve characteristic similar to stn } 34 \text {; data only } \\
\text { up to about } 5 \mathrm{~s} \text { with gap between } 0.01 \mathrm{~s} \text { to } 0.02 \mathrm{~s} \text {; } \\
\text { TE and TM mode curves has very small shift and } \\
\text { shows almost 1-D }\end{array}$ & 1 & \\
\hline 42 & $\begin{array}{l}\text { Reliable data reaching up to }>400 \mathrm{~s} \text { with gap be- } \\
\text { tween } 0.01 \mathrm{~s} \text { and } 0.04 \mathrm{~s} \text {; TE and TM mode curves } \\
\text { has very small shift but splits at } 0.6 \mathrm{~s} \text {; indicates } \\
\text { a thick conductive layer; } 1 \text {-D at short period but } \\
\text { 2-D at }>10 \mathrm{~s}\end{array}$ & 3 & 15 \\
\hline 43 & $\begin{array}{l}\text { Good data up to about } 200 \mathrm{~s} \text { with gap between } \\
0.01 \mathrm{~s} \text { to } 0.04 \mathrm{~s} \text {; very small static shift between the } \\
\text { TE and TM curves but split at about } 80 \mathrm{~s} \text {; a thick } \\
\text { conductive layer is indicated; } 2-\mathrm{D} \text { characteristic }\end{array}$ & 3 & -80 \\
\hline 44 & $\begin{array}{l}\text { Data is only up to } 3 \mathrm{~s} \text { and contaminated by noise; } \\
\text { large shift between TE and TM curves }\end{array}$ & 1 & \\
\hline 45 & $\begin{array}{l}\text { Data is only up to } 1 \mathrm{~s} \text { with noise in the phase at } \\
<.01 \mathrm{~s} \text {; large shift between TE and TM curves }\end{array}$ & 1 & \\
\hline 46 & $\begin{array}{l}\text { Data reaches up to } 200 \mathrm{~s} \text { but with noise in the } \\
\text { phase data at }>1 \mathrm{~s} \text {; TE and TM curves have a } \\
\text { very small shift }\end{array}$ & 1 & \\
\hline 47 & $\begin{array}{l}\text { Data only up to about } 8 \mathrm{~s} \text { with gap between } 0.01 \mathrm{~s} \\
\text { to } 0.04 \mathrm{~s} \text {; TE and TM mode curves has very small } \\
\text { shift and shows almost 1-D characteristic }\end{array}$ & 2 & \\
\hline 48 & $\begin{array}{l}\text { Good data reaching up to }>400 \mathrm{~s} \text { with gap be- } \\
\text { tween } 0.007 \mathrm{~s} \text { and } 0.05 \mathrm{~s} \text {; TE and TM mode curves } \\
\text { has very small shift but splits at } 4 \mathrm{~s} ; 3-\mathrm{D} \text { at }>100 \\
\mathrm{~s}\end{array}$ & 1 & 90 \\
\hline
\end{tabular}




\begin{tabular}{|c|c|c|c|}
\hline $\begin{array}{l}\text { Station } \\
\text { ID }\end{array}$ & Data description and analysis & Rank & $\begin{array}{l}\text { Semi-major } \\
\text { angle (deg) }\end{array}$ \\
\hline 49 & $\begin{array}{l}\text { Data up to about } 100 \mathrm{~s} \text { but with gap between } 4 \\
\mathrm{~s} \text { to } 10 \mathrm{~s} \text { and distorted at }<1 \mathrm{~s} \text { and }>10 \mathrm{~s} \text {; large } \\
\text { static shift between the TE and TM curves; 3-D } \\
\text { at }>0.1 \mathrm{~s}\end{array}$ & 1 & -20 \\
\hline 50 & $\begin{array}{l}\text { Data is only up to } 10 \mathrm{~s} \text { with gap between } 0.09 \mathrm{~s} \\
\text { and } 0.3 \mathrm{~s} \text {; very small shift between TE and TM } \\
\text { curves }\end{array}$ & 1 & \\
\hline 51 & $\begin{array}{l}\text { Good data extending up to } 300 \mathrm{~s} \text { with noise in } \\
\text { the phase at }>100 \mathrm{~s} \text {; small shift between TE and } \\
\text { TM curves; } 2-\mathrm{D} \text { at }>1 \mathrm{~s} \text { then } 3-\mathrm{D} \text { at }>100 \mathrm{~s}\end{array}$ & 3 & 0 \\
\hline 53 & $\begin{array}{l}\text { Fair data reaching up to } 30 \mathrm{~s} \text { with increasing er- } \\
\text { ror bars in the phase at }>2 \mathrm{~s} \text {; large shift between } \\
\mathrm{TE} \text { and TM curves; shows } 3 \text {-D characteristic at } \\
>1 \mathrm{~s}\end{array}$ & 2 & -45 \\
\hline 54 & $\begin{array}{l}\text { Fair data only up to about } 8 \mathrm{~s} \text { with noisy data be- } \\
\text { tween } 0.007 \mathrm{~s} \text { to } 0.1 \mathrm{~s} \text {; TE and TM curves have } \\
\text { very small shift }\end{array}$ & 2 & \\
\hline 55 & $\begin{array}{l}\text { Data up to }>100 \text { s but contaminated with noise; } \\
\text { TE and TM mode curves show no shift }\end{array}$ & 1 & \\
\hline 56 & $\begin{array}{l}\text { Reliable data only up to about } 3 \mathrm{~s} \text { with significant } \\
\text { static shift between the TE and TM curves that } \\
\text { shows 1-D characteristic }\end{array}$ & 1 & \\
\hline 57 & $\begin{array}{l}\text { Data only up to } 1 \mathrm{~s} \text { with noise on the lower pe- } \\
\text { riod range }<0.1 \mathrm{~s} \text {; small shift between TE and TM } \\
\text { curves; shows } 2 \text {-D effects on the longer period } \\
\text { end }\end{array}$ & 1 & -85 \\
\hline
\end{tabular}




\begin{tabular}{|c|c|c|c|}
\hline $\begin{array}{l}\text { Station } \\
\text { ID }\end{array}$ & Data description and analysis & Rank & $\begin{array}{l}\text { Semi-major } \\
\text { angle (deg) }\end{array}$ \\
\hline 58 & $\begin{array}{l}\text { Data reaching up to } 200 \mathrm{~s} \text { but with scattered } \\
\text { phase data starting at }>2 \mathrm{~s} \text {; very small shift be- } \\
\text { tween TE and TM curves; 3-D effects shown at } \\
>10 \mathrm{~s}\end{array}$ & 2 & -85 \\
\hline 59 & $\begin{array}{l}\text { Data only up to about } 2 \mathrm{~s} ; \mathrm{TE} \text { and TM curves } \\
\text { have a large shift }\end{array}$ & 1 & \\
\hline 60 & $\begin{array}{l}\text { Very smooth data curve up to } 400 \mathrm{~s} ; \mathrm{TE} \text { and TM } \\
\text { mode curves have small shift but splits at } 3 \mathrm{~s} \text {; } \\
\text { shows }>2 \text {-D effects at } 2 \mathrm{~s} \text { and 3-D effects at }>70 \mathrm{~s}\end{array}$ & 3 & \\
\hline 61 & $\begin{array}{l}\text { Very good data reaching up to } 700 \mathrm{~s} \text { but with gap } \\
\text { between } 0.01 \mathrm{~s} \text { to } 0.04 \mathrm{~s} \text {; TE and TM mode curves } \\
\text { have large shift and splits at } 1 \mathrm{~s} ; 3 \text {-D characteris- } \\
\text { tic at }>10 \mathrm{~s}\end{array}$ & 3 & 90 \\
\hline 62 & $\begin{array}{l}\text { Data up to about } 9 \mathrm{~s} \text { but relatively noisy at peri- } \\
\text { ods }<0.1 \text { s; almost no static shift between the TE } \\
\text { and TM curves; shows 2-D characteristic }\end{array}$ & 1 & -90 \\
\hline 63 & $\begin{array}{l}\text { Fair data up to about } 100 \mathrm{~s} \text { but with noise on the } \\
5 \mathrm{~s} \text { to } 20 \mathrm{~s} \text { period range; small shift between TE } \\
\text { and TM curves; show 3-D effects at long periods }\end{array}$ & 2 & -85 \\
\hline 64 & $\begin{array}{l}\text { Reliable data only up to about } 2 \mathrm{~s} ; \mathrm{TE} \text { and TM } \\
\text { mode curves have very minimal shift and shows } \\
\text { 1-D characteristic }\end{array}$ & 1 & \\
\hline 66 & $\begin{array}{l}\text { Data only up to about } 0.7 \mathrm{~s} \text { with gap between } \\
\text { periods } 0.01 \mathrm{~s} \text { to } 0.07 \mathrm{~s} \text { range; TE and TM curves } \\
\text { have no shift and show 1-D characteristic }\end{array}$ & 1 & \\
\hline 67 & $\begin{array}{l}\text { Relatively good data up to } 500 \mathrm{~s} \text { with gap be- } \\
\text { tween } 0.01 \mathrm{~s} \text { to } 0.05 \mathrm{~s} \text { range; TE and TM mode } \\
\text { curves have small shift and splits at } 3 \mathrm{~s} \text {; shows } \\
\text { 3-D effects at }>100 \mathrm{~s}\end{array}$ & 3 & 15 \\
\hline
\end{tabular}




\begin{tabular}{|c|c|c|c|}
\hline $\begin{array}{l}\text { Station } \\
\text { ID }\end{array}$ & Data description and analysis & Rank & $\begin{array}{l}\text { Semi-major } \\
\text { angle (deg) }\end{array}$ \\
\hline 69 & $\begin{array}{l}\text { Noisy data up to about } 2 \mathrm{~s} \text { only with gaps on } \\
\text { the lower period range }<0.1 \mathrm{~s} ; \mathrm{TE} \text { and TM mode } \\
\text { curves have small shift }\end{array}$ & 1 & \\
\hline 70 & $\begin{array}{l}\text { Data only up to about } 4 \mathrm{~s} \text { with noise and in- } \\
\text { consistencies in the phase data; very small static } \\
\text { shift between the TE and TM curves; 1-D charac- } \\
\text { teristic }\end{array}$ & 1 & \\
\hline 71 & $\begin{array}{l}\text { Data extend up to about } 300 \mathrm{~s} \text { but is relatively } \\
\text { noisy esp. the phase curve making it unreliable } \\
\text { at longer periods; large shift between TE and TM } \\
\text { curves }\end{array}$ & 1 & \\
\hline 73 & $\begin{array}{l}\text { Data reaches up to about } 100 \mathrm{~s} \text { but has gaps } \\
\text { between } 0.01 \mathrm{~s} \text { to } 0.1 \mathrm{~s} \text { and is noisy } / \mathrm{scattered} \\
\text { (phase) at }>10 \mathrm{~s} \text {; large shift between TE and TM } \\
\text { curves }\end{array}$ & 1 & \\
\hline 75 & $\begin{array}{l}\text { Data reaches up to about } 50 \mathrm{~s} \text { but highly dis- } \\
\text { torted and noisy starting at }>8 \mathrm{~s} \text {; very large shift } \\
\text { between TE and TM curves }\end{array}$ & 1 & \\
\hline 76 & $\begin{array}{l}\text { Relatively good data up to } 40 \mathrm{~s} \text { with noise } \\
\text { present }>10 \mathrm{~s} \text {; TE and TM mode curves have } \\
\text { small }\end{array}$ & 2 & \\
\hline 77 & $\begin{array}{l}\text { Data up to about } 100 \mathrm{~s} \text { but with gap between } 3 \mathrm{~s} \\
\text { to } 14 \mathrm{~s} \text { and large phase error bars starting at }>10 \\
\mathrm{~s} ; \mathrm{TE} \text { and TM mode curves have small shift and } \\
\text { is almost } 1-\mathrm{D} \text { at periods }<1 \mathrm{~s} \text { and } 3-\mathrm{D} \text { at }>10 \mathrm{~s}\end{array}$ & 2 & -45 \\
\hline 80 & $\begin{array}{l}\text { Data extend to } 300 \mathrm{~s} \text { but with missing data points } \\
\text { from } 0.9 \mathrm{~s} \text { to } 11 \mathrm{~s} \text { and scattered phase data at } \\
>90 \mathrm{~s} \text {; large static shift between the TE and TM } \\
\text { curves }\end{array}$ & 1 & \\
\hline
\end{tabular}




\begin{tabular}{|c|c|c|c|}
\hline $\begin{array}{l}\text { Station } \\
\text { ID }\end{array}$ & Data description and analysis & Rank & $\begin{array}{l}\text { Semi-major } \\
\text { angle (deg) }\end{array}$ \\
\hline 81 & $\begin{array}{l}\text { Very smooth data curve extending up to about } \\
400 \mathrm{~s} \text {; almost no static shift but TE and TM curves } \\
\text { split at about } 0.1 \mathrm{~s} \text {; shows } 2 \text {-D effects at periods } \\
>1 \mathrm{~s}\end{array}$ & 3 & -90 \\
\hline 82 & $\begin{array}{l}\text { Almost similar in configuration to station } 81 \text { but } \\
\text { noisier with larger error bars at periods }>100 \mathrm{~s} \text {; } \\
\text { small shift between TE and TM modes; } 2-\mathrm{D} \text { ef- } \\
\text { fects are indicated even on the short periods }\end{array}$ & 3 & \\
\hline 83 & $\begin{array}{l}\text { Relatively good data that extends to about } 700 \\
\text { s; large shift between TE and TM curves; simi- } \\
\text { lar configuration with Stn } 81 \text { but with the curve } \\
\text { modes interchanged; 2-D effects at periods of } \\
\text { about }>50 \mathrm{~s}\end{array}$ & 3 & 45 \\
\hline 84 & $\begin{array}{l}\text { Similar to station } 83 \text { but smoother and has } \\
\text { smaller static shift between TE and TM curves; } \\
\text { 2-D effects at }>20 \mathrm{~s} \text {; curve level at about } 20 \mathrm{ohm}- \\
\mathrm{m} \text { indicates very thick conductor }\end{array}$ & 3 & 30 \\
\hline 85 & $\begin{array}{l}\text { Fair data reaching up to about } 500 \mathrm{~s} \text { but with gap } \\
\text { between } 2 \mathrm{~s} \text { to } 8 \mathrm{~s} \text {; TE and TM mode curves have } \\
\text { very small shift; similar curve configuration to } \\
\text { stations } 83 \text { and } 84 \text { except for the steeper resistiv- } \\
\text { ity gradients; } 3 \text {-D effects at periods }>10 \mathrm{~s}\end{array}$ & 3 & -65 \\
\hline 86 & $\begin{array}{l}\text { Data extends to } 100 \mathrm{~s} \text { but with missing data } \\
\text { points from } 3 \mathrm{~s} \text { to } 20 \mathrm{~s} \text {; very large static shift be- } \\
\text { tween the TE and TM curves; show 3-D effects at } \\
\text { periods }>10 \mathrm{~s}\end{array}$ & 2 & -60 \\
\hline 88 & $\begin{array}{l}\text { Data only up to about } 3 \mathrm{~s} \text { with a considerable } \\
\text { static shift between the TE and TM curves; 2-D } \\
\text { effects even at short periods }\end{array}$ & 1 & 0 \\
\hline
\end{tabular}




\begin{tabular}{|c|c|c|c|}
\hline $\begin{array}{l}\text { Station } \\
\text { ID }\end{array}$ & Data description and analysis & Rank & $\begin{array}{l}\text { Semi-major } \\
\text { angle (deg) }\end{array}$ \\
\hline 89 & $\begin{array}{l}\text { Relatively noisy data up to about } 2 \mathrm{~s} \text {; large shift } \\
\text { between TE and TM modes }\end{array}$ & 1 & \\
\hline 91 & $\begin{array}{l}\text { Noisy data up to } 1 \mathrm{~s} \text { with large static shift be- } \\
\text { tween TE and TM modes }\end{array}$ & 1 & \\
\hline 92 & $\begin{array}{l}\text { Data up to periods of about } 2 \mathrm{~s} \text { but }<0.1 \mathrm{~s} \text { satu- } \\
\text { rated by noise and with small shift between TE } \\
\text { and TM curves }\end{array}$ & 1 & \\
\hline 93 & $\begin{array}{l}\text { Data up to about } 100 \mathrm{~s} \text { but missing data points } \\
\text { between } 2 \mathrm{~s} \text { to } 20 \mathrm{~s} \text { and noisy starting at }>3 \\
\mathrm{~s} \text {; very large shift between TE and TM curves; } \\
\text { highly distorted ( } 2 \text {-D effects) even at high fre- } \\
\text { quency range }\end{array}$ & 1 & -85 \\
\hline 94 & $\begin{array}{l}\text { Data up to period of } 1000 \text { s but is noisy and scat- } \\
\text { tered at }>100 \mathrm{~s} \text {; TE and TM curves have signifi- } \\
\text { cant shift and show 3-D characteristic at long pe- } \\
\text { riods }\end{array}$ & 2 & -85 \\
\hline 95 & $\begin{array}{l}\text { Data extend up to } 1000 \mathrm{~s} \text { but is highly distorted } \\
\text { and noisy starting at }>1 \mathrm{~s} \text {; very large static shift } \\
\text { between TE and TM curves; 2-D effects at short } \\
\text { periods }\end{array}$ & 1 & 0 \\
\hline 96 & $\begin{array}{l}\text { Relatively good data }>500 \mathrm{~s} \text { with noisy data } \\
\text { from } 2 \mathrm{~s} \text { to } 100 \mathrm{~s} \text { range; TE and TM curves have a } \\
\text { small shift and exhibit 1-D characteristic at short } \\
\text { periods ( }<1 \mathrm{~s}) \text { and 3-D effects at long periods }\end{array}$ & 3 & 85 \\
\hline 97 & $\begin{array}{l}\text { Reliable data up to about } 200 \mathrm{~s} \text { with noise from } \\
5 \mathrm{~s} \text { to } 20 \mathrm{~s} \text {; TE and TM curves show minimum } \\
\text { shift; } 2 \text {-D effects startinga at }>0.5 \mathrm{~s}\end{array}$ & 3 & -15 \\
\hline
\end{tabular}




\begin{tabular}{|c|c|c|c|}
\hline $\begin{array}{l}\text { Station } \\
\text { ID }\end{array}$ & Data description and analysis & Rank & $\begin{array}{l}\text { Semi-major } \\
\text { angle (deg) }\end{array}$ \\
\hline 98 & $\begin{array}{l}\text { Reliable data only up to about } 2 \mathrm{~s} ; \mathrm{TE} \text { and TM } \\
\text { curves have large static shift and show distortion } \\
\text { even at lower periods }\end{array}$ & 1 & 5 \\
\hline 99 & $\begin{array}{l}\text { Data extend up to periods of about } 1000 \mathrm{~s} \text { but } \\
\text { noisy from } 2 \mathrm{~s} \text { to } 20 \mathrm{~s} \text { and }>200 \mathrm{~s} \text {; Large shift be- } \\
\text { tween TE and TM curves; Highly distorted even } \\
\text { at short periods; } 3 \text {-D effects at }>10 \mathrm{~s}\end{array}$ & 2 & -60 \\
\hline 100 & $\begin{array}{l}\text { Reliable data only up to about } 2 \mathrm{~s} \text {; TE and TM } \\
\text { curves show large shift; shows 2-D characteristic } \\
\text { at short periods }\end{array}$ & 1 & 25 \\
\hline 101 & $\begin{array}{l}\text { Data extend up to } 1000 \mathrm{~s} \text { but is highly distorted } \\
\text { and noisy starting at }>0.2 \mathrm{~s} \text {; very large static shift } \\
\text { between TE and TM curves; } 3 \text {-D effects at }>30 \mathrm{~s}\end{array}$ & 1 & -30 \\
\hline 102 & $\begin{array}{l}\text { Relatively good data that extends to }>500 \mathrm{~s} \text { but } \\
\text { with noisy data from } 2 \mathrm{~s} \text { to } 25 \mathrm{~s} \text { range; TE and } \\
\text { TM curves have a large shift; 2-D effects at } 0.03 \mathrm{~s} \\
\text { to } 0.2 \mathrm{~s} \text { and 3-D effects at }>7 \mathrm{~s}\end{array}$ & 3 & -80 \\
\hline 103 & $\begin{array}{l}\text { Relatively good data that extend to periods } \\
>100 \text { s but with noisy portion from } 2 \mathrm{~s} \text { to } 20 \mathrm{~s} \text {; } \\
\text { TE and TM curves have a large shift; shows 3-D } \\
\text { characteristic at }>100 \mathrm{~s}\end{array}$ & 3 & 60 \\
\hline 104 & $\begin{array}{l}\text { Data is noisy starting at }>0.2 \mathrm{~s} \text {; TE and TM } \\
\text { curves have small shift; 3-D effects at }>3 \mathrm{~s}\end{array}$ & 1 & -85 \\
\hline 105 & $\begin{array}{l}\text { Data reaches up to }>300 \mathrm{~s} \text { but is noisy esp. at } \\
\text { mid range of } 0.2 \mathrm{~s} \text { to } 20 \mathrm{~s} \text {; TE and TM curves have } \\
\text { large shift; highly distorted even at short periods }\end{array}$ & 1 & -85 \\
\hline
\end{tabular}




\begin{tabular}{|c|c|c|c|}
\hline $\begin{array}{l}\text { Station } \\
\text { ID }\end{array}$ & Data description and analysis & Rank & $\begin{array}{l}\text { Semi-major } \\
\text { angle (deg) }\end{array}$ \\
\hline 106 & $\begin{array}{l}\text { Smooth data curves reaching up to }>100 \mathrm{~s} \text { with } \\
\text { some noise in the xy curve; TE and TM curves } \\
\text { show minimum shift and splits at about } 0.2 \mathrm{~s} \text {; } \\
\text { shows } 1 \text {-D at short periods and 2-D/3-D effects } \\
\text { at }>1 \mathrm{~s}\end{array}$ & 3 & -85 \\
\hline 107 & $\begin{array}{l}\text { Fair data up to periods }>200 \mathrm{~s} \text { with noisy data in } \\
\text { the range of } 0.2 \mathrm{~s} \text { to } 20 \mathrm{~s} \text {; TE and TM curves show } \\
\text { minimum shift; } 3 \text {-D effects at long periods }\end{array}$ & 2 & -85 \\
\hline 108 & $\begin{array}{l}\text { Relatively good data reaching up to }>200 \mathrm{~s} \text { with } \\
\text { noise in the } 2 \mathrm{~s} \text { to } 20 \mathrm{~s} \text { range and }>70 \mathrm{~s} \text { esp in } \\
\text { the yx curve; TE and TM curves show small shift } \\
\text { and show } 1 \mathrm{D} \text { characteristic at short periods then } \\
\text { 2-D/3-D effects at periods }>0.6 \mathrm{~s}\end{array}$ & 1 & \\
\hline 109 & $\begin{array}{l}\text { Data up to }>200 \mathrm{~s} \text { but is noisy esp from } 0.2 \mathrm{~s} \text { to } \\
30 \mathrm{~s} \text {; small shift between TE and TM curves; 3-D } \\
\text { effects at long periods }\end{array}$ & 2 & 85 \\
\hline 110 & $\begin{array}{l}\text { Data up to about } 7 \mathrm{~s} \text { but is noisy all throughout; } \\
\text { TE and TM curves have large shift and highly } \\
\text { distorted (2-D effect) at short periods }\end{array}$ & 1 & \\
\hline 111 & $\begin{array}{l}\text { Reliable data only up to about } 2 \mathrm{~s} \text {; TE and TM } \\
\text { curves have large shift and show 1-D character- } \\
\text { istic at short periods and 2-D at } 1 \mathrm{~s}\end{array}$ & 1 & 45 \\
\hline 112 & $\begin{array}{l}\text { Data extends only up to about } 0.4 \mathrm{~s} \text { but noisy; TE } \\
\text { and TM curves show large shift }\end{array}$ & 1 & \\
\hline 113 & $\begin{array}{l}\text { Reliable data only up to about } 0.7 \mathrm{~s} ; \mathrm{TE} \text { and TM } \\
\text { curves show large shift }\end{array}$ & 1 & \\
\hline 115 & $\begin{array}{l}\text { Reliable data only up to about } 2 \mathrm{~s} \text {; TE and TM } \\
\text { curves show large shift and 1-D characteristic at } \\
\text { short periods }\end{array}$ & 1 & \\
\hline
\end{tabular}




\begin{tabular}{|c|c|c|c|}
\hline $\begin{array}{l}\text { Station } \\
\text { ID }\end{array}$ & Data description and analysis & Rank & $\begin{array}{l}\text { Semi-major } \\
\text { angle (deg) }\end{array}$ \\
\hline 116 & $\begin{array}{l}\text { Reliable data only up to about } 2 \mathrm{~s} ; \mathrm{TE} \text { and TM } \\
\text { curves show small shift and 1-D characteristic at } \\
\text { short periods }\end{array}$ & 1 & \\
\hline 118 & $\begin{array}{l}\text { Reliable data only up to about } 1 \mathrm{~s} \text { because of high } \\
\text { noise at periods }>1 \mathrm{~s} \text {; TE and TM curves have } \\
\text { almost no shift and show 1-D characteristic at } \\
\text { shorter periods }\end{array}$ & 1 & \\
\hline 119 & $\begin{array}{l}\text { Reliable data only up to about } 0.3 \text { s; very small } \\
\text { shift between TE and TM curves }\end{array}$ & 1 & \\
\hline 120 & $\begin{array}{l}\text { Relatively good data up to about } 200 \mathrm{~s} \text { but with } \\
\text { noise from } 1 \mathrm{~s} \text { to } 10 \mathrm{~s} \text {; TE and TM curves show } \\
\text { large shift; } 2 \text {-D effects at periods }>20 \mathrm{~s}\end{array}$ & 3 & -40 \\
\hline 122 & $\begin{array}{l}\text { Reliable data only up to about } 1 \mathrm{~s} \text {; TE and TM } \\
\text { curves show small shift; } 2 \text {-D effects even at short } \\
\text { periods }\end{array}$ & 1 & -10 \\
\hline 123 & $\begin{array}{l}\text { Extremely noisy data even at the lower pe- } \\
\text { riod range; high noise signal is suspected to be } \\
\text { caused by its proximity to a cell-site tower }\end{array}$ & & \\
\hline 124 & $\begin{array}{l}\text { Another station that is located near a cellsite } \\
\text { tower; extremely noisy with scattered phase } \\
\text { curves }\end{array}$ & & \\
\hline 125 & $\begin{array}{l}\text { Reliable data is only up to about } 1 \mathrm{~s} ; \mathrm{TE} \text { and TM } \\
\text { curves have a very large shift }\end{array}$ & 1 & \\
\hline 127 & $\begin{array}{l}\text { Reliable data is only up to about } 0.5 \mathrm{~s} \text { since it is } \\
\text { highly noisy and scattered at longer periods; a } \\
\text { large shift between curves }\end{array}$ & 1 & \\
\hline
\end{tabular}




\begin{tabular}{|c|c|c|c|}
\hline $\begin{array}{l}\text { Station } \\
\text { ID }\end{array}$ & Data description and analysis & Rank & $\begin{array}{l}\text { Semi-major } \\
\text { angle (deg) }\end{array}$ \\
\hline 129 & $\begin{array}{l}\text { Reliable data can be retrieved up to about } 30 \mathrm{~s} \\
\text { since it is highly noisy and scattered at longer } \\
\text { periods; large shift between curves; highly dis- } \\
\text { torted at longer periods }\end{array}$ & 2 & -45 \\
\hline 131 & $\begin{array}{l}\text { Reliable data only up to about } 1 \mathrm{~s} ; \mathrm{TE} \text { and TM } \\
\text { curves show small shift and 1-D characteristic at } \\
\text { short periods }\end{array}$ & 1 & \\
\hline 133 & $\begin{array}{l}\text { Very good data up to about } 200 \mathrm{~s} \text { when scattering } \\
\text { of the xy phase curve starts to occur; noisy data } \\
\text { is also present from } 2 \mathrm{~s} \text { to } 8 \mathrm{~s} \text { (indicated by the } \\
\text { hump); TE and TM curves have large static shift; } \\
\text { shows 3-D effects at periods }>80 \mathrm{~s}\end{array}$ & 3 & 65 \\
\hline 134 & $\begin{array}{l}\text { Relatively good data up to about } 500 \mathrm{~s} \text { but noise } \\
\text { in } 2 \mathrm{~s} \text { to } 20 \mathrm{~s} \text { range; TE and TM curves have small } \\
\text { shift and splits at about } 30 \mathrm{~s} \text {; 3-D effects are indi- } \\
\text { cated at }>10 \mathrm{~s}\end{array}$ & 3 & -85 \\
\hline 137 & $\begin{array}{l}\text { Relatively good data up to about } 10 \text { os with } \\
\text { higher noise saturation in the } 2 \mathrm{~s} \text { to } 20 \mathrm{~s} \text { range; TE } \\
\text { and TM curves show almost no shift and splits at } \\
\text { about } 30 \mathrm{~s} \text {; shows } 3-\mathrm{D} \text { at }>10 \mathrm{~s}\end{array}$ & 3 & 0 \\
\hline 138 & $\begin{array}{l}\text { Data extends up to about } 200 \mathrm{~s} \text { but scattering oc- } \\
\text { curs at higher periods; large shift between TE } \\
\text { and TM curves; shows almost 1-D at short pe- } \\
\text { riods and 3-D effects starting at }>1 \text { s }\end{array}$ & 2 & 45 \\
\hline 140 & $\begin{array}{l}\text { Reliable data is only up to about } 2 \mathrm{~s} \text { since scatter- } \\
\text { ing occurs at higher periods; small shift between } \\
\text { TE and TM curves }\end{array}$ & 1 & \\
\hline
\end{tabular}




\begin{tabular}{|c|c|c|c|}
\hline $\begin{array}{l}\text { Station } \\
\text { ID }\end{array}$ & Data description and analysis & Rank & $\begin{array}{l}\text { Semi-major } \\
\text { angle (deg) }\end{array}$ \\
\hline 141 & $\begin{array}{l}\text { Good data up to about } 50 \mathrm{~s} \text { with noisy section } \\
\text { from } 1 \mathrm{~s} \text { to } 12 \mathrm{~s} \text {; TE and TM curves show large } \\
\text { shift; 3-D is indicated at long periods }\end{array}$ & 2 & 10 \\
\hline 142 & $\begin{array}{l}\text { Reliable data is only up to about } 1 \mathrm{~s} \text { since scatter- } \\
\text { ing occurs at longer periods; TE and TM curves } \\
\text { show very large static shift }\end{array}$ & 1 & \\
\hline 143 & $\begin{array}{l}\text { Good data up to periods }>600 \mathrm{~s} \text { but with noisy } \\
\text { section from } 1 \mathrm{~s} \text { to } 13 \mathrm{~s} \text {; TE and TM curves show } \\
\text { almost no shift but splits at about } 40 \mathrm{~s} \text {; indicates } \\
\text { 2-D at }>80 \mathrm{~s}\end{array}$ & 3 & -85 \\
\hline 144 & $\begin{array}{l}\text { Reliable data is only until } 0.8 \mathrm{~s} \text { as extreme scat- } \\
\text { tering occur at higher periods; TE and TM curves } \\
\text { have very large shift; } 2 \text {-D effects can be seen at } \\
\text { short periods }\end{array}$ & 1 & -80 \\
\hline 145 & $\begin{array}{l}\text { Fair data up to } 100 \mathrm{~s} \text { with gap } 1 \mathrm{~s} \text { to } 15 \mathrm{~s} \text { because } \\
\text { of noise; very small shift between curves; shows } \\
\text { 3-D characteristic }>10 \mathrm{~s}\end{array}$ & 2 & -85 \\
\hline 146 & $\begin{array}{l}\text { Reliable data only up to } 1 \mathrm{~s} \text {; scattering and large } \\
\text { error bar at longer periods; TE and TM curves } \\
\text { show very large shift; 2-D is indicated at short } \\
\text { periods }\end{array}$ & 1 & -90 \\
\hline 147 & $\begin{array}{l}\text { Fair data only up to about } 200 \mathrm{~s} \text { with noisy sec- } \\
\text { tions esp in the } 2 \mathrm{~s} \text { to } 20 \mathrm{~s} \text { range; TE and TM } \\
\text { curves show minimum shift and 1-D characteris- } \\
\text { tic at short periods but 3-D is indicated at longer } \\
\text { periods }\end{array}$ & 2 & 40 \\
\hline
\end{tabular}




\begin{tabular}{|c|c|c|c|}
\hline $\begin{array}{l}\text { Station } \\
\text { ID }\end{array}$ & Data description and analysis & Rank & $\begin{array}{l}\text { Semi-major } \\
\text { angle (deg) }\end{array}$ \\
\hline 148 & $\begin{array}{l}\text { Relatively good data until about } 200 \mathrm{~s} \text { with noisy } \\
\text { data between } 2 \mathrm{~s} \text { to } 20 \mathrm{~s} \text {; TE and TM curves } \\
\text { show large shift; 3-D is indicated at longer pe- } \\
\text { riods }>100 \mathrm{~s}\end{array}$ & 3 & 0 \\
\hline 149 & $\begin{array}{l}\text { Reliable data can be extracted up to about } 200 \mathrm{~s} \\
\text { but with noisy section from } 2 \mathrm{~s} \text { to about } 20 \mathrm{~s} \text {; al- } \\
\text { most no shift between TE and TM curves; shows } \\
\text { 3-D at long periods }\end{array}$ & 2 & 70 \\
\hline 150 & $\begin{array}{l}\text { Reliable data is only up to about } 2 \mathrm{~s} ; \mathrm{TE} \text { and TM } \\
\text { curves show large shift }\end{array}$ & 1 & \\
\hline 151 & $\begin{array}{l}\text { Data up to } 1 \mathrm{~s} \text { marked by noise; very large static } \\
\text { shift between TE and TM curves }\end{array}$ & 1 & \\
\hline 153 & $\begin{array}{l}\text { Data up to } 1 \mathrm{~s} \text { marked by noise and scattering; } \\
\text { large static shift between TE and TM curves }\end{array}$ & 1 & \\
\hline 154 & $\begin{array}{l}\text { Fair data up to about } 300 \mathrm{~s} \text { but with noisy data } \\
\text { from } 2 \mathrm{~s} \text { to } 20 \mathrm{~s} \text {; TE and TM curves show very } \\
\text { large; 1-D is indicated at short periods and 3-D } \\
\text { at periods }>70 \mathrm{~s}\end{array}$ & 2 & 45 \\
\hline 155 & $\begin{array}{l}\text { Reliable data only up to about } 0.5 \mathrm{~s} ; \mathrm{TE} \text { and TM } \\
\text { curves have small static shift }\end{array}$ & 1 & \\
\hline 156 & $\begin{array}{l}\text { Reliable data only up to about } 0.7 \mathrm{~s} \text {; very large } \\
\text { shift between TE and TM curves }\end{array}$ & 1 & \\
\hline 157 & $\begin{array}{l}\text { Reliable data only up to about } 0.2 \mathrm{~s} ; \mathrm{TE} \text { and TM } \\
\text { curves show small shift }\end{array}$ & 1 & \\
\hline 158 & $\begin{array}{l}\text { Reliable data only up to about } 1 \mathrm{~s} \text {; very large shift } \\
\text { between TE and TM curves }\end{array}$ & 1 & \\
\hline
\end{tabular}




\section{Appendix III: Static shift correction applied}

\begin{tabular}{ccc}
\hline \hline Station ID & $\mathrm{xy}$ & $\mathrm{yx}$ \\
\hline 1 & 1 & 1 \\
2 & 0.512 & 0.645 \\
3 & 1 & 1 \\
4 & 0.615 & 0.564 \\
5 & 1 & 1 \\
6 & 1 & 0.698 \\
7 & 1 & 1 \\
8 & 3.072 & 1 \\
9 & 1 & 1 \\
10 & 0.82 & 0.775 \\
11 & 1.705 & 1.287 \\
12 & 1.185 & 1.754 \\
13 & 1 & 1 \\
14 & 1.881 & 1.753 \\
15 & 0.42 & 0.491 \\
16 & 1.915 & 2.082 \\
17 & 1.107 & 1 \\
18 & 4.99 & 5.411 \\
19 & 1 & 1 \\
20 & 1.888 & 2.111 \\
& 187 & \\
& &
\end{tabular}




\begin{tabular}{|c|c|c|}
\hline Station ID & xy & yx \\
\hline 22 & 0.816 & 0.864 \\
\hline 23 & 1 & 1 \\
\hline 24 & 1.047 & 1.254 \\
\hline 25 & 1 & 1 \\
\hline 26 & 1.296 & 1.293 \\
\hline 27 & 0.801 & 1.546 \\
\hline 28 & 1.159 & 1.277 \\
\hline 29 & 0.241 & 0.273 \\
\hline 30 & 1 & 1 \\
\hline 31 & 1 & 1 \\
\hline 32 & 1.648 & 1.296 \\
\hline 33 & 1 & 1 \\
\hline 34 & 1.04 & 1.231 \\
\hline 35 & 0.618 & 0.799 \\
\hline 37 & 1 & 1.187 \\
\hline 39 & 1 & 1 \\
\hline 41 & 1 & 1 \\
\hline 42 & 0.883 & 0.876 \\
\hline 43 & 0.647 & 0.583 \\
\hline 44 & 0.87 & 0.481 \\
\hline 45 & 1.846 & 1.861 \\
\hline 46 & 2.488 & 3.805 \\
\hline 47 & 1.467 & 1.191 \\
\hline 48 & 1 & 1 \\
\hline 49 & 1.376 & 1 \\
\hline 50 & 1 & 1 \\
\hline 51 & 1 & 1 \\
\hline 53 & 0.846 & 0.734 \\
\hline 54 & 1 & 1 \\
\hline 55 & 1 & 1 \\
\hline
\end{tabular}




\begin{tabular}{ccc}
\hline \hline Station ID & $\mathrm{xy}$ & $\mathrm{yx}$ \\
\hline 56 & 0.339 & 0.332 \\
57 & 1 & 1 \\
58 & 1 & 1 \\
59 & 1 & 1 \\
60 & 1 & 1 \\
61 & 1 & 1 \\
62 & 1.224 & 1.691 \\
63 & 0.878 & 0.857 \\
64 & 1 & 1 \\
66 & 1.236 & 1.383 \\
67 & 0.768 & 0.874 \\
68 & 0.641 & 1 \\
69 & 0.824 & 0.908 \\
70 & 1 & 1 \\
71 & 0.9862 & 0.68 \\
73 & 0.663 & 0.522 \\
75 & 0.876 & 0.579 \\
76 & 1 & 1 \\
77 & 1 & 1 \\
80 & 1.95 & 1.734 \\
81 & 5.001 & 2.976 \\
82 & 4.412 & 6.286 \\
83 & 1.322 & 1.309 \\
84 & 2.702 & 2.659 \\
85 & 1 & 1 \\
86 & 0.648 & 1 \\
88 & 1.965 & 1 \\
89 & 1.322 & 1.545 \\
92 & 1.289 & 1.615 \\
93 & 3.668 & 4.115
\end{tabular}




\begin{tabular}{ccc}
\hline \hline Station ID & xy & $y x$ \\
\hline 94 & 2.336 & 1.978 \\
95 & 1.413 & 0.65 \\
96 & 3.382 & 3.166 \\
97 & 5.233 & 5.973 \\
99 & 3.741 & 2.636 \\
101 & 1 & 1.56 \\
102 & 1.381 & 1.411 \\
103 & 1.397 & 1.482 \\
104 & 1.832 & 1.925 \\
105 & 2.353 & 2.341 \\
106 & 2.353 & 2.341 \\
107 & 1.75 & 1.843 \\
108 & 0.773 & 0.874 \\
109 & 1.136 & 1.076 \\
111 & 3.702 & 3.273 \\
113 & 2.167 & 2.54 \\
114 & 1 & 1 \\
115 & 1.55 & 1.401 \\
116 & 1.423 & 1.39 \\
117 & 1 & 1 \\
118 & 1 & 1 \\
120 & 1 & 1 \\
122 & 1.521 & 1.494 \\
124 & 1.113 & 1.21 \\
125 & 0.29 & 0.563 \\
127 & 1 & 0.894 \\
129 & 1.114 & 1 \\
131 & 1 & 1 \\
133 & 0.78 & 0.788 \\
134 & 0.296 & 0.293
\end{tabular}


APPENDIX III: STATIC SHIFT CORRECTION APPLIED

\begin{tabular}{ccc}
\hline \hline Station ID & $\mathrm{xy}$ & $\mathrm{yx}$ \\
\hline 136 & 1 & 1 \\
137 & 0.644 & 0.638 \\
138 & 0.934 & 0.814 \\
140 & 2.221 & 1.852 \\
141 & 0.529 & 0.529 \\
143 & 1 & 1 \\
144 & 1.519 & 1.718 \\
145 & 0.411 & 0.421 \\
147 & 1 & 1 \\
148 & 1.699 & 1.629 \\
149 & 1.49 & 1.241 \\
150 & 0.66 & 1.285 \\
151 & 1 & 0.748 \\
154 & 0.659 & 0.767 \\
155 & 0.627 & 0.659 \\
156 & 0.559 & 0.693 \\
157 & 2.288 & 2.179 \\
158 & 0.878 & 1.211 \\
\hline
\end{tabular}




\section{Appendix IV: 3-D inversion data file}


APPENDIX IV: 3-D INVERSION DATA FILE

\section{3-D inversion data file}

37148

Station_Location:N-S

$\begin{array}{rrrrrrrr}2.75 \mathrm{E}+03 & 7.50 \mathrm{E}+02 & 7.50 \mathrm{E}+02 & -2.50 \mathrm{E}+02 & -1.25 \mathrm{E}+03 & 7.50 \mathrm{E}+02 & -3.25 \mathrm{E}+03 & -2.25 \mathrm{E}+03 \\ 7.50 \mathrm{E}+02 & -7.50 \mathrm{E}+02 & -1.25 \mathrm{E}+03 & -7.50 \mathrm{E}+02 & -2.50 \mathrm{E}+02 & 1.75 \mathrm{E}+03 & 1.75 \mathrm{E}+03 & 1.25 \mathrm{E}+03 \\ 2.25 \mathrm{E}+03 & 2.25 \mathrm{E}+03 & 2.75 \mathrm{E}+03 & -1.75 \mathrm{E}+03 & 4.25 \mathrm{E}+03 & 4.25 \mathrm{E}+03 & 1.25 \mathrm{E}+03 & 7.50 \mathrm{E}+02 \\ 1.25 \mathrm{E}+03 & 2.25 \mathrm{E}+03 & -2.50 \mathrm{E}+02 & -7.50 \mathrm{E}+02 & -1.25 \mathrm{E}+03 & -1.75 \mathrm{E}+03 & -2.75 \mathrm{E}+03 & -1.25 \mathrm{E}+03 \\ -1.75 \mathrm{E}+03 & 2.50 \mathrm{E}+02 & -2.75 \mathrm{E}+03 & -3.25 \mathrm{E}+03 & -4.75 \mathrm{E}+03 & & & \end{array}$

Station_Location:E-W

$-2.50 \mathrm{E}+02 \quad 2.50 \mathrm{E}+02 \quad 1.25 \mathrm{E}+03 \quad 2.75 \mathrm{E}+03$

$3.75 \mathrm{E}+03$

$-2.75 \mathrm{E}+03$

$3.75 \mathrm{E}+03$

$-3.25 E+03$

$-4.25 \mathrm{E}+03-2.50 \mathrm{E}+02$

$7.50 \mathrm{E}+02$

$7.50 \mathrm{E}+02$

$-2.25 \mathrm{E}+03$

$2.50 \mathrm{E}+02$

$-1.75 E+03$

$-7.50 \mathrm{E}+02$

$-2.75 \mathrm{E}+03 \quad 2.50 \mathrm{E}+02$

$7.50 \mathrm{E}+02$

$-2.25 \mathrm{E}+03$

$-2.50 \mathrm{E}+02$

$-1.75 \mathrm{E}+03$

$2.75 \mathrm{E}+03$

$2.75 \mathrm{E}+03$

$3.25 \mathrm{E}+03$

$1.25 \mathrm{E}+03$

$1.25 \mathrm{E}+03$

$1.75 \mathrm{E}+03$

$2.25 \mathrm{E}+03$

$2.25 \mathrm{E}+03$

$7.50 \mathrm{E}+02$

$-7.50 \mathrm{E}+02$

DATA_Period:

6.90E-03

4.27E-03

2.78E-03

4.96E-02

$-2.20 \mathrm{E}-01$

$-6.18 \mathrm{E}-02$

2.19E-01

2.52E-03

$-4.09 E-03$

$-4.90 \mathrm{E}-03 \quad-2.46 \mathrm{E}-02$

1.32E-01

$-2.03 \mathrm{E}-01$

4.08E-01

1.06E-02

$-2.66 \mathrm{E}-02$

1.25E-02 8.03E-04

1.57E-01

$-3.23 \mathrm{E}-01$

$-1.59 \mathrm{E}-01$

3.37E-01

$-1.41 \mathrm{E}-02$

$-1.18 \mathrm{E}-02$

3.96E-03 3.76E-02

1.89E-01

$-3.94 \mathrm{E}-01$

$-2.26 \mathrm{E}-03$

$-3.96 \mathrm{E}-02$

$1.68 \mathrm{E}-01$

$-1.75 \mathrm{E}-01$

3.11E-01

$-8.78 \mathrm{E}-03$

$-2.58 \mathrm{E}-03$

7.92E-03 1.84E-02

1.25E-01

$-2.83 \mathrm{E}-01$

$-1.85 \mathrm{E}-01$

2.97E-01

3.42E-02

$-2.70 \mathrm{E}-03$

$-4.04 \mathrm{E}-03 \quad-9.72 \mathrm{E}-03$

1.73E-01

$-3.50 \mathrm{E}-01$

$-1.29 \mathrm{E}-01$

3.17E-01

$-8.70 \mathrm{E}-03$

$-1.06 \mathrm{E}-02$

5.00E-03 3.01E-03

1.17E-01

$-2.27 \mathrm{E}-01$

$-1.75 \mathrm{E}-01$

2.03E-01

4.50E-03

6.25E-03

$-1.09 \mathrm{E}-01$

1.90E-01

$-3.54 \mathrm{E}-03$

1.51E-03

$-1.25 \mathrm{E}-03 \quad-1.67 \mathrm{E}-03$

$-6.18 \mathrm{E}-02$

3.97E-02

$-7.34 \mathrm{E}-04$

$-3.08 \mathrm{E}-03$

9.22E-02 -2.97E-01

$23 \mathrm{E}-02$

2.80E-01

$-2.56 \mathrm{E}-02$

$-1.86 \mathrm{E}-03$

1.13E-03 -1.73E-02

1.40E-01

$-3.20 \mathrm{E}-01$

8.02E-02

$-2.61 \mathrm{E}-01$

$-1.67 \mathrm{E}-01$

3.34E-01

$1.38 \mathrm{E}-03$

1.20E-02

$-1.47 \mathrm{E}-02 \quad-5.28 \mathrm{E}-03$

1.17E-01 -2.13E-01

$-9.51 \mathrm{E}-02$

2.06E-01

$-1.88 \mathrm{E}-03$

$-5.63 \mathrm{E}-05$

$-5.89 \mathrm{E}-03 \quad 5.84 \mathrm{E}-03$

9.88E-02

$-1.20 \mathrm{E}-01$

2.02E-01

2.98E-03

7.84E-04

9.24E-03 -2.58E-03

$-2.17 \mathrm{E}-01$

$-9.79 E-02$

2.05E-01

$-2.90 \mathrm{E}-03$

$-2.99 \mathrm{E}-03$

1.41E-01 -4.44E-01

2.84E-01

$-1.96 \mathrm{E}-02$

$6.34 \mathrm{E}-02$

6.22E-02 -2.77E-02

1.02E-01

$-3.44 \mathrm{E}-01$

$-2.14 \mathrm{E}-01$

3.79E-01

2.48E-02

$-5.19 \mathrm{E}-02$

2.51E-02 -8.54E-04

1.22E-01

$-2.32 \mathrm{E}-01$

$-8.74 \mathrm{E}-02$

2.36E-01

9.61E-03

$-2.96 \mathrm{E}-02$

4.11E-03 2.88E-04

1.40E-01

$-3.15 \mathrm{E}-01$

$-9.58 \mathrm{E}-02$

3.75E-01

$-7.60 \mathrm{E}-03$

6.14E-03

1.50E-01

$-3.44 \mathrm{E}-01$

$-1.97 \mathrm{E}-01$

3.62E-01

2.54E-03

$-3.03 E-03$

1.70E-03 9.00E-03

1.40E-01

$-2.79 \mathrm{E}-01$

2.73E-01

$-5.05 \mathrm{E}-03$

1.11E-02

5.06E-02 -2.09E-01

$-6.13 \mathrm{E}-02$

1.82E-01

5.34E-03

6.80E-03

$-1.20 \mathrm{E}-03$ 7.17E-04

6.49E-02

$-8.66 \mathrm{E}-02$

$-7.37 \mathrm{E}-02$

1.14E-01

$-2.69 \mathrm{E}-04$

2.43E-04

7.44E-02

$-1.39 \mathrm{E}-01$

$-7.99 \mathrm{E}-02$

9.26E-02

$-2.02 \mathrm{E}-03$

5.33E-03

9.18E-03 6.14E-03

7.39E-02

$-2.50 \mathrm{E}-01$

$-9.42 \mathrm{E}-02$

2.46E-01

2.72E-03

$-8.11 \mathrm{E}-03$

$-6.53 \mathrm{E}-03 \quad-3.38 \mathrm{E}-03$

1.08E-01

$-1.18 \mathrm{E}-01$

$-1.10 \mathrm{E}-01$

1.14E-01

3.85E-03

1.11E-03

1.39E-02 5.97E-03

1.17E-01

$-2.73 \mathrm{E}-01$

$-1.24 \mathrm{E}-01$

2.81E-01

3.29E-03

$-9.83 \mathrm{E}-03$ 
APPENDIX IV: 3-D INVERSION DATA FILE

\begin{tabular}{|c|c|c|c|c|c|c|c|}
\hline 1.39E-02 & $1.12 \mathrm{E}-02$ & $1.04 \mathrm{E}-01$ & $-2.82 E-01$ & $-1.55 \mathrm{E}-01$ & 2.61E-01 & $-6.67 E-03$ & $-6.63 E-03$ \\
\hline$-3.88 \mathrm{E}-03$ & $-2.99 \mathrm{E}-03$ & $1.85 \mathrm{E}-01$ & $-2.77 \mathrm{E}-01$ & $-1.79 E-01$ & $2.84 \mathrm{E}-01$ & $-5.69 \mathrm{E}-03$ & $6.46 \mathrm{E}-04$ \\
\hline $8.65 \mathrm{E}-03$ & $8.13 \mathrm{E}-03$ & $1.30 \mathrm{E}-01$ & $-2.27 E-01$ & $-1.27 E-01$ & $2.15 \mathrm{E}-01$ & $-9.02 E-03$ & $-1.66 \mathrm{E}-02$ \\
\hline $1.64 \mathrm{E}-03$ & $2.05 \mathrm{E}-03$ & 1.14E-01 & $-1.24 \mathrm{E}-01$ & $-1.14 \mathrm{E}-01$ & $1.25 \mathrm{E}-01$ & $-6.89 \mathrm{E}-03$ & $-7.78 \mathrm{E}-03$ \\
\hline$-3.60 \mathrm{E}-03$ & $-4.91 \mathrm{E}-03$ & 1.31E-01 & $-3.25 \mathrm{E}-01$ & $-1.34 \mathrm{E}-01$ & $3.25 \mathrm{E}-01$ & $6.58 \mathrm{E}-03$ & 7.43E-03 \\
\hline 2.38E-03 & 6.80E-03 & $1.21 \mathrm{E}-01$ & $-2.18 \mathrm{E}-01$ & $-1.12 \mathrm{E}-01$ & 2.39E-01 & $-9.51 E-04$ & $-3.09 E-03$ \\
\hline $1.21 \mathrm{E}-02$ & 1.07E-02 & $1.35 \mathrm{E}-01$ & $-2.66 \mathrm{E}-01$ & $-1.35 \mathrm{E}-01$ & $2.66 \mathrm{E}-01$ & $-6.92 E-03$ & $-6.63 E-03$ \\
\hline$-2.65 E-03$ & $-2.20 \mathrm{E}-03$ & 1.63E-01 & $-3.51 E-01$ & $-1.58 \mathrm{E}-01$ & $3.60 \mathrm{E}-01$ & $3.35 \mathrm{E}-03$ & $6.83 \mathrm{E}-03$ \\
\hline$-4.39 E-03$ & $-3.15 E-03$ & 1.41E-01 & $-2.42 \mathrm{E}-01$ & $-1.47 \mathrm{E}-01$ & $2.29 \mathrm{E}-01$ & 1.39E-03 & 2.30E-03 \\
\hline$-7.43 E-04$ & 8.75E-03 & 8.70E-02 & $-1.80 \mathrm{E}-01$ & $-8.05 E-02$ & $1.88 \mathrm{E}-01$ & $1.11 \mathrm{E}-04$ & $-1.72 \mathrm{E}-03$ \\
\hline$-4.89 \mathrm{E}-04$ & $6.20 \mathrm{E}-03$ & $1.06 \mathrm{E}-01$ & $-1.82 \mathrm{E}-01$ & $-1.08 \mathrm{E}-01$ & $2.03 \mathrm{E}-01$ & $6.86 \mathrm{E}-03$ & $1.50 \mathrm{E}-02$ \\
\hline TA_Period: & $2.08 \mathrm{E}-02$ & & & & & & \\
\hline $3.32 \mathrm{E}-04$ & $1.55 \mathrm{E}-04$ & $2.21 \mathrm{E}-02$ & $-8.81 E-02$ & $-1.56 \mathrm{E}-02$ & $8.56 \mathrm{E}-02$ & 8.73E-04 & $-2.93 \mathrm{E}-03$ \\
\hline$-1.05 E-03$ & 3.79E-03 & 4.42E-02 & $-1.24 \mathrm{E}-01$ & $-4.14 \mathrm{E}-02$ & $1.34 \mathrm{E}-01$ & $-2.39 \mathrm{E}-03$ & $-3.21 E-03$ \\
\hline$-2.18 \mathrm{E}-03$ & $-1.01 \mathrm{E}-03$ & 5.34E-02 & $-1.33 \mathrm{E}-01$ & $-5.69 \mathrm{E}-02$ & $1.43 \mathrm{E}-01$ & 4.59E-04 & $-3.71 E-04$ \\
\hline 4.18E-03 & $1.25 \mathrm{E}-02$ & 5.63E-02 & $-1.71 E-01$ & $-6.16 \mathrm{E}-02$ & $1.39 \mathrm{E}-01$ & $-5.64 E-03$ & $-4.19 E-03$ \\
\hline $2.20 \mathrm{E}-03$ & $-6.98 \mathrm{E}-03$ & 7.04E-02 & $-1.24 \mathrm{E}-01$ & $-5.38 \mathrm{E}-02$ & $1.35 \mathrm{E}-01$ & $-1.03 E-02$ & $-5.72 E-03$ \\
\hline 1.99E-03 & $-2.23 \mathrm{E}-03$ & 4.50E-02 & $-1.54 \mathrm{E}-01$ & $-3.85 \mathrm{E}-02$ & $1.45 \mathrm{E}-01$ & $1.03 \mathrm{E}-02$ & $-5.01 E-03$ \\
\hline$-2.87 \mathrm{E}-03$ & $-3.87 E-03$ & 7.77E-02 & $-1.15 E-01$ & $-8.03 E-02$ & $9.57 \mathrm{E}-02$ & 3.59E-03 & $6.22 \mathrm{E}-03$ \\
\hline 4.73E-03 & 8.30E-04 & 5.40E-02 & $-1.21 \mathrm{E}-01$ & $-4.59 \mathrm{E}-02$ & $9.33 \mathrm{E}-02$ & $-2.68 \mathrm{E}-03$ & $-3.56 \mathrm{E}-04$ \\
\hline$-1.25 E-03$ & $-1.67 \mathrm{E}-03$ & 9.63E-03 & $-6.18 \mathrm{E}-02$ & $-2.23 \mathrm{E}-02$ & $3.97 \mathrm{E}-02$ & $-7.34 \mathrm{E}-04$ & $-3.08 E-03$ \\
\hline$-5.98 E-03$ & 2.59E-03 & 8.02E-02 & $-2.09 E-01$ & $-8.36 \mathrm{E}-02$ & $2.08 \mathrm{E}-01$ & $-4.43 E-03$ & 6.30E-03 \\
\hline$-1.16 E-04$ & $-2.35 \mathrm{E}-02$ & $1.05 \mathrm{E}-01$ & $-2.36 \mathrm{E}-01$ & $-1.09 E-01$ & $2.56 \mathrm{E}-01$ & 5.05E-03 & $-5.03 E-04$ \\
\hline$-7.08 \mathrm{E}-04$ & $-4.91 E-03$ & 3.16E-02 & $-1.06 \mathrm{E}-01$ & $-2.83 \mathrm{E}-02$ & 7.04E-02 & 2.60E-03 & 2.53E-04 \\
\hline$-2.04 \mathrm{E}-03$ & 5.86E-04 & $2.20 \mathrm{E}-02$ & $-5.36 \mathrm{E}-02$ & $-2.35 \mathrm{E}-02$ & $5.26 \mathrm{E}-02$ & $3.35 E-04$ & $-3.29 E-04$ \\
\hline$-3.36 E-03$ & $-2.13 \mathrm{E}-03$ & $3.40 \mathrm{E}-02$ & $-8.48 \mathrm{E}-02$ & $-2.87 \mathrm{E}-02$ & 8.67E-02 & $5.27 \mathrm{E}-03$ & 1.12E-03 \\
\hline $9.61 E-03$ & $-1.06 \mathrm{E}-02$ & $2.46 \mathrm{E}-02$ & $-1.31 E-01$ & $-2.25 \mathrm{E}-02$ & $1.43 \mathrm{E}-01$ & $2.25 \mathrm{E}-03$ & $-3.22 \mathrm{E}-03$ \\
\hline$-6.37 E-03$ & 1.47E-02 & $6.53 \mathrm{E}-02$ & $-1.95 \mathrm{E}-01$ & $-7.99 E-02$ & $1.32 \mathrm{E}-01$ & $-8.60 \mathrm{E}-03$ & $1.15 \mathrm{E}-02$ \\
\hline $4.74 \mathrm{E}-03$ & $-7.05 E-03$ & 4.01E-02 & $-9.23 \mathrm{E}-02$ & $-2.89 \mathrm{E}-02$ & $7.40 \mathrm{E}-02$ & $-1.98 \mathrm{E}-03$ & $-1.02 E-02$ \\
\hline $2.06 \mathrm{E}-04$ & $-1.41 E-04$ & $3.56 \mathrm{E}-02$ & -1.07E-01 & $-2.82 \mathrm{E}-02$ & $1.20 \mathrm{E}-01$ & $-1.84 \mathrm{E}-03$ & 4.08E-03 \\
\hline 7.34E-03 & $-1.29 E-02$ & $8.42 \mathrm{E}-02$ & $-2.45 \mathrm{E}-01$ & $-1.06 \mathrm{E}-01$ & $2.32 \mathrm{E}-01$ & 1.77E-03 & $-1.80 \mathrm{E}-02$ \\
\hline 5.54E-03 & $7.00 \mathrm{E}-03$ & 8.86E-02 & $-1.85 E-01$ & $-7.81 \mathrm{E}-02$ & 1.65E-01 & $-1.61 \mathrm{E}-03$ & 7.73E-03 \\
\hline$-2.92 \mathrm{E}-04$ & $-7.16 \mathrm{E}-04$ & 1.97E-02 & $-7.87 E-02$ & $-2.13 \mathrm{E}-02$ & $7.28 \mathrm{E}-02$ & 1.77E-03 & $2.46 \mathrm{E}-03$ \\
\hline$-7.73 E-04$ & $-9.16 \mathrm{E}-04$ & $2.76 \mathrm{E}-02$ & $-3.92 \mathrm{E}-02$ & $-2.52 \mathrm{E}-02$ & $4.86 \mathrm{E}-02$ & $1.01 \mathrm{E}-03$ & $1.13 \mathrm{E}-03$ \\
\hline$-2.68 \mathrm{E}-05$ & 3.09E-03 & $2.01 \mathrm{E}-02$ & $-5.57 E-02$ & $-2.51 \mathrm{E}-02$ & $4.62 \mathrm{E}-02$ & $-4.98 \mathrm{E}-04$ & $1.55 \mathrm{E}-03$ \\
\hline$-4.74 \mathrm{E}-03$ & $1.95 \mathrm{E}-03$ & 4.49E-02 & $-1.15 E-01$ & $-4.18 \mathrm{E}-02$ & $1.14 \mathrm{E}-01$ & $3.12 \mathrm{E}-03$ & 5.93E-04 \\
\hline$-6.42 E-04$ & $-2.00 \mathrm{E}-03$ & $5.00 \mathrm{E}-02$ & $-5.00 \mathrm{E}-02$ & $-4.72 \mathrm{E}-02$ & $5.73 \mathrm{E}-02$ & $9.01 \mathrm{E}-04$ & $2.90 \mathrm{E}-03$ \\
\hline $2.08 \mathrm{E}-03$ & $3.92 \mathrm{E}-03$ & $9.27 \mathrm{E}-02$ & $-2.10 \mathrm{E}-01$ & $-9.79 E-02$ & $2.17 \mathrm{E}-01$ & $-1.22 \mathrm{E}-03$ & $-5.83 E-03$ \\
\hline $1.46 \mathrm{E}-03$ & $5.06 \mathrm{E}-03$ & 2.67E-02 & $-1.30 \mathrm{E}-01$ & $-6.18 \mathrm{E}-02$ & $1.37 \mathrm{E}-01$ & $-4.19 E-03$ & $9.12 \mathrm{E}-04$ \\
\hline $6.81 \mathrm{E}-03$ & 2.71E-03 & 8.01E-02 & $-1.51 E-01$ & $-7.01 \mathrm{E}-02$ & $1.48 \mathrm{E}-01$ & $-5.57 E-03$ & -1.89E-06 \\
\hline 4.57E-03 & $3.65 \mathrm{E}-03$ & $6.93 \mathrm{E}-02$ & $-1.20 \mathrm{E}-01$ & $-4.95 \mathrm{E}-02$ & $1.15 \mathrm{E}-01$ & 4.17E-04 & $-1.37 \mathrm{E}-02$ \\
\hline $1.35 \mathrm{E}-03$ & $4.32 \mathrm{E}-03$ & $5.89 \mathrm{E}-02$ & $-7.84 \mathrm{E}-02$ & $-6.00 \mathrm{E}-02$ & $7.53 \mathrm{E}-02$ & $-4.55 E-03$ & $-3.40 \mathrm{E}-03$ \\
\hline
\end{tabular}


APPENDIX IV: 3-D INVERSION DATA FILE

\begin{tabular}{|c|c|c|c|c|c|c|c|}
\hline$-1.79 E-03$ & $-2.42 \mathrm{E}-03$ & $6.20 \mathrm{E}-02$ & $-1.56 \mathrm{E}-01$ & $-5.12 \mathrm{E}-02$ & $1.53 \mathrm{E}-01$ & $2.00 \mathrm{E}-03$ & $2.41 \mathrm{E}-03$ \\
\hline $2.16 \mathrm{E}-03$ & 4.13E-03 & $5.00 \mathrm{E}-02$ & $-1.09 E-01$ & $-4.79 E-02$ & $1.15 \mathrm{E}-01$ & $-1.10 \mathrm{E}-03$ & $-1.20 \mathrm{E}-03$ \\
\hline $1.14 \mathrm{E}-02$ & $6.27 \mathrm{E}-03$ & $5.84 \mathrm{E}-02$ & $-1.34 \mathrm{E}-01$ & $-6.15 E-02$ & $1.33 \mathrm{E}-01$ & $-4.59 \mathrm{E}-03$ & $-4.76 \mathrm{E}-03$ \\
\hline$-6.87 E-04$ & $2.72 \mathrm{E}-04$ & 5.95E-02 & $-1.59 \mathrm{E}-01$ & $-5.51 E-02$ & $1.54 \mathrm{E}-01$ & 9.57E-04 & $2.08 \mathrm{E}-03$ \\
\hline$-2.00 \mathrm{E}-03$ & $-2.22 \mathrm{E}-03$ & 6.09E-02 & $-1.25 \mathrm{E}-01$ & $-5.89 E-02$ & $1.23 \mathrm{E}-01$ & $-1.68 \mathrm{E}-05$ & $1.68 \mathrm{E}-03$ \\
\hline $2.10 \mathrm{E}-03$ & 4.09E-03 & $3.50 \mathrm{E}-02$ & $-8.52 \mathrm{E}-02$ & $-3.33 \mathrm{E}-02$ & 8.60E-02 & $-1.00 \mathrm{E}-03$ & $-1.39 \mathrm{E}-03$ \\
\hline $1.46 \mathrm{E}-03$ & $1.77 \mathrm{E}-03$ & $4.99 \mathrm{E}-02$ & $-9.23 \mathrm{E}-02$ & $-4.60 \mathrm{E}-02$ & $1.00 \mathrm{E}-01$ & $1.25 \mathrm{E}-03$ & $3.92 \mathrm{E}-03$ \\
\hline TA_Period: & 4.17E-02 & & & & & & \\
\hline $9.94 \mathrm{E}-04$ & $-6.71 E-04$ & $1.29 \mathrm{E}-02$ & $-4.69 \mathrm{E}-02$ & $-1.32 \mathrm{E}-02$ & 4.79E-02 & $1.21 \mathrm{E}-03$ & $-2.62 \mathrm{E}-03$ \\
\hline$-3.85 \mathrm{E}-04$ & $1.75 \mathrm{E}-03$ & $2.94 \mathrm{E}-02$ & $-7.53 \mathrm{E}-02$ & $-2.74 \mathrm{E}-02$ & $7.58 \mathrm{E}-02$ & $8.62 \mathrm{E}-04$ & $-1.93 \mathrm{E}-03$ \\
\hline $1.45 \mathrm{E}-03$ & 4.40E-04 & 3.09E-02 & $-7.62 \mathrm{E}-02$ & $-3.24 \mathrm{E}-02$ & 7.88E-02 & $-3.44 \mathrm{E}-04$ & $-7.26 \mathrm{E}-04$ \\
\hline $1.57 \mathrm{E}-03$ & $5.43 \mathrm{E}-03$ & $3.35 \mathrm{E}-02$ & $-9.73 E-02$ & $-3.67 \mathrm{E}-02$ & 8.20E-02 & $-1.36 \mathrm{E}-03$ & $-1.78 \mathrm{E}-03$ \\
\hline $3.81 \mathrm{E}-03$ & $-6.00 \mathrm{E}-04$ & $3.21 \mathrm{E}-02$ & $-7.74 \mathrm{E}-02$ & $-3.32 E-02$ & 7.94E-02 & $-2.50 \mathrm{E}-03$ & $-2.41 E-03$ \\
\hline $1.21 \mathrm{E}-03$ & $1.86 \mathrm{E}-03$ & 3.07E-02 & $-8.70 \mathrm{E}-02$ & $-2.81 \mathrm{E}-02$ & 8.37E-02 & $-1.45 \mathrm{E}-03$ & $-1.37 \mathrm{E}-03$ \\
\hline$-2.60 \mathrm{E}-04$ & $-1.87 \mathrm{E}-03$ & $5.65 \mathrm{E}-02$ & $-7.12 \mathrm{E}-02$ & $-5.78 \mathrm{E}-02$ & 6.64E-02 & $2.92 \mathrm{E}-03$ & $3.20 \mathrm{E}-03$ \\
\hline $3.46 \mathrm{E}-03$ & $1.76 \mathrm{E}-03$ & $2.40 \mathrm{E}-02$ & $-7.41 \mathrm{E}-02$ & $-2.87 \mathrm{E}-02$ & 5.67E-02 & $-1.30 \mathrm{E}-03$ & $-1.96 \mathrm{E}-04$ \\
\hline$-1.25 E-03$ & $-1.67 \mathrm{E}-03$ & $9.63 \mathrm{E}-03$ & $-6.18 \mathrm{E}-02$ & $-2.23 \mathrm{E}-02$ & 3.97E-02 & $-7.34 \mathrm{E}-04$ & $-3.08 \mathrm{E}-03$ \\
\hline $1.23 \mathrm{E}-03$ & $3.15 \mathrm{E}-03$ & $2.41 \mathrm{E}-02$ & $-7.31 \mathrm{E}-02$ & $-2.12 \mathrm{E}-02$ & 7.40E-02 & $-5.60 \mathrm{E}-04$ & $3.46 \mathrm{E}-03$ \\
\hline 8.50E-04 & $-4.68 \mathrm{E}-03$ & $2.91 \mathrm{E}-02$ & $-8.61 \mathrm{E}-02$ & $-3.17 \mathrm{E}-02$ & $9.35 \mathrm{E}-02$ & 3.13E-03 & 2.90E-03 \\
\hline 4.17E-04 & $-3.60 \mathrm{E}-03$ & $1.68 \mathrm{E}-02$ & $-6.32 \mathrm{E}-02$ & $-1.50 \mathrm{E}-02$ & $4.28 \mathrm{E}-02$ & $1.36 \mathrm{E}-03$ & $-1.33 E-03$ \\
\hline$-2.04 \mathrm{E}-03$ & $5.86 \mathrm{E}-04$ & $2.20 \mathrm{E}-02$ & $-5.36 \mathrm{E}-02$ & $-2.35 \mathrm{E}-02$ & $5.26 \mathrm{E}-02$ & $3.35 \mathrm{E}-04$ & $-3.29 E-04$ \\
\hline$-3.07 E-04$ & $-3.07 E-05$ & $1.96 \mathrm{E}-02$ & $-5.34 \mathrm{E}-02$ & $-1.80 \mathrm{E}-02$ & 5.41E-02 & $-5.06 E-04$ & $5.44 \mathrm{E}-04$ \\
\hline$-2.47 \mathrm{E}-03$ & $-9.37 \mathrm{E}-03$ & $2.76 \mathrm{E}-02$ & $-8.79 \mathrm{E}-02$ & $-7.60 \mathrm{E}-03$ & 8.96E-02 & 5.35E-03 & $1.55 \mathrm{E}-02$ \\
\hline -1.09E-03 & $1.80 \mathrm{E}-03$ & $4.02 \mathrm{E}-02$ & $-1.00 \mathrm{E}-01$ & $-2.20 \mathrm{E}-02$ & 8.69E-02 & $-1.08 \mathrm{E}-03$ & 4.62E-03 \\
\hline $1.18 \mathrm{E}-03$ & $-1.16 \mathrm{E}-03$ & $2.88 \mathrm{E}-02$ & $-6.75 E-02$ & $-2.77 \mathrm{E}-02$ & 7.03E-02 & $1.72 \mathrm{E}-03$ & $-1.20 \mathrm{E}-03$ \\
\hline$-9.39 E-05$ & $-2.34 \mathrm{E}-04$ & $2.44 \mathrm{E}-02$ & $-7.99 E-02$ & $-2.32 \mathrm{E}-02$ & $9.35 \mathrm{E}-02$ & $-1.24 \mathrm{E}-03$ & $2.76 \mathrm{E}-03$ \\
\hline$-7.71 E-04$ & $1.60 \mathrm{E}-03$ & $3.34 \mathrm{E}-02$ & $-1.06 \mathrm{E}-01$ & $-3.54 \mathrm{E}-02$ & $9.77 \mathrm{E}-02$ & $-2.87 \mathrm{E}-03$ & $-4.93 \mathrm{E}-03$ \\
\hline$-2.12 \mathrm{E}-03$ & $1.46 \mathrm{E}-03$ & 2.19E-02 & $-5.16 \mathrm{E}-02$ & $-3.01 E-02$ & $5.20 \mathrm{E}-02$ & 8.62E-03 & $3.23 \mathrm{E}-03$ \\
\hline 8.08E-04 & $-5.67 \mathrm{E}-04$ & $1.34 \mathrm{E}-02$ & $-4.59 \mathrm{E}-02$ & $-1.12 \mathrm{E}-02$ & 4.10E-02 & $1.15 \mathrm{E}-03$ & 1.79E-03 \\
\hline$-7.35 \mathrm{E}-04$ & $-1.19 \mathrm{E}-03$ & $2.18 \mathrm{E}-02$ & $-3.01 \mathrm{E}-02$ & $-1.92 \mathrm{E}-02$ & $3.69 \mathrm{E}-02$ & $1.74 \mathrm{E}-03$ & $1.75 \mathrm{E}-03$ \\
\hline$-2.20 \mathrm{E}-03$ & $-1.28 \mathrm{E}-04$ & $1.05 \mathrm{E}-02$ & $-2.89 \mathrm{E}-02$ & $-1.35 \mathrm{E}-02$ & $2.66 \mathrm{E}-02$ & 6.69E-04 & $1.21 \mathrm{E}-03$ \\
\hline $1.46 \mathrm{E}-03$ & $2.08 \mathrm{E}-03$ & $3.22 \mathrm{E}-02$ & $-7.13 E-02$ & $-3.45 E-02$ & $6.98 \mathrm{E}-02$ & $-9.87 E-04$ & $-2.84 \mathrm{E}-03$ \\
\hline$-2.59 \mathrm{E}-04$ & $-5.27 \mathrm{E}-04$ & $3.96 \mathrm{E}-02$ & $-4.20 \mathrm{E}-02$ & $-3.67 \mathrm{E}-02$ & 4.84E-02 & $5.33 \mathrm{E}-04$ & $2.18 \mathrm{E}-03$ \\
\hline 5.97E-04 & $1.21 \mathrm{E}-03$ & $2.40 \mathrm{E}-02$ & $-7.20 \mathrm{E}-02$ & $-2.40 \mathrm{E}-02$ & 7.30E-02 & $-2.53 \mathrm{E}-03$ & $-2.52 E-03$ \\
\hline$-1.30 \mathrm{E}-03$ & $-2.56 \mathrm{E}-04$ & $1.45 \mathrm{E}-02$ & $-6.93 E-02$ & $-3.07 E-02$ & 7.87E-02 & $-1.26 \mathrm{E}-04$ & $1.44 \mathrm{E}-03$ \\
\hline $6.54 \mathrm{E}-04$ & $1.80 \mathrm{E}-03$ & $3.48 \mathrm{E}-02$ & $-8.83 \mathrm{E}-02$ & $-3.48 \mathrm{E}-02$ & $8.28 \mathrm{E}-02$ & $-3.08 \mathrm{E}-03$ & $3.01 \mathrm{E}-04$ \\
\hline $1.63 \mathrm{E}-03$ & $1.85 \mathrm{E}-03$ & $3.91 \mathrm{E}-02$ & $-7.33 E-02$ & $-2.25 \mathrm{E}-02$ & 6.53E-02 & $1.36 \mathrm{E}-03$ & $-9.95 E-03$ \\
\hline $2.49 \mathrm{E}-04$ & $3.49 \mathrm{E}-03$ & $3.12 \mathrm{E}-02$ & $-5.15 E-02$ & $-3.44 \mathrm{E}-02$ & 4.91E-02 & $-2.62 E-03$ & $-1.12 \mathrm{E}-03$ \\
\hline 3.71E-04 & $-8.76 \mathrm{E}-04$ & 3.31E-02 & $-8.91 \mathrm{E}-02$ & $-3.21 \mathrm{E}-02$ & 8.57E-02 & $1.33 \mathrm{E}-03$ & $1.09 \mathrm{E}-03$ \\
\hline $9.48 \mathrm{E}-04$ & $2.36 \mathrm{E}-03$ & $2.46 \mathrm{E}-02$ & $-6.12 \mathrm{E}-02$ & $-2.03 E-02$ & $6.38 \mathrm{E}-02$ & $-1.58 \mathrm{E}-04$ & $-1.23 \mathrm{E}-04$ \\
\hline $6.06 \mathrm{E}-03$ & $3.05 E-03$ & $2.90 \mathrm{E}-02$ & $-7.61 \mathrm{E}-02$ & $-3.36 \mathrm{E}-02$ & 7.63E-02 & $-2.31 \mathrm{E}-03$ & $-2.99 \mathrm{E}-03$ \\
\hline $2.03 \mathrm{E}-04$ & 5.62E-04 & $3.22 \mathrm{E}-02$ & $-8.28 \mathrm{E}-02$ & $-3.19 E-02$ & 7.70E-02 & $1.08 \mathrm{E}-03$ & $1.23 \mathrm{E}-03$ \\
\hline
\end{tabular}


APPENDIX IV: 3-D INVERSION DATA FILE

\begin{tabular}{|c|c|c|c|c|c|c|c|}
\hline 4.49E-04 & $-6.37 E-04$ & $3.02 \mathrm{E}-02$ & $-7.26 \mathrm{E}-02$ & $-3.12 \mathrm{E}-02$ & 7.10E-02 & $-1.62 \mathrm{E}-03$ & $2.78 \mathrm{E}-04$ \\
\hline $1.21 \mathrm{E}-03$ & $2.13 \mathrm{E}-03$ & 1.69E-02 & $-4.62 \mathrm{E}-02$ & $-1.57 \mathrm{E}-02$ & 4.71E-02 & $-4.69 \mathrm{E}-04$ & $-7.02 E-04$ \\
\hline 4.32E-04 & $1.48 \mathrm{E}-03$ & $2.80 \mathrm{E}-02$ & $-5.33 E-02$ & $-2.50 \mathrm{E}-02$ & $5.74 \mathrm{E}-02$ & $1.79 \mathrm{E}-03$ & $1.44 \mathrm{E}-03$ \\
\hline TA_Period: & $1.11 \mathrm{E}-01$ & & & & & & \\
\hline$-7.38 \mathrm{E}-05$ & $-1.23 \mathrm{E}-04$ & 5.21E-03 & $-1.50 \mathrm{E}-02$ & $-5.59 \mathrm{E}-03$ & $1.54 \mathrm{E}-02$ & $-1.20 \mathrm{E}-04$ & $-7.35 E-04$ \\
\hline$-4.36 \mathrm{E}-05$ & 8.39E-04 & 1.19E-02 & $-3.36 \mathrm{E}-02$ & $-1.05 \mathrm{E}-02$ & 3.19E-02 & $-1.38 \mathrm{E}-03$ & $-1.27 \mathrm{E}-03$ \\
\hline $1.83 \mathrm{E}-03$ & $-2.35 \mathrm{E}-04$ & $1.71 \mathrm{E}-02$ & $-3.48 \mathrm{E}-02$ & $-1.73 \mathrm{E}-02$ & $3.52 \mathrm{E}-02$ & $-1.20 \mathrm{E}-03$ & $-1.69 \mathrm{E}-03$ \\
\hline $1.90 \mathrm{E}-04$ & 7.37E-04 & $1.23 \mathrm{E}-02$ & $-3.12 \mathrm{E}-02$ & $-1.30 \mathrm{E}-02$ & $2.93 \mathrm{E}-02$ & $3.63 \mathrm{E}-05$ & $-7.29 E-04$ \\
\hline$-5.36 \mathrm{E}-04$ & 4.00E-04 & $1.44 \mathrm{E}-02$ & $-3.65 \mathrm{E}-02$ & $-1.40 \mathrm{E}-02$ & $3.44 \mathrm{E}-02$ & $-5.58 \mathrm{E}-04$ & $3.96 \mathrm{E}-04$ \\
\hline 2.87E-04 & $1.55 \mathrm{E}-03$ & $1.44 \mathrm{E}-02$ & $-3.96 \mathrm{E}-02$ & $-1.57 \mathrm{E}-02$ & 3.63E-02 & $-1.19 E-03$ & $-1.65 E-03$ \\
\hline$-2.92 \mathrm{E}-03$ & $-9.68 \mathrm{E}-04$ & $2.89 \mathrm{E}-02$ & $-3.73 \mathrm{E}-02$ & $-3.20 \mathrm{E}-02$ & $3.85 \mathrm{E}-02$ & $-1.02 \mathrm{E}-05$ & $1.91 \mathrm{E}-03$ \\
\hline$-9.32 E-04$ & $-7.36 \mathrm{E}-04$ & $1.32 \mathrm{E}-02$ & $-3.53 \mathrm{E}-02$ & $-5.12 \mathrm{E}-03$ & 3.13E-02 & $-1.78 \mathrm{E}-03$ & 7.10E-05 \\
\hline$-1.87 E-03$ & $-2.85 \mathrm{E}-03$ & $1.53 \mathrm{E}-02$ & $-2.59 \mathrm{E}-02$ & $-1.21 \mathrm{E}-02$ & $2.42 \mathrm{E}-02$ & $1.54 \mathrm{E}-03$ & $-1.92 \mathrm{E}-03$ \\
\hline $2.49 \mathrm{E}-04$ & $8.18 \mathrm{E}-04$ & $1.03 \mathrm{E}-02$ & $-3.39 \mathrm{E}-02$ & $-1.08 \mathrm{E}-02$ & 3.34E-02 & $-2.99 \mathrm{E}-04$ & $1.08 \mathrm{E}-03$ \\
\hline$-3.63 E-03$ & $-5.38 \mathrm{E}-03$ & $1.50 \mathrm{E}-02$ & $-3.81 \mathrm{E}-02$ & $-1.18 \mathrm{E}-02$ & 4.19E-02 & 8.04E-05 & $-2.15 E-03$ \\
\hline $1.23 \mathrm{E}-03$ & $-9.63 \mathrm{E}-04$ & $1.26 \mathrm{E}-02$ & $-3.28 \mathrm{E}-02$ & $-9.31 E-03$ & $3.19 \mathrm{E}-02$ & $-4.75 E-04$ & $-1.19 \mathrm{E}-03$ \\
\hline 5.01E-04 & $1.35 \mathrm{E}-03$ & $1.86 \mathrm{E}-02$ & $-4.06 \mathrm{E}-02$ & $-1.75 \mathrm{E}-02$ & 4.01E-02 & $-4.17 \mathrm{E}-04$ & $-6.36 \mathrm{E}-04$ \\
\hline$-8.70 \mathrm{E}-05$ & $1.66 \mathrm{E}-03$ & $9.81 \mathrm{E}-03$ & $-2.27 \mathrm{E}-02$ & $-1.04 \mathrm{E}-02$ & $2.25 \mathrm{E}-02$ & $-2.86 \mathrm{E}-03$ & $1.84 \mathrm{E}-05$ \\
\hline$-9.34 \mathrm{E}-04$ & $-1.93 \mathrm{E}-03$ & $6.41 \mathrm{E}-03$ & $-2.81 \mathrm{E}-02$ & $-6.01 E-03$ & $2.80 \mathrm{E}-02$ & 7.44E-04 & $1.13 \mathrm{E}-03$ \\
\hline 8.39E-05 & 2.09E-03 & $1.39 \mathrm{E}-02$ & $-3.35 \mathrm{E}-02$ & $-1.20 \mathrm{E}-02$ & $2.74 \mathrm{E}-02$ & $1.66 \mathrm{E}-04$ & $1.49 \mathrm{E}-03$ \\
\hline $5.20 \mathrm{E}-04$ & $-1.78 \mathrm{E}-03$ & 8.80E-03 & $-2.37 \mathrm{E}-02$ & $-7.45 \mathrm{E}-03$ & 2.03E-02 & $1.34 \mathrm{E}-04$ & $-1.91 E-03$ \\
\hline $3.43 E-05$ & $-3.17 E-04$ & $9.72 \mathrm{E}-03$ & $-2.63 \mathrm{E}-02$ & $-7.83 E-03$ & 2.94E-02 & $-1.93 \mathrm{E}-04$ & 7.74E-04 \\
\hline $2.72 \mathrm{E}-04$ & $8.54 \mathrm{E}-04$ & $1.23 \mathrm{E}-02$ & $-3.25 \mathrm{E}-02$ & $-1.24 \mathrm{E}-02$ & $3.20 \mathrm{E}-02$ & $-8.54 \mathrm{E}-04$ & $-1.38 \mathrm{E}-03$ \\
\hline$-8.33 E-04$ & $-7.54 \mathrm{E}-04$ & $1.38 \mathrm{E}-02$ & $-3.45 \mathrm{E}-02$ & $-1.68 \mathrm{E}-02$ & $3.95 \mathrm{E}-02$ & $-1.53 \mathrm{E}-04$ & $-9.64 E-04$ \\
\hline$-3.79 E-04$ & $-4.54 \mathrm{E}-04$ & 4.85E-03 & $-1.53 \mathrm{E}-02$ & $-4.93 E-03$ & $1.34 \mathrm{E}-02$ & $3.34 \mathrm{E}-04$ & 2.67E-04 \\
\hline$-2.10 \mathrm{E}-06$ & $1.93 \mathrm{E}-04$ & 9.97E-03 & $-1.59 \mathrm{E}-02$ & $-8.95 \mathrm{E}-03$ & $1.81 \mathrm{E}-02$ & $3.55 \mathrm{E}-04$ & 7.19E-04 \\
\hline $5.06 \mathrm{E}-04$ & 1.97E-04 & 9.71E-03 & $-1.10 \mathrm{E}-02$ & $-1.00 \mathrm{E}-02$ & $1.18 \mathrm{E}-02$ & $-1.99 \mathrm{E}-04$ & $-4.31 \mathrm{E}-04$ \\
\hline $6.02 \mathrm{E}-04$ & $-4.21 \mathrm{E}-04$ & $1.95 \mathrm{E}-02$ & $-2.63 \mathrm{E}-02$ & $-1.34 \mathrm{E}-02$ & $2.89 \mathrm{E}-02$ & 1.77E-03 & $-1.81 \mathrm{E}-03$ \\
\hline $2.78 \mathrm{E}-04$ & $2.83 \mathrm{E}-04$ & $2.48 \mathrm{E}-02$ & $-2.48 \mathrm{E}-02$ & $-2.10 \mathrm{E}-02$ & $2.75 \mathrm{E}-02$ & $5.98 \mathrm{E}-04$ & 8.32E-04 \\
\hline $1.40 \mathrm{E}-03$ & $1.54 \mathrm{E}-03$ & 1.47E-02 & $-3.19 E-02$ & $-1.17 \mathrm{E}-02$ & 3.47E-02 & $2.26 \mathrm{E}-03$ & $9.39 \mathrm{E}-04$ \\
\hline 4.75E-05 & $-1.74 \mathrm{E}-03$ & $8.46 \mathrm{E}-03$ & $-3.28 \mathrm{E}-02$ & $-1.56 \mathrm{E}-02$ & $3.92 \mathrm{E}-02$ & $-6.06 \mathrm{E}-04$ & 1.10E-04 \\
\hline $6.61 \mathrm{E}-07$ & $1.18 \mathrm{E}-03$ & $1.66 \mathrm{E}-02$ & $-4.47 \mathrm{E}-02$ & $-1.70 \mathrm{E}-02$ & 4.19E-02 & $-1.52 \mathrm{E}-03$ & $4.68 \mathrm{E}-04$ \\
\hline $3.72 \mathrm{E}-04$ & $1.13 \mathrm{E}-03$ & $1.93 \mathrm{E}-02$ & $-4.14 \mathrm{E}-02$ & $-9.99 E-03$ & $3.24 \mathrm{E}-02$ & $6.59 \mathrm{E}-04$ & $-6.05 E-03$ \\
\hline$-4.87 E-04$ & $1.05 \mathrm{E}-03$ & $1.59 \mathrm{E}-02$ & $-2.87 \mathrm{E}-02$ & $-1.80 \mathrm{E}-02$ & $2.90 \mathrm{E}-02$ & $6.54 \mathrm{E}-05$ & $8.42 \mathrm{E}-04$ \\
\hline$-2.43 \mathrm{E}-04$ & $-2.01 \mathrm{E}-04$ & $1.54 \mathrm{E}-02$ & $-4.53 \mathrm{E}-02$ & $-1.26 \mathrm{E}-02$ & 4.14E-02 & $5.32 \mathrm{E}-04$ & $1.10 \mathrm{E}-03$ \\
\hline 2.31E-04 & $6.10 \mathrm{E}-04$ & $1.18 \mathrm{E}-02$ & $-3.16 \mathrm{E}-02$ & $-1.10 \mathrm{E}-02$ & $3.22 \mathrm{E}-02$ & $1.09 \mathrm{E}-04$ & $-3.81 E-04$ \\
\hline $2.65 \mathrm{E}-03$ & 1.09E-03 & $1.24 \mathrm{E}-02$ & $-3.85 \mathrm{E}-02$ & $-1.61 \mathrm{E}-02$ & 4.08E-02 & $-9.72 \mathrm{E}-04$ & $-1.52 \mathrm{E}-03$ \\
\hline$-6.05 E-04$ & $2.82 \mathrm{E}-04$ & $1.84 \mathrm{E}-02$ & $-4.11 \mathrm{E}-02$ & $-1.74 \mathrm{E}-02$ & $3.75 \mathrm{E}-02$ & $6.61 \mathrm{E}-04$ & $1.02 \mathrm{E}-03$ \\
\hline 3.17E-05 & $-4.04 \mathrm{E}-04$ & $1.45 \mathrm{E}-02$ & $-3.81 \mathrm{E}-02$ & $-1.44 \mathrm{E}-02$ & 3.73E-02 & $2.10 \mathrm{E}-05$ & $3.28 \mathrm{E}-04$ \\
\hline 3.05E-04 & $9.26 \mathrm{E}-04$ & 8.05E-03 & $-2.38 \mathrm{E}-02$ & $-7.76 \mathrm{E}-03$ & 2.37E-02 & $-1.98 \mathrm{E}-04$ & $-3.67 E-04$ \\
\hline $1.25 \mathrm{E}-03$ & $6.60 \mathrm{E}-04$ & $1.64 \mathrm{E}-02$ & $-2.89 \mathrm{E}-02$ & $-1.28 \mathrm{E}-02$ & 2.92E-02 & 2.09E-04 & $-4.22 \mathrm{E}-04$ \\
\hline & $2.22 \mathrm{E}-01$ & & & & & & \\
\hline
\end{tabular}


APPENDIX IV: 3-D INVERSION DATA FILE

\begin{tabular}{|c|c|c|c|c|c|c|c|}
\hline$-5.26 \mathrm{E}-05$ & $-4.13 E-05$ & 4.58E-03 & $-1.16 \mathrm{E}-02$ & $-4.69 \mathrm{E}-03$ & 1.19E-02 & $-2.26 \mathrm{E}-04$ & $-5.79 E-04$ \\
\hline $6.84 \mathrm{E}-04$ & $5.95 \mathrm{E}-04$ & 7.95E-03 & $-1.88 \mathrm{E}-02$ & $-6.88 \mathrm{E}-03$ & $1.86 \mathrm{E}-02$ & $-2.95 \mathrm{E}-04$ & $-6.26 \mathrm{E}-04$ \\
\hline 4.33E-05 & 5.04E-05 & $1.26 \mathrm{E}-02$ & $-2.07 E-02$ & $-1.23 \mathrm{E}-02$ & $2.14 \mathrm{E}-02$ & $-1.72 \mathrm{E}-04$ & $-2.33 E-04$ \\
\hline $1.26 \mathrm{E}-03$ & $1.61 \mathrm{E}-03$ & $9.97 \mathrm{E}-03$ & $-2.47 \mathrm{E}-02$ & $-1.11 \mathrm{E}-02$ & $2.36 \mathrm{E}-02$ & $-6.52 E-04$ & $-7.70 \mathrm{E}-04$ \\
\hline $2.63 \mathrm{E}-04$ & $-9.47 \mathrm{E}-04$ & 9.50E-03 & $-2.08 \mathrm{E}-02$ & $-1.07 E-02$ & $2.12 \mathrm{E}-02$ & $1.12 \mathrm{E}-03$ & $-5.93 E-05$ \\
\hline 4.63E-04 & 8.89E-04 & 8.58E-03 & $-2.44 \mathrm{E}-02$ & $-1.04 \mathrm{E}-02$ & $2.48 \mathrm{E}-02$ & $-1.07 \mathrm{E}-03$ & -1.19E-03 \\
\hline $4.93 \mathrm{E}-04$ & $6.16 \mathrm{E}-04$ & $1.98 \mathrm{E}-02$ & $-2.56 \mathrm{E}-02$ & $-2.18 \mathrm{E}-02$ & $2.85 \mathrm{E}-02$ & $-8.77 \mathrm{E}-04$ & $-4.13 E-04$ \\
\hline $5.14 \mathrm{E}-04$ & $9.53 \mathrm{E}-05$ & 6.17E-03 & $-1.95 \mathrm{E}-02$ & $-7.09 E-03$ & $1.71 \mathrm{E}-02$ & $9.63 \mathrm{E}-05$ & 2.00E-04 \\
\hline$-1.35 E-04$ & $-8.48 \mathrm{E}-04$ & $9.32 \mathrm{E}-03$ & $-1.73 E-02$ & $-8.66 \mathrm{E}-03$ & $1.62 \mathrm{E}-02$ & $-7.92 \mathrm{E}-04$ & $-1.21 \mathrm{E}-03$ \\
\hline$-3.60 \mathrm{E}-05$ & $8.41 \mathrm{E}-05$ & $5.64 \mathrm{E}-03$ & $-1.92 \mathrm{E}-02$ & $-5.91 \mathrm{E}-03$ & $1.88 \mathrm{E}-02$ & $1.05 \mathrm{E}-03$ & 8.19E-04 \\
\hline$-3.81 E-04$ & $-1.16 \mathrm{E}-03$ & 9.16E-03 & $-2.33 \mathrm{E}-02$ & $-8.77 \mathrm{E}-03$ & $2.40 \mathrm{E}-02$ & $3.61 \mathrm{E}-04$ & 7.12E-04 \\
\hline$-4.42 E-04$ & $-4.32 \mathrm{E}-04$ & 4.86E-03 & $-1.60 \mathrm{E}-02$ & $-5.44 \mathrm{E}-03$ & $1.31 \mathrm{E}-02$ & $-2.05 E-04$ & $-3.98 E-04$ \\
\hline $2.25 \mathrm{E}-04$ & $5.12 \mathrm{E}-04$ & 8.43E-03 & $-1.97 E-02$ & $-8.60 \mathrm{E}-03$ & $1.95 \mathrm{E}-02$ & $-2.85 \mathrm{E}-04$ & $-4.49 E-04$ \\
\hline $3.55 \mathrm{E}-07$ & $2.34 \mathrm{E}-04$ & $6.36 \mathrm{E}-03$ & $-1.36 \mathrm{E}-02$ & $-6.29 \mathrm{E}-03$ & $1.46 \mathrm{E}-02$ & $-5.10 \mathrm{E}-04$ & 1.09E-04 \\
\hline$-8.82 E-04$ & $-1.53 \mathrm{E}-03$ & 5.21E-03 & $-2.19 \mathrm{E}-02$ & $-5.00 \mathrm{E}-03$ & $2.13 \mathrm{E}-02$ & 7.63E-04 & 8.23E-04 \\
\hline$-1.78 \mathrm{E}-03$ & $-4.08 \mathrm{E}-04$ & 8.42E-03 & $-2.41 E-02$ & $-6.16 \mathrm{E}-03$ & 2.67E-02 & $-1.45 \mathrm{E}-03$ & -1.57E-04 \\
\hline $3.56 \mathrm{E}-04$ & $-9.81 \mathrm{E}-04$ & 7.09E-03 & $-1.88 \mathrm{E}-02$ & $-6.06 \mathrm{E}-03$ & $1.74 \mathrm{E}-02$ & $5.41 \mathrm{E}-04$ & $-9.01 E-04$ \\
\hline$-5.87 \mathrm{E}-05$ & $-3.00 \mathrm{E}-04$ & 8.29E-03 & $-2.04 \mathrm{E}-02$ & $-7.04 \mathrm{E}-03$ & 2.29E-02 & $-1.76 \mathrm{E}-04$ & 6.10E-04 \\
\hline$-1.85 E-05$ & 4.30E-04 & $1.12 \mathrm{E}-02$ & $-2.53 \mathrm{E}-02$ & $-1.04 \mathrm{E}-02$ & $2.53 \mathrm{E}-02$ & $-1.27 \mathrm{E}-04$ & $-9.35 E-04$ \\
\hline $3.68 \mathrm{E}-04$ & 7.65E-04 & $6.55 \mathrm{E}-03$ & $-1.97 \mathrm{E}-02$ & $-7.42 \mathrm{E}-03$ & $1.89 \mathrm{E}-02$ & $1.03 \mathrm{E}-04$ & 1.14E-03 \\
\hline$-4.44 \mathrm{E}-04$ & $-3.48 \mathrm{E}-04$ & 3.94E-03 & $-1.19 E-02$ & $-4.32 \mathrm{E}-03$ & $1.03 \mathrm{E}-02$ & $2.70 \mathrm{E}-04$ & $1.22 \mathrm{E}-04$ \\
\hline$-2.07 \mathrm{E}-04$ & $-2.54 \mathrm{E}-04$ & 7.06E-03 & $-1.05 E-02$ & $-5.60 \mathrm{E}-03$ & $1.13 \mathrm{E}-02$ & $3.50 \mathrm{E}-04$ & 4.86E-04 \\
\hline$-2.39 E-05$ & $3.25 \mathrm{E}-04$ & 9.16E-03 & $-9.45 E-03$ & $-8.48 \mathrm{E}-03$ & $1.01 \mathrm{E}-02$ & $-4.02 \mathrm{E}-04$ & $-1.61 E-04$ \\
\hline$-4.12 \mathrm{E}-04$ & $4.55 \mathrm{E}-04$ & $1.81 \mathrm{E}-02$ & $-2.26 \mathrm{E}-02$ & $-1.08 \mathrm{E}-02$ & $2.20 \mathrm{E}-02$ & $-1.06 \mathrm{E}-03$ & $2.76 \mathrm{E}-05$ \\
\hline$-1.71 E-04$ & $-2.79 E-04$ & $1.81 \mathrm{E}-02$ & $-1.77 E-02$ & $-1.32 \mathrm{E}-02$ & $1.96 \mathrm{E}-02$ & $-1.79 E-04$ & 1.70E-04 \\
\hline$-8.43 E-04$ & $-3.97 \mathrm{E}-04$ & $9.44 \mathrm{E}-03$ & $-1.96 \mathrm{E}-02$ & $-7.98 \mathrm{E}-03$ & $2.11 \mathrm{E}-02$ & $-2.30 \mathrm{E}-04$ & $-5.97 E-04$ \\
\hline $3.15 \mathrm{E}-03$ & $2.89 \mathrm{E}-03$ & $3.58 \mathrm{E}-03$ & $-1.95 \mathrm{E}-02$ & $-9.92 E-03$ & $2.60 \mathrm{E}-02$ & $-2.19 \mathrm{E}-03$ & 4.08E-04 \\
\hline $5.86 \mathrm{E}-04$ & $2.08 \mathrm{E}-03$ & 9.18E-03 & $-2.48 \mathrm{E}-02$ & $-1.14 \mathrm{E}-02$ & $2.31 \mathrm{E}-02$ & $-2.46 \mathrm{E}-03$ & $-8.24 \mathrm{E}-04$ \\
\hline $1.22 \mathrm{E}-03$ & 8.47E-04 & $1.05 \mathrm{E}-02$ & $-2.35 \mathrm{E}-02$ & $-6.35 E-03$ & $1.79 \mathrm{E}-02$ & $-3.99 E-04$ & $-4.07 E-03$ \\
\hline$-9.38 \mathrm{E}-04$ & $-2.56 \mathrm{E}-04$ & $1.01 \mathrm{E}-02$ & $-1.75 \mathrm{E}-02$ & $-1.18 \mathrm{E}-02$ & $1.75 \mathrm{E}-02$ & $7.22 \mathrm{E}-04$ & 9.91E-04 \\
\hline$-4.80 \mathrm{E}-04$ & $-1.03 E-04$ & 8.86E-03 & $-2.60 \mathrm{E}-02$ & $-7.86 \mathrm{E}-03$ & $2.64 \mathrm{E}-02$ & $3.64 \mathrm{E}-04$ & 1.37E-03 \\
\hline$-9.85 E-05$ & $5.94 \mathrm{E}-04$ & 6.19E-03 & $-1.87 \mathrm{E}-02$ & $-5.65 E-03$ & $1.92 \mathrm{E}-02$ & $-2.63 E-04$ & $-1.13 \mathrm{E}-04$ \\
\hline $1.36 \mathrm{E}-03$ & $4.43 \mathrm{E}-04$ & 7.29E-03 & $-2.26 \mathrm{E}-02$ & $-9.30 \mathrm{E}-03$ & $2.40 \mathrm{E}-02$ & $-5.43 E-04$ & $-9.15 E-04$ \\
\hline$-9.36 E-04$ & $-3.10 \mathrm{E}-04$ & $1.36 \mathrm{E}-02$ & $-2.48 \mathrm{E}-02$ & $-1.29 E-02$ & $2.32 \mathrm{E}-02$ & $6.02 \mathrm{E}-04$ & 6.17E-04 \\
\hline$-3.08 \mathrm{E}-04$ & 2.71E-04 & $9.22 \mathrm{E}-03$ & $-2.21 \mathrm{E}-02$ & $-7.46 \mathrm{E}-03$ & 2.17E-02 & $-9.11 \mathrm{E}-04$ & $1.86 \mathrm{E}-04$ \\
\hline $1.64 \mathrm{E}-04$ & $6.50 \mathrm{E}-04$ & 4.61E-03 & $-1.39 \mathrm{E}-02$ & $-5.49 \mathrm{E}-03$ & $1.36 \mathrm{E}-02$ & $-9.92 \mathrm{E}-05$ & $-2.38 \mathrm{E}-04$ \\
\hline $9.90 \mathrm{E}-04$ & $-2.65 E-04$ & $1.13 \mathrm{E}-02$ & $-1.79 E-02$ & $-7.55 \mathrm{E}-03$ & $1.67 \mathrm{E}-02$ & $-2.81 \mathrm{E}-04$ & $3.98 \mathrm{E}-04$ \\
\hline Period: & 4.44E-01 & & & & & & \\
\hline$-8.52 \mathrm{E}-05$ & $7.85 \mathrm{E}-05$ & 3.37E-03 & $-6.45 E-03$ & $-3.19 E-03$ & $6.75 \mathrm{E}-03$ & $-4.27 \mathrm{E}-04$ & $-4.38 E-04$ \\
\hline 8.90E-04 & $4.82 \mathrm{E}-04$ & 5.49E-03 & $-1.08 \mathrm{E}-02$ & $-4.84 \mathrm{E}-03$ & $1.05 \mathrm{E}-02$ & $-5.02 \mathrm{E}-04$ & $-5.73 E-04$ \\
\hline$-1.16 \mathrm{E}-04$ & $-1.30 \mathrm{E}-05$ & $9.18 \mathrm{E}-03$ & $-1.27 \mathrm{E}-02$ & $-8.71 \mathrm{E}-03$ & $1.32 \mathrm{E}-02$ & $1.46 \mathrm{E}-05$ & $-7.32 \mathrm{E}-05$ \\
\hline$-4.17 \mathrm{E}-05$ & $6.50 \mathrm{E}-04$ & 8.54E-03 & $-1.40 \mathrm{E}-02$ & $-8.72 \mathrm{E}-03$ & $1.44 \mathrm{E}-02$ & $-9.26 \mathrm{E}-05$ & $-2.85 E-04$ \\
\hline
\end{tabular}


APPENDIX IV: 3-D INVERSION DATA FILE

\begin{tabular}{|c|c|c|c|c|c|c|c|}
\hline$-8.03 E-04$ & $-8.48 \mathrm{E}-05$ & 8.21E-03 & $-1.26 \mathrm{E}-02$ & $-7.61 \mathrm{E}-03$ & $1.29 \mathrm{E}-02$ & $1.54 \mathrm{E}-04$ & 3.14E-04 \\
\hline $3.22 \mathrm{E}-04$ & 7.01E-04 & 4.39E-03 & $-1.42 \mathrm{E}-02$ & $-5.96 \mathrm{E}-03$ & $1.44 \mathrm{E}-02$ & $-2.07 \mathrm{E}-04$ & $-4.01 \mathrm{E}-04$ \\
\hline 8.86E-04 & $9.43 \mathrm{E}-04$ & $1.52 \mathrm{E}-02$ & $-1.71 \mathrm{E}-02$ & $-1.53 \mathrm{E}-02$ & $1.83 \mathrm{E}-02$ & $-1.18 \mathrm{E}-03$ & $-8.83 E-04$ \\
\hline $2.68 \mathrm{E}-05$ & $6.30 \mathrm{E}-05$ & 3.81E-03 & $-1.15 \mathrm{E}-02$ & $-4.28 \mathrm{E}-03$ & $1.01 \mathrm{E}-02$ & $6.82 \mathrm{E}-05$ & $1.81 \mathrm{E}-04$ \\
\hline$-2.47 \mathrm{E}-04$ & $-2.21 \mathrm{E}-04$ & $5.22 \mathrm{E}-03$ & $-1.08 \mathrm{E}-02$ & $-5.45 E-03$ & $9.98 \mathrm{E}-03$ & $-1.63 \mathrm{E}-04$ & $-2.96 \mathrm{E}-04$ \\
\hline 1.17E-04 & $-1.02 \mathrm{E}-04$ & 4.89E-03 & $-1.14 \mathrm{E}-02$ & $-4.83 \mathrm{E}-03$ & $1.10 \mathrm{E}-02$ & $6.64 \mathrm{E}-04$ & 4.16E-04 \\
\hline$-1.24 \mathrm{E}-04$ & $-7.80 \mathrm{E}-04$ & 6.49E-03 & $-1.35 \mathrm{E}-02$ & $-6.11 \mathrm{E}-03$ & $1.38 \mathrm{E}-02$ & $1.07 \mathrm{E}-04$ & 3.05E-04 \\
\hline$-3.50 \mathrm{E}-05$ & $-1.85 \mathrm{E}-04$ & $3.41 \mathrm{E}-03$ & $-8.65 \mathrm{E}-03$ & $-4.07 \mathrm{E}-03$ & 8.03E-03 & $-1.46 \mathrm{E}-04$ & $-3.50 \mathrm{E}-04$ \\
\hline $3.94 \mathrm{E}-04$ & $3.50 \mathrm{E}-04$ & 4.95E-03 & $-1.16 \mathrm{E}-02$ & $-4.99 \mathrm{E}-03$ & $1.18 \mathrm{E}-02$ & $-1.85 \mathrm{E}-04$ & $-2.75 E-04$ \\
\hline $1.30 \mathrm{E}-04$ & $-1.31 \mathrm{E}-05$ & 4.84E-03 & $-7.86 \mathrm{E}-03$ & $-4.13 E-03$ & 8.95E-03 & $-4.49 \mathrm{E}-04$ & $-7.20 \mathrm{E}-05$ \\
\hline$-1.94 \mathrm{E}-04$ & $-9.83 E-04$ & $4.20 \mathrm{E}-03$ & $-1.20 \mathrm{E}-02$ & $-3.91 \mathrm{E}-03$ & $1.20 \mathrm{E}-02$ & $2.18 \mathrm{E}-04$ & $3.73 \mathrm{E}-04$ \\
\hline$-2.09 E-03$ & $-3.18 \mathrm{E}-03$ & 5.60E-03 & $-1.95 \mathrm{E}-02$ & $-1.17 \mathrm{E}-02$ & $1.40 \mathrm{E}-02$ & $-2.98 \mathrm{E}-03$ & $-2.92 E-06$ \\
\hline$-1.33 E-04$ & $1.14 \mathrm{E}-04$ & 4.39E-03 & $-1.07 E-02$ & $-4.33 \mathrm{E}-03$ & $1.12 \mathrm{E}-02$ & $-1.89 \mathrm{E}-04$ & 9.69E-05 \\
\hline$-2.10 \mathrm{E}-04$ & $-3.29 \mathrm{E}-04$ & 5.37E-03 & $-1.15 \mathrm{E}-02$ & $-5.08 \mathrm{E}-03$ & $1.21 \mathrm{E}-02$ & $-4.33 E-06$ & $3.26 \mathrm{E}-04$ \\
\hline $1.63 \mathrm{E}-04$ & $5.68 \mathrm{E}-04$ & 6.93E-03 & $-1.46 \mathrm{E}-02$ & $-6.46 \mathrm{E}-03$ & $1.50 \mathrm{E}-02$ & $-4.49 \mathrm{E}-04$ & $-5.69 E-04$ \\
\hline $1.56 \mathrm{E}-04$ & $1.68 \mathrm{E}-04$ & 4.73E-03 & $-1.27 \mathrm{E}-02$ & $-4.53 \mathrm{E}-03$ & 1.17E-02 & $6.15 \mathrm{E}-05$ & $3.00 \mathrm{E}-04$ \\
\hline$-2.78 E-04$ & $-2.40 \mathrm{E}-04$ & 2.77E-03 & $-6.76 \mathrm{E}-03$ & $-2.85 \mathrm{E}-03$ & 5.92E-03 & $1.75 \mathrm{E}-04$ & 8.22E-05 \\
\hline $1.24 \mathrm{E}-04$ & $-5.90 \mathrm{E}-05$ & $5.24 \mathrm{E}-03$ & $-6.87 E-03$ & $-3.72 \mathrm{E}-03$ & $6.73 \mathrm{E}-03$ & $5.68 \mathrm{E}-04$ & 5.87E-04 \\
\hline 4.99E-05 & $-1.04 \mathrm{E}-05$ & $6.62 \mathrm{E}-03$ & $-6.56 \mathrm{E}-03$ & $-6.02 \mathrm{E}-03$ & $7.28 \mathrm{E}-03$ & $-1.27 \mathrm{E}-04$ & $-1.70 \mathrm{E}-04$ \\
\hline$-1.59 E-03$ & $-6.50 \mathrm{E}-04$ & $1.38 \mathrm{E}-02$ & $-1.52 \mathrm{E}-02$ & $-6.31 E-03$ & $1.60 \mathrm{E}-02$ & $-1.80 \mathrm{E}-03$ & $1.01 \mathrm{E}-03$ \\
\hline $5.36 \mathrm{E}-05$ & $1.22 \mathrm{E}-04$ & $1.33 \mathrm{E}-02$ & $-1.29 \mathrm{E}-02$ & $-8.81 \mathrm{E}-03$ & $1.24 \mathrm{E}-02$ & $8.21 \mathrm{E}-06$ & $2.82 \mathrm{E}-04$ \\
\hline$-8.06 E-04$ & $-8.46 \mathrm{E}-04$ & 6.61E-03 & $-1.19 \mathrm{E}-02$ & $-5.35 \mathrm{E}-03$ & $1.31 \mathrm{E}-02$ & $1.62 \mathrm{E}-04$ & 4.47E-05 \\
\hline 2.07E-03 & $-2.86 \mathrm{E}-05$ & $1.43 \mathrm{E}-04$ & $-9.70 \mathrm{E}-03$ & $-6.67 E-03$ & $1.37 \mathrm{E}-02$ & $-1.53 \mathrm{E}-03$ & $-3.69 E-04$ \\
\hline $1.61 \mathrm{E}-04$ & 7.01E-04 & 9.27E-03 & $-1.49 \mathrm{E}-02$ & $-8.52 \mathrm{E}-03$ & $1.53 \mathrm{E}-02$ & $-9.10 \mathrm{E}-04$ & $2.68 \mathrm{E}-04$ \\
\hline $1.14 \mathrm{E}-03$ & $7.65 \mathrm{E}-04$ & 7.05E-03 & $-1.39 \mathrm{E}-02$ & $-3.91 \mathrm{E}-03$ & $9.71 \mathrm{E}-03$ & $-3.08 \mathrm{E}-04$ & $-2.95 \mathrm{E}-03$ \\
\hline $2.63 \mathrm{E}-04$ & $-8.07 E-04$ & $5.90 \mathrm{E}-03$ & $-1.19 E-02$ & $-9.36 \mathrm{E}-03$ & $1.01 \mathrm{E}-02$ & $5.24 \mathrm{E}-04$ & 8.41E-04 \\
\hline $4.46 \mathrm{E}-04$ & $1.73 \mathrm{E}-04$ & 5.84E-03 & $-1.50 \mathrm{E}-02$ & $-7.39 E-03$ & $1.38 \mathrm{E}-02$ & $1.90 \mathrm{E}-04$ & $6.51 \mathrm{E}-04$ \\
\hline$-4.34 \mathrm{E}-05$ & $3.33 \mathrm{E}-04$ & $4.12 \mathrm{E}-03$ & $-1.17 \mathrm{E}-02$ & $-3.88 \mathrm{E}-03$ & $1.15 \mathrm{E}-02$ & $6.34 \mathrm{E}-05$ & $-1.35 \mathrm{E}-05$ \\
\hline $5.72 \mathrm{E}-04$ & 8.93E-05 & 4.61E-03 & $-1.25 \mathrm{E}-02$ & $-5.78 \mathrm{E}-03$ & $1.35 \mathrm{E}-02$ & $-1.36 \mathrm{E}-04$ & $-5.07 E-04$ \\
\hline$-8.05 E-04$ & $-2.64 \mathrm{E}-04$ & $1.01 \mathrm{E}-02$ & $-1.56 \mathrm{E}-02$ & $-9.96 \mathrm{E}-03$ & $1.49 \mathrm{E}-02$ & 4.49E-04 & 4.30E-04 \\
\hline $7.88 \mathrm{E}-04$ & $3.64 \mathrm{E}-04$ & $4.24 \mathrm{E}-03$ & $-1.25 \mathrm{E}-02$ & $-7.85 \mathrm{E}-03$ & $1.45 \mathrm{E}-02$ & $4.15 \mathrm{E}-04$ & $-8.64 \mathrm{E}-05$ \\
\hline$-2.58 \mathrm{E}-05$ & 4.19E-04 & 3.31E-03 & $-7.99 E-03$ & $-4.09 \mathrm{E}-03$ & 8.02E-03 & $-6.84 \mathrm{E}-05$ & $-1.49 E-04$ \\
\hline $5.31 \mathrm{E}-04$ & $-4.38 \mathrm{E}-04$ & 8.49E-03 & $-1.15 E-02$ & $-5.32 \mathrm{E}-03$ & $1.02 \mathrm{E}-02$ & $-2.37 \mathrm{E}-04$ & $6.28 \mathrm{E}-04$ \\
\hline Period: & 8.89E-01 & & & & & & \\
\hline$-1.29 E-04$ & $1.10 \mathrm{E}-04$ & 2.65E-03 & $-3.72 \mathrm{E}-03$ & $-2.49 \mathrm{E}-03$ & $3.95 \mathrm{E}-03$ & $-1.86 \mathrm{E}-04$ & $-1.05 E-04$ \\
\hline $6.48 \mathrm{E}-04$ & $5.00 \mathrm{E}-04$ & 3.69E-03 & $-6.47 E-03$ & $-3.68 \mathrm{E}-03$ & $6.40 \mathrm{E}-03$ & $-5.74 \mathrm{E}-04$ & $-6.50 \mathrm{E}-04$ \\
\hline$-4.61 E-04$ & $-2.88 \mathrm{E}-04$ & $6.64 \mathrm{E}-03$ & $-8.30 \mathrm{E}-03$ & $-5.98 \mathrm{E}-03$ & 8.13E-03 & $2.26 \mathrm{E}-04$ & $-6.57 E-06$ \\
\hline$-2.71 \mathrm{E}-04$ & $4.36 \mathrm{E}-04$ & $6.10 \mathrm{E}-03$ & $-8.31 E-03$ & $-5.77 E-03$ & $9.06 \mathrm{E}-03$ & $-5.10 \mathrm{E}-05$ & $-8.43 E-05$ \\
\hline$-9.12 \mathrm{E}-04$ & $2.14 \mathrm{E}-05$ & $6.53 \mathrm{E}-03$ & $-7.86 \mathrm{E}-03$ & $-5.29 E-03$ & $-3.61 \mathrm{E}-05$ & 5.77E-04 & $3.51 \mathrm{E}-04$ \\
\hline $3.42 \mathrm{E}-04$ & $2.32 \mathrm{E}-04$ & $2.74 \mathrm{E}-03$ & $-7.95 \mathrm{E}-03$ & $-3.86 \mathrm{E}-03$ & 8.63E-03 & $-3.13 E-04$ & $-6.08 \mathrm{E}-04$ \\
\hline $1.01 \mathrm{E}-03$ & $1.11 \mathrm{E}-03$ & $1.14 \mathrm{E}-02$ & $-1.14 \mathrm{E}-02$ & $-1.00 \mathrm{E}-02$ & $1.25 \mathrm{E}-02$ & $-6.52 E-04$ & $-1.19 E-03$ \\
\hline $3.30 \mathrm{E}-05$ & $-1.58 \mathrm{E}-05$ & $2.10 \mathrm{E}-03$ & $-6.38 \mathrm{E}-03$ & $-2.45 \mathrm{E}-03$ & 5.91E-03 & 4.53E-05 & 7.37E-05 \\
\hline
\end{tabular}


APPENDIX IV: 3-D INVERSION DATA FILE

\begin{tabular}{|c|c|c|c|c|c|c|c|}
\hline $6.40 \mathrm{E}-05$ & $-4.55 E-05$ & 3.05E-03 & $-6.60 \mathrm{E}-03$ & $-3.58 \mathrm{E}-03$ & $6.05 E-03$ & 8.39E-05 & $-8.36 \mathrm{E}-05$ \\
\hline $2.87 \mathrm{E}-04$ & $-4.59 E-04$ & 3.36E-03 & $-8.64 \mathrm{E}-03$ & $-4.04 \mathrm{E}-03$ & 8.04E-03 & $5.68 \mathrm{E}-04$ & $1.98 \mathrm{E}-04$ \\
\hline $9.28 \mathrm{E}-05$ & $-3.31 \mathrm{E}-04$ & 4.77E-03 & $-8.06 \mathrm{E}-03$ & $-4.85 E-03$ & $8.02 \mathrm{E}-03$ & $-1.89 \mathrm{E}-04$ & $1.92 \mathrm{E}-04$ \\
\hline$-1.10 \mathrm{E}-05$ & $-2.58 \mathrm{E}-04$ & 2.37E-03 & $-4.91 E-03$ & $-3.06 \mathrm{E}-03$ & 5.07E-03 & $-6.65 E-05$ & $-3.23 \mathrm{E}-04$ \\
\hline 1.97E-04 & $2.03 \mathrm{E}-04$ & $2.82 \mathrm{E}-03$ & $-6.86 \mathrm{E}-03$ & $-3.01 \mathrm{E}-03$ & $6.83 \mathrm{E}-03$ & $-5.34 \mathrm{E}-05$ & $-1.49 \mathrm{E}-04$ \\
\hline $3.36 \mathrm{E}-05$ & 9.56E-05 & 3.66E-03 & $-4.68 \mathrm{E}-03$ & $-2.70 \mathrm{E}-03$ & $5.16 \mathrm{E}-03$ & $-3.40 \mathrm{E}-04$ & $6.81 \mathrm{E}-05$ \\
\hline 8.87E-05 & $-5.95 E-04$ & 3.17E-03 & $-6.81 E-03$ & $-3.57 \mathrm{E}-03$ & 7.21E-03 & $1.96 \mathrm{E}-04$ & $5.89 \mathrm{E}-05$ \\
\hline$-5.52 \mathrm{E}-05$ & $1.55 \mathrm{E}-04$ & $4.60 \mathrm{E}-03$ & $-8.62 \mathrm{E}-03$ & $-3.46 \mathrm{E}-03$ & $7.55 \mathrm{E}-03$ & $2.78 \mathrm{E}-05$ & $6.14 \mathrm{E}-05$ \\
\hline$-2.07 E-04$ & $1.26 \mathrm{E}-04$ & $2.58 \mathrm{E}-03$ & $-6.00 \mathrm{E}-03$ & $-3.05 E-03$ & $6.71 \mathrm{E}-03$ & $-1.39 \mathrm{E}-04$ & $9.16 \mathrm{E}-05$ \\
\hline$-3.05 E-04$ & $-2.92 \mathrm{E}-04$ & $3.75 \mathrm{E}-03$ & $-6.87 E-03$ & $-3.92 \mathrm{E}-03$ & $6.53 \mathrm{E}-03$ & $2.42 \mathrm{E}-04$ & $2.72 \mathrm{E}-04$ \\
\hline$-1.57 \mathrm{E}-04$ & $3.66 \mathrm{E}-04$ & $5.74 \mathrm{E}-03$ & $-8.41 \mathrm{E}-03$ & $-4.47 \mathrm{E}-03$ & $8.84 \mathrm{E}-03$ & $-1.30 \mathrm{E}-04$ & $-2.28 \mathrm{E}-04$ \\
\hline $1.87 \mathrm{E}-04$ & $1.29 \mathrm{E}-04$ & 2.81E-03 & $-7.00 \mathrm{E}-03$ & $-2.57 \mathrm{E}-03$ & $6.65 \mathrm{E}-03$ & $-1.27 \mathrm{E}-04$ & $6.94 \mathrm{E}-05$ \\
\hline$-2.38 \mathrm{E}-05$ & $-1.23 \mathrm{E}-04$ & 2.09E-03 & $-3.77 E-03$ & $-1.96 \mathrm{E}-03$ & $3.45 \mathrm{E}-03$ & $1.09 \mathrm{E}-04$ & $1.28 \mathrm{E}-04$ \\
\hline 2.09E-04 & $4.28 \mathrm{E}-05$ & 3.07E-03 & $-4.08 \mathrm{E}-03$ & $-2.19 \mathrm{E}-03$ & $3.92 \mathrm{E}-03$ & 9.67E-05 & $3.92 \mathrm{E}-06$ \\
\hline$-2.42 E-04$ & $-8.41 E-05$ & 5.16E-03 & $-4.47 E-03$ & $-4.27 \mathrm{E}-03$ & $5.00 \mathrm{E}-03$ & $-3.48 \mathrm{E}-05$ & $-1.28 \mathrm{E}-05$ \\
\hline$-4.46 \mathrm{E}-04$ & $-3.07 E-04$ & 9.93E-03 & $-1.06 \mathrm{E}-02$ & $-5.56 \mathrm{E}-03$ & 8.89E-03 & $-4.43 \mathrm{E}-04$ & $2.28 \mathrm{E}-04$ \\
\hline $1.72 \mathrm{E}-04$ & $-3.66 \mathrm{E}-04$ & $9.16 \mathrm{E}-03$ & $-9.05 E-03$ & $-5.97 E-03$ & $7.94 \mathrm{E}-03$ & 5.69E-04 & $3.73 E-04$ \\
\hline$-3.56 E-04$ & $-2.47 \mathrm{E}-04$ & 4.63E-03 & $-6.78 \mathrm{E}-03$ & $-3.74 \mathrm{E}-03$ & $6.85 \mathrm{E}-03$ & 4.41E-04 & 4.13E-04 \\
\hline$-1.18 \mathrm{E}-04$ & $-3.34 \mathrm{E}-04$ & $4.72 \mathrm{E}-03$ & $-6.85 E-03$ & $-5.66 \mathrm{E}-03$ & $9.10 \mathrm{E}-03$ & 1.19E-05 & 2.06E-04 \\
\hline$-5.76 \mathrm{E}-04$ & $4.62 \mathrm{E}-04$ & $5.94 \mathrm{E}-03$ & $-9.00 \mathrm{E}-03$ & $-4.95 E-03$ & $9.05 E-03$ & $-3.40 \mathrm{E}-04$ & 4.48E-04 \\
\hline 5.67E-04 & $6.42 \mathrm{E}-04$ & $4.73 \mathrm{E}-03$ & $-8.85 E-03$ & $-4.15 \mathrm{E}-03$ & 5.87E-03 & $-2.72 \mathrm{E}-04$ & $-1.10 \mathrm{E}-03$ \\
\hline$-1.46 \mathrm{E}-04$ & $-3.13 E-04$ & $4.22 \mathrm{E}-03$ & $-7.48 \mathrm{E}-03$ & $-7.36 \mathrm{E}-03$ & $6.65 \mathrm{E}-03$ & $-1.58 \mathrm{E}-05$ & 2.26E-04 \\
\hline$-1.01 E-04$ & $-5.35 E-04$ & 4.49E-03 & $-1.10 \mathrm{E}-02$ & $-5.15 E-03$ & $9.87 E-03$ & 5.15E-05 & $-8.95 E-04$ \\
\hline 4.99E-05 & 4.56E-05 & 3.11E-03 & $-6.84 \mathrm{E}-03$ & $-2.74 \mathrm{E}-03$ & $6.74 \mathrm{E}-03$ & $-9.70 \mathrm{E}-05$ & $-1.62 \mathrm{E}-04$ \\
\hline 2.63E-04 & $2.02 \mathrm{E}-04$ & $3.25 \mathrm{E}-03$ & $-6.93 E-03$ & $-3.91 \mathrm{E}-03$ & 7.67E-03 & $-1.93 \mathrm{E}-04$ & $-2.67 E-04$ \\
\hline$-1.67 \mathrm{E}-04$ & 3.35E-04 & 6.91E-03 & $-1.08 \mathrm{E}-02$ & $-8.61 \mathrm{E}-03$ & $1.06 \mathrm{E}-02$ & $1.68 \mathrm{E}-04$ & $-9.01 E-05$ \\
\hline$-2.51 E-04$ & $8.41 \mathrm{E}-05$ & $3.01 \mathrm{E}-03$ & $-7.10 \mathrm{E}-03$ & $-2.75 E-03$ & $9.10 \mathrm{E}-03$ & $-4.78 \mathrm{E}-04$ & 3.73E-04 \\
\hline $1.00 \mathrm{E}-04$ & $3.26 \mathrm{E}-04$ & $2.29 \mathrm{E}-03$ & $-4.52 \mathrm{E}-03$ & $-3.19 \mathrm{E}-03$ & $4.88 \mathrm{E}-03$ & $3.46 \mathrm{E}-05$ & $-1.26 \mathrm{E}-04$ \\
\hline $3.06 \mathrm{E}-04$ & $-3.50 \mathrm{E}-04$ & $6.04 \mathrm{E}-03$ & $-7.19 \mathrm{E}-03$ & $-4.32 \mathrm{E}-03$ & $6.76 \mathrm{E}-03$ & $-2.13 \mathrm{E}-04$ & $6.13 \mathrm{E}-04$ \\
\hline Period: & $1.78 \mathrm{E}+00$ & & & & & & \\
\hline$-1.60 \mathrm{E}-04$ & 3.71E-05 & $2.16 \mathrm{E}-03$ & $-2.36 \mathrm{E}-03$ & $-2.05 \mathrm{E}-03$ & $2.35 \mathrm{E}-03$ & $-7.80 \mathrm{E}-06$ & $1.01 \mathrm{E}-04$ \\
\hline 3.39E-04 & 1.49E-04 & 2.93E-03 & $-3.74 \mathrm{E}-03$ & $-2.53 \mathrm{E}-03$ & $3.98 \mathrm{E}-03$ & $-4.01 \mathrm{E}-04$ & $-3.11 E-04$ \\
\hline$-5.49 E-04$ & $-4.00 E-04$ & $4.53 \mathrm{E}-03$ & $-5.58 \mathrm{E}-03$ & $-4.60 \mathrm{E}-03$ & $5.03 \mathrm{E}-03$ & 1.17E-04 & $1.91 \mathrm{E}-04$ \\
\hline$-6.66 \mathrm{E}-05$ & $-2.46 \mathrm{E}-04$ & 5.16E-03 & $-5.75 E-03$ & $-3.78 \mathrm{E}-03$ & $6.11 \mathrm{E}-03$ & $5.45 E-04$ & $-1.37 \mathrm{E}-04$ \\
\hline$-3.00 \mathrm{E}-04$ & $-8.57 \mathrm{E}-04$ & $3.84 \mathrm{E}-03$ & $-5.54 \mathrm{E}-03$ & $-4.50 \mathrm{E}-03$ & 5.11E-03 & $2.85 \mathrm{E}-04$ & $1.91 \mathrm{E}-04$ \\
\hline$-2.91 \mathrm{E}-05$ & 4.43E-04 & $1.64 \mathrm{E}-03$ & $-4.62 \mathrm{E}-03$ & $-3.30 \mathrm{E}-03$ & $4.88 \mathrm{E}-03$ & $-2.54 \mathrm{E}-04$ & $-4.10 E-04$ \\
\hline $8.44 \mathrm{E}-04$ & $5.08 \mathrm{E}-04$ & 8.07E-03 & $-7.84 \mathrm{E}-03$ & $-6.01 \mathrm{E}-03$ & $8.24 \mathrm{E}-03$ & $-3.45 E-04$ & $-9.05 E-04$ \\
\hline$-8.68 \mathrm{E}-05$ & $-2.41 \mathrm{E}-05$ & $1.48 \mathrm{E}-03$ & $-3.66 \mathrm{E}-03$ & $-1.58 \mathrm{E}-03$ & $3.45 \mathrm{E}-03$ & $8.22 \mathrm{E}-05$ & $8.69 \mathrm{E}-05$ \\
\hline $1.08 \mathrm{E}-04$ & $-5.84 \mathrm{E}-05$ & 1.94E-03 & $-3.63 \mathrm{E}-03$ & $-2.39 \mathrm{E}-03$ & $3.62 \mathrm{E}-03$ & $-5.82 \mathrm{E}-05$ & $-2.24 \mathrm{E}-04$ \\
\hline$-9.93 E-06$ & $-3.15 E-04$ & $2.37 \mathrm{E}-03$ & $-4.49 E-03$ & $-2.66 \mathrm{E}-03$ & $4.33 \mathrm{E}-03$ & $1.96 \mathrm{E}-04$ & $6.65 \mathrm{E}-05$ \\
\hline $2.35 \mathrm{E}-04$ & $-1.31 \mathrm{E}-04$ & $3.50 \mathrm{E}-03$ & $-4.98 \mathrm{E}-03$ & $-3.50 \mathrm{E}-03$ & $4.96 \mathrm{E}-03$ & $-3.20 \mathrm{E}-04$ & $-5.81 E-05$ \\
\hline $6.10 \mathrm{E}-05$ & $-7.34 \mathrm{E}-05$ & 2.39E-03 & $-3.23 \mathrm{E}-03$ & $-2.20 \mathrm{E}-03$ & $3.23 \mathrm{E}-03$ & $-6.13 \mathrm{E}-05$ & $-1.64 \mathrm{E}-04$ \\
\hline
\end{tabular}


APPENDIX IV: 3-D INVERSION DATA FILE

\begin{tabular}{|c|c|c|c|c|c|c|c|}
\hline 3.77E-05 & 4.07E-05 & 1.97E-03 & $-4.07 \mathrm{E}-03$ & $-2.03 E-03$ & 4.07E-03 & $-7.90 \mathrm{E}-05$ & $-1.46 \mathrm{E}-04$ \\
\hline$-4.29 E-06$ & $2.36 \mathrm{E}-05$ & 3.03E-03 & $-2.95 \mathrm{E}-03$ & $-1.81 \mathrm{E}-03$ & 2.99E-03 & $-2.96 \mathrm{E}-04$ & 1.01E-04 \\
\hline 2.39E-04 & $-1.37 \mathrm{E}-04$ & 3.01E-03 & $-4.17 E-03$ & $-3.29 E-03$ & $5.56 \mathrm{E}-03$ & 5.41E-05 & 2.92E-04 \\
\hline$-8.86 E-05$ & $1.35 \mathrm{E}-04$ & 2.47E-03 & $-4.65 E-03$ & $-3.20 \mathrm{E}-03$ & $4.68 \mathrm{E}-03$ & $-4.33 E-04$ & $-3.55 E-04$ \\
\hline 4.48E-05 & 1.63E-04 & $2.09 \mathrm{E}-03$ & $-3.79 \mathrm{E}-03$ & $-2.14 \mathrm{E}-03$ & $4.14 \mathrm{E}-03$ & $-1.35 \mathrm{E}-04$ & $-5.60 \mathrm{E}-05$ \\
\hline$-5.06 E-04$ & $-3.59 E-04$ & 3.10E-03 & $-4.17 E-03$ & $-3.14 \mathrm{E}-03$ & $3.65 \mathrm{E}-03$ & $3.08 \mathrm{E}-04$ & $3.42 \mathrm{E}-04$ \\
\hline$-4.07 E-04$ & $2.68 \mathrm{E}-04$ & 4.95E-03 & $-4.86 \mathrm{E}-03$ & $-3.14 \mathrm{E}-03$ & $5.13 \mathrm{E}-03$ & 1.09E-04 & $-2.35 E-05$ \\
\hline$-9.12 \mathrm{E}-06$ & $2.06 \mathrm{E}-05$ & $1.64 \mathrm{E}-03$ & $-3.77 \mathrm{E}-03$ & $-1.61 \mathrm{E}-03$ & $3.56 \mathrm{E}-03$ & $-1.03 E-04$ & $2.14 \mathrm{E}-05$ \\
\hline 7.97E-05 & $-3.00 \mathrm{E}-05$ & $1.76 \mathrm{E}-03$ & $-2.19 \mathrm{E}-03$ & $-1.70 \mathrm{E}-03$ & $2.25 \mathrm{E}-03$ & $5.28 \mathrm{E}-05$ & 1.09E-04 \\
\hline $1.80 \mathrm{E}-04$ & $-6.21 E-06$ & 2.47E-03 & $-2.72 \mathrm{E}-03$ & -1.77E-03 & 2.39E-03 & $1.81 \mathrm{E}-04$ & 3.73E-05 \\
\hline$-6.63 \mathrm{E}-04$ & $-2.10 \mathrm{E}-04$ & $5.31 \mathrm{E}-03$ & $-2.93 \mathrm{E}-03$ & $-3.65 \mathrm{E}-03$ & $3.56 \mathrm{E}-03$ & $-2.68 \mathrm{E}-04$ & $-8.29 \mathrm{E}-05$ \\
\hline$-7.39 E-04$ & $-2.53 \mathrm{E}-04$ & 7.03E-03 & -7.27E-03 & $-4.33 E-03$ & $6.38 \mathrm{E}-03$ & $-1.09 \mathrm{E}-04$ & $1.03 \mathrm{E}-03$ \\
\hline$-1.57 E-04$ & $-3.82 E-04$ & $6.81 \mathrm{E}-03$ & $-6.18 \mathrm{E}-03$ & $-4.31 \mathrm{E}-03$ & 4.99E-03 & $2.25 \mathrm{E}-04$ & 3.64E-04 \\
\hline$-3.68 \mathrm{E}-04$ & $-3.94 \mathrm{E}-04$ & $3.28 \mathrm{E}-03$ & $-3.16 \mathrm{E}-03$ & $-2.49 \mathrm{E}-03$ & $3.64 \mathrm{E}-03$ & $-2.00 \mathrm{E}-04$ & $3.24 \mathrm{E}-04$ \\
\hline 5.09E-04 & $-8.60 \mathrm{E}-04$ & 2.65E-03 & $-6.91 E-03$ & $-4.42 \mathrm{E}-03$ & $5.70 \mathrm{E}-03$ & 5.80E-04 & $1.72 \mathrm{E}-04$ \\
\hline 2.17E-04 & $-1.19 E-03$ & 3.40E-03 & $-7.60 \mathrm{E}-03$ & $-5.66 \mathrm{E}-03$ & $6.35 \mathrm{E}-03$ & 4.61E-04 & $5.98 \mathrm{E}-04$ \\
\hline 7.05E-04 & $2.96 \mathrm{E}-04$ & $2.89 \mathrm{E}-03$ & $-5.90 \mathrm{E}-03$ & $-3.54 \mathrm{E}-03$ & 4.10E-03 & $-2.59 \mathrm{E}-04$ & $-8.27 \mathrm{E}-04$ \\
\hline$-8.67 E-05$ & $-1.49 E-04$ & 2.31E-03 & $-4.63 E-03$ & $-5.85 \mathrm{E}-03$ & $4.85 \mathrm{E}-03$ & $-6.32 E-05$ & $3.52 E-05$ \\
\hline$-6.03 E-04$ & 3.49E-05 & $2.68 \mathrm{E}-03$ & $-6.61 E-03$ & $-3.61 \mathrm{E}-03$ & $5.71 \mathrm{E}-03$ & 5.71E-04 & 8.83E-04 \\
\hline$-2.32 \mathrm{E}-04$ & $5.05 \mathrm{E}-04$ & 3.07E-03 & $-5.00 \mathrm{E}-03$ & $-2.53 \mathrm{E}-03$ & $5.10 \mathrm{E}-03$ & $-5.95 E-04$ & 7.94E-05 \\
\hline$-1.25 \mathrm{E}-04$ & $1.45 \mathrm{E}-04$ & $2.42 \mathrm{E}-03$ & $-4.29 E-03$ & $-2.80 \mathrm{E}-03$ & 4.61E-03 & $-2.07 E-04$ & $-1.25 E-04$ \\
\hline$-4.32 \mathrm{E}-04$ & $-1.29 E-04$ & $5.08 \mathrm{E}-03$ & $-6.94 \mathrm{E}-03$ & $-7.19 E-03$ & $8.80 \mathrm{E}-03$ & $-6.87 \mathrm{E}-04$ & $-3.95 E-04$ \\
\hline $6.56 \mathrm{E}-04$ & $-6.30 \mathrm{E}-04$ & $3.92 \mathrm{E}-03$ & $-6.12 E-03$ & $-1.34 \mathrm{E}-03$ & 7.29E-03 & 3.81E-04 & 1.10E-03 \\
\hline$-8.92 E-05$ & 2.89E-04 & $1.29 \mathrm{E}-03$ & $-2.83 E-03$ & $-1.76 \mathrm{E}-03$ & $3.52 \mathrm{E}-03$ & 2.74E-06 & $2.22 \mathrm{E}-05$ \\
\hline $6.21 \mathrm{E}-05$ & $2.96 \mathrm{E}-04$ & 4.76E-03 & $-5.41 E-03$ & $-4.56 \mathrm{E}-03$ & $6.90 \mathrm{E}-03$ & $-2.55 \mathrm{E}-04$ & $3.76 \mathrm{E}-04$ \\
\hline Period: & $3.55 E+00$ & & & & & & \\
\hline$-2.02 E-04$ & $7.85 \mathrm{E}-05$ & $1.71 \mathrm{E}-03$ & $-1.57 \mathrm{E}-03$ & $-2.15 \mathrm{E}-03$ & $1.30 \mathrm{E}-03$ & $1.05 \mathrm{E}-04$ & 2.40E-04 \\
\hline$-3.33 E-05$ & $-5.30 \mathrm{E}-04$ & $3.04 \mathrm{E}-03$ & $-2.94 \mathrm{E}-03$ & $-1.29 \mathrm{E}-03$ & $2.42 \mathrm{E}-03$ & $-1.23 \mathrm{E}-04$ & $1.56 \mathrm{E}-04$ \\
\hline$-2.61 \mathrm{E}-04$ & $-1.22 \mathrm{E}-04$ & $3.11 \mathrm{E}-03$ & $-3.67 E-03$ & $-3.81 \mathrm{E}-03$ & $3.15 \mathrm{E}-03$ & $-1.07 E-04$ & 8.60E-05 \\
\hline$-1.13 E-03$ & $-3.25 \mathrm{E}-04$ & 4.02E-03 & $-3.56 \mathrm{E}-03$ & $-2.74 \mathrm{E}-03$ & $3.74 \mathrm{E}-03$ & $6.68 \mathrm{E}-04$ & 1.39E-04 \\
\hline $1.23 \mathrm{E}-04$ & $-3.11 E-04$ & $1.89 \mathrm{E}-03$ & $-3.69 \mathrm{E}-03$ & $-3.78 \mathrm{E}-03$ & $3.38 \mathrm{E}-03$ & $2.85 \mathrm{E}-04$ & $2.86 \mathrm{E}-04$ \\
\hline $3.31 \mathrm{E}-05$ & 4.86E-04 & $1.91 \mathrm{E}-03$ & $-2.57 \mathrm{E}-03$ & $-2.61 \mathrm{E}-03$ & $2.86 \mathrm{E}-03$ & $-8.86 \mathrm{E}-05$ & $3.88 \mathrm{E}-05$ \\
\hline 7.39E-04 & 2.97E-04 & 6.19E-03 & $-5.84 \mathrm{E}-03$ & $-4.67 \mathrm{E}-03$ & $5.32 \mathrm{E}-03$ & $-2.65 E-04$ & $-5.19 E-04$ \\
\hline$-1.04 \mathrm{E}-04$ & $1.45 \mathrm{E}-04$ & $1.85 \mathrm{E}-03$ & $-2.19 \mathrm{E}-03$ & $-1.50 \mathrm{E}-03$ & $2.17 \mathrm{E}-03$ & $-6.12 E-05$ & 7.67E-05 \\
\hline$-1.33 E-04$ & $2.29 \mathrm{E}-04$ & $1.76 \mathrm{E}-03$ & $-2.36 \mathrm{E}-03$ & $-1.77 \mathrm{E}-03$ & $1.95 \mathrm{E}-03$ & $-1.24 \mathrm{E}-04$ & 4.09E-05 \\
\hline $1.88 \mathrm{E}-04$ & $-3.12 \mathrm{E}-04$ & $2.04 \mathrm{E}-03$ & $-2.51 E-03$ & $-1.91 \mathrm{E}-03$ & 2.79E-03 & 3.59E-04 & $-6.70 \mathrm{E}-05$ \\
\hline $2.29 \mathrm{E}-05$ & $-5.79 E-05$ & $2.59 \mathrm{E}-03$ & $-2.58 \mathrm{E}-03$ & $-2.38 \mathrm{E}-03$ & $3.03 E-03$ & $-3.67 \mathrm{E}-04$ & 4.48E-05 \\
\hline$-2.54 \mathrm{E}-04$ & $-1.39 E-04$ & $1.59 \mathrm{E}-03$ & $-2.55 \mathrm{E}-03$ & $-1.72 \mathrm{E}-03$ & $2.35 \mathrm{E}-03$ & $-1.76 \mathrm{E}-04$ & $-1.61 E-04$ \\
\hline $1.16 \mathrm{E}-04$ & 2.31E-05 & 1.79E-03 & $-2.34 \mathrm{E}-03$ & $-1.66 \mathrm{E}-03$ & $2.35 \mathrm{E}-03$ & $-1.16 \mathrm{E}-05$ & $-1.24 \mathrm{E}-04$ \\
\hline 8.39E-05 & 5.51E-05 & $2.41 \mathrm{E}-03$ & $-2.02 \mathrm{E}-03$ & $-1.41 \mathrm{E}-03$ & $1.69 \mathrm{E}-03$ & $-1.01 \mathrm{E}-04$ & 1.39E-04 \\
\hline$-4.38 \mathrm{E}-05$ & $1.20 \mathrm{E}-04$ & $3.46 \mathrm{E}-03$ & $-2.85 \mathrm{E}-03$ & $-3.03 E-03$ & $3.61 E-03$ & $-2.63 \mathrm{E}-04$ & 1.10E-04 \\
\hline$-7.48 \mathrm{E}-05$ & $-7.28 \mathrm{E}-05$ & $2.83 \mathrm{E}-03$ & $-3.13 \mathrm{E}-03$ & $-3.72 \mathrm{E}-03$ & $2.88 \mathrm{E}-03$ & $-1.63 \mathrm{E}-04$ & $-3.36 \mathrm{E}-04$ \\
\hline
\end{tabular}


APPENDIX IV: 3-D INVERSION DATA FILE

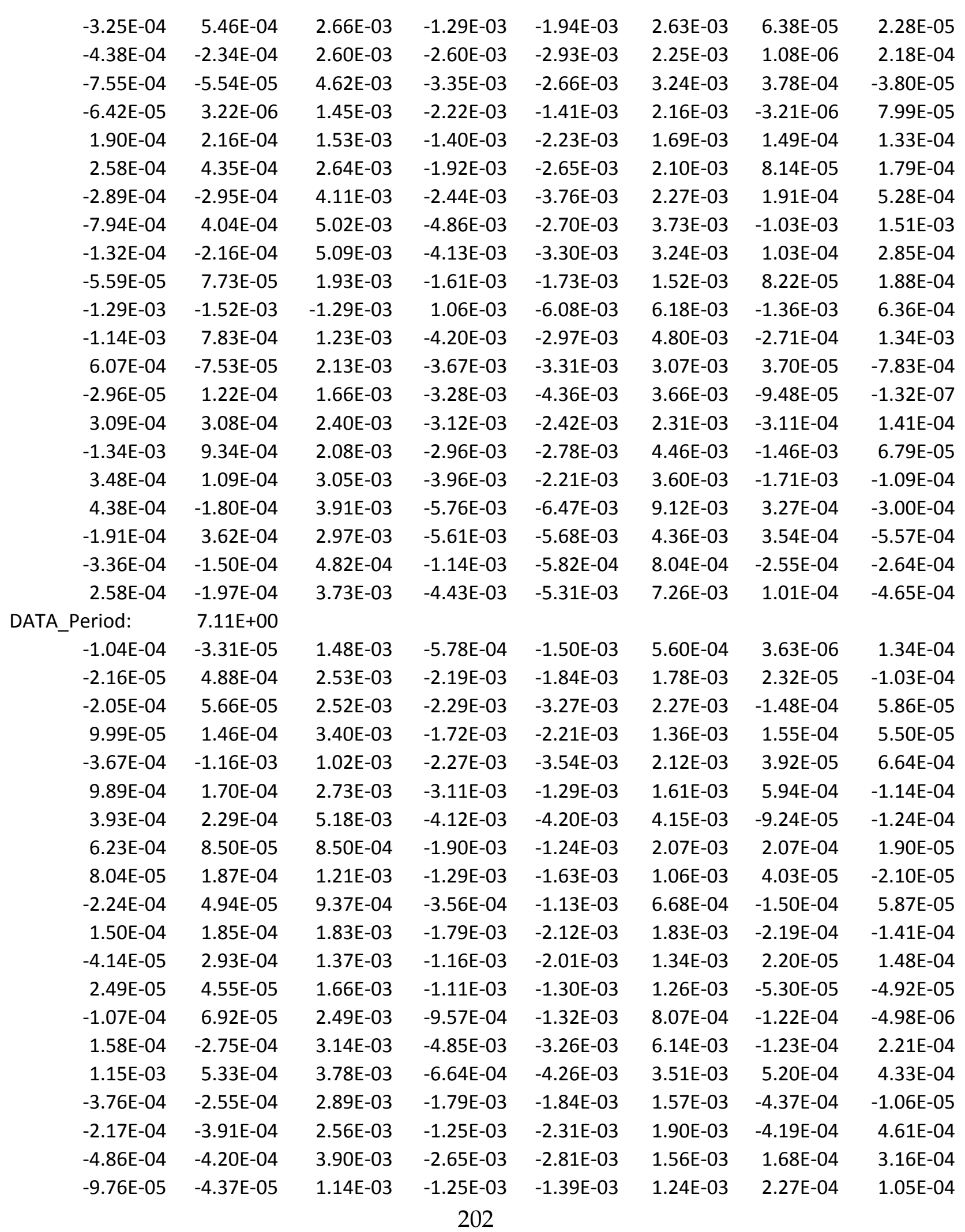


APPENDIX IV: 3-D INVERSION DATA FILE

\begin{tabular}{|c|c|c|c|c|c|c|c|}
\hline $9.55 \mathrm{E}-05$ & $-5.33 E-06$ & $2.34 \mathrm{E}-03$ & $-1.42 \mathrm{E}-03$ & $-2.03 E-03$ & $1.39 \mathrm{E}-03$ & 4.27E-06 & 8.68E-05 \\
\hline 1.13E-04 & $-3.23 E-05$ & $2.02 \mathrm{E}-03$ & $-3.47 \mathrm{E}-04$ & $-1.48 \mathrm{E}-03$ & $5.44 \mathrm{E}-04$ & $1.11 \mathrm{E}-04$ & 7.96E-05 \\
\hline$-2.65 \mathrm{E}-04$ & $-1.98 \mathrm{E}-04$ & $.77 E-03$ & $-1.22 \mathrm{E}-03$ & $-3.06 \mathrm{E}-03$ & $1.91 \mathrm{E}-03$ & $-2.19 \mathrm{E}-06$ & $-8.66 \mathrm{E}-06$ \\
\hline$-2.09 E-04$ & 5.52E-06 & $4.54 \mathrm{E}-03$ & $-2.62 \mathrm{E}-03$ & $-2.58 \mathrm{E}-03$ & $1.85 \mathrm{E}-03$ & $-4.43 \mathrm{E}-04$ & 3.07E-04 \\
\hline$-1.38 \mathrm{E}-04$ & $-1.15 \mathrm{E}-04$ & $4.56 \mathrm{E}-03$ & $-2.41 \mathrm{E}-03$ & $-2.99 \mathrm{E}-03$ & $2.01 \mathrm{E}-03$ & $9.92 \mathrm{E}-06$ & $4.89 \mathrm{E}-04$ \\
\hline$-3.29 E-04$ & $-1.51 \mathrm{E}-05$ & 8.82E-04 & $-7.90 \mathrm{E}-04$ & $-2.48 \mathrm{E}-03$ & $9.49 E-04$ & $-2.45 E-04$ & $-3.65 E-04$ \\
\hline $1.12 \mathrm{E}-02$ & 4.30E-03 & $3.92 \mathrm{E}-03$ & $-7.61 E-03$ & $-4.11 \mathrm{E}-03$ & 8.11E-03 & $1.01 \mathrm{E}-03$ & -7.77E-04 \\
\hline$-1.01 \mathrm{E}-03$ & $-6.70 \mathrm{E}-04$ & $1.42 \mathrm{E}-03$ & $-2.84 \mathrm{E}-03$ & $-4.13 E-03$ & $3.22 \mathrm{E}-03$ & $-4.78 \mathrm{E}-04$ & $5.68 \mathrm{E}-04$ \\
\hline $5.03 E-04$ & $-5.69 E-05$ & $1.83 \mathrm{E}-03$ & $-2.26 \mathrm{E}-03$ & $-3.08 \mathrm{E}-03$ & $2.36 \mathrm{E}-03$ & $1.46 \mathrm{E}-04$ & $-3.36 \mathrm{E}-04$ \\
\hline$-1.90 E-04$ & $2.60 \mathrm{E}-04$ & $1.38 \mathrm{E}-03$ & $-1.85 \mathrm{E}-03$ & $-3.40 \mathrm{E}-03$ & 2.12E-03 & $-1.49 \mathrm{E}-04$ & 2.78E-04 \\
\hline $1.01 \mathrm{E}-03$ & $-1.23 \mathrm{E}-03$ & $2.41 \mathrm{E}-03$ & $-8.34 \mathrm{E}-04$ & $-1.08 \mathrm{E}-02$ & $3.87 \mathrm{E}-03$ & $1.22 \mathrm{E}-03$ & $-3.10 \mathrm{E}-03$ \\
\hline$-3.72 E-04$ & $1.45 \mathrm{E}-04$ & 3.13E-03 & $-2.08 \mathrm{E}-03$ & $-1.35 \mathrm{E}-03$ & $1.90 \mathrm{E}-03$ & $-1.56 \mathrm{E}-04$ & $-8.73 E-05$ \\
\hline$-7.24 \mathrm{E}-04$ & $-5.17 \mathrm{E}-05$ & $2.53 \mathrm{E}-03$ & $-2.24 \mathrm{E}-03$ & $-1.70 \mathrm{E}-03$ & $2.54 \mathrm{E}-03$ & $-2.44 \mathrm{E}-04$ & $-5.61 E-05$ \\
\hline 5.87E-04 & 4.51E-04 & $3.70 \mathrm{E}-03$ & $-2.54 \mathrm{E}-03$ & $-5.11 \mathrm{E}-03$ & $4.60 \mathrm{E}-03$ & $-3.96 \mathrm{E}-04$ & $-1.39 \mathrm{E}-04$ \\
\hline$-1.63 E-03$ & 4.67E-04 & $9.26 \mathrm{E}-04$ & $-4.09 E-03$ & $-1.84 \mathrm{E}-03$ & $2.36 \mathrm{E}-03$ & 9.17E-05 & -1.97E-04 \\
\hline$-2.86 \mathrm{E}-04$ & $1.38 \mathrm{E}-04$ & $1.08 \mathrm{E}-03$ & $-1.37 E-03$ & $-9.96 \mathrm{E}-04$ & $1.28 \mathrm{E}-03$ & $-2.16 \mathrm{E}-04$ & $-2.83 E-06$ \\
\hline$-8.43 E-05$ & 2.74E-04 & 4.48E-03 & $-4.01 E-03$ & $-3.66 \mathrm{E}-03$ & $2.54 \mathrm{E}-03$ & $-3.51 E-05$ & 8.99E-04 \\
\hline Period: & $1.42 \mathrm{E}+01$ & & & & & & \\
\hline$-1.04 \mathrm{E}-04$ & $-3.31 \mathrm{E}-05$ & $1.48 \mathrm{E}-03$ & $-5.78 \mathrm{E}-04$ & $-1.50 \mathrm{E}-03$ & $5.60 \mathrm{E}-04$ & $3.63 E-06$ & $1.34 \mathrm{E}-04$ \\
\hline $1.06 \mathrm{E}-04$ & 4.63E-04 & 3.18E-03 & $-1.60 \mathrm{E}-03$ & $-9.06 \mathrm{E}-04$ & $9.17 \mathrm{E}-04$ & $1.21 \mathrm{E}-04$ & $-2.61 E-04$ \\
\hline$-3.17 E-04$ & 2.13E-05 & 2.96E-03 & $-7.40 \mathrm{E}-04$ & $-2.59 \mathrm{E}-03$ & $1.09 \mathrm{E}-03$ & $-1.90 \mathrm{E}-04$ & $1.28 \mathrm{E}-05$ \\
\hline 9.99E-05 & $1.46 \mathrm{E}-04$ & $3.40 \mathrm{E}-03$ & $-1.72 \mathrm{E}-03$ & $-2.21 \mathrm{E}-03$ & $1.36 \mathrm{E}-03$ & $1.55 \mathrm{E}-04$ & 5.50E-05 \\
\hline$-4.57 E-04$ & $-4.30 \mathrm{E}-04$ & $1.65 \mathrm{E}-03$ & $-9.54 \mathrm{E}-04$ & $-3.01 \mathrm{E}-03$ & $1.74 \mathrm{E}-03$ & $-7.56 \mathrm{E}-05$ & 5.13E-05 \\
\hline $2.75 \mathrm{E}-04$ & $-4.59 E-04$ & $1.45 \mathrm{E}-03$ & $-1.16 \mathrm{E}-03$ & $-8.77 \mathrm{E}-04$ & $1.47 \mathrm{E}-03$ & $1.68 \mathrm{E}-04$ & $-3.80 \mathrm{E}-04$ \\
\hline $3.57 \mathrm{E}-04$ & $-1.98 \mathrm{E}-04$ & 3.97E-03 & $-1.52 E-03$ & $-2.38 \mathrm{E}-03$ & $1.63 \mathrm{E}-03$ & 3.33E-05 & $-3.28 \mathrm{E}-04$ \\
\hline 3.44E-05 & $-6.07 E-05$ & 1.47E-03 & $-7.84 \mathrm{E}-04$ & $-9.76 \mathrm{E}-04$ & 7.57E-04 & 5.35E-05 & 3.57E-05 \\
\hline$-3.23 E-05$ & $1.80 \mathrm{E}-04$ & $1.38 \mathrm{E}-03$ & $-6.28 E-04$ & $-1.72 \mathrm{E}-03$ & $6.56 \mathrm{E}-04$ & $-1.08 \mathrm{E}-04$ & $-2.16 E-04$ \\
\hline$-1.92 \mathrm{E}-04$ & 1.34E-04 & $1.08 \mathrm{E}-03$ & $-8.45 E-04$ & $-1.49 \mathrm{E}-03$ & $9.37 \mathrm{E}-04$ & $-2.40 \mathrm{E}-04$ & $-1.81 E-05$ \\
\hline$-5.59 \mathrm{E}-05$ & $1.28 \mathrm{E}-04$ & $1.79 \mathrm{E}-03$ & $-1.25 \mathrm{E}-03$ & $-1.86 \mathrm{E}-03$ & $1.15 \mathrm{E}-03$ & $-2.16 \mathrm{E}-04$ & $-3.21 E-05$ \\
\hline 4.10E-04 & $4.52 \mathrm{E}-04$ & $1.80 \mathrm{E}-03$ & $-4.02 E-04$ & $-1.50 \mathrm{E}-03$ & $8.81 E-04$ & 8.71E-05 & 1.29E-04 \\
\hline 8.06E-06 & 4.23E-05 & $1.53 \mathrm{E}-03$ & $-6.48 \mathrm{E}-04$ & $-1.09 \mathrm{E}-03$ & 8.00E-04 & $-6.55 E-05$ & $-2.32 E-05$ \\
\hline$-6.17 E-05$ & $-5.65 E-05$ & $2.46 \mathrm{E}-03$ & $-9.04 \mathrm{E}-04$ & $-1.21 \mathrm{E}-03$ & $7.66 \mathrm{E}-04$ & $-1.50 \mathrm{E}-04$ & 5.99E-05 \\
\hline$-2.75 E-04$ & 5.44E-05 & 3.05E-03 & $-1.47 \mathrm{E}-03$ & $-2.16 \mathrm{E}-03$ & 8.27E-04 & $-5.63 E-04$ & $1.53 \mathrm{E}-04$ \\
\hline 4.54E-04 & $-8.48 \mathrm{E}-04$ & 2.05E-03 & $-1.00 \mathrm{E}-03$ & $-3.46 \mathrm{E}-03$ & $1.07 \mathrm{E}-03$ & 3.84E-04 & $-1.91 \mathrm{E}-04$ \\
\hline$-1.66 \mathrm{E}-04$ & $-4.77 E-05$ & $1.65 \mathrm{E}-03$ & $-8.50 \mathrm{E}-04$ & $-1.49 \mathrm{E}-03$ & $8.41 \mathrm{E}-04$ & $-2.45 \mathrm{E}-04$ & $-1.58 \mathrm{E}-04$ \\
\hline$-1.51 E-04$ & $-1.76 \mathrm{E}-04$ & $2.36 \mathrm{E}-03$ & $-8.65 E-04$ & $-2.38 \mathrm{E}-03$ & $1.08 \mathrm{E}-03$ & $-2.32 \mathrm{E}-04$ & 2.41E-04 \\
\hline$-6.47 \mathrm{E}-04$ & $-4.46 \mathrm{E}-04$ & $4.06 \mathrm{E}-03$ & $-1.57 \mathrm{E}-03$ & $-2.57 \mathrm{E}-03$ & $8.51 \mathrm{E}-04$ & $-6.83 E-05$ & $-5.85 E-05$ \\
\hline$-2.10 \mathrm{E}-05$ & $1.56 \mathrm{E}-04$ & $9.15 \mathrm{E}-04$ & $-6.31 E-04$ & $-1.93 \mathrm{E}-03$ & $8.55 E-04$ & 7.26E-05 & $-2.69 \mathrm{E}-04$ \\
\hline$-2.59 \mathrm{E}-04$ & $3.58 \mathrm{E}-04$ & $1.34 \mathrm{E}-03$ & $2.74 \mathrm{E}-04$ & $-2.58 \mathrm{E}-03$ & 8.93E-04 & -8.07E-05 & 4.47E-04 \\
\hline $1.13 \mathrm{E}-04$ & $-3.23 \mathrm{E}-05$ & $2.02 \mathrm{E}-03$ & $-3.47 E-04$ & $-1.48 \mathrm{E}-03$ & $5.44 \mathrm{E}-04$ & $1.11 \mathrm{E}-04$ & 7.96E-05 \\
\hline$-5.39 E-04$ & $1.92 \mathrm{E}-05$ & 3.54E-03 & $-1.21 \mathrm{E}-03$ & $-2.76 \mathrm{E}-03$ & $1.49 \mathrm{E}-03$ & $-6.58 \mathrm{E}-05$ & 3.03E-04 \\
\hline$-1.07 E-04$ & $-4.76 \mathrm{E}-05$ & $4.45 \mathrm{E}-03$ & $-1.91 \mathrm{E}-03$ & $-2.50 \mathrm{E}-03$ & $1.32 \mathrm{E}-03$ & $-2.87 \mathrm{E}-04$ & 2.47E-04 \\
\hline
\end{tabular}


APPENDIX IV: 3-D INVERSION DATA FILE

\begin{tabular}{|c|c|c|c|c|c|c|c|}
\hline 4.03E-05 & 5.15E-05 & 4.31E-03 & $-1.65 \mathrm{E}-03$ & $-2.75 \mathrm{E}-03$ & $-2.93 \mathrm{E}-05$ & $2.93 \mathrm{E}-05$ & 2.57E-04 \\
\hline$-3.32 E-04$ & $3.05 E-05$ & 8.78E-04 & $-6.19 E-04$ & $-3.67 \mathrm{E}-03$ & 1.36E-03 & $-2.06 \mathrm{E}-04$ & $-2.77 E-04$ \\
\hline$-6.49 E-04$ & $-3.01 \mathrm{E}-04$ & 4.97E-03 & $-5.58 E-03$ & $-5.02 \mathrm{E}-03$ & 7.30E-03 & $2.66 \mathrm{E}-04$ & $3.25 E-04$ \\
\hline$-1.60 \mathrm{E}-03$ & $-6.06 \mathrm{E}-04$ & 4.74E-03 & $-2.70 \mathrm{E}-03$ & $-5.76 \mathrm{E}-03$ & 3.19E-03 & 4.13E-05 & $1.74 \mathrm{E}-03$ \\
\hline $2.41 \mathrm{E}-04$ & $1.82 \mathrm{E}-04$ & 1.67E-03 & $-9.80 \mathrm{E}-04$ & $-1.70 \mathrm{E}-03$ & $1.02 \mathrm{E}-03$ & $-1.55 \mathrm{E}-04$ & $-5.61 E-04$ \\
\hline$-2.88 \mathrm{E}-05$ & $6.51 \mathrm{E}-05$ & 1.29E-03 & $-2.42 \mathrm{E}-03$ & $-3.89 \mathrm{E}-03$ & $1.71 \mathrm{E}-03$ & $-6.33 E-05$ & $1.85 \mathrm{E}-05$ \\
\hline $6.25 \mathrm{E}-05$ & $-2.61 \mathrm{E}-06$ & $1.24 \mathrm{E}-03$ & $-1.21 \mathrm{E}-03$ & $-8.97 \mathrm{E}-04$ & $1.02 \mathrm{E}-03$ & $1.26 \mathrm{E}-04$ & $-1.87 E-05$ \\
\hline $1.92 \mathrm{E}-04$ & 4.32E-05 & $1.63 \mathrm{E}-03$ & $-1.40 \mathrm{E}-03$ & $-7.54 \mathrm{E}-04$ & $6.16 \mathrm{E}-04$ & $-2.48 \mathrm{E}-05$ & $-9.54 \mathrm{E}-05$ \\
\hline$-3.87 E-05$ & $2.34 \mathrm{E}-05$ & $1.05 \mathrm{E}-03$ & $-8.40 \mathrm{E}-04$ & $-1.32 \mathrm{E}-03$ & $9.96 \mathrm{E}-04$ & 7.17E-05 & 8.85E-05 \\
\hline $2.56 \mathrm{E}-04$ & $6.61 \mathrm{E}-05$ & 2.59E-03 & $-1.63 E-03$ & $-3.59 \mathrm{E}-03$ & $3.15 \mathrm{E}-03$ & $9.38 \mathrm{E}-04$ & 4.65E-04 \\
\hline$-2.86 \mathrm{E}-04$ & $3.36 \mathrm{E}-04$ & $1.60 \mathrm{E}-03$ & $-1.56 \mathrm{E}-03$ & $-1.09 \mathrm{E}-03$ & $4.86 \mathrm{E}-04$ & $1.96 \mathrm{E}-04$ & $6.41 \mathrm{E}-04$ \\
\hline $1.91 \mathrm{E}-04$ & 3.69E-04 & $5.88 \mathrm{E}-04$ & $-5.70 \mathrm{E}-04$ & $-7.86 \mathrm{E}-04$ & $9.16 \mathrm{E}-04$ & $-4.21 \mathrm{E}-05$ & 3.83E-05 \\
\hline 6.17E-04 & $3.06 \mathrm{E}-04$ & $1.46 \mathrm{E}-03$ & $-1.09 E-03$ & $-3.59 \mathrm{E}-03$ & $2.65 \mathrm{E}-03$ & $5.13 \mathrm{E}-04$ & $-2.68 \mathrm{E}-04$ \\
\hline eriod: & $2.13 E+01$ & & & & & & \\
\hline $1.97 \mathrm{E}-05$ & $-8.68 \mathrm{E}-05$ & $1.38 \mathrm{E}-03$ & $-4.50 \mathrm{E}-04$ & $-1.31 \mathrm{E}-03$ & $5.26 \mathrm{E}-04$ & $9.96 \mathrm{E}-05$ & $1.08 \mathrm{E}-04$ \\
\hline$-3.61 E-04$ & $2.23 \mathrm{E}-04$ & $2.36 \mathrm{E}-03$ & $-1.41 \mathrm{E}-03$ & $-8.15 E-04$ & $6.16 \mathrm{E}-04$ & $-2.46 \mathrm{E}-04$ & $-1.02 \mathrm{E}-04$ \\
\hline -3.17E-04 & $2.13 \mathrm{E}-05$ & 2.96E-03 & $-7.40 \mathrm{E}-04$ & $-2.59 \mathrm{E}-03$ & $1.09 \mathrm{E}-03$ & $-1.90 \mathrm{E}-04$ & $1.28 \mathrm{E}-05$ \\
\hline$-2.69 E-04$ & $-2.95 \mathrm{E}-04$ & $2.88 \mathrm{E}-03$ & $-1.32 \mathrm{E}-03$ & $-1.79 E-03$ & 1.10E-03 & $2.34 \mathrm{E}-04$ & 4.43E-05 \\
\hline $2.62 \mathrm{E}-04$ & $-1.45 \mathrm{E}-04$ & $1.14 \mathrm{E}-03$ & $-8.67 E-04$ & $-2.18 \mathrm{E}-03$ & 9.07E-04 & $2.23 \mathrm{E}-04$ & $-6.25 E-05$ \\
\hline$-8.53 \mathrm{E}-05$ & $-1.14 \mathrm{E}-04$ & $1.33 \mathrm{E}-03$ & $-1.40 \mathrm{E}-04$ & $-8.84 \mathrm{E}-04$ & $3.70 \mathrm{E}-04$ & $-5.02 \mathrm{E}-05$ & $-1.14 \mathrm{E}-04$ \\
\hline $3.57 \mathrm{E}-04$ & $-1.98 \mathrm{E}-04$ & 3.97E-03 & $-1.52 \mathrm{E}-03$ & $-2.38 \mathrm{E}-03$ & $1.63 \mathrm{E}-03$ & $3.33 \mathrm{E}-05$ & $-3.28 \mathrm{E}-04$ \\
\hline 4.25E-05 & $-4.07 E-05$ & 1.11E-03 & $-4.96 \mathrm{E}-04$ & $-8.59 \mathrm{E}-04$ & $5.26 \mathrm{E}-04$ & $4.41 E-05$ & $3.88 \mathrm{E}-05$ \\
\hline$-9.36 E-06$ & 1.27E-04 & 1.47E-03 & $-6.46 \mathrm{E}-04$ & $-1.66 \mathrm{E}-03$ & $5.56 \mathrm{E}-04$ & $-2.10 \mathrm{E}-05$ & $-9.45 E-05$ \\
\hline$-1.41 E-04$ & 5.99E-05 & 1.11E-03 & $-7.04 \mathrm{E}-04$ & $-1.39 \mathrm{E}-03$ & 6.61E-04 & $-1.48 \mathrm{E}-04$ & $4.88 \mathrm{E}-06$ \\
\hline 8.94E-06 & $1.99 \mathrm{E}-04$ & 1.57E-03 & $-1.04 \mathrm{E}-03$ & $-1.80 \mathrm{E}-03$ & 7.83E-04 & $-7.64 \mathrm{E}-05$ & 4.31E-05 \\
\hline $2.82 \mathrm{E}-04$ & $2.22 \mathrm{E}-04$ & $1.54 \mathrm{E}-03$ & $-4.47 \mathrm{E}-04$ & $-1.39 \mathrm{E}-03$ & $3.86 \mathrm{E}-04$ & $1.30 \mathrm{E}-04$ & $-5.94 \mathrm{E}-05$ \\
\hline $2.66 \mathrm{E}-05$ & $7.58 \mathrm{E}-05$ & $1.54 \mathrm{E}-03$ & $-5.68 \mathrm{E}-04$ & $-1.10 \mathrm{E}-03$ & $5.86 \mathrm{E}-04$ & $-8.43 E-05$ & $-6.84 \mathrm{E}-05$ \\
\hline$-2.85 E-05$ & $2.22 \mathrm{E}-05$ & $2.40 \mathrm{E}-03$ & $-7.10 \mathrm{E}-04$ & $-1.06 \mathrm{E}-03$ & $4.44 \mathrm{E}-04$ & $-1.07 \mathrm{E}-04$ & $8.32 \mathrm{E}-06$ \\
\hline$-2.75 E-04$ & $5.44 \mathrm{E}-05$ & $3.05 \mathrm{E}-03$ & $-1.47 \mathrm{E}-03$ & $-2.16 \mathrm{E}-03$ & 8.27E-04 & $-5.63 E-04$ & $1.53 \mathrm{E}-04$ \\
\hline$-1.63 E-04$ & $-2.11 \mathrm{E}-04$ & 1.63E-03 & $-6.15 E-04$ & $-2.66 \mathrm{E}-03$ & $5.76 \mathrm{E}-04$ & $-1.91 \mathrm{E}-04$ & $-1.70 \mathrm{E}-04$ \\
\hline$-1.02 \mathrm{E}-04$ & $-5.10 \mathrm{E}-04$ & $1.54 \mathrm{E}-03$ & $-3.55 \mathrm{E}-04$ & $-1.42 \mathrm{E}-03$ & $8.72 \mathrm{E}-04$ & $-4.47 \mathrm{E}-05$ & $-7.14 \mathrm{E}-04$ \\
\hline$-2.28 \mathrm{E}-04$ & $-1.56 \mathrm{E}-04$ & 2.19E-03 & $-8.42 E-04$ & $-2.23 \mathrm{E}-03$ & $8.82 \mathrm{E}-04$ & $-2.08 \mathrm{E}-04$ & 4.08E-04 \\
\hline$-5.05 E-04$ & $-2.18 \mathrm{E}-05$ & 4.21E-03 & $-1.41 \mathrm{E}-03$ & $-2.12 \mathrm{E}-03$ & $1.22 \mathrm{E}-03$ & $2.06 \mathrm{E}-04$ & $-4.56 \mathrm{E}-05$ \\
\hline $2.74 \mathrm{E}-05$ & 7.39E-05 & 7.96E-04 & $-3.74 \mathrm{E}-04$ & $-1.58 \mathrm{E}-03$ & 8.51E-04 & $-9.11 \mathrm{E}-05$ & $-1.33 E-04$ \\
\hline$-2.47 E-04$ & $-2.24 \mathrm{E}-04$ & $1.44 \mathrm{E}-03$ & $-7.43 E-05$ & $-1.86 \mathrm{E}-03$ & $9.11 \mathrm{E}-04$ & $1.82 \mathrm{E}-04$ & $-8.87 E-05$ \\
\hline 7.09E-06 & 8.17E-05 & 1.76E-03 & $-7.87 E-04$ & $-1.12 \mathrm{E}-03$ & $3.79 \mathrm{E}-04$ & $-2.71 \mathrm{E}-04$ & $-2.01 E-04$ \\
\hline$-5.78 E-05$ & $-2.04 \mathrm{E}-04$ & 1.77E-03 & $-1.26 \mathrm{E}-03$ & $-1.88 \mathrm{E}-03$ & 5.67E-04 & $-4.82 \mathrm{E}-05$ & $1.72 \mathrm{E}-04$ \\
\hline$-1.88 \mathrm{E}-04$ & $-1.79 E-04$ & 4.07E-03 & $-1.73 E-03$ & $-2.39 \mathrm{E}-03$ & $1.06 \mathrm{E}-03$ & $-2.73 E-04$ & $2.68 \mathrm{E}-04$ \\
\hline$-1.74 \mathrm{E}-06$ & $-2.46 \mathrm{E}-05$ & 4.01E-03 & $-1.47 \mathrm{E}-03$ & $-2.60 \mathrm{E}-03$ & $1.31 \mathrm{E}-03$ & $5.02 \mathrm{E}-06$ & $2.57 \mathrm{E}-04$ \\
\hline$-3.36 \mathrm{E}-04$ & $-4.57 \mathrm{E}-05$ & $1.13 \mathrm{E}-03$ & $-2.80 \mathrm{E}-04$ & $-3.65 E-03$ & $1.23 \mathrm{E}-03$ & $-2.49 \mathrm{E}-04$ & $-3.43 E-04$ \\
\hline $3.32 \mathrm{E}-04$ & $3.63 \mathrm{E}-04$ & $1.42 \mathrm{E}-03$ & $-1.84 \mathrm{E}-03$ & $-2.47 \mathrm{E}-03$ & $1.24 \mathrm{E}-03$ & $5.16 \mathrm{E}-05$ & $2.56 \mathrm{E}-04$ \\
\hline -1.87E-04 & $-9.71 E-05$ & $1.60 \mathrm{E}-03$ & $-1.18 \mathrm{E}-03$ & $-2.42 \mathrm{E}-03$ & $1.14 \mathrm{E}-03$ & $-1.21 \mathrm{E}-04$ & $2.45 \mathrm{E}-04$ \\
\hline
\end{tabular}


APPENDIX IV: 3-D INVERSION DATA FILE

\begin{tabular}{|c|c|c|c|c|c|c|c|}
\hline $2.13 \mathrm{E}-04$ & $1.34 \mathrm{E}-04$ & $1.29 \mathrm{E}-03$ & $-8.13 E-04$ & $-1.30 \mathrm{E}-03$ & $9.03 \mathrm{E}-04$ & 5.00E-05 & $-3.48 E-04$ \\
\hline$-9.51 E-05$ & 7.54E-05 & $8.42 \mathrm{E}-04$ & $-5.84 \mathrm{E}-04$ & $-2.47 \mathrm{E}-03$ & $1.10 \mathrm{E}-03$ & $-1.00 \mathrm{E}-04$ & $6.36 \mathrm{E}-05$ \\
\hline 2.31E-05 & 7.11E-05 & $1.24 \mathrm{E}-03$ & $-8.30 \mathrm{E}-04$ & $-8.85 E-04$ & $7.46 \mathrm{E}-04$ & $-1.16 \mathrm{E}-04$ & $-8.82 E-05$ \\
\hline$-6.19 E-05$ & $-4.93 E-05$ & $9.65 \mathrm{E}-04$ & $-6.53 \mathrm{E}-04$ & $-7.33 \mathrm{E}-04$ & 5.19E-04 & $-1.42 \mathrm{E}-05$ & $-1.41 \mathrm{E}-05$ \\
\hline$-9.95 E-05$ & 4.05E-05 & 1.00E-03 & $-6.28 \mathrm{E}-04$ & $-1.25 \mathrm{E}-03$ & $8.21 \mathrm{E}-04$ & $1.58 \mathrm{E}-05$ & 7.89E-05 \\
\hline$-5.16 E-05$ & $-2.07 \mathrm{E}-05$ & 2.31E-03 & $-9.18 E-04$ & $-2.40 \mathrm{E}-03$ & $1.28 \mathrm{E}-03$ & $-6.55 E-05$ & $-2.04 \mathrm{E}-05$ \\
\hline$-6.05 E-05$ & 1.69E-06 & $1.13 \mathrm{E}-03$ & $-6.88 \mathrm{E}-04$ & $-1.06 \mathrm{E}-03$ & $5.84 \mathrm{E}-04$ & $-1.73 E-05$ & $-8.24 \mathrm{E}-05$ \\
\hline$-4.01 E-05$ & 6.67E-05 & $6.13 \mathrm{E}-04$ & $-3.76 \mathrm{E}-04$ & $-6.62 \mathrm{E}-04$ & $5.18 \mathrm{E}-04$ & 2.17E-06 & $1.85 \mathrm{E}-05$ \\
\hline$-7.00 \mathrm{E}-05$ & $-1.44 \mathrm{E}-04$ & $9.32 \mathrm{E}-04$ & $-6.27 E-04$ & $-1.90 \mathrm{E}-03$ & $1.27 \mathrm{E}-03$ & 2.33E-04 & $1.68 \mathrm{E}-04$ \\
\hline TA_Period: & $4.27 \mathrm{E}+01$ & & & & & & \\
\hline$-1.04 \mathrm{E}-04$ & $-4.95 \mathrm{E}-05$ & $1.08 \mathrm{E}-03$ & $-4.92 E-04$ & $-1.29 E-03$ & $3.28 \mathrm{E}-04$ & 1.17E-04 & $-1.06 \mathrm{E}-06$ \\
\hline$-1.89 E-04$ & $-7.36 \mathrm{E}-05$ & 1.97E-03 & $-8.19 E-04$ & $-8.68 \mathrm{E}-04$ & $3.46 \mathrm{E}-04$ & $2.25 \mathrm{E}-05$ & 7.73E-05 \\
\hline$-1.77 \mathrm{E}-04$ & 7.90E-05 & 2.15E-03 & $-1.03 E-03$ & $-2.44 \mathrm{E}-03$ & $6.66 \mathrm{E}-04$ & -1.17E-04 & $-9.14 \mathrm{E}-05$ \\
\hline$-2.67 \mathrm{E}-04$ & $-3.58 \mathrm{E}-04$ & 2.27E-03 & -1.17E-03 & $-1.83 \mathrm{E}-03$ & 7.87E-04 & 5.34E-05 & $2.48 \mathrm{E}-04$ \\
\hline 7.96E-05 & $-1.25 \mathrm{E}-04$ & $1.25 \mathrm{E}-03$ & $-9.05 E-04$ & $-2.33 \mathrm{E}-03$ & $5.91 \mathrm{E}-04$ & 8.90E-05 & $-1.76 \mathrm{E}-04$ \\
\hline $1.08 \mathrm{E}-04$ & $-1.31 \mathrm{E}-05$ & 7.53E-04 & $-7.14 \mathrm{E}-04$ & $-1.02 \mathrm{E}-03$ & $4.41 \mathrm{E}-04$ & 3.70E-05 & 1.90E-04 \\
\hline $4.28 \mathrm{E}-04$ & 4.75E-04 & 3.55E-03 & $-1.38 \mathrm{E}-03$ & $-1.92 \mathrm{E}-03$ & $1.29 \mathrm{E}-03$ & $-2.16 \mathrm{E}-05$ & $-2.31 \mathrm{E}-04$ \\
\hline $1.31 \mathrm{E}-04$ & $-8.31 \mathrm{E}-05$ & 1.01E-03 & $-4.19 E-04$ & $-7.70 \mathrm{E}-04$ & $2.93 \mathrm{E}-04$ & 7.75E-05 & 8.43E-05 \\
\hline$-2.96 \mathrm{E}-05$ & $1.45 \mathrm{E}-04$ & 1.29E-03 & $-3.24 \mathrm{E}-04$ & $-1.57 \mathrm{E}-03$ & $5.32 \mathrm{E}-04$ & $-9.10 \mathrm{E}-05$ & $-5.89 E-05$ \\
\hline$-2.57 \mathrm{E}-04$ & $-8.03 E-05$ & 1.00E-03 & $-4.68 \mathrm{E}-04$ & $-1.11 \mathrm{E}-03$ & $6.72 \mathrm{E}-04$ & $-1.24 \mathrm{E}-04$ & 5.71E-05 \\
\hline$-3.82 E-05$ & $2.38 \mathrm{E}-04$ & $1.48 \mathrm{E}-03$ & $-9.79 E-04$ & $-1.62 \mathrm{E}-03$ & $4.42 \mathrm{E}-04$ & -1.07E-04 & $1.98 \mathrm{E}-04$ \\
\hline$-1.21 E-04$ & $3.32 \mathrm{E}-05$ & 8.63E-04 & $-3.40 \mathrm{E}-04$ & $-1.14 \mathrm{E}-03$ & $3.88 \mathrm{E}-04$ & $-4.50 \mathrm{E}-05$ & $1.96 \mathrm{E}-05$ \\
\hline$-5.77 E-05$ & $-1.84 \mathrm{E}-05$ & $1.32 \mathrm{E}-03$ & $-4.75 E-04$ & $-9.59 E-04$ & 4.07E-04 & 5.06E-05 & 4.18E-06 \\
\hline $1.91 \mathrm{E}-05$ & $-2.56 \mathrm{E}-04$ & 2.13E-03 & $-7.63 E-04$ & $-8.94 \mathrm{E}-04$ & $5.22 \mathrm{E}-04$ & $-5.43 E-05$ & 1.79E-04 \\
\hline$-2.75 E-04$ & $5.44 \mathrm{E}-05$ & $3.05 \mathrm{E}-03$ & $-1.47 E-03$ & $-2.16 \mathrm{E}-03$ & $8.27 E-04$ & $-5.63 E-04$ & $1.53 \mathrm{E}-04$ \\
\hline $9.09 \mathrm{E}-05$ & $6.33 \mathrm{E}-05$ & $1.54 \mathrm{E}-03$ & $-4.89 E-04$ & $-1.83 \mathrm{E}-03$ & $1.04 \mathrm{E}-03$ & $-2.17 \mathrm{E}-04$ & $-1.68 \mathrm{E}-04$ \\
\hline$-1.39 E-04$ & $-9.54 \mathrm{E}-05$ & 8.45E-04 & $-8.37 E-04$ & $-1.19 \mathrm{E}-03$ & $5.06 \mathrm{E}-04$ & $-1.03 E-04$ & $-9.67 E-05$ \\
\hline$-2.29 \mathrm{E}-04$ & $-1.61 \mathrm{E}-04$ & $1.91 \mathrm{E}-03$ & $-8.75 E-04$ & $-2.07 E-03$ & $5.74 \mathrm{E}-04$ & $-2.10 \mathrm{E}-04$ & 4.63E-05 \\
\hline$-2.62 \mathrm{E}-04$ & $-1.35 \mathrm{E}-04$ & $3.25 \mathrm{E}-03$ & $-1.84 \mathrm{E}-03$ & $-2.02 \mathrm{E}-03$ & $5.35 \mathrm{E}-04$ & $-4.35 E-06$ & $-1.30 \mathrm{E}-04$ \\
\hline 2.67E-06 & $-3.79 E-05$ & 7.60E-04 & $-2.80 \mathrm{E}-04$ & $-1.53 \mathrm{E}-03$ & 8.03E-04 & 6.54E-05 & $-5.96 \mathrm{E}-05$ \\
\hline$-4.77 E-05$ & $3.46 \mathrm{E}-04$ & $1.25 \mathrm{E}-03$ & $-5.13 E-04$ & $-2.33 \mathrm{E}-03$ & $5.20 \mathrm{E}-04$ & $-3.95 E-05$ & $-2.61 \mathrm{E}-04$ \\
\hline 1.11E-04 & 9.04E-05 & $1.55 \mathrm{E}-03$ & $-6.65 E-04$ & $-1.26 \mathrm{E}-03$ & $2.54 \mathrm{E}-04$ & 5.83E-05 & 8.16E-05 \\
\hline$-5.78 E-05$ & $-2.04 \mathrm{E}-04$ & 1.77E-03 & $-1.26 \mathrm{E}-03$ & $-1.88 \mathrm{E}-03$ & 5.67E-04 & $-4.82 E-05$ & $1.72 \mathrm{E}-04$ \\
\hline$-2.57 E-04$ & $-3.10 \mathrm{E}-04$ & $3.46 \mathrm{E}-03$ & $-1.55 \mathrm{E}-03$ & $-2.10 \mathrm{E}-03$ & $8.70 \mathrm{E}-04$ & $-1.84 \mathrm{E}-04$ & $3.26 \mathrm{E}-04$ \\
\hline 5.16E-05 & $-3.84 \mathrm{E}-04$ & 3.53E-03 & $-1.37 E-03$ & $-2.03 E-03$ & $1.07 E-03$ & 2.07E-04 & $3.12 \mathrm{E}-04$ \\
\hline$-1.83 E-04$ & $1.33 \mathrm{E}-04$ & 9.91E-04 & $-4.04 \mathrm{E}-04$ & $-3.44 \mathrm{E}-03$ & $9.04 \mathrm{E}-04$ & $-4.72 E-05$ & $-1.95 E-04$ \\
\hline$-2.46 \mathrm{E}-04$ & $-2.15 E-04$ & $1.34 \mathrm{E}-03$ & $-6.56 \mathrm{E}-04$ & $-1.33 E-03$ & $7.55 \mathrm{E}-04$ & $1.75 \mathrm{E}-04$ & 2.57E-04 \\
\hline$-2.17 \mathrm{E}-04$ & $2.40 \mathrm{E}-06$ & $1.26 \mathrm{E}-03$ & $-9.05 E-04$ & $-2.18 \mathrm{E}-03$ & $7.21 \mathrm{E}-04$ & $-2.19 E-04$ & $2.23 \mathrm{E}-05$ \\
\hline $1.71 \mathrm{E}-04$ & $1.09 \mathrm{E}-04$ & 1.10E-03 & $-4.73 E-04$ & $-1.09 E-03$ & 7.61E-04 & $1.86 \mathrm{E}-04$ & $-3.52 E-04$ \\
\hline$-9.43 E-05$ & 4.44E-05 & 6.77E-04 & $-6.34 \mathrm{E}-04$ & $-2.35 \mathrm{E}-03$ & $7.83 \mathrm{E}-04$ & $-1.25 \mathrm{E}-04$ & $-1.11 \mathrm{E}-04$ \\
\hline 8.20E-05 & $1.12 \mathrm{E}-04$ & $1.05 \mathrm{E}-03$ & $-5.52 E-04$ & $-8.39 E-04$ & $5.05 \mathrm{E}-04$ & $-7.05 E-06$ & $-1.07 \mathrm{E}-04$ \\
\hline$-7.89 E-05$ & $-8.48 \mathrm{E}-06$ & $8.21 \mathrm{E}-04$ & $-4.06 \mathrm{E}-04$ & $-7.15 E-04$ & $3.35 \mathrm{E}-04$ & $-3.42 \mathrm{E}-05$ & $5.28 \mathrm{E}-06$ \\
\hline
\end{tabular}


APPENDIX IV: 3-D INVERSION DATA FILE

\begin{tabular}{|c|c|c|c|c|c|c|c|}
\hline$-5.32 E-05$ & $-8.14 \mathrm{E}-05$ & 8.63E-04 & $-5.02 E-04$ & $-1.11 \mathrm{E}-03$ & $5.33 \mathrm{E}-04$ & $5.42 \mathrm{E}-05$ & $1.05 \mathrm{E}-04$ \\
\hline$-7.79 E-05$ & $1.52 \mathrm{E}-05$ & 2.03E-03 & $-6.38 E-04$ & $-1.73 E-03$ & $1.22 \mathrm{E}-03$ & $-1.63 \mathrm{E}-04$ & 6.94E-05 \\
\hline $8.16 \mathrm{E}-06$ & $-1.08 \mathrm{E}-05$ & 9.91E-04 & $-5.22 E-04$ & $-9.12 \mathrm{E}-04$ & $3.34 \mathrm{E}-04$ & 7.69E-06 & $-1.43 E-07$ \\
\hline 4.41E-05 & 7.35E-05 & 5.53E-04 & $-2.47 \mathrm{E}-04$ & $-5.90 \mathrm{E}-04$ & 4.91E-04 & 2.79E-05 & 4.81E-07 \\
\hline$-1.28 \mathrm{E}-06$ & $-1.23 \mathrm{E}-04$ & 8.38E-04 & $-4.16 E-04$ & $-1.53 \mathrm{E}-03$ & $9.56 \mathrm{E}-04$ & $2.95 \mathrm{E}-04$ & 1.87E-04 \\
\hline ATA_Period: & $8.53 E+01$ & & & & & & \\
\hline$-1.20 \mathrm{E}-04$ & $-8.98 \mathrm{E}-06$ & 7.50E-04 & $-6.18 \mathrm{E}-04$ & $-1.25 \mathrm{E}-03$ & $2.70 \mathrm{E}-04$ & $1.04 \mathrm{E}-04$ & $-1.51 E-04$ \\
\hline$-3.26 \mathrm{E}-04$ & $-4.97 \mathrm{E}-05$ & $1.33 \mathrm{E}-03$ & $-1.00 \mathrm{E}-03$ & $-8.40 \mathrm{E}-04$ & $2.22 \mathrm{E}-04$ & $6.76 \mathrm{E}-05$ & $-1.47 \mathrm{E}-05$ \\
\hline$-2.77 \mathrm{E}-04$ & $-1.98 \mathrm{E}-05$ & $1.44 \mathrm{E}-03$ & $-1.18 \mathrm{E}-03$ & $-2.24 \mathrm{E}-03$ & $5.65 \mathrm{E}-04$ & $-2.09 \mathrm{E}-04$ & $-1.37 \mathrm{E}-04$ \\
\hline$-8.40 \mathrm{E}-05$ & $-1.62 \mathrm{E}-04$ & 1.75E-03 & $-9.67 E-04$ & $-1.50 \mathrm{E}-03$ & 7.02E-04 & $9.88 \mathrm{E}-05$ & 1.72E-04 \\
\hline$-2.36 \mathrm{E}-05$ & $-2.20 \mathrm{E}-04$ & $8.28 \mathrm{E}-04$ & $-5.76 \mathrm{E}-04$ & $-2.02 \mathrm{E}-03$ & $4.80 \mathrm{E}-04$ & $2.65 \mathrm{E}-05$ & $1.02 \mathrm{E}-04$ \\
\hline$-4.10 \mathrm{E}-05$ & $4.36 \mathrm{E}-05$ & $1.09 \mathrm{E}-03$ & $-6.75 E-04$ & $-7.99 \mathrm{E}-04$ & $2.51 \mathrm{E}-04$ & $3.52 \mathrm{E}-05$ & $5.50 \mathrm{E}-05$ \\
\hline $6.49 \mathrm{E}-04$ & $2.60 \mathrm{E}-04$ & $3.24 \mathrm{E}-03$ & $-1.17 E-03$ & $-1.42 \mathrm{E}-03$ & 1.10E-03 & $3.43 \mathrm{E}-04$ & $-2.89 \mathrm{E}-04$ \\
\hline $1.88 \mathrm{E}-04$ & $-1.48 \mathrm{E}-04$ & $9.41 \mathrm{E}-04$ & $-3.88 \mathrm{E}-04$ & $-7.00 \mathrm{E}-04$ & $2.05 \mathrm{E}-04$ & 8.17E-05 & 7.81E-05 \\
\hline$-7.16 E-05$ & $-3.62 \mathrm{E}-05$ & 1.11E-03 & $-2.39 E-04$ & $-1.30 \mathrm{E}-03$ & $6.60 \mathrm{E}-04$ & $-2.53 \mathrm{E}-05$ & $-1.06 \mathrm{E}-06$ \\
\hline$-2.26 \mathrm{E}-04$ & $-4.43 E-05$ & 9.09E-04 & $-2.71 E-04$ & $-9.51 \mathrm{E}-04$ & $5.98 \mathrm{E}-04$ & $-5.44 \mathrm{E}-05$ & 7.69E-05 \\
\hline$-1.14 \mathrm{E}-04$ & $6.73 \mathrm{E}-05$ & $1.20 \mathrm{E}-03$ & $-8.12 E-04$ & $-1.42 \mathrm{E}-03$ & 4.23E-04 & $-2.97 \mathrm{E}-05$ & -1.79E-04 \\
\hline 8.62E-05 & $-9.07 E-05$ & 4.68E-04 & $-2.76 \mathrm{E}-04$ & $-9.62 \mathrm{E}-04$ & $3.53 \mathrm{E}-04$ & $1.35 \mathrm{E}-04$ & $1.55 \mathrm{E}-04$ \\
\hline$-1.29 E-04$ & $-1.48 \mathrm{E}-04$ & $9.72 \mathrm{E}-04$ & $-6.13 E-04$ & $-9.09 E-04$ & $2.90 \mathrm{E}-04$ & $-9.74 \mathrm{E}-05$ & 1.67E-05 \\
\hline 4.69E-06 & $-1.96 \mathrm{E}-04$ & $1.74 \mathrm{E}-03$ & $-5.29 E-04$ & $-6.33 E-04$ & $2.98 \mathrm{E}-04$ & $-4.58 \mathrm{E}-05$ & $2.38 \mathrm{E}-05$ \\
\hline$-2.75 E-04$ & $5.44 \mathrm{E}-05$ & 3.05E-03 & $-1.47 E-03$ & $-2.16 \mathrm{E}-03$ & 8.27E-04 & $-5.63 E-04$ & $1.53 \mathrm{E}-04$ \\
\hline$-2.41 E-04$ & $-8.35 \mathrm{E}-05$ & $1.51 \mathrm{E}-03$ & $-3.40 \mathrm{E}-04$ & $-1.88 \mathrm{E}-03$ & $1.14 \mathrm{E}-03$ & $-3.35 \mathrm{E}-04$ & $-1.11 \mathrm{E}-04$ \\
\hline$-4.28 \mathrm{E}-05$ & $-1.11 \mathrm{E}-04$ & 8.58E-04 & $-4.50 \mathrm{E}-04$ & $-1.32 \mathrm{E}-03$ & 5.31E-05 & $-9.35 \mathrm{E}-05$ & $-4.42 E-05$ \\
\hline$-3.39 E-04$ & $-2.91 \mathrm{E}-04$ & $1.48 \mathrm{E}-03$ & $-1.07 E-03$ & $-1.94 \mathrm{E}-03$ & $4.50 E-04$ & $-1.41 \mathrm{E}-04$ & $-2.60 \mathrm{E}-04$ \\
\hline$-4.63 E-05$ & $-1.60 \mathrm{E}-04$ & $2.41 \mathrm{E}-03$ & $-1.46 \mathrm{E}-03$ & $-1.80 \mathrm{E}-03$ & $4.25 \mathrm{E}-04$ & $-6.31 E-06$ & $5.42 \mathrm{E}-05$ \\
\hline$-5.91 E-05$ & $3.70 \mathrm{E}-06$ & 6.97E-04 & $-1.86 \mathrm{E}-04$ & $-1.16 \mathrm{E}-03$ & 7.57E-04 & $6.73 \mathrm{E}-05$ & $1.25 \mathrm{E}-05$ \\
\hline$-4.77 E-05$ & $3.46 \mathrm{E}-04$ & $1.25 \mathrm{E}-03$ & $-5.13 E-04$ & $-2.33 \mathrm{E}-03$ & $5.20 \mathrm{E}-04$ & $-3.95 \mathrm{E}-05$ & $-2.61 E-04$ \\
\hline 7.43E-05 & $-5.07 E-05$ & $1.46 \mathrm{E}-03$ & $-4.46 \mathrm{E}-04$ & -1.17E-03 & $2.72 \mathrm{E}-04$ & 4.31E-05 & $-1.51 \mathrm{E}-04$ \\
\hline$-1.63 E-04$ & $-2.25 \mathrm{E}-04$ & $1.24 \mathrm{E}-03$ & $-8.66 \mathrm{E}-04$ & $-1.70 \mathrm{E}-03$ & $5.26 \mathrm{E}-04$ & $-3.25 \mathrm{E}-05$ & $2.05 \mathrm{E}-04$ \\
\hline$-3.81 E-04$ & $-5.55 E-04$ & $2.82 \mathrm{E}-03$ & $-1.34 \mathrm{E}-03$ & $-1.73 E-03$ & $8.12 \mathrm{E}-04$ & $-3.56 \mathrm{E}-05$ & 3.99E-04 \\
\hline$-4.58 \mathrm{E}-05$ & $-5.74 \mathrm{E}-04$ & $2.98 \mathrm{E}-03$ & $-9.56 \mathrm{E}-04$ & $-1.68 \mathrm{E}-03$ & $1.18 \mathrm{E}-03$ & $-1.12 \mathrm{E}-04$ & $2.91 \mathrm{E}-04$ \\
\hline$-3.50 \mathrm{E}-04$ & $1.58 \mathrm{E}-04$ & $9.05 E-04$ & $-4.33 E-04$ & $-2.68 \mathrm{E}-03$ & $9.55 \mathrm{E}-04$ & $-4.52 \mathrm{E}-04$ & $-5.01 E-04$ \\
\hline 2.64E-05 & $-1.58 \mathrm{E}-04$ & $1.05 \mathrm{E}-03$ & $-4.25 E-04$ & $-1.22 \mathrm{E}-03$ & $6.28 \mathrm{E}-04$ & $1.45 \mathrm{E}-04$ & $2.16 \mathrm{E}-04$ \\
\hline$-2.44 \mathrm{E}-04$ & $-9.04 \mathrm{E}-05$ & $9.20 \mathrm{E}-04$ & $-7.74 \mathrm{E}-04$ & $-1.94 \mathrm{E}-03$ & $4.28 \mathrm{E}-04$ & $-2.50 \mathrm{E}-04$ & $2.23 \mathrm{E}-05$ \\
\hline $1.02 \mathrm{E}-04$ & $8.68 \mathrm{E}-05$ & 9.70E-04 & $-3.00 \mathrm{E}-04$ & $-8.28 \mathrm{E}-04$ & 7.00E-04 & $2.53 \mathrm{E}-04$ & $-3.61 E-04$ \\
\hline$-9.32 E-05$ & $-9.59 E-07$ & $5.28 \mathrm{E}-04$ & $-4.07 E-04$ & $-2.14 \mathrm{E}-03$ & $5.44 \mathrm{E}-04$ & $-9.28 \mathrm{E}-05$ & 6.01E-05 \\
\hline $1.32 \mathrm{E}-04$ & $1.27 \mathrm{E}-04$ & $8.68 \mathrm{E}-04$ & $-4.16 \mathrm{E}-04$ & $-6.98 \mathrm{E}-04$ & $4.78 \mathrm{E}-04$ & 7.79E-05 & $-2.49 \mathrm{E}-04$ \\
\hline$-2.16 \mathrm{E}-04$ & $5.91 \mathrm{E}-05$ & 8.53E-04 & $-1.56 \mathrm{E}-04$ & $-5.34 \mathrm{E}-04$ & 4.73E-04 & $8.08 \mathrm{E}-05$ & 9.02E-05 \\
\hline$-6.00 \mathrm{E}-05$ & $-1.77 \mathrm{E}-04$ & $6.72 \mathrm{E}-04$ & $-4.52 E-04$ & $-1.05 \mathrm{E}-03$ & 3.99E-04 & 3.27E-05 & 1.27E-04 \\
\hline$-6.80 \mathrm{E}-05$ & $3.36 \mathrm{E}-05$ & $1.85 \mathrm{E}-03$ & $-5.14 \mathrm{E}-04$ & $-1.43 \mathrm{E}-03$ & $1.11 \mathrm{E}-03$ & $-7.63 E-05$ & 2.63E-05 \\
\hline $2.18 \mathrm{E}-05$ & $-2.25 \mathrm{E}-05$ & 7.13E-04 & $-5.09 E-04$ & $-8.48 \mathrm{E}-04$ & $2.11 \mathrm{E}-04$ & $-9.54 \mathrm{E}-06$ & $-2.50 \mathrm{E}-05$ \\
\hline 5.69E-06 & $1.09 \mathrm{E}-05$ & 5.66E-04 & $-1.67 E-04$ & $-4.97 \mathrm{E}-04$ & $3.05 E-04$ & $2.50 \mathrm{E}-05$ & $-3.60 \mathrm{E}-06$ \\
\hline
\end{tabular}


APPENDIX IV: 3-D INVERSION DATA FILE

\begin{tabular}{|c|c|c|c|c|c|c|c|}
\hline$-1.72 E-05$ & $-1.60 \mathrm{E}-04$ & 4.59E-04 & $-2.61 \mathrm{E}-04$ & $-1.42 \mathrm{E}-03$ & 4.29E-04 & $1.31 \mathrm{E}-04$ & $1.34 \mathrm{E}-04$ \\
\hline ROR_Period: & $6.90 \mathrm{E}-03$ & & & & & & \\
\hline 6.09E-02 & $-6.09 E-02$ & $3.96 \mathrm{E}-02$ & $-3.96 \mathrm{E}-02$ & $1.77 \mathrm{E}-01$ & -1.77E-01 & $1.23 \mathrm{E}-01$ & $-1.23 \mathrm{E}-01$ \\
\hline $2.40 \mathrm{E}+01$ & $-2.40 \mathrm{E}+01$ & $2.59 E+01$ & $-2.59 E+01$ & $1.30 \mathrm{E}+01$ & $-1.30 E+01$ & $1.21 \mathrm{E}+01$ & $-1.21 \mathrm{E}+01$ \\
\hline $2.87 E+00$ & $-2.87 E+00$ & $2.53 E+00$ & $-2.53 E+00$ & $1.18 \mathrm{E}+00$ & $-1.18 E+00$ & $1.25 \mathrm{E}+00$ & $-1.25 E+00$ \\
\hline $2.45 \mathrm{E}-01$ & $-2.45 \mathrm{E}-01$ & $1.21 \mathrm{E}+00$ & $-1.21 E+00$ & $1.63 \mathrm{E}-01$ & $-1.63 \mathrm{E}-01$ & $6.00 \mathrm{E}-02$ & $-6.00 \mathrm{E}-02$ \\
\hline $4.76 \mathrm{E}-01$ & $-4.76 \mathrm{E}-01$ & $5.90 \mathrm{E}+00$ & $-5.90 E+00$ & $2.86 \mathrm{E}+00$ & $-2.86 E+00$ & $2.02 \mathrm{E}-01$ & $-2.02 E-01$ \\
\hline 4.46E-02 & $-4.46 \mathrm{E}-02$ & $8.24 \mathrm{E}-01$ & $-8.24 \mathrm{E}-01$ & 3.31E-01 & $-3.31 \mathrm{E}-01$ & 7.59E-02 & $-7.59 E-02$ \\
\hline $9.60 \mathrm{E}-02$ & $-9.60 \mathrm{E}-02$ & $6.32 \mathrm{E}-01$ & $-6.32 E-01$ & $1.79 E+00$ & $-1.79 E+00$ & $9.96 \mathrm{E}-02$ & $-9.96 \mathrm{E}-02$ \\
\hline $1.96 \mathrm{E}-02$ & $-1.96 \mathrm{E}-02$ & $1.31 \mathrm{E}+00$ & $-1.31 E+00$ & $3.27 \mathrm{E}-02$ & $-3.27 \mathrm{E}-02$ & 5.07E-03 & $-5.07 E-03$ \\
\hline $2.67 E+00$ & $-2.67 E+00$ & $2.54 \mathrm{E}+00$ & $-2.54 \mathrm{E}+00$ & $1.40 \mathrm{E}+00$ & $-1.40 \mathrm{E}+00$ & $1.34 \mathrm{E}+00$ & $-1.34 \mathrm{E}+00$ \\
\hline 6.67E-02 & $-6.67 \mathrm{E}-02$ & 3.32E-01 & $-3.32 \mathrm{E}-01$ & $1.32 \mathrm{E}-01$ & $-1.32 \mathrm{E}-01$ & $9.40 \mathrm{E}-02$ & $-9.40 \mathrm{E}-02$ \\
\hline $1.87 \mathrm{E}-01$ & $-1.87 \mathrm{E}-01$ & 3.63E-01 & $-3.63 \mathrm{E}-01$ & 3.56E-01 & $-3.56 \mathrm{E}-01$ & 4.30E-02 & $-4.30 \mathrm{E}-02$ \\
\hline $3.57 \mathrm{E}-02$ & $-3.57 \mathrm{E}-02$ & 7.34E-02 & $-7.34 \mathrm{E}-02$ & $1.58 \mathrm{E}-02$ & $-1.58 \mathrm{E}-02$ & $2.18 \mathrm{E}-02$ & $-2.18 \mathrm{E}-02$ \\
\hline 4.04E-02 & $-4.04 \mathrm{E}-02$ & $2.50 \mathrm{E}-02$ & $-2.50 \mathrm{E}-02$ & 7.80E-03 & $-7.80 \mathrm{E}-03$ & $1.53 \mathrm{E}-02$ & $-1.53 \mathrm{E}-02$ \\
\hline $4.50 \mathrm{E}-02$ & $-4.50 \mathrm{E}-02$ & 3.96E-01 & $-3.96 \mathrm{E}-01$ & 8.97E-02 & $-8.97 \mathrm{E}-02$ & $2.75 \mathrm{E}-02$ & $-2.75 E-02$ \\
\hline $2.80 \mathrm{E}+00$ & $-2.80 \mathrm{E}+00$ & $3.40 \mathrm{E}+01$ & $-3.40 E+01$ & $1.03 \mathrm{E}+02$ & $-1.03 E+02$ & $4.63 \mathrm{E}+00$ & $-4.63 E+00$ \\
\hline $4.33 \mathrm{E}+00$ & $-4.33 E+00$ & $4.29 E+01$ & $-4.29 E+01$ & $3.22 \mathrm{E}+01$ & $-3.22 \mathrm{E}+01$ & $2.98 \mathrm{E}+00$ & $-2.98 \mathrm{E}+00$ \\
\hline 7.92E-02 & $-7.92 \mathrm{E}-02$ & $9.34 \mathrm{E}-01$ & $-9.34 \mathrm{E}-01$ & $1.13 E+00$ & $-1.13 E+00$ & $1.31 \mathrm{E}-01$ & $-1.31 \mathrm{E}-01$ \\
\hline 3.39E-02 & $-1.40 \mathrm{E}-01$ & 3.30E-01 & $-3.30 \mathrm{E}-01$ & $1.01 \mathrm{E}+00$ & $-1.01 E+00$ & $9.68 \mathrm{E}-02$ & $-9.68 \mathrm{E}-02$ \\
\hline $1.96 \mathrm{E}-01$ & $-1.96 \mathrm{E}-01$ & $3.17 \mathrm{E}+00$ & $-3.17 E+00$ & 4.25E-01 & $-4.25 \mathrm{E}-01$ & 7.17E-02 & $-7.17 \mathrm{E}-02$ \\
\hline $3.16 \mathrm{E}-02$ & $-3.16 \mathrm{E}-02$ & 5.27E-01 & $-5.27 \mathrm{E}-01$ & 8.56E-01 & $-8.56 E-01$ & $1.36 \mathrm{E}-01$ & $-1.36 \mathrm{E}-01$ \\
\hline $2.88 \mathrm{E}-02$ & $-2.88 \mathrm{E}-02$ & $1.40 \mathrm{E}-01$ & $-1.40 \mathrm{E}-01$ & $9.08 \mathrm{E}-02$ & $-9.08 \mathrm{E}-02$ & $1.40 \mathrm{E}-02$ & $-1.40 \mathrm{E}-02$ \\
\hline 8.69E-03 & $-8.69 \mathrm{E}-03$ & 1.14E-01 & $-1.14 \mathrm{E}-01$ & $1.14 \mathrm{E}+00$ & $-1.14 \mathrm{E}+00$ & $1.87 \mathrm{E}-02$ & $-1.87 \mathrm{E}-02$ \\
\hline $1.02 \mathrm{E}-02$ & $-1.02 \mathrm{E}-02$ & 3.34E-01 & $-3.34 \mathrm{E}-01$ & 5.06E-02 & $-5.06 E-02$ & $3.58 \mathrm{E}-03$ & $-3.58 \mathrm{E}-03$ \\
\hline 4.20E-02 & $-4.20 \mathrm{E}-02$ & $1.35 \mathrm{E}-01$ & $-1.35 \mathrm{E}-01$ & $1.01 \mathrm{E}+00$ & $-1.01 E+00$ & $5.18 \mathrm{E}-02$ & $-5.18 \mathrm{E}-02$ \\
\hline $9.42 \mathrm{E}-03$ & $-9.42 \mathrm{E}-03$ & $2.12 \mathrm{E}-01$ & $-2.12 \mathrm{E}-01$ & 4.65E-01 & $-4.65 \mathrm{E}-01$ & $1.09 \mathrm{E}-02$ & $-1.09 \mathrm{E}-02$ \\
\hline 8.53E-02 & $-8.53 \mathrm{E}-02$ & 5.00E-01 & $-5.00 \mathrm{E}-01$ & $1.12 \mathrm{E}+00$ & $-1.12 \mathrm{E}+00$ & $7.20 \mathrm{E}-02$ & $-7.20 \mathrm{E}-02$ \\
\hline $6.27 \mathrm{E}-02$ & $-6.27 E-02$ & $1.49 E+00$ & $-1.49 E+00$ & $1.09 \mathrm{E}-01$ & $-1.09 \mathrm{E}-01$ & 1.17E-02 & $-1.17 \mathrm{E}-02$ \\
\hline 2.10E-02 & $-2.10 \mathrm{E}-02$ & $9.80 \mathrm{E}-01$ & $-9.80 \mathrm{E}-01$ & 3.03E-01 & $3 \mathrm{E}-01$ & $2.30 \mathrm{E}-02$ & $-2.30 \mathrm{E}-02$ \\
\hline $1.37 \mathrm{E}-02$ & $-1.37 E-02$ & $5.45 \mathrm{E}-02$ & $-5.45 E-02$ & 6.30E-01 & $-6.30 \mathrm{E}-01$ & 5.11E-02 & $-5.11 \mathrm{E}-02$ \\
\hline $7.16 \mathrm{E}-03$ & $-7.16 \mathrm{E}-03$ & $1.63 \mathrm{E}-02$ & $-1.63 \mathrm{E}-02$ & $7.22 \mathrm{E}-03$ & $-7.22 \mathrm{E}-03$ & 3.91E-02 & $-3.91 \mathrm{E}-02$ \\
\hline $1.23 \mathrm{E}-02$ & $-1.23 \mathrm{E}-02$ & $2.33 \mathrm{E}-02$ & $-2.33 \mathrm{E}-02$ & $5.44 \mathrm{E}-01$ & $-5.44 \mathrm{E}-01$ & $1.63 \mathrm{E}-02$ & $-1.63 \mathrm{E}-02$ \\
\hline $1.34 \mathrm{E}-02$ & $-1.34 \mathrm{E}-02$ & $2.51 \mathrm{E}-02$ & $-2.51 \mathrm{E}-02$ & $4.22 \mathrm{E}-03$ & $-4.22 \mathrm{E}-03$ & 2.98E-03 & $-2.98 \mathrm{E}-03$ \\
\hline $1.46 \mathrm{E}-02$ & $-1.46 \mathrm{E}-02$ & $9.48 \mathrm{E}-03$ & $-9.48 \mathrm{E}-03$ & $1.26 \mathrm{E}-03$ & $-1.26 \mathrm{E}-03$ & 5.31E-03 & $-5.31 \mathrm{E}-03$ \\
\hline 5.77E-03 & $-5.77 E-03$ & $9.62 \mathrm{E}-02$ & $-9.62 E-02$ & $1.04 \mathrm{E}-01$ & $-1.04 \mathrm{E}-01$ & $1.56 \mathrm{E}-02$ & $-1.56 \mathrm{E}-02$ \\
\hline $7.13 \mathrm{E}-03$ & $-7.13 E-03$ & $1.14 \mathrm{E}-02$ & $-1.14 \mathrm{E}-02$ & $1.42 \mathrm{E}-02$ & $-1.42 \mathrm{E}-02$ & $3.58 \mathrm{E}-03$ & $-3.58 \mathrm{E}-03$ \\
\hline $1.17 \mathrm{E}-02$ & $-1.17 E-02$ & $1.41 \mathrm{E}-02$ & $-1.41 E-02$ & $1.71 \mathrm{E}-03$ & $-1.71 \mathrm{E}-03$ & $2.52 \mathrm{E}-03$ & $-2.52 \mathrm{E}-03$ \\
\hline $1.21 \mathrm{E}-02$ & $-1.21 \mathrm{E}-02$ & $2.93 \mathrm{E}-02$ & $-2.93 \mathrm{E}-02$ & $2.78 \mathrm{E}-02$ & $-2.78 \mathrm{E}-02$ & $3.60 \mathrm{E}-02$ & $-3.60 \mathrm{E}-02$ \\
\hline RROR_Period: & $2.08 \mathrm{E}-02$ & & & & & & \\
\hline $6.32 \mathrm{E}-04$ & $-6.32 E-04$ & $4.56 \mathrm{E}-03$ & $-4.56 \mathrm{E}-03$ & 7.64E-03 & $-7.64 \mathrm{E}-03$ & $2.65 \mathrm{E}-03$ & $-2.65 E-03$ \\
\hline \\
\hline
\end{tabular}


APPENDIX IV: 3-D INVERSION DATA FILE

\begin{tabular}{|c|c|c|c|c|c|c|c|}
\hline 4.63E-03 & $-4.63 E-03$ & $1.53 \mathrm{E}-02$ & $-1.53 \mathrm{E}-02$ & $2.76 \mathrm{E}-03$ & $-2.76 \mathrm{E}-03$ & 4.73E-03 & $-4.73 \mathrm{E}-03$ \\
\hline 8.67E-03 & $-8.67 E-03$ & $4.83 \mathrm{E}-03$ & $-4.83 E-03$ & $1.84 \mathrm{E}-03$ & $-1.84 \mathrm{E}-03$ & $2.88 \mathrm{E}-03$ & $-2.88 \mathrm{E}-03$ \\
\hline $1.99 \mathrm{E}-02$ & -1.99E-02 & $1.45 \mathrm{E}-02$ & $-1.45 E-02$ & $1.31 \mathrm{E}-03$ & $-1.31 \mathrm{E}-03$ & $3.48 \mathrm{E}-03$ & $-3.48 E-03$ \\
\hline 3.11E-02 & $-3.11 \mathrm{E}-02$ & $2.25 \mathrm{E}-02$ & $-2.25 \mathrm{E}-02$ & 7.49E-03 & $-7.49 \mathrm{E}-03$ & $2.15 \mathrm{E}-02$ & $-2.15 E-02$ \\
\hline $1.32 \mathrm{E}-02$ & $-1.32 \mathrm{E}-02$ & 1.92E-01 & $-1.92 \mathrm{E}-01$ & $9.15 \mathrm{E}-02$ & $-9.15 E-02$ & $1.55 \mathrm{E}-02$ & $-1.55 E-02$ \\
\hline $1.71 \mathrm{E}-02$ & $-1.71 \mathrm{E}-02$ & $4.96 \mathrm{E}-02$ & $-4.96 \mathrm{E}-02$ & $1.54 \mathrm{E}-01$ & $-1.54 \mathrm{E}-01$ & $1.39 \mathrm{E}-02$ & $-1.39 E-02$ \\
\hline 4.14E-03 & $-4.14 \mathrm{E}-03$ & $1.42 \mathrm{E}-01$ & $-1.42 \mathrm{E}-01$ & $3.25 \mathrm{E}-03$ & $-3.25 E-03$ & $1.14 \mathrm{E}-03$ & $-1.14 \mathrm{E}-03$ \\
\hline $1.33 \mathrm{E}+00$ & $-1.33 E+00$ & $1.27 \mathrm{E}+00$ & $-1.27 E+00$ & 7.00E-01 & $-7.00 \mathrm{E}-01$ & 6.69E-01 & $-6.69 E-01$ \\
\hline $3.41 E+00$ & $-3.41 E+00$ & $3.84 E+00$ & $-3.84 \mathrm{E}+00$ & $1.38 \mathrm{E}+00$ & $-1.38 E+00$ & $6.64 \mathrm{E}+00$ & $-6.64 E+00$ \\
\hline $8.88 \mathrm{E}+00$ & $-8.88 \mathrm{E}+00$ & $4.81 E+00$ & $-4.81 E+00$ & $3.62 E+00$ & $-3.62 E+00$ & $2.89 E+00$ & $-2.89 E+00$ \\
\hline 4.50E-03 & $-4.50 \mathrm{E}-03$ & $5.60 \mathrm{E}-02$ & $-5.60 \mathrm{E}-02$ & $9.29 \mathrm{E}-03$ & $-9.29 E-03$ & 3.33E-03 & $-3.33 E-03$ \\
\hline $2.59 \mathrm{E}-01$ & $-2.59 \mathrm{E}-01$ & $1.98 \mathrm{E}-01$ & $-1.98 \mathrm{E}-01$ & 7.40E-02 & $-7.40 \mathrm{E}-02$ & 9.97E-02 & $-9.97 \mathrm{E}-02$ \\
\hline $9.63 \mathrm{E}-03$ & $-9.63 \mathrm{E}-03$ & 7.43E-02 & $-7.43 \mathrm{E}-02$ & $2.12 \mathrm{E}-02$ & $-2.12 \mathrm{E}-02$ & $5.81 \mathrm{E}-03$ & $-5.81 \mathrm{E}-03$ \\
\hline $2.78 \mathrm{E}-01$ & $-2.78 \mathrm{E}-01$ & $2.96 \mathrm{E}+00$ & $-2.96 E+00$ & $5.91 \mathrm{E}+00$ & $-5.91 E+00$ & 4.09E-01 & $-2.66 \mathrm{E}-01$ \\
\hline 3.73E-01 & $-3.73 E-01$ & $4.07 E+00$ & $-4.07 E+00$ & $2.82 \mathrm{E}+00$ & $-2.82 E+00$ & $2.66 \mathrm{E}-01$ & $-2.66 \mathrm{E}-01$ \\
\hline $1.90 \mathrm{E}-01$ & $-1.90 \mathrm{E}-01$ & $2.70 \mathrm{E}-01$ & $-2.70 \mathrm{E}-01$ & $2.83 \mathrm{E}-01$ & $-2.83 \mathrm{E}-01$ & $3.83 \mathrm{E}-01$ & $-3.83 \mathrm{E}-01$ \\
\hline $1.58 \mathrm{E}-01$ & $-1.58 \mathrm{E}-01$ & 1.31E-01 & $-1.31 \mathrm{E}-01$ & 3.68E-01 & $-3.68 \mathrm{E}-01$ & $2.94 \mathrm{E}-01$ & $-2.94 \mathrm{E}-01$ \\
\hline $5.33 E+00$ & $-5.33 E+00$ & $7.31 \mathrm{E}+00$ & $-7.31 E+00$ & $1.22 \mathrm{E}+00$ & $-1.22 \mathrm{E}+00$ & $1.69 \mathrm{E}+00$ & $-1.69 E+00$ \\
\hline $8.14 \mathrm{E}-01$ & $-8.14 \mathrm{E}-01$ & $1.30 \mathrm{E}+00$ & $-1.30 E+00$ & $2.07 E+00$ & $-2.07 E+00$ & $3.25 \mathrm{E}+00$ & $-3.25 E+00$ \\
\hline $3.93 \mathrm{E}-03$ & $-3.93 \mathrm{E}-03$ & 4.56E-03 & $-4.56 \mathrm{E}-03$ & $2.72 \mathrm{E}-03$ & $-2.72 \mathrm{E}-03$ & $2.50 \mathrm{E}-03$ & $-2.50 \mathrm{E}-03$ \\
\hline $5.68 \mathrm{E}-02$ & $-5.68 \mathrm{E}-02$ & $1.08 \mathrm{E}-01$ & $-1.08 \mathrm{E}-01$ & $6.85 \mathrm{E}-01$ & $-6.85 E-01$ & $1.89 \mathrm{E}-01$ & $-1.89 E-01$ \\
\hline 1.19E-03 & $-1.19 E-03$ & $2.60 \mathrm{E}-02$ & $-2.60 \mathrm{E}-02$ & $5.42 \mathrm{E}-03$ & $-5.42 E-03$ & $3.08 \mathrm{E}-04$ & $-3.08 \mathrm{E}-04$ \\
\hline $9.42 \mathrm{E}-03$ & $-9.42 E-03$ & 4.64E-02 & $-4.64 \mathrm{E}-02$ & $2.27 \mathrm{E}-01$ & $-2.27 \mathrm{E}-01$ & 1.79E-02 & $-1.79 E-02$ \\
\hline 8.71E-02 & $-8.71 E-02$ & $2.28 \mathrm{E}-01$ & $-2.28 \mathrm{E}-01$ & 4.25E-01 & $-4.25 \mathrm{E}-01$ & $1.16 \mathrm{E}-01$ & $-1.16 \mathrm{E}-01$ \\
\hline $5.45 E+00$ & $-5.45 E+00$ & $3.26 \mathrm{E}+00$ & $-3.26 E+00$ & $7.17 E+00$ & $-7.17 \mathrm{E}+00$ & $4.71 E+00$ & $-4.71 E+00$ \\
\hline $1.52 \mathrm{E}-02$ & $-1.52 E-02$ & $6.31 \mathrm{E}-02$ & $-6.31 E-02$ & $1.23 \mathrm{E}-02$ & $-1.23 \mathrm{E}-02$ & $1.68 \mathrm{E}-03$ & $-1.68 \mathrm{E}-03$ \\
\hline $3.49 \mathrm{E}-03$ & $-3.49 E-03$ & $1.86 \mathrm{E}-02$ & $-1.86 \mathrm{E}-02$ & 4.71E-03 & $-4.71 E-03$ & 4.20E-03 & $-4.20 \mathrm{E}-03$ \\
\hline $2.11 \mathrm{E}-03$ & $-2.11 \mathrm{E}-03$ & $1.44 \mathrm{E}-02$ & $-1.44 \mathrm{E}-02$ & $9.82 \mathrm{E}-02$ & $-9.82 E-02$ & $1.21 \mathrm{E}-02$ & $-1.21 \mathrm{E}-02$ \\
\hline 1.99E-03 & -1.99E-03 & $8.98 \mathrm{E}-04$ & $-8.98 \mathrm{E}-04$ & 4.17E-04 & $-4.17 \mathrm{E}-04$ & 1.05E-02 & $-1.05 E-02$ \\
\hline $1.54 \mathrm{E}-03$ & $-1.54 \mathrm{E}-03$ & 8.16E-04 & $-8.16 \mathrm{E}-04$ & $1.54 \mathrm{E}-02$ & $-1.54 \mathrm{E}-02$ & $3.29 E-03$ & $-3.29 E-03$ \\
\hline $2.57 \mathrm{E}-03$ & $-2.57 \mathrm{E}-03$ & 4.39E-03 & $-4.39 \mathrm{E}-03$ & $8.20 \mathrm{E}-04$ & $-8.20 \mathrm{E}-04$ & $5.75 \mathrm{E}-04$ & $-5.75 E-04$ \\
\hline $3.10 \mathrm{E}-03$ & $-3.10 \mathrm{E}-03$ & $1.81 \mathrm{E}-03$ & $-1.81 \mathrm{E}-03$ & $2.96 \mathrm{E}-04$ & $-2.96 \mathrm{E}-04$ & $1.01 \mathrm{E}-03$ & $-1.01 \mathrm{E}-03$ \\
\hline 7.99E-04 & -7.99E-04 & 2.67E-03 & $-2.67 \mathrm{E}-03$ & 2.69E-03 & $-2.69 \mathrm{E}-03$ & $2.25 \mathrm{E}-03$ & $-2.25 \mathrm{E}-03$ \\
\hline $1.18 \mathrm{E}-03$ & $-1.18 \mathrm{E}-03$ & $2.23 \mathrm{E}-03$ & $-2.23 E-03$ & $2.61 \mathrm{E}-03$ & $-2.61 \mathrm{E}-03$ & $1.46 \mathrm{E}-03$ & $-1.46 \mathrm{E}-03$ \\
\hline $2.15 \mathrm{E}-03$ & $-2.15 \mathrm{E}-03$ & $2.36 \mathrm{E}-03$ & $-2.36 \mathrm{E}-03$ & $3.98 \mathrm{E}-04$ & $-3.98 \mathrm{E}-04$ & 4.69E-04 & $-4.69 \mathrm{E}-04$ \\
\hline $2.26 \mathrm{E}-03$ & $-2.26 \mathrm{E}-03$ & $6.58 \mathrm{E}-03$ & $-6.58 \mathrm{E}-03$ & $5.06 \mathrm{E}-03$ & $-5.06 E-03$ & 8.00E-03 & $-8.00 \mathrm{E}-03$ \\
\hline OR_Period: & 4.17E-02 & & & & & & \\
\hline $3.15 E-04$ & $-3.15 E-04$ & $2.84 \mathrm{E}-04$ & $-2.84 \mathrm{E}-04$ & 8.70E-04 & $-8.70 \mathrm{E}-04$ & 8.60E-04 & $-8.60 \mathrm{E}-04$ \\
\hline $2.24 \mathrm{E}-03$ & $-2.24 \mathrm{E}-03$ & 6.99E-03 & $-6.99 E-03$ & $1.32 \mathrm{E}-03$ & $-1.32 \mathrm{E}-03$ & 2.19E-03 & $-2.19 E-03$ \\
\hline 3.01E-03 & $-3.01 E-03$ & 1.79E-03 & -1.79E-03 & $6.74 \mathrm{E}-04$ & $-6.74 \mathrm{E}-04$ & $1.04 \mathrm{E}-03$ & -1.04E-03 \\
\hline 7.29E-03 & $-7.29 E-03$ & $5.36 \mathrm{E}-03$ & $-5.36 \mathrm{E}-03$ & $5.28 \mathrm{E}-04$ & $-5.28 \mathrm{E}-04$ & $1.30 \mathrm{E}-03$ & $-1.30 \mathrm{E}-03$ \\
\hline \multirow[t]{2}{*}{$9.51 \mathrm{E}-03$} & $-9.51 E-03$ & $3.69 \mathrm{E}-03$ & $-3.69 \mathrm{E}-03$ & $1.72 \mathrm{E}-03$ & $-1.72 \mathrm{E}-03$ & $3.99 \mathrm{E}-03$ & $-3.99 E-03$ \\
\hline & & & & & & & \\
\hline
\end{tabular}


APPENDIX IV: 3-D INVERSION DATA FILE

\begin{tabular}{|c|c|c|c|c|c|c|c|}
\hline $1.84 \mathrm{E}-03$ & $-1.84 \mathrm{E}-03$ & 4.51E-03 & $-4.51 E-03$ & 1.37E-03 & $-1.37 \mathrm{E}-03$ & 4.27E-03 & $-4.27 E-03$ \\
\hline $8.28 \mathrm{E}-03$ & $-8.28 \mathrm{E}-03$ & 4.75E-03 & $-4.75 E-03$ & $1.47 \mathrm{E}-02$ & $-1.47 \mathrm{E}-02$ & $6.22 \mathrm{E}-03$ & $-6.22 E-03$ \\
\hline 1.70E-03 & $-1.70 \mathrm{E}-03$ & 5.81E-03 & $-5.81 E-03$ & $2.62 \mathrm{E}-04$ & $-2.62 \mathrm{E}-04$ & $2.55 \mathrm{E}-04$ & $-2.55 E-04$ \\
\hline $1.33 \mathrm{E}-02$ & $-1.33 \mathrm{E}-02$ & $6.36 \mathrm{E}-02$ & $-6.36 \mathrm{E}-02$ & $3.50 \mathrm{E}-02$ & $-3.50 \mathrm{E}-02$ & $6.69 \mathrm{E}-03$ & $-6.69 \mathrm{E}-03$ \\
\hline $2.61 \mathrm{E}-03$ & $-2.61 \mathrm{E}-03$ & $3.39 \mathrm{E}-03$ & $-3.39 E-03$ & $1.05 \mathrm{E}-03$ & $-1.05 E-03$ & $5.96 \mathrm{E}-03$ & $-5.96 E-03$ \\
\hline 4.94E-01 & $-4.94 \mathrm{E}-01$ & $2.42 \mathrm{E}-02$ & $-2.42 \mathrm{E}-02$ & $1.84 \mathrm{E}-02$ & $-1.84 \mathrm{E}-02$ & $2.96 \mathrm{E}-03$ & $-2.96 \mathrm{E}-03$ \\
\hline $2.48 \mathrm{E}-03$ & $-2.48 \mathrm{E}-03$ & $2.18 \mathrm{E}-02$ & $-2.18 \mathrm{E}-02$ & 4.71E-03 & $-4.71 \mathrm{E}-03$ & $1.36 \mathrm{E}-03$ & $-1.36 \mathrm{E}-03$ \\
\hline 2.59E-01 & $-2.59 \mathrm{E}-01$ & $1.98 \mathrm{E}-01$ & $-1.98 \mathrm{E}-01$ & $7.40 \mathrm{E}-02$ & $-7.40 \mathrm{E}-02$ & $9.97 \mathrm{E}-02$ & $-9.97 \mathrm{E}-02$ \\
\hline $2.88 \mathrm{E}-03$ & $-2.88 \mathrm{E}-03$ & $2.23 \mathrm{E}-02$ & $-2.23 \mathrm{E}-02$ & $6.21 \mathrm{E}-03$ & $-6.21 \mathrm{E}-03$ & $1.71 \mathrm{E}-03$ & $-1.71 E-03$ \\
\hline $6.50 \mathrm{E}-02$ & $-6.50 \mathrm{E}-02$ & $5.48 \mathrm{E}-01$ & $-5.48 \mathrm{E}-01$ & $5.74 \mathrm{E}-01$ & $-5.74 \mathrm{E}-01$ & $1.61 \mathrm{E}-01$ & $-1.61 \mathrm{E}-01$ \\
\hline 7.50E-02 & $-7.50 \mathrm{E}-02$ & $4.62 \mathrm{E}-01$ & $-4.62 \mathrm{E}-01$ & $2.73 \mathrm{E}-01$ & $-2.73 \mathrm{E}-01$ & $5.93 \mathrm{E}-02$ & $-5.93 \mathrm{E}-02$ \\
\hline 4.00E-03 & $-4.00 \mathrm{E}-03$ & 4.27E-03 & $-4.27 E-03$ & 5.90E-03 & $-5.90 \mathrm{E}-03$ & $6.01 \mathrm{E}-03$ & $-6.01 E-03$ \\
\hline 2.53E-03 & $-2.53 \mathrm{E}-03$ & $1.85 \mathrm{E}-03$ & $-1.85 E-03$ & $5.43 \mathrm{E}-03$ & $-5.43 E-03$ & $3.66 \mathrm{E}-03$ & $-3.66 \mathrm{E}-03$ \\
\hline $7.29 \mathrm{E}-03$ & $-7.29 \mathrm{E}-03$ & $7.58 \mathrm{E}-02$ & $-7.58 \mathrm{E}-02$ & $8.01 \mathrm{E}-03$ & $-8.01 \mathrm{E}-03$ & $3.43 \mathrm{E}-03$ & $-3.43 E-03$ \\
\hline 3.84E-01 & $-3.84 \mathrm{E}-01$ & 3.86E-01 & $-3.86 \mathrm{E}-01$ & $9.35 \mathrm{E}-01$ & $-9.35 \mathrm{E}-01$ & $9.12 \mathrm{E}-01$ & $-9.12 E-01$ \\
\hline $1.45 \mathrm{E}-03$ & $-1.45 \mathrm{E}-03$ & 2.29E-03 & $-2.29 \mathrm{E}-03$ & 1.17E-03 & $-1.17 \mathrm{E}-03$ & $1.36 \mathrm{E}-03$ & $-1.36 \mathrm{E}-03$ \\
\hline 7.33E-04 & $-7.33 \mathrm{E}-04$ & $1.41 \mathrm{E}-03$ & $-1.41 \mathrm{E}-03$ & $8.14 \mathrm{E}-03$ & $-8.14 \mathrm{E}-03$ & $2.69 \mathrm{E}-03$ & $-2.69 \mathrm{E}-03$ \\
\hline 8.76E-03 & $-8.76 \mathrm{E}-03$ & 1.64E-02 & $-1.64 \mathrm{E}-02$ & $3.89 \mathrm{E}-03$ & $-3.89 \mathrm{E}-03$ & $2.43 \mathrm{E}-03$ & $-2.43 E-03$ \\
\hline $6.32 \mathrm{E}-03$ & $-6.32 \mathrm{E}-03$ & $2.72 \mathrm{E}-02$ & $-2.72 \mathrm{E}-02$ & $1.55 \mathrm{E}-01$ & $-1.55 \mathrm{E}-01$ & $1.04 \mathrm{E}-02$ & $-1.04 \mathrm{E}-02$ \\
\hline $1.11 \mathrm{E}-03$ & $-1.11 \mathrm{E}-03$ & $2.91 \mathrm{E}-03$ & $-2.91 \mathrm{E}-03$ & $5.20 \mathrm{E}-03$ & $-5.20 \mathrm{E}-03$ & $1.53 \mathrm{E}-03$ & $-1.53 \mathrm{E}-03$ \\
\hline 3.49E-03 & $-3.49 \mathrm{E}-03$ & $2.35 \mathrm{E}-03$ & $-2.35 E-03$ & $4.65 \mathrm{E}-03$ & $-4.65 \mathrm{E}-03$ & $3.42 \mathrm{E}-03$ & $-3.42 E-03$ \\
\hline 4.97E-03 & $-4.97 \mathrm{E}-03$ & 2.11E-02 & $-2.11 E-02$ & $3.66 \mathrm{E}-03$ & $-3.66 \mathrm{E}-03$ & 5.15E-04 & $-5.15 E-04$ \\
\hline $1.03 \mathrm{E}-03$ & $-1.03 \mathrm{E}-03$ & $3.66 \mathrm{E}-03$ & $-3.66 \mathrm{E}-03$ & $1.25 \mathrm{E}-03$ & $-1.25 \mathrm{E}-03$ & 8.94E-04 & $-8.94 \mathrm{E}-04$ \\
\hline 4.17E-04 & $-4.17 \mathrm{E}-04$ & 4.44E-03 & $-4.44 \mathrm{E}-03$ & $1.99 \mathrm{E}-02$ & $-1.99 E-02$ & $3.56 \mathrm{E}-03$ & $-3.56 \mathrm{E}-03$ \\
\hline $6.43 \mathrm{E}-04$ & $-6.43 E-04$ & 2.47E-04 & $-2.47 \mathrm{E}-04$ & $1.28 \mathrm{E}-04$ & $-1.28 \mathrm{E}-04$ & $2.93 \mathrm{E}-03$ & $-2.93 E-03$ \\
\hline 5.70E-04 & $-5.70 \mathrm{E}-04$ & 2.14E-04 & $-2.14 \mathrm{E}-04$ & $6.10 \mathrm{E}-03$ & $-6.10 \mathrm{E}-03$ & $9.38 \mathrm{E}-04$ & $-9.38 E-04$ \\
\hline $4.81 \mathrm{E}-04$ & $-4.81 \mathrm{E}-04$ & $1.08 \mathrm{E}-03$ & $-1.08 \mathrm{E}-03$ & $1.85 \mathrm{E}-04$ & $-1.85 \mathrm{E}-04$ & $1.81 \mathrm{E}-04$ & $-1.81 E-04$ \\
\hline $9.25 \mathrm{E}-04$ & $-9.25 \mathrm{E}-04$ & 4.51E-04 & $-4.51 E-04$ & $8.66 \mathrm{E}-05$ & $-8.66 \mathrm{E}-05$ & $2.52 \mathrm{E}-04$ & $-2.52 E-04$ \\
\hline 2.64E-04 & $-2.64 \mathrm{E}-04$ & 7.75E-04 & $-7.75 E-04$ & $9.13 \mathrm{E}-04$ & $-9.13 E-04$ & $6.60 \mathrm{E}-04$ & $-6.60 \mathrm{E}-04$ \\
\hline $3.28 \mathrm{E}-04$ & $-3.28 \mathrm{E}-04$ & $5.52 \mathrm{E}-04$ & $-5.52 E-04$ & $6.44 \mathrm{E}-04$ & $-6.44 \mathrm{E}-04$ & $1.93 \mathrm{E}-04$ & $-1.93 E-04$ \\
\hline 4.83E-04 & $-4.83 E-04$ & 5.53E-04 & $-5.53 E-04$ & $9.24 \mathrm{E}-05$ & $-9.24 \mathrm{E}-05$ & $1.12 \mathrm{E}-04$ & $-1.12 E-04$ \\
\hline $6.72 \mathrm{E}-04$ & $-6.72 \mathrm{E}-04$ & $2.06 \mathrm{E}-03$ & $-2.06 \mathrm{E}-03$ & $1.49 \mathrm{E}-03$ & $-1.49 \mathrm{E}-03$ & $2.52 \mathrm{E}-03$ & $-2.52 \mathrm{E}-03$ \\
\hline OR_Period: & $1.11 \mathrm{E}-01$ & & & & & & \\
\hline $4.26 \mathrm{E}-03$ & $-4.26 \mathrm{E}-03$ & $3.43 \mathrm{E}-03$ & $-3.43 E-03$ & $1.32 \mathrm{E}-02$ & $-1.32 \mathrm{E}-02$ & $1.20 \mathrm{E}-02$ & $-1.20 \mathrm{E}-02$ \\
\hline $6.15 \mathrm{E}-04$ & $-6.15 E-04$ & $1.43 \mathrm{E}-03$ & $-1.43 E-03$ & $3.44 \mathrm{E}-04$ & $-3.44 \mathrm{E}-04$ & $5.09 \mathrm{E}-04$ & $-5.09 E-04$ \\
\hline 1.11E-03 & $-1.11 \mathrm{E}-03$ & 7.88E-04 & $-7.88 \mathrm{E}-04$ & $3.10 \mathrm{E}-04$ & $-3.10 \mathrm{E}-04$ & 4.30E-04 & $-4.30 \mathrm{E}-04$ \\
\hline $8.21 \mathrm{E}-02$ & $-8.21 \mathrm{E}-02$ & $6.26 \mathrm{E}-02$ & $-6.26 \mathrm{E}-02$ & $4.29 \mathrm{E}-03$ & $-4.29 \mathrm{E}-03$ & $1.50 \mathrm{E}-02$ & $-1.50 \mathrm{E}-02$ \\
\hline $2.49 \mathrm{E}-03$ & $-2.49 \mathrm{E}-03$ & $1.51 \mathrm{E}-03$ & $-1.51 E-03$ & $6.96 \mathrm{E}-04$ & $-6.96 \mathrm{E}-04$ & 1.19E-03 & $-1.19 E-03$ \\
\hline 7.40E-04 & $-7.40 \mathrm{E}-04$ & $1.22 \mathrm{E}-03$ & $-1.22 \mathrm{E}-03$ & $5.44 \mathrm{E}-04$ & $-5.44 \mathrm{E}-04$ & 1.10E-03 & $-1.10 \mathrm{E}-03$ \\
\hline 2.73E-03 & $-2.73 E-03$ & $1.32 \mathrm{E}-03$ & $-1.32 \mathrm{E}-03$ & $4.91 \mathrm{E}-03$ & $-4.91 \mathrm{E}-03$ & $1.81 \mathrm{E}-03$ & $-1.81 \mathrm{E}-03$ \\
\hline $1.42 \mathrm{E}-03$ & $-1.42 \mathrm{E}-03$ & $1.52 \mathrm{E}-02$ & $-1.52 \mathrm{E}-02$ & $1.15 \mathrm{E}-03$ & $-1.15 \mathrm{E}-03$ & $2.85 \mathrm{E}-04$ & $-2.85 E-04$ \\
\hline $3.68 \mathrm{E}-02$ & $-3.68 \mathrm{E}-02$ & $1.89 \mathrm{E}-01$ & $-1.89 \mathrm{E}-01$ & $9.83 \mathrm{E}-02$ & $-9.83 E-02$ & $2.01 \mathrm{E}-02$ & $-2.01 \mathrm{E}-02$ \\
\hline
\end{tabular}


APPENDIX IV: 3-D INVERSION DATA FILE

\begin{tabular}{|c|c|c|c|c|c|c|c|}
\hline 1.00E-03 & $-1.00 \mathrm{E}-03$ & 1.07E-03 & -1.07E-03 & 4.50E-04 & $-4.50 \mathrm{E}-04$ & $1.34 \mathrm{E}-03$ & $-1.34 \mathrm{E}-03$ \\
\hline $2.02 \mathrm{E}-03$ & $-2.02 \mathrm{E}-03$ & $1.78 \mathrm{E}-03$ & $-1.78 \mathrm{E}-03$ & 1.07E-03 & $-1.07 \mathrm{E}-03$ & $1.12 \mathrm{E}-03$ & $-1.12 \mathrm{E}-03$ \\
\hline 2.69E-01 & $-2.69 \mathrm{E}-01$ & 3.79E-01 & $-3.79 E-01$ & $9.58 \mathrm{E}-02$ & $-9.58 E-02$ & $1.22 \mathrm{E}-01$ & $-1.22 \mathrm{E}-01$ \\
\hline 2.19E-03 & $-2.19 \mathrm{E}-03$ & $1.92 \mathrm{E}-03$ & $-1.92 \mathrm{E}-03$ & 7.16E-04 & $-7.16 \mathrm{E}-04$ & $9.16 \mathrm{E}-04$ & $-9.16 \mathrm{E}-04$ \\
\hline $1.78 \mathrm{E}-03$ & $-1.78 \mathrm{E}-03$ & $2.13 \mathrm{E}-03$ & $-2.13 E-03$ & 7.93E-04 & $-7.93 \mathrm{E}-04$ & $8.92 \mathrm{E}-04$ & $-8.92 \mathrm{E}-04$ \\
\hline $1.15 \mathrm{E}-01$ & $-1.15 \mathrm{E}-01$ & 2.51E-01 & $-2.51 \mathrm{E}-01$ & $1.69 \mathrm{E}+00$ & $-1.69 E+00$ & $3.47 \mathrm{E}-01$ & $-3.47 E-01$ \\
\hline $1.52 E+00$ & $-1.52 E+00$ & $1.71 \mathrm{E}+00$ & $-1.71 E+00$ & $1.13 \mathrm{E}+00$ & $-1.13 E+00$ & $1.13 \mathrm{E}+00$ & $-1.13 E+00$ \\
\hline $1.12 \mathrm{E}-02$ & $-1.12 \mathrm{E}-02$ & $1.64 \mathrm{E}-02$ & $-1.64 \mathrm{E}-02$ & $1.82 \mathrm{E}-02$ & $-1.82 \mathrm{E}-02$ & $2.36 \mathrm{E}-02$ & $-2.36 \mathrm{E}-02$ \\
\hline $2.47 \mathrm{E}-02$ & $-2.47 \mathrm{E}-02$ & 1.91E-02 & $-1.91 E-02$ & 7.13E-02 & $-7.13 E-02$ & $5.32 \mathrm{E}-02$ & $-5.32 E-02$ \\
\hline $9.51 \mathrm{E}-02$ & $-9.51 E-02$ & $3.18 \mathrm{E}-01$ & $-3.18 \mathrm{E}-01$ & $1.92 \mathrm{E}-02$ & $-1.92 \mathrm{E}-02$ & 7.07E-02 & -7.07E-02 \\
\hline $2.63 \mathrm{E}-01$ & $-2.63 \mathrm{E}-01$ & 2.81E-01 & $-2.81 \mathrm{E}-01$ & $6.40 \mathrm{E}-01$ & $-6.40 \mathrm{E}-01$ & $6.73 \mathrm{E}-01$ & $-6.73 E-01$ \\
\hline $1.58 \mathrm{E}-02$ & $-1.58 \mathrm{E}-02$ & $2.16 \mathrm{E}-02$ & $-2.16 \mathrm{E}-02$ & $8.55 \mathrm{E}-03$ & $-8.55 E-03$ & $8.28 \mathrm{E}-03$ & $-8.28 \mathrm{E}-03$ \\
\hline 2.79E-04 & $-2.79 \mathrm{E}-04$ & 4.16E-04 & $-4.16 \mathrm{E}-04$ & 2.09E-03 & $-2.09 \mathrm{E}-03$ & 8.66E-04 & $-8.66 \mathrm{E}-04$ \\
\hline $1.82 \mathrm{E}-04$ & $-1.82 \mathrm{E}-04$ & 5.70E-04 & $-5.70 \mathrm{E}-04$ & $8.14 \mathrm{E}-05$ & $-8.14 \mathrm{E}-05$ & $6.16 \mathrm{E}-05$ & $-6.16 \mathrm{E}-05$ \\
\hline 8.87E-03 & $-8.87 \mathrm{E}-03$ & $6.68 \mathrm{E}-03$ & $-6.68 \mathrm{E}-03$ & $2.13 \mathrm{E}-02$ & $-2.13 \mathrm{E}-02$ & $2.73 \mathrm{E}-02$ & $-2.73 \mathrm{E}-02$ \\
\hline $4.42 \mathrm{E}-04$ & $-4.42 \mathrm{E}-04$ & $1.21 \mathrm{E}-03$ & $-1.21 \mathrm{E}-03$ & $1.81 \mathrm{E}-03$ & $-1.81 \mathrm{E}-03$ & 7.02E-04 & $-7.02 E-04$ \\
\hline $1.16 \mathrm{E}-03$ & $-1.16 \mathrm{E}-03$ & 1.13E-03 & $-1.13 E-03$ & $1.62 \mathrm{E}-03$ & $-1.62 \mathrm{E}-03$ & $1.66 \mathrm{E}-03$ & $-1.66 \mathrm{E}-03$ \\
\hline $3.53 \mathrm{E}-03$ & $-3.53 \mathrm{E}-03$ & $2.22 \mathrm{E}-02$ & $-2.22 \mathrm{E}-02$ & 3.99E-03 & $-3.99 E-03$ & $9.62 \mathrm{E}-04$ & $-9.62 E-04$ \\
\hline $7.08 \mathrm{E}-04$ & $-7.08 \mathrm{E}-04$ & 1.07E-03 & -1.07E-03 & 4.86E-04 & $-4.86 \mathrm{E}-04$ & $2.92 \mathrm{E}-04$ & $-2.92 E-04$ \\
\hline $6.71 \mathrm{E}-04$ & $-6.71 E-04$ & $1.49 \mathrm{E}-03$ & $-1.49 \mathrm{E}-03$ & 4.04E-03 & $-4.04 \mathrm{E}-03$ & 4.73E-03 & $-4.73 E-03$ \\
\hline 2.04E-04 & $-2.04 \mathrm{E}-04$ & 8.84E-05 & $-8.84 \mathrm{E}-05$ & 7.13E-05 & $-7.13 E-05$ & 7.98E-04 & $-7.98 \mathrm{E}-04$ \\
\hline $6.71 \mathrm{E}-04$ & $-6.71 E-04$ & 4.79E-04 & $-4.79 E-04$ & $1.52 \mathrm{E}-03$ & $-1.52 \mathrm{E}-03$ & $6.40 \mathrm{E}-04$ & $-6.40 \mathrm{E}-04$ \\
\hline $1.73 \mathrm{E}-04$ & $-1.73 \mathrm{E}-04$ & 2.97E-04 & $-2.97 \mathrm{E}-04$ & $8.15 \mathrm{E}-05$ & $-8.15 E-05$ & 8.47E-05 & $-8.47 \mathrm{E}-05$ \\
\hline 2.19E-04 & $-2.19 \mathrm{E}-04$ & $9.61 \mathrm{E}-05$ & $-9.61 E-05$ & $2.75 \mathrm{E}-05$ & $-2.75 E-05$ & 5.97E-05 & $-5.97 E-05$ \\
\hline 1.69E-04 & -1.69E-04 & 3.40E-04 & $-3.40 \mathrm{E}-04$ & 4.11E-04 & $-4.11 E-04$ & 3.50E-04 & $-3.50 E-04$ \\
\hline $1.06 \mathrm{E}-04$ & $-1.06 \mathrm{E}-04$ & $2.35 \mathrm{E}-04$ & $-2.35 \mathrm{E}-04$ & $1.75 \mathrm{E}-04$ & $-1.75 E-04$ & $1.58 \mathrm{E}-04$ & $-1.58 \mathrm{E}-04$ \\
\hline $1.46 \mathrm{E}-04$ & $-1.46 \mathrm{E}-04$ & $1.38 \mathrm{E}-04$ & $-1.38 \mathrm{E}-04$ & $3.79 \mathrm{E}-05$ & $-3.79 E-05$ & $3.16 \mathrm{E}-05$ & $-3.16 \mathrm{E}-05$ \\
\hline $2.23 \mathrm{E}-04$ & $-2.23 \mathrm{E}-04$ & 7.36E-04 & $-7.36 \mathrm{E}-04$ & $4.81 \mathrm{E}-04$ & $-4.81 \mathrm{E}-04$ & $9.18 \mathrm{E}-04$ & $-9.18 \mathrm{E}-04$ \\
\hline Period: & $2.22 \mathrm{E}-01$ & & & & & & \\
\hline $3.00 \mathrm{E}-05$ & $-3.00 \mathrm{E}-05$ & $2.66 \mathrm{E}-05$ & $-2.66 \mathrm{E}-05$ & $9.30 \mathrm{E}-05$ & $-9.30 \mathrm{E}-05$ & $9.31 \mathrm{E}-05$ & $-9.31 \mathrm{E}-05$ \\
\hline $1.09 \mathrm{E}-04$ & $-1.09 \mathrm{E}-04$ & 4.70E-04 & $-4.70 \mathrm{E}-04$ & $6.62 \mathrm{E}-05$ & $-6.62 E-05$ & $1.39 \mathrm{E}-04$ & $-1.39 E-04$ \\
\hline $3.44 \mathrm{E}-04$ & $-3.44 \mathrm{E}-04$ & $1.98 \mathrm{E}-04$ & $-1.98 \mathrm{E}-04$ & $5.68 \mathrm{E}-05$ & $-5.68 E-05$ & $1.26 \mathrm{E}-04$ & $-1.26 \mathrm{E}-04$ \\
\hline $6.12 \mathrm{E}-04$ & $-6.12 \mathrm{E}-04$ & 4.14E-04 & $-4.14 \mathrm{E}-04$ & 3.36E-05 & $-3.36 \mathrm{E}-05$ & $9.90 \mathrm{E}-05$ & $-9.90 \mathrm{E}-05$ \\
\hline $9.01 E-04$ & $-9.01 E-04$ & 2.67E-04 & $-2.67 \mathrm{E}-04$ & $1.30 \mathrm{E}-04$ & $-1.30 \mathrm{E}-04$ & $3.13 \mathrm{E}-04$ & $-3.13 E-04$ \\
\hline 1.97E-04 & $-1.97 \mathrm{E}-04$ & $3.28 \mathrm{E}-04$ & $-3.28 \mathrm{E}-04$ & 1.49E-04 & $-1.49 E-04$ & 3.16E-04 & $-3.16 \mathrm{E}-04$ \\
\hline $1.14 \mathrm{E}-03$ & $-1.14 \mathrm{E}-03$ & 5.29E-04 & $-5.29 \mathrm{E}-04$ & 2.01E-03 & $-2.01 E-03$ & $6.49 \mathrm{E}-04$ & $-6.49 E-04$ \\
\hline $7.93 E-05$ & $-7.93 E-05$ & $3.62 \mathrm{E}-04$ & $-3.62 E-04$ & $1.29 \mathrm{E}-05$ & $-1.29 E-05$ & $1.36 \mathrm{E}-05$ & $-1.36 \mathrm{E}-05$ \\
\hline $2.02 \mathrm{E}-04$ & $-2.02 E-04$ & $5.24 \mathrm{E}-04$ & $-5.24 \mathrm{E}-04$ & $9.83 \mathrm{E}-05$ & $-9.83 E-05$ & $2.41 \mathrm{E}-04$ & $-2.41 \mathrm{E}-04$ \\
\hline 8.55E-05 & $-8.55 E-05$ & $1.11 \mathrm{E}-04$ & $-1.11 \mathrm{E}-04$ & $1.95 \mathrm{E}-05$ & $-1.95 \mathrm{E}-05$ & $2.92 \mathrm{E}-04$ & $-2.92 \mathrm{E}-04$ \\
\hline $4.95 \mathrm{E}-04$ & $-4.95 E-04$ & 2.70E-04 & $-2.70 \mathrm{E}-04$ & $1.82 \mathrm{E}-04$ & $-1.82 \mathrm{E}-04$ & $1.56 \mathrm{E}-04$ & $-1.56 \mathrm{E}-04$ \\
\hline $5.38 \mathrm{E}-05$ & $-5.38 \mathrm{E}-05$ & 2.00E-04 & $-2.00 \mathrm{E}-04$ & 3.00E-05 & $-3.00 \mathrm{E}-05$ & $5.60 \mathrm{E}-05$ & $-5.60 \mathrm{E}-05$ \\
\hline 1.47E-04 & $-1.47 \mathrm{E}-04$ & 6.92E-05 & $-6.92 \mathrm{E}-05$ & 1.39E-05 & $-1.39 \mathrm{E}-05$ & $5.29 \mathrm{E}-05$ & $-5.29 E-05$ \\
\hline
\end{tabular}


APPENDIX IV: 3-D INVERSION DATA FILE

\begin{tabular}{|c|c|c|c|c|c|c|c|}
\hline 1.47E-04 & $-1.47 \mathrm{E}-04$ & $2.96 \mathrm{E}-04$ & $-2.96 \mathrm{E}-04$ & $5.65 \mathrm{E}-05$ & $-5.65 \mathrm{E}-05$ & $9.84 \mathrm{E}-05$ & $-9.84 \mathrm{E}-05$ \\
\hline $8.12 \mathrm{E}-04$ & $-8.12 \mathrm{E}-04$ & 1.67E-03 & $-1.67 \mathrm{E}-03$ & 1.17E-02 & $-1.17 \mathrm{E}-02$ & $2.42 \mathrm{E}-03$ & $-2.42 \mathrm{E}-03$ \\
\hline $9.74 \mathrm{E}-02$ & $-9.74 \mathrm{E}-02$ & $1.04 \mathrm{E}-01$ & $-1.04 \mathrm{E}-01$ & $6.96 \mathrm{E}-02$ & $-6.96 \mathrm{E}-02$ & 7.07E-02 & -7.07E-02 \\
\hline $7.24 \mathrm{E}-05$ & $-7.24 \mathrm{E}-05$ & $1.06 \mathrm{E}-04$ & $-1.06 \mathrm{E}-04$ & $1.18 \mathrm{E}-04$ & $-1.18 \mathrm{E}-04$ & $1.53 \mathrm{E}-04$ & $-1.53 \mathrm{E}-04$ \\
\hline $9.98 \mathrm{E}-05$ & $-9.98 \mathrm{E}-05$ & $6.96 \mathrm{E}-05$ & $-6.96 \mathrm{E}-05$ & $2.88 \mathrm{E}-04$ & $-2.88 \mathrm{E}-04$ & $1.94 \mathrm{E}-04$ & $-1.94 \mathrm{E}-04$ \\
\hline 3.36E-04 & $-3.36 \mathrm{E}-04$ & 1.31E-03 & $-1.31 E-03$ & $6.81 \mathrm{E}-05$ & $-6.81 E-05$ & 2.91E-04 & $-2.91 \mathrm{E}-04$ \\
\hline 7.41E-05 & $-7.41 \mathrm{E}-05$ & 9.90E-05 & $-9.90 \mathrm{E}-05$ & $2.13 E-04$ & $-2.13 E-04$ & 2.61E-04 & $-2.61 E-04$ \\
\hline $1.22 \mathrm{E}-04$ & $-1.22 \mathrm{E}-04$ & $1.43 \mathrm{E}-04$ & $-1.43 \mathrm{E}-04$ & $6.61 \mathrm{E}-05$ & $-6.61 \mathrm{E}-05$ & $5.48 \mathrm{E}-05$ & $-5.48 \mathrm{E}-05$ \\
\hline 4.89E-05 & $-4.89 \mathrm{E}-05$ & $1.31 \mathrm{E}-04$ & $-1.31 E-04$ & $6.56 \mathrm{E}-04$ & $-6.56 \mathrm{E}-04$ & $2.23 \mathrm{E}-04$ & $-2.23 E-04$ \\
\hline $1.20 \mathrm{E}-04$ & $-1.20 \mathrm{E}-04$ & 5.07E-04 & $-5.07 E-04$ & $5.74 \mathrm{E}-05$ & $-5.74 \mathrm{E}-05$ & 5.37E-05 & $-5.37 E-05$ \\
\hline $6.18 \mathrm{E}-04$ & $-6.18 \mathrm{E}-04$ & $2.51 \mathrm{E}-03$ & $-2.51 E-03$ & 7.47E-03 & $-7.47 \mathrm{E}-03$ & $2.22 \mathrm{E}-03$ & $-2.22 \mathrm{E}-03$ \\
\hline $1.45 \mathrm{E}-04$ & $-1.45 \mathrm{E}-04$ & $6.00 \mathrm{E}-04$ & $-6.00 E-04$ & $6.75 \mathrm{E}-04$ & $-6.75 E-04$ & 3.07E-04 & $-3.07 E-04$ \\
\hline $3.26 \mathrm{E}-04$ & $-3.26 \mathrm{E}-04$ & 2.63E-04 & $-2.63 E-04$ & $4.18 \mathrm{E}-04$ & $-4.18 \mathrm{E}-04$ & 3.71E-04 & $-3.71 E-04$ \\
\hline $1.45 \mathrm{E}-03$ & $-1.45 \mathrm{E}-03$ & 5.39E-04 & $-5.39 E-04$ & $2.97 \mathrm{E}-04$ & $-2.97 E-04$ & $9.41 E-05$ & $-9.41 E-05$ \\
\hline $2.29 \mathrm{E}-04$ & $-2.29 E-04$ & 3.35E-04 & $-3.35 E-04$ & $1.61 \mathrm{E}-04$ & $-1.61 \mathrm{E}-04$ & 8.77E-05 & $-8.77 E-05$ \\
\hline 7.17E-05 & $-7.17 \mathrm{E}-05$ & $1.22 \mathrm{E}-04$ & $-1.22 \mathrm{E}-04$ & $3.94 \mathrm{E}-04$ & $-3.94 \mathrm{E}-04$ & 3.76E-04 & $-3.76 E-04$ \\
\hline 7.66E-05 & $-7.66 \mathrm{E}-05$ & $1.36 \mathrm{E}-04$ & $-1.36 \mathrm{E}-04$ & $1.05 \mathrm{E}-04$ & $-1.05 E-04$ & $3.14 \mathrm{E}-04$ & $-3.14 \mathrm{E}-04$ \\
\hline $1.42 \mathrm{E}-04$ & $-1.42 \mathrm{E}-04$ & $1.85 \mathrm{E}-04$ & $-1.85 E-04$ & 8.03E-04 & $-8.03 E-04$ & 7.56E-04 & $-7.56 \mathrm{E}-04$ \\
\hline $6.08 \mathrm{E}-05$ & $-6.08 \mathrm{E}-05$ & 8.97E-05 & -8.97E-05 & $3.55 \mathrm{E}-05$ & $-3.55 \mathrm{E}-05$ & 2.97E-05 & $-2.97 \mathrm{E}-05$ \\
\hline 7.13E-05 & $-7.13 E-05$ & 3.09E-05 & $-3.09 E-05$ & 7.10E-06 & $-7.10 \mathrm{E}-06$ & $1.79 \mathrm{E}-05$ & $-1.79 E-05$ \\
\hline $5.27 \mathrm{E}-05$ & $-5.27 \mathrm{E}-05$ & $1.44 \mathrm{E}-04$ & $-1.44 \mathrm{E}-04$ & $1.64 \mathrm{E}-04$ & $-1.64 \mathrm{E}-04$ & 1.27E-04 & $-1.27 \mathrm{E}-04$ \\
\hline 5.94E-05 & $-5.94 \mathrm{E}-05$ & 1.09E-04 & $-1.09 E-04$ & $1.36 \mathrm{E}-04$ & $-1.36 \mathrm{E}-04$ & $1.63 \mathrm{E}-04$ & $-1.63 E-04$ \\
\hline $6.86 \mathrm{E}-05$ & $-6.86 \mathrm{E}-05$ & 4.70E-05 & $-4.70 \mathrm{E}-05$ & 2.17E-05 & $-2.17 \mathrm{E}-05$ & $1.45 \mathrm{E}-05$ & $-1.45 E-05$ \\
\hline $9.21 \mathrm{E}-05$ & $-9.21 \mathrm{E}-05$ & $3.62 \mathrm{E}-04$ & $-3.62 E-04$ & $1.60 \mathrm{E}-04$ & $-1.60 \mathrm{E}-04$ & 4.28E-04 & $-4.28 E-04$ \\
\hline Period: & $4.44 \mathrm{E}-01$ & & & & & & \\
\hline $1.42 \mathrm{E}-05$ & $-1.42 \mathrm{E}-05$ & $1.50 \mathrm{E}-05$ & $-1.50 \mathrm{E}-05$ & 4.36E-05 & $-4.36 \mathrm{E}-05$ & 5.19E-05 & $-5.19 E-05$ \\
\hline $5.88 \mathrm{E}-05$ & $-5.88 \mathrm{E}-05$ & $2.25 \mathrm{E}-04$ & $-2.25 \mathrm{E}-04$ & $3.43 \mathrm{E}-05$ & $-3.43 E-05$ & $6.68 \mathrm{E}-05$ & $-6.68 \mathrm{E}-05$ \\
\hline $1.74 \mathrm{E}-04$ & $-1.74 \mathrm{E}-04$ & $1.06 \mathrm{E}-04$ & $-1.06 \mathrm{E}-04$ & $2.93 \mathrm{E}-05$ & $-2.93 \mathrm{E}-05$ & 6.76E-05 & $-6.76 E-05$ \\
\hline 3.73E-04 & $-3.73 E-04$ & 1.51E-03 & $-1.51 E-03$ & $9.96 \mathrm{E}-05$ & $-9.96 \mathrm{E}-05$ & 7.26E-05 & $-7.26 \mathrm{E}-05$ \\
\hline 4.67E-04 & $-4.67 \mathrm{E}-04$ & $1.93 \mathrm{E}-04$ & $-1.93 \mathrm{E}-04$ & $6.90 \mathrm{E}-05$ & $-6.90 \mathrm{E}-05$ & $2.36 \mathrm{E}-04$ & $-2.36 \mathrm{E}-04$ \\
\hline $6.61 \mathrm{E}-05$ & $-6.61 E-05$ & 8.58E-05 & $-8.58 \mathrm{E}-05$ & 5.01E-05 & $-5.01 \mathrm{E}-05$ & 8.26E-05 & $-8.26 \mathrm{E}-05$ \\
\hline $5.55 \mathrm{E}-04$ & $-5.55 E-04$ & $3.05 \mathrm{E}-04$ & $-3.05 E-04$ & $9.74 \mathrm{E}-04$ & $-9.74 \mathrm{E}-04$ & 3.69E-04 & $-3.69 \mathrm{E}-04$ \\
\hline $3.13 E-05$ & $-3.13 E-05$ & $1.42 \mathrm{E}-04$ & $-1.42 \mathrm{E}-04$ & 5.31E-06 & $-5.31 \mathrm{E}-06$ & $5.84 \mathrm{E}-06$ & $-5.84 \mathrm{E}-06$ \\
\hline $8.28 \mathrm{E}-05$ & $-8.28 \mathrm{E}-05$ & $1.68 \mathrm{E}-04$ & $-1.68 \mathrm{E}-04$ & 4.04E-05 & $-4.04 \mathrm{E}-05$ & $7.72 \mathrm{E}-05$ & $-7.72 E-05$ \\
\hline $5.83 \mathrm{E}-05$ & $-5.83 E-05$ & $8.26 \mathrm{E}-05$ & $-8.26 \mathrm{E}-05$ & $1.31 \mathrm{E}-05$ & $-1.31 \mathrm{E}-05$ & 2.19E-04 & $-2.19 \mathrm{E}-04$ \\
\hline $2.43 \mathrm{E}-04$ & $-2.43 \mathrm{E}-04$ & $1.38 \mathrm{E}-04$ & $-1.38 \mathrm{E}-04$ & $9.04 \mathrm{E}-05$ & $-9.04 \mathrm{E}-05$ & 8.05E-05 & $-8.05 E-05$ \\
\hline 3.13E-05 & $-3.13 E-05$ & $1.00 \mathrm{E}-04$ & $-1.00 \mathrm{E}-04$ & $1.71 \mathrm{E}-05$ & $-1.71 \mathrm{E}-05$ & $2.81 \mathrm{E}-05$ & $-2.81 E-05$ \\
\hline $5.36 \mathrm{E}-05$ & $-5.36 \mathrm{E}-05$ & $2.74 \mathrm{E}-05$ & $-2.74 \mathrm{E}-05$ & $6.06 \mathrm{E}-06$ & $-6.06 \mathrm{E}-06$ & 1.97E-05 & $-1.97 E-05$ \\
\hline $6.70 \mathrm{E}-05$ & $-6.70 \mathrm{E}-05$ & $1.73 \mathrm{E}-04$ & $-1.73 \mathrm{E}-04$ & $2.60 \mathrm{E}-05$ & $-2.60 \mathrm{E}-05$ & $5.79 \mathrm{E}-05$ & $-5.79 E-05$ \\
\hline $4.48 \mathrm{E}-04$ & $-4.48 \mathrm{E}-04$ & $1.06 \mathrm{E}-03$ & $-1.06 \mathrm{E}-03$ & 7.07E-03 & $-7.07 E-03$ & $1.35 \mathrm{E}-03$ & $-1.35 E-03$ \\
\hline $9.40 \mathrm{E}-01$ & $-9.40 \mathrm{E}-01$ & $9.22 \mathrm{E}-01$ & $-9.22 \mathrm{E}-01$ & $7.23 \mathrm{E}-01$ & $-7.23 E-01$ & $6.53 \mathrm{E}-01$ & $-6.53 \mathrm{E}-01$ \\
\hline 3.57E-05 & $-3.57 \mathrm{E}-05$ & 4.04E-05 & $-4.04 \mathrm{E}-05$ & $5.88 \mathrm{E}-05$ & $-5.88 \mathrm{E}-05$ & $5.82 \mathrm{E}-05$ & $-5.82 E-05$ \\
\hline
\end{tabular}


APPENDIX IV: 3-D INVERSION DATA FILE

\begin{tabular}{|c|c|c|c|c|c|c|c|}
\hline 5.32E-05 & $-5.32 \mathrm{E}-05$ & 3.09E-05 & $-3.09 E-05$ & $1.54 \mathrm{E}-04$ & $-1.54 \mathrm{E}-04$ & $8.58 \mathrm{E}-05$ & $-8.58 \mathrm{E}-05$ \\
\hline $1.29 \mathrm{E}-04$ & $-1.29 \mathrm{E}-04$ & 5.05E-04 & $-5.05 E-04$ & $2.62 \mathrm{E}-05$ & $-2.62 \mathrm{E}-05$ & $1.12 \mathrm{E}-04$ & $-1.12 \mathrm{E}-04$ \\
\hline $2.76 \mathrm{E}-05$ & $-2.76 \mathrm{E}-05$ & 5.13E-05 & $-5.13 E-05$ & 7.94E-05 & $-7.94 \mathrm{E}-05$ & $1.35 \mathrm{E}-04$ & $-1.35 E-04$ \\
\hline $5.34 \mathrm{E}-05$ & $-5.34 \mathrm{E}-05$ & 7.08E-05 & $-7.08 \mathrm{E}-05$ & $2.92 \mathrm{E}-05$ & $-2.92 \mathrm{E}-05$ & $2.74 \mathrm{E}-05$ & $-2.74 \mathrm{E}-05$ \\
\hline $2.32 \mathrm{E}-05$ & $-2.32 \mathrm{E}-05$ & 7.39E-05 & $-7.39 \mathrm{E}-05$ & $2.90 \mathrm{E}-04$ & $-2.90 \mathrm{E}-04$ & $1.40 \mathrm{E}-04$ & $-1.40 \mathrm{E}-04$ \\
\hline $6.69 \mathrm{E}-05$ & $-6.69 \mathrm{E}-05$ & $2.68 \mathrm{E}-04$ & $-2.68 \mathrm{E}-04$ & $3.06 \mathrm{E}-05$ & $-3.06 \mathrm{E}-05$ & $2.96 \mathrm{E}-05$ & $-2.96 \mathrm{E}-05$ \\
\hline $2.25 \mathrm{E}-04$ & $-2.25 \mathrm{E}-04$ & $1.28 \mathrm{E}-03$ & $-1.28 \mathrm{E}-03$ & $2.71 \mathrm{E}-03$ & $-2.71 \mathrm{E}-03$ & $1.20 \mathrm{E}-03$ & $-1.20 \mathrm{E}-03$ \\
\hline $7.00 \mathrm{E}-05$ & $-7.00 \mathrm{E}-05$ & $3.29 \mathrm{E}-04$ & $-3.29 \mathrm{E}-04$ & $3.08 \mathrm{E}-04$ & $-3.08 \mathrm{E}-04$ & $1.73 \mathrm{E}-04$ & $-1.73 \mathrm{E}-04$ \\
\hline $1.57 \mathrm{E}-04$ & $-1.57 \mathrm{E}-04$ & 1.37E-04 & $-1.37 E-04$ & $2.03 E-04$ & $-2.03 E-04$ & $1.94 \mathrm{E}-04$ & $-1.94 \mathrm{E}-04$ \\
\hline $1.76 \mathrm{E}-02$ & $-1.76 \mathrm{E}-02$ & 7.92E-03 & $-7.92 \mathrm{E}-03$ & $1.30 \mathrm{E}-03$ & $-1.30 \mathrm{E}-03$ & $5.64 \mathrm{E}-04$ & $-5.64 E-04$ \\
\hline $1.90 \mathrm{E}-04$ & $-1.90 \mathrm{E}-04$ & 3.17E-04 & $-3.17 \mathrm{E}-04$ & $1.48 \mathrm{E}-04$ & $-1.48 \mathrm{E}-04$ & $9.46 \mathrm{E}-05$ & $-9.46 \mathrm{E}-05$ \\
\hline 3.15E-04 & $-3.15 \mathrm{E}-04$ & 4.74E-04 & $-4.74 \mathrm{E}-04$ & $1.01 \mathrm{E}-03$ & $-1.01 \mathrm{E}-03$ & $1.09 \mathrm{E}-03$ & $-1.09 E-03$ \\
\hline $9.46 \mathrm{E}-05$ & $-9.46 \mathrm{E}-05$ & $6.63 \mathrm{E}-05$ & $-6.63 E-05$ & 2.77E-05 & $-2.77 \mathrm{E}-05$ & $1.29 \mathrm{E}-04$ & $-1.29 E-04$ \\
\hline $5.53 \mathrm{E}-04$ & $-5.53 E-04$ & $1.01 \mathrm{E}-03$ & $-1.01 \mathrm{E}-03$ & $2.83 \mathrm{E}-03$ & $-2.83 \mathrm{E}-03$ & $4.82 \mathrm{E}-03$ & $-4.82 E-03$ \\
\hline $1.11 \mathrm{E}-04$ & $-1.11 \mathrm{E}-04$ & $1.12 \mathrm{E}-04$ & $-1.12 \mathrm{E}-04$ & 5.49E-05 & $-5.49 \mathrm{E}-05$ & 4.69E-05 & $-4.69 E-05$ \\
\hline $2.80 \mathrm{E}-05$ & $-2.80 \mathrm{E}-05$ & $1.29 \mathrm{E}-05$ & $-1.29 \mathrm{E}-05$ & $2.94 \mathrm{E}-06$ & $-2.94 \mathrm{E}-06$ & 7.38E-06 & $-7.38 \mathrm{E}-06$ \\
\hline $7.16 \mathrm{E}-05$ & $-7.16 \mathrm{E}-05$ & 1.47E-04 & $-1.47 \mathrm{E}-04$ & $2.15 \mathrm{E}-04$ & $-2.15 \mathrm{E}-04$ & $2.57 \mathrm{E}-04$ & $-2.57 \mathrm{E}-04$ \\
\hline 2.27E-04 & $-2.27 \mathrm{E}-04$ & $1.78 \mathrm{E}-04$ & $-1.78 \mathrm{E}-04$ & $5.18 \mathrm{E}-04$ & $-5.18 \mathrm{E}-04$ & $3.91 \mathrm{E}-04$ & $-3.91 E-04$ \\
\hline 4.93E-04 & $-4.93 \mathrm{E}-04$ & $3.14 \mathrm{E}-04$ & $-3.14 \mathrm{E}-04$ & $3.34 \mathrm{E}-04$ & $-3.34 \mathrm{E}-04$ & $2.04 \mathrm{E}-04$ & $-2.04 \mathrm{E}-04$ \\
\hline $3.65 \mathrm{E}-05$ & $-3.65 E-05$ & $1.96 \mathrm{E}-04$ & $-1.96 \mathrm{E}-04$ & 7.61E-05 & $-7.61 \mathrm{E}-05$ & 2.39E-04 & $-2.39 E-04$ \\
\hline R_Period: & 8.89E-01 & & & & & & \\
\hline 8.89E-06 & $-8.89 \mathrm{E}-06$ & 9.34E-06 & $-9.34 \mathrm{E}-06$ & $2.69 \mathrm{E}-05$ & $-2.69 \mathrm{E}-05$ & $3.20 \mathrm{E}-05$ & $-3.20 \mathrm{E}-05$ \\
\hline $3.41 \mathrm{E}-05$ & $-3.41 \mathrm{E}-05$ & $1.02 \mathrm{E}-04$ & $-1.02 \mathrm{E}-04$ & $1.99 \mathrm{E}-05$ & $-1.99 \mathrm{E}-05$ & 3.07E-05 & $-3.07 E-05$ \\
\hline 8.33E-05 & $-8.33 E-05$ & $5.61 \mathrm{E}-05$ & $-5.61 E-05$ & $1.46 \mathrm{E}-05$ & $-1.46 \mathrm{E}-05$ & $3.58 \mathrm{E}-05$ & $-3.58 \mathrm{E}-05$ \\
\hline $1.66 \mathrm{E}-04$ & $-1.66 \mathrm{E}-04$ & 1.57E-04 & $-1.57 \mathrm{E}-04$ & $9.52 \mathrm{E}-06$ & $-9.52 \mathrm{E}-06$ & $3.76 \mathrm{E}-05$ & $-3.76 \mathrm{E}-05$ \\
\hline $2.30 \mathrm{E}-04$ & $-2.30 \mathrm{E}-04$ & $6.36 \mathrm{E}-04$ & $-6.36 \mathrm{E}-04$ & $1.81 \mathrm{E}-03$ & $-1.81 \mathrm{E}-03$ & $1.50 \mathrm{E}-04$ & $-1.50 \mathrm{E}-04$ \\
\hline $2.96 \mathrm{E}-05$ & $-2.96 \mathrm{E}-05$ & 3.55E-05 & $-3.55 \mathrm{E}-05$ & $2.25 \mathrm{E}-05$ & $-2.25 \mathrm{E}-05$ & $3.38 \mathrm{E}-05$ & $-3.38 \mathrm{E}-05$ \\
\hline 2.39E-04 & $-2.39 \mathrm{E}-04$ & $1.76 \mathrm{E}-04$ & $-1.76 \mathrm{E}-04$ & $4.18 \mathrm{E}-04$ & $-4.18 \mathrm{E}-04$ & $2.16 \mathrm{E}-04$ & $-2.16 \mathrm{E}-04$ \\
\hline 9.97E-06 & $-9.97 E-06$ & $4.28 \mathrm{E}-05$ & $-4.28 \mathrm{E}-05$ & $1.69 \mathrm{E}-06$ & $-1.69 \mathrm{E}-06$ & $1.74 \mathrm{E}-06$ & $-1.74 \mathrm{E}-06$ \\
\hline 4.07E-05 & $-4.07 E-05$ & $3.15 E-04$ & $-3.15 E-04$ & $1.01 \mathrm{E}-04$ & $-1.01 \mathrm{E}-04$ & $2.94 \mathrm{E}-05$ & $-2.94 \mathrm{E}-05$ \\
\hline 4.55E-03 & $-4.55 \mathrm{E}-03$ & 4.59E-03 & $-4.59 E-03$ & $1.15 \mathrm{E}-03$ & $-1.15 \mathrm{E}-03$ & 1.07E-02 & -1.07E-02 \\
\hline $1.55 \mathrm{E}-04$ & $-1.55 \mathrm{E}-04$ & $3.88 \mathrm{E}-04$ & $-3.88 \mathrm{E}-04$ & $2.92 \mathrm{E}-04$ & $-2.92 \mathrm{E}-04$ & $4.54 \mathrm{E}-05$ & $-4.54 \mathrm{E}-05$ \\
\hline $9.53 \mathrm{E}-05$ & $-9.53 E-05$ & $2.51 \mathrm{E}-04$ & $-2.51 E-04$ & 5.07E-05 & $-5.07 E-05$ & $7.12 \mathrm{E}-05$ & $-7.12 \mathrm{E}-05$ \\
\hline $2.18 \mathrm{E}-05$ & $-2.18 \mathrm{E}-05$ & 1.15E-05 & $-1.15 E-05$ & $3.16 \mathrm{E}-06$ & $-3.16 \mathrm{E}-06$ & $7.48 \mathrm{E}-06$ & $-7.48 \mathrm{E}-06$ \\
\hline $3.08 \mathrm{E}-05$ & $-3.08 \mathrm{E}-05$ & $1.01 \mathrm{E}-04$ & $-1.01 E-04$ & $1.21 \mathrm{E}-05$ & $-1.21 \mathrm{E}-05$ & $3.38 \mathrm{E}-05$ & $-3.38 \mathrm{E}-05$ \\
\hline $3.64 \mathrm{E}-04$ & $-3.64 \mathrm{E}-04$ & $3.02 \mathrm{E}-03$ & $-3.02 \mathrm{E}-03$ & $2.93 \mathrm{E}-02$ & $-2.93 \mathrm{E}-02$ & $7.80 \mathrm{E}-04$ & $-7.80 \mathrm{E}-04$ \\
\hline $2.10 \mathrm{E}-04$ & $-2.10 \mathrm{E}-04$ & $4.25 \mathrm{E}-04$ & $-4.25 E-04$ & $1.94 \mathrm{E}-04$ & $-1.94 \mathrm{E}-04$ & $2.24 \mathrm{E}-04$ & $-2.24 \mathrm{E}-04$ \\
\hline $1.86 \mathrm{E}-05$ & $-1.86 \mathrm{E}-05$ & $1.53 \mathrm{E}-05$ & $-1.53 E-05$ & $3.04 \mathrm{E}-05$ & $-3.04 \mathrm{E}-05$ & $2.20 \mathrm{E}-05$ & $-2.20 \mathrm{E}-05$ \\
\hline $3.34 \mathrm{E}-05$ & $-3.34 \mathrm{E}-05$ & $1.83 \mathrm{E}-05$ & $-1.83 \mathrm{E}-05$ & $9.60 \mathrm{E}-05$ & $-9.60 \mathrm{E}-05$ & 4.99E-05 & $-4.99 E-05$ \\
\hline $6.58 \mathrm{E}-05$ & $-6.58 \mathrm{E}-05$ & $3.48 \mathrm{E}-04$ & $-3.48 \mathrm{E}-04$ & $1.34 \mathrm{E}-05$ & $-1.34 \mathrm{E}-05$ & 7.74E-05 & $-7.74 \mathrm{E}-05$ \\
\hline $9.86 \mathrm{E}-06$ & $-9.86 \mathrm{E}-06$ & $1.90 \mathrm{E}-05$ & $-1.90 \mathrm{E}-05$ & $2.77 \mathrm{E}-05$ & $-2.77 E-05$ & $4.96 \mathrm{E}-05$ & $-4.96 \mathrm{E}-05$ \\
\hline $2.53 \mathrm{E}-05$ & $-2.53 \mathrm{E}-05$ & 4.07E-05 & $-4.07 \mathrm{E}-05$ & $1.40 \mathrm{E}-05$ & $-1.40 \mathrm{E}-05$ & 1.60E-05 & $-1.60 \mathrm{E}-05$ \\
\hline
\end{tabular}


APPENDIX IV: 3-D INVERSION DATA FILE

\begin{tabular}{|c|c|c|c|c|c|c|c|}
\hline $9.24 \mathrm{E}-06$ & $-9.24 \mathrm{E}-06$ & $2.64 \mathrm{E}-05$ & $-2.64 \mathrm{E}-05$ & $1.02 \mathrm{E}-04$ & $-1.02 \mathrm{E}-04$ & $4.56 \mathrm{E}-05$ & $-4.56 \mathrm{E}-05$ \\
\hline 4.02E-05 & $-4.02 E-05$ & 1.69E-04 & $-1.69 E-04$ & 1.79E-05 & $-1.79 E-05$ & 2.01E-05 & $-2.01 E-05$ \\
\hline 1.49E-04 & $-1.49 E-04$ & $.32 \mathrm{E}-04$ & $-1.32 E-04$ & $3.51 \mathrm{E}-04$ & $-3.51 \mathrm{E}-04$ & $6.09 E-04$ & $-6.09 E-04$ \\
\hline 3.52E-05 & $-3.52 E-05$ & $1.58 \mathrm{E}-04$ & $-1.58 \mathrm{E}-04$ & $1.45 \mathrm{E}-04$ & $-1.45 \mathrm{E}-04$ & 8.89E-05 & $-8.89 E-05$ \\
\hline 7.54E-05 & $-7.54 \mathrm{E}-05$ & 6.81E-05 & $-6.81 E-05$ & $9.77 \mathrm{E}-05$ & $-9.77 \mathrm{E}-05$ & $9.61 \mathrm{E}-05$ & $-9.61 E-05$ \\
\hline $1.69 \mathrm{E}-03$ & $-1.69 E-03$ & 2.70E-03 & $-2.70 \mathrm{E}-03$ & $2.70 \mathrm{E}-04$ & $-2.70 \mathrm{E}-04$ & $3.06 \mathrm{E}-04$ & $-3.06 E-04$ \\
\hline $1.98 \mathrm{E}-04$ & $-1.98 \mathrm{E}-04$ & $2.72 \mathrm{E}-04$ & $-2.72 \mathrm{E}-04$ & $1.44 \mathrm{E}-04$ & $-1.44 \mathrm{E}-04$ & $1.38 \mathrm{E}-04$ & $-1.38 \mathrm{E}-04$ \\
\hline $5.18 \mathrm{E}-05$ & $-5.18 \mathrm{E}-05$ & 2.64E-04 & $-2.64 \mathrm{E}-04$ & $1.89 \mathrm{E}-04$ & $-1.89 \mathrm{E}-04$ & $1.14 \mathrm{E}-04$ & $-1.14 \mathrm{E}-04$ \\
\hline 3.83E-05 & $-3.83 E-05$ & $1.04 \mathrm{E}-05$ & $-1.04 \mathrm{E}-05$ & $1.02 \mathrm{E}-05$ & $-1.02 \mathrm{E}-05$ & 5.67E-05 & $-5.67 E-05$ \\
\hline $1.10 \mathrm{E}-03$ & $-1.10 \mathrm{E}-03$ & 1.07E-02 & $-1.07 E-02$ & $2.18 \mathrm{E}-02$ & $-2.18 \mathrm{E}-02$ & $8.26 \mathrm{E}-03$ & $-8.26 \mathrm{E}-03$ \\
\hline $8.26 \mathrm{E}-05$ & $-8.26 \mathrm{E}-05$ & $3.48 \mathrm{E}-04$ & $-3.48 \mathrm{E}-04$ & $2.51 \mathrm{E}-04$ & $-2.51 \mathrm{E}-04$ & $3.59 \mathrm{E}-05$ & $-3.59 \mathrm{E}-05$ \\
\hline $1.53 \mathrm{E}-05$ & $-1.53 \mathrm{E}-05$ & 4.77E-05 & $-4.77 E-05$ & $1.59 \mathrm{E}-05$ & $-1.59 \mathrm{E}-05$ & $6.00 \mathrm{E}-06$ & $-6.00 \mathrm{E}-06$ \\
\hline $1.18 \mathrm{E}-04$ & $-1.18 \mathrm{E}-04$ & $1.25 \mathrm{E}-04$ & $-1.25 E-04$ & $1.93 \mathrm{E}-04$ & $-1.93 \mathrm{E}-04$ & $1.46 \mathrm{E}-04$ & $-1.46 \mathrm{E}-04$ \\
\hline 2.47E-05 & $-2.47 \mathrm{E}-05$ & $1.18 \mathrm{E}-04$ & $-1.18 \mathrm{E}-04$ & $1.68 \mathrm{E}-03$ & $-1.68 \mathrm{E}-03$ & $2.76 \mathrm{E}-04$ & $-2.76 \mathrm{E}-04$ \\
\hline 2.11E-04 & $-2.11 \mathrm{E}-04$ & $1.35 \mathrm{E}-04$ & $-1.35 E-04$ & $1.43 \mathrm{E}-04$ & $-1.43 \mathrm{E}-04$ & $1.03 \mathrm{E}-04$ & $-1.03 E-04$ \\
\hline 3.76E-05 & $-3.76 \mathrm{E}-05$ & 1.09E-04 & $-1.09 E-04$ & 7.13E-05 & $-7.13 E-05$ & $1.36 \mathrm{E}-04$ & $-1.36 \mathrm{E}-04$ \\
\hline ROR_Period: & $1.78 \mathrm{E}+00$ & & & & & & \\
\hline 7.45E-06 & $-7.45 \mathrm{E}-06$ & E-06 & E-06 & $E-05$ & $-2.07 \mathrm{E}-05$ & -05 & $-2.34 \mathrm{E}-05$ \\
\hline 2.31E-05 & $-2.31 \mathrm{E}-05$ & 7.20E-05 & $-7.20 \mathrm{E}-05$ & $1.32 \mathrm{E}-05$ & $-1.32 \mathrm{E}-05$ & $2.32 \mathrm{E}-05$ & $-2.32 E-05$ \\
\hline 4.96E-05 & $-4.96 \mathrm{E}-05$ & $2.66 \mathrm{E}-05$ & $-2.66 \mathrm{E}-05$ & 8.97E-06 & $-8.97 \mathrm{E}-06$ & $1.69 \mathrm{E}-05$ & $-1.69 \mathrm{E}-05$ \\
\hline $9.32 \mathrm{E}-05$ & $-9.32 E-05$ & $1.32 \mathrm{E}-04$ & $-1.32 \mathrm{E}-04$ & $9.75 \mathrm{E}-06$ & $-9.75 E-06$ & $3.18 \mathrm{E}-05$ & $-3.18 \mathrm{E}-05$ \\
\hline $1.78 \mathrm{E}-04$ & $-1.78 \mathrm{E}-04$ & 5.93E-05 & $-5.93 E-05$ & $3.16 \mathrm{E}-05$ & $-3.16 \mathrm{E}-05$ & $5.98 \mathrm{E}-05$ & $-5.98 E-05$ \\
\hline $3.27 \mathrm{E}-05$ & $-3.27 \mathrm{E}-05$ & 2.57E-05 & $-2.57 \mathrm{E}-05$ & 2.39E-05 & $-2.39 \mathrm{E}-05$ & $2.12 \mathrm{E}-05$ & $-2.12 \mathrm{E}-05$ \\
\hline $9.88 \mathrm{E}-05$ & $-9.88 E-05$ & $1.02 \mathrm{E}-03$ & $-1.02 E-03$ & $1.79 \mathrm{E}-03$ & $-1.79 E-03$ & $1.39 \mathrm{E}-04$ & $-1.39 E-04$ \\
\hline $1.11 \mathrm{E}-05$ & $-1.11 \mathrm{E}-05$ & 2.80E-05 & $-2.80 \mathrm{E}-05$ & $1.81 \mathrm{E}-06$ & $-1.81 \mathrm{E}-06$ & $1.95 \mathrm{E}-06$ & $-1.95 E-06$ \\
\hline $2.16 \mathrm{E}-05$ & $-2.16 \mathrm{E}-05$ & $2.91 \mathrm{E}-05$ & $-2.91 E-05$ & $1.08 \mathrm{E}-05$ & $-1.08 \mathrm{E}-05$ & $1.38 \mathrm{E}-05$ & $-1.38 \mathrm{E}-05$ \\
\hline $3.64 \mathrm{E}-05$ & $-3.64 \mathrm{E}-05$ & 3.85E-05 & $-3.85 \mathrm{E}-05$ & $1.43 \mathrm{E}-05$ & $-1.43 E-05$ & $6.14 \mathrm{E}-05$ & $-6.14 \mathrm{E}-05$ \\
\hline $8.41 \mathrm{E}-05$ & $-8.41 \mathrm{E}-05$ & $4.50 \mathrm{E}-05$ & $-4.50 \mathrm{E}-05$ & $3.24 \mathrm{E}-05$ & $-3.24 \mathrm{E}-05$ & $2.64 \mathrm{E}-05$ & $-2.64 \mathrm{E}-05$ \\
\hline 8.01E-05 & $-8.01 E-05$ & $2.71 \mathrm{E}-04$ & $-2.71 E-04$ & $3.68 \mathrm{E}-05$ & $-3.68 \mathrm{E}-05$ & 7.77E-05 & $-7.77 \mathrm{E}-05$ \\
\hline $1.23 \mathrm{E}-05$ & $-1.23 \mathrm{E}-05$ & 7.91E-06 & $-7.91 E-06$ & $2.44 \mathrm{E}-06$ & $-2.44 \mathrm{E}-06$ & 4.57E-06 & $-4.57 E-06$ \\
\hline $1.54 \mathrm{E}-05$ & $-1.54 \mathrm{E}-05$ & $6.93 \mathrm{E}-05$ & $-6.93 \mathrm{E}-05$ & $6.20 \mathrm{E}-06$ & $-6.20 \mathrm{E}-06$ & $2.34 \mathrm{E}-05$ & $-2.34 \mathrm{E}-05$ \\
\hline $3.25 \mathrm{E}-04$ & $-3.25 E-04$ & $2.78 \mathrm{E}-03$ & $-2.78 \mathrm{E}-03$ & $2.49 \mathrm{E}-02$ & $-2.49 \mathrm{E}-02$ & $6.96 \mathrm{E}-04$ & $-6.96 \mathrm{E}-04$ \\
\hline $1.24 \mathrm{E}-04$ & $-1.24 \mathrm{E}-04$ & $1.65 \mathrm{E}-04$ & $-1.65 E-04$ & $1.28 \mathrm{E}-04$ & $-1.28 \mathrm{E}-04$ & $9.63 \mathrm{E}-05$ & $-9.63 E-05$ \\
\hline $1.32 \mathrm{E}-05$ & $-1.32 \mathrm{E}-05$ & $1.39 \mathrm{E}-05$ & $-1.39 \mathrm{E}-05$ & $2.04 \mathrm{E}-05$ & $-2.04 \mathrm{E}-05$ & $1.96 \mathrm{E}-05$ & $-1.96 \mathrm{E}-05$ \\
\hline $2.22 \mathrm{E}-05$ & $-2.22 \mathrm{E}-05$ & $1.34 \mathrm{E}-05$ & $-1.34 \mathrm{E}-05$ & $6.17 \mathrm{E}-05$ & $-6.17 \mathrm{E}-05$ & $3.33 \mathrm{E}-05$ & $-3.33 E-05$ \\
\hline $3.87 \mathrm{E}-05$ & $-3.87 E-05$ & $2.62 \mathrm{E}-04$ & $-2.62 E-04$ & 8.09E-06 & $-8.09 E-06$ & $5.83 \mathrm{E}-05$ & $-5.83 E-05$ \\
\hline $4.52 \mathrm{E}-06$ & $-4.52 E-06$ & 7.27E-06 & $-7.27 E-06$ & $1.23 \mathrm{E}-05$ & $-1.23 \mathrm{E}-05$ & 1.87E-05 & $-1.87 \mathrm{E}-05$ \\
\hline $2.03 E-05$ & $-2.03 \mathrm{E}-05$ & 3.00E-05 & $-3.00 \mathrm{E}-05$ & 1.19E-05 & $-1.19 \mathrm{E}-05$ & $1.27 \mathrm{E}-05$ & $-1.27 \mathrm{E}-05$ \\
\hline 1.05E-05 & $-1.05 E-05$ & $2.16 \mathrm{E}-05$ & $-2.16 \mathrm{E}-05$ & $7.92 \mathrm{E}-05$ & $-7.92 \mathrm{E}-05$ & 4.37E-05 & $-4.37 E-05$ \\
\hline 4.99E-05 & $-4.99 E-05$ & 1.99E-04 & $-1.99 \mathrm{E}-04$ & $1.96 \mathrm{E}-05$ & $-1.96 \mathrm{E}-05$ & $2.65 \mathrm{E}-05$ & $-2.65 E-05$ \\
\hline $1.33 \mathrm{E}-04$ & $-1.33 \mathrm{E}-04$ & $1.09 \mathrm{E}-04$ & $-1.09 E-04$ & $3.39 E-04$ & $-3.39 E-04$ & 4.34E-04 & $-4.34 \mathrm{E}-04$ \\
\hline 1.99E-05 & $-1.99 \mathrm{E}-05$ & 8.90E-05 & $-8.90 \mathrm{E}-05$ & 7.84E-05 & $-7.84 \mathrm{E}-05$ & 5.01E-05 & $-5.01 \mathrm{E}-05$ \\
\hline
\end{tabular}


APPENDIX IV: 3-D INVERSION DATA FILE

\begin{tabular}{|c|c|c|c|c|c|c|c|}
\hline 3.84E-05 & $-3.84 \mathrm{E}-05$ & $3.78 \mathrm{E}-05$ & $-3.78 \mathrm{E}-05$ & 5.11E-05 & $-5.11 \mathrm{E}-05$ & $5.42 \mathrm{E}-05$ & $-5.42 E-05$ \\
\hline 7.36E-03 & $-7.36 \mathrm{E}-03$ & $1.85 \mathrm{E}-02$ & $-1.85 \mathrm{E}-02$ & $2.15 \mathrm{E}-03$ & $-2.15 \mathrm{E}-03$ & 3.17E-04 & $-3.17 E-04$ \\
\hline $1.06 \mathrm{E}-03$ & $-1.06 \mathrm{E}-03$ & 1.17E-03 & $-1.17 E-03$ & $4.86 \mathrm{E}-03$ & $-4.86 \mathrm{E}-03$ & $5.25 \mathrm{E}-04$ & $-5.25 E-04$ \\
\hline 6.51E-05 & $-6.51 E-05$ & $2.61 \mathrm{E}-04$ & $-2.61 E-04$ & $1.65 \mathrm{E}-04$ & $-1.65 E-04$ & $7.49 E-05$ & -7.49E-05 \\
\hline 2.33E-05 & $-2.33 \mathrm{E}-05$ & $1.16 \mathrm{E}-05$ & $-1.16 \mathrm{E}-05$ & $1.05 \mathrm{E}-05$ & $-1.05 \mathrm{E}-05$ & 2.04E-05 & $-2.04 \mathrm{E}-05$ \\
\hline 3.87E-04 & $-3.87 E-04$ & $3.22 \mathrm{E}-03$ & $-3.22 \mathrm{E}-03$ & $1.08 \mathrm{E}-02$ & $-1.08 \mathrm{E}-02$ & $3.51 \mathrm{E}-03$ & $-3.51 E-03$ \\
\hline $2.39 \mathrm{E}-04$ & $-2.39 \mathrm{E}-04$ & $3.61 \mathrm{E}-03$ & $-3.61 E-03$ & $4.57 \mathrm{E}-03$ & $-4.57 \mathrm{E}-03$ & $1.62 \mathrm{E}-04$ & $-1.62 \mathrm{E}-04$ \\
\hline $9.42 \mathrm{E}-06$ & $-9.42 \mathrm{E}-06$ & $7.55 \mathrm{E}-06$ & $-7.55 \mathrm{E}-06$ & $1.96 \mathrm{E}-06$ & $-1.96 \mathrm{E}-06$ & $3.81 \mathrm{E}-06$ & $-3.81 E-06$ \\
\hline $1.72 \mathrm{E}-04$ & $-1.72 \mathrm{E}-04$ & $3.66 \mathrm{E}-03$ & $-3.66 \mathrm{E}-03$ & $2.08 \mathrm{E}-02$ & $-2.08 \mathrm{E}-02$ & 3.97E-04 & $-3.97 E-04$ \\
\hline 8.31E-04 & $-8.31 E-04$ & 4.04E-02 & $-4.04 \mathrm{E}-02$ & $6.41 \mathrm{E}-02$ & $-6.41 E-02$ & $1.24 \mathrm{E}-03$ & $-1.24 \mathrm{E}-03$ \\
\hline $2.45 \mathrm{E}-04$ & $-2.45 \mathrm{E}-04$ & $1.72 \mathrm{E}-03$ & $-1.72 \mathrm{E}-03$ & $2.73 \mathrm{E}-03$ & $-2.73 \mathrm{E}-03$ & $1.92 \mathrm{E}-04$ & $-1.92 \mathrm{E}-04$ \\
\hline $1.03 \mathrm{E}-04$ & $-1.03 E-04$ & $5.87 E-04$ & $-5.87 E-04$ & $1.04 \mathrm{E}-03$ & $-1.04 \mathrm{E}-03$ & $1.85 \mathrm{E}-04$ & $-1.85 E-04$ \\
\hline OR_Period: & $3.55 \mathrm{E}+00$ & & & & & & \\
\hline $1.36 \mathrm{E}-05$ & $-1.36 \mathrm{E}-05$ & $1.09 \mathrm{E}-05$ & $-1.09 \mathrm{E}-05$ & $3.18 \mathrm{E}-05$ & $-3.18 \mathrm{E}-05$ & $2.50 \mathrm{E}-05$ & $-2.50 \mathrm{E}-05$ \\
\hline 1.71E-04 & $-1.71 E-04$ & $2.35 \mathrm{E}-03$ & $-2.35 \mathrm{E}-03$ & 8.91E-04 & $-8.91 \mathrm{E}-04$ & $1.07 \mathrm{E}-04$ & -1.07E-04 \\
\hline 3.89E-05 & $-3.89 E-05$ & $1.77 \mathrm{E}-05$ & $-1.77 E-05$ & 8.30E-06 & $-8.30 \mathrm{E}-06$ & $1.03 \mathrm{E}-05$ & $-1.03 E-05$ \\
\hline $1.43 \mathrm{E}-04$ & $-1.43 \mathrm{E}-04$ & $1.69 \mathrm{E}-04$ & $-1.69 \mathrm{E}-04$ & $2.97 \mathrm{E}-05$ & $-2.97 \mathrm{E}-05$ & $4.23 \mathrm{E}-05$ & $-4.23 E-05$ \\
\hline $1.65 \mathrm{E}-04$ & $-1.65 \mathrm{E}-04$ & $3.10 \mathrm{E}-04$ & $-3.10 \mathrm{E}-04$ & $2.15 \mathrm{E}-04$ & $-2.15 \mathrm{E}-04$ & $3.86 \mathrm{E}-05$ & $-3.86 E-05$ \\
\hline $6.29 E-05$ & $-6.29 E-05$ & $6.65 \mathrm{E}-05$ & $-6.65 E-05$ & 4.47E-05 & $-4.47 \mathrm{E}-05$ & $5.08 \mathrm{E}-05$ & $-5.08 E-05$ \\
\hline $7.98 \mathrm{E}-05$ & $-7.98 \mathrm{E}-05$ & $8.04 \mathrm{E}-05$ & $-8.04 \mathrm{E}-05$ & $1.53 \mathrm{E}-04$ & $-1.53 \mathrm{E}-04$ & $1.27 \mathrm{E}-04$ & $-1.27 \mathrm{E}-04$ \\
\hline 4.10E-05 & $-4.10 \mathrm{E}-05$ & 6.97E-05 & $-6.97 E-05$ & $6.57 \mathrm{E}-06$ & $-6.57 \mathrm{E}-06$ & 7.11E-06 & -7.11E-06 \\
\hline 4.06E-05 & $-4.06 \mathrm{E}-05$ & 5.07E-05 & $-5.07 E-05$ & $2.13 E-05$ & $-2.13 E-05$ & 2.57E-05 & $-2.57 \mathrm{E}-05$ \\
\hline $3.26 \mathrm{E}-05$ & $-3.26 \mathrm{E}-05$ & $3.78 \mathrm{E}-05$ & $-3.78 \mathrm{E}-05$ & $1.48 \mathrm{E}-05$ & $-1.48 \mathrm{E}-05$ & 5.07E-05 & $-5.07 \mathrm{E}-05$ \\
\hline 4.00E-05 & $-4.00 \mathrm{E}-05$ & $2.52 \mathrm{E}-05$ & $-2.52 E-05$ & $1.57 \mathrm{E}-05$ & $-1.57 \mathrm{E}-05$ & $1.47 \mathrm{E}-05$ & $-1.47 \mathrm{E}-05$ \\
\hline 1.69E-04 & $-1.69 E-04$ & $2.50 \mathrm{E}-04$ & $-2.50 \mathrm{E}-04$ & $6.40 \mathrm{E}-05$ & $-6.40 E-05$ & 7.91E-05 & -7.91E-05 \\
\hline $1.28 \mathrm{E}-05$ & $-1.28 \mathrm{E}-05$ & $1.03 \mathrm{E}-05$ & $-1.03 E-05$ & $3.48 \mathrm{E}-06$ & $-3.48 \mathrm{E}-06$ & $5.36 \mathrm{E}-06$ & $-5.36 E-06$ \\
\hline 1.69E-05 & $-1.69 E-05$ & 5.09E-05 & $-5.09 E-05$ & $7.23 E-06$ & $-7.23 E-06$ & $1.81 \mathrm{E}-05$ & $-1.81 \mathrm{E}-05$ \\
\hline 4.56E-04 & $-4.56 \mathrm{E}-04$ & 4.49E-03 & $-4.49 E-03$ & $2.24 \mathrm{E}-02$ & $-2.24 \mathrm{E}-02$ & $1.14 \mathrm{E}-03$ & $-1.14 \mathrm{E}-03$ \\
\hline 2.32E-04 & $-2.32 \mathrm{E}-04$ & $2.85 \mathrm{E}-04$ & $-2.85 E-04$ & 2.17E-04 & $-2.17 \mathrm{E}-04$ & $1.73 \mathrm{E}-04$ & $-1.73 E-04$ \\
\hline $2.86 \mathrm{E}-05$ & $-2.86 \mathrm{E}-05$ & $3.54 \mathrm{E}-05$ & $-3.54 \mathrm{E}-05$ & 4.06E-05 & $-4.06 \mathrm{E}-05$ & $4.88 \mathrm{E}-05$ & $-4.88 \mathrm{E}-05$ \\
\hline 2.12E-05 & $-2.12 \mathrm{E}-05$ & $1.32 \mathrm{E}-05$ & $-1.32 \mathrm{E}-05$ & $5.58 \mathrm{E}-05$ & $-5.58 \mathrm{E}-05$ & $2.78 \mathrm{E}-05$ & $-2.78 \mathrm{E}-05$ \\
\hline $5.06 \mathrm{E}-05$ & $-5.06 \mathrm{E}-05$ & $2.45 \mathrm{E}-04$ & $-2.45 E-04$ & $1.12 \mathrm{E}-05$ & $-1.12 \mathrm{E}-05$ & $5.49 \mathrm{E}-05$ & $-5.49 E-05$ \\
\hline 4.86E-06 & $-4.86 \mathrm{E}-06$ & 6.99E-06 & $-6.99 \mathrm{E}-06$ & $1.25 \mathrm{E}-05$ & $-1.25 \mathrm{E}-05$ & $1.75 \mathrm{E}-05$ & $-1.75 E-05$ \\
\hline 4.43E-05 & $-4.43 \mathrm{E}-05$ & $3.32 \mathrm{E}-05$ & $-3.32 \mathrm{E}-05$ & $3.11 \mathrm{E}-05$ & $-3.11 \mathrm{E}-05$ & 2.17E-05 & $-2.17 \mathrm{E}-05$ \\
\hline $6.39 \mathrm{E}-05$ & $-6.39 E-05$ & 7.13E-05 & $-7.13 E-05$ & $2.89 \mathrm{E}-04$ & $-2.89 \mathrm{E}-04$ & 1.77E-04 & $-1.77 \mathrm{E}-04$ \\
\hline $9.76 \mathrm{E}-05$ & $-9.76 \mathrm{E}-05$ & $1.74 \mathrm{E}-04$ & $-1.74 \mathrm{E}-04$ & 3.37E-05 & $-3.37 \mathrm{E}-05$ & $3.31 E-05$ & $-3.31 E-05$ \\
\hline $1.05 \mathrm{E}-04$ & $-1.05 \mathrm{E}-04$ & 4.96E-04 & $-4.96 \mathrm{E}-04$ & $1.46 \mathrm{E}-03$ & $-1.46 \mathrm{E}-03$ & $3.60 \mathrm{E}-04$ & $-3.60 \mathrm{E}-04$ \\
\hline $1.65 \mathrm{E}-05$ & $-1.65 \mathrm{E}-05$ & 5.47E-05 & $-5.47 \mathrm{E}-05$ & $5.27 \mathrm{E}-05$ & $-5.27 \mathrm{E}-05$ & $3.47 \mathrm{E}-05$ & $-3.47 \mathrm{E}-05$ \\
\hline $4.22 \mathrm{E}-03$ & $-4.22 \mathrm{E}-03$ & 3.79E-03 & $-3.79 E-03$ & $6.12 \mathrm{E}-03$ & $-6.12 \mathrm{E}-03$ & $5.71 E-03$ & $-5.71 E-03$ \\
\hline $1.38 \mathrm{E}-01$ & $-1.38 \mathrm{E}-01$ & $1.25 \mathrm{E}-01$ & $-1.25 \mathrm{E}-01$ & $3.73 \mathrm{E}-02$ & $-3.73 E-02$ & $3.41 \mathrm{E}-02$ & $-3.41 \mathrm{E}-02$ \\
\hline 4.14E-03 & $-4.14 \mathrm{E}-03$ & $1.13 \mathrm{E}-02$ & $-1.13 E-02$ & $2.13 \mathrm{E}-02$ & $-2.13 \mathrm{E}-02$ & $2.31 \mathrm{E}-03$ & $-2.31 E-03$ \\
\hline $5.87 \mathrm{E}-05$ & $-5.87 E-05$ & $3.16 \mathrm{E}-04$ & $-3.16 E-04$ & $1.91 \mathrm{E}-04$ & $-1.91 \mathrm{E}-04$ & $1.30 \mathrm{E}-04$ & $-1.30 \mathrm{E}-04$ \\
\hline & & & & & & & \\
\hline
\end{tabular}


APPENDIX IV: 3-D INVERSION DATA FILE

\begin{tabular}{|c|c|c|c|c|c|c|c|}
\hline 3.47E-05 & $-3.47 \mathrm{E}-05$ & $2.62 \mathrm{E}-05$ & $-2.62 \mathrm{E}-05$ & 3.69E-05 & $-3.69 \mathrm{E}-05$ & 4.46E-05 & $-4.46 \mathrm{E}-05$ \\
\hline $2.66 \mathrm{E}-04$ & $-2.66 \mathrm{E}-04$ & $6.17 \mathrm{E}-04$ & $-6.17 \mathrm{E}-04$ & $6.00 \mathrm{E}-03$ & $-6.00 \mathrm{E}-03$ & $5.47 \mathrm{E}-04$ & $-5.47 \mathrm{E}-04$ \\
\hline $1.03 \mathrm{E}-03$ & $-1.03 \mathrm{E}-03$ & $6.88 \mathrm{E}-03$ & $-6.88 \mathrm{E}-03$ & $6.58 \mathrm{E}-03$ & $-6.58 \mathrm{E}-03$ & 4.35E-04 & $-4.35 E-04$ \\
\hline $1.76 \mathrm{E}-04$ & $-1.76 \mathrm{E}-04$ & $1.92 \mathrm{E}-04$ & $-1.92 \mathrm{E}-04$ & 8.67E-05 & $-8.67 \mathrm{E}-05$ & $1.04 \mathrm{E}-04$ & $-1.04 \mathrm{E}-04$ \\
\hline 8.57E-04 & $-8.57 \mathrm{E}-04$ & $4.54 \mathrm{E}-03$ & $-4.54 \mathrm{E}-03$ & $8.68 \mathrm{E}-03$ & $-8.68 \mathrm{E}-03$ & $1.81 \mathrm{E}-03$ & $-1.81 \mathrm{E}-03$ \\
\hline $2.23 \mathrm{E}-03$ & $-2.23 \mathrm{E}-03$ & $1.00 \mathrm{E}-02$ & $-1.00 \mathrm{E}-02$ & 1.07E-02 & $-1.07 \mathrm{E}-02$ & 4.71E-04 & $-4.71 E-04$ \\
\hline $5.78 \mathrm{E}-04$ & $-5.78 E-04$ & 8.67E-03 & $-8.67 E-03$ & 4.34E-03 & $-4.34 \mathrm{E}-03$ & 6.51E-04 & $-6.51 E-04$ \\
\hline $9.26 \mathrm{E}-04$ & $-9.26 \mathrm{E}-04$ & 5.91E-03 & $-5.91 \mathrm{E}-03$ & 2.00E-02 & $-2.00 \mathrm{E}-02$ & $1.24 \mathrm{E}-03$ & $-1.24 \mathrm{E}-03$ \\
\hline ROR_Period: & $7.11 \mathrm{E}+00$ & & & & & & \\
\hline $5.25 \mathrm{E}-04$ & $-5.25 E-04$ & $4.98 \mathrm{E}-04$ & $-4.98 \mathrm{E}-04$ & $1.32 \mathrm{E}-03$ & $-1.32 \mathrm{E}-03$ & $1.35 \mathrm{E}-03$ & $-1.35 E-03$ \\
\hline 4.32E-05 & $-4.32 E-05$ & 4.04E-03 & $-4.04 \mathrm{E}-03$ & 2.01E-03 & $-2.01 \mathrm{E}-03$ & 4.11E-04 & $-4.11 E-04$ \\
\hline $9.88 \mathrm{E}-05$ & $-9.88 \mathrm{E}-05$ & $8.25 \mathrm{E}-05$ & $-8.25 E-05$ & $3.94 \mathrm{E}-05$ & $-3.94 \mathrm{E}-05$ & 4.04E-05 & $-4.04 E-05$ \\
\hline $1.08 \mathrm{E}-02$ & $-1.08 \mathrm{E}-02$ & $1.31 \mathrm{E}-02$ & $-1.31 \mathrm{E}-02$ & 2.31E-03 & $-2.31 \mathrm{E}-03$ & 3.30E-03 & $-3.30 \mathrm{E}-03$ \\
\hline $8.14 \mathrm{E}-04$ & $-8.14 \mathrm{E}-04$ & $6.90 \mathrm{E}-04$ & $-6.90 \mathrm{E}-04$ & $3.80 \mathrm{E}-04$ & $-3.80 \mathrm{E}-04$ & $3.55 \mathrm{E}-04$ & $-3.55 E-04$ \\
\hline 6.69E-04 & $-6.69 \mathrm{E}-04$ & 6.97E-03 & $-6.97 \mathrm{E}-03$ & 4.66E-03 & $-4.66 \mathrm{E}-03$ & 4.93E-04 & $-4.93 E-04$ \\
\hline 2.44E-02 & $-2.44 \mathrm{E}-02$ & 2.39E-02 & $-2.39 \mathrm{E}-02$ & $5.23 \mathrm{E}-02$ & $-5.23 E-02$ & 4.95E-02 & $-4.95 E-02$ \\
\hline $3.82 \mathrm{E}-02$ & $-3.82 \mathrm{E}-02$ & 3.77E-02 & $-3.77 E-02$ & $6.02 \mathrm{E}-03$ & $-6.02 E-03$ & $5.91 \mathrm{E}-03$ & $-5.91 E-03$ \\
\hline 4.66E-05 & $-4.66 \mathrm{E}-05$ & $2.42 \mathrm{E}-04$ & $-2.42 \mathrm{E}-04$ & $1.23 \mathrm{E}-04$ & $-1.23 \mathrm{E}-04$ & 2.10E-05 & $-2.52 E-05$ \\
\hline 1.69E-05 & $-1.69 \mathrm{E}-05$ & 4.34E-05 & $-4.34 \mathrm{E}-05$ & $1.80 \mathrm{E}-05$ & $-1.80 \mathrm{E}-05$ & 8.48E-06 & $-8.48 E-06$ \\
\hline $1.97 \mathrm{E}-04$ & $-1.97 \mathrm{E}-04$ & $5.49 \mathrm{E}-05$ & $-5.49 E-05$ & $5.24 \mathrm{E}-05$ & $-5.24 \mathrm{E}-05$ & $6.32 \mathrm{E}-06$ & $-6.32 E-06$ \\
\hline 4.35E-04 & $-4.35 \mathrm{E}-04$ & 4.80E-04 & $-4.80 \mathrm{E}-04$ & $1.58 \mathrm{E}-04$ & $-1.58 \mathrm{E}-04$ & 1.61E-04 & $-1.61 \mathrm{E}-04$ \\
\hline 8.00E-06 & $-8.00 \mathrm{E}-06$ & 7.27E-06 & $-7.27 \mathrm{E}-06$ & $2.22 \mathrm{E}-06$ & $-2.22 \mathrm{E}-06$ & $3.94 \mathrm{E}-06$ & $-3.94 \mathrm{E}-06$ \\
\hline $3.10 \mathrm{E}-05$ & $-3.10 \mathrm{E}-05$ & $6.89 \mathrm{E}-05$ & $-6.89 \mathrm{E}-05$ & $1.38 \mathrm{E}-05$ & $-1.38 \mathrm{E}-05$ & 2.60E-05 & $-2.60 \mathrm{E}-05$ \\
\hline 3.13E-02 & $-3.13 E-02$ & $5.96 \mathrm{E}-02$ & $-5.96 \mathrm{E}-02$ & 4.88E-01 & $-4.88 \mathrm{E}-01$ & 7.35E-02 & $-7.35 E-02$ \\
\hline 5.63E-04 & $-5.63 E-04$ & 6.67E-04 & $-6.67 E-04$ & $4.72 \mathrm{E}-04$ & $-4.72 \mathrm{E}-04$ & 4.24E-04 & $-4.24 \mathrm{E}-04$ \\
\hline 8.51E-05 & $-8.51 \mathrm{E}-05$ & $9.54 \mathrm{E}-05$ & $-9.54 \mathrm{E}-05$ & 1.16E-04 & $-1.16 \mathrm{E}-04$ & $1.29 \mathrm{E}-04$ & $-1.29 E-04$ \\
\hline $1.59 \mathrm{E}-05$ & $-1.59 \mathrm{E}-05$ & $1.30 \mathrm{E}-05$ & $-1.30 \mathrm{E}-05$ & 4.29E-05 & $-4.29 \mathrm{E}-05$ & $3.32 \mathrm{E}-05$ & $-3.32 \mathrm{E}-05$ \\
\hline 8.49E-05 & $-8.49 \mathrm{E}-05$ & $2.04 \mathrm{E}-04$ & $-2.04 \mathrm{E}-04$ & 2.29E-05 & $-2.29 \mathrm{E}-05$ & 4.88E-05 & $-4.88 E-05$ \\
\hline 7.50E-06 & -7.50E-06 & 7.96E-06 & $-7.96 \mathrm{E}-06$ & $1.83 \mathrm{E}-05$ & $-1.83 \mathrm{E}-05$ & 1.89E-05 & -1.89E-05 \\
\hline 7.94E-05 & $-7.94 \mathrm{E}-05$ & $1.03 \mathrm{E}-04$ & $-1.03 E-04$ & 7.52E-05 & $-7.52 \mathrm{E}-05$ & 8.03E-05 & $-8.03 E-05$ \\
\hline 7.90E-03 & $-7.90 \mathrm{E}-03$ & 8.90E-03 & $-8.90 \mathrm{E}-03$ & 2.53E-02 & $-2.53 \mathrm{E}-02$ & 2.34E-02 & $-2.34 \mathrm{E}-02$ \\
\hline $1.02 \mathrm{E}-04$ & $-1.02 \mathrm{E}-04$ & $1.71 \mathrm{E}-03$ & $-1.71 \mathrm{E}-03$ & 3.36E-04 & $-3.36 \mathrm{E}-04$ & $3.48 \mathrm{E}-05$ & $-3.48 \mathrm{E}-05$ \\
\hline $3.08 \mathrm{E}-05$ & $-3.08 \mathrm{E}-05$ & $1.28 \mathrm{E}-04$ & $-1.28 \mathrm{E}-04$ & $3.56 \mathrm{E}-04$ & $-3.56 \mathrm{E}-04$ & $1.23 \mathrm{E}-04$ & $-1.23 E-04$ \\
\hline $1.22 \mathrm{E}-05$ & $-1.22 \mathrm{E}-05$ & $2.14 \mathrm{E}-04$ & $-2.14 \mathrm{E}-04$ & 2.07E-04 & $-4.96 \mathrm{E}-05$ & $2.61 \mathrm{E}-05$ & $-2.61 E-05$ \\
\hline 3.97E-05 & $-3.97 \mathrm{E}-05$ & $6.43 E-04$ & $-6.43 E-04$ & 2.67E-04 & $-2.67 \mathrm{E}-04$ & 1.97E-05 & -1.97E-05 \\
\hline $8.41 E+00$ & $-8.41 E+00$ & $5.47 \mathrm{E}+00$ & $-5.47 E+00$ & $1.48 \mathrm{E}+00$ & $-1.48 \mathrm{E}+00$ & 9.66E-01 & $-9.66 \mathrm{E}-01$ \\
\hline $1.00 \mathrm{E}-02$ & $-1.00 \mathrm{E}-02$ & $4.71 \mathrm{E}-02$ & $-4.71 \mathrm{E}-02$ & 6.77E-02 & $-6.77 E-02$ & $1.28 \mathrm{E}-02$ & $-1.28 \mathrm{E}-02$ \\
\hline 2.03E-04 & $-2.03 E-04$ & $1.39 \mathrm{E}-04$ & $-1.39 \mathrm{E}-04$ & $8.58 \mathrm{E}-04$ & $-8.58 \mathrm{E}-04$ & $5.52 \mathrm{E}-04$ & $-5.52 E-04$ \\
\hline 7.11E-05 & $-7.11 \mathrm{E}-05$ & 1.10E-04 & $-1.10 \mathrm{E}-04$ & $1.36 \mathrm{E}-05$ & $-1.36 \mathrm{E}-05$ & $1.31 \mathrm{E}-04$ & $-1.31 \mathrm{E}-04$ \\
\hline 5.57E-04 & $-5.57 E-04$ & $1.81 \mathrm{E}-03$ & $-1.81 \mathrm{E}-03$ & 5.98E-01 & $-5.98 \mathrm{E}-01$ & $3.80 \mathrm{E}-03$ & $-3.80 \mathrm{E}-03$ \\
\hline $5.20 \mathrm{E}-04$ & $-5.20 \mathrm{E}-04$ & $1.23 \mathrm{E}-01$ & $-1.23 \mathrm{E}-01$ & 7.32E-03 & $-7.32 \mathrm{E}-03$ & 8.55E-04 & $-8.55 E-04$ \\
\hline $6.24 \mathrm{E}-04$ & $-6.24 \mathrm{E}-04$ & 8.35E-04 & $-8.35 E-04$ & $1.70 \mathrm{E}-04$ & $-1.70 \mathrm{E}-04$ & $2.35 \mathrm{E}-04$ & $-2.35 \mathrm{E}-04$ \\
\hline
\end{tabular}


APPENDIX IV: 3-D INVERSION DATA FILE

\begin{tabular}{|c|c|c|c|c|c|c|c|}
\hline $1.02 \mathrm{E}-03$ & $-1.02 \mathrm{E}-03$ & $2.14 \mathrm{E}-02$ & $-2.14 \mathrm{E}-02$ & $2.01 \mathrm{E}-01$ & $-2.01 \mathrm{E}-01$ & $8.29 \mathrm{E}-04$ & $-8.29 E-04$ \\
\hline 1.62E-02 & $-1.62 \mathrm{E}-02$ & 8.97E-01 & -8.97E-01 & 1.09E-01 & -1.09E-01 & 3.02E-03 & $-3.02 E-03$ \\
\hline 6.90E-04 & $-6.90 \mathrm{E}-04$ & 2.39E-03 & $-2.39 E-03$ & 1.31E-03 & $-1.31 \mathrm{E}-03$ & $1.81 \mathrm{E}-04$ & $-1.81 \mathrm{E}-04$ \\
\hline $9.83 \mathrm{E}-04$ & $-9.83 E-04$ & $2.25 \mathrm{E}-02$ & $-2.25 \mathrm{E}-02$ & $1.78 \mathrm{E}-02$ & $-1.78 \mathrm{E}-02$ & $4.03 \mathrm{E}-03$ & $-4.03 E-03$ \\
\hline ROR_Period: & $1.42 \mathrm{E}+01$ & & & & & & \\
\hline 5.25E-06 & $-5.25 E-06$ & $2.49 \mathrm{E}-05$ & $-2.49 \mathrm{E}-05$ & $6.60 \mathrm{E}-05$ & $-6.60 \mathrm{E}-05$ & $1.35 \mathrm{E}-05$ & $-1.35 E-05$ \\
\hline $9.03 \mathrm{E}-04$ & $-9.03 E-04$ & $4.89 \mathrm{E}-03$ & $-4.89 \mathrm{E}-03$ & $2.34 \mathrm{E}-03$ & $-2.34 \mathrm{E}-03$ & $4.90 \mathrm{E}-04$ & $-4.90 \mathrm{E}-04$ \\
\hline $6.61 \mathrm{E}-03$ & $-6.61 \mathrm{E}-03$ & $6.39 \mathrm{E}-03$ & $-6.39 \mathrm{E}-03$ & $2.66 \mathrm{E}-03$ & $-2.66 \mathrm{E}-03$ & $3.19 \mathrm{E}-03$ & $-3.19 E-03$ \\
\hline $1.08 \mathrm{E}-04$ & $-1.08 \mathrm{E}-04$ & $1.31 \mathrm{E}-04$ & $-1.31 \mathrm{E}-04$ & $2.31 \mathrm{E}-05$ & $-2.31 \mathrm{E}-05$ & 3.30E-05 & $-3.30 \mathrm{E}-05$ \\
\hline 3.61E-04 & $-3.61 E-04$ & $2.88 \mathrm{E}-03$ & $-2.88 \mathrm{E}-03$ & 7.98E-04 & $-7.98 \mathrm{E}-04$ & $1.55 \mathrm{E}-04$ & $-1.55 \mathrm{E}-04$ \\
\hline 2.67E-02 & $-2.67 \mathrm{E}-02$ & $2.80 \mathrm{E}-02$ & $-2.80 \mathrm{E}-02$ & 1.93E-02 & $-1.93 \mathrm{E}-02$ & $2.04 \mathrm{E}-02$ & $-2.04 \mathrm{E}-02$ \\
\hline 1.87E-02 & $-1.87 \mathrm{E}-02$ & $1.95 \mathrm{E}-02$ & $-1.95 \mathrm{E}-02$ & 4.08E-02 & $-4.08 E-02$ & 4.11E-02 & $-4.11 E-02$ \\
\hline $1.11 \mathrm{E}-05$ & $-1.11 \mathrm{E}-05$ & $1.50 \mathrm{E}-04$ & $-1.50 \mathrm{E}-04$ & 8.90E-06 & $-8.90 \mathrm{E}-06$ & $2.30 \mathrm{E}-06$ & $-2.30 \mathrm{E}-06$ \\
\hline 1.57E-05 & $-1.57 \mathrm{E}-05$ & $9.70 \mathrm{E}-05$ & $-9.70 \mathrm{E}-05$ & $4.00 \mathrm{E}-05$ & $-4.00 \mathrm{E}-05$ & $9.50 \mathrm{E}-06$ & $-9.50 \mathrm{E}-06$ \\
\hline 8.56E-06 & $-8.56 \mathrm{E}-06$ & 7.20E-06 & $-7.20 \mathrm{E}-06$ & $3.45 E-06$ & $-3.45 E-06$ & $1.20 \mathrm{E}-05$ & $-1.20 \mathrm{E}-05$ \\
\hline $2.23 \mathrm{E}-05$ & $-2.23 \mathrm{E}-05$ & 5.31E-05 & $-5.31 E-05$ & 4.12E-05 & $-4.12 E-05$ & $6.12 \mathrm{E}-06$ & $-6.12 E-06$ \\
\hline 5.67E-05 & $-5.67 \mathrm{E}-05$ & $3.85 \mathrm{E}-04$ & $-3.85 \mathrm{E}-04$ & $1.01 \mathrm{E}-04$ & $-1.01 \mathrm{E}-04$ & $2.48 \mathrm{E}-05$ & $-2.48 \mathrm{E}-05$ \\
\hline 3.75E-06 & $-3.75 E-06$ & $3.59 E-06$ & $-3.59 E-06$ & 7.97E-07 & -7.97E-07 & $2.28 \mathrm{E}-06$ & $-2.28 \mathrm{E}-06$ \\
\hline $1.92 \mathrm{E}-05$ & $-1.92 \mathrm{E}-05$ & $5.70 \mathrm{E}-05$ & $-5.70 \mathrm{E}-05$ & $8.44 \mathrm{E}-06$ & $-8.44 \mathrm{E}-06$ & $2.06 \mathrm{E}-05$ & $-2.06 \mathrm{E}-05$ \\
\hline $2.92 \mathrm{E}-04$ & $-2.92 \mathrm{E}-04$ & $3.51 \mathrm{E}-03$ & $-3.51 \mathrm{E}-03$ & 1.19E-02 & $-1.19 \mathrm{E}-02$ & $9.83 \mathrm{E}-04$ & $-9.83 E-04$ \\
\hline 2.79E-04 & $-2.79 \mathrm{E}-04$ & 1.47E-03 & $-1.47 E-03$ & $1.22 \mathrm{E}-03$ & $-1.22 \mathrm{E}-03$ & $1.91 \mathrm{E}-04$ & $-1.91 \mathrm{E}-04$ \\
\hline $1.81 \mathrm{E}-05$ & $-1.81 \mathrm{E}-05$ & $1.98 \mathrm{E}-05$ & $-1.98 \mathrm{E}-05$ & 2.57E-05 & $-2.57 \mathrm{E}-05$ & $2.74 \mathrm{E}-05$ & $-2.74 \mathrm{E}-05$ \\
\hline $1.38 \mathrm{E}-05$ & $-1.38 \mathrm{E}-05$ & 8.65E-06 & $-8.65 E-06$ & 3.90E-05 & $-3.90 \mathrm{E}-05$ & $2.32 \mathrm{E}-05$ & $-2.32 E-05$ \\
\hline 6.62E-05 & $-6.62 \mathrm{E}-05$ & $2.32 \mathrm{E}-04$ & $-2.32 E-04$ & $1.70 \mathrm{E}-05$ & $-1.70 \mathrm{E}-05$ & 5.54E-05 & $-5.54 \mathrm{E}-05$ \\
\hline $1.05 \mathrm{E}-05$ & $-1.05 E-05$ & $2.76 \mathrm{E}-06$ & $-2.76 \mathrm{E}-06$ & $2.34 \mathrm{E}-05$ & $-2.34 \mathrm{E}-05$ & 6.43E-06 & $-6.43 E-06$ \\
\hline $1.42 \mathrm{E}-02$ & $-1.42 \mathrm{E}-02$ & $1.15 \mathrm{E}-02$ & $-1.15 E-02$ & 1.37E-02 & $-1.37 E-02$ & 1.19E-02 & -1.19E-02 \\
\hline 7.90E-05 & $-7.90 \mathrm{E}-05$ & 8.90E-05 & $-8.90 \mathrm{E}-05$ & $2.53 \mathrm{E}-04$ & $-2.53 \mathrm{E}-04$ & $2.34 \mathrm{E}-04$ & $-2.34 \mathrm{E}-04$ \\
\hline 8.70E-03 & $-8.70 \mathrm{E}-03$ & 1.49E-02 & $-1.49 E-02$ & 2.86E-03 & $-2.86 \mathrm{E}-03$ & 3.00E-03 & $-3.00 E-03$ \\
\hline 2.69E-05 & $-2.69 \mathrm{E}-05$ & 2.34E-05 & $-2.34 \mathrm{E}-05$ & $6.13 \mathrm{E}-05$ & $-6.13 E-05$ & $1.13 \mathrm{E}-04$ & $-1.13 E-04$ \\
\hline $1.06 \mathrm{E}-05$ & $-1.06 \mathrm{E}-05$ & $1.91 \mathrm{E}-04$ & $-1.91 \mathrm{E}-04$ & $1.75 \mathrm{E}-04$ & $-1.75 E-04$ & $2.32 \mathrm{E}-05$ & $-2.32 E-05$ \\
\hline 7.42E-05 & $-7.42 \mathrm{E}-05$ & $6.49 \mathrm{E}-04$ & $-6.49 E-04$ & 4.85E-04 & $-4.85 E-04$ & 2.00E-05 & $-2.00 \mathrm{E}-05$ \\
\hline $3.98 \mathrm{E}-02$ & $-3.98 \mathrm{E}-02$ & $6.77 \mathrm{E}-02$ & $-6.77 E-02$ & $5.29 \mathrm{E}-03$ & $-5.29 E-03$ & $6.99 \mathrm{E}-03$ & $-6.99 \mathrm{E}-03$ \\
\hline $5.08 \mathrm{E}-03$ & $-5.08 \mathrm{E}-03$ & $2.90 \mathrm{E}-02$ & $-2.90 \mathrm{E}-02$ & $3.12 \mathrm{E}-02$ & $-3.12 E-02$ & 7.08E-03 & $-7.08 \mathrm{E}-03$ \\
\hline $2.98 \mathrm{E}-04$ & $-2.98 \mathrm{E}-04$ & $6.00 \mathrm{E}-04$ & $-6.00 \mathrm{E}-04$ & $1.26 \mathrm{E}-03$ & $-1.26 \mathrm{E}-03$ & $2.40 \mathrm{E}-03$ & $-2.40 \mathrm{E}-03$ \\
\hline $1.04 \mathrm{E}-04$ & $-1.04 \mathrm{E}-04$ & $1.25 \mathrm{E}-02$ & $-1.25 \mathrm{E}-02$ & $1.32 \mathrm{E}-03$ & $-1.32 \mathrm{E}-03$ & $3.31 \mathrm{E}-04$ & $-3.31 E-04$ \\
\hline 4.31E-06 & $-4.31 E-06$ & $1.50 \mathrm{E}-04$ & $-1.50 \mathrm{E}-04$ & $1.18 \mathrm{E}-04$ & $-1.18 \mathrm{E}-04$ & 7.21E-05 & $-7.21 E-05$ \\
\hline 1.14E-05 & $-1.14 \mathrm{E}-05$ & $2.38 \mathrm{E}-02$ & $-2.38 \mathrm{E}-02$ & $1.59 \mathrm{E}-04$ & $-1.59 \mathrm{E}-04$ & $6.92 \mathrm{E}-04$ & $-6.92 E-04$ \\
\hline $1.52 \mathrm{E}-03$ & $-1.52 \mathrm{E}-03$ & $1.43 \mathrm{E}-03$ & $-1.43 E-03$ & 4.06E-03 & $-4.06 \mathrm{E}-03$ & 3.80E-03 & $-3.80 \mathrm{E}-03$ \\
\hline $5.95 \mathrm{E}-06$ & $-5.95 E-06$ & $2.21 \mathrm{E}-04$ & $-2.21 \mathrm{E}-04$ & $2.34 \mathrm{E}-04$ & $-2.34 \mathrm{E}-04$ & $2.20 \mathrm{E}-06$ & $-2.20 \mathrm{E}-06$ \\
\hline 5.83E-05 & $-5.83 E-05$ & 4.07E-03 & $-4.07 E-03$ & $1.04 \mathrm{E}-03$ & $-1.04 \mathrm{E}-03$ & $3.60 \mathrm{E}-04$ & $-3.60 \mathrm{E}-04$ \\
\hline 7.39E-04 & $-7.39 \mathrm{E}-04$ & $1.65 \mathrm{E}-04$ & $-1.65 E-04$ & $1.72 \mathrm{E}-03$ & $-1.72 \mathrm{E}-03$ & $1.52 \mathrm{E}-05$ & $-1.52 E-05$ \\
\hline $1.73 \mathrm{E}-03$ & $-1.73 \mathrm{E}-03$ & $3.70 \mathrm{E}-04$ & $-3.70 \mathrm{E}-04$ & $5.66 \mathrm{E}-03$ & $-5.66 \mathrm{E}-03$ & $5.14 \mathrm{E}-05$ & $-5.14 \mathrm{E}-05$ \\
\hline
\end{tabular}


APPENDIX IV: 3-D INVERSION DATA FILE

\begin{tabular}{cc} 
ERROR_Period: & $2.13 \mathrm{E}+01$ \\
$3.15 \mathrm{E}-06$ & $-3.15 \mathrm{E}-06$ \\
$1.50 \mathrm{E}-04$ & $-1.50 \mathrm{E}-04$ \\
$6.61 \mathrm{E}-05$ & $-6.61 \mathrm{E}-05$ \\
$6.95 \mathrm{E}-05$ & $-6.95 \mathrm{E}-05$ \\
$4.95 \mathrm{E}-04$ & $-4.95 \mathrm{E}-04$ \\
$1.93 \mathrm{E}-03$ & $-1.93 \mathrm{E}-03$ \\
$1.87 \mathrm{E}-02$ & $-1.87 \mathrm{E}-02$ \\
$2.47 \mathrm{E}-06$ & $-2.47 \mathrm{E}-06$ \\
$2.20 \mathrm{E}-05$ & $-2.20 \mathrm{E}-05$ \\
$9.78 \mathrm{E}-06$ & $-9.78 \mathrm{E}-06$ \\
$2.21 \mathrm{E}-05$ & $-2.21 \mathrm{E}-05$ \\
$1.28 \mathrm{E}-02$ & $-1.28 \mathrm{E}-02$ \\
$6.95 \mathrm{E}-06$ & $-6.95 \mathrm{E}-06$ \\
$1.81 \mathrm{E}-05$ & $-1.81 \mathrm{E}-05$ \\
$2.92 \mathrm{E}-02$ & $-2.92 \mathrm{E}-02$ \\
$5.54 \mathrm{E}-03$ & $-5.54 \mathrm{E}-03$ \\
$1.99 \mathrm{E}-05$ & $-1.99 \mathrm{E}-05$ \\
$1.33 \mathrm{E}-05$ & $-1.33 \mathrm{E}-05$ \\
$1.06 \mathrm{E}-04$ & $-1.06 \mathrm{E}-04$ \\
$6.53 \mathrm{E}-06$ & $-6.53 \mathrm{E}-06$ \\
$6.06 \mathrm{E}-05$ & $-6.06 \mathrm{E}-05$ \\
$2.63 \mathrm{E}-05$ & $-2.63 \mathrm{E}-05$ \\
$1.22 \mathrm{E}-05$ & $-1.22 \mathrm{E}-05$ \\
$2.45 \mathrm{E}-03$ & $-2.45 \mathrm{E}-03$ \\
$7.44 \mathrm{E}-06$ & $-7.44 \mathrm{E}-06$ \\
$7.25 \mathrm{E}-05$ & $-7.25 \mathrm{E}-05$ \\
$7.84 \mathrm{E}-03$ & $-7.84 \mathrm{E}-03$ \\
$5.13 \mathrm{E}-06$ & $-5.13 \mathrm{E}-06$ \\
$1.06 \mathrm{E}-05$ & $-1.06 \mathrm{E}-05$ \\
$5.82 \mathrm{E}-06$ & $-5.82 \mathrm{E}-06$ \\
$3.03 \mathrm{E}-04$ & $-3.03 \mathrm{E}-04$ \\
$5.00 \mathrm{E}-06$ & $-5.00 \mathrm{E}-06$ \\
$3.33 \mathrm{E}-06$ & $-3.33 \mathrm{E}-06$ \\
$1.46 \mathrm{E}-05$ & $-1.46 \mathrm{E}-05$ \\
$3.91 \mathrm{E}-07$ & $-3.91 \mathrm{E}-07$ \\
$3.75 \mathrm{E}-05$ & $-3.75 \mathrm{E}-05$ \\
$5.44 \mathrm{E}-05$ & $-5.44 \mathrm{E}-05$ \\
\hline & \\
\hline $.99 \mathrm{E}-06$ & $-2.99 \mathrm{E}-06$ \\
$6.14 \mathrm{E}-06$ & $-6.14 \mathrm{E}-06$ \\
$2.39 \mathrm{E}-05$ & $-2.39 \mathrm{E}-05$
\end{tabular}

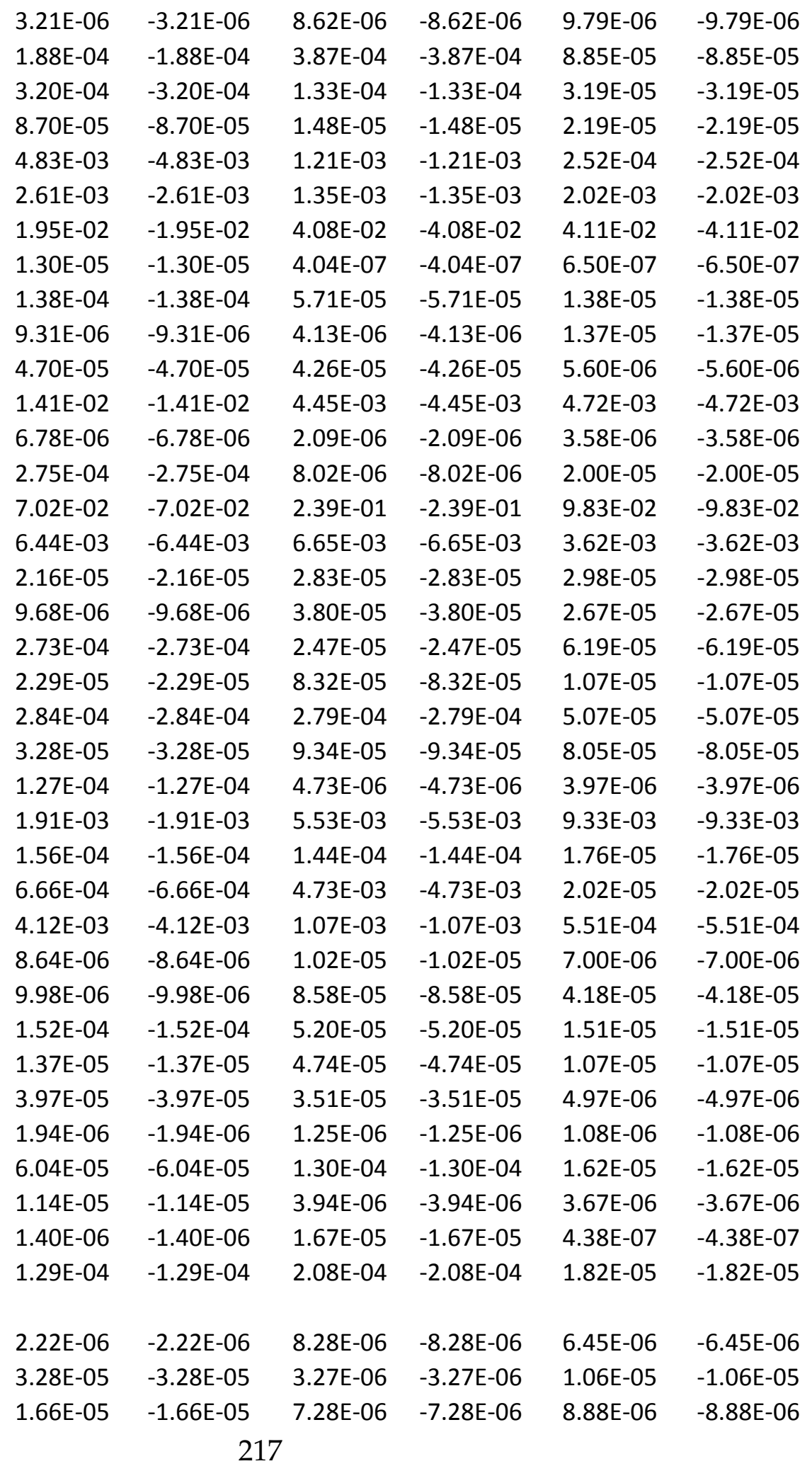


APPENDIX IV: 3-D INVERSION DATA FILE

\begin{tabular}{|c|c|c|c|c|c|c|c|}
\hline 2.50E-05 & $-2.50 \mathrm{E}-05$ & $2.95 \mathrm{E}-05$ & $-2.95 \mathrm{E}-05$ & 3.11E-06 & $-3.11 E-06$ & $7.26 \mathrm{E}-06$ & $-7.26 \mathrm{E}-06$ \\
\hline $7.28 \mathrm{E}-05$ & $-7.28 \mathrm{E}-05$ & $1.74 \mathrm{E}-04$ & $-1.74 \mathrm{E}-04$ & $1.11 \mathrm{E}-04$ & $-1.11 \mathrm{E}-04$ & $2.16 \mathrm{E}-05$ & $-2.16 \mathrm{E}-05$ \\
\hline 7.48E-06 & $-7.48 \mathrm{E}-06$ & 4.05E-05 & $-4.05 E-05$ & $2.71 \mathrm{E}-05$ & $-2.71 E-05$ & 6.37E-06 & $-6.37 E-06$ \\
\hline 2.00E-05 & $-2.00 \mathrm{E}-05$ & $1.43 \mathrm{E}-04$ & $-1.43 E-04$ & $2.01 \mathrm{E}-04$ & $-2.01 E-04$ & 4.65E-05 & $-4.65 E-05$ \\
\hline 2.53E-06 & $-2.53 \mathrm{E}-06$ & 1.10E-05 & $-1.10 \mathrm{E}-05$ & $3.88 \mathrm{E}-07$ & $-3.88 E-07$ & 5.92E-07 & $-5.92 E-07$ \\
\hline $1.27 \mathrm{E}-05$ & $-1.27 \mathrm{E}-05$ & 8.08E-05 & $-8.08 \mathrm{E}-05$ & $3.24 \mathrm{E}-05$ & $-3.24 \mathrm{E}-05$ & 7.91E-06 & -7.91E-06 \\
\hline 6.80E-06 & $-6.80 \mathrm{E}-06$ & 6.87E-06 & $-6.87 E-06$ & $3.46 \mathrm{E}-06$ & $-3.46 \mathrm{E}-06$ & $1.08 \mathrm{E}-05$ & $-1.08 \mathrm{E}-05$ \\
\hline 2.15E-05 & $-2.15 \mathrm{E}-05$ & 5.98E-05 & $-5.98 \mathrm{E}-05$ & 4.70E-05 & $-4.70 \mathrm{E}-05$ & 7.46E-06 & $-7.46 \mathrm{E}-06$ \\
\hline 6.90E-03 & $-6.90 \mathrm{E}-03$ & 7.31E-03 & $-7.31 E-03$ & $2.43 \mathrm{E}-03$ & $-2.43 E-03$ & $2.48 \mathrm{E}-03$ & $-2.48 \mathrm{E}-03$ \\
\hline $3.95 \mathrm{E}-06$ & $-3.95 E-06$ & $3.72 \mathrm{E}-06$ & $-3.72 E-06$ & $1.06 \mathrm{E}-06$ & $-1.06 E-06$ & $2.15 \mathrm{E}-06$ & $-2.15 E-06$ \\
\hline 1.47E-05 & $-1.47 \mathrm{E}-05$ & 2.19E-04 & $-2.19 E-04$ & $3.29 E-05$ & $-3.29 E-05$ & 1.60E-05 & $-1.60 \mathrm{E}-05$ \\
\hline $2.92 \mathrm{E}-02$ & $-2.92 \mathrm{E}-02$ & 7.02E-02 & $-7.02 E-02$ & 2.39E-01 & $-2.39 \mathrm{E}-01$ & $9.83 \mathrm{E}-02$ & $-9.83 E-02$ \\
\hline 3.69E-05 & $-3.69 \mathrm{E}-05$ & 5.41E-05 & $-5.41 E-05$ & $3.93 \mathrm{E}-05$ & $-3.93 E-05$ & 3.01E-05 & $-3.01 E-05$ \\
\hline 1.99E-05 & $-1.99 \mathrm{E}-05$ & $9.79 \mathrm{E}-05$ & $-9.79 E-05$ & $1.40 \mathrm{E}-04$ & $-1.40 \mathrm{E}-04$ & $-1.03 E-04$ & $-2.70 \mathrm{E}-05$ \\
\hline $9.98 \mathrm{E}-06$ & $-9.98 \mathrm{E}-06$ & $6.87 \mathrm{E}-06$ & $-6.87 E-06$ & $3.03 E-05$ & $-3.03 E-05$ & $2.21 \mathrm{E}-05$ & $-2.21 E-05$ \\
\hline $1.68 \mathrm{E}-05$ & $-1.68 \mathrm{E}-05$ & $1.48 \mathrm{E}-04$ & $-1.48 \mathrm{E}-04$ & $3.88 \mathrm{E}-06$ & $-3.88 \mathrm{E}-06$ & 3.73E-05 & $-3.73 E-05$ \\
\hline $6.22 \mathrm{E}-06$ & $-6.22 \mathrm{E}-06$ & $9.65 \mathrm{E}-06$ & $-9.65 E-06$ & $8.14 \mathrm{E}-05$ & $-8.14 \mathrm{E}-05$ & $4.92 \mathrm{E}-06$ & $-4.92 E-06$ \\
\hline 8.75E-05 & $-8.75 E-05$ & $6.47 \mathrm{E}-05$ & $-6.47 E-05$ & 7.91E-05 & $-7.91 \mathrm{E}-05$ & $6.31 \mathrm{E}-05$ & $-6.31 E-05$ \\
\hline $1.58 \mathrm{E}-05$ & $-1.58 \mathrm{E}-05$ & $2.00 \mathrm{E}-05$ & $-2.00 \mathrm{E}-05$ & $6.95 \mathrm{E}-05$ & $-6.95 E-05$ & $4.85 \mathrm{E}-05$ & $-4.85 E-05$ \\
\hline $1.22 \mathrm{E}-05$ & $-1.22 \mathrm{E}-05$ & $2.55 \mathrm{E}-05$ & $-2.55 E-05$ & $4.73 E-06$ & $-4.73 E-06$ & 3.97E-06 & $-3.97 E-06$ \\
\hline $1.89 \mathrm{E}-05$ & $-1.89 \mathrm{E}-05$ & $1.37 \mathrm{E}-05$ & $-1.37 E-05$ & $4.24 \mathrm{E}-05$ & $-4.24 \mathrm{E}-05$ & $6.70 \mathrm{E}-05$ & $-6.70 \mathrm{E}-05$ \\
\hline 4.60E-06 & $-4.60 \mathrm{E}-06$ & 1.19E-04 & $-1.19 E-04$ & $8.78 \mathrm{E}-05$ & $-8.78 \mathrm{E}-05$ & $1.35 \mathrm{E}-05$ & $-1.35 \mathrm{E}-05$ \\
\hline 6.64E-05 & $-6.64 \mathrm{E}-05$ & $6.68 \mathrm{E}-04$ & $-6.68 E-04$ & $4.36 \mathrm{E}-03$ & $-4.36 \mathrm{E}-03$ & $2.04 \mathrm{E}-05$ & $-2.04 \mathrm{E}-05$ \\
\hline 3.32E-04 & $-3.32 \mathrm{E}-04$ & $2.70 \mathrm{E}-04$ & $-2.70 \mathrm{E}-04$ & $5.63 \mathrm{E}-05$ & $-5.63 E-05$ & $3.28 \mathrm{E}-05$ & $-3.28 \mathrm{E}-05$ \\
\hline 3.13E-06 & $-3.13 E-06$ & 4.45E-06 & $-4.45 E-06$ & 4.12E-06 & $-4.12 \mathrm{E}-06$ & $1.26 \mathrm{E}-06$ & $-1.26 \mathrm{E}-06$ \\
\hline 9.36E-06 & $-9.36 \mathrm{E}-06$ & 6.39E-06 & $-6.39 E-06$ & $6.03 \mathrm{E}-05$ & $-6.03 E-05$ & $1.76 \mathrm{E}-05$ & $-1.76 E-05$ \\
\hline 3.67E-06 & $-3.67 \mathrm{E}-06$ & $7.42 \mathrm{E}-06$ & $-7.42 E-06$ & $8.36 \mathrm{E}-06$ & $-8.36 \mathrm{E}-06$ & 3.37E-06 & $-3.37 E-06$ \\
\hline 3.50E-07 & $-3.50 \mathrm{E}-07$ & 8.08E-07 & $-8.08 \mathrm{E}-07$ & $2.08 \mathrm{E}-05$ & $-2.08 \mathrm{E}-05$ & $8.42 \mathrm{E}-07$ & $-8.42 E-07$ \\
\hline 4.58E-06 & $-4.58 \mathrm{E}-06$ & 1.67E-05 & $-1.67 E-05$ & $1.96 \mathrm{E}-05$ & $-1.96 \mathrm{E}-05$ & $2.15 \mathrm{E}-06$ & $-2.15 E-06$ \\
\hline 7.17E-06 & -7.17E-06 & $3.41 \mathrm{E}-06$ & $-3.41 E-06$ & $2.42 \mathrm{E}-06$ & $-2.42 E-06$ & $2.41 \mathrm{E}-06$ & $-2.41 E-06$ \\
\hline $1.96 \mathrm{E}-05$ & $-1.96 \mathrm{E}-05$ & $1.75 \mathrm{E}-05$ & $-1.75 \mathrm{E}-05$ & 8.47E-05 & -8.47E-05 & 2.81E-06 & $-2.81 E-06$ \\
\hline 2.83E-07 & $-2.83 E-07$ & 3.36E-06 & $-3.36 \mathrm{E}-06$ & $3.02 E-06$ & $-3.02 E-06$ & $6.22 \mathrm{E}-07$ & $-6.22 E-07$ \\
\hline $6.87 \mathrm{E}-05$ & $-6.87 \mathrm{E}-05$ & 7.53E-07 & $-7.53 \mathrm{E}-07$ & $3.72 \mathrm{E}-05$ & $-3.72 E-05$ & $2.02 \mathrm{E}-07$ & $-2.02 E-07$ \\
\hline $7.48 \mathrm{E}-05$ & $-7.48 \mathrm{E}-05$ & 1.87E-04 & $-1.87 E-04$ & $2.80 \mathrm{E}-04$ & $-2.80 \mathrm{E}-04$ & $2.72 \mathrm{E}-05$ & $-2.72 E-05$ \\
\hline Period: & $8.53 E+01$ & & & & & & \\
\hline 3.39E-06 & $-3.39 E-06$ & $1.03 \mathrm{E}-05$ & $-1.03 E-05$ & $8.79 E-06$ & $-8.79 E-06$ & $4.82 \mathrm{E}-06$ & $-4.82 E-06$ \\
\hline $6.21 \mathrm{E}-06$ & $-6.21 \mathrm{E}-06$ & $8.58 \mathrm{E}-05$ & $-8.58 \mathrm{E}-05$ & $3.16 \mathrm{E}-06$ & $-3.16 \mathrm{E}-06$ & 5.94E-06 & $-5.94 \mathrm{E}-06$ \\
\hline 2.18E-05 & $-2.18 \mathrm{E}-05$ & $1.36 \mathrm{E}-05$ & $-1.36 \mathrm{E}-05$ & 7.03E-06 & $-7.03 E-06$ & $6.98 \mathrm{E}-06$ & $-6.98 E-06$ \\
\hline 2.74E-05 & $-2.74 \mathrm{E}-05$ & 2.89E-05 & $-2.89 \mathrm{E}-05$ & 4.83E-06 & $-4.83 E-06$ & $7.25 \mathrm{E}-06$ & $-7.25 E-06$ \\
\hline 4.80E-05 & $-4.80 \mathrm{E}-05$ & $1.83 \mathrm{E}-05$ & $-1.83 E-05$ & $1.29 \mathrm{E}-05$ & -1.29E-05 & 1.09E-05 & $-1.09 E-05$ \\
\hline $3.55 \mathrm{E}-06$ & $-3.55 \mathrm{E}-06$ & 3.77E-05 & $-3.77 E-05$ & $2.54 \mathrm{E}-06$ & $-2.54 \mathrm{E}-06$ & $6.63 \mathrm{E}-06$ & $-6.63 E-06$ \\
\hline $1.88 \mathrm{E}-05$ & $-1.88 \mathrm{E}-05$ & $2.96 \mathrm{E}-05$ & $-2.96 \mathrm{E}-05$ & $3.88 \mathrm{E}-05$ & $-3.88 \mathrm{E}-05$ & 5.10E-05 & $-5.10 \mathrm{E}-05$ \\
\hline & & & & & & & \\
\hline
\end{tabular}


APPENDIX IV: 3-D INVERSION DATA FILE

\begin{tabular}{|c|c|c|c|c|c|c|c|}
\hline 7.27E-06 & $-4.27 E-06$ & $1.16 \mathrm{E}-05$ & $-1.16 \mathrm{E}-05$ & $6.45 \mathrm{E}-07$ & $-6.45 E-07$ & $8.42 \mathrm{E}-07$ & $-8.42 E-07$ \\
\hline $23 \mathrm{E}-06$ & $-6.23 E-06$ & $4.58 \mathrm{E}-05$ & $-4.58 \mathrm{E}-05$ & $1.56 \mathrm{E}-05$ & $-1.56 \mathrm{E}-05$ & 4.34E-06 & $-4.34 \mathrm{E}-06$ \\
\hline 56E-06 & $-3.56 \mathrm{E}-06$ & $1.95 \mathrm{E}-05$ & $-1.95 \mathrm{E}-05$ & 8.97E-06 & -8.97E-06 & 7.96E-06 & -7.96E-06 \\
\hline $.73 E-05$ & $-1.73 \mathrm{E}-05$ & $9.25 \mathrm{E}-06$ & $-9.25 E-06$ & $7.82 \mathrm{E}-06$ & $-7.82 \mathrm{E}-06$ & $5.93 \mathrm{E}-06$ & $-5.93 E-06$ \\
\hline 76E-05 & $-4.76 \mathrm{E}-05$ & $4.96 \mathrm{E}-05$ & $-4.96 \mathrm{E}-05$ & $1.81 \mathrm{E}-05$ & $-1.81 \mathrm{E}-05$ & $1.66 \mathrm{E}-05$ & $-1.66 \mathrm{E}-05$ \\
\hline $52 \mathrm{E}-06$ & $-4.52 E-06$ & $3.91 \mathrm{E}-06$ & $-3.91 \mathrm{E}-06$ & 1.39E-06 & $-1.39 E-06$ & $1.93 \mathrm{E}-06$ & -1.93E-06 \\
\hline 1.57E-05 & $-1.57 \mathrm{E}-05$ & $1.77 \mathrm{E}-04$ & $-1.77 \mathrm{E}-04$ & $3.58 \mathrm{E}-05$ & $-3.58 \mathrm{E}-05$ & $1.35 \mathrm{E}-05$ & $-1.35 \mathrm{E}-05$ \\
\hline $84 \mathrm{E}-02$ & $-5.84 \mathrm{E}-02$ & $1.40 \mathrm{E}-01$ & $-1.40 \mathrm{E}-01$ & 4.78E-01 & $-4.78 \mathrm{E}-01$ & 1.97E-01 & -1.97E-01 \\
\hline $65 \mathrm{E}-05$ & $-6.65 E-05$ & $3.94 \mathrm{E}-04$ & $-3.94 \mathrm{E}-04$ & 3.01E-04 & $-3.01 E-04$ & $4.84 \mathrm{E}-05$ & $-4.84 \mathrm{E}-05$ \\
\hline $1.35 \mathrm{E}-05$ & $-1.35 \mathrm{E}-05$ & $6.00 \mathrm{E}-05$ & $-6.00 \mathrm{E}-05$ & $1.95 \mathrm{E}-05$ & $-1.95 \mathrm{E}-05$ & $1.66 \mathrm{E}-05$ & $-1.66 \mathrm{E}-05$ \\
\hline $.93 \mathrm{E}-06$ & $-9.93 E-06$ & $7.65 \mathrm{E}-06$ & $-7.65 E-06$ & $3.22 \mathrm{E}-05$ & $-3.22 \mathrm{E}-05$ & $2.96 \mathrm{E}-05$ & $-2.96 \mathrm{E}-05$ \\
\hline $1.14 \mathrm{E}-05$ & $-1.14 \mathrm{E}-05$ & $8.52 \mathrm{E}-05$ & $-8.52 \mathrm{E}-05$ & $2.82 \mathrm{E}-06$ & $-2.82 \mathrm{E}-06$ & $2.58 \mathrm{E}-05$ & $-2.58 \mathrm{E}-05$ \\
\hline $5.27 \mathrm{E}-06$ & $-6.27 E-06$ & $2.50 \mathrm{E}-06$ & $-2.50 \mathrm{E}-06$ & $1.60 \mathrm{E}-05$ & $-1.60 \mathrm{E}-05$ & $6.31 \mathrm{E}-06$ & $-6.31 E-06$ \\
\hline $.75 \mathrm{E}-05$ & $-8.75 E-05$ & $6.47 \mathrm{E}-05$ & $-6.47 \mathrm{E}-05$ & 7.91E-05 & -7.91E-05 & $6.31 \mathrm{E}-05$ & $-6.31 E-05$ \\
\hline 4.57E-05 & $-4.57 \mathrm{E}-05$ & 5.07E-05 & $-5.07 E-05$ & $1.46 \mathrm{E}-04$ & $-1.46 \mathrm{E}-04$ & $1.32 \mathrm{E}-04$ & $-1.32 \mathrm{E}-04$ \\
\hline $.14 \mathrm{E}-06$ & $-8.14 \mathrm{E}-06$ & $6.60 \mathrm{E}-05$ & $-6.60 \mathrm{E}-05$ & $3.40 \mathrm{E}-06$ & $-3.40 \mathrm{E}-06$ & 2.17E-06 & $-2.17 E-06$ \\
\hline $1.38 \mathrm{E}-05$ & $-1.38 \mathrm{E}-05$ & $9.80 \mathrm{E}-06$ & $-9.80 \mathrm{E}-06$ & 3.12E-05 & $-3.12 \mathrm{E}-05$ & 4.61E-05 & $-4.61 \mathrm{E}-05$ \\
\hline $3.40 \mathrm{E}-06$ & $-3.40 \mathrm{E}-06$ & $1.72 \mathrm{E}-05$ & $-1.72 \mathrm{E}-05$ & $1.23 \mathrm{E}-05$ & $-1.23 \mathrm{E}-05$ & $9.49 \mathrm{E}-06$ & $-9.49 E-06$ \\
\hline $.82 \mathrm{E}-05$ & $-3.82 E-05$ & 7.15E-06 & $-7.15 E-06$ & 4.95E-05 & $-4.95 E-05$ & $1.06 \mathrm{E}-05$ & $-1.06 \mathrm{E}-05$ \\
\hline $6.80 \mathrm{E}-05$ & $-6.80 \mathrm{E}-05$ & $1.15 \mathrm{E}-04$ & $-1.15 \mathrm{E}-04$ & $1.30 \mathrm{E}-05$ & $-1.30 \mathrm{E}-05$ & 1.17E-05 & -1.17E-05 \\
\hline $2.86 \mathrm{E}-06$ & $-2.86 \mathrm{E}-06$ & $2.56 \mathrm{E}-05$ & $-2.56 \mathrm{E}-05$ & $4.71 \mathrm{E}-06$ & $-4.71 \mathrm{E}-06$ & $1.42 \mathrm{E}-05$ & $-1.42 \mathrm{E}-05$ \\
\hline 5.31E-05 & $-5.31 E-05$ & $1.93 \mathrm{E}-05$ & $-1.93 \mathrm{E}-05$ & $1.12 \mathrm{E}-04$ & $-1.12 \mathrm{E}-04$ & $3.46 \mathrm{E}-05$ & $-3.46 \mathrm{E}-05$ \\
\hline $2.48 \mathrm{E}-06$ & $-2.48 \mathrm{E}-06$ & 8.97E-05 & -8.97E-05 & $6.86 \mathrm{E}-07$ & $-6.86 E-07$ & $3.54 \mathrm{E}-04$ & $-3.54 \mathrm{E}-04$ \\
\hline $3.42 \mathrm{E}-06$ & $-3.42 \mathrm{E}-06$ & $1.54 \mathrm{E}-05$ & $-1.54 \mathrm{E}-05$ & 4.67E-05 & $-4.67 \mathrm{E}-05$ & $6.56 \mathrm{E}-06$ & $-6.56 \mathrm{E}-06$ \\
\hline $1.66 \mathrm{E}-04$ & $-1.66 \mathrm{E}-04$ & $1.02 \mathrm{E}-04$ & $-1.02 \mathrm{E}-04$ & $2.25 \mathrm{E}-04$ & $-2.25 \mathrm{E}-04$ & $2.74 \mathrm{E}-05$ & $-2.74 \mathrm{E}-05$ \\
\hline $9.02 \mathrm{E}-07$ & $-9.02 E-07$ & $1.39 \mathrm{E}-06$ & $-1.39 E-06$ & 7.33E-07 & $-7.33 E-07$ & 2.37E-07 & $-2.37 E-07$ \\
\hline $1.06 \mathrm{E}-04$ & $-1.06 \mathrm{E}-04$ & $1.68 \mathrm{E}-05$ & $-1.68 \mathrm{E}-05$ & $2.58 \mathrm{E}-04$ & $-2.58 \mathrm{E}-04$ & $2.40 \mathrm{E}-06$ & $-2.40 \mathrm{E}-06$ \\
\hline $2.67 \mathrm{E}-07$ & $-2.67 \mathrm{E}-07$ & $5.87 \mathrm{E}-06$ & $-5.87 \mathrm{E}-06$ & 3.01E-06 & $-3.01 E-06$ & $3.34 \mathrm{E}-06$ & $-3.34 \mathrm{E}-06$ \\
\hline $1.68 \mathrm{E}-04$ & $-1.68 \mathrm{E}-04$ & 5.87E-06 & $-5.87 \mathrm{E}-06$ & $6.14 \mathrm{E}-04$ & $-6.14 \mathrm{E}-04$ & $5.31 \mathrm{E}-07$ & $-5.31 E-07$ \\
\hline $3.90 \mathrm{E}-06$ & $-3.90 \mathrm{E}-06$ & $1.55 \mathrm{E}-05$ & $-1.55 \mathrm{E}-05$ & $3.32 \mathrm{E}-05$ & $-3.32 \mathrm{E}-05$ & $3.34 \mathrm{E}-06$ & $-3.34 \mathrm{E}-06$ \\
\hline
\end{tabular}


Appendix V: 3-D inversion curve fit 
APPENDIX V: 3-D INVERSION CURVE FIT

Apparent Resistivity (XY,YX) for site 3 Apparent Resistivity (XX,YM) for site 3
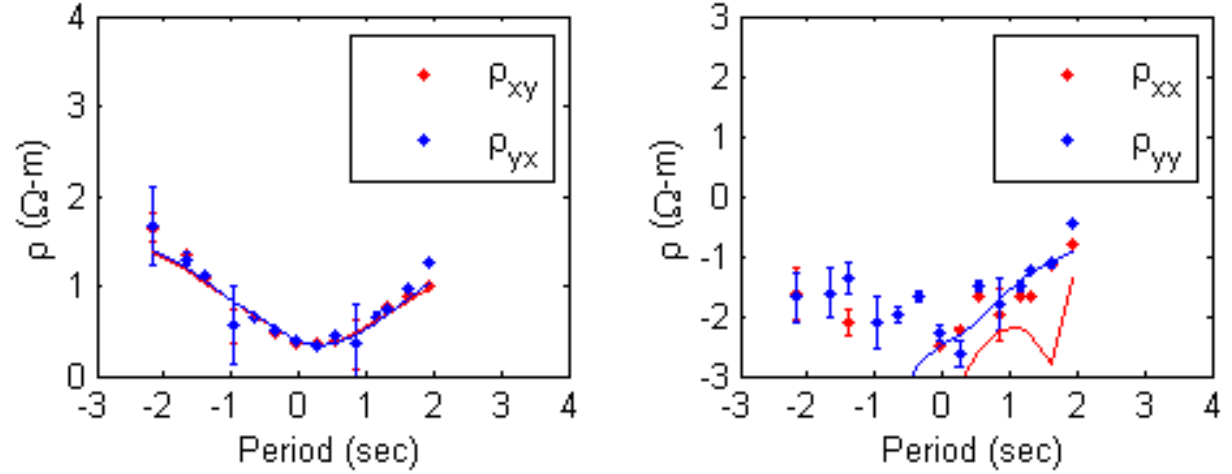

Phase (XY,YX) for site 3

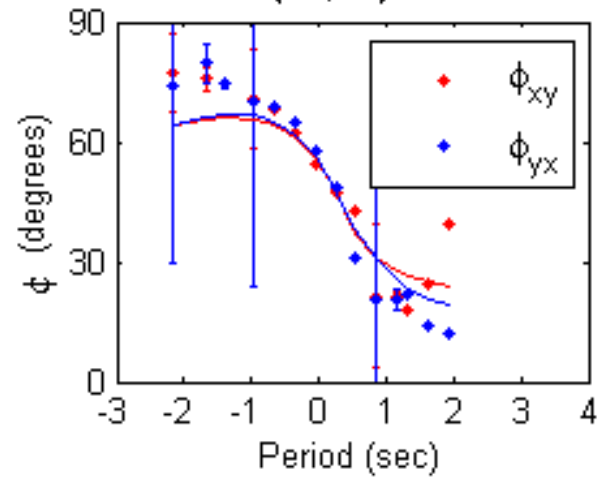

Phase $(X X, Y)$ for site 3

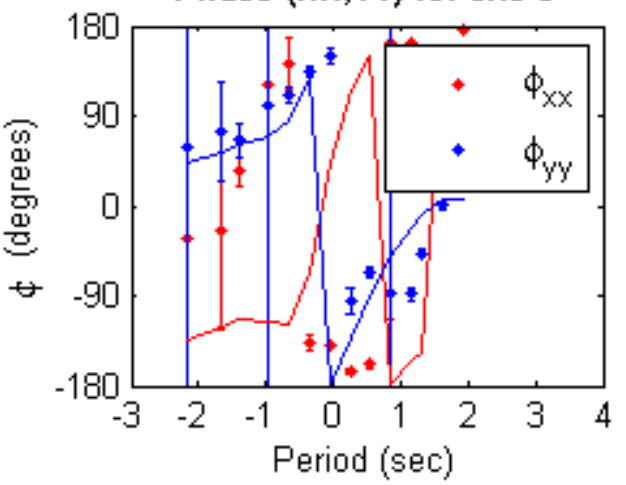

Apparent Resistivity (XY,YX) for site 4 Apparent Resistivity (XX,YY) for site 4
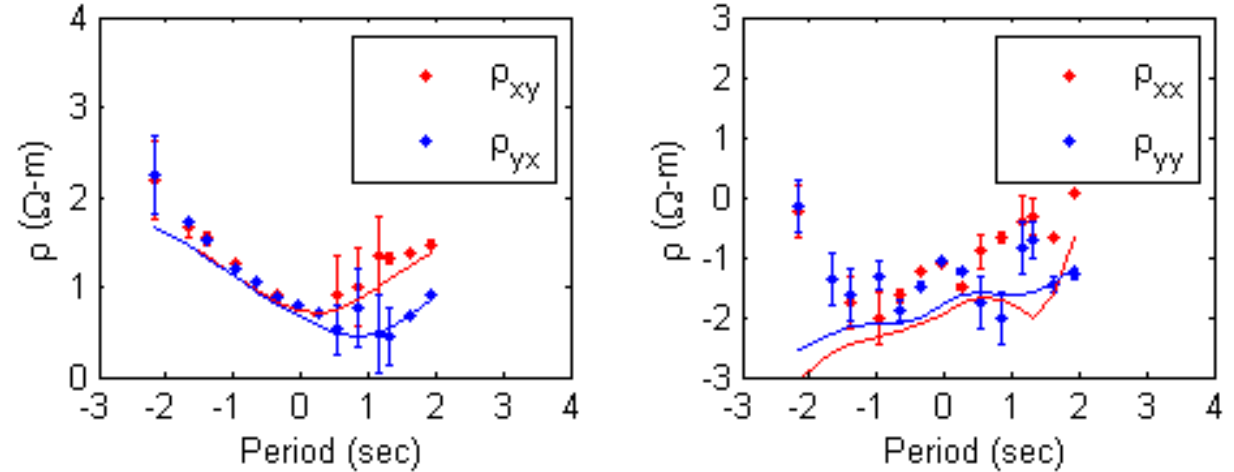

Phase $(X Y, Y X)$ for site 4
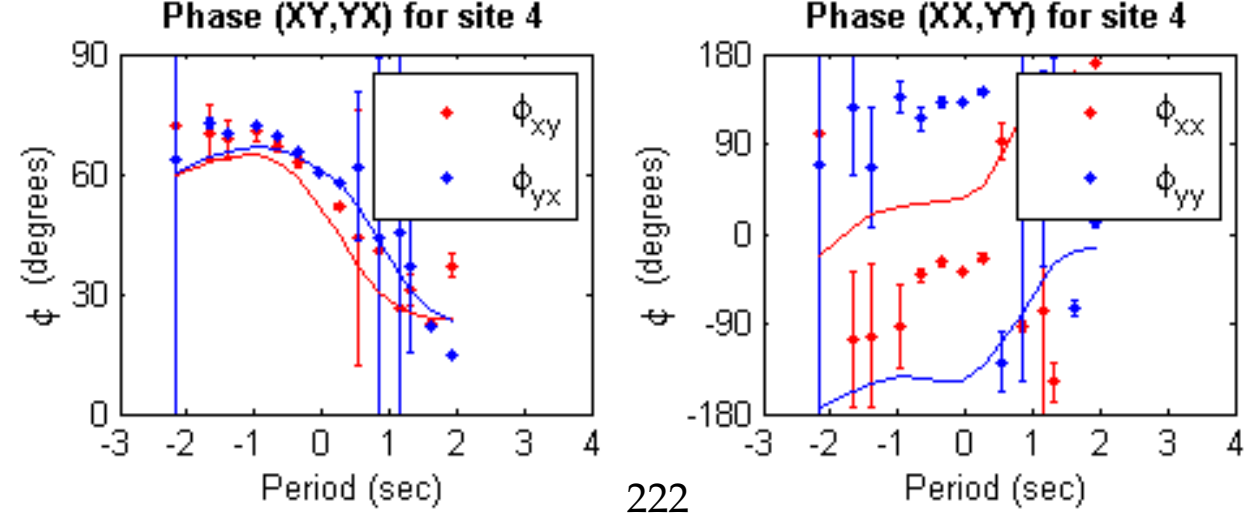
APPENDIX V: 3-D INVERSION CURVE FIT

Apparent Resistivity (XY,YX) for site 10 Apparent Resistivity (XX,Y) for site 10
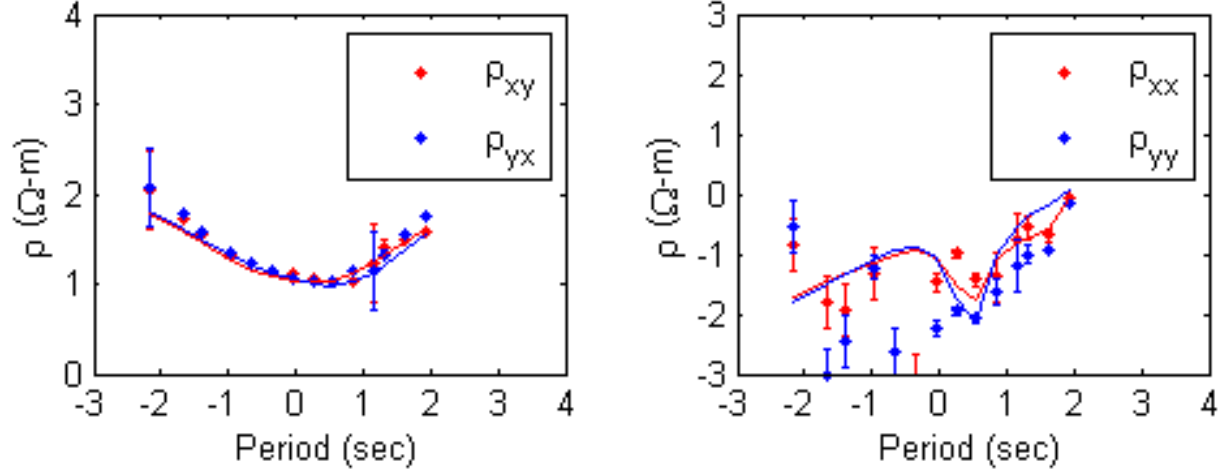

Phase $(X Y, Y X)$ for site 10

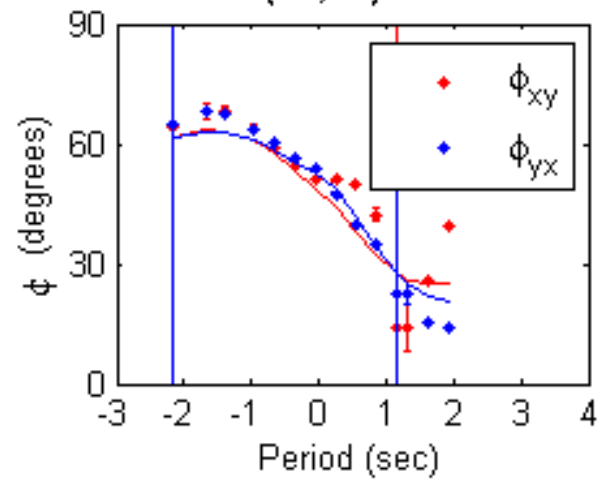

Phase (XX,YM) for site 10

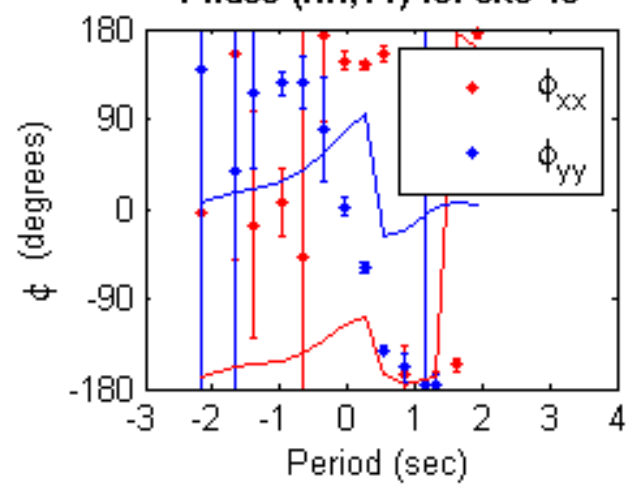

Apparent Resistivity (XY,YX) for site 12 Apparent Resistivity (XX,M) for site 12
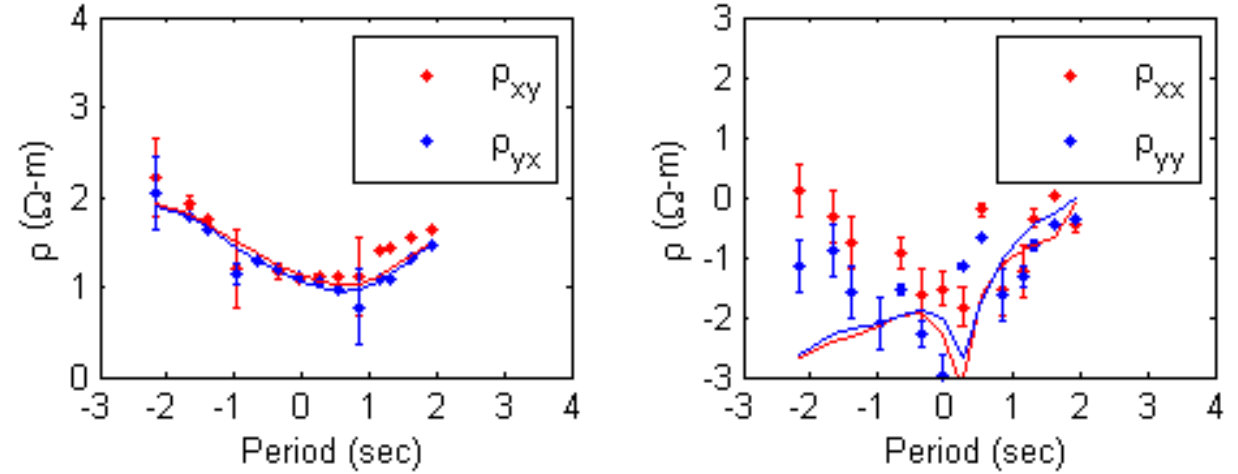

Phase $(X Y, Y X)$ for site 12
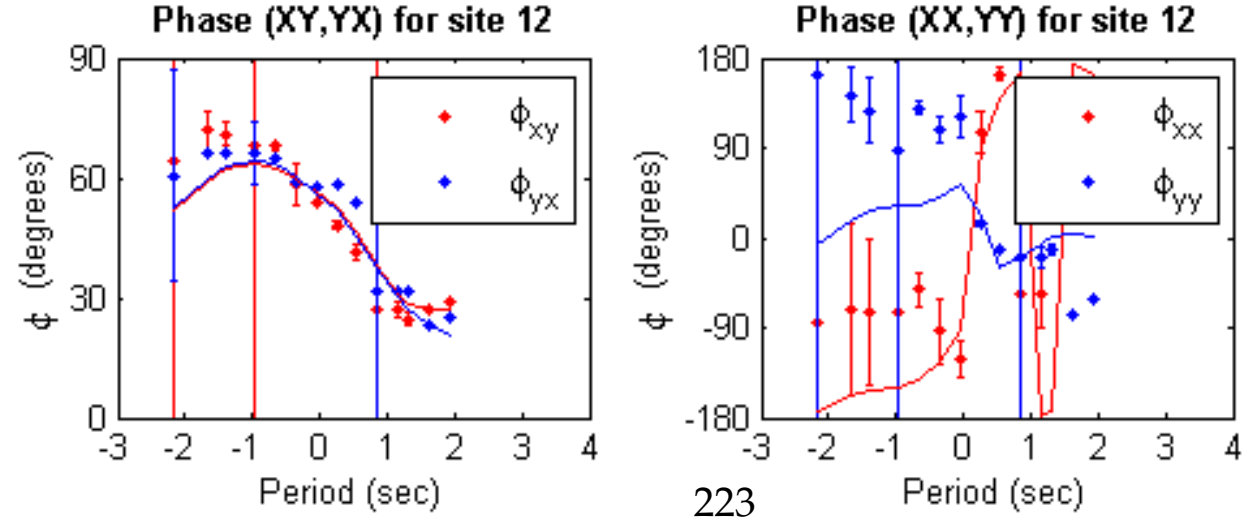
APPENDIX V: 3-D INVERSION CURVE FIT

Apparent Resistivity (XY,YX) for site 14 Apparent Resistivity (XX,YM) for site 14
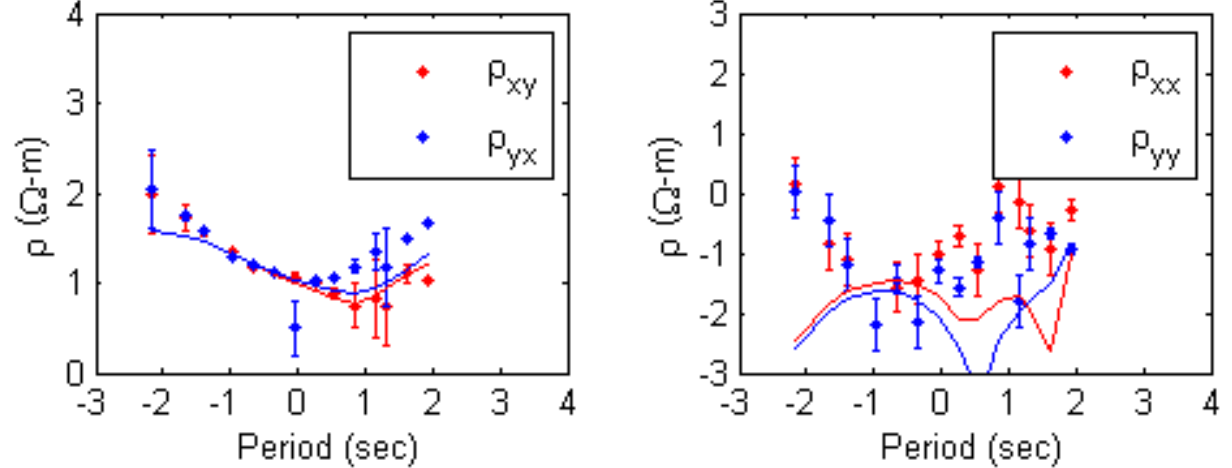

Phase $(X Y, Y X)$ for site 14

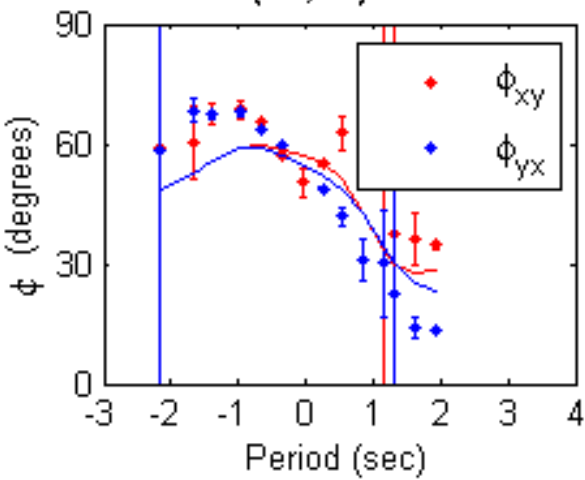

Phase (XX,Y) for site 14

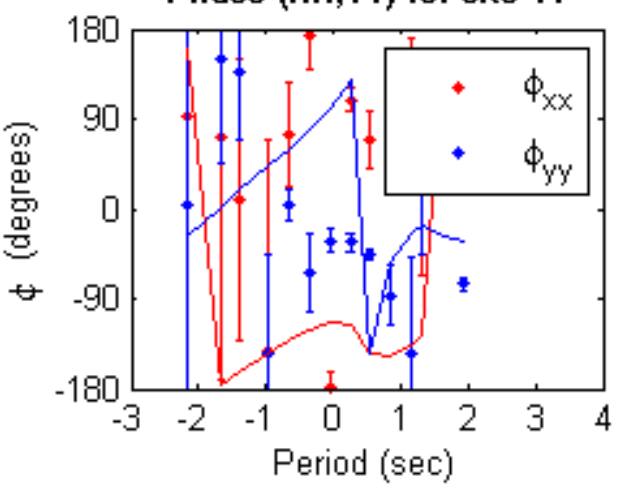

Apparent Resistivity (XY,YX) for site 19 Apparent Resistivity (XX,M) for site 19
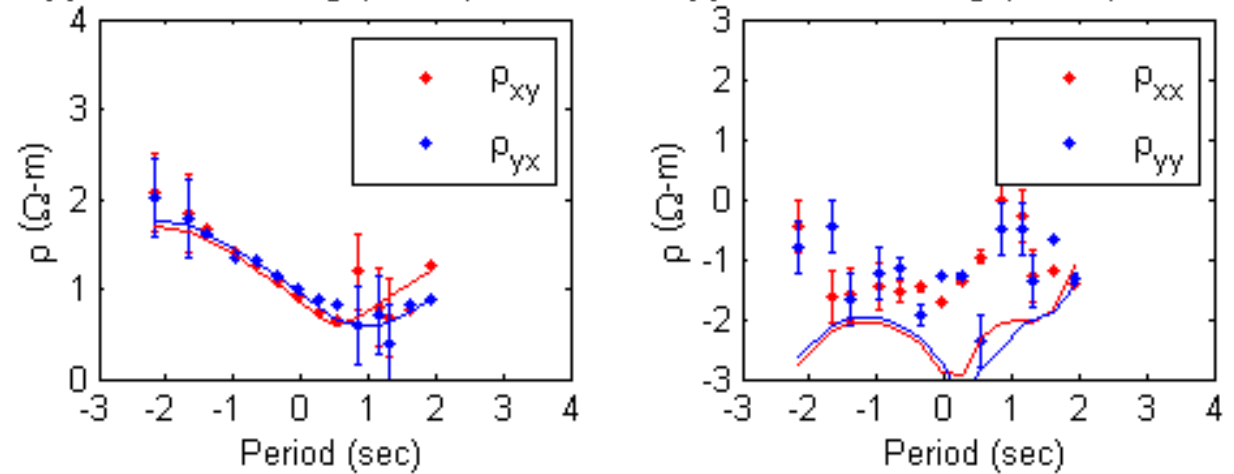

Phase $(X Y, Y X)$ for site 19
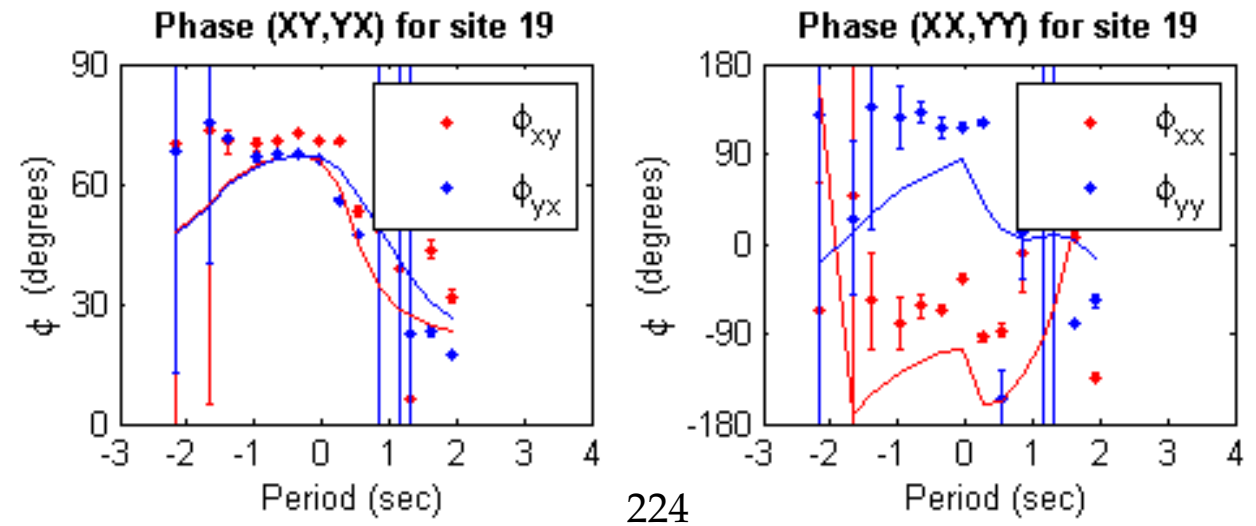
APPENDIX V: 3-D INVERSION CURVE FIT

Apparent Resistivity (XY,YX) for site 24 Apparent Resistivity (XX,Y) for site 24
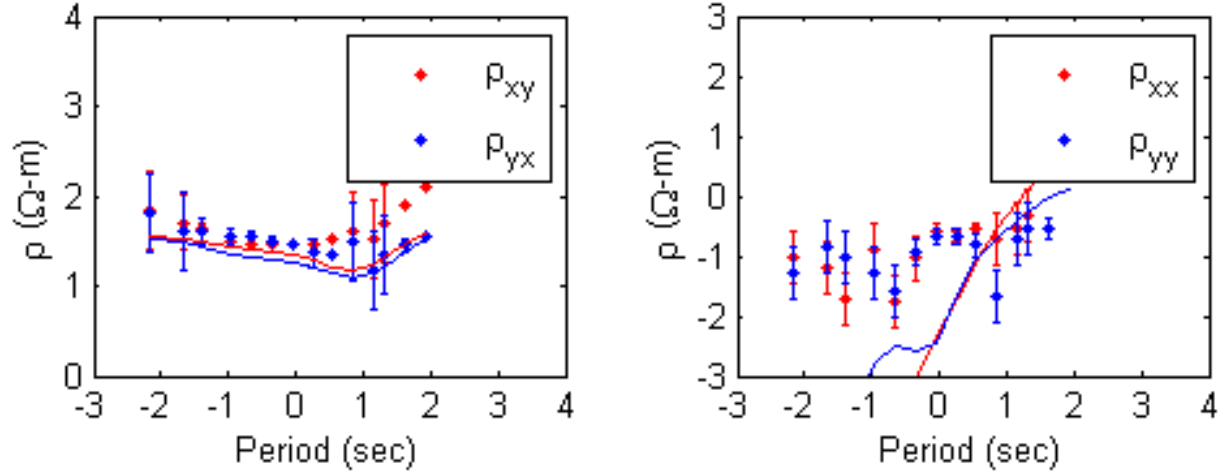

Phase (XY,YX) for site 24

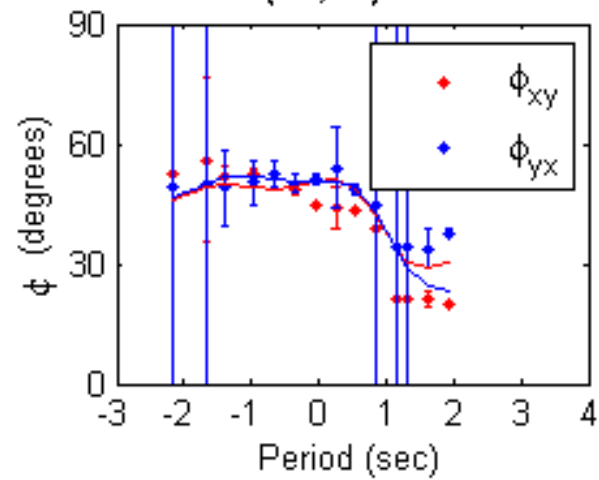

Phase (XX,Y) for site 24

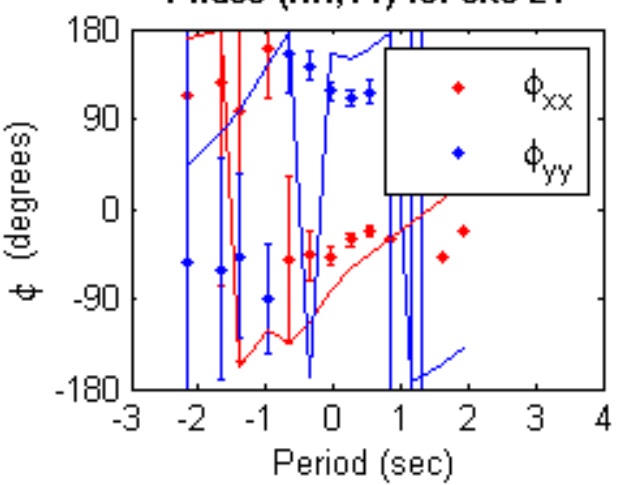

Apparent Resistivity (XY,YX) for site 27 Apparent Resistivity (XX,Y) for site 27
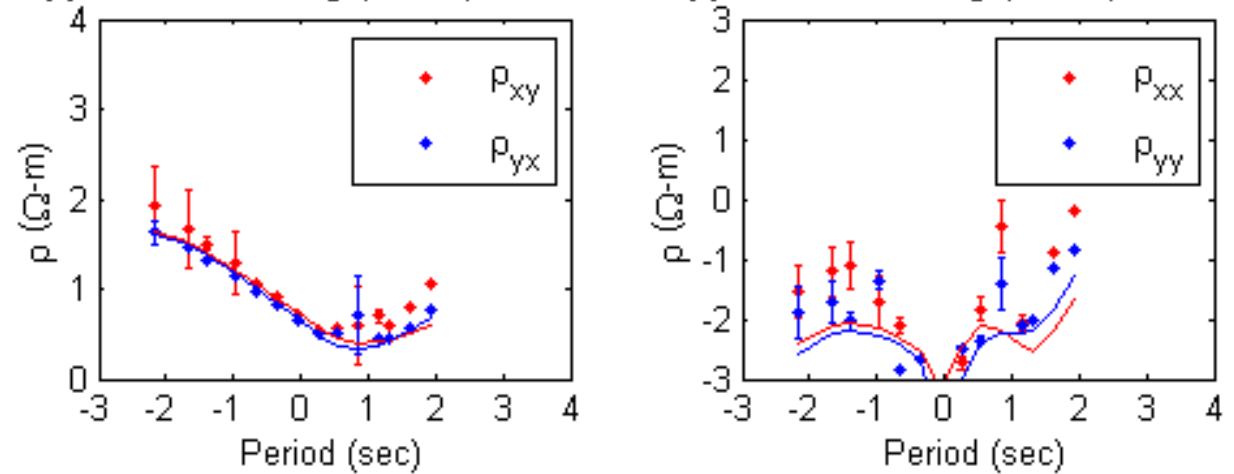

Phase $(X Y, Y X)$ for site 27
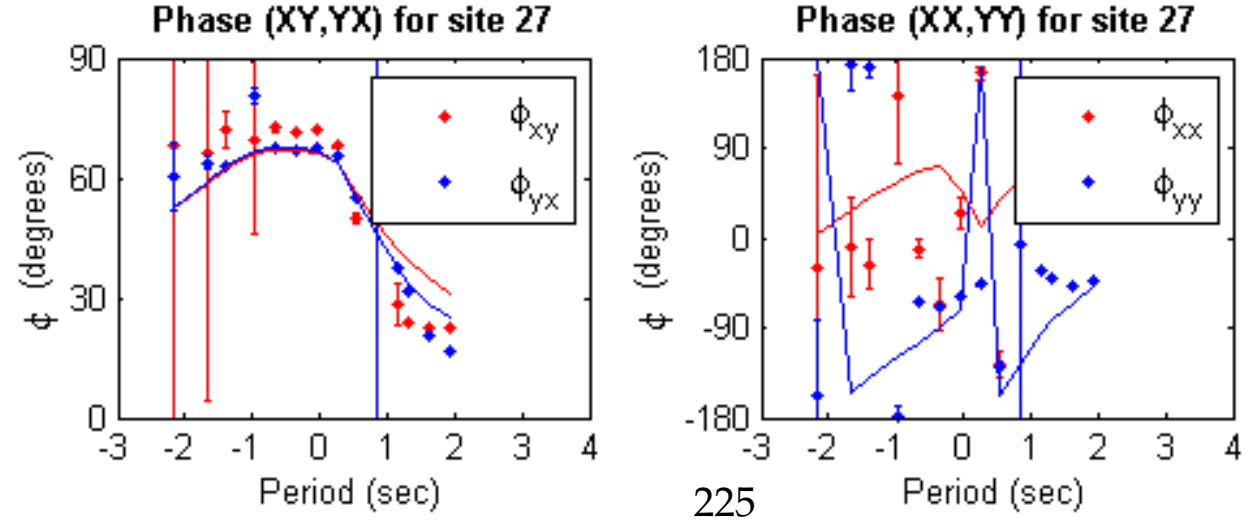
APPENDIX V: 3-D INVERSION CURVE FIT

Apparent Resistivity (XY,YX) for site 37 Apparent Resistivity (XX,YM) for site 37
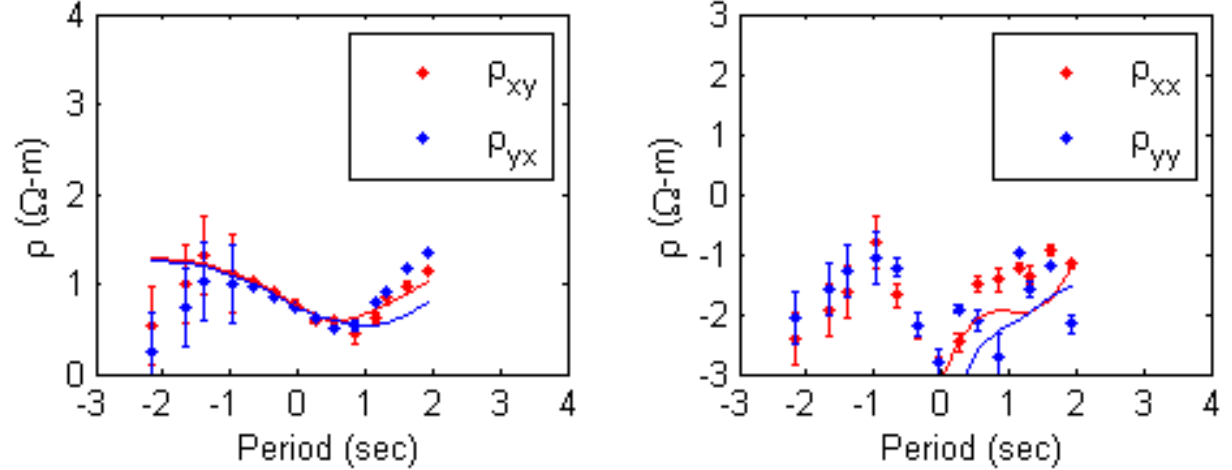

Phase (XY,YX) for site 37

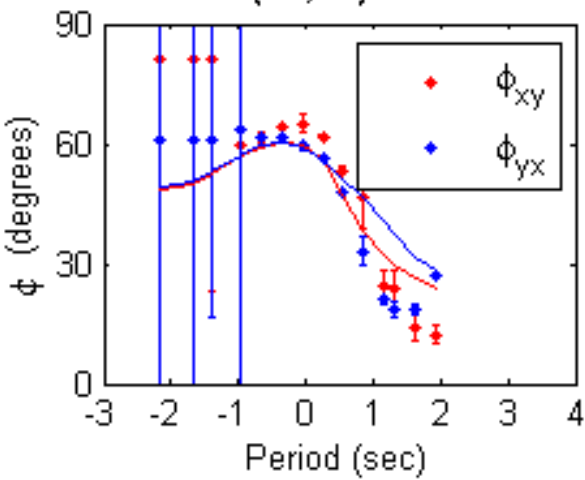

Phase (XX,Y) for site 37

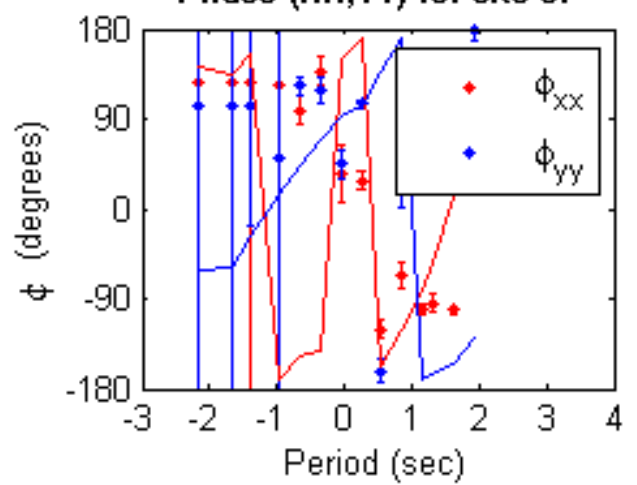

Apparent Resistivity (XY,YX) for site 42 Apparent Resistivity (XX,M) for site 42
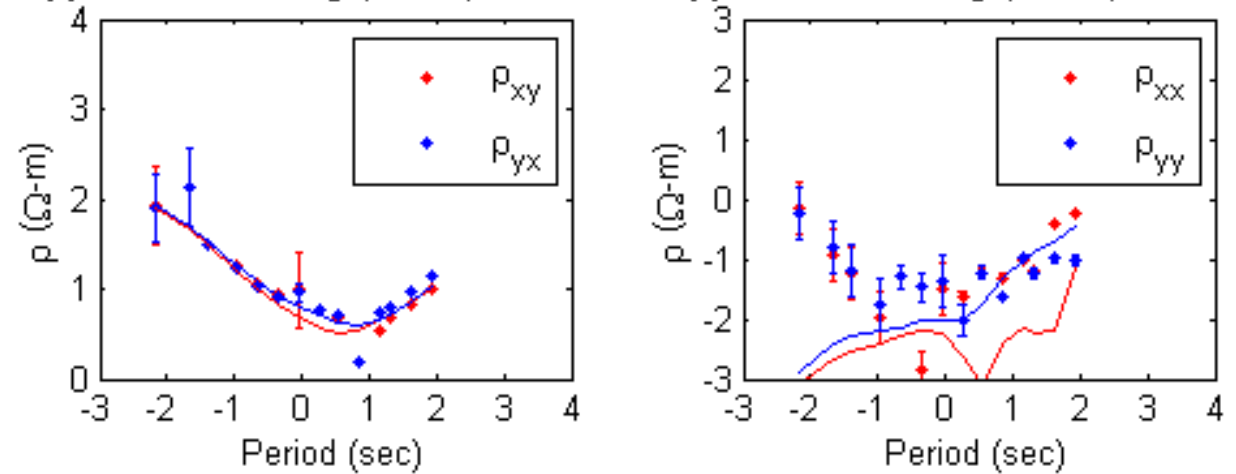

Phase $(X Y, Y X)$ for site 42
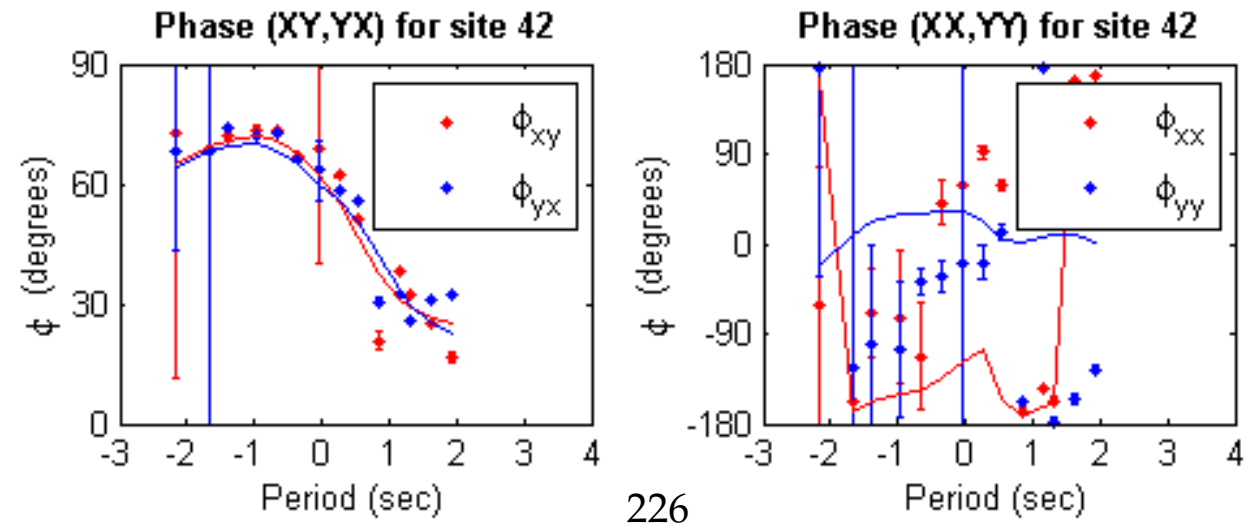
APPENDIX V: 3-D INVERSION CURVE FIT

Apparent Resistivity (XY,YX) for site 43 Apparent Resistivity (XX,M) for site 43
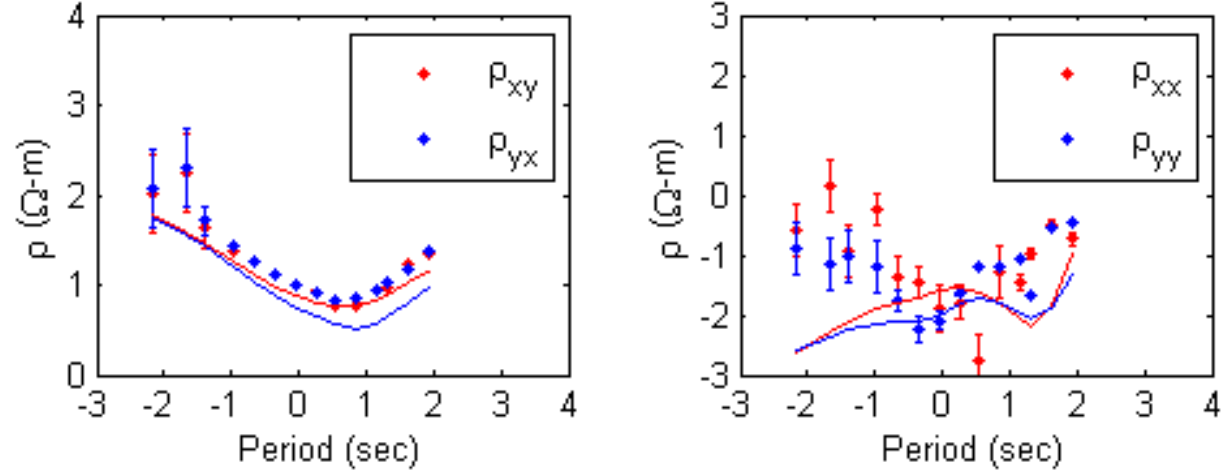

Phase $(X Y, Y X)$ for site 43

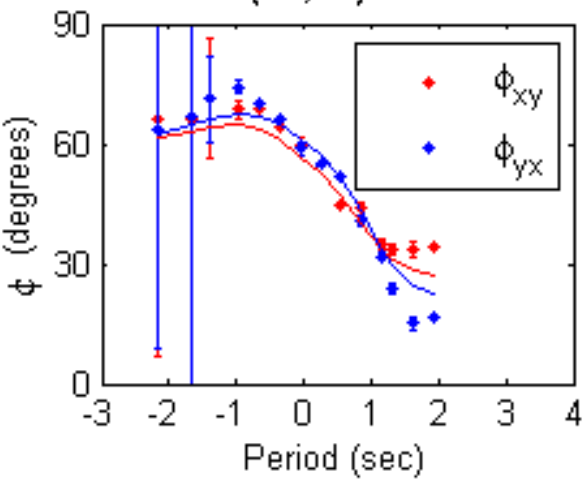

Phase (XX,Y) for site 43

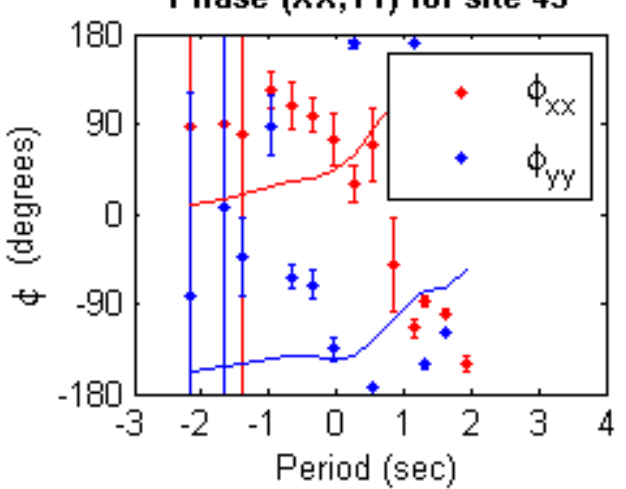

Apparent Resistivity (XY,YX) for site 46 Apparent Resistivity (XX,Y) for site 46
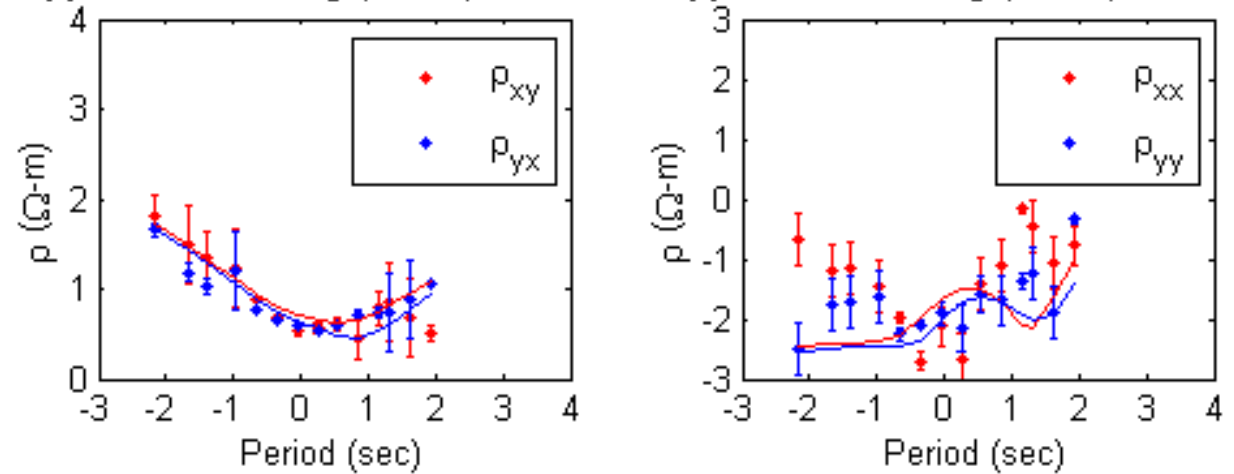

Phase $(X Y, Y X)$ for site 46
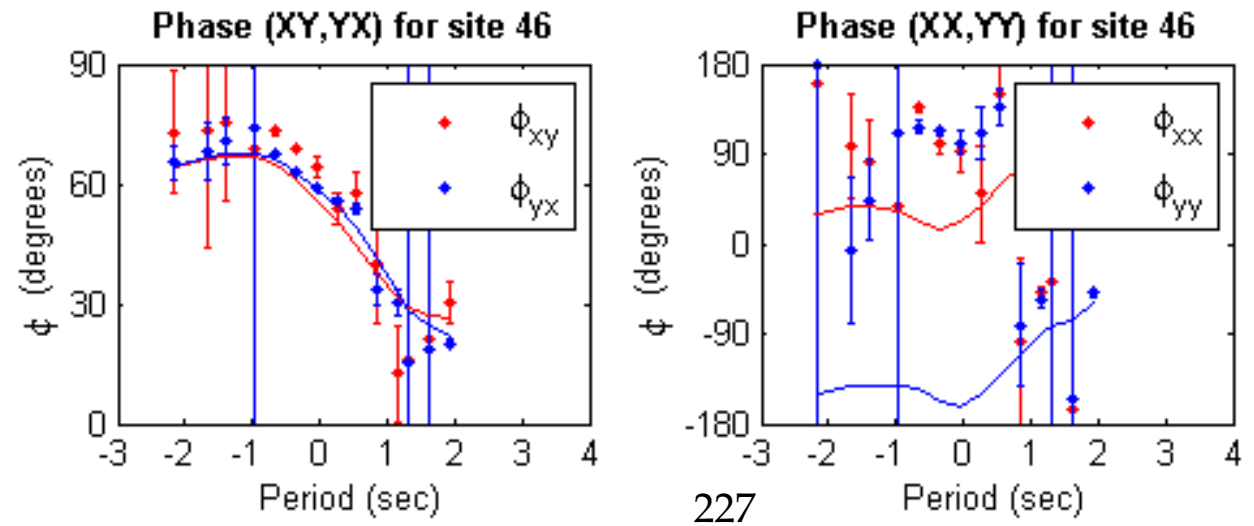
APPENDIX V: 3-D INVERSION CURVE FIT

Apparent Resistivity (XY,YX) for site 48 Apparent Resistivity (XX,YM) for site 48
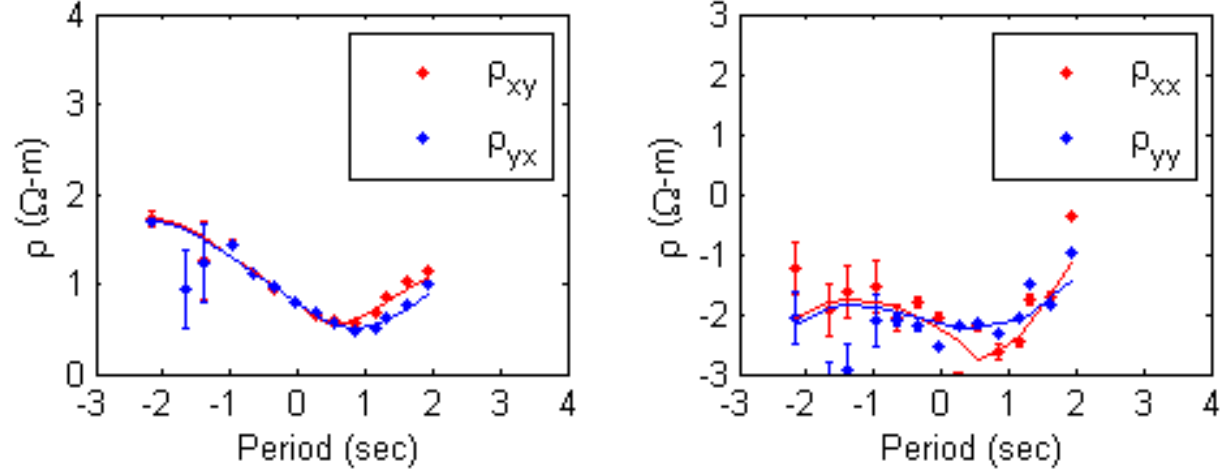

Phase $(X Y, Y X)$ for site 48

Phase (XX,Y) for site 48
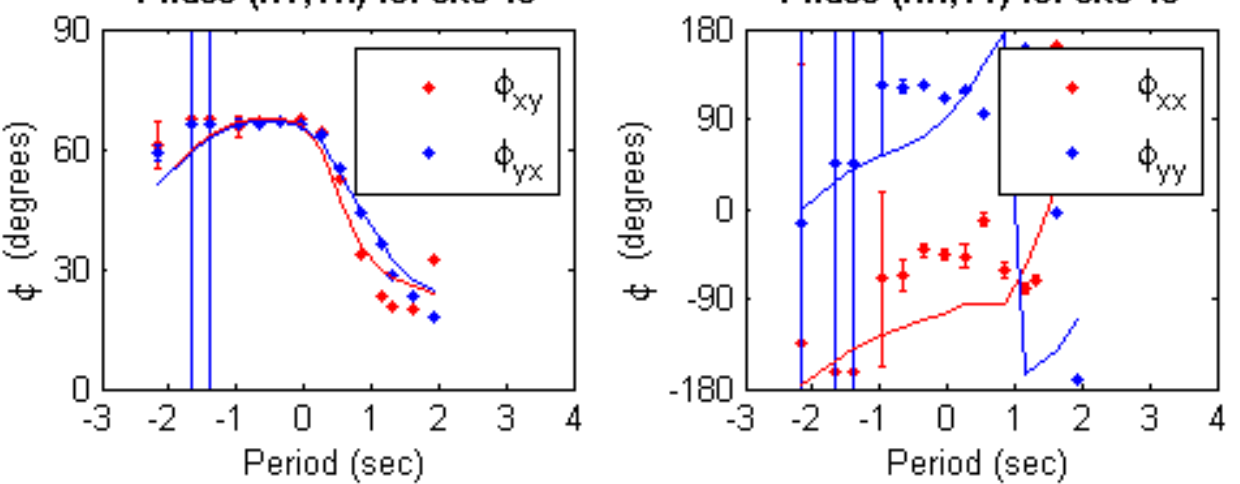

Apparent Resistivity (XY,YX) for site 51 Apparent Resistivity (XX,M) for site 51
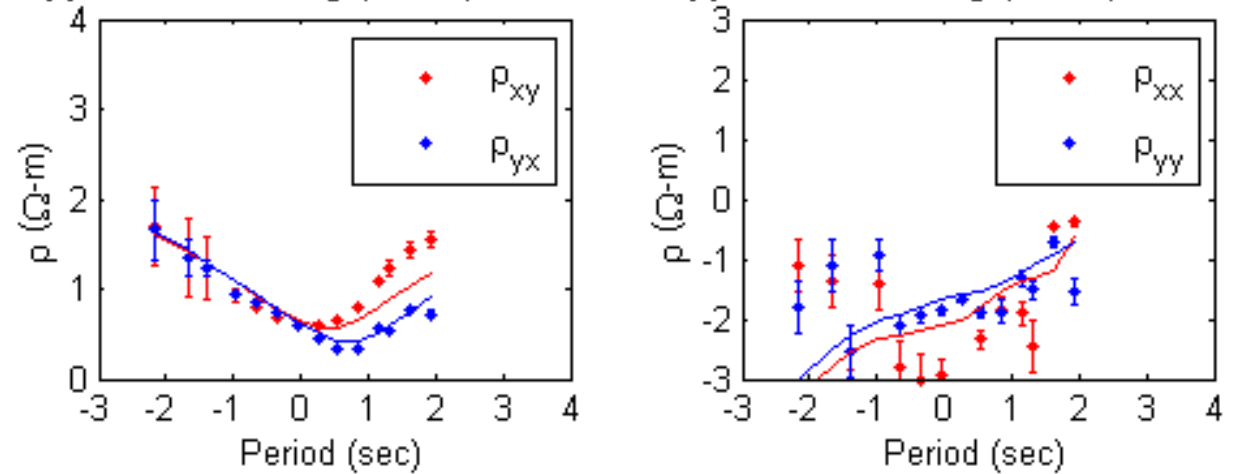

Phase $(X Y, Y X)$ for site 51
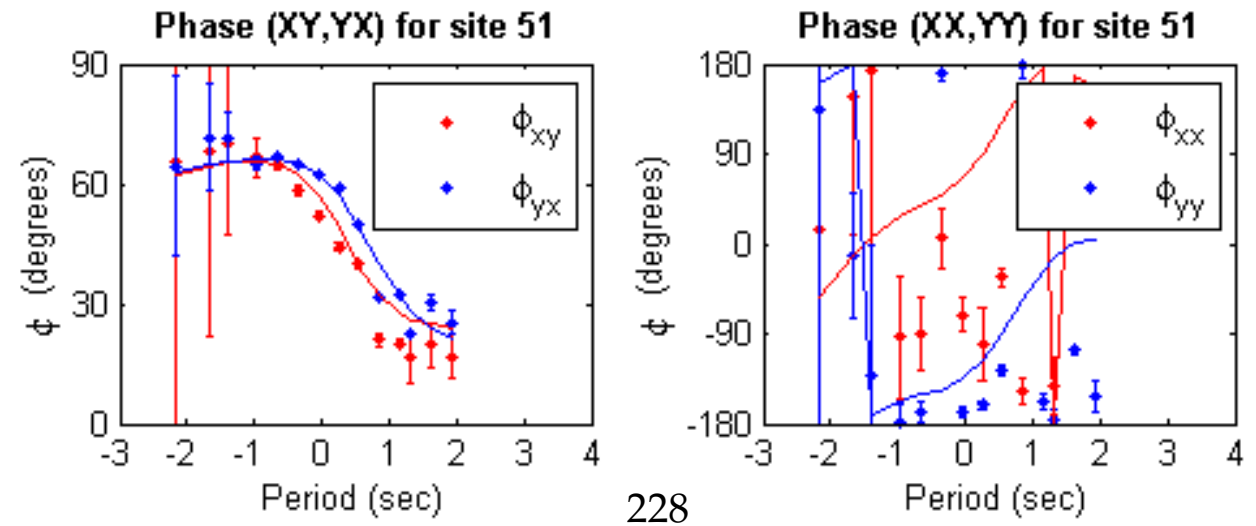
APPENDIX V: 3-D INVERSION CURVE FIT

Apparent Resistivity (XY,YX) for site 54 Apparent Resistivity (XX,Y) for site 54
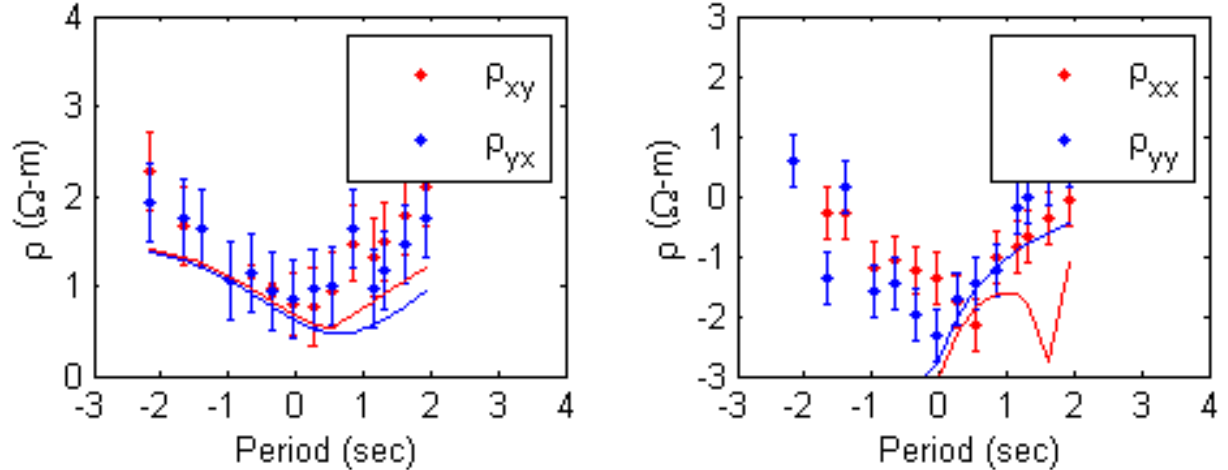

Phase (XY,YX) for site $\mathbf{5 4}$

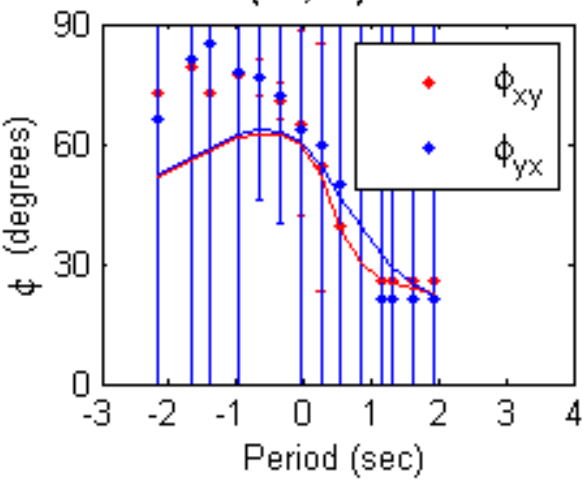

Phase (XX,YY) for site $\mathbf{5 4}$

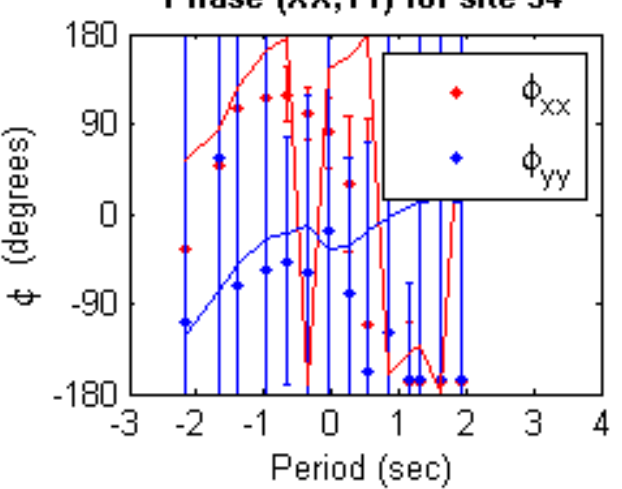

Apparent Resistivity (XY,YX) for site 55 Apparent Resistivity (XX,M) for site 55
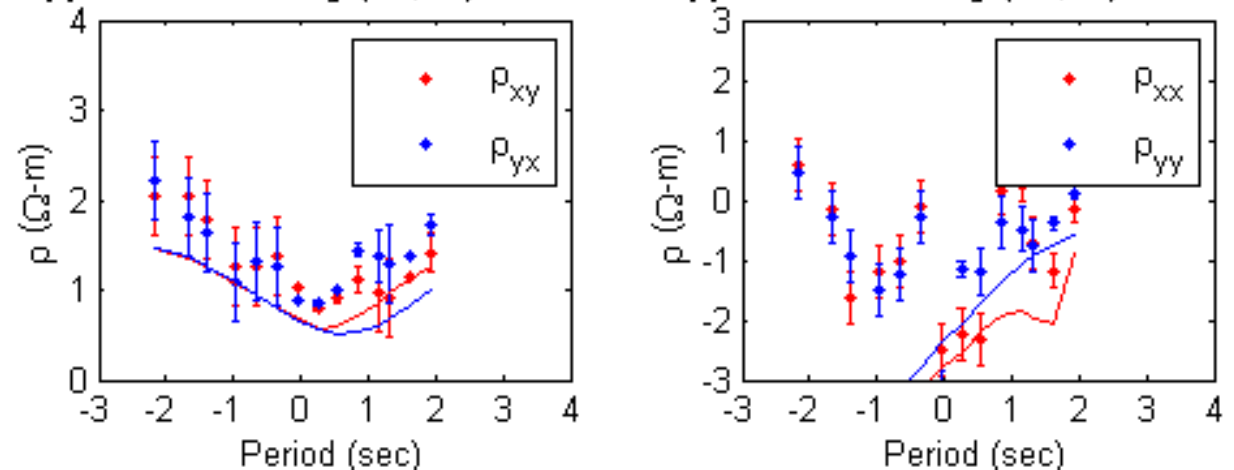

Phase (XY,YX) for site 55
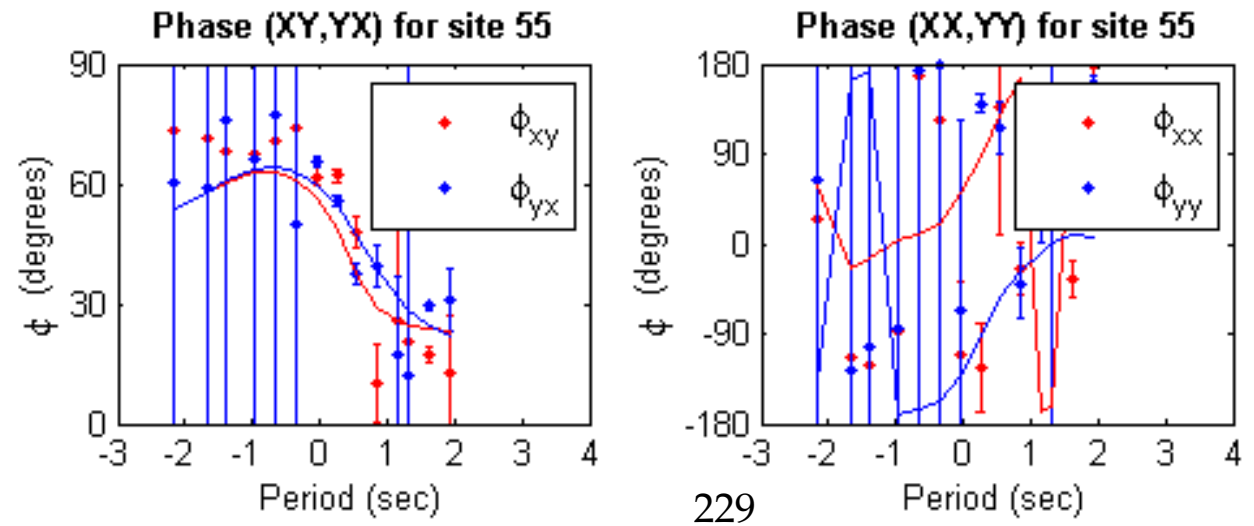
APPENDIX V: 3-D INVERSION CURVE FIT

Apparent Resistivity (XY,YX) for site 58 Apparent Resistivity (XX,Y) for site 58
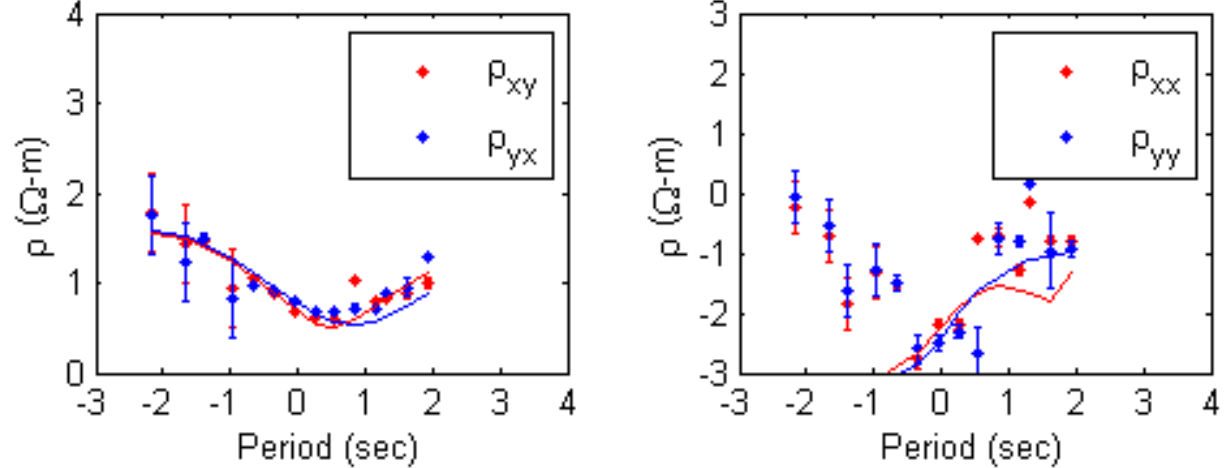

Phase $(X Y, Y X)$ for site 58

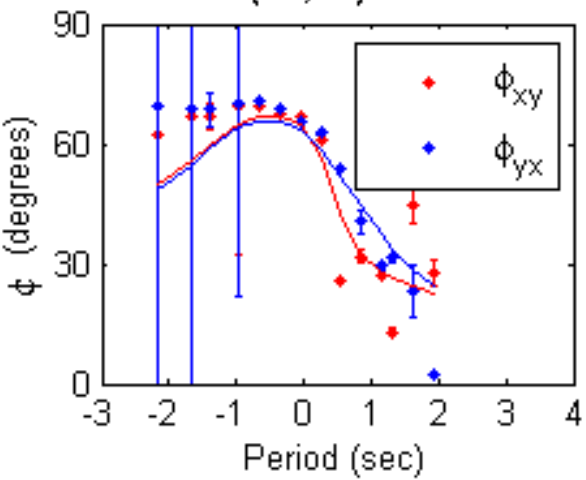

Phase $(X X, Y)$ for site 58

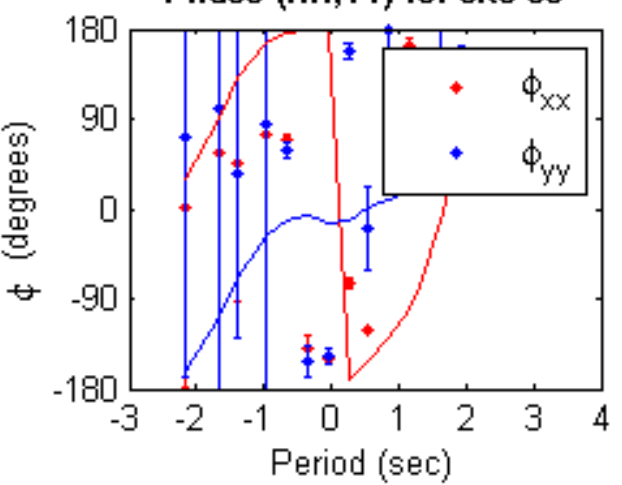

Apparent Resistivity (XY,YX) for site 60 Apparent Resistivity (XX,M) for site 60
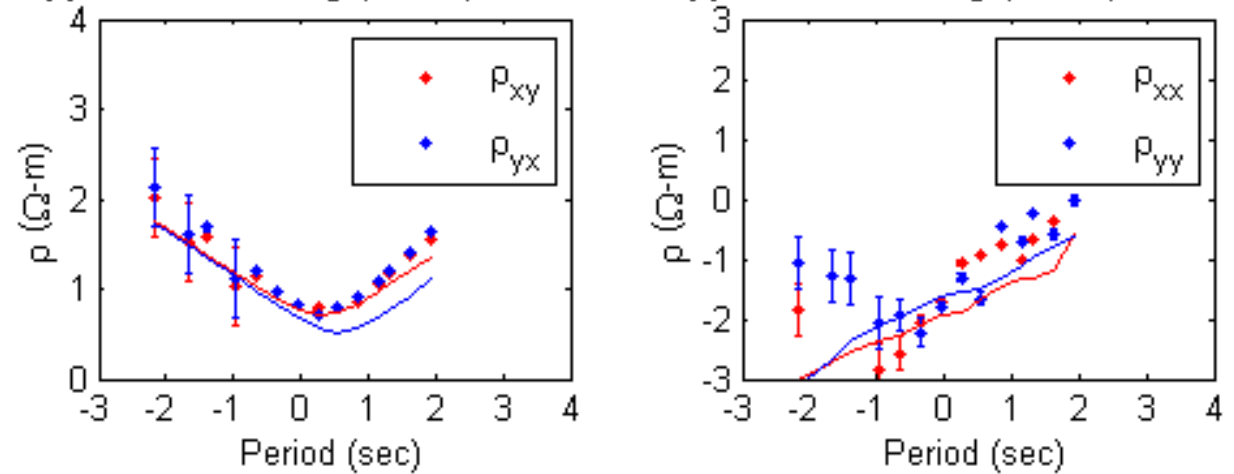

Phase $(X Y, Y X)$ for site 60
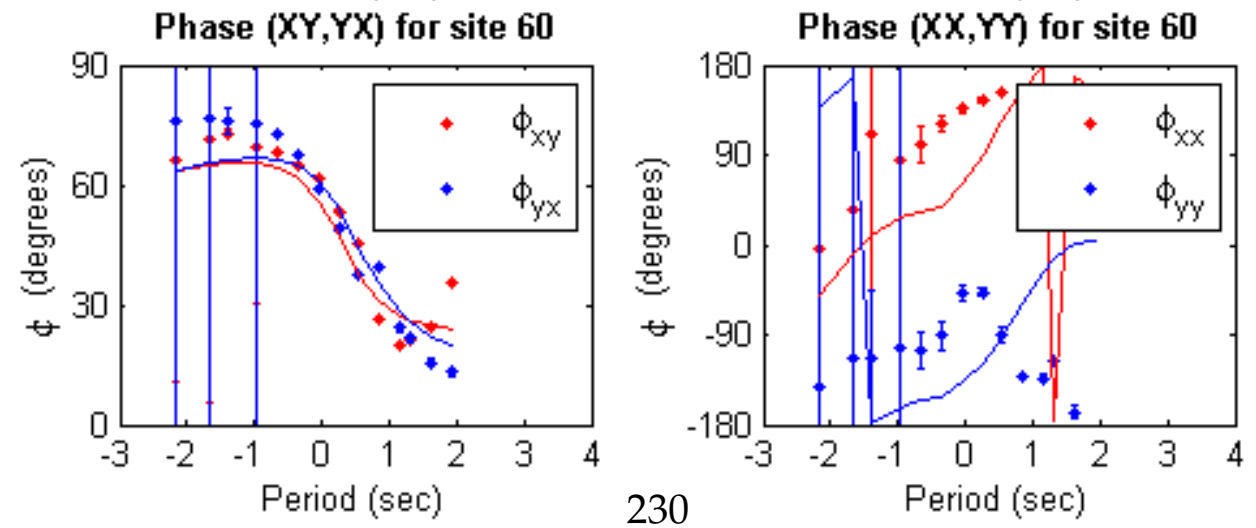
APPENDIX V: 3-D INVERSION CURVE FIT

Apparent Resistivity (XY,YX) for site 61 Apparent Resistivity (XX,Y) for site 61
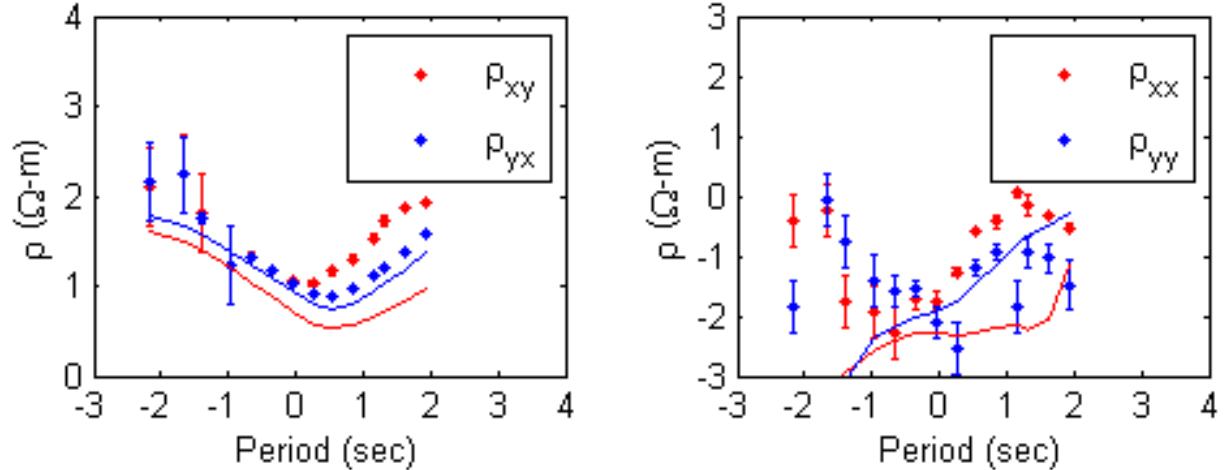

Phase $(X Y, Y X)$ for site 61

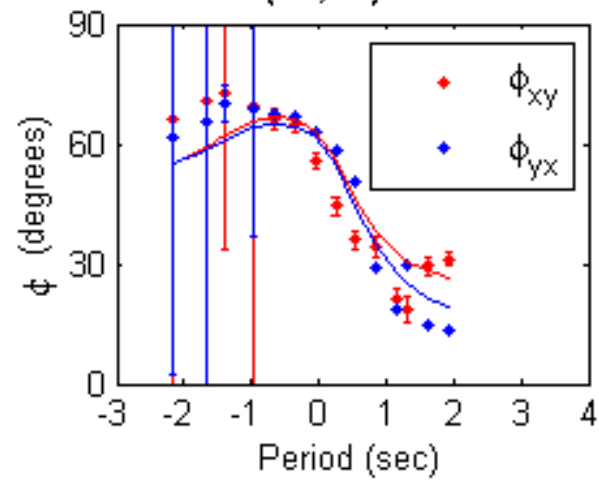

Phase (XX,Y) for site 61

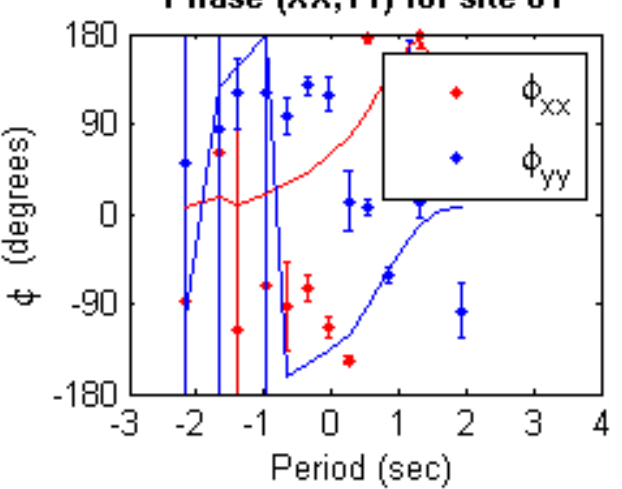

Apparent Resistivity (XY,YX) for site 67 Apparent Resistivity (XX,M) for site 67
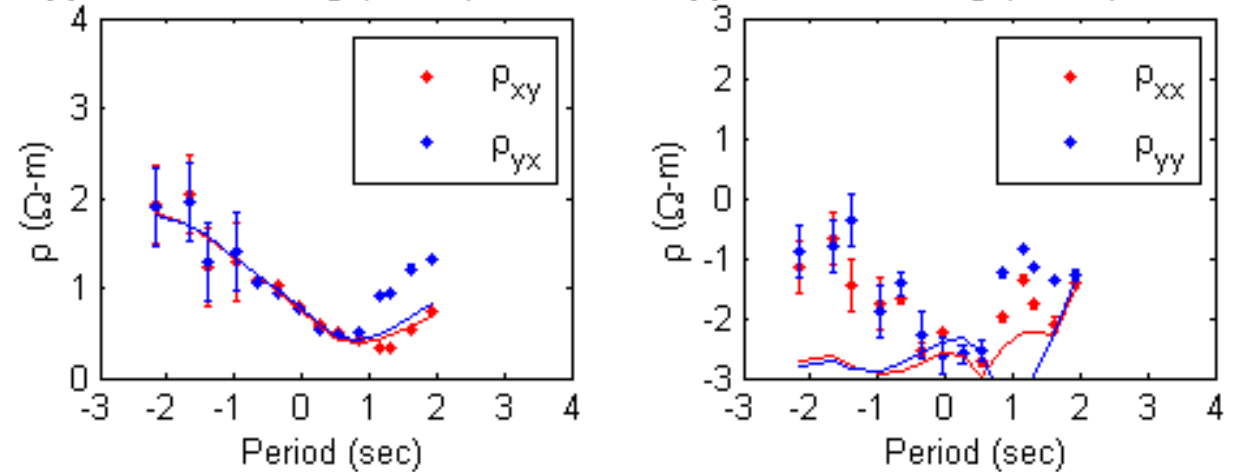

Phase $(X Y, Y X)$ for site 67
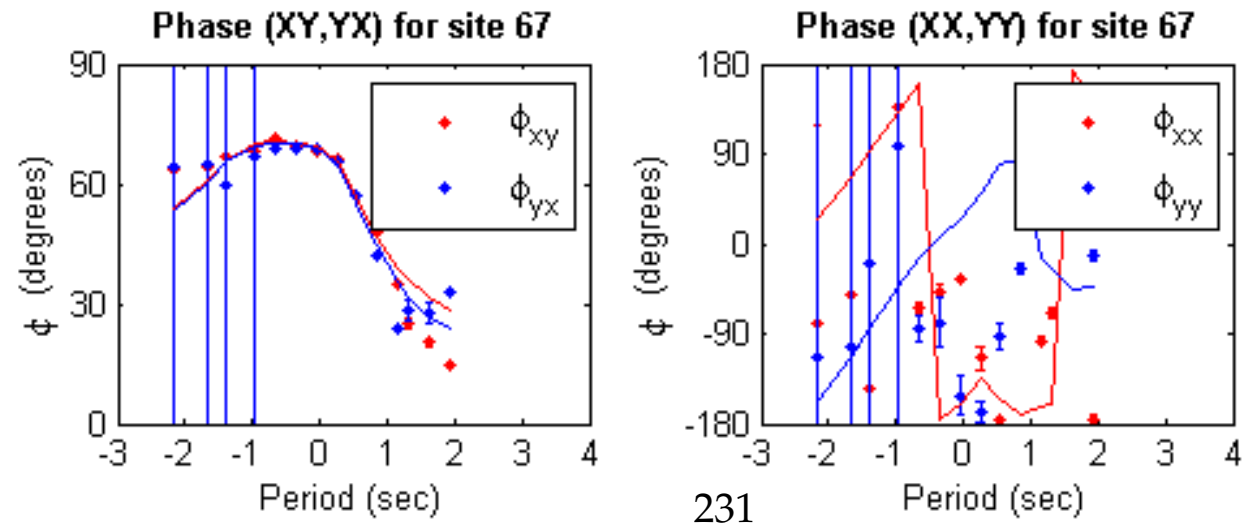
APPENDIX V: 3-D INVERSION CURVE FIT

Apparent Resistivity (XY,YX) for site 76 Apparent Resistivity (XX,Y) for site 76
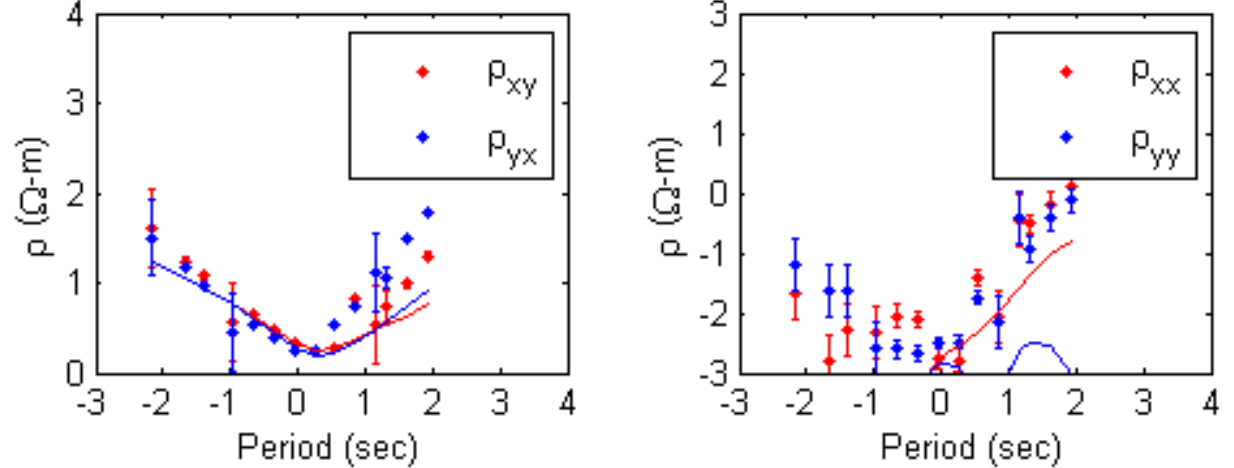

Phase $(X Y, Y X)$ for site 76

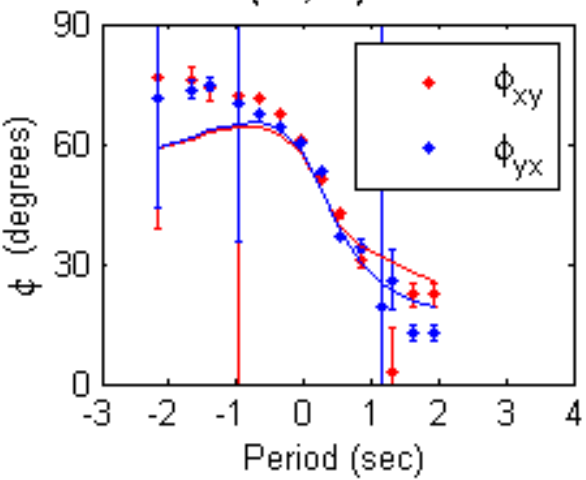

Phase $(X X, Y)$ for site 76

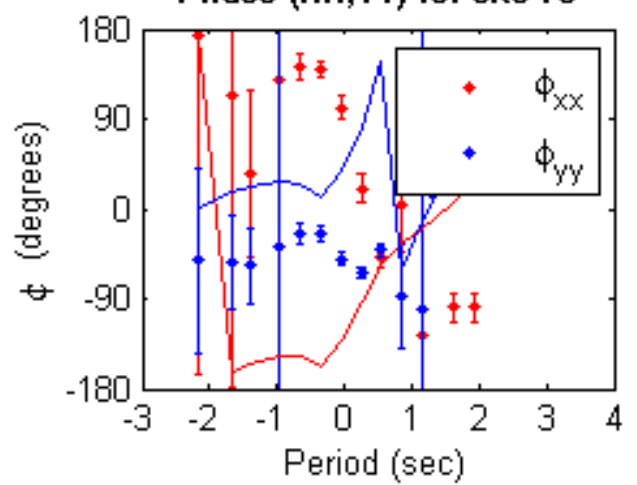

Apparent Resistivity (XY,YX) for site 77 Apparent Resistivity (XX,M) for site 77
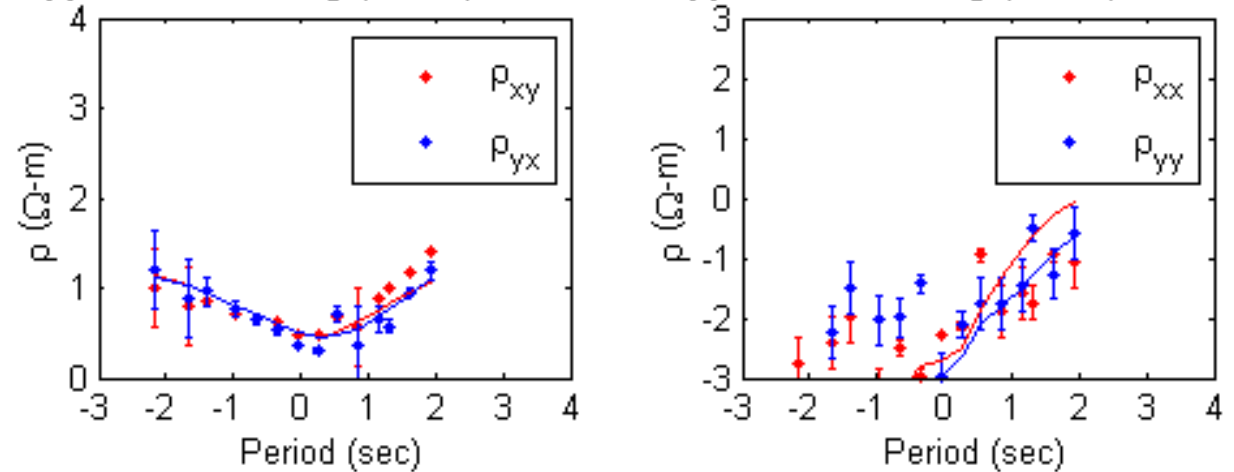

Phase $(X Y, Y X)$ for site 77
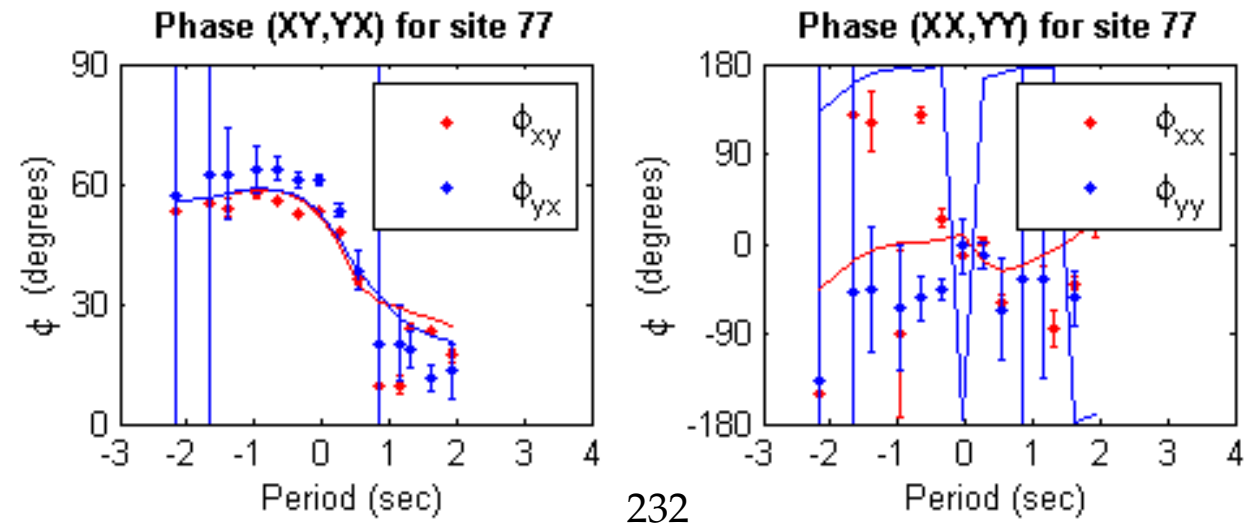
APPENDIX V: 3-D INVERSION CURVE FIT

Apparent Resistivity (XY,YX) for site 82 Apparent Resistivity (XX,Y) for site 82
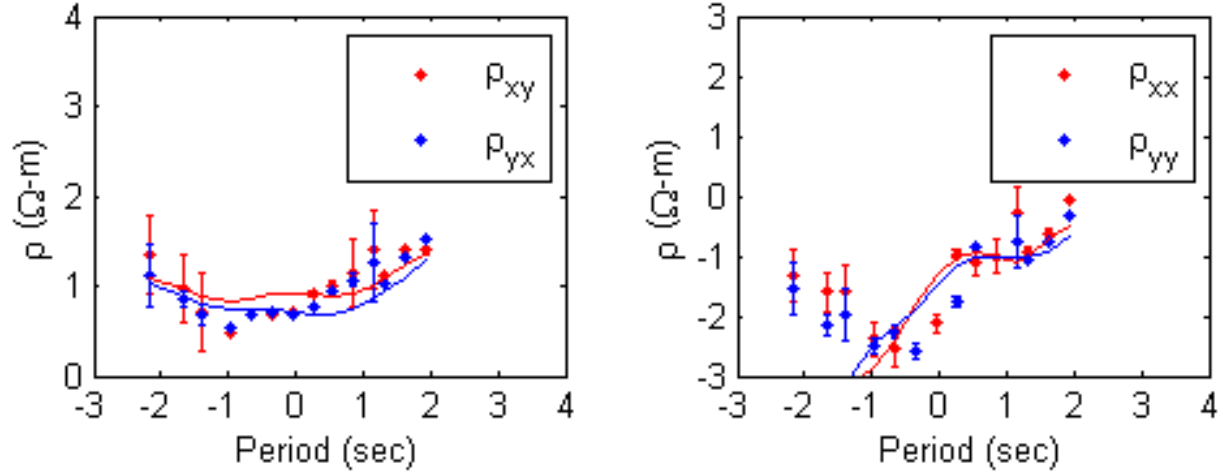

Phase $(X Y, Y X)$ for site 82

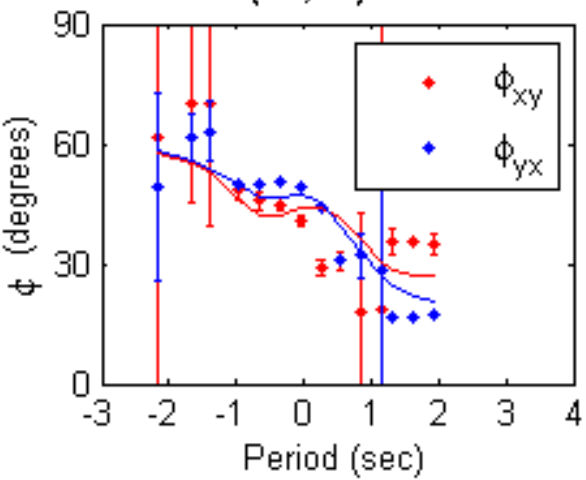

Phase (XX,Y) for site 82

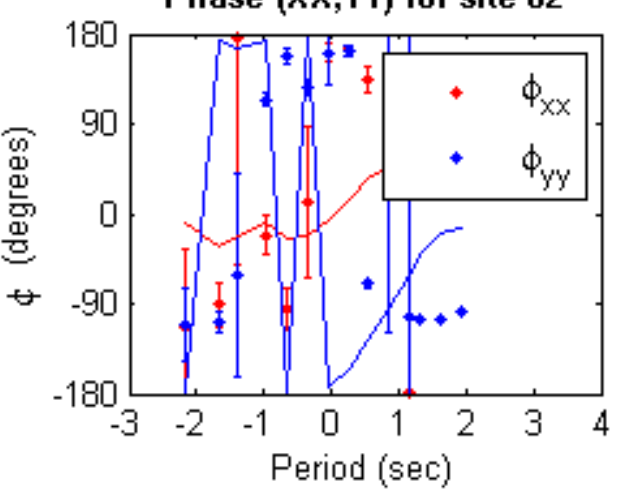

Apparent Resistivity (XY,YX) for site 83 Apparent Resistivity (XX,M) for site 83
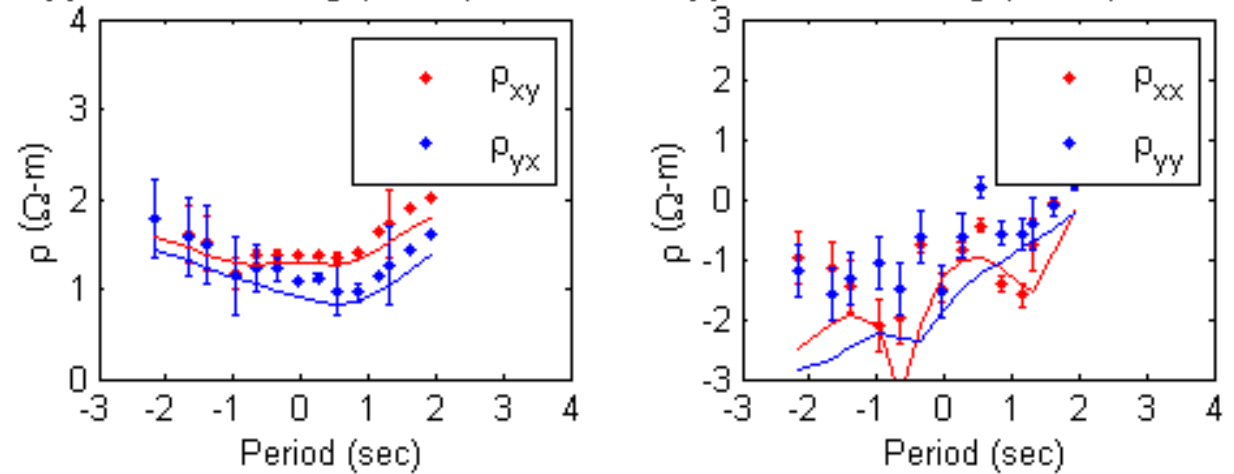

Phase $(X Y, Y X)$ for site 83

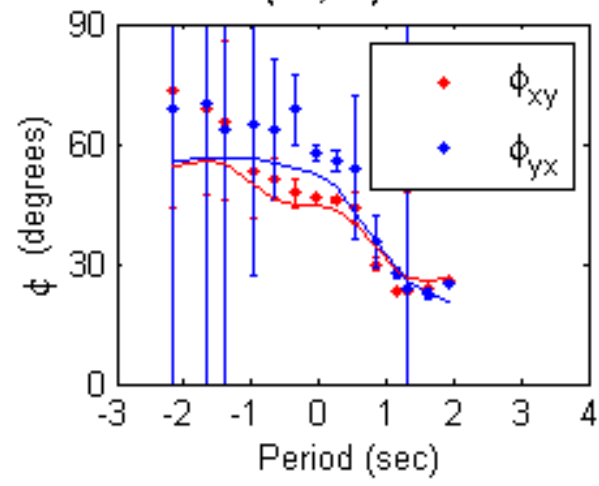

Phase $(\mathrm{XX}, \mathrm{YM})$ for site 83

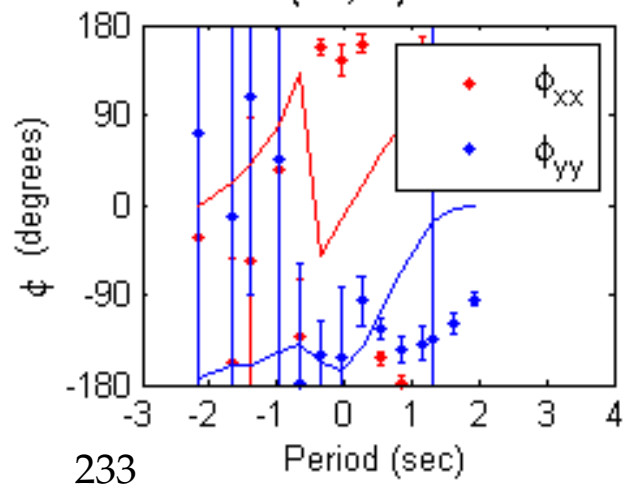


APPENDIX V: 3-D INVERSION CURVE FIT

Apparent Resistivity (XY,YX) for site 84 Apparent Resistivity (XX,YM) for site 84
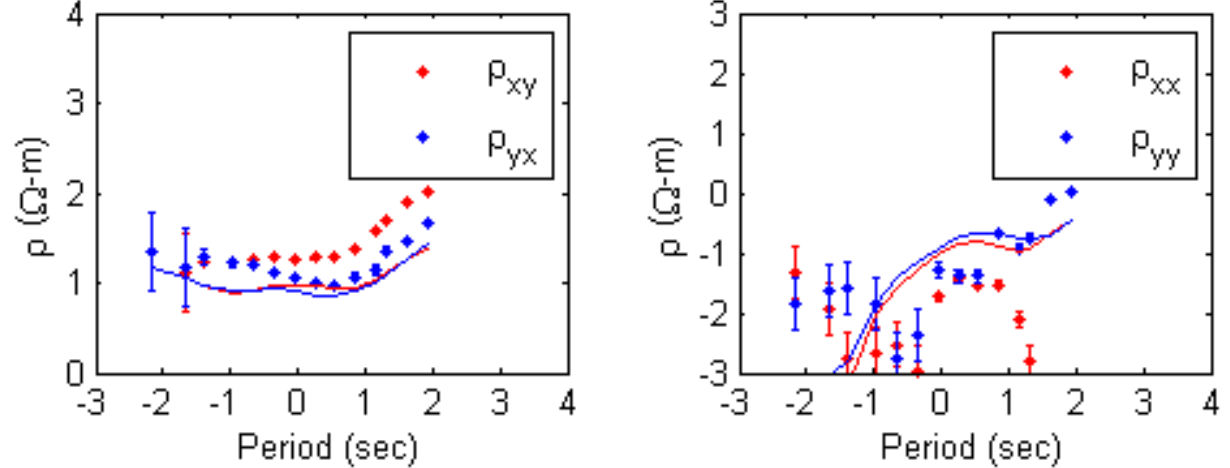

Phase $(X Y, Y X)$ for site 84

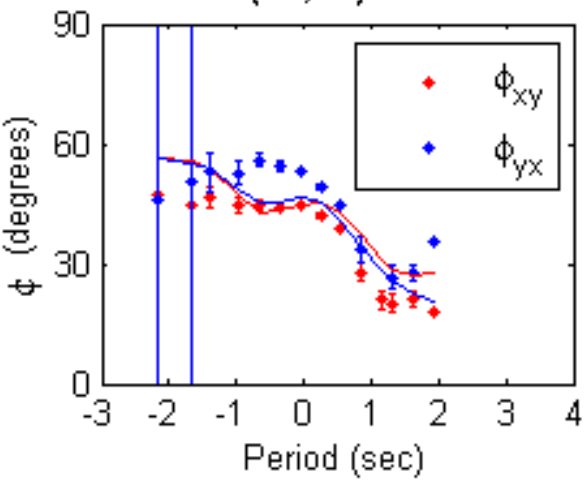

Phase (XX,Y) for site 84

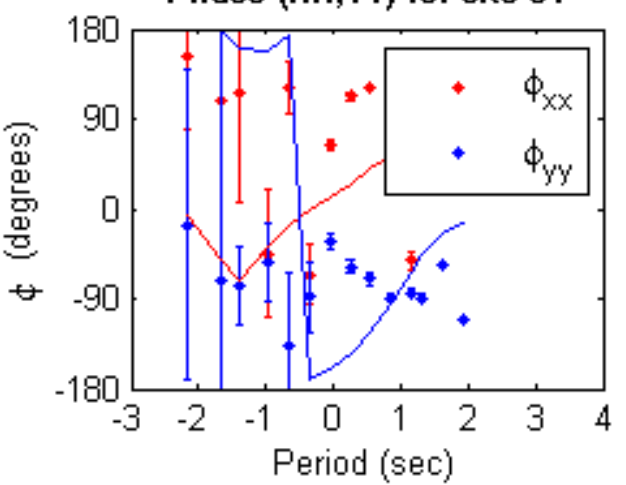

Apparent Resistivity (XY,YX) for site 85 Apparent Resistivity (XX,M) for site 85
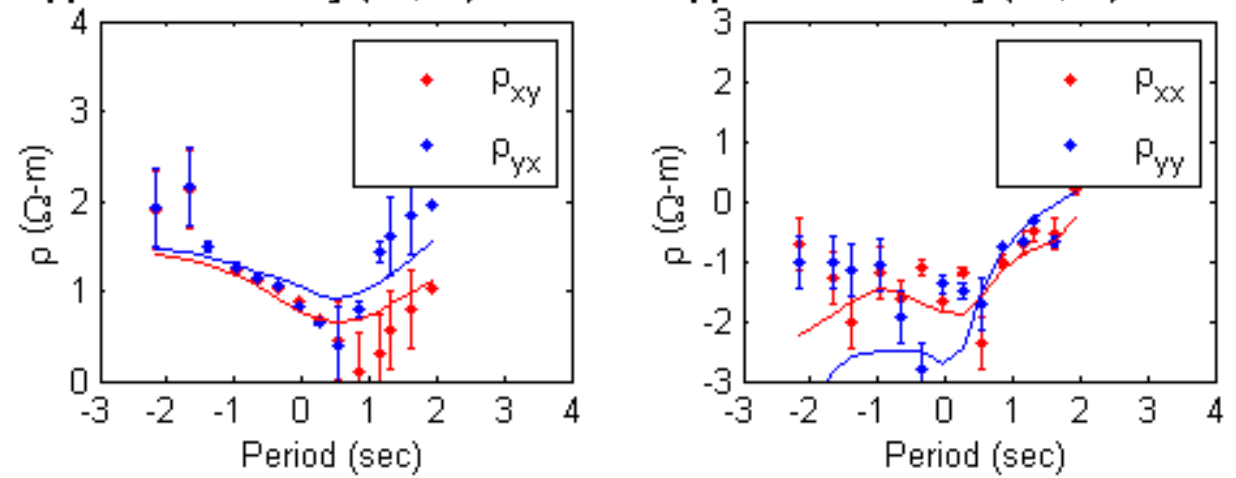

Phase $(X Y, Y X)$ for site 85
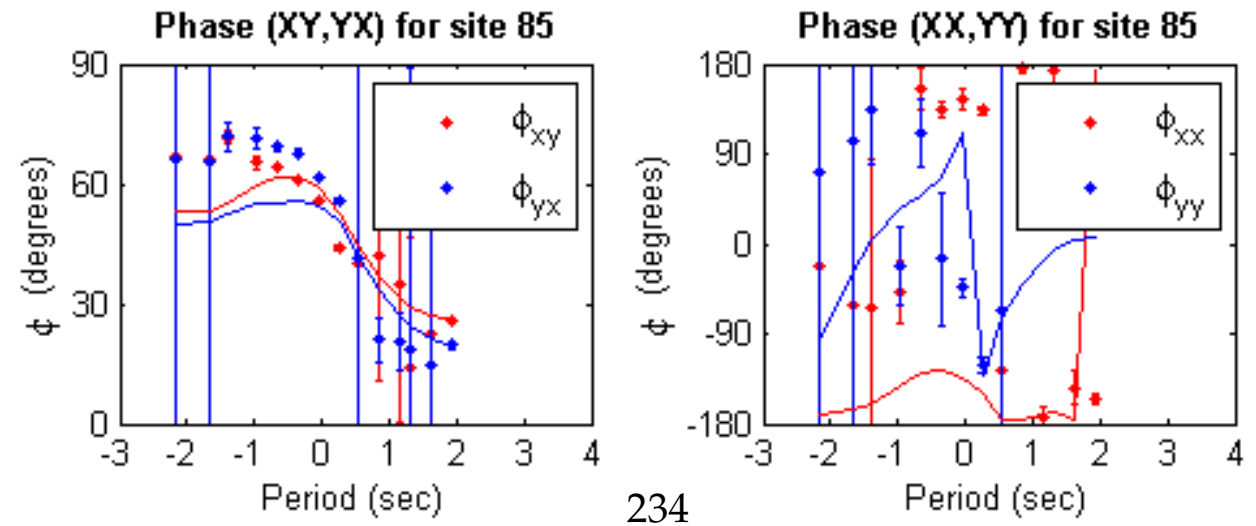
APPENDIX V: 3-D INVERSION CURVE FIT

Apparent Resistivity (XY,YX) for site 93 Apparent Resistivity (XX,Y) for site 93
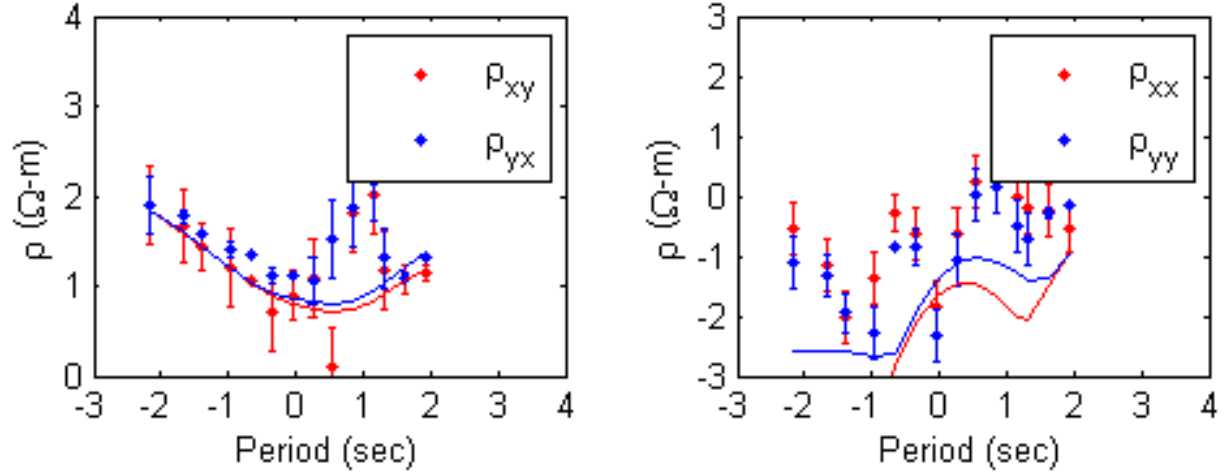

Phase (XY,YX) for site 93

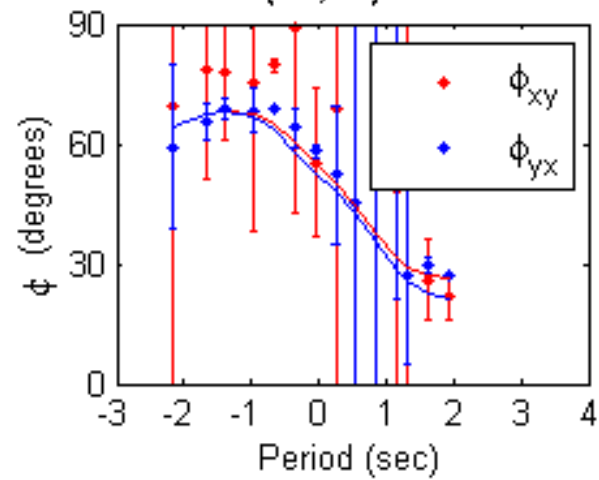

Phase (XX,Y) for site 93

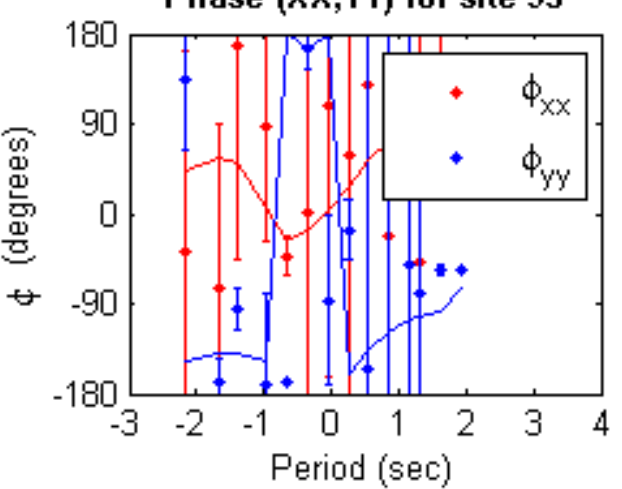

Apparent Resistivity (XY,YX) for site 96 Apparent Resistivity (XX,M) for site 96
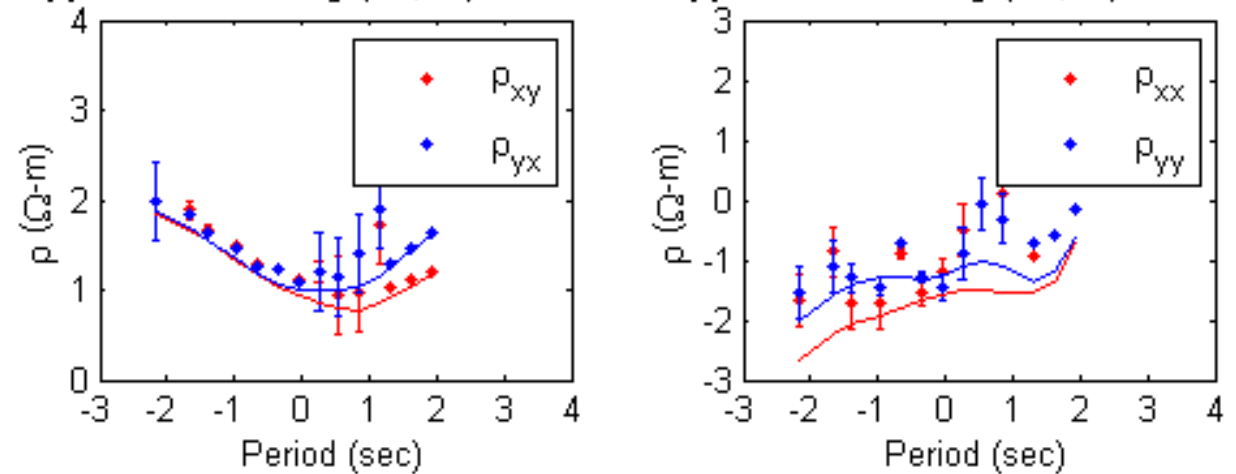

Phase $(X Y, Y X)$ for site 96
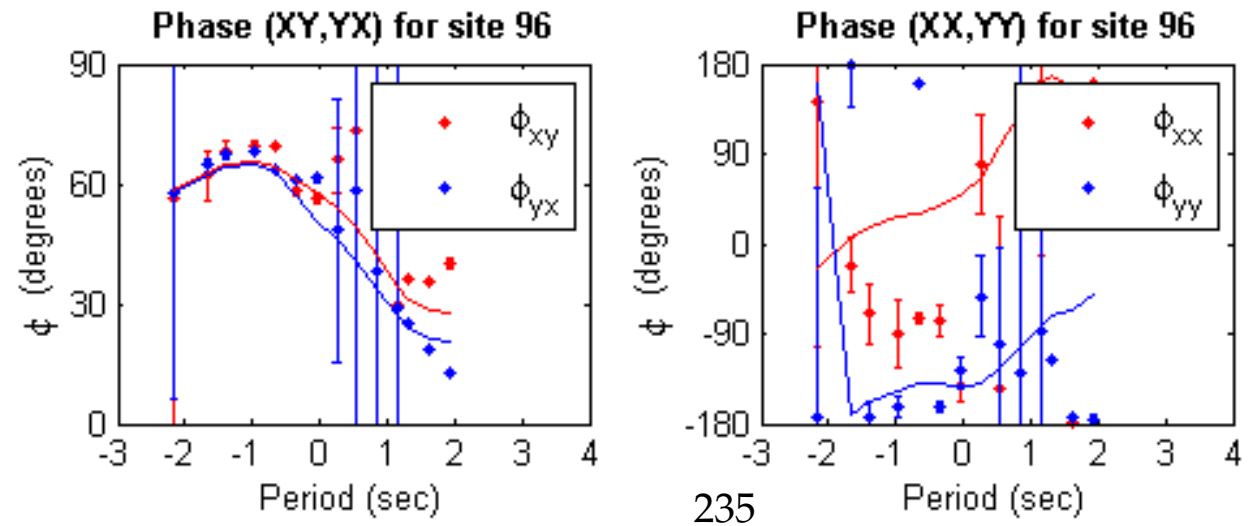
APPENDIX V: 3-D INVERSION CURVE FIT

Apparent Resistivity $(X Y, Y X)$ for site 102Apparent Resistivity (XX,Y) for site 102
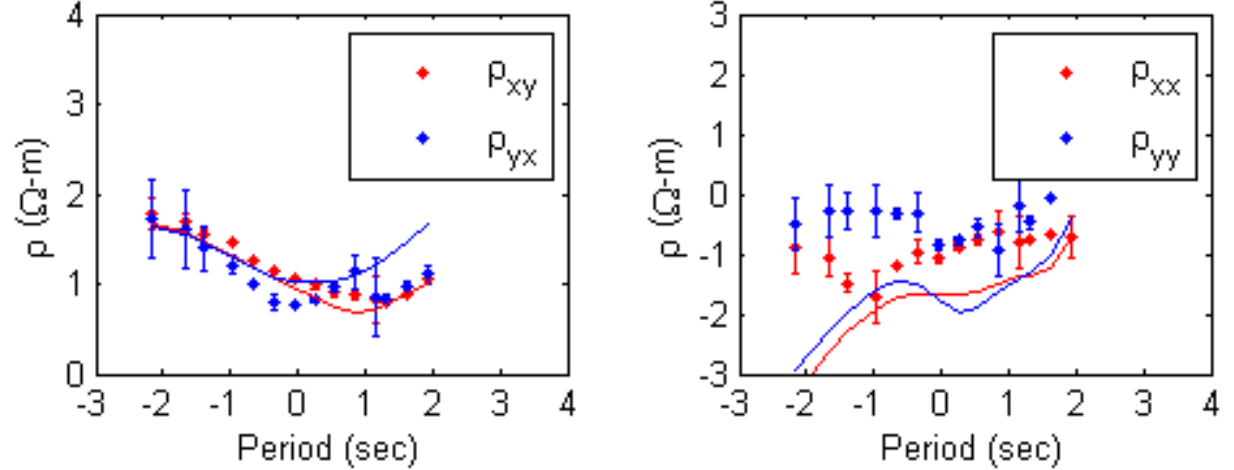

Phase (XY,YX) for site 102

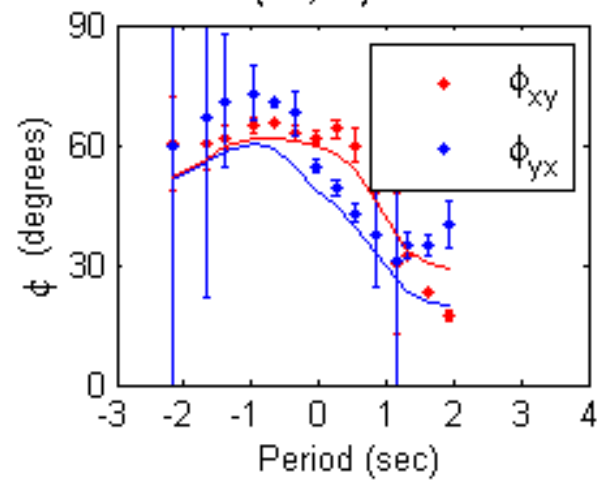

Phase $(X X, Y)$ for site 102

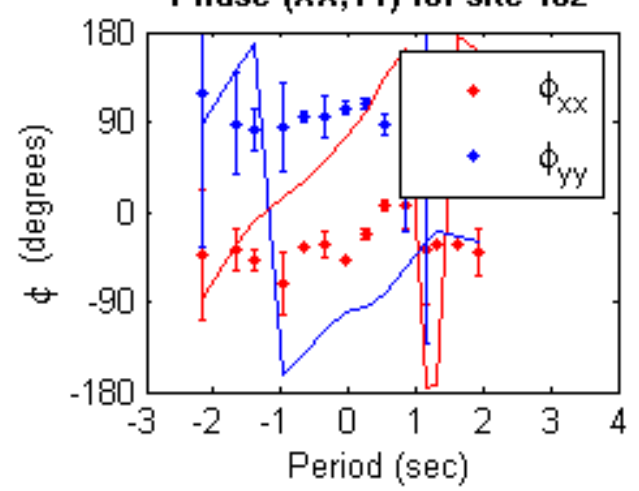

Apparent Resistivity (XY,YX) for site 106Apparent Resistivity (XX,YM for site 106
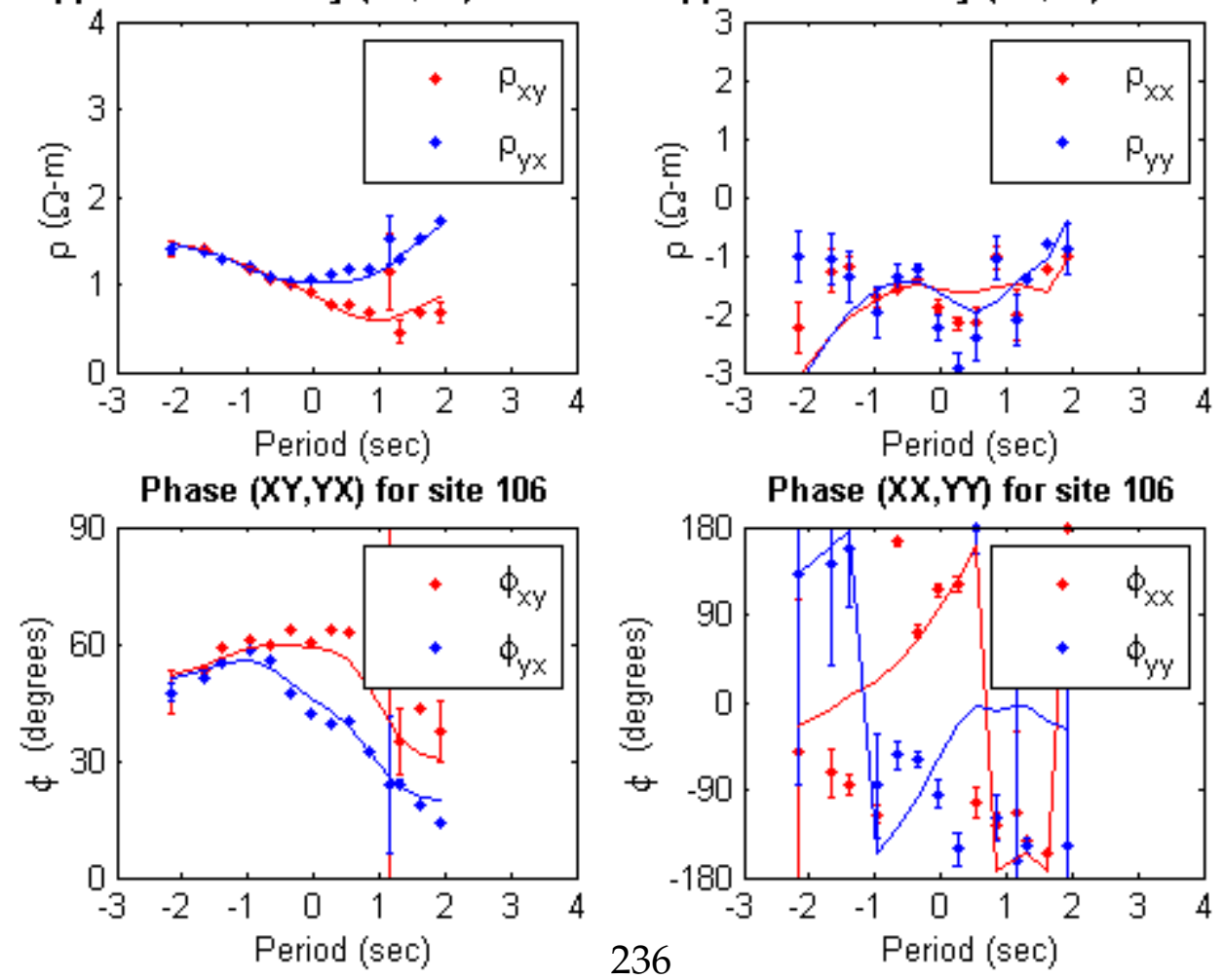
APPENDIX V: 3-D INVERSION CURVE FIT
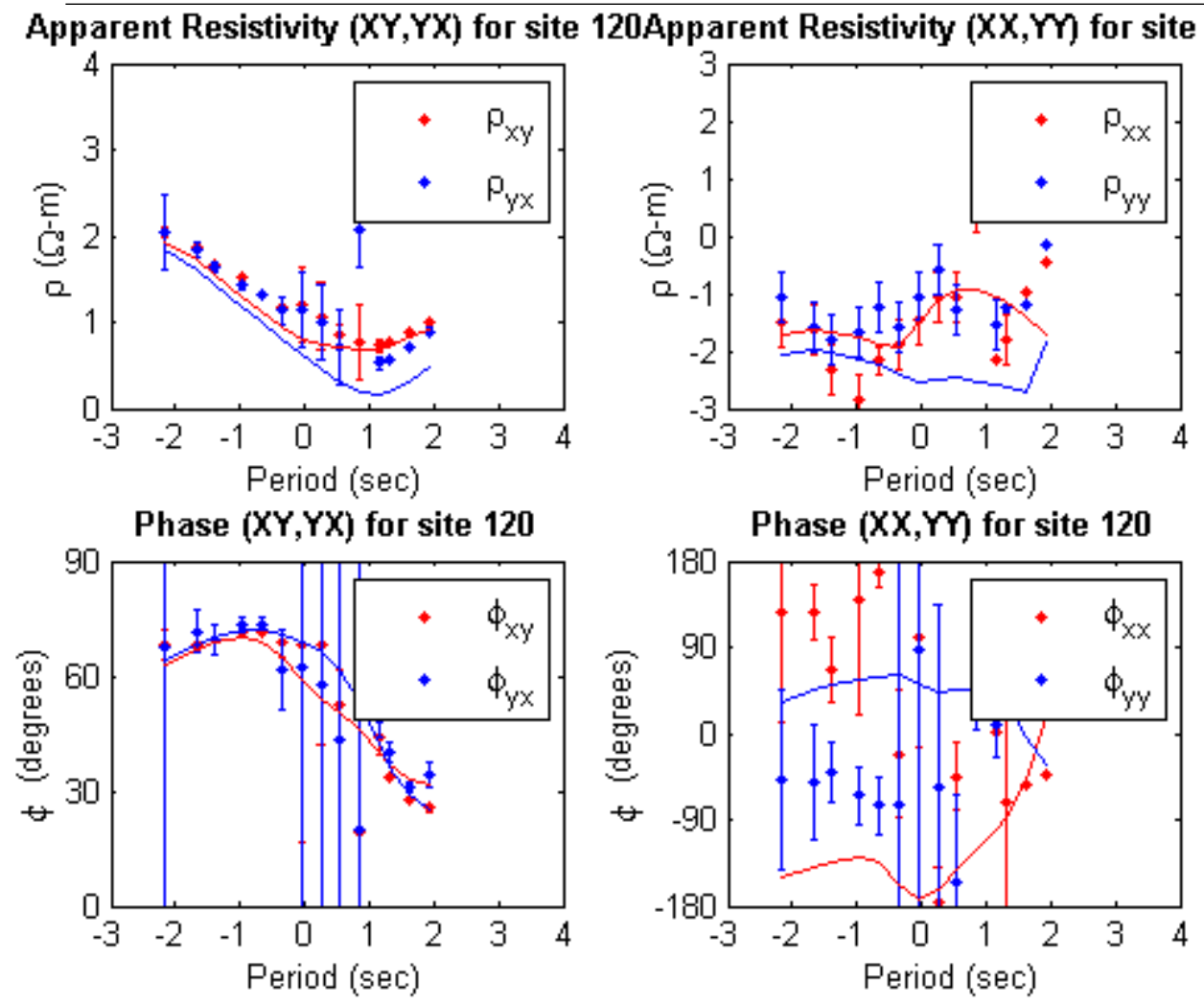

Apparent Resistivity (XY,YX) for site 129Apparent Resistivity (XX,Y) for site 129
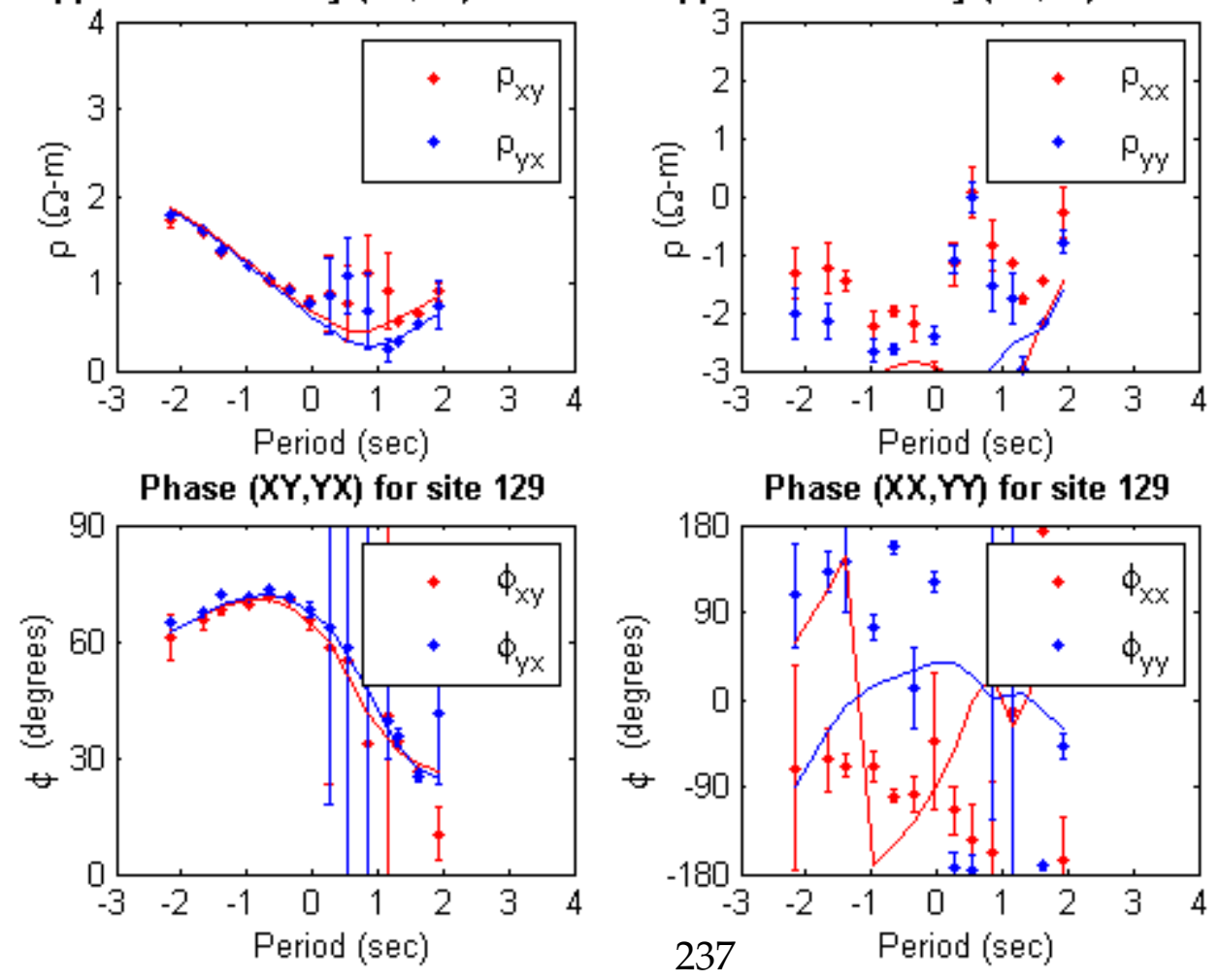
APPENDIX V: 3-D INVERSION CURVE FIT

\section{Apparent Resistivity (XY,YX) for site 133Apparent Resistivity (XX,YM) for site 133}
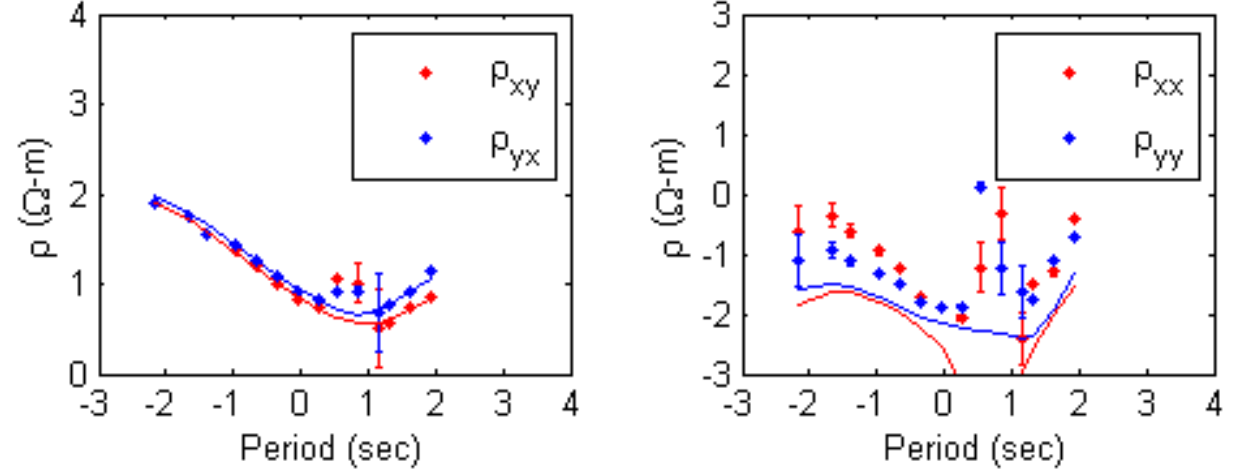

Phase (XY,YX) for site 133

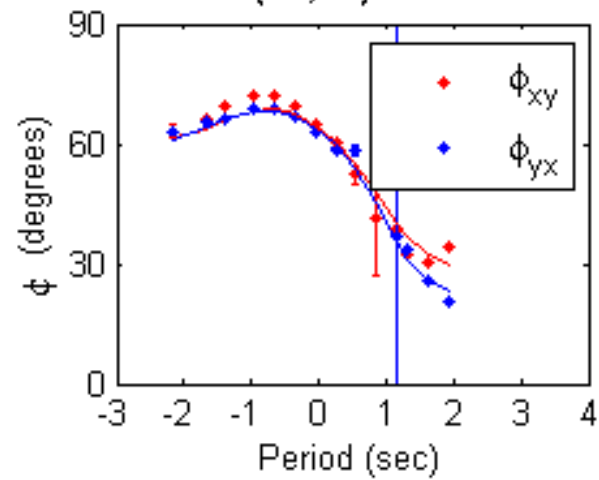

Phase $(X X, Y)$ for site 133

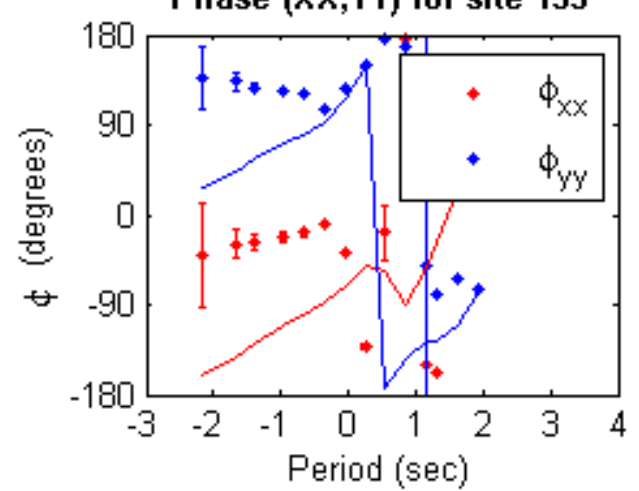

Apparent Resistivity (XY,YX) for site 137Apparent Resistivity (XX,Y) for site 137
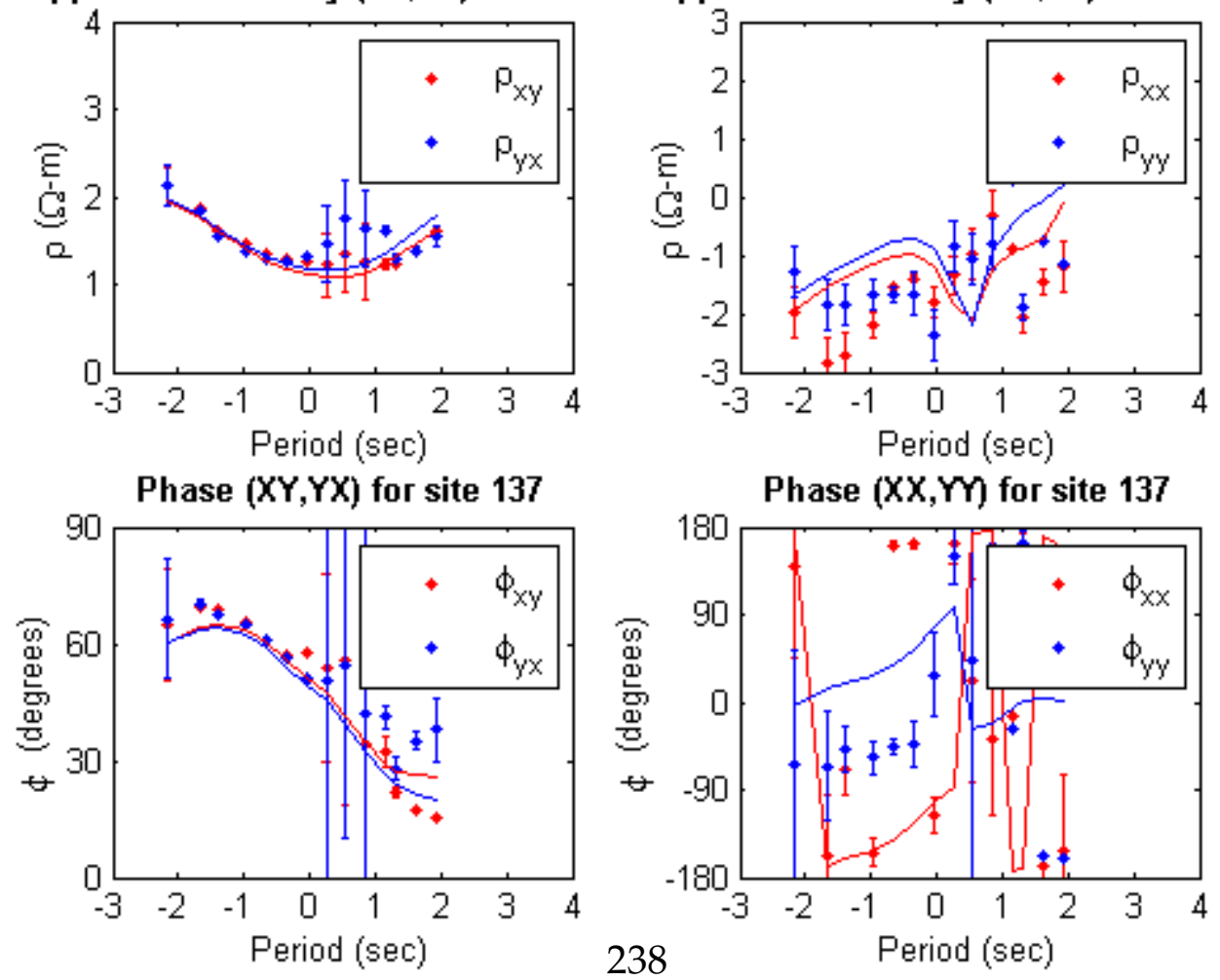
APPENDIX V: 3-D INVERSION CURVE FIT

Apparent Resistivity (XY,YX) for site 143Apparent Resistivity (XX,YY) for site 143
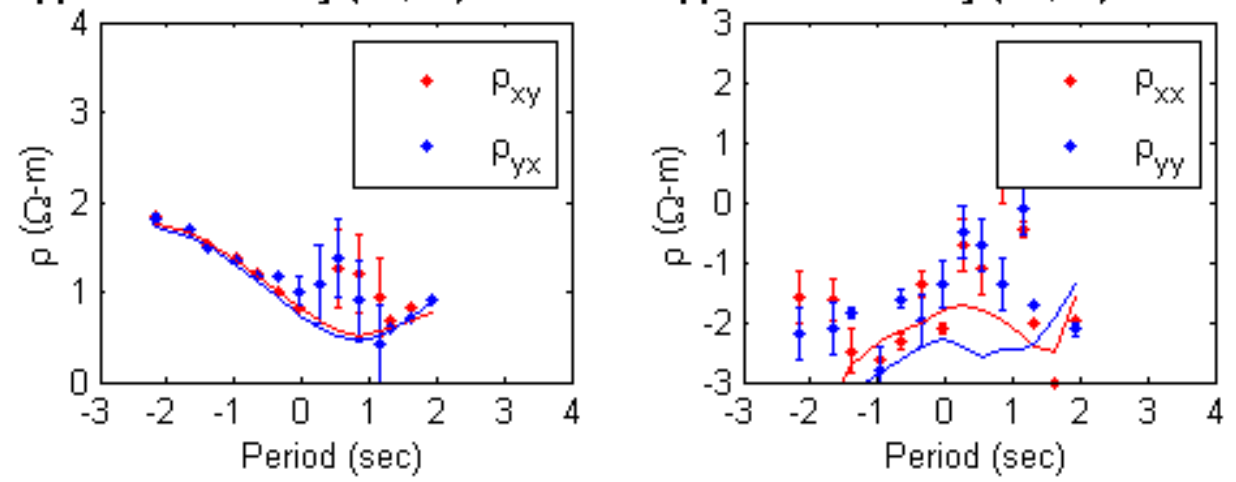

Phase $(X Y, Y X)$ for site 143
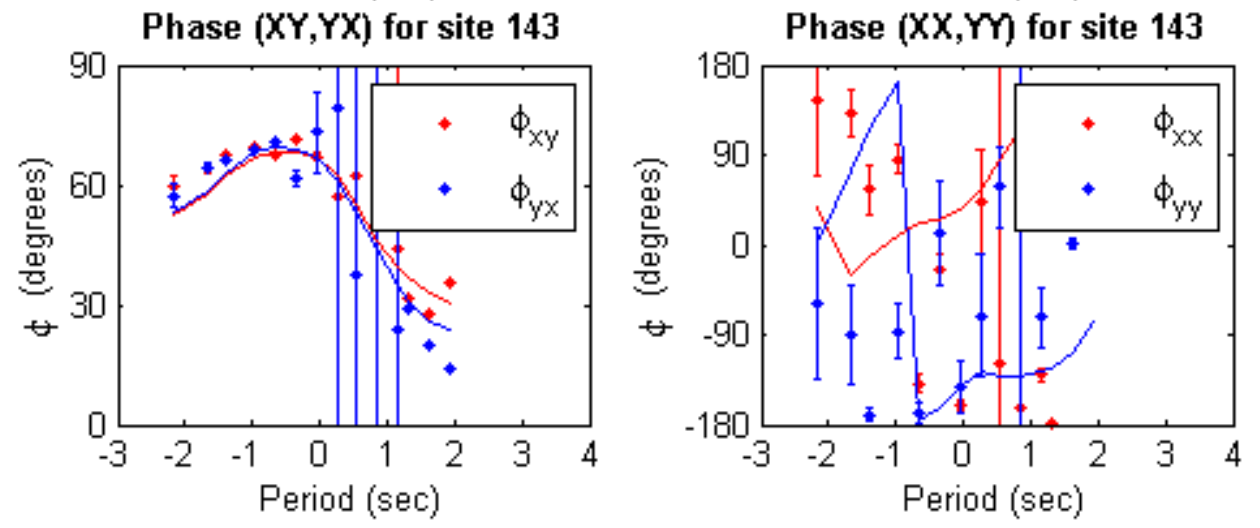

Apparent Resistivity (XY,YX) for site 148Apparent Resistivity (XX,Y) for site 148
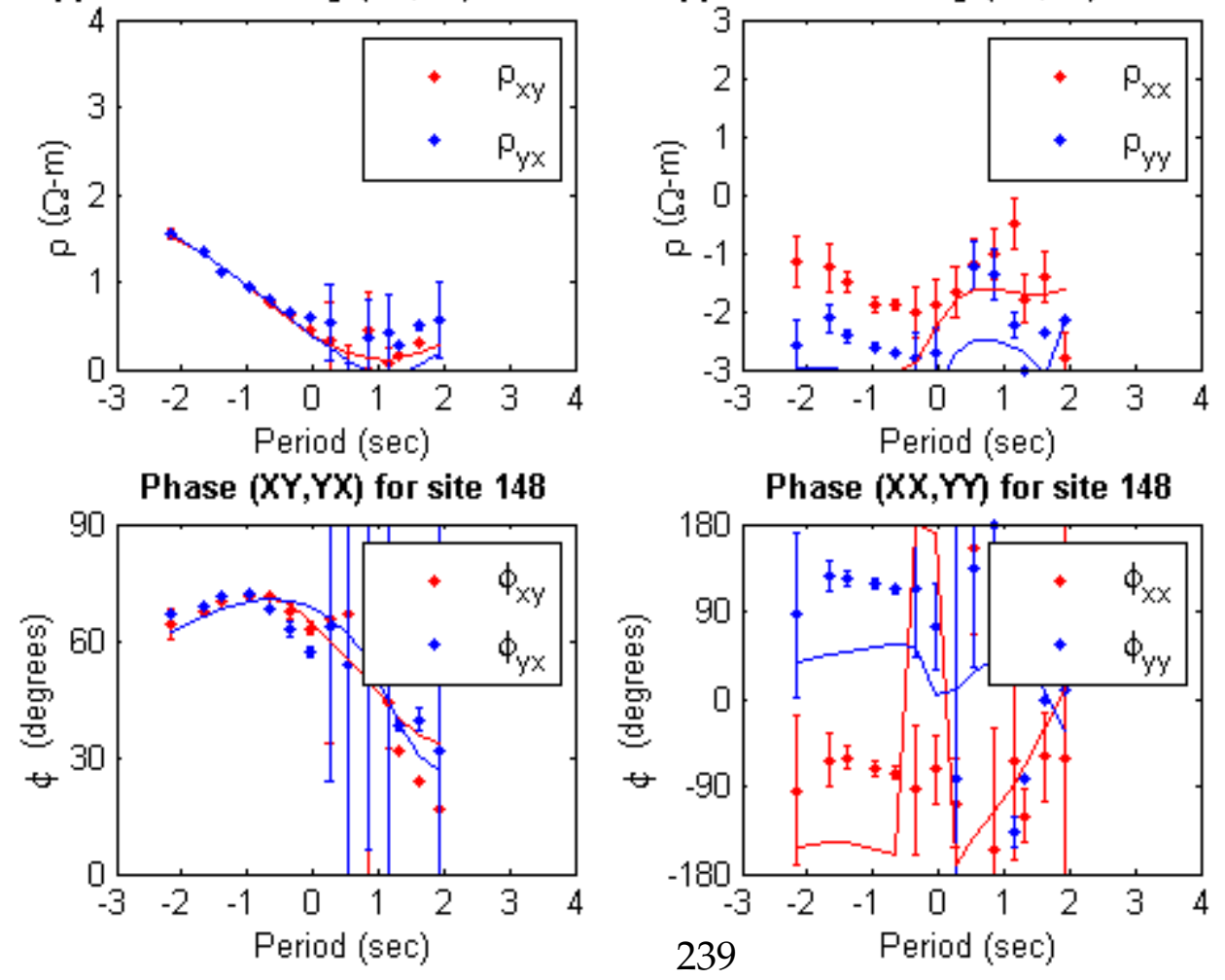
APPENDIX V: 3-D INVERSION CURVE FIT

Apparent Resistivity (XY,YX) for site 149Apparent Resistivity (XX,YY) for site 149
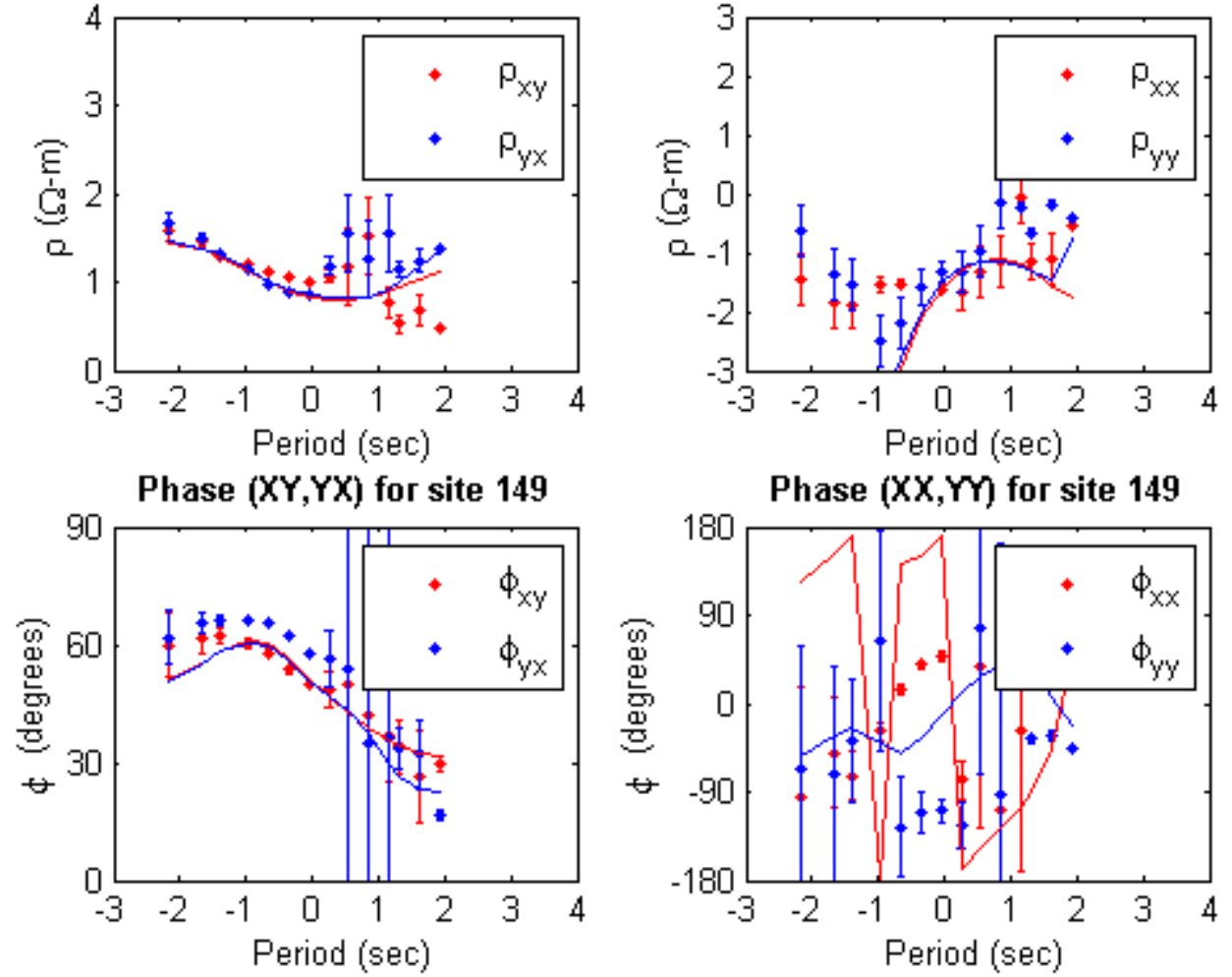